\title{
Testing and Data Recovery Excavations at 11 Native American Archeological Sites Along the U.S. Highway 271 Mount Pleasant Relief Route, Titus County, Texas Volume II
}

Ross C. Fields

Prewitt and Associates, Inc.

Virginia L. Hatfield

Prewitt and Associates, Inc.

Damon Burden

Prewitt and Associates, Inc.

Eloise Frances Gadus

Prewitt and Associates, Inc.

Michael C. Wilder

Prewitt and Associates, Inc.

See next page for additional authors

Follow this and additional works at: https://scholarworks.sfasu.edu/ita

Part of the American Material Culture Commons, Archaeological Anthropology Commons, Environmental Studies Commons, Other American Studies Commons, Other Arts and Humanities Commons, Other History of Art, Architecture, and Archaeology Commons, and the United States History Commons

Tell us how this article helped you.

This Article is brought to you for free and open access by the Center for Regional Heritage Research at SFA ScholarWorks. It has been accepted for inclusion in Index of Texas Archaeology: Open Access Gray Literature from the Lone Star State by an authorized editor of SFA ScholarWorks. For more information, please contact cdsscholarworks@sfasu.edu. 


\title{
Testing and Data Recovery Excavations at 11 Native American Archeological Sites Along the U.S. Highway 271 Mount Pleasant Relief Route, Titus County, Texas Volume II
}

\author{
Authors \\ Kibler \\ Creative Commons License \\ (c) $\mathbb{( 1 ) \Theta \Theta}$
}

Ross C. Fields, Virginia L. Hatfield, Damon Burden, Eloise Frances Gadus, Michael C. Wilder, and Karl W.

This work is licensed under a Creative Commons Attribution-NonCommercial-No Derivative Works 4.0 International License. 


\title{
TESTING AND DATA RECOVERY EXCAVATIONS AT 11 NATIVE AMERICAN ARCHEOLOGICAL SITES ALONG THE U.S. HIGHWAY 271 MOUNT PLEASANT RELIEF ROUTE, TITUS COUNTY, TEXAS
}

\author{
VOLUME II \\ by \\ Ross C. Fields \\ Virginia L. Hatfield \\ Damon Burden \\ Eloise Frances Gadus \\ Michael C. Wilder \\ and \\ Karl W. Kibler
}

Principal Investigator: Ross C. Fields

REPORTS OF INVESTIGATIONS, NUMBER 168

submitted to

PTP, LP

The Woodlands, Texas

and

Titus County, Texas

by

Prewitt and Associates, Inc.

Cultural Resources Services

Austin, Texas

PAI Nos. 204042, 205010, 206053, 208001, and 209032

May 2014

TEXAS ANTIQUITIES PERMIT NOS. 3786, 4303, and 5495 


\section{VOLUME I}

CHAPTER 1: Introduction

CHAPTER 2: Testing At 41TT6, 41TT846, 41TT847, 41TT851-41TT854, 41TT858, 41TT862, 41TT865, and 41TT866

CHAPTER 3: Research Design and Field and Analysis Methods for Data Recovery Excavations

CHAPTER 4: Results of Excavations In Subarea 1 of the George Richey Site, 41TT851

CHAPTER 5: Results of Excavations in Subarea 1 of the William Ford Site, 41TT852

CHAPTER 6: Results of Excavations at the James Richey Site, 41TT853

CHAPTER 7: The Thomas B. Caldwell and A. P. Williams Cemeteries and Titus Phase Mortuary Behavior

CHAPTER 8: Interpretations and Conclusions

REFERENCES CITED

\section{VOLUME II}

APPENDIX A: Research Design for Test Excavations

APPENDIX B: Archaeogeophysical Survey

APPENDIX C: Stratigraphic Integrity Analysis for 41TT852 and 41TT853

APPENDIX D: Historic Landscape Study

APPENDIX E: Metric Data for Stone Tools (compact disk only)

APPENDIX F: Macrobotanical Plant Remains

APPENDIX G: Vertebrate Remains

APPENDIX H: Invertebrate Faunal Remains

APPENDIX I: Neutron Activation Analysis of Caddo Ceramics

APPENDIX J: Petrographic Analysis of Pottery

APPENDIX K: Analysis of the Anderson Collection 


\section{TABLE OF CONTENTS}

\section{VOLUME II}

APPENDIX A: Research Design for Test Excavations ...................................................... 491

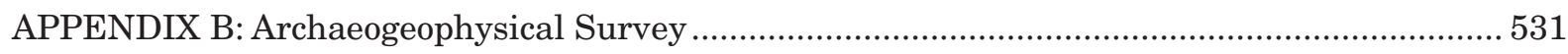

APPENDIX C: Stratigraphic Integrity Analysis for 41TT852 and 41TT853.............................. 557

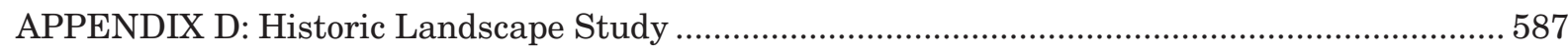

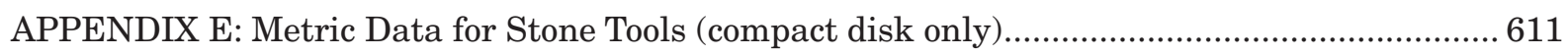

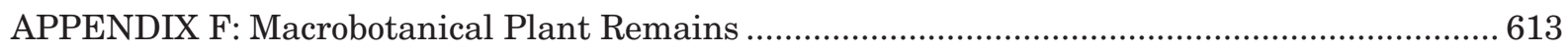

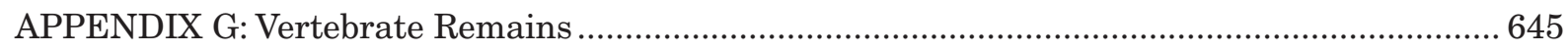

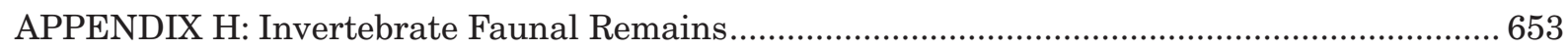

APPENDIX I: Neutron Activation Analysis of Caddo Ceramics ................................................ 657

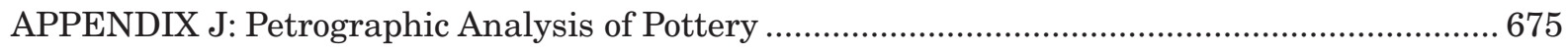

APPENDIX K: Analysis of the Anderson Collection ........................................................... 705 


\section{LIST OF FIGURES}

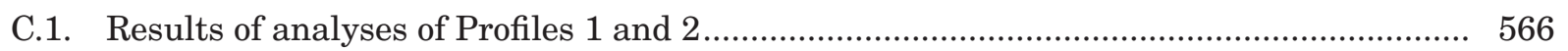

C.2. Histograms of grain-age distributions for OSL samples from 41TT852 ......................... 569

C.3. Magnetic susceptibility and total phosphorus values of Profiles 1 and 2 ....................... 572

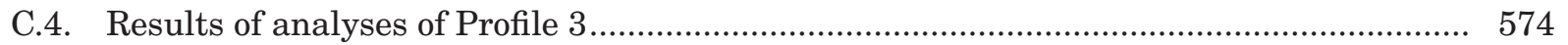

C.5. Histograms of grain-age distributions for OSL samples from 41TT853 ......................... 576

C.6. Mean particle size versus sorting (standard deviation) for sandy epipedons and the subsoil argillic horizons

C.7. Main OSL age component determined by finite mixture modeling as a function of depth for each profile, as well as all of the samples together ................................... 579

C.8. Grain-age frequency distribution changes as a function of depth................................... 580

C.9. Plot of the percent of zero-dose grains in each profile by depth ...................................... 581

C.10. Depth distributions of cesium-137 ............................................................................... 582

D.1. Map showing the location of the historic landscape study area..................................... 590

D.2. The historic landscape study area superimposed on an excerpt from a 1949 map showing Texas General Land Office surveys.

D.3. The historic landscape study area superimposed on an excerpt from the 1909 soil survey map

D.4. The historic landscape study area superimposed on an excerpt from the 1936 State Highway Department map .....

D.5. Plotted, but likely inaccurate, location of the Thomas B. Caldwell cemetery (as 41TT6) on the Timothy McAlester et ux land parcel, and suggested true location of the cemetery as part of 41TT846 on the Charles S. Caldwell et al. and Priefert Development Corporation land parcels .

D.6. A 1935 aerial photograph of the likely location of the Thomas B. Caldwell cemetery with the 1934 excavation superimposed.

F.1. Conjoined corn cupules from smudge pit Feature 546 at 41TT852 .............................. 631

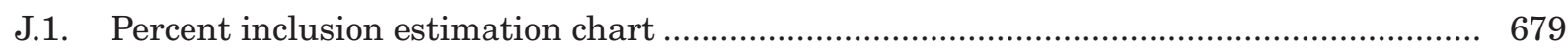

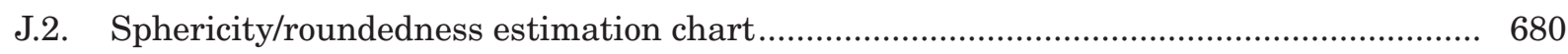

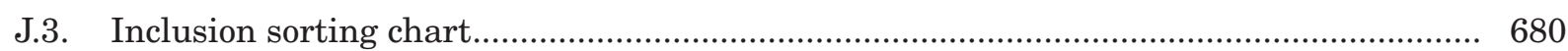

K.1. Ripley Engraved compound bowl (Vessel 1) from 41TT18 ............................................ 709

K.2. Ripley Engraved bottle (Vessel 2) from 41TT18 …........................................................ 710

K.3. Pease Brushed-Incised jar (Vessel 3) from 41TT18 ....................................................... 711

K.4. Belcher Ridged jar (Vessel 4) from 41TT18 ............................................................... 712

K.5. Untyped simple bowl (Vessel 5) from 41TT18 ............................................................ 713

K.6. Untyped red-slipped simple bowl (Vessel 6) from 41TT18 .......................................... 714

K.7. Untyped brushed jar (Vessel 7) from 41TT18 ............................................................. 715 
K.8. Untyped punctated jar (Vessel 8) from 41TT18 …................................................... 716

K.9. Ripley Engraved bottle (Vessel 9) from 41TT18 ........................................................ 717

K.10. Effigy bowl (Vessel 10) from 41TT18.............................................................................. 719

K.11. Untyped incised jar (Vessel 11) from 41TT18 .......................................................... 720

K.12. A grooved axe and two celts from 41TT18 in the Anderson collection............................ 721

K.13. Arrow points in the Anderson collection........................................................................ 731

K.14. Dart points in the Anderson collection …...................................................................... 732

K.15. Dart points in the Anderson collection .................................................................... 734

K.16. Dart points in the Anderson collection …….................................................................... 735

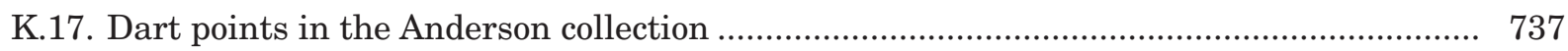

K.18. Dart points in the Anderson collection ..................................................................... 738

K.19. Dart points in the Anderson collection ........................................................................ 740 


\section{LIST OF TABLES}

B.1. Processing steps for conductivity data

537

B.2. Processing steps for magnetometer data 538

B.3. Processing steps for resistivity data 539

B.4. Processing steps for magnetic susceptibility data. 541

C.1. Results of texture and cesium-137 analyses of three soil profiles from 41TT852 and 41TT853

C.2. Results of magnetic susceptibility and phosphorus analyses of three soil profiles from $41 \mathrm{TT} 852$ and $41 \mathrm{TT} 853$

C.3. Single-grain statistics derived from analysis of OSL samples 565

C.4. Profile 1 description 567

C.5. Profile 2 description 570

C.6. Profile 3 description 575

D.1. Trees as witness points on land grant surveys in the historic landscape study area 595

D.2. Type and number of trees as witness points on land grant surveys in the historic landscape study area.

F.1. Hand-collected macrobotanical samples. 617

F.2. Analyzed flotation samples by feature type 620

F.3. Uncarbonized seeds from flotation samples 621

F.4. Carbonized plant material from flotation samples 623

F.5. Carbonized plant material from flotation by feature type for 41TT851 625

F.6. Carbonized plant material from flotation by feature type for 41TT852 . 626

F.7. Carbonized plant material from flotation by feature type for 41TT853 ........................ 628

F.8. Measurements of conjoined corn cupules ...................................................................... 632

F.9. Corn (Zea mays) cupule measurements from sites in northeast Texas .......................... 632

F.10. Late Prehistoric sites in northeast Texas and northwestern Louisiana with native starchy seeds 634

F.11. Proximate analysis of three edible tree nuts. 636

G.1. Number of identified vertebrate faunal specimens by site. 648

G.2. Minimum numbers of individuals in the vertebrate faunal remains by site 649

G.3. Taphonomy in vertebrate faunal remains by site 650

H.1. Inventory of invertebrate faunal remains 655

I.1. Group membership probabilities based on a Mahalanobis distance projection using the first seven principal components 667

K.1. Metric attributes of the chipped stone tools in the Anderson collection 723 


\section{APPENDIX A: Research Design for}

Test Excavations

Charles D. Frederick

October 2005 



\section{INTRODUCTION}

This is a research design for National Register of Historic Places and State Antiquities Landmark testing of 11 prehistoric sites that will be impacted by construction of the proposed U.S. Highway 271 relief route around Mount Pleasant in Titus County, Texas. The work was done in 2005 for the Texas Department of Transportation's Environmental Affairs Division under Contract No. 575XXSA006, Work Authorization No. 57501SA006. This research design provides support for a scope of work for testing, prepared as a separate document.

The primary relevant historic context for future work on this project is The Development of Agriculture in Northeast Texas Before A.D. 1600 (Kenmotsu and Perttula 1993). Significant information on all nine study units defined for that context (chronology and typology, settlement systems, subsistence systems, social and political complexity, demographic change, mortuary practices, local and extralocal trade and exchange, technological change, and material culture) may be recovered. The overall project goal is to identify and explore Caddo community structure, with an emphasis on behavior and how people interacted and organized space at different spatial scales, including within single houses, on individual house lots, within villages, between one or more contemporaneous villages, and as villages and other components of the settlement system (e.g., field houses, mounds, cemeteries, agricultural fields, ceremonial centers).

Some of the issues we would like to address through subsequent data recovery include (but are not limited to):

- How Caddo land use affected the environment in which they lived, specifically vegetation structure and composition as well as soil stability and fertility, and how this may have influenced, if at all, their behavior.

- If sedentary occupations of more than one age are present, we want to explore how community life, structure, and regional interaction changed through time.

- If one or more communities are discovered, we want to document and explore the details of Caddo community spatial organization and look in detail at use of space within a single community as well as com- pare more than one settlement, if possible.

- Explore how Caddo communities were organized with respect to the production and acquisition of durable goods like ceramics and tools (at the household level, community level, or regional level).

- Investigate the organization and structure of Caddo houses and house lots to examine issues of activity and discard areas, evidence of social structure (from artifactual as well as architectural evidence), and duration of occupation.

- Add to our understanding of Caddo agriculture in terms of the location and artifact association of fields, as well as look for evidence of the encouragement of wild plants for food, clothing, or construction.

- Examine the field methods appropriate for finding and recovering community-scale information from settlement sites.

- Delineate how the use and organization of space changed through time in this region.

To get there, several things have to occur at the testing phase. Most notably, archeological evidence of communities (i.e., structures and other features) must be found. There are a number of reasons to think that this will be the case at some of the sites in the project corridor. First, a Late Caddo Titus phase cemetery was excavated in or adjacent to the project area, probably at $41 \mathrm{TT} 846$, in 1934, and a local informant reports that at least one other cemetery, probably also Titus phase, lies not far west of the north end of the project area. Second, one site in the project area (41TT865) contains a Titus phase midden reflecting intensive, presumably domiciliary, activities. And third, four other sites in the project area (41TT851, 41TT852, 41TT853, and 41TT854) contain spatially restricted scatters of ceramic and lithic artifacts that appear to be good candidates for residential loci.

The goals of the testing are to: determine if archeological evidence of communities (i.e., structures and other features) is present, and if so, to gather sufficient information about them to design a data recovery program; test the utility of geophysical methods in identifying cultural features; determine the integrity of the deposits; and perform ancillary studies that will provide a broader image of this landscape and its 
recent history and compile data sets useful for more-involved analyses. Eight research themes are employed to structure these investigations, and discussion of them constitutes the body of this research design:

- Finding cultural features through geophysical survey.

- Site integrity.

- Looking for structures when geophysics lets you down: the scrape and peck approach.

- Paleoenvironmental change.

- Finding Caddo agricultural/horticultural land scapes.

- Background sampling for ceramic studies.

- Background sampling for lithic studies.

- Historic landscapes.

\section{RESEARCH THEME: FINDING CULTURAL FEATURES THROUGH GEOPHYSICS}

\section{Theoretical Rationale}

Geophysical survey is an increasingly common form of archeological field investigation that is used to direct excavations toward areas of the landscape or archeological sites that are most likely to yield information of interest to archeologists, or features or structures that may be useful in addressing research issues (Gaffney and Gater 2003:24). In traditional archeological fieldwork, limited test excavations are used to identify areas where additional investigations, normally excavation, may yield productive data. This process, in its most basic form, is performed blind, with field workers making educated guesses about where cultural features or deposits of interest may lie hidden beneath the surface. Geophysical methods have the potential to greatly enhance archeological excavation by providing a relatively rapid image of what lies below the ground surface in a noninvasive and nondestructive manner. Such information often permits more directed investigations and a more comprehensive image of past activities at a site.

A wide variety of methods are available for archeological use (refer to Clark [1996], David [1995], Nishimura [2001], and Scollar et al. [1990] for excellent overviews of the various methods and their strengths and limitations), and the most-successful applications of geophysical remote sensing employ more than one method. The reason for this is that each method works on a different physical process and is capable of identifying different types of cultural features. For instance, magnetic methods detect spatial variations in the magnetic properties of the soil, which may be significantly influenced by burning, among other things. Hence, this method readily identifies hearths and burned structures, whereas resistivity-conductivity methods permit identification of moist or dry areas in the subsurface that may relate to depressions such as pits or burials, or structural elements like walls.

The application of geophysical methods traditionally has been associated with archeological sites with architecture (or other significant features such as walls, ditches, middens, etc.); they have been less-widely applied to hunter-gatherer sites. They are widely applied in Europe (e.g., Clark 1996; David 1995; Gaffney and Gater 2003; Pasquinucci and Trément 2000), and in places like Britain geophysical prospection methods are considered a standard part of the archeological repertoire.

In Texas, geophysical investigations, typically magnetometer surveys, have been employed with a range of success at a variety of site types, including prehistoric hunter gatherer sites in alluvial settings (Abbott and Frederick 1989, 1990a, 1993; Frederick and Abbott 1992), sandy mantle uplands (Rogers 1999, 2000), rock shelters (Simpson and Peterson 2004), burned rock middens (Abbott and Frederick 1991), prehistoric settlements with architecture (Creel et al. 2005), and historic sites (Bruseth et al. 2004). In some cases, the results have been spectacular and of considerable use in guiding archeological field investigations (e.g., Presidio La Bahía [Bruseth et al. 2004], the George C. Davis site [Creel et al. 2005]), whereas in other instances the results were disappointing owing to a variety of reasons, at least some of which are geological in nature (e.g., background noise caused by gravel [Abbott and Frederick 1994]).

\section{Expectations for Caddo Archeology}

From a theoretical perspective, several of the known elements of Caddo settlement sites are potentially detectable through geophysical 
methods. For instance, pits, hearths, posts, middens, burned buildings with daub, and earthen mounds may all be found by means of magnetic survey (e.g., total field, gradiometry, or magnetic susceptibility), if the cultural processes that created the features resulted in the spatial juxtaposition of deposits with different magnetic susceptibility. Negative-relief features such as pits, burials, and post molds may also be detectable by resistivity-conductivity methods if the depressions lead to spatial irregularities in soil moisture. Broad enrichment of the soil by cultural processes such as burning refuse, disposing of ash, or burning crop remains in their fields may lead to the formation of broad magnetic susceptibility anomalies that would be poorly resolved by other magnetic methods.

Actual geophysical surveys of Caddo sites support these expectations. For instance, Lockhart and Schambach (2005) used a variety of geophysical methods to locate a burned and unburned Caddo structures, hearths, and graves at the Tom Jones site in southwest Arkansas. Similarly promising but less well groundtruthed results were obtained by Lockhart et al. (2005) for the Mississippian Parkin site in northeast Arkansas. In Texas, the recent and extensive magnetic survey of the George C. Davis site (Creel et al. 2005) resulted in the identification of a wide range of possible prehistoric structural features such as houses, shaft graves, hearths, and postholes, as well as more-recent historic features like roads and former excavation blocks.

\section{Research Questions}

- Can prehistoric cultural features be identified by geophysical methods? Typically, Caddo structures are only recognized by finding postholes at the B horizon interface by mechanical scraping, well below where any floor surface would have been. If geophysical survey can locate some prehistoric features, then we stand a good chance of recovering more-detailed artifact assemblages from meaningful contexts (e.g., houses, paths, plazas or open areas, etc.) and making headway in linking artifact scatters with specific behaviors. However, if the only way to identify such structures is to remove the occupation surface, then recovering meaningful artifact assemblag- es from specific cultural contexts will be much more opportunistic and incomplete, given that some of the occupation surface had to be destroyed to identify evidence of spatial structure. Geophysical investigations should assist in finding cemeteries if present within the surveyed areas, but if cemeteries are present in the project area and have not been identified as areas of artifact concentrations by the original survey and auger sampling, they will probably not be found by the geophysical investigations.

- Which geophysical methods best capture or illustrate the locations of cultural features? Most of the geophysical methods discussed below operate on fundamentally different physical bases and therefore are suited to finding specific kinds of features. For instance, magnetometer surveys map out the manner in which cultural features warp the earth's magnetic field on a very small scale, and they are particularly suited to finding thermal features (e.g., hearths and kilns) and thermally altered materials (e.g., ceramics) or subtle differences between the magnetic properties of feature fills and the surrounding natural soil. Conductivity and resistivity measure the ease or difficulty by which an electrical current may move through the soil, and therefore they are particularly suited to identifying cultural features that concentrate moisture (which allows a current to move easily) like pits or ditches, or features that are dry and hinder the passage of electrical current (like masonry walls, stones, etc.). Ground-penetrating radar measures spatial and stratigraphic differences in the dielectric constant of the soil, and features that present contrasts of this property are detectable by this method.

- What edaphic conditions inhibit or enhance the effectiveness of geophysical prospection? A variety of physical factors control the success of geophysical survey (e.g., depth of features, diameter of features, contrast of measurable properties between features and surrounding soil [magnetic susceptibility, moisture, etc.], postdepositional disturbance, and background noise), and for this reason, geophysical survey has met with mixed success in prehistoric archeological applications in the past. Rather 
than simply conclude that an approach works or not, understanding why it did or did not work would aid future projects.

\section{Relevance}

The point of applying geophysical survey methods to the testing phase is to provide us with an opportunity to find and target specific structural features (e.g., houses, middens, hearths, pits, pathways, and burials) before we start digging. This approach, if successful, opens the door to a higher level of archeological investigation. Although it may be true that sandy substrates are less favorable than clayey ones for magnetic survey (James Bruseth, personal communication 2005; Gaffney and Gater 2003:79), that does not necessarily mean that these soils will be as problematic for other methods such as resistivity or EM conductivity.

\section{Data Requirements}

- Geophysical survey using several different methods (methods described in detail below).

- Ground-truthing of selected anomalies by hand excavation.

\section{Methods Used to Gather Data}

\section{Magnetic Methods}

Magnetic methods are the most widely employed geophysical prospection tool in archeology, and all of them measure directly or indirectly the magnetic properties of the soil. A variety of cultural and natural processes are responsible for cultural features being detectable by this form of survey. Perhaps the most important are thermoremanence and enhanced magnetic susceptibility. Thermoremanence is a magnetic field that develops after an object (but more importantly, a feature like a hearth or kiln) is heated above the Curie point. It forms when magnetic particles realign themselves with the earth's magnetic field, thereby resulting in a stronger magnetic signature.

Magnetic susceptibility is measured by a nondestructive technique based upon the principle that magnetic minerals become more-strongly magnetized in the presence of a weak external magnetic field. As Dalan and
Bannerjee (1998:6) note, it is essentially a measure of the degree to which a sample may be magnetized. The magnetic susceptibility is the ratio of the magnetism induced in the sample to the strength of the applied magnetic field. In small alternating magnetic fields, the process of induced magnetization is reversible and the magnetism of the sample returns to its original state after the field is removed. The magnitude of the magnetic susceptibility of any given sample reflects: (1) the mineralogy, (2) the concentration of magnetic minerals, and (3) the magnetic mineral grain size and shape. Magnetic susceptibility is not very useful in identifying which magnetic minerals are present, but rather is a rough index of the amount of magnetic minerals present. It reflects the concentration of magnetic minerals in a sample if only one magnetic mineral is present.

Magnetic susceptibility may be enhanced by organic and inorganic processes. Organic processes responsible for increases in soil magnetic susceptibility through the creation of magnetite or maghaemite include bacteria that fix and create magnetic minerals such as magnetite (organisms known as magnetotactic bacteria). Inorganic processes that lead to magnetic enhancement in soils include low- and high-temperature chemical reactions. The most common process in prehistoric archeological contexts in the New World is the formation of magnetite or maghaemite during heating of earth or rocks in hearths. Three particular magnetic methods are important here: total field survey, gradiometer survey, and magnetic susceptibility survey.

\section{TOTAL FIELD SURVEY}

Total field magnetic survey maps the strength of the earth's magnetic field and is able to locate archeological features of interest because of the manner in which these features warp or distort the earth's magnetic field on a local basis. This form of survey relies upon two magnetometers, one that records temporal (or diurnal) variations in the earth's magnetic field at a single place during the field survey, and another that is used to record spatial variations of the earth's magnetic field. The stationary or diurnal record is subtracted from the spatial record to remove temporal drift in the earth's field which, if not removed could be mistaken 
for spatial variation. This form of survey has been the most common one in the past but is gradually being replaced by gradiometer survey.

\section{GRADIOMETER SURVEY}

Gradiometric survey is similar to total field survey, except that it uses two magnetic sensors placed one above the other to simultaneously record the vertical gradient (or vertical component) of the earth's magnetic field. Basically, this method results in a map that is more sensitive to magnetic anomalies (either variations in magnetic susceptibility or thermoremanence) associated with objects or features in the soil (Gaffney and Gater 2003).

\section{MAGNETIC SUSCEPTIBILITY SURVEY}

Magnetic susceptibility is one of the more commonly measured magnetic properties of a deposit, and it is easily measured in the field or lab (Dalan and Bannerjee 1998). The magnetic properties of sediments and soils, like magnetic susceptibility, are conveniently measured and can be applied to a wide range of environmental problems (see Walden et al. [1999] for details concerning the measurement and use of mineral magnetics in environmental studies). In general, magnetic susceptibility is a measure of how magnetic a sample becomes when it is placed in a strong magnetic field, and it is a rough measure of the quantity of magnetic minerals present. The rationale behind its analysis in archeological contexts is that human activities often create or concentrate magnetic minerals and that the locations of these activities may identified by examining the stratigraphic or spatial distribution of these minerals. Gaffney and Gater (2003:44) also note that, in archeological contexts, enhanced magnetic susceptibility is often due to the destruction and dispersion of underlying archeological features like hearths by plowing or natural processes. Spatial mapping of magnetic susceptibility is accomplished by a probe that is placed on the ground surface and that directly measures the volume-based magnetic susceptibility.

\section{Resistance Survey}

Resistance surveying measures the ability of soil to pass an electrical current and involves placing two metal probes or electrodes into the soil and passing an electrical current from one to the other, thereby measuring the resistance to flow. The depth of sensing is proportional to the width between the electrodes, with narrower spacing providing shallower sensing depth. Up to four electrodes are commonly used, and the spacing between the electrodes may be configured in a variety of ways.

In general terms, low-resistance conditions include wet ground and typical low-resistance archeological features include pits, graves, and presence of metal. High resistance is encountered when the soil is dry, or deposits at depth have large voids as in gravel or rubble; archeological features in this category include roads, walls, and foundations. The success of resistivity survey depends upon seasonal variations in soil moisture, and during dry conditions there may be insufficient moisture in the soil to make acceptable contact (a problem referred to as contact resistance).

\section{Electromagnetic Conductivity (EMC)}

Conductivity is the reciprocal of resistivity, and therefore, in principle, the results of an electromagnetic conductivity survey should be similar to, but opposite of, a resistance survey. But because of differences in the operation of the instruments, the two methods yield somewhat different results. Conductivity instruments generate an electromagnetic field from a transmitter coil at one end of the instrument, which creates an electrical current in the ground. That current generates a secondary magnetic field that is picked up by a receiver coil at the other end of the instrument. The magnetic field generated by the current in the ground is proportional to the conductivity of the soil between the transmitter and the receiver.

Unlike resistance survey, conductivity survey does not require direct contact with the soil, which can be a distinct advantage in some circumstances, such as arid landscapes where resistance meters often encounter contact resistance problems The lack of direct contact also makes EM survey quicker to perform, which translates into larger areas surveyed in the same amount of time. As with resistance survey, the depth of sensing is proportional to the distance between the transmitter and the receiver, and 
this can also be influenced by the orientation of the coils. However, because this distance between the coils is usually fixed on EM instruments, they are not as flexible as resistivity meters where the sensing distance can be varied to adjust the distance between the electrodes. The kinds of archeological features that can be found with EM conductivity survey are similar to those identified with resistivity survey.

\section{Ground-Penetrating Radar}

This prospection method works by emitting a short pulse of very high-frequency radio energy from a transmitter into the earth, and this energy is then reflected back toward the surface by strata interfaces or objects with different dielectric constants. The difference in time between the emission of the pulse and the returning echo (referred to as a travel time) is primarily a function of depth. The depth of detection and resolution of the method are determined by the frequency of the emitted radio pulse, with high frequencies having higher resolution but shallower penetration depths (Gaffney and Gater 2003:47-51).

In this particular setting, GPR can be expected to show the clay-sand interface clearly, and possibly identify pits or postholes excavated into it. However, to effectively do this will require a high-spatial-resolution survey, which can be stitched together to form a three-dimensional data set that can then be resampled and plotted horizontally to form maps that are essentially time slices (or more specifically travel time slices). The probability of identifying such small features will be a direct function of the distance between the transects, and this may be best used to confirm the nature of specific features identified.

\section{RESEARCH THEME: SITE INTEGRITY}

\section{Theoretical Rationale}

The issue of stratigraphic integrity with respect to archeological sites situated in upland sandy environments of east Texas is a prominent one, particularly when attempting to establish site significance. This issue is identified in the East Texas Plan in general (Kenmotsu and Perttula 1993:10) and by most of the research themes identified in it in particular (e.g., Perttula 1993:134; Perttula et al. 1993:111) as a critical attribute relevant to establishing the significance of a site. The reason for this fairly straightforward. If a site's integrity has been destroyed by postdepositional disturbance, the ability of the site to yield specific information that addresses important research questions, such as those established in the East Texas Plan (Kenmotsu and Perttula 1993), may be significantly, but not necessarily completely, compromised. Hence, the issue of integrity is directly relevant to the goals of this phase of work.

Unfortunately, integrity is an elusive concept in these landscapes. Although the issue is discussed in finite terms that may seem binary (a site either has integrity or it does not), the reality is always far from black and white, and typically expressed in a myriad of subtle shades of gray that seem to be infinitely debatable. In part, this is because there are still major questions concerning the geologic evolution of the soils in these environments, whether they are dynamic or static entities, and if dynamic, what are the specific processes and mechanics associated with their movement. All of these seemingly unrelated geologic issues are directly relevant to understanding how any given site may have formed and whether the site has integrity or not.

Recent accounts in the Texas archeological literature concerning how these soils have formed can be distilled into three basic models: (1) geomorphic stability together with extensive pedoturbation; (2) geological deposition attributable to geomorphic instability in the form of overland flow processes (sheetwash and gullying) and creep; and (3) some combination of pedoturbation and dynamic geomorphic events working in tandem (polygenesis).

\section{Stable Landscapes}

The first school of thought holds that these soils, which consist of a sandy zone resting on a pedogenically derived clay or sandy clay (a Bt horizon), which are sometimes referred to as texture contrast soils, are evidence of long-term geomorphic stability. Indeed, the prominent Alfisols and Ultisols found in these settings, according to normal soil-geomorphic principles, imply a long period of relatively stability has occurred in order for them to form. The presence and degree of development 
of Bt horizons is often used to estimate the age of Quaternary deposits in the absence of absolute dates (cf. Birkeland 1999:216-217), and substantial argillic horizons are thought to require long periods of time (generally more than 10,000 years) to form. Hence, deposits exhibiting such soils are typically assumed to be of Pleistocene age. Incipient forms, however, such as clay lamellae, may form quite rapidly (e.g., Gile 1979) and are thought to be of little chronological utility despite the fact that they may increase in thickness and frequency with time and eventually merge to form a Bt horizon (Birkeland 1999). If cultural materials are found at depth within a soil of considerable antiquity, the advocates of the geomorphic stability school consider pedoturbation (soil mixing) as the mechanism to account for burial.

There is an emerging and extensive literature on the effects of pedoturbation on archeological residues and soil profiles from various authors starting with Charles Darwin (1881) and continuing to this day with the writings of Don Johnson (e.g., Johnson 1989, 1990a, 1990b, 1993a, 1993b, 1994, 1997, 1999, 2002; Johnson and Balek 1991; Johnson and Hole 1994; Johnson and Watson-Stegner 1987; Johnson et al. 1987, 2002, 2003, 2005a, 2005b) and Julieann van Nest (2002) that have highlighted the manner in which soil digging (or fossorial) soil fauna may effect the burial of cultural residues left on the ground surface. In general, the manner and size of the sediment moved by postdepositional disturbance processes lead to some predictable effects on the distribution of rocks and artifacts of different sizes within the soil profile. Small animals, often arthropods or worms, tend to move the smallest portion of the soil and typically exhume sediment, which results in net burial of items left on the ground surface causing those items to appear to sink in the profile. Because they do not move most of the artifacts directly, these animals can cause the burial and downward movement of nearly complete artifact assemblages and create pseudodepositional stratigraphy. Larger animals like gophers are less discriminating in their movement of soil, but in general terms, they do not move items larger than they are. Hence, these animals tend to mix small artifacts and stones and cause large ones to sink as they avoid them. Other processes like tree throw are not size selective, and they tend to homogenize or mix in a fragmentary manner the entire soil profile down to the depth of the base of the root plate.

Clearly, postdepositional disturbance may completely destroy the integrity of a site, or in some cases may actually be responsible for its preservation (e.g., van Nest 2002). Which occurs, and the deleterious effects of the disturbance, depend upon the agent, its size, and degree of activity.

\section{Dynamic Landscapes}

Although a Bt horizon may require considerable time to form, its presence at depth does not require it to have formed from the sand overlying it, a point frequently noted by advocates of dynamic slope sedimentation. Inspection of the modern landscape today reveals that denudation of the sandy soils down to the top of the Bt horizon is common, and subsequent slope sedimentation may rebuild profiles that look intact but have considerably more-complex histories than advocates of the stable landscape school infer. This was the conclusion drawn by Frederick et al. (2001) from work done at 41LE177, where there was clear evidence of more than one phase of slope erosion down to the top of the Bt horizon. It is also clear in modern landscapes and archeological investigations alike that gullying is now and has been common in some areas during the Holocene. Although dynamic erosion and sedimentation may account for some buried archeological sites, or at least portions of some sites, it is difficult to advocate this process as the major one, especially in flat to gently rolling uplands.

\section{Polygenetic Processes}

Reality is probably closest to the third scenario, given that the evidence in hand includes testament to geomorphic instability (in the form of buried soils, erosional depressions like gullies cut into the underlying Bt horizon, and apparent depositional stratigraphy [with respect to the position of Uvalde Gravels], as well as apparently in situ burned rock features with broken but integral fire-cracked rocks, or in some instances charcoal-stained matrix [Bousman and Fields 1991:16]) and pervasive bioturbation (in the form of deeply buried and dispersed prehistoric and historic-age artifacts at many [but not all] sites). This suggests that these 
landscapes are mosaics, with some effectively stable areas where pedoturbation may be the predominant process, more geologically active areas where effectively normal slope erosion and sedimentation may occur, and areas where both processes occur to one degree or another.

Some researchers in Texas, most notably Alston Thoms, have attempted to integrate both of the aforementioned processes into their conceptual model of sandy mantle formation (e.g., Thoms 1995; Thoms and Olive 1993; Thoms et al. 1994), which appears to draw heavily on or at least parallel the largely theoretical work of Don Johnson. Also consistent with polygenesis is recent process geomorphological research concerning how sediment is transported on sandy slopes by Gabet (2000) and Gabet et al. (2003), which highlights how bioturbation (either exhumation by small animals or tree throw) may augment downslope transport processes by exposing sediment above the vegetation where it is effectively made available for downslope transport by overland flow, rainsplash, and other processes.

As if this situation was not complex enough, the existence of a microtopographic mounded landscape across the uplands of this region prior to historic clearance and agriculture (clearly visible on the 1935 aerial photographs of the project area, and prominently present on at least one site today) raises the geological ambiguity to another level. The geomorphic origin of these small mounds, locally referred to as pimple mounds but more widely called mima mounds in the geomorphic and archeological literature, are widely debated and generally unresolved, although one specific school of thought appears to be emerging. The most comprehensive discussion of these features in Texas landscapes, including their formation processes and geoarcheological implications, is found in Abbott (2001:91-97). Basically, Abbott describes five models of pimple mound formation: relict fluvial bedforms, burrowing disturbance, differential erosion by alluvial or eolian processes, eolian deposition, and polygenesis. In general terms, determining the formation process of such mounds in a sandy environment is likely to suffer from problems of equifinality, given that at least two processes (pedoturbation and eolian deposition) may result in similar landforms and deposits. However, if Johnson (following earlier arguments by George Cox [e.g., Cox 1984; Cox and Gakahu 1986]) is correct (Horwath 2002;
Horwath et al. 2002; Don Johnson, personal communication 2005; Johnson et al. 1999, 2002, 2003 ;) and pedoturbation by fossorial rodents is the principal formation process of these features, then this has significant implications for the integrity of sites situated upon and within pimple mounds. But this remains a far from widely accepted hypothesis at this time.

\section{Research Questions}

- Is there evidence (analytical or stratigraphic) that the deposits above the subsoil retain stratigraphic integrity? Field evidence in the form of cultural stratigraphy, matrix-defined features, discrete artifact distributions, and apparently in situ features may provide basic clues to the integrity of the deposits. Analytical methods such as ${ }^{137} \mathrm{Cs}$ and ${ }^{210} \mathrm{~Pb}$ (described in detail below) will indicate how vertically mobile the deposits have been recently, and single-grain optically stimulated luminescence may provide a longer-term image of particle mobility. Stratigraphic variations in particle size distribution, magnetic susceptibility, and total phosphorous content may also delineate stratigraphic features that are not readily visible with the naked eye.

- What processes (natural or cultural) have or are affecting deposit integrity? The specific disturbance processes that have affected a soil profile may be difficult to determine with precision, but the depth distribution of various small particles will provide clues to these processes. There is a significant literature on the impact of cultivation on the distribution of radionuclides, and pedoturbation by insects and worms will be expressed differently than that created by fossorial mammals. The relevance here is that how a soil has been disturbed has a significant impact on the distribution of cultural material at depth. For instance, Frederick et al. (2005) recently demonstrated that archeological site burial by insects in Florida resulted in sites that retain a high degree of apparent stratigraphic integrity (as viewed by the vertical distribution of artifacts at depth), whereas Bateman et al. (n.d.) compared this luminescence profile with previously excavat- 
ed archeological sites at the Jewett Mine in east-central Texas, where a significantly different pattern is present, most likely associated with bioturbation by fossorial mammals such as gophers. Observations from these sites (depending upon sample locations) may be relevant to sites found in mima (pimple) mounds elsewhere.

- Are there segments of the landscape within the sites with greater stratigraphic integrity than others? It is possible that postdepositional disturbance processes may have adversely affected some parts of the landscape more than others. For instance, if soil disturbance is primarily associated with a biological agent, water-spreading slopes may have experienced a different level of disturbance than water-gathering slopes, or pimple mounds may be more disturbed than nonmounded portions of the landscape.

- Are shallow sandy profiles more disturbed than thick ones? This has long been assumed but rarely demonstrated. However, it is logical to conclude that if the spatial intensity of postdepositional disturbance processes is evenly distributed across the landscape, then shallower profiles may experience greater disturbance, especially if the thickness of the soil is less than the average activity level in deeper soils. So, for instance, if gophers typically burrow in the top $30 \mathrm{~cm}$, it is likely that a soil profile only $20 \mathrm{~cm}$ thick may be more frequently affected by gopher burrowing than a deeper profile. It is potentially erroneous to assume, however, that disturbance processes are spatially uniform.

\section{Relevance}

Previous work on sandy sites such as 41LE177 (Ricklis 2001) suggests that some may possess stratigraphic integrity despite the fact that the deposits lack visible evidence of it. So, just because a site does not exhibit visibly distinctive bedding does not mean it is not stratified. The analytical methods proposed here are designed to permit us to evaluate if the deposits are intact and depositional, or significantly disturbed by postdepositional processes The breadth of analytical approaches will provide a better-than-average image of potential cultural attributes (e.g., depth distribution of artifacts, culturally related chemical additions such as phosphorous, and magnetic susceptibility) as well as a measure of how rapidly and often particles are moved up or down the profile. This knowledge will be useful in determining if the sites contain important information.

This work will not necessarily provide definitive answers to the more-philosophical question of how much vertical displacement of artifacts is acceptable before a site loses sufficient integrity as to be able to contribute new information toward understanding the prehistory of this region, but it will yield data useful in exploring this issue. In general terms, how this general question is answered depends upon the research questions posed, and how much they rely upon stratigraphic integrity. Stratigraphic integrity is irrelevant for some research issues, and critical for others.

\section{Data Requirements}

- Detailed sampling and analytical documentation of soil profiles from the sites, and from various different landscape positions within them.

- Determination of depth profiles of ${ }^{137} \mathrm{Cs}$, ${ }^{210} \mathrm{~Pb}$, and single-grain OSL.

- Physical characterization of the profiles for granulometry, organic carbon, total phosphorus, and magnetic susceptibility.

\section{Methods Used to Gather Data}

The methods we propose to use to assess site integrity include the depth distribution of Cesium-137 $\left.{ }^{137} \mathrm{Cs}\right)$, Lead-210 $\left({ }^{210} \mathrm{~Pb}\right)$, single-grain optically stimulated luminescence dating, and magnetic susceptibility, in conjunction with other measures that characterize the nature of a deposit such as granulometry, organic carbon, and phosphorous content (total P). The fundamental bases of these methods are described below, but in general terms, they provide different ways of assessing the vertical mobility of particles within the profile, and when the results are viewed in conjunction with the results of hand excavation units, they should facilitate evaluating the stratigraphic integrity of the deposits. 
Stratigraphic integrity of the sands can be evaluated by single-grain OSL dating as has recently been demonstrated by Frederick et al. (2005) and Bateman et al. (n.d.). OSL dating determines the amount of time that has passed since a sand grain has been exposed to sunlight. A single-grain OSL date consists of OSL dates on as many as 150 individual sand grains, which permits discrimination of deposits comprised of grains of the same age (which is typical for deposition or stratigraphically integral sands) from those that contain a wide range of ages associated with postdepositional disturbance. Indications of the magnitude of recent disturbance can be assessed through the depth distribution of radionuclides that have been deposited on the surface recently such as ${ }^{137} \mathrm{Cs}$ and ${ }^{210} \mathrm{~Pb}$ (cf. Bunzl 2002; Fujiyoshi and Sawamura 2004; Tyler et al. 2001). Recent work by Hall (2003) at the Mescalero sands in New Mexico successfully employed a similar (but not identical) suite of samples to evaluate the age and integrity of mesquite coppice dunes. Magnetic susceptibility may also be used to evaluate the stratigraphic integrity of site deposits (cf. Frederick et al. 2001).

\section{Overview of Cesium-137 ( $\left.{ }^{137} \mathrm{Cs}\right)$ and Its Use}

Cesium is an alkali metal that has a single stable isotope and 35 unstable isotopes, none of which are naturally occurring. One of these unstable isotopes, ${ }^{137} \mathrm{Cs}$, is widely employed in the earth sciences because it has a relatively long half-life (37.17 years). The decay of ${ }^{137} \mathrm{Cs}$ to ${ }^{137} \mathrm{Ba}$ results in the emission of a beta particle and a gamma ray, the latter of which can be measured by gamma-ray spectrometry (Faure and Mensing 2005:678). The source of ${ }^{137} \mathrm{Cs}$ is fallout from atmospheric nuclear testing and atmospheric release from accidents like the Chernobyl reactor explosion, and the atmospheric deposition has varied through time, with a prominent peak in early 1960s (Beer et al. 1985; Faure and Mensing 2005). Faure and Mensing (2005) note that ${ }^{137} \mathrm{Cs}$ is strongly sorbed in soil and clay minerals, and more than 50 percent of ${ }^{137} \mathrm{Cs}$ may be retained in soil profiles and not leachable even with strong reagents.

The use of ${ }^{137} \mathrm{Cs}$ as a chronometer by correlation in paleoenvironmental studies is common in situations where rapid recent sedimentation is expected, such as some lake cores. However, because it has been deposited on the surface recently and is strongly sorbed onto mineral and organic matter, it has also been used as a tracer in studies of pedoturbation (cf. Hall 2003; Southard and Graham 1992) and soil erosion (Bajracharya et al. 1998). For instance, Hall (2002) used ${ }^{137} \mathrm{Cs}$ to demonstrate that coppice dunes in the Mescalero sands are essentially intact, by showing that ${ }^{137} \mathrm{Cs}$ is not distributed down the soil profile, but rather is concentrated near the modern ground surface.

The use of ${ }^{137} \mathrm{Cs}$ envisioned here is to examine the extent of recent vertical movements in the soil. If the soils are intact and have experienced little recent disturbance, then ${ }^{137} \mathrm{Cs}$ should be concentrated near the modern ground surface. If, however, the soils are experiencing significant physical disturbance, ${ }^{137} \mathrm{Cs}$ will be found at depth below the modern surface. Theoretically, the depth distribution of ${ }^{137} \mathrm{Cs}$ will provide some indication of the depth of recent disturbance.

\section{Overview of Lead-210 ( $\left.{ }^{210} \mathrm{~Pb}\right)$ and Its Use}

The naturally occurring unstable isotope ${ }^{210} \mathrm{~Pb}$ is a byproduct of the decay of the common, long-lived unstable isotope ${ }^{238} \mathrm{U}$ and has a useful half-life of 22.6 years (Faure and Mensing 2005:497-498). It is widely distributed globally from the atmosphere by precipitation and dry fallout. The decay of ${ }^{210} \mathrm{~Pb}$ to ${ }^{210} \mathrm{Bi}$ releases a low-energy beta particle that is difficult to measure, so the next decay product is measured, which is ${ }^{210} \mathrm{Bi}$. This unstable isotope decays to ${ }^{210} \mathrm{Po}$ with the release of a more-measurable beta particle with a half-life of five days, and it is assumed to be in equilibrium with ${ }^{210} \mathrm{~Pb}$ (Faure and Mensing 2005). Lead-210 is strongly retained by soil organic matter and sorbed onto mineral surfaces in streams and lakes, and it is widely employed as a chronometer for lacustrine studies (e.g., Appleby and Oldfield 1992; McCall, et al. 1984; Robbins 1984). Unlike ${ }^{137} \mathrm{Cs}$, deposition of ${ }^{210} \mathrm{~Pb}$ is continuous.

The use of ${ }^{210} \mathrm{~Pb}$ here is similar to that of cesium-137, which is as a tracer for recent soil disturbance. If the soils are relatively undisturbed, most of the ${ }^{210} \mathrm{~Pb}$ in the profile should be concentrated near the present ground surface. If, however, the soils have experienced significant vertical movement recently, ${ }^{210} \mathrm{~Pb}$ is expected to be distributed at depths below the surface that reflect the nature of the disturbed zone. 


\section{Single-Grain Optically Stimulated Luminescence Dating and Its Use}

Optically stimulated luminescence dating is a method that is used to determine how much time has elapsed since one or more sand grains were last exposed to sunlight. Most common minerals (but specifically quartz and feldspar) are able to store energy in traps or defects in their crystalline structure. This energy typically is provided by ionizing radiation (e.g., alpha, beta, and gamma radiation) derived from minerals, as well as cosmogenic sources. The amount of energy trapped or stored in the minerals increases with the period of time the crystal is exposed to the radioactivity, and this energy can be released by exposure of the mineral to light and/or heat. When this occurs, the traps release their stored energy in the form of light or luminescence. By measuring the amount of light given off by a sample, and then determining the amount of radiation required to elicit this response (a property known as the equivalent dose or paleodose [abbreviated $\mathrm{D}_{\mathrm{e}}$ and measured in Grays $\{\mathrm{Gy}\}]$ ), it is possible to determine how much time has elapsed since the sample was last exposed to sunlight by dividing the equivalent dose by the dose rate (the rate at which the sample was exposed to radiation in the burial environment, measured in Grays per thousand years [Gy kyr-1]).

There are two common forms of OSL dating: standard aliquot dating and single-grain dating. In standard aliquot dating, the sample age is derived from measurements of populations of sand grains on one or more 1-cm-diameter discs (where each measured disc is an 'aliquot'). Typically, a single disc will hold around 2,000 grains, and a single standard aliquot OSL date may involve the measurement of 15 to 25 discs, computing the average age from the age yielded by each disc. Recent developments in luminescence dating now permit measuring the $\mathrm{D}_{\mathrm{e}}$ values and therefore OSL ages for individual sand grains (cf. Duller 2004), and this method permits more-accurate depositional ages to be determined, especially where more than one equivalent dose population is present or suspected. Because OSL dating relies upon a physical process (exposure to sunlight) to reset the clock, this technique has been used for dating the transportation of sand grains in the natural environment, as well as examining a variety of other natural processes such postdepositional disturbance, and granular mobility within a deposit (cf. Bateman et al. n.d.; Frederick et al. 2005; Heimsath et al. 2002).

For this study, incremental samples of sand will be collected in the field in light-tight tubes, and then processed in the lab to determine the age distribution of grains within each sample in order to examine how much vertical mobility is present within the sands. Given that the upper age limit of OSL dating is typically in excess of 100,000 years, these data are expected to show the detail of granular movement within the soil for a period of time considerably longer than either Lead-210 or Cesium-137. The results of this work will depend upon the formation process of the deposit, the degree to which the deposit has been disturbed by postdepositional processes, and when the events occurred.

\section{RESEARCH THEME: LOOKING FOR STRUCTURES WHEN GEOPHYSICS LETS YOU DOWN}

\section{Theoretical Rationale}

If the geophysical surveys fail to return anomalies that are clearly or potentially associated with prehistoric habitation, then testing investigations must revert to more-traditional approaches of finding prehistoric activity areas and structures. It is clear from a review of geophysical work in Texas (above) that these methods, although widely extolled, do not always yield positive results. Gaffney and Gater (2003) and David (1995) describe the suitability of various geological substrates for archeogeophysical survey and note that some conditions are more favorable than others. Sand and alluvium in particular are less than ideal, and previous work in Texas has reached the same conclusions independently (cf. Frederick and Abbott 1992; James Bruseth, personal communication 2005). However, it is generally impossible to predict the success of geophysical investigations in advance, and for this reason, they will be performed.

In the absence of useful geophysical survey data, we propose to employ field methods more commonly used in Caddo archeology, specifically limited hand excavation in areas of dense artifact scatters and mechanical scraping in conjunction 
with shovel skimming, to find structural evidence of prehistoric habitations. These general methods have been in use for some time (cf. Thomas et al. 1980) and have been employed on a number of Caddo sites (e.g., Perttula 2005; Rogers and Perttula 2004). They involve removing sand down to the clay (Bt horizon) interface and searching for pits and post molds, typically in areas of elevated artifact recovery. The survey information and follow-up auger sampling (Perttula et al. 2002; Perttula and Nelson 2005; Wilder and Fields 2005) have provided us with an excellent image of the geographical distribution of ceramic and lithic artifacts, and these data are the primary information upon which test excavation locations will be based if geophysical survey fails to yield useful information.

Although artifact distributions appear to be the most-relevant way of identifying Caddo structures, we also intend to examine whether pimple mounds influenced the spatial selection of locations for Caddo structures or other prehistoric activities. Johnson (2005) noted the use of mima-like mounds for habitation by a wide variety of Native American prehistoric groups and commented that there are far more mima mounds than mounds with sites in them. In some parts of Texas, prehistoric occupation of mima or pimple mounds is commonplace (such as the coastal plain; cf. Abbott 2001), and in the northeast Texas region there are hints that this also may have occurred among the Caddo. For instance, Perttula (2005) noted the seeming co-occurrence of prehistoric artifacts on some "natural mounds" which may be indicative of such a process. The results of the auger sampling for this project (Wilder and Fields 2005) showed a prominent correlation between thicker soils (as defined by the depth to clay) and the spatial distribution of ceramics, with sherds being found within or immediately adjacent to thicker soils. Soil thickness information was collected during the auger sampling as a proxy for the spatial location of pimple mounds, and the area of thicker soils and known, easily visible pimple mounds compare favorably at sites like 41TT851, where mounded topography is present and clearly visible today.

\section{Research Questions}

- Can postholes or other negative-relief features such as burials be identified at the sand-clay interface by mechanical and shovel stripping?

- Were pimple (mima) mounds used as preferred locations for prehistoric structures?

- How can we minimize damage from stripping to enable us to later recover house-level provenienced artifacts for house to house comparisons (within-community artifact analysis). The main downside to this approach is that the discovery process destroys our ability to recover artifact assemblages from specific structure contexts except from negative-relief features (e.g., pits, hearths, postholes).

- How many postholes do we need to see before we can proceed with hand or other form of horizontally provenienced excavation?

- Does vertical provenience matter in excavating recent prehistoric structures if there is no obvious stratigraphy? Presumably not, if the site is single component, which is consistent with comments made by Perttula (1993:134). However, if multiple different-age components are present, then this is a different issue (cf. comments by Perttula et al. 1993:111). Data from hand excavations performed during testing should permit evaluation of this issue.

\section{Relevance}

It is critical for field investigations to be amenable to finding the kinds of archeological features that may be present in order to maximize the probability of discovery. In this particular case, evidence of prehistoric dwellings in the form of post molds, as well as other features such as burials, pits, and hearths are expected. The strategies to be employed in the field follow traditionally successful methods employed at similar sites in this region.

Furthermore, if sites with evidence of architecture are discovered, it is necessary at the testing level to investigate the relevance of vertically provenienced excavation for subsequent data recovery investigations. One of the larger goals of the project is to capture broad, large-scale patterns of past land use, and this can only be done if the rate of excavation can be improved, either by abandoning vertical provenience or adopting extensive mechanical stripping. 


\section{Data Requirements}

- Alignments of postholes.

- Normal (10-cm level) hand excavation of one structure per site.

\section{Methods Used to Gather Data}

The methods to be employed for this work are traditional forms of archeological excavation. In general terms, this work will entail limited hand excavation, often arranged in small blocks to increase the probability of encountering evidence of structures, machine stripping performed in conjunction with shovel skimming, and detailed mapping. Hand excavations will be performed in 10-cm levels, assuming no natural strata (specifically cultural stratigraphy, not soil horizons) are encountered. After the fieldwork is completed, field data will be explored to examine the significance of vertical provenience on interpretation to evaluate the potential for morerapid but extensive excavation during the data recovery phase if additional work is warranted.

\section{RESEARCH THEME: PALEOENVIRONMENTAL CHANGE}

\section{Theoretical Rationale}

One of the goals of environmental history is to put into context the delicate interplay between human populations and their surrounding environment (Butzer 2005). The way in which human activities affect the composition and structure of vegetation may have significant implications for the stability of the landscape in general and soils in particular, depending upon how and when the vegetation is modified and the social and physical measures implemented to offset these impacts.

For some time, it was widely believed that prehistoric hunter-gatherer populations had little affect on vegetation and soils and that native Americans lived "in the unspoiled wilderness" in harmony with nature (Butzer 1996; Delcourt and Delcourt 2004:3). This idyllic view of the distant past, sometimes referred to as the pristine myth, has, in the last decade or so since the passing of the Columbian Quincentennary, come under close and critical scrutiny (e.g., Denevan 1992; Redman 1999). Denevan (1999) in particular argued that the American landscape of 1492 was significantly altered from the natural by a variety of aboriginal activities, ranging from urban settlements, large-scale earth moving, and widespread agriculture to more-subtle but nonetheless significant changes brought about by burning undergrowth in forests and the encouragement of natural useful plants (see also discussions in Fritz [2000:242] and Fish [2000:272-274]). There also have been numerous studies of North American landscapes that have demonstrated that the activities of Native American populations, especially among sedentary groups practicing agriculture, evoked landscape changes that ranged from subtle to significant alteration of vegetation composition and structure (Delcourt 1987; Delcourt and Delcourt 1997; Delcourt et al. 1998; Denevan 1992; Jurney et al. 2000), to soil erosion (Delcourt 1987:44; Frederick 1995; Peacock et al. 2005). Studies that have searched for evidence of land use effects attributable to prehistoric agricultural groups in the midcontinental and eastern U.S. (e.g., Mississippian, Caddoan, among others) are rare (cf. Byrne and Finlayson 1998; McLauchlan 2003; Peacock et al. 2005), but the subject is of considerable interest among researchers in several disciplines (Fritz 2000:242) and the subject of local speculation (cf. Hubbard and Jurney 1998).

\section{Vegetation Change}

Records of past vegetation change derived from palynological study of wetland sedimentary deposits can provide unique insights into the ancient floristic environment and serve as a point of reference for understanding and inferring natural and/or anthropogenic vegetation changes (Delcourt and Delcourt 2004). Unfortunately, the conditions necessary for the preservation of pollen are fairly rare in Texas, although much less so in the eastern part of the state than the rest. It is for this reason that there have been few studies of Holocene vegetation change from Texas (cf. Bryant and Holloway 1992), but it is also why Collins and Bousman (1993:65) recommend that all projects in east Texas should evaluate each project area for the potential to contribute new paleoenvironmental data. In particular, Collins 
and Bousman (1993:64) give the example of how "a Late Caddoan Period midden site with only fair preservation of bone, pollen or other types of paleoenvironmental data would merit a narrow set of investigations. Nevertheless, there may be a relatively undisturbed bog or marsh deposit in the immediate vicinity that would warrant assessment."

Tankersley Creek is an environmental setting where wetland deposits may be preserved, specifically in abandoned channels or swales, which typically support wetland habitats for some time following abandonment. Recent palynological investigations by Albert (2004) suggest that meaningful pollen assemblages may be preserved in such settings in Texas.

\section{Soil Erosion}

In addition to evidence of floristic change, the issue of soil erosion is one that is of specific interest in this region. The consequences of deforestation on hydrology and soil stability are well known in general terms (Eshleman 2004) and involve increases in runoff and soil loss. The nature of the geomorphic response is a function of the size of the impacted area, its slope, substrate texture, magnitude and timing of precipitation, and postdeforestation land use practices. In this region, the erodibility of the sandy soils on the upland Eocene outcrop in the historic period is well known, and in some instances is of a sufficient magnitude as to be mappable at a regional scale (e.g., Henry and Basciano 1979).

Whether prehistoric land use by sedentary agricultural groups in this region was of sufficient scale and intensity to adversely affect the integrity of the soil is unknown, and it seems to have been unaddressed previously. The effect of Caddo agriculture on soil stability depended, at least in part, upon where the Caddo situated their fields. If their fields were on the easily worked upland sandy soils, then some evidence of soil erosion is to be expected. If Caddo agriculture focused on the floodplain or lowland deposits (as was Mississippian agriculture elsewhere [see discussion in Woods 1987]), the probability of soil erosion would have been lower, given the lack of potential energy for erosion to occur.

Evidence of site-specific soil erosion is typically found in places that form sedimentary sinks such as colluvial toe slopes and alluvial floodplains. Colluvial deposits often provide temporally fragmented and very local records of slope instability, and will reflect the history of specific slopes. Slightly more-average records of local sediment yield are to be found in the nearby streams. Examination of the alluvial stratigraphic records of streams in eastcentral Texas supports arguments (e.g., Henry and Basciano 1979) that recent (historic and possibly late prehistoric) deforestation has had a significant adverse influence on the stability of upland sandy soils in some places (cf. Abbott 1996; Bousman and Fields 1991; Bruseth et al. 1987; Frederick 2005; Schroeder 2005).

\section{Research Questions}

- How has vegetation changed through time in the project area?

- Is there palynological evidence of prehistoric and historic forest clearance and the timing of these events?

- If there is palynological evidence of clearance, are these events associated with elevated amounts of microcharcoal? Longterm changes in vegetation in this region are generally thought to have been fairly negligible. But there is also ethnographic evidence from various places in the southeastern U.S. of aboriginal use of fire in modifying vegetation structure and composition and in association with hunting (see Jurney et al. [2000] for a local recitation). Palynological documentation of long-term vegetation change in this region, which was relatively densely settled in the late prehistoric period, may provide insights on prehistoric silviculture, clearance, and woodland management.

- Did soil erosion occur in association with Caddo or historic settlement? The upland landscape in proximity to several of these sites is intensely gullied. Is this an artifact of recent or ancient erosion?

- Did prehistoric land use cause more or less soil erosion than historic land use? Soil erosion, following deforestation, is one way in which agriculture may have adversely affected landscape stability and land use. Soil erosion associated with historic clearance has been noted in several parts of east 
Texas. It is logical to assume that prehistoric land use and agriculture may have evoked a similar geomorphic response. Alternatively, if Caddo agriculture was as small scale and intensive as the Teran map indicates, then it may have had negligible influence on soil stability. Looking for evidence of erosion on the small streams draining areas of archeological sites in the project area, as well as the larger Tankersley Creek drainage, would provide information relative to this issue.

- Did declining soil fertility affect Caddo or historic agriculture, land use, and settlement? This may be an unanswerable question, but there may be some information in historic archives that addresses this issue from the historic period. Alternatively, if some of the Titus phase Caddo sites in the project area are villages that do not to overlap chronologically, this may be evidence of moving a settlement away from nutrient-exhausted soils.

\section{Relevance}

The coordinated paleoenvironmental investigation proposed here will directly address issues relevant to Caddo and historic period land use in this region that have been discussed but not investigated previously, and that are directly relevant to understanding the nature of landscape transformations in the Holocene. Some of the information derived from this work is directly relevant to other research themes defined for this project. For instance, the age and chronology of alluvial toe slopes and local floodplains are directly relevant to evaluating the idea of whether Caddo agriculture was situated on the floodplains, and if so, where stratigraphically within those deposits those surfaces may be located today. Likewise, some palynological information on the timing and the nature of Caddo agriculture is expected to be present in wetland sediments if a suitable sedimentary record can be located nearby. Furthermore, northeast Texas is one of the few areas in the state where evidence of landscape change in the recent past may be compared with annual records of past precipitation based on tree-ring records in nearby northwest Louisiana (e.g., Stahle and Cleaveland 1995; see also Perttula 2005).
Together, geomorphological and palynological studies of paleoenvironmental change comprise a powerful tool for exploring prehistoric land use and landscape response, as well as environmental change associated with natural processes. This project is ideally situated to investigate the issue of how sedentary prehistoric groups like the Caddo affected their local environment, and the studies proposed here will address this issue by investigating a range of local sedimentary archives with an appropriate suite of analytical methods.

\section{Data Requirements}

- Stratigraphic records of alluvial deposition on concave (water-gathering slopes) in proximity to prehistoric sites in the project area.

- Stratigraphic records of alluvial deposition along Tankersley Creek.

- Stratigraphic exploration of wetland settings on Tankersley Creek for possible pollen cores.

- Detailed and precise chronology for stratigraphic records.

- Pollen record of wetland sedimentary deposit in proximity to the project area.

- Dendroclimatological records for the region.

\section{Methods Used to Gather Data}

The work proposed here can be divided into three basic tasks: stratigraphic examination and documentation of colluvial and alluvial deposits, and the search for a suitable pollen locality on Tankersley Creek.

\section{Tasks 1 \& 2: Evaluating Colluvial and Alluvial Sedimentary Records for Evidence of Soil Erosion}

Fieldwork for the first two tasks will be basically identical but performed in slightly different landscape positions. Excavation of likely settings will be performed with a backhoe, and the walls of these trenches will be cleaned, described, and sampled if warranted. Dating of colluvial and alluvial deposits will be critical if identifying where in the stratigraphic sequence 
occupation surfaces of different age may be located, especially if this is not evident in the field from artifact distributions.

Dating these deposits will be critical to the success of this work and the goals of other research themes in this research design, and more than one method is recommended. Previous studies in east-central Texas have demonstrated that dating erosion events may be difficult with bulk sediment/soil radiocarbon ages as such samples often yield erroneous results during phases of soil erosion (Abbott 1996). Once these profiles have been cleaned and described, an assessment of the best means of dating the deposits will be made and then appropriate samples collected The most likely dating methods to be employed will be singlegrain OSL, and radiocarbon (charcoal and/or bulk sediment/soil).

\section{Task 3: Searching for a Pollen Record}

It is possible that the Tankersley Creek floodplain may have geological settings suitable for preserving a time series of pollen preservation, and a limited search for such deposits is planned. We propose to first scrutinize the available aerial photographs and then examine in the field depressions on the valley floor that hold the potential of preserving wetland deposits. The most likely setting for these deposits will be abandoned channels or sloughs. If promising locations are found, we propose coring the deposits to examine the sediments, and if favorable deposits are encountered, one or more cores will be extracted and a feasibility study of pollen preservation will be performed. If the deposits are found to be pollen bearing, then a limited number of radiocarbon dates will be run to determine the period of time covered by the deposits, and a proposal for detailed study of the pollen record will be compiled.

\section{RESEARCH THEME: FINDING CADDO AGRICULTURAL OR HORTICULTURAL LANDSCAPES}

\section{Theoretical Rationale}

The shift in subsistence from a foraging to a farming lifestyle by the Caddo appears to have been a gradual one that has been best illustrated by the progressive change in diet suggested by the paleobotanical evidence and stable carbon isotope analysis of human bones through time (Perttula and Nelson 2005:18). This gradual change undoubtedly affected land use and settlement practices, but the details of such aspects of Caddo life rarely emerge from the archeological record. It is clear from historical accounts of the Caddo (and here the term Caddo is broadly construed to mean reference to all of the Caddoan groups, as summarized by Griffith [1954] and Swanton [1996], rather than any one group) that their subsistence, although considerably more oriented toward domesticated plants than other native groups in Texas, was a mixed one that relied upon farming of traditional Mesoamerican plants, cultivation or at least encouragement of trees that yielded edible fruit and nuts, foraging for a wide range of wild edible and useful plants, and the hunting of various wild animals. Although the historical record provides a wealth of detail on these practices in the early years following European contact, there are several facets of Caddo agriculture that are little known.

The physical relationship between agricultural or horticultural fields and domiciles, as well as the physical subdivision and layout of these activity areas, are almost unknown. All published discussions of Caddo agriculture refer to the Teran map, which depicts agricultural fields and houses together in direct proximity to one another, and often surrounded by a vegetative barrier that resembles a hedge. Ethnographic information on Caddo fields depicts them as small (e.g., see the Teran map; Doolittle [2000:156] paraphrases Weltfish's [1937:39] description of Caddo fields as "described in the context of city streets; 'half a block' by 'a block and a half"'). The proximity of domiciles to the fields is seemingly supported by the observations Henri Joutel (1906:167), who in 1687 reported that Indians in east Texas (not specifically the Caddo) lived in "cottages...that are in the midst of their fields and gardens." Although this general relationship is widely assumed, it is still unclear where Caddo fields would have been located in areas like the one to be examined by this project. Does the apparent floodplain focus of many of the sites in the northern half of the project area reflect agricultural activities on the lowlands, or were the fields in the uplands overlooking the sites? 
In addition to traditional agriculture/ horticulture, the issue of cultivation or encouragement of edible and useful trees, or arboriculture or agroforestry, by the Caddo has recently been resurrected by Albert (2004). There are several historical accounts that recorded Caddo orchards, but most of these were late enough to represent adoption of European introductions such as the peach. For instance, Anthony Glass visited the floodplain village of the Kadohadacho in 1808 and saw "the remains of Caddo huts and many peach trees" (Flores 1985:40), and Goldborer (2002:84) notes that peaches were introduced to Louisiana by the Spanish prior to French settlement and by the English to their colonies in 1629. Griffith (1954:107-108) notes that Gaspar José de Solís observed Hasinai orchards containing various edible fruits, and Griffith speculated that these observations could be interpreted to mean the cultivation of introduced species or areas "of wild growth which served the same purpose as cultivated orchards."

\section{Research Questions}

- Can the locations of Caddo agricultural fields be identified?

- Are there artifact assemblages that are unique to agricultural fields?

- Where were Caddo agricultural fields located? Does the apparent location of sites (presumably houses) on the floodplain end of interfluvial ridges overlooking the valley floor of Tankersley Creek imply fields on the adjacent floodplain? Or were these fields situated on the sandy uplands immediately above the apparent artifact concentrations, or in both settings?

- Did the Caddo have field houses or other outfield structures (e.g., scaffolds for scaring away birds [cf. Doolittle 2000:159], poles at the corners of fields, or isolated posts for scarecrows)?

- Is there detectable evidence of field features/boundaries such as the hedge-like structures depicted on the Teran map?

- Beyond the meager ethnographic evidence, little is known about the location of Caddo fields or what may be their archeological manifestation. Part of the goal of these questions is to see if it is possible to identify such fields primarily on the basis of chemical evidence (see below) or artifactual evidence. If spatial anomalies consistent with prehistoric maize fields can be identified, subsequent sampling by excavation and limited geophysical work may be warranted to sample the kinds of artifacts that occur there, and possibly date sherds and burned lithics using thermoluminescence to demonstrate contemporaneity, if this cannot be achieved on physical attributes alone.

- Can pollen studies identify any native taxa that might have been encouraged by the Caddo for food (e.g., fruits such as wild plums or nuts like pecans [the advantages of which have been discussed by Hall $\{2000\}$ and as has been recently argued by Albert \{2004\} at 41UT77]), wood (as could be used for building [coppice-like behavior for wattle panels]), cloth (cf. Schambach 2004), or grass for thatching? Fritz (2000:241-242), on the basis of European observations of Native American orchards (specifically Hammett 1992), speculated that managed fruit and nut orchards may have been prominent features on the aboriginal landscape since the Archaic period.

\section{Relevance}

Given the dearth of information and previous investigations relating to this topic, any contribution on this front would be useful. But searching for evidence of agriculture may be one of diminishing returns. Hunting for chemical evidence of Caddo agriculture logically occurs on and near sites where evidence of structures can be found. So this line of investigation should follow (in terms of schedule) the more-basic testing procedures and only be implemented if this condition is met. Spatial search for chemical traces of agriculture seems the most efficient approach and could be followed by a second round of work at higher spatial resolution, with limited excavation to recover artifacts and limited geophysical work if promising anomalies are identified.

\section{Data Requirements}

- Spatial variation in stable carbon isotopes, total phosphorus, and magnetic 
susceptibility of the topsoil.

- Pollen data from a nearby wetland environment.

\section{Methods Used to Gather Data}

It is remotely possible that geophysical survey may identify the locations of prehistoric agricultural fields, but this is considered unlikely, especially since most of the geophysical grids will be situated in immediate proximity to the main occupation areas.

\section{Spatial Sampling}

The methods we propose to use to search for Caddo agricultural fields involve coarse spatial sampling of the soil for preservation of materials that may have been concentrated in the soil as a result of prehistoric agricultural activity, specifically maize cultivation. On the uplands these samples will be collected from the modern soil A horizon using a small soil auger or by excavating a small hole with a shovel and collecting a sample from the exposed profile. On the Holocene valley floor of Tankersley Creek and at the foot of colluvial slopes, it is possible that Caddo-age occupation surfaces may lie buried beneath the modern surface, and so sampling in these potentially more-dynamic areas will be performed following the initial results of dating of the alluvial and colluvial deposits.

\section{Stable Carbon Isotopes}

Terrestrial plants can be divided into one of three major photosynthetic pathways, each of which fractionates carbon in a different fashion. The isotopic composition of carbon within each photosynthetic pathway, known as $\mathrm{C}_{3}, \mathrm{C}_{4}$, and CAM, is sufficiently different to allow chemical discrimination. In general terms, nearly all trees and cool-season grasses have $\mathrm{C}_{3}$ photosynthetic pathway and are characterized by $\delta^{13} \mathrm{C}$ values of about $-27 \%$. On the other hand, $\mathrm{C}_{4}$ plants, principally warm-season grasses, are isotopically heavier and have $\delta^{13} \mathrm{C}$ values around $-13 \%$. Although there is some variation within each group, $\mathrm{C}_{3}$ and $\mathrm{C}_{4}$ plants have distinct $\delta^{13} \mathrm{C}$ values that do not overlap and differ by about $14 \%$ (Boutton 1991). Plants with the Crassulacean acid metabolism (CAM) photosynthetic pathway generally have $\delta^{13} \mathrm{C}$ values similar to $\mathrm{C}_{4}$ plants and range between -28 and $-10 \%$, although values between -20 and $-10 \%$ are most common. Plants falling in this category include cacti, euphorbias, and other desert and semiarid taxa. Given these general guidelines, the relative composition of the vegetation in a basin or at a specific locality may be reconstructed in very basic terms by analyzing the isotopic composition of soil organic matter (SOM).

Soil A horizons have repeatedly been shown to be reasonable natural archives for evaluating recent as well as ancient vegetation change (Cerling et al. 1989; Dzurec et al. 1985; Kelly et al. 1993; Nordt 2001; Wang et al. 1993). The rationale behind the use of stable isotopic ratio analysis of SOM is to search for areas where maize may have been cultivated in the past. Maize (Zea mays), being a $\mathrm{C}_{4}$ grass, may leave a carbon isotopic signature in soil organic matter that is distinctly different from the naturally occurring forest (which will impart a $\mathrm{C}_{3}$ isotopic signature). Potential complications arise with modern coastal Bermuda grass, which is also $\mathrm{C}_{4}$, but prehistoric fields would presumably exhibit a spatial pattern that articulates with prehistoric settlement, whereas modern Bermuda grass signature would respect morerecent field boundaries.

\section{Phosphorus Analysis}

Spatial correlation between the distribution of the element phosphorus and areas of past human activity was first noted by Olaf Arrhenius in the 1920s and subsequently developed as an archeological prospection tool by Cook and Heizer (1965) and Eidt (1984). The chemistry associated with soil phosphorus is complex (Heron 2001), and there is a sizable literature concerning the mobility, fixation, and liberation of the element in soils, largely due to its significance to plant growth. In general terms, phosphorus is common in plant and animal tissues and is present in increasing amounts as one progresses up the food chain. In the form of plant and animal tissues, phosphorus is relatively mobile, especially in regard to human activities (Taylor 2000). Once these organic materials are deposited on the ground surface, they are rapidly fixed into relatively insoluble forms, and over time the rate of phosphorus addition greatly exceeds phosphorus dissolution 
and uptake by plants, leading to detectable spatial concentrations where anthrogenic additions occurred. Cultural activities that add phosphorus to soils are generally the deposition of organic matter, organic waste, ash, burials, and manuring of agricultural fields.

A number of different chemical analytical methods have been used over the years to examine the distribution of this element, ranging from labile or soluble forms that plants can access, to complex fractionation of different chemical forms based on the major binding element, or a general assay of all forms referred to as total phosphorus. Which of these is most useful is the subject of considerable debate (Heron 2001; Taylor 2000), and at least in part a function of soil $\mathrm{pH}$ and chemistry, which largely determine how phosphorus is bound in the soil. There seems to be a reasonable consensus that total phosphorus is the best measure, but that this is a slow and somewhat expensive analysis and does not lend itself well to field assessment. Total phosphorus has been successfully used in sandy soils in Florida by Scudder (1995, 2003), and given the ubiquity of iron in the project area, fixation of prehistoric anthrogenic phosphorus is to be expected. The use of phophorus here will involve assay of total P.

\section{Magnetic Susceptibility Analysis}

As was discussed earlier, magnetic susceptibility is the degree to which a substance becomes magnetized when placed in an external magnetic field. Certain cultural activities may affect the spatial distribution of magnetic susceptibility by either physically moving the earth, or by in situ enhancement, the most common of which is through burning. Heating of the soil changes the common mineral hematite, which has relatively low magnetic susceptibility, to much more highly magnetic minerals such as maghaemite (Cole et al. 1995; Tite and Mullins 1971). Hence, spatial survey of magnetic susceptibility may be used to identify areas that experienced repeated burning or the disposal of thermal refuse like ash. Cole et al. (1995) compared field observations of magnetic susceptibility gathered with several different instruments to areas of cultural activity identified via magnetometer surveys and concluded that magnetic susceptibility is a relatively rapid and inexpensive means of locating areas of former human occupation.

\section{Palynology}

Pollen analysis work for this task is covered under the paleoenvironmental investigations. But in general terms, if a depositional setting conducive to the preservation of pollen can be found that is contemporaneous with Caddo and historic occupation of this landscape, then it should be possible to examine and compare in some detail the specifics of prehistoric and historic land use in terms of timing, activities, and relative impact on the landscape The paleoenvironmental literature has numerous examples illustrating the effects of land clearance and cultivation on ancient flora (cf. Delcourt and Delcourt [2004] for a few examples), as well as how some of the more-subtle issues such as arboriculture may be deduced.

\section{Artifacts in Fields}

If this work successfully identifies chemical patterns that are thought to be consistent with agricultural fields, then it will be worth performing additional work designed to search for evidence of field organization through additional geophysical survey and limited excavation in order to recover a sample of artifacts from the fields.

\section{RESEARCH THEME: BACKGROUND SAMPLING FOR CERAMIC STUDIES}

Scientific analysis of ceramics offers one of the best and most-direct means of demonstrating Caddo regional interaction by facilitating recognition of spatial variation in pottery production and the subsequent movement of pots across the landscape by means of trade, exchange, or group mobility. Although stylistic analysis may contribute toward this goal, it is the ability of compositional studies to distinguish local vs. extralocal ceramics, and to permit the identification of regional variations in pottery production, that makes this form of analysis so useful. Two analytical methods have been successfully used in the past in this region: elemental composition by instrumental neutron activation analysis (INAA) and ceramic petrology. 


\section{Instrumental Neutron Activation Analysis}

Determining the chemical composition of pottery by means of neutron activation analysis has become an increasingly common form of compositional analysis in recent years (cf. Neff 1992), in large part due to a grant from the National Science Foundation to the Missouri University Research Reactor that has subsidized part of the analysis cost and made the method more affordable. Neutron activation analysis is a destructive analysis method that involves exposing prepared samples of pottery fragments to a neutron beam, which results in some of the constituent elements being turned into unstable radioactive isotopes. The decay of these shortlived isotopes results in the emission of gamma rays with discrete and measurable energies that are diagnostic of specific elements. By measuring the amounts and frequencies of these gamma rays, the quantities of the various elements in a sample may be determined with great precision (Glascock 1992:12).

\section{Ceramic Petrography}

The identification of rock-forming minerals by examining $0.3-\mathrm{mm}$-thick slices mounted on glass slides (or thin sections as they are commonly referred to) with a polarizing light microscope is one that was first developed by Henry Sorby in Sheffield, England, in the nineteenth century. The method today is one of the most widely employed means of studying rocks and minerals. Application of this method to the study of ceramics, known as ceramic petrography, is becoming increasingly common, and in some places, such as Europe, is widely performed owing to its cost, relative ease of use, and sensitivity to production-related issues such as identification of tempering materials and methods of construction. For this method, samples of pottery fragments are cut with a rock saw to sections about $2-3 \mathrm{~cm}$ long, and then are polished and adhered to a glass slide with epoxy. The remaining portion of the sherd is trimmed away with a rock saw and then ground down to a thickness of $0.3 \mathrm{~mm}$, after which it is possible to identify the coarse constituent minerals by viewing the slide under a polarizing light compound microscope. From this perspective, it is possible to identify aspects of the production method like coiling from the fabric, visually identify temper (nonplastic inclusions such as minerals, bone, shell, or grog) from the coarse fraction, and establish compositional groups based on the appearance of the fabric and presence of inclusions like microfossils. Whitbread (1995) provides a thorough set of procedures for ceramic petrographic description which, at least in terms of the descriptive part, largely follows Bullock et al.'s (1985) handbook for soil micromorphology. This approach is widely applied in Europe, whereas Stoltman (2001) summarizes the methods of analysis most commonly employed in North American archeological sites.

Together, these methods provide a powerful set of analytical tools to examine issues of pottery production and composition. That said, they are not without their problems. Paste composition determined by NAA may be adversely affected by the inclusion of temper materials added by potters that were not in the raw clay, thereby yielding erroneous results. Petrography may permit identification of such exogenous tempers, but the establishment of compositional/fabric groups is a rather subjective enterprise (Whitbread 1995:366), and potentially prone to error. Furthermore, petrography works best in landscapes that exhibit distinct spatial variation in bedrock geology, and geological homogeneity may diminish the potential of this method to yield spatially significant results. Advocates of each method have strong opinions on the issue, but it is clear that when combined a more comprehensive image of ceramic composition and variability is achieved.

Although it is possible to work from artifact collections alone, these methods become more useful if potential sources of raw materials (clay and mineral temper) are included in the sampling. Raw material sampling for ceramic petrography often includes the production of samples that are fired at different temperatures to examine the variation firing temperature has on paste appearance (which can result in significantly different petrographic appearance; cf. comment in Skokan and Perttula [1998:281] and detailed discussion in Whitbread [1995:390 396]), as well as experimental production of samples designed to reproduce archeological fabrics with locally available raw materials.

\section{Regional Examples}

Ceramic petrography has been used in east Texas archeology in a somewhat occasional 
manner since at least the middle 1980s (cf. Ferring and Perttula 1987). However, during the last several years, Timothy Perttula has systematically established a series of studies of Caddo ceramic composition from sites in a variety of settings in east Texas and elsewhere. Several site reports have included both forms of analysis (e.g., the Hurricane Hill site [Iruegas 1999; Neff et al. 1999], the Oak Hill Village site [Cogwell et al. 2004; Skokan-Switek 2004], and the Mockingbird site [Neff et al. 1998; Skokan and Perttula 1998]) to examine the issue of regional production and movement of pottery by Caddo groups, and this work, although somewhat difficult to use at first, is starting to be genuinely useful in its stated goals.

Early on, the implementation of these studies was somewhat less than ideal as the two forms of analysis were performed on different samples and therefore the results were not directly comparable. For instance, both methods were employed at the Oak Hill village site (41RK214), but the 124 ceramic petrography samples examined by Skokan-Switek (2004) were all from the site assemblage, whereas the 81 samples examined by INAA were drawn from five separate sites (Cogwell et al. 2004). Neither of these studies benefited from a suite of raw material samples, local or otherwise. Not surprisingly, the INAA study was able to obtain more-interesting results because of the breadth of the samples examined, as well as the ability of the authors to draw upon other work performed elsewhere in the region.

At the Mockingbird site, both INAA and petrography were applied to the same samples, but no significant attempt at integrating the results was made, and the ceramic petrographic work made no attempt to establish fabric groups. Again, no raw material samples were examined. One recent and interesting study employing these methods is the examination of Caddo sherds recovered from archeological sites in the vicinity of Fort Hood (Perttula et al. 2003), and it is in this study that the long-term benefit of Perttula's efforts comes into clear focus. This study examined 27 sherds using both methods, and the results were directly compared. Compositional groups identified by each method were broadly comparable, but the existing database of INAA results clearly permitted more geographically specific comparisons. Perhaps because of the unique geographic setting (that is, outside the Caddo core area), this study clearly illustrates the analytical advantage such studies may provide.

Despite a few comments to the contrary, the benefit of local raw material samples is yet to appear in any of the studies, in part due to funding constraints. In fact, the lack of raw material samples was commented upon by almost every study (e.g., Cogwell et al. 2004:319; Skokan and Perttula 1998) and stands as a glaring gap in the existing application of these methods to northeast Texas ceramic assemblages. The implementation of a ceramic composition study that includes raw material samples, specifically clays, from local sources and possibly major environmental settings (such as river terraces) and various bedrock sources nearby could make a very interesting contribution to this growing and clearly significant body of information. This is especially true when the probable nature of the sites in the project area is considered (most likely are small farm houses or hamlets).

\section{Research Questions}

- Do the various clays (e.g., Bt horizons in the uplands, clay in the bedrock below the Bt horizon, and alluvial clays in Tankersley Creek) in proximity to the sites have distinctive petrographic or chemical attributes? These are the three most-likely local sources, and they should have fairly distinctive chemical and petrographic properties and logical reasons for this are due to weathering and selective erosion and redeposition. Whether one could distinguish between samples up and down Tankersley Creek collected at different places is a fundamental question that may set limits on how geographically precise such work may be in reality.

- Do the sands in proximity to the sites have distinctive petrographic attributes?

- Do sands and clays from surrounding stream valleys (the Red River, Big Cypress Creek, and others) have distinctive petrographic or chemical attributes? This has been argued by some and is relatively easily tested with a limited number of alluvial clay samples from major stream and terrace deposits from different hydrologic catchments. 
- Can distinctive types and varieties of pots and raw material selection patterns be identified during testing excavations?

- Do sherds from the sites match local raw materials?

- Is there more than one local source that is used for ceramic production among the sites in the project area?

- Is there published information on the mineralogy of local bedrock sources in the geologic literature?

\section{Relevance}

The basic background source work necessary to empower both of these analytical methods as geographical research tools has yet to be performed in detail, thereby limiting the utility of the methods to obvious major differences between sherds and making any inference on spatial movement speculative. Collecting base line geological samples from raw material sources in proximity to the sites and limited regional sources (like major stream deposits) provides a set of background samples that may make subsequent artifact studies geographically significant. Previous studies have been limited to artifacts, and therefore the background variation in raw material sources has been inferred rather than demonstrated. The work proposed here would establish a local and perhaps a regional data base that could be used in data recovery analyses and further strengthen Perttula's efforts to date. Furthermore, a pilot study of ceramic wares recovered from testing will provide information useful in understanding prehistoric resource use and the degree of regional interaction associated with the sites in the project area.

\section{Data Requirements}

- Clay samples from suitable deposits in proximity to sites in the project area. Three major sources are immediately recognized as potentially relevant: Bt horizons (which should be weathered and exhibit diminished amounts of minerals like feldspar), bedrock clay beneath the Bt horizon (which should retain the easily weathered minerals like feldspar if it was present to start with), and alluvial clay, of which there may be more than one age identified during trenching.

- Basic manipulation and thin sectioning of clay samples for petrographic work. Specifically, clays should be processed to record basic properties such as shrinkage and color change upon firing at different temperatures.

- Sand samples from alluvial deposits, upland sandy soils, and concentrated sand separates from the clay sources on and near sites should be examined by thin-section analysis and the mineralogical variation documented.

- Search the geological literature for petrographic information on the mineralogical composition of local bedrock geology. These data undoubtedly exist for various Tertiary geological units, and a limited search of the literature and discussions with researchers who have done this kind of work (e.g., Earle McBride, The University of Texas at Austin) may yield a directly relevant and immediately useful database.

\section{Methods Used to Gather Data}

The methods to be used for this work have been described in general terms above, specifically INAA and petrography. It is important that samples collected for this work use both methods on the same material so the results are directly comparable. Samples for this work may be collected during trenching on and near sites for paleoenvironmental reasons. A literature search, in conjunction with discussions with geologists who have worked on Tertiary-age deposits of east Texas, may yield substantial, essentially free information.

\section{RESEARCH THEME: BACKGROUND SAMPLING FOR LITHIC STUDIES}

Lithic raw materials are the other major category of materials used by prehistoric societies that can be drawn upon to support arguments of prehistoric trade, exchange, or mobility. In regions relatively poor in lithic raw materials, like this one, it is logical to presume that stone tools may have been as mobile or even more so than pottery. The ability to determine this relies upon basic knowledge of the spatial distribution, composition, 
and appearance of naturally occurring raw materials like chert, silicified wood, and quartzite. Some work has been done on lithic raw materials in this region (mostly to the west and east of the project area, though; e.g., Banks 1990, 1992; Heinrich 1984), and archeological studies in the region often make reference to major sources of lithic raw materials in the macroregion (cf. Perttula 2005), but collections of material for direct comparison are generally unavailable or the results of personal efforts. Often, reasonable collections of locally available material may be made by perusing detailed descriptions of the landscape published in the form of soil surveys, geological maps, and discussions with local landowners and artifact collectors.

The most likely sources of raw materials in this region are silicified wood from the Tertiaryage deposits (cf. Heinrich 1984), although the Bureau of Economic Geology (1979) does not describe silicified wood as a constituent of any of the local bedrock deposits in this region, ancient fluvial or "Uvalde" gravels often found on drainage divides, and late Quaternary alluvial gravels from either modern channels or Pleistocene terraces cropping out adjacent to valley walls. Unusual occurrences such as locally silica-cemented sandstones within the Wilcox group are known to occur but not widespread.

Potential "nearby" alluvial gravel sources include, but are probably not limited to:

1. White Oak Bayou north of Mount Pleasant, which has extensive Pleistocene terraces mapped by the Bureau of Economic Geology (1979) along the valley margins and a fairly extensive catchment that has its headwaters 40 miles to the west of Mount Pleasant west of Sulphur Springs;

2. the Sulphur River, immediately north of White Oak Bayou, which also has extensive Pleistocene terraces (Bureau of Economic Geology 1979);

3. Big Cypress Creek, of which Tankersley Creek is a tributary, that has some Pleistocene terraces mapped by the Bureau of Economic Geology (1975) southeast of Mount Pleasant;

4. possibly Tankersley Creek itself, although the actual potential of this is somewhat dubious given the size and substrate of the catchment.
Larger rivers at a greater distance may afford some of the most-reliable sources of knappable stone, and these include:

1. the Red River, for which the Bureau of Economic Geology (1975) has mapped several Pleistocene terraces, the most promising of which appears to be Qt4, which is a dissected, high gravel sand and silt deposit that lies about $35 \mathrm{~m}$ above the present stream channel; the closest mapped outcrop lie about 35 miles to the north of the project area on the drainage divide between the Red River and the Sulphur River;

2. the Sabine river, which has numerous Pleistocene-age terrace fragments bordering its valley at a distance of 35-40 miles south of the project area (Bureau of Economic Geology 1975).

The high or "Uvalde" gravels are more difficult to pinpoint in the abstract, but geologically they are most likely to occur on the divide between major drainage basins. Hence, the most likely location for Uvalde-like high gravels is the drainage divide between White Oak Bayou and Cypress Creek, located at the head of Tankersley Creek immediately north and west of the project area. There is also a potential for these kinds of gravels to the south near Pittsburg on the drainage divide between Little and Big Cypress Creeks.

The location of any specific lithic raw material sources are unknown at the present time, although discussion with local experts (e.g., Timothy Perttula, Larry Banks, or Paul Heinrich) may yield productive information. If such deposits can be found, they should be sampled, described (hand specimen and petrographically), and experimentally heat treated.

\section{Research Questions}

- Where are lithic raw material sources with respect to the project area, and what is their composition (lithology) and appearance? Identification of the location and appearance of local lithic raw materials is critical if we want to be able to discuss local production vs. trade or mobility by 
Caddo groups using the archeologically recovered lithic assemblage. If the local sources are high gravels (like the Uvalde gravels), some effort should be directed at identifying how much compositional variation there is within this geologic unit on a regional scale, as it is possible that it may not be feasible to distinguish a truly "local" lithic source from these kinds of materials.

- Can local lithic raw materials be distinguished on the basis of lithology and appearance from major extralocal sources known to have been used by the Caddo? Perttula frequently refers to Red River gravels, local Uvalde gravels, and stone sources from the Ozark Mountains (eastern Oklahoma and Arkansas). Manning fused glass may have been used as well. How much overlap is there in the appearance of these materials?

- How does the appearance of local raw materials change in response to heat treating? Heat treatment, which was widely used in prehistory to improve the workability of lithic raw materials, often changes the appearance of the stone in terms of color and luster, and these changes can be dramatic and surprising. Documenting how local sources change following such technological treatments is critical to be able to recognize these materials in archeological collections.

- Are there easy ways to distinguish major sources of lithic raw materials, like UV light, that apply in this region? Previous work by researchers like Mike Collins has demonstrated that inspection of lithic materials under a UV light may permit rapid identification of raw materials from different geologic sources. Any collection and characterization work performed should examine UV fluorescence response under short- and long-wave radiation.

\section{Data Requirements}

- Comparative hand samples of nearby high Uvalde gravel raw materials.

- Comparative hand samples of gravels from reasonably close major stream deposits (as described above).

- Observations of raw materials in raw and heat-treated states, and description of their appearance under plain light, UV light, and in thin section.

\section{Methods Used to Gather Data}

Searching for lithic raw material sources is a challenging issue given the geologic intangibles (e.g., are there high gravels in this area?), issues of land access, and the functional problem that we will never approach the mental map the Caddo would have had for the location of raw material in this region. Nevertheless, searching for these materials using sound geological reasoning, and consultation with local residents and experts with experience in the region, may permit identification and sampling of such deposits in the landscape near the project area. Logically, this work should start locally with examination of Tankersley Creek and expand outward from the project area.

The locations of outcrops identified from published sources in the archeological and geological literature (if any) as well as the locations of likely outcrops will be examined in road cuts, or with permission of landowners if not publicly accessible. Searching will involve crisscrossing likely portions of the landscape on highways and county roads where exposures of gravels may be observed. Samples, once collected, will be described in terms of size, lithology, and appearance according to methods described in Leudtke (1992), and the appearance of workable stone under long- and short-wave ultraviolet light will also be described. Physical changes upon heat treating will be documented by heating and subsequently cooling a subsample in $50^{\circ} \mathrm{F}$ increments every hour up to $450^{\circ} \mathrm{F}$ in a domestic oven and subsequently describing the results in terms of changes in color and new fracture surface roughness. Finally, comparison of the raw material sources with artifacts recovered from test excavations will be performed to evaluate raw material procurement practices, if it is possible to distinguish discrete raw material sources from one another on the basis of readily observed physical attributes.

\section{RESEARCH THEME: HISTORIC LANDSCAPES}

\section{Theoretical Rationale}

In most parts of Texas, the changes that accompanied Euro-American settlement repre- 
sented a dramatic shift in land use activities as well as the magnitude of landscape modification. Even where historic land use followed similar prehistoric practices (e.g., deforestation, cultivation, etc.), the scale of activity eventually, if not immediately, eclipsed prehistoric aboriginal activities. The relative contrast may have been less dramatic in the Caddo heartland than elsewhere in the state, as this region had been the seat of sedentary agricultural populations for a significant period prior to Euro-American incursion, unlike much of the rest of Texas. But because so many questions remain about the nature and magnitude of Caddo land use, it is difficult to form a solid image of the extent of this contrast. Compiling information on how Euro-American use of this landscape progressed-from earliest settlement to later plantations and yeoman farms, to the gradual shift to industrial/agribusiness land use-can provide a coherent image of how the landscape continued to evolve after the Caddo were removed from their ancestral lands. This historic landscape study is intended to determine historic occupation and land use that affected the study area over time and possible consequences to archeological features. As a first phase, this study has specific research goals. If these initial research and analysis methods prove useful, further research and analysis may be recommended.

The earliest Euro-American layout of space and subsequent restructuring reveal much about values that change and those that retain a semblance of continuity. Even a small plot of ground identifies its occupant, gives status, and establishes relationships with the next plot over. Along with the natural limits that waterways and topographic features define, fences, fields, roads, windbreaks, schools, dwellings, and industrial complexes all have boundaries. Boundaries both divide one occupant from another and bind each together. A network of boundaries and the way a people living within them organizes space reflect the shifting nature of priorities and culture. More importantly for this project, peeling back layers of information can convey how the environment of this place changed over almost two centuries. Local records will reveal the size and location of land parcels, early speculative activity, and settlement patterns through time. Tracing ownership history and tax records, in conjunction with county-level agricultural census data, may illustrate change or continu- ity in land use over time for each parcel. Early maps and county commissioner's and district court records may exhibit how plantations, farmsteads, roads, fencing, and drainage shaped the landscape. State and federal population census, both aggregate and manuscript, will monitor local demographic change that might have influenced land use as the result of ethnic affiliations, family size, and, before the Civil War, the slave population. Source materials available for the twentieth century, including historic aerial photographs and soil survey maps, will document agricultural activities.

\section{Research Questions}

- How has the vegetation in the project area changed in the historic period? This issue is related to a similar question posed under the paleoenvironmental change research domain, but here the question is approached from a documentary rather than analytical perspective. One way of addressing it is through examination of the witness trees identified on the nineteenth-century land grants archived at the Texas General Land Office. Original GLO land surveys denoted property boundaries by referencing one or more trees near property corners (called witness trees), and this record of vegetation has been used for some time by ecologists, biologists, geographers, and historians as a legitimate sample of the vegetation at that time. GLO surveys also occasionally made note of the width of the channels on streams, prairie-forest boundaries, and other useful information relevant to this issue.

- How did land ownership (and therefore partitioning) and land use change through time?

- Can archival information and oral interviews clarify the location of a Caddo cemetery affiliated with $41 \mathrm{TT} 6$ or $41 \mathrm{TT} 846 ?$

- Can we find historic maps of the project area that identify specific land use information? The National Archives and Records Administration hold early Department of Agriculture records that might contain manuscript soil survey field sheets developed for Titus County ca. 1909. These field sheets may have recorded detailed docu- 
mentation of the landscape, e.g., pastureland, timberland, cropland, waterways, roads, fence lines, buildings, structures, and topographical features.

\section{Relevance}

Linking historical land use identified in archival sources with features on the ground and identifying their implications for specific archeological features will result in a morecomprehensive historic landscape analysis that approaches historic landscape archeology as practiced in Europe (cf. Muir 2001; Rippon 2004). The feasibility of this approach is highly contingent upon the quality of evidence obtained from the archival sources as well as evidence on the ground in the field. Ultimately, the relevance of this work may increase if it can be linked with paleoenvironmental data.

\section{Data Requirements}

- Maps.

- Agricultural census data.

- Historical aerial photographs.

- Land survey and patent records.

- Tax records.

- Census data.

- Deeds.

- Oral history.

- Field map of historic features visible on the ground at one or more sites.

\section{Methods Used to Gather Data \\ Texas General Land Office Survey Records}

The goal of this work is to document information about the landscape during the earliest period of Euro-American settlement using records available from the Texas General Land Office. Research and analysis of original field notes for the eight surveys in the study area will reveal descriptors of witness points such as trees (or the lack thereof), waterways, roads, fence and property lines, and other identified points. The survey and patent dates and acreage of these land grants will be compared with those in the rest of the county to determine how the study area fits into initial local settlement patterns. The content of this documentation will be analyzed for quantity, quality, and potential to provide useful information for the project. Recommendations may include similar research for surrounding land grants to provide greater breadth.

\section{Researching Local and State-Held Historical Records}

This work will address two distinct issues: (1) evidence of landscape change, and (2) the location of the Titus phase Caldwell cemetery. Archival research will be used to determine whether available written sources can identify locations of historic landscape features for periods subsequent to initial settlement. Local records research for three parcels of land in the study area will serve as a model. Deeds, ad valorem taxes, and manuscript population and agricultural census records will be examined for the three parcels of land on which 41TT851 is situated. This will entail research in Red River and Titus Counties and at the Texas State Library and Archives. For the period between 1846 and the mid-1890s, Titus County deeds are limited to a local title company's collection, which can be accessed for an hourly rate. Analysis should convey specific land use for these parcels of land and examine how successful and accurate this type of research would be for the larger project area.

To clarify the location of the Caldwell cemetery probably affiliated with 41TT6 or 41TT846, we intend to consult archival records such as chain of title for three parcels of land on which these sites are situated. The cemetery has previously been identified as having been on land the Caldwell family owned. Site documentation, however, has the cemetery mapped on adjacent property. The intent of this research is to clarify which land belonged to the Caldwells, as well as which did not, and to possibly find reference to the cemetery in deeds.

\section{Oral History}

Interviewing knowledgeable oral informants will be performed primarily to clarify the location of the Caldwell cemetery, which was excavated by Goldschmidt (1934, 1935). Inter- 
views with local informants will include previous landholders, their knowledgeable relatives, or past tenants of the property.

\section{Field Survey}

On sites with significant historic presence (e.g., 41TT851), limited field survey performed in conjunction with aerial photographs will be used to identify features on the ground associated with historic land use, which ranged from early farming to various forms of industrial use recently. Many historic features are still standing today (fence lines, barns, pens, house foundations, etc.), and the locations of former boundaries or paths such as old fence lines or haul roads may be delineated from microtopographic features such as low earthen banks and shallow scrape marks. The goal is to determine how historic occupation and land use affected specific sites through time and the possible consequences of these activities for archeological features.

\section{REFERENCES CITED}

Abbott, James T.

1996 Geomorphic Investigations of the Lowlands. In Cultural Resource Survey of Area F of the Jewett Mine, Freestone County, Texas, by Jay Peck, James T. Abbott, Charles D. Frederick, Patrick L. O’Neill, and Abby C. Treece, pp. 131-160, and Appendix C. TRC Mariah Associates, Inc., Austin.

1997 Late Quaternary Alluviation and Soil Erosion in Southern Italy. Ph.D. dissertation, The University of Texas at Austin.

2001 Houston Area Geoarchaeology: A Framework for Archeological Investigation and Cultural Resource Management in the Houston Highway District. Archeological Studies Program Report 27. Environmental Affairs Division, Texas Department of Transportation, Austin.

Abbott, James T., and Charles D. Frederick

1989 Subsurface Magnetic Prospection at Palo Duro Creek Reservoir during Testing Phase Investigations, June, 1989. In Prairie Hinterland: The Archaeology of Palo Duro Creek, Phase II: Testing, edited by John A. Peterson, pp. 467-482. Archaeological Research, Inc., Austin. 1990a Magnetometer Surveys at 41GR323 and 41KT53. In Phase II Investigations at Prehistoric and Rock Art Sites, Justiceburg Reservoir, Garza and Kent Counties, Texas, by Douglas K. Boyd, James T. Abbott, William A. Bryan, Colin M. Garvey, Steve A. Tomka, and Ross C. Fields, pp. 345-362. Report of Investigations No. 71. Prewitt and Associates, Inc., Austin.

1990b Proton Magnetometer Investigations of Burned Rock Middens in West-Central Texas: Clues to Formation Processes. Journal of Archaeological Science 17:535-545.

1991 Prospection and Burned Feature Investigation with Portable Proton Magnetometers at Stacy Reservoir: Final Report. In Test Excavations at 40 Prehistoric Sites and Assessment of Rock Cairn Features in the O. H. Ivie Reservoir, Concho, Coleman, and Runnels Counties, Texas. Mariah Associates, Inc., Austin.

1993 Proton Magnetometer Investigations at 41KT53. In Data Recovery at Justiceburg Reservoir (Lake Alan Henry), Garza and Kent Counties, Texas: Phase III, Season 2 , by Douglas K. Boyd, Jay Peck, Steve A. Tomka, and Karl W. Kibler, pp. 445-454. Reports of Investigations No. 88. Prewitt and Associates, Inc., Austin. 
1994 Magnetometer Investigations at the Barton Site (41HY202) and the Mustang Branch Site (41HY209). In Archaic and Late Prehistoric Human Ecology in the Middle Onion Creek Valley, Hays County Texas, Volume 2: Topical Studies, edited by R. A. Ricklis and M. B. Collins, pp. 539548. Studies in Archeology 19. Texas Archeological Research Laboratory, The University of Texas at Austin.

Albert, Bruce

2004 Pollen Analysis of Middle to Late Holocene Paleochannel Deposits from the Big Sandy Creek Floodplain Adjacent to 41UR77 in Upshur County, Texas. Manuscript in possession of the author and on file at Texas Department of Transportation, Environmental Affairs Division, Austin.

Appleby, P. G., and F. Oldfield

1992 Applications of Lead-210 to Sedimentation Studies. In Uranium Series Disequilibria: Applications to Earth, Marine and Environmental Sciences, edited by M. Ivanovich and R. S. Harmon, pp. 731-778. Clarendon, Oxford, United Kingdom.

Bajracharya, Roshan M., Rattan Lal, and John M. Kimble

1998 Use of Radioactive Fallout Cesium137 to Estimate Soil Erosion on Three Farms in West Central Ohio. Soil Science 163:133-142.

Banks, Larry

1990 From Mountain Peaks to Alligator Stomachs: A Review of Lithic Sources in the Trans-Mississippi South, the Southern Plains, and Adjacent Southwest. Memoir No. 4. Oklahoma Anthropological Society, Norman.

1992 Identification of Lithic Resources in the Sulphur River Basin and Adjacent Areas of Northeast Texas. Manuscript on file at Prewitt and Associates, Inc., Austin.

Bateman M. D., C. H. Boulter, A. S. Carr, C. D. Frederick, D. Peter, and M. Wilder

n.d. Preserving the Paleoenvironmental Record in Drylands: Bioturbation and Its Significance for Luminescence-Derived Chronologies. Sedimentary Geology 195(1-2):5-19.
Beer, J. , M. Andreé, H. Oeschger, B. Stauffer, R. Balzer, G. Bonani, C. Stoller, M. Suter, and W. Wölfli

198510 Be Variations in Polar Ice Cores. In Greenland Ice Core: Geophysics, Geochemistry, and the Environment, edited by C. C. Langway, Jr., H. Oeschger, and W. Dansgaard, pp. 66-70. Geophysical Monograph 33. American Geophysical Union, Washington D.C.

Birkeland, Peter W.

1999 Soils and Geomorphology. Third Edition. Oxford University Press, Oxford.

Bousman, C. Britt, and Ross C. Fields

1991 Environmental Setting. In Excavation at the Bottoms, Rena Branch, and Moccasin Springs Sites, Jewett Mine Project, Freestone and Leon Counties, Texas, by Ross C. Fields, L. Wayne Klement, C. Britt Bousman, Steve A. Tomka, Eloise F. Gadus, and Margaret A. Howard, pp. 5-20. Reports of Investigations No. 82. Prewitt and Associates, Inc., Austin.

Boutton, Thomas W.

1991 Stable Carbon Isotope Ratios of Natural Materials II: Atmospheric, Terrestrial, Marine and Freshwater Environments. In Carbon Isotope Techniques, edited by David C. Coleman and Brian Fry, pp. 173-185. Academic Press, New York.

Bruseth, James E., Jeffrey J. Durst, Tiffany Osburn, Kathleen Gilmore, Kay Hindes, Nancy Reese, Barbara Meissner, and Mike Davis

2004 A Clash of Two Cultures: Presidio La Bahía on the Texas Coast As a Deterrent to French Incursion. Historical Archaeology 38(3):78-93.

Bruseth, James E., Mark L. Raab, and Daniel E. McGregor

1987 Late Holocene Paleoecology of the Prairie Margin of Texas. In Introduction to the Richland Creek Archaeological Project: Environmental Background and Cultural Setting, edited by James E. Bruseth and Randall Moir, pp. 29-38. Richland Creek Technical Series Volume I. Archaeology Research Program, Institute for the Study of Earth and Man, Southern Methodist University, Dallas. 
Bryant, Vaughn M., Jr., and Richard G. Holloway 1992 A Late Quaternary Paleoenvironmental Record of Texas: An Overview of the Pollen Evidence. In Pollen Records of Late Quaternary North American Sediments, edited by Vaughn M. Bryant and Richard G. Holloway, pp. 39-70. American Association of Stratigraphic Palynologists Foundation, Dallas.

Bullock, P., N. Federoff, A. Jongerius, G. Stoops, and T. Tursina

1985 The Handbook of Soil Thin Section Description. Wayne Research, Wolverhampton, United Kingdom.

Bunzl, K.

2002 Transport of Fallout Radiocesium in the Soil by Bioturbation: A Random Walk Model and Application to a Forest Soil with a High Abundance of Earthworms. The Science of the Total Environment 293:191-200.

Bureau of Economic Geology

1975 Geologic Atlas of Texas, Tyler Sheet. Bureau of Economic Geology, The University of Texas at Austin.

1979 Geologic Atlas of Texas, Texarkana Sheet. Bureau of Economic Geology, The University of Texas at Austin.

Butzer, Karl W.

1996 Ecology in the Long View: Settlement Histories, Agrosystemic Strategies and Ecological Performance. Journal of Field Archaeology 23:141-150.

2005 Environmental History in the Mediterranean World: Cross-Disciplinary Investigation of Cause-and-Effect for Degradation and Soil Erosion. Journal of Archaeological Science 32:1773-1800.

Byrne, R., and R. D. Finlayson

1998 Iroquoian Agriculture and Forest Clearance at Crawford Lake, Ontario. In Iroquoian Peoples of the Land of Rocks and Water, A.D. 1000-1650: A Study in Settlement Archaeology, edited by W. D. Finlayson, pp.94-107.London Museum of Archaeology, University of Western Ontario, London.

Cerling, T. E., J. Quade, Y. Wang, and J. R. Bowman 1989 Carbon Isotopes in Soils and Palaeosols as Ecology and Palaeoecology Indicators. Nature 341:138-139.
Clark, Anthony

1996 Seeing Beneath the Soil: Prospecting Methods in Archaeology. Second edition. B. T. Batsford, Ltd., London.

Cogwell, James W, Hector Neff, and Michael Glascock 2004 Chemical Variation in Northeast Texas Ceramics. In The Oak Hill Village Site (41RK214), Rusk County, Texas, by Robert Rogers and Timothy K. Perttula, pp. 307322. Document No. 030083. PBS\&J, Inc., Austin.

Cole, M. A., N. T. Linford, A. W. Payne, and P. K. Linford 1995 Soil Magnetic Susceptibility Measurements and Their Application to Archaeological Site Investigation. In Science and Site, edited by John Beavis and Katherine Barker, pp. 144-162. School of Conservation Sciences Occasional Paper 1. Bournemouth University, Poole, United Kingdom.

Collins, Michael B., and C. Britt Bousman

1993 Quaternary Environments and Archaeology in Northeast Texas. In Archeology in the Eastern Planning Region, Texas: A Planning Document, edited by Nancy Adele Kenmotsu and Timothy K. Perttula, pp. 49-68. Cultural Resource Management Report 3. Department of Antiquities Protection, Texas Historical Commission, Austin.

Cook, S. F., and R. F. Heizer

1965 Studies in Chemical Analysis of Archaeological Sites. Publications in Anthropology No. 2. University of California, Berkeley.

Cox, George W.

1984 Mounds of Mystery. Natural History 6:36-45.

Cox, George W., and C. G. Gakahu

1986 A Latitudinal Test of the Fossorial Rodent Hypothesis of Mima Mound Origin. Zeitschrift für Geomorfologie 30:485-501.

Creel, Darrel, Dale Hudler, Samuel Wilson, Clay Schultz, and Chet Walker

2005 A Magnetometer Survey of Caddoan Mounds State Historical Site. Technical Report No. 51. Texas Archeological Research Laboratory, The University of Texas at Austin.

Dalan, Rinita A., and Subir K. Bannerjee

1998 Solving Archaeological Problems Using Techniques of Soil Magnetism. Geoarchaeology: An International Journal 13:3-36. 
Darwin, Charles

1881 The Formation of Vegetable Mould Through

the Actions of Worms. Appleton, New York.

David, Andrew

1995 Geophysical Survey in Archaeological Field

Evaluation. Research and Professional

Guideline No. 1. Ancient Monument

Laboratory, English Heritage Society, London.

Delcourt, Hazel R.

1987 The Impact of Prehistoric Agriculture and Land Occupation on Natural Vegetation. Trends in Ecology \& Evolution 2:39-44.

Delcourt, Paul A., and Hazel R. Delcourt

1997 Pre-Columbian Native American Use of Fire on Southern Appalachian Landscapes. Conservation Biology 11(4):1010-1014.

2004 Prehistoric Native Americans and Ecological Change: Human Ecosystems in Eastern North America Since the Pleistocene. Cambridge University Press, Cambridge, United Kingdom.

Delcourt, Paul A., Hazel R. Delcourt, Cecil R. Ison, William E. Sharp, and Kristen J. Gremillion

1998 Prehistoric Human Use of Fire, the Eastern Agricultural Complex, and Appalachian Oak-Chestnut Forests: Paleoecology of Cliff Palace Pond, Kentucky. American Antiquity 63:263-278.

Denevan, William M.

1992 The Pristine Myth: The Landscape of the Americas in 1492. In The Americas Before and After Columbus: Current Geographical Research, edited by Karl W. Butzer. Annals of the Association of American Geographers 82(3):369-385.

Doolittle, W. E.,

2000 Cultivated Landscapes of Native North America. Oxford University Press, Oxford, United Kingdom.

Dzurec, R. S., T. W. Boutton, M. M. Caldwell, and B. N. Smith

1985 Carbon Isotope Ratios of Soil Organic Matter and Their Use in Assessing Community Composition Changes in Curlew Valley, Utah. Oecologia 66:17-24.
Eidt, Robert C.

1984 Advances in Abandoned Settlement Analysis: Applications to Prehistoric Anthrosols in Columbia, South America. University of Wisconsin, Milwaukee.

Eshleman, Keith N.

2004 Hydrological Consequences of Land Use Change: A Review of the State-of-Science. In Ecosystems and Land Use Change, edited by Ruth S. DeFries, Gregory P. Asner, and Richard A. Houghton, pp. 13-29. Geophysical Monograph Series 153. American Geophysical Union, Washington, D.C.

Faure, Gunter, and Teresa M. Mensing

2005 Isotopes:Principles and Applications. Third Edition. John Wiley \& Sons, New York.

Ferring, C. Reid, and Timothy K. Perttula

1987 Defining the Provenance of Red-Slipped Pottery from Texas and Oklahoma by Petrographic Methods. Journal of Archaeological Science 14:437-456.

Fish, Suzanne K.

2000 Hohokam Impacts on Sonoran Desert Environment. In Imperfect Balance: Landscape Transformations in the Precolumbian Americas, edited by David L. Lentz, pp. 252-280. Columbia University Press, New York.

Flores, Dan L.

1985 Journal of an Indian Trader:Anthony Glass and the Texas Trading Frontier, 1790-1810. Texas A\&M University Press, College Station.

Frederick, Charles D.

1995 Fluvial Response to Late Quaternary Climate Change and Land Use in Central Mexico. Ph.D. dissertation, The University of Texas at Austin.

2005 Geomorphic Investigations at the Kosse Mine FFYA. In Cultural Resources Survey of the Proposed Kosse Mine First Five-Year Area, Limestone County, Texas (draft), by David L. Sherman, pp. 69-103. Document No. 050143. PBS\&J, Austin.

Frederick, Charles D., and J. T. Abbott

1992 Magnetic Prospection of Prehistoric Sites in an Alluvial Environment: Examples From Northwest and West-Central Texas. Journal of Field Archaeology 19(2):139-153. 
Frederick, Charles D., and M. D. Bateman 2001 OSL Dating and Sandy Mantle Sites in East Texas: A Reply. Current Archaeology in Texas 3(2):14-18.

Frederick, Charles D., Mark D. Bateman, and Andy Carr

2005 Evaluating the Formation Processes of Sandy Sites in Flat Landscapes at Avon Park Air Force Range. In Archaeological and Geomorphological Investigations on the Avon Park Air Force Range, Highlands and Polk Counties, Florida, by Michael Wilder and Charles D. Frederick. GeoMarine Inc., Plano, Texas.

Frederick, Charles D., Mark D. Bateman, and P. H. Lehman

2001 Geoarchaeological Investigations. In National Register Eligibility Testing at 41LE177,ALCOASandow Mine, Lee County, Texas: Archaeological, Geoarchaeological, and Paleoenvironmental Assessment of an Upland Sandy Mantle Site, by Robert A. Ricklis, pp. 83-123. Coastal Archaeological Research, Inc., Corpus Christi, Texas.

Fritz, Gayle

2000 Native Farming Systems and Ecosystems in the Mississippi River Valley. In Imperfect Balance: Landscape Transformations in the Precolumbian Americas, edited by David L. Lentz, pp. 225-250. Columbia University Press, New York.

Fujiyoshi, R., and S. Sawamura

2004 Mesoscale Variability of Vertical Profiles of Environmental Radionuclides $\left({ }^{40} \mathrm{~K},{ }^{226} \mathrm{Ra}\right.$, ${ }^{210} \mathrm{~Pb},{ }^{137} \mathrm{Cs}$ ) in Temperate Forest Soils in Germany. Science of the Total Environment 320:177-188.

Gabet, E. J.

2000 Gopher Bioturbation: Field Evidence for Non-Linear Hillslope Diffusion. Earth Surface Processes and Landforms 25:1419-1428.

Gabet, Emmanuel J., O. J. Reichman, and Eric W. Seabloom

2003 The Effects of Bioturbation on Soil Processes and Sediment Transport.Annual Review of Earth and Planetary Science 31:249-273.
Gaffney, Chris, and John Gater

2003 Revealing the Buried Past: Geophysics for Archaeologists. Tempus Publishing Ltd., Stroud, United Kingdom.

Gale, Stephen J., and Peter G. Hoare

1991 Quaternary Sediments: Petrographic Methods for the Study of Unlithified Rocks. Belhaven Press, London.

Gile, L. H.

1979 Holocene Soils in Eolian Sediments in Bailey County, Texas. Soil Science Society of America Proceedings 43:994-1003.

Glascock, Michael D.

1992 Characterization of Archaeological Ceramics at MURR by Neutron Activation Analysis and Multivariate Statistics. In Chemical Characterization of Ceramic Pastes in Archaeology, edited by Hector Neff, pp. 11-26. Monographs in World Archaeology No. 7. Prehistory Press, Madison, Wisconsin.

Goldborer, S. Eileen

2002 Macrobotanical Evidence of Subsistence at Timber Hill. In Finding Sha'chahdinnih (Timber Hill): The Last Village of the Kadohadacho in the Caddo Homeland, by Mark L. Parsons, James E. Bruseth, Jacques Bagur, S. Eileen Goldborer, and Claude McCrocklin, pp. 81-86. Archeological Reports Series No. 3. Texas Historical Commission, Austin.

Goldschmidt, Walter R.

1934 Excavation of a Burial Site on Thomas B. Caldwell Plantation in Titus County, Texas. Manuscript on file, Texas Archeological Research Laboratory, The University of Texas at Austin.

1935 Some Archeological Sites in Titus County and Their Relation to East Texas Prehistory. Master's thesis, Department of Anthropology, The University of Texas at Austin.

Griffith, William J.

1954 The Hasinai Indians of East Texas as Seen by Europeans, 1687-1772. Philological and Documentary Studies 2(3):43-167. Middle American Research Institute, Tulane University, New Orleans. 
Hall, Grant. D.

2000 Pecan Food Potential in Prehistoric North America. Economic Botany 54(1):103-112.

Hall, S. A.

2002 Field Guide to the Geoarchaeology of the Mescalero Sands, Southeastern New Mexico. Prepared for the State of New Mexico Historic Preservation Division and the New Mexico Bureau of Land Management. Manuscript in possession of the author.

Hammett, J. E.

1992 Ethnohistory of Aboriginal Landscapes in the Southeastern United States. Southern Indian Studies 41:1-50.

Heinrich, Paul V.

1984 Lithic Resources of Western Louisiana. Louisiana Archaeology 11:165-190.

Henry, Christopher D., and Joyce M. Basciano

1979 Environmental Geology of the Wilcox Group Lignite Belt, East Texas. Report of Investigations No. 98. Bureau of Economic Geology, The University of Texas at Austin.

Heron, C.

2001 Geochemical Prospecting. In Handbook of Archaeological Sciences, edited by D. R Brothwell and A. M. Pollard, pp. 565-573. John Wiley \& Sons, London.

Horwath, J. L.

2002 An Assessment of Mima-Type Mounds, Their Soils, and Associated Vegetation, Newton County, Missouri. Master's thesis, University of Illinois, Champaign-Urbana.

Horwath, J. L., D. L. Johnson, and A. J. Stumpf

2002 Evolution of a Gravelly Mima-Type Moundfield in Southwestern Missouri. Geological Society of America Abstracts with Programs 34(6):369.

Hubbard, Velicia R., and David H. Jurney

1998 Reconstruction of the Past Vegetation on the Headwaters of the Piney Creek Watershed in Houston and Trinity Counties, Texas. Journal of Northeast Texas Archaeology 11:55-65.

Iruegas, Sergio A.

1999 The Petrographic Analysis of Caddoan Ceramics from the Hurricane Hill Site (41HP106), Hopkins County, Texas. In The Hurricane Hill Site (41HP106): The Archaeology of a Late Archaic/Early
Ceramic and Early-Middle Caddoan Settlement in Northeast Texas, edited by Timothy K. Perttula, pp. 279-290. Special Publication No. 4. Friends of Northeast Texas Archaeology, Pittsburg and Austin.

Johnson, D. L.

1989 Subsurface Stone Lines, Stone Zones, Artifact-Manuport Layers, and Biomantles Produced by Bioturbation via Pocket Gophers (Thomomys bottae). American Antiquity 54:370-89.

1990a Biomantle Evolution and the Redistribution of Earth Materials and Artifacts. Soil Science 149:84-102.

1990b The Soil Evolution Model as a Framework for Evaluating Pedoturbation in Archaeological Site Formation. Geological Society of America Centennial Special Volume 4:541-60. Geological Society of America, Boulder, Colorado.

1993a Biomechanical Processes and the Gaia Paradigm in a Pedo-geomorphic and Pedo-Archaeologic Framework: Dynamic Denudation. In Proceedings of the First International Conference on Pedo-archaeology, edited by J. E. Foss, M. W. Morris, and M. E. Timpson, pp. 41-68. Special Publication, Agriculture Experiment Station, University of Tennessee, Knoxville.

1993b Dynamic Denudation Evolution of Tropical, Subtropical, and Temperate Landscapes with Three Tiered Soils: Toward a General Theory of Landscape Evolution. Quaternary International 17:67-78.

1994 Reassessment of Early and Modern Soil Horizon Designation Frameworks and Associated Pedogenetic Processes: Are Midlatitude A E B-C Horizons Equivalent to Tropical M S W Horizons? Soil Science (Trends in Agricultural Science) 2:77-91.

1997 Geomorphological, Geoecological, Geoarchaeological and Surficial Mapping Study of McGregor Guided Missile Range, Fort Bliss, New Mexico. Miscellaneous Report of Investigations No. 157. Geo-Marine, Inc., Plano, Texas. 
1999 Darwin the Archaeologist: A Lesson in Unfulfilled Language. Discovering Archaeology 1:6-7.

2002 Darwin Would Be Proud: Bioturbation, Dynamic Denudation, and the Power of Theory in Science. Geoarchaeology17:7-40.

2005 Pre-Cultivation Mima-Type Mounds in North America and Eurasia: Templates for Mound-Builders and Khourgan-Builders. Geological Society of America Abstracts with Programs 37(7):155.

Johnson, D. L., and C. L. Balek

1991 The Genesis of Quaternary Landscapes with Stone-Lines. Physical Geography 12:385-395.

Johnson, D. L., J. E. J. Domier, and D. N. Johnson 2005 Reflections on the Nature of Soil and Its Biomantle. Annals of the Association of American Geographers 95(1):11-31.

2005b Animating the Biodynamics of Soil Thickness Using Process Vector Analysis: A Dynamic Denudation Approach to Soil Formation. Geomorphology 67(1):23-46.

Johnson, D. L., and F. D. Hole

1994 Soil Formation Theory: A Summary of Its Principal Impacts on Geography, Geomorphology, Soil-geomorphology, Quaternary Geology and Paleopedology. In Factors of Soil Formation: A Fiftieth Anniversary Retrospective, pp. 111-126. Special Publication 33. Soil Science Society of America, Madison, Wisconsin.

Johnson, D. L., J. Horwath, and D. N. Johnson 2003 Mima and Other Animal Mounds As Point Centered Biomantles. Geological Society of America Abstracts with Programs 34 (7):258.

Johnson, D. L., D. N. Johnson, and J. Horwath 2002 In Praise of the Coarse Fraction and Bioturbation: Gravelly Mima Mounds as Two-Layered Biomantles. Geological Society of America Abstracts with Programs 34(6):369.

Johnson, D. L., D. N. Johnson, and R. C. West 1999 Pocket Gopher Origins of Some Midcontinental Mima-Type Mounds: Regional and Interregional Genetic Implications. Geological Society of America Abstracts with Programs 31(7):A-179.
Johnson, D. L., and D. Watson-Stegner

1987 Evolution Model of Pedogenesis. Soil Science 143:349-366.

Johnson, D. L., D. Watson-Stegner, D. N. Johnson, and R. J. Schaetzl

1987 Proisotropic and Proanisotropic Processes of Pedoturbation. Soil Science 143:278-292.

Joutel, Henri

1906 [1687] Joutel's Journal of LaSalle's Last Voyage: 1684-1687. Joseph McDonough, Albany, New York.

Jurney, David H., John Ippolito, and Velicia Bergstrom 2000 The Frequency of Fire in East Texas Forests. Journal of Northeast Texas Archaeology 13:40-49.

Kelly, Eugene F., Caroline Yonker, and Bruno Marino 1993 Stable Carbon Isotope Composition of Paleosols: An Application to Holocene. In Climate Change in Continental Isotopic Record, pp. 233-238. Geophysical Monograph 78. American Geophysical Union.

Kenmotsu, Nancy Adele, and Timothy K. Perttula 1993 Introduction. In Archaeology in the Eastern Planning Region, Texas: A Planning Document, edited by Nancy Adele Kenmotsu and Timothy K. Perttula, pp. 3-14. Cultural Resource Management Report 3. Department of Antiquities Protection, Texas Historical Commission, Austin.

Leudtke, Barbara E.

1992 An Archaeologist's Guide to Chert and Flint. Archaeological Research Tools 7. Institute of Archaeology, University of California, Los Angeles.

Lockhart, Jami J., Jeffrey M. Mitchem, and Timothy S. Mulvihill

2005 Archaeogeophysical Investigations at the Late Mississippian Parkin Site in Arkansas. Electronic document, http:// www.uark.edu/campus-resources/archinfo/ parkin_rs.html, accessed January 25, 2005.

Lockhart, Jami J., and Frank F. Schambach

2005 Archaeogeophysics and Archaeology at a Caddo Mound Center in Southwestern Arkansas: The Tom Jones Site (3HE40) at Grandview Ranch. Electronic document, http://www.uark.edu/campus-resources/ archinfo/grandview.html, accessed January 25,2005 . 
McCall, P. L., J. A. Robbins, and G. Matisof

$1984 \quad{ }^{137} \mathrm{Cs}$ and ${ }^{210} \mathrm{~Pb}$ Transport and Geochronologies in Urbanized Reservoirs with Rapidly Increasing Sedimentation Rates. Chemical Geology 44:33-65.

McLauchlan, Kendra

2003 Plant Cultivation and Forest Clearance by Prehistoric North Americans: Pollen Evidence from Fort Ancient, Ohio, USA. The Holocene 13(4):557-566.

Muir, Richard

2001 Landscape Detective: Discovering a Countryside. Windgatherer Press, Macclesfield, Cheshire, United Kingdom.

Neff, Hector (editor)

1992 Chemical Characterization of Ceramic Pastes in Archaeology. Monographs in World Archaeology No. 7. Prehistory Press, Madison, Wisconsin.

Neff, Hector, J. W. Cogswell, and Michael D. Glascock 1998 Compositional Analysis of Caddoan Ceramics from the Mockingbird Site (41TT550) in Northeast Texas. In Analysis of the Titus Phase Mortuary Assemblage at the Mockingbird or "Kahbakayammaahin" Site (41TT550), by Timothy K. Perttula, M. Tate, H. Neff, J. W. Cogswell, M. D. Glascock, E. Skokan, S. Mulholland, R. Rogers, and B. Nelson, pp. 255-272. Document No. 970849. PBS\&J, Inc., Austin.

1999 Compositional Analysis of Caddoan Ceramics from Northeast Texas. In The Hurricane Hill Site (41HP106): The Archaeology of a Late Archaic/Early Ceramic and Early-Middle Caddoan Settlement in Northeast Texas, edited by Timothy K. Perttula, pp. 309-319. Special Publication No. 4. Friends of Northeast Texas Archaeology, Pittsburg and Austin.

Nishimura, I.

2001 Geophysical Prospection in Archaeology. In Handbook of Archaeological Sciences, edited by D. R. Brothwell and A. M. Pollard, pp. 543-553. John Wiley and Sons, London,

Nordt, Lee C.

2001 Stable Carbon Isotopes in Soils:Applications for Archaeological Research. In Earth Sciences and Archaeology, edited by Paul Goldberg, Vance T. Holliday, and C. Reid Ferring, pp. 419-448. Kluwer Academic/ Plenum Publishers, New York.
Pasquinucci, Marinella, and Frédéric Trément (editors)

2000 Non-Destructive Techniques Applied to Landscape Archaeology. The Archaeology of Mediterranean Landscapes, Vol. 4. Oxbow Books, Oxford, United Kingdom.

Peacock, Evan

1998 Historical and Applied Perspectives on Prehistoric Land Use in Eastern North America. Environment \& History 4:1-29.

Peacock, Evan, Wendell R. Haag, and Melvin L. Warren 2005 Prehistoric Decline in Freshwater Mussels Coincident with Advent of Maize Agriculture. Conservation Biology 19(2):547-551.

Perttula, Timothy K.

1993 The Development of Agriculture in Northeast Texas before A.D. 1600. In Archaeology in the Eastern Planning Region, Texas: A Planning Document, edited by Nancy Adele Kenmotsu and Timothy K. Perttula, pp. 121-146. Cultural Resource Management Report 3. Department of Antiquities Protection, Texas Historical Commission, Austin.

2005 Archeological Investigations at the Pilgrim's Pride Site (41CP304), a Titus Phase Community in the Big Cypress Creek Basin, Camp County, Texas. Report of Investigations No. 30. Archeological and Environmental Consultants, LLC, Austin.

Perttula, Timothy K., Ross C. Fields, James E. Corbin, and Nancy Adele Kenmotsu

1993 The Emergence of Sedentism in Northeast Texas, ca. 500 B.C. to A.D. 1000 . In Archaeology in the Eastern Planning Region, Texas: A Planning Document, edited by Nancy Adele Kenmotsu and Timothy K. Perttula, pp. 97-120. Cultural Resource Management Report 3. Department of Antiquities Protection, Texas Historical Commission, Austin.

Perttula, Timothy K., Sergio A. Iruegas, and Hector Neff

2003 Caddoan Pottery in Central Texas: Geochemical Analysis of Ceramics from Fort Hood and Vicinity. Archeological Resource Management Series Research Report No, 51. United States Army, Fort Hood, Texas. 
Appendix A: Research Design for Test Excavations

Perttula, Timothy K., and Bo Nelson

2005 Archeological Surveys and Impact Evaluations in the Texas Department of Transportation's Atlanta, Lufkin and Tyler Districts, 2001-2003 (Contract 572XXSA001). Archeological Studies Program, Report No. 72. Texas Department of Transportation, Environmental Affairs Division, Austin, Texas. Report of Investigations No. 61. Archeological and Environmental Consultants, LLC, Austin.

Perttula, Timothy K., Bo Nelson, and T. Clay Schultz 2002 Archeological Survey of the U.S. 271, Mt. Pleasant Loop, Titus County, Texas, for the Texas Department of Transportation. Interim report prepared by Archeological and Environmental Consultants, LLC, Austin.

Redman, Charles L.

1999 Human Impact on Ancient Environments. The University of Arizona Press, Tucson.

Ricklis, Robert A. (editor)

2001 National Register Eligibility Testing at 41LE177, ALCOA Sandow Mine, Lee County, Texas: Archaeological, Geoarchaeological and Paleoenvironmental Assessment of an Upland Sandy Mantle Site. Coastal Archaeological Research, Inc., Corpus Christi, Texas.

Rippon, Stephen

2004 Historic Landscape Analysis: Deciphering the Countryside. Practical Handbooks in Archaeology No. 16. Council for British Archaeology, York, United Kingdom.

Ritchie, Jerry C., and Carol A. Ritchie

2005 Bibliography of Publications of ${ }^{137}$ Cesium Studies Related to Erosion and Sediment Deposition. http:/hydrolab.arsusda.gov/ cesium137bib.htm, accessed October 2005.

Robbins, J. A. (editor)

1984 Geochronology of Recent Deposits. Chemical Geology 44(1):1-348.

Rogers, Robert

1999 Excavations at the Walleye Creek Site (41LE57), Lee County, Texas. Document No. 981670. PBS\&J, Inc., Austin.

2000 Excavations at Site 41HP200, Hopkins County, Texas. Document No. 000211. PBS\&J, Inc., Austin.
Rogers, Robert, and Timothy K. Perttula

2004 The Oak Hill Village Site (41RK214), Rusk County, Texas. Document No. 030083. PBS\&J, Inc., Austin Texas.

Schambach, Frank

2004 Letter to Bruce Albert titled "Comments on Pollen Analysis of Middle to Late Holocene Palaeo-channel Deposits from Big Sandy Creek Floodplain adjacent to $41 \mathrm{UR77}$ in Upshur County, Texas." Manuscript on file at Texas Department of Transportation, Environmental Affairs Division, Austin.

Schroeder, Eric

2005 Geomorphology. In Cultural Resources Survey of the Proposed Marlin Reservoir Project Area, Falls County, Texas, unsubmitted draft report, by Marie J. Archambeault, J. Michael Quigg, and Eric Schroeder. TRC, Austin.

Scollar, I., A. Tabbagh, A. Hesse, and I. Herzog 1990 Archaeological Prospecting and Remote Sensing. Cambridge University Press, Cambridge, UK.

Scudder, Sylvia

1995 Soils Investigations at the Colorado Site, Hernando County, Florida. Draft report submitted to Archaeological Consultants Inc., Sarasota, Florida. Manuscript in possession of the author.

2003 Deep Sand: Soil and Landscape Relationships at the Blueberry Site (8HG678), Highlands County, Florida. Bulletin of the Florida Museum of Natural History 44(1):17-26.

Simpson, Duane, and Ryan Peterson

2004 Non-Invasive Burial Determination Using Near-Surface Geophysical Survey and Soil Chemical Testing at Fort Hood, Texas, and Camp Lejeune, North Carolina. Archeological Resources Management Series, Research Report No. 55. United States Army, Fort Hood, Texas.

Skokan, E., and Timothy K. Perttula

1998 The Petrographic Analysis of Ceramic Thin Sections from the Mockingbird Site (41TT550), Titus County, Texas. In Analysis of the Titus Phase Mortuary Assemblage at the Mockingbird or "Kahbakayammaahin" Site (41TT550), by Timothy K. Perttula, M. Tate, H. Neff, J. W. Cogswell, M. D. Glascock, E. Skokan, S. Mulholland, R. Rogers, and B. Nelson, pp. 273-288. Document No. 970849, PBS\&J, Inc., Austin. 
Skokan-Switek, Elizabeth

2004 Petrographic Analysis of Ceramics. In The Oak Hill Village Site (41RK214), Rusk County, Texas, by Robert Rogers and Timothy K. Perttula, pp. 295-306. Document No. 030083. PBS\&J, Inc., Austin.

Southard, R. J., and R. C. Graham

1992 Cesium-137 Distribution in a California Pelloxerert: Evidence of Pedoturbation. Soil Science Society of America Journal 56:202-207.

Stahle, D. W., and M. K. Cleaveland

1995 Texas Paleoclimatic Data from Daily to Millennial Time Scales. In Changing Climate of Texas: Predictability and Implications for the Future, edited by J. Norwine, J. R. Giardina, G. R. North, and J. B. Valdes, pp. 49-69. GeoBooks, College of Geosciences and Maritime Studies, Texas A\&M University, College Station.

Stoltman, James B.

2001 The Role of Petrography in the Study of Archeological Ceramics. In Earth Sciences and Archaeology, edited by Paul Goldberg, Vance T. Holliday, and C. Reid Ferring, pp. 297-326. Kluwer Academic/Plenum Publishers, New York.

Swanton, John R.

1996 Source Material on the History and Ethnology of the Caddo Indians. University of Oklahoma Press, Norman.

Taylor, Jeremy

2000 Soil Phosphate Survey. In Non-Destructive Techniques Applied to Landscape Archaeology, edited by Marinella Pasquinucci and Frédéric Trément, pp. 182-189. Oxbow Books, Oxford, United Kingdom.

Thomas Jr., Prentice Marquet, L. Janice Campbell, and Steven R. Ahler

1980 The Hanna Site: An Alto Village in Red River Parish. Louisiana Archaeology 5.

Thoms, Alston V.

1995 Sediments and Natural Site Formation Processes at 41WT5. In The Anson Jones Plantation: Archaeological and Historical Investigations at 41WT5 and 41WT6, Washington County, Texas, edited by Shawn Bonath Carlson, pp. 107-132. Reports of Investigations No. 2. Center for Environmental Archaeology, Texas A\&M University, College Station.
Thoms, Alston V., and Ben A. Olive

1993 The ASTRC Landscape and Natural Site Formation Processes: Sandy Mantle Sediments and Reconstituted Cultural Stratigraphy. In The Brazos Valley Slopes Archaeological Project, edited by Alston V. Thoms, pp. 61-80. Reports of Investigations No. 14. Archaeological Research Laboratory, Texas A\&M University, College Station.

Thoms, Alston V., Ben W. Olive, and Patricia Clabaugh 1994 Disarticulation of the Valley Branch Site: Landscape Evolution and Natural Site Formation Processes. In The Valley Branch Archaeological Project: Excavations at an Archaic site (41MU55) in the Cross Timbers Uplands, North Central Texas, edited by Alston V. Thoms, pp. 167192. Reports of Investigations No. 15. Archaeological Research Laboratory, Texas A\&M University, College Station.

Tite, M. S., and C. E. Mullins

1971 Enhancement of the Magnetic Susceptibility of Soils on Archaeological Sites. Archaeometry 13:209-219.

Tyler, A. N., S. Carter, D. A. Davidson, D. J. Long, and R. Tipping

2001 The Extent and Significance of Bioturbation on ${ }^{137} \mathrm{Cs}$ Distributions in Upland Soils. Catena 43:81-99.

van Nest, J.

2002 The Good Earthworm: How Natural Processes Preserve Upland Archaic Archaeological Sites of Western Illinois, U.S.A. Geoarchaeology 17:53-90.

Walden, J., Oldfield, F., and J. Smith (editors)

1999 Environmental Magnetism: A Practical Guide. Technical Guide No. 6. Quaternary Research Association, London.

Wang, Yang, T. E. Cerling, and W. R. Effland

1993 Stable Isotope Ratios of Soil Carbonate and Soil Organic Matter As Indicators of Prairie Near Ames, Iowa. Oecologia 74: 365-369.

Weltfish, Gene

1937 Caddoan Texts: Pawnee, South Band Dialects. Publications of the American Ethnology Society, Volume 17, edited by Franz Boas. G. E. Stechert and Company, New York. 
Whitbread, Ian K.

1995 Greek Transport Amphorae: A Petrological and Archaeological Study. Fitch Laboratory Occasional Paper 4. The British School at Athens. The Short Run Press, Exeter, United Kingdom.

Wilder, Michael, and Ross C. Fields

2005 Interim Report on Auger Sampling of 10 Sites, U.S. Highway 271 Mount Pleasant Relief Route, Titus County, Texas (CSJ 0919-30-027). Prewitt and Associates, Inc., Austin.
Woods, William I.

1987 Maize Agriculture and the Late Prehistoric: A Characterization of Settlement Location Strategies. In Emergent Horticultural Economies of the Eastern Woodlands, edited by William F. Keegan, pp. 275294. Occasional Paper No. 7. Center for Archaeological Investigations, Southern Illinois University, Carbondale. 



\title{
APPENDIX B: Archaeogeophysical Survey
}

\author{
Chester P. Walker \\ Archaeo-Geophysical Associates, LLC \\ and Timothy K. Perttula
}





\section{INTRODUCTION}

Based on consultation with archeologists at Prewitt and Associates, Inc. (PAI), surveys using multiple geophysical methods were conducted to identify potential archeological featuresparticularly post-A.D. 900 Caddo archeological features and archeological areas of interest-at 11 prehistoric sites along the U.S. Highway 271 Mount Pleasant relief route in Titus County, Texas. Following a discussion of the specific geophysical findings at each of the sites, we conclude with a summary consideration of the geophysical results.

\section{AREAS OF INVESTIGATION AND METHODOLOGY}

The geophysical surveys were conducted using a GeoScan Research RM15 resistivity meter, a Bartington Grad601-2 dual-sensor fluxgate gradiometer, and a Geonics EM38B (in both quadrature phase and inphase) for conductivity and magnetic susceptibility. A GSSI SIR-2000 Ground Penetrating Radar (GPR) with a 400$\mathrm{MHz}$ dipole antenna was used at 41TT865 to enhance the resolution of specific anomalies. Geophysical data were collected at several different times, due to logistical considerations, with a conductivity meter, magnetometer, resistivity meter, and magnetic susceptibility meter over 16 grid areas totaling $24,800 \mathrm{~m}^{2}$, or approximately 6.1 acres (Walker 2007a, 2007b, 2007c). Using artifact density maps based on results from previous augering investigations (Wilder and Fields 2005) and the current extent of the proposed project right of way, archeologists from PAI chose the locations of the geophysical survey areas at each site.

The surveys were divided up among the 11 sites as follows: $2,400 \mathrm{~m}^{2}$ at $41 \mathrm{TT} 6 ; 4,000 \mathrm{~m}^{2}$ at 41 TT846 consisting of $1,600 \mathrm{~m}^{2}$ in one grid in Subarea 1 and $2,400 \mathrm{~m}^{2}$ in two grids in Subarea $2 ; 1,600 \mathrm{~m}^{2}$ at $41 \mathrm{TT} 847 ; 3,200 \mathrm{~m}^{2}$ in Subarea 1 at the George Richey site (41TT851); 4,250 $\mathrm{m}^{2}$ at the William Ford site (41TT852) consisting of $2,400 \mathrm{~m}^{2}$ in Subarea $1,1,050 \mathrm{~m}^{2}$ in Subarea 3, and $800 \mathrm{~m}^{2}$ in Subarea 4; 1,600 $\mathrm{m}^{2}$ at the James Richey site (41TT853); $1,600 \mathrm{~m}^{2}$ at $41 \mathrm{TT} 854$; $750 \mathrm{~m}^{2}$ at $41 \mathrm{TT} 858 ; 1,600 \mathrm{~m}^{2}$ at $41 \mathrm{TT} 862 ; 1,400$ $\mathrm{m}^{2}$ at $41 \mathrm{TT} 865$; and $2,400 \mathrm{~m}^{2}$ in two grids at 41TT866. The GPR survey at 41TT865 totaled $200 \mathrm{~m}^{2}$ in area.
Archeologists from PAI laid out the geophysical survey areas using a submeter satellite-corrected differential GPS unit. Individual 20x20-m survey grids were laid out using two tape measures. One side of the grid was staked out, and the two opposite corners were triangulated to achieve square corners. After corner stakes were in place, stakes were placed every $2 \mathrm{~m}$ on the north and south sides of each grid. North-south ropes marked every $1 \mathrm{~m}$ were then placed at 2-m intervals across each survey grid.

Archeologists from PAI recorded the UTM coordinates of the outside corners of the survey areas with a satellite-corrected differential GPS. When the 41TT865 geophysical grid location was slightly modified after PAI collected the GPS data, additional GPS coordinates were recorded for this survey area using a consumer-grade WAAS-enabled GPS (sub-3-m accuracy).

\section{SUMMARY OF TECHNICAL INFORMATION}

Archaeogeophysical investigation employs a range of techniques for the nondestructive prospecting of archeological deposits. These techniques have been developed for various applications, mostly geological in nature, but they have been adapted for specific use in archeology through rigorous field survey techniques and unique data processing programs specifically developed for archaeogeophysical use.

In general, all archaeogeophysical techniques map, record, or sense different variables or properties of the soil and the objects that are contained within the soil. The instruments are differentially affected by variables such as moisture, metal trash or debris, and transmission of signals from cell phones and transmission lines. Data collection is also impacted differently for each of the geophysical instruments by physical impediments such as trees, pavement, fences, and vegetation.

Archeologists have found that the principal line of defense against this complex matrix of variables is to come to the field prepared to collect data with several different instruments. The multiple-technique approach not only increases the margin of success but can often enhance the visibility of the archeological target or area of interest (Kvamme et al. 2006:251; Kvamme 2006a:57-58). Archaeogeophysical surveys have had a long history of success in helping focus 
archeological excavations toward specific locations within sites, and in the right conditions archaeogeophysical evidence can be used as a primary source of interpretable archeological data (Kvamme 2003).

\section{Conductivity}

Conductivity surveys measure the ability to conduct an electric current (Clay 2006:79). This measurement is the theoretical inverse to resistivity; however, measuring conductivity entails a much more complex set of procedures than does resistivity (Bevan 1983:51; Clay 2006:79). Conductivity instruments differ greatly from resistivity instruments in that no probes are inserted into the earth. The conductivity meter has a set of wire coils, one transmitting a low-frequency signal and one receiving the signal. It is simply carried above the earth surface, and conductivity data are logged automatically, making conductivity surveys time and labor efficient (although not as efficient as the magnetometer for geophysical surveys).

Conductivity meters can resolve data at different depths simply through changing the separation of the transmission and receiving coils and by transmitting its signal at different frequencies. Some instruments allow these variables to be changed; others, like the Geonics EM38- the most widespread conductivity meter used in American archeology-are not adjustable. The Geonics EM38B was employed for both the magnetic conductivity and magnetic susceptibility geophysical surveys on this project. The EM38B measures conductivity to approximately $1.5 \mathrm{~m}$ below the surface when set in the vertical dipole mode (Ernenwein 2008:133).

Conductivity has proven to be a useful tool at different scales in landscape archeology. Berle Clay's (2006) work at the Hollywood site in northern Mississippi has demonstrated conductivity's ability to obtain detailed information about prehistoric Native American architecture by producing results that appear comparable to those produced by magnetometer surveys. Grealy and Conyers (2008) and Conyers et al. (2008) have demonstrated a much more broadscale use for conductivity by mapping large tracts of land for geomorphological features (i.e., old channels, buried point bar and levee deposits, etc.) and revealing relict meander scars in major river floodplains.

\section{Magnetometer}

Magnetometer and gradiometer surveys are noninvasive and passive techniques that measure slight variations in the magnetic properties of soil. Magnetometers and gradiometers have become the primary tool for archaeogeophysicists due in part to the fact that magnetic data can be collected and processed rapidly and efficiently. When conditions are right due to the properties of specific soils, magnetometers and gradiometers have proven useful in locating negative relief features such as pits and postholes as well as thermally altered features such as fire hearths and burned structures (Gaffney et al. 2000; Kvamme 2006b).

Magnetometers and gradiometers record the minute fluctuations that sediments and objects have on the earth's magnetic field. This is known as induced magnetism because the object does not maintain its own magnetic field. If the effects of this induced magnetism are strong enough compared to the magnetism of the surrounding soil matrix, even small pit features or postholes can be identified or resolved in the geophysical data along with the larger features (i.e., structures). A second type of magnetism called remnant magnetism is created when an object maintains its own magnetic field. In prehistoric archeological examples, this occurs when objects are thermally altered, thus creating a magnetic state called thermoremanent magnetism (Kvamme 2006b:207). The properties of the specific magnetometer used in this study-a Bartington Grad601-2 fluxgate gradiometer-are discussed in detail by Bartington and Chapman (2004).

\section{Electrical Resistance}

Electrical resistance has proven to be one of the most successfully and widely employed methods used by archaeogeophysicists (Bevan 1998:7; Somers 2006:109-110). Resistance surveys measure the resistance to the flow of electric currents through the ground (Gaffney and Gater 2003:26). Resistance surveys can record differences in soil compaction and moisture content and locations of highly resistant features such as stone (as in stone walls or stone foundations). Depending on local site and soil conditions, in North American prehistoric archeological sites, most features recorded with resistance will be 
negative resistance features, meaning that they fall below the background resistivity of the site (Somers 2006:112). This is due to the fact that most prehistoric features in such sites are composed mainly of soil disturbances.

Resistivity surveys are controlled by constant variables including electric current, voltage, and the geometry of the resistivity probe array. The most common probe configuration is known as the twin probe array, which was developed specifically for archeological purposes (Gaffney and Gater 2003:27-34; Somers 2006:112-115). This array uses a set of mobile probes, one injecting the current and one recording the reading (which is an average of the resistance in the area between the two probes), usually spaced with a $0.5-\mathrm{m}$ separation. Probe spacing can be changed to resolve geophysical data to different depths. The $0.5-\mathrm{m}$ separation has proven to be the most useful in electrical resistance for shallow archeological deposits (Gaffney and Gater 2003:60), like the soil conditions at the Mount Pleasant sites. A set of probes is placed off the survey grid at a distance 30 times the mobile probe separation from any point on the grid (i.e., $15 \mathrm{~m}$ off the grid when using a $0.5-\mathrm{m}$ separation). The GeoScan Research RM15 resistivity meter was used during the investigations at the Mount Pleasant sites.

Resistance surveys are suited to the geological conditions of the desert and Great Plains and for locating the well-defined archeological targets such as pit houses and adobe structures that are found in those regions; burned structures in general are readily detectable through resistance survey. In Maki's (2008) recent resistance survey at the Kansas Monument site (14RP1), he was able to obtain very clear geophysical signatures of Great Plains earth lodges, revealing their specific sizes, shapes, and orientations. Another excellent example of resistance data comes from Mission San Marcos along the Georgia coast (Somers 2006:126, Figure 6.11). The resistance data from the mission clearly showed the outlines of a building's foundation as well as considerable internal construction details of the building.

\section{Magnetic Susceptibility}

Magnetic susceptibility is a measurement of a material's ability to be magnetized (Dalan
2006:161). Changes or contrasts in the magnetic susceptibility of sediments are the result of a conversion of weakly magnetic oxides and hydroxides to more strongly magnetic forms (Dalan 2006:162). The magnetic enhancement of anthropogenic soils can be caused by burning episodes (both natural and human caused) as well as organic and inorganic pedogenic processes (Dalan 2006:162-163).

Magnetic susceptibility instruments differ from magnetometers in that they only measure fields resulting from induced magnetism, as compared to magnetometers, which record the net effect of induced and remnant magnetism (Dalan 2006:162; Kvamme 2006b:207-210). These two instruments produce data sets that are both complementary and unique. They are complementary in that magnetic susceptibility data can aid in the interpretation of magnetometer data (Dalan 2006:162-163), and magnetic susceptibility data are unique in that they can be used to address entirely different research questions, such as tracking broad magnetic changes across the landscape (David 1995:20).

Magnetic susceptibility, like magnetic conductivity, has the potential to produce archaeogeophysical results that are quite similar in appearance and information content to that obtained by magnetometer surveys. One of the best examples of this is from the Tom Jones site (3HE40), a fourteenth-fifteenth-century Caddo mound center in southwestern Arkansas (Dalan 2006:182, Figure 8.9). Furthermore, Dalan has repeatedly demonstrated magnetic susceptibility's utility in both soil characterization and site formation issues (Dalan 2006, 2008; Dalan and Banerjee 1998).

\section{Ground-Penetrating Radar (GPR)}

GPR is an active, noninvasive technique that uses a shielded surface antenna to transmit pulses of radar energy, generally high-frequency electromagnetic waves, that reflect off buried objects, features, or geological bedding contacts and are detected using a receiving antenna (Conyers 2004:23-28). The waves detected reflect the two-way travel time of the radar energy and are recorded in nanoseconds (ns). Fairly accurate approximations of the depths of recorded anomalies can be determined through velocity analysis (Conyers and Lucius 1996). 
While GPR is one of the more widely used techniques in archeological geophysics, its success, like that of the other archaeogeophysics techniques discussed herein, varies based on such site conditions as soil type, sediment mineralogy, and moisture content (Conyers 2004; Kvamme 2003). Ideal soil types for GPR include dry homogenous soils with minimal clay. On the other extreme, radar energy will become quickly attenuated in more conductive mediums such as clay and poorly drained soils or in mediums with high magnetic permeability (Conyers 2004).

\section{FIELD METHODS}

Geophysical data were collected in a series of grids (most 20x20-m) at each of the Mount Pleasant sites. The specific settings used for the instruments differ greatly; however, a few general concepts of data collection apply to all of the geophysical technologies used.

Magnetic data were collected using a 1-m traverse interval and a $0.125-\mathrm{m}$ ( 8 readings per meter) sample interval. Resistance data were collected using a twin probe array with a $0.5-\mathrm{m}$ probe separation; a $1.0-\mathrm{m}$ traverse interval and $0.5-\mathrm{m}$ sample interval were also used. Conductivity and magnetic susceptibility data were collected on a 1.0-m traverse interval and a $0.5-\mathrm{m}$ sample interval. At 41TT865, radar data were collected at a $0.5-\mathrm{m}$ traverse interval, and 64 samples per meter were recorded (a 0.015625-m sample interval). All instruments were passed over the survey grids in a zigzag or back-and-forth pattern.

Quality-control data processing was conducted the night after the geophysical data were collected at each site. If there were any issues concerning data quality, the area was resurveyed as a first priority. This minimized the possibility of collection errors and helped maintain a consistent geophysical data set.

\section{DATA PROCESSING}

The data collection techniques discussed above have dramatically different workflows for postsurvey data processing. All data were processed and filtered to remove extraneous false readings (spikes and dropouts). Processing levels the data sets so adjacent grids are combined into a single image with no "grid lines." Data sets were processed to enhance the visibility of any target features or anomalies through statistical manipulation of the recorded data as well as through image processing of the image file output.

The general goal of data processing is to lessen the effects of background "noise" and to enhance the quality of the "signal" or "target." In field geophysics in general and archaeogeophysics in particular, the term "noise" is used to discuss any return that is not a result of the object under investigation, which is referred to as the "target" or "signal." Hence, in some cases what is discussed as noise can in another case be the signal or target (Milsom 2005:13-14). Accuracy of the geophysical readings are not as important for resolving targets as the contrast between the target and its surrounding matrix.

The major data processing techniques are discussed in this section (for more detail on data processing, consult the ArchaeoSurveyor or GPR Slice user manuals), along with details on the specific data processing workflow applied to each survey grid at the different Mount Pleasant sites. Kvamme (2006c:236) is followed in the general approach to data processing. After each processing step, the results are closely compared to their previous state to assure that data manipulation is not in fact decreasing the clarity and quality of the data, thus avoiding artifacts of data processing.

Tables B.1-B.4 outline the data processing steps employed in processing the conductivity, magnetometer, resistivity, and magnetic susceptibility geophysical data from the 11 sites on the U.S. Highway 271 Mount Pleasant relief route.

\section{Clipping}

Clipping replaces all values outside a specified minimum and maximum range. These minimum and maximum values are specified in either absolute values or \pm standard deviations (SD). This process is used to remove extreme data point values and aids in normalizing the histogram of the data. Archeological details are subtle, and having a normal distribution of data allows the fine detail to show through with clarity.

\section{Destripe}

Destriping is a process used to equalize the underlying differences between grids caused by instrument drift, inconsistencies during setup, 


\begin{tabular}{|c|c|c|c|c|c|c|c|c|c|c|c|c|c|c|c|}
\hline & - & & & 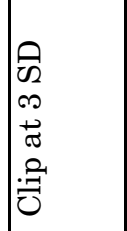 & & & & & & & & & 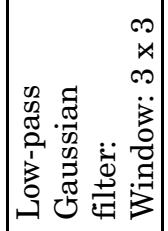 & & \\
\hline & 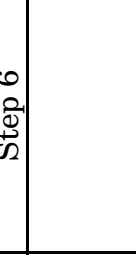 & & 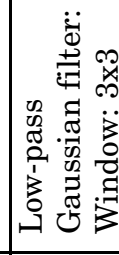 & 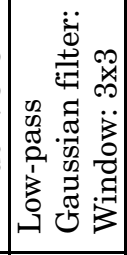 & & & & & & & & & 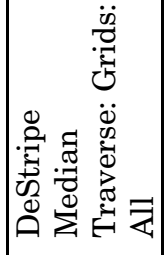 & & \\
\hline & 造 & & 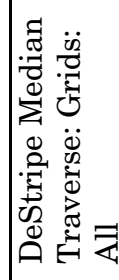 & 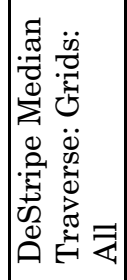 & & 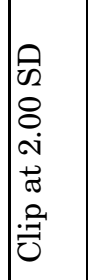 & & & & & & & 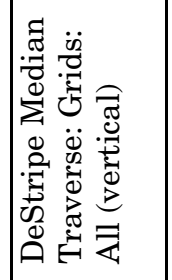 & & \\
\hline & 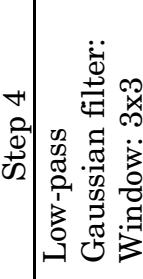 & 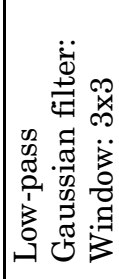 & 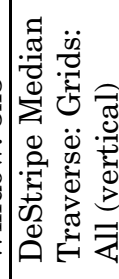 & 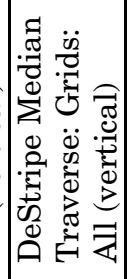 & & 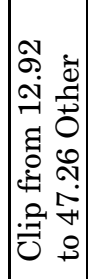 & & 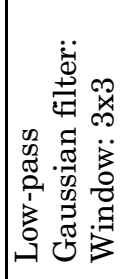 & & & & & 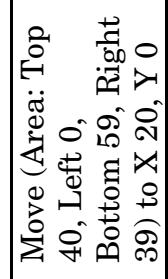 & & \\
\hline & 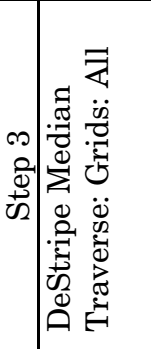 & 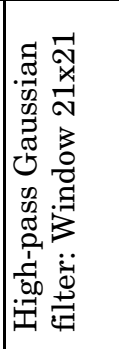 & 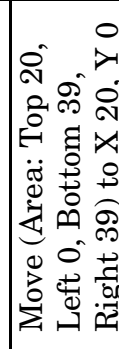 & 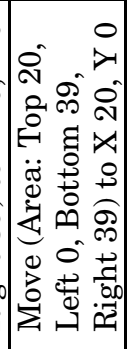 & 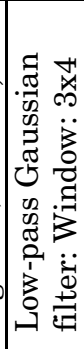 & 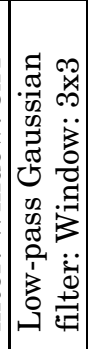 & 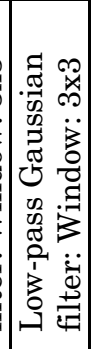 & 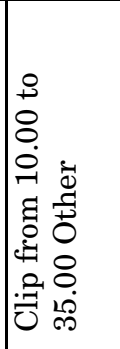 & 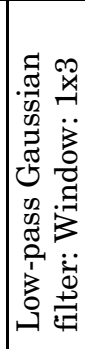 & 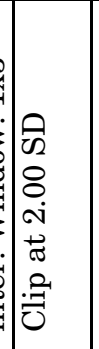 & 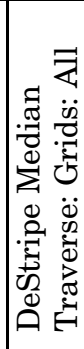 & 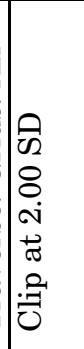 & 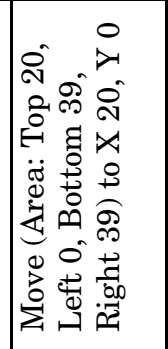 & & 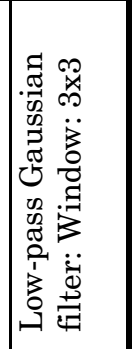 \\
\hline & 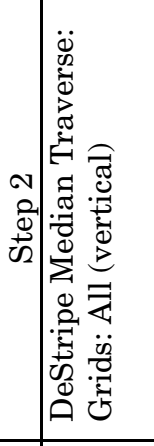 & 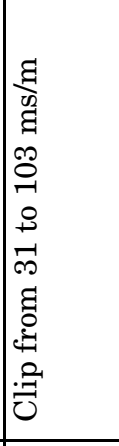 & 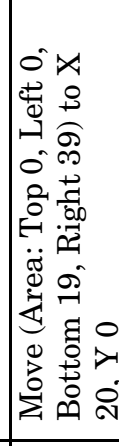 & 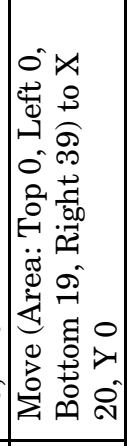 & 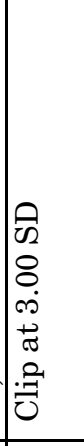 & 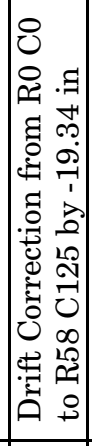 & 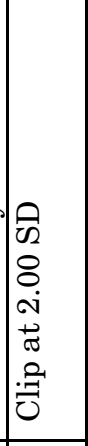 & 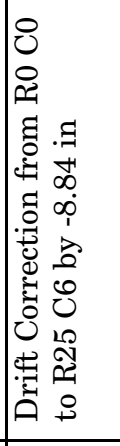 & 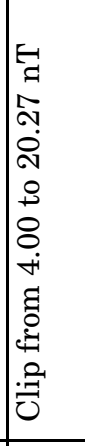 & 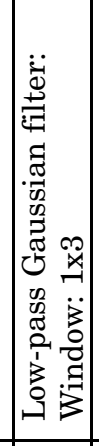 & 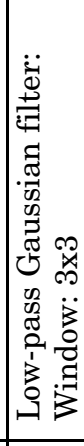 & 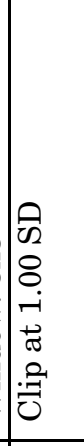 & 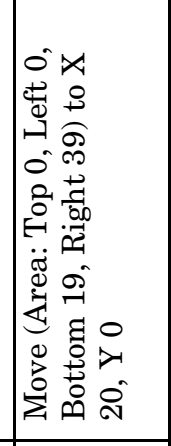 & 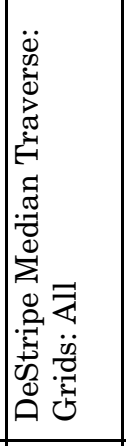 & 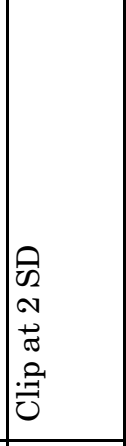 \\
\hline & 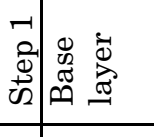 & 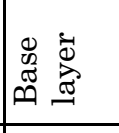 & 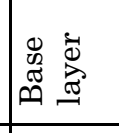 & 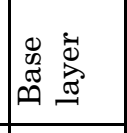 & 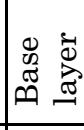 & 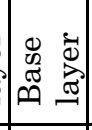 & 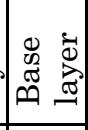 & 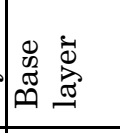 & 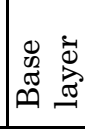 & 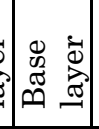 & 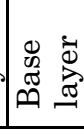 & 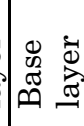 & 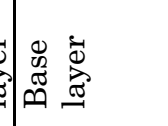 & 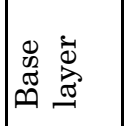 & 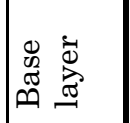 \\
\hline & $\begin{array}{l}0 \\
\qquad \\
\qquad \\
F \\
F\end{array}$ & 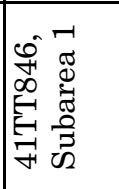 & 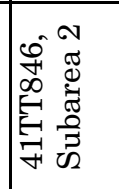 & 告 & 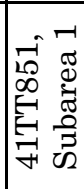 & 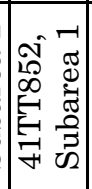 & 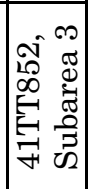 & 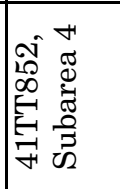 & 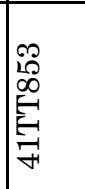 & 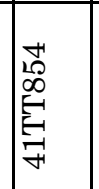 & 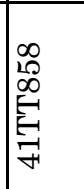 & 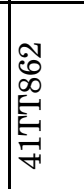 & 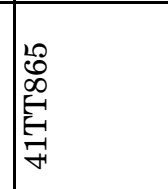 & 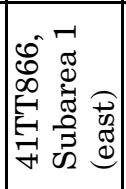 & 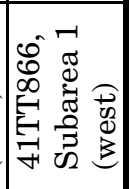 \\
\hline
\end{tabular}




\begin{tabular}{|c|c|c|c|c|c|c|c|c|c|c|c|c|c|c|}
\hline & & 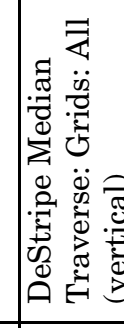 & & & & & & & & & & & & \\
\hline & & 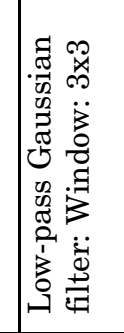 & & & & & & 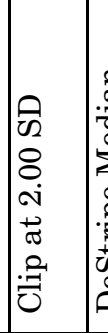 & $\equiv$ & & & 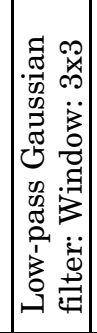 & & \\
\hline 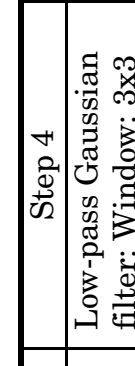 & & 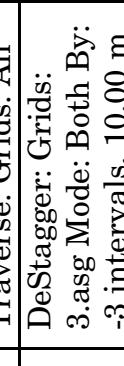 & 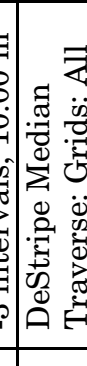 & & 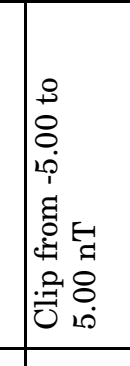 & 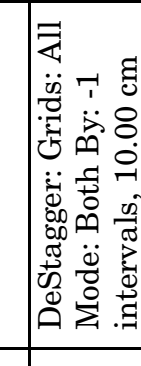 & & 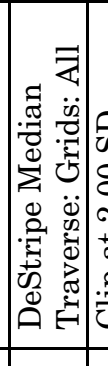 & & 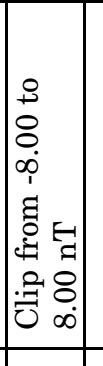 & & 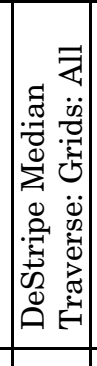 & & 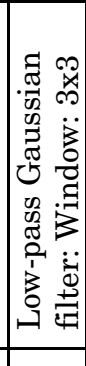 \\
\hline 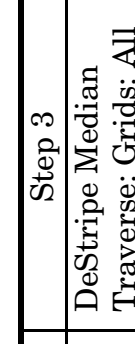 & 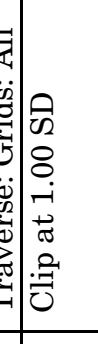 & 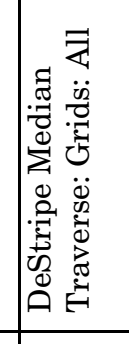 & 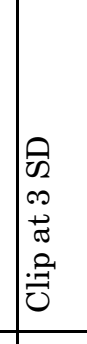 & 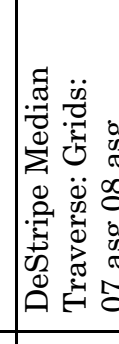 & 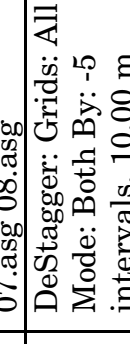 & 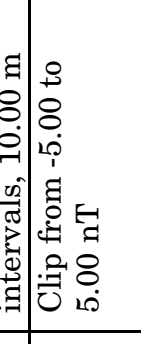 & 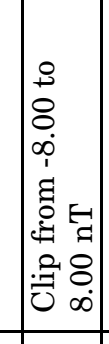 & 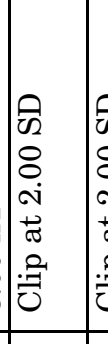 & & 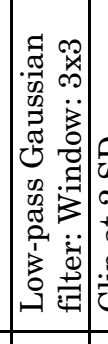 & & 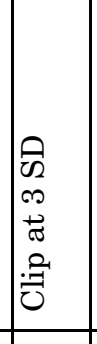 & 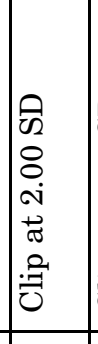 & 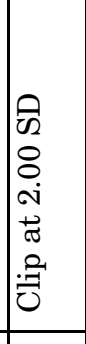 \\
\hline 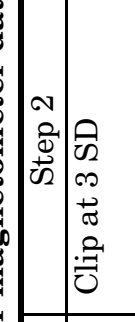 & 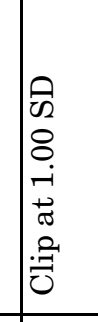 & 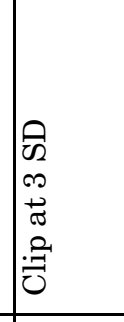 & 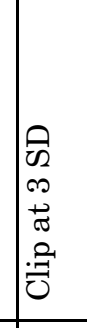 & 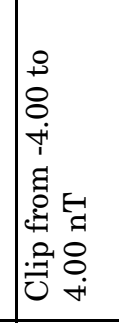 & 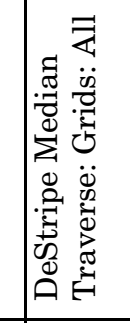 & 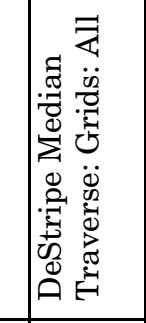 & 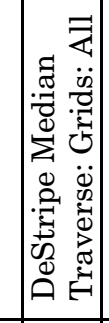 & 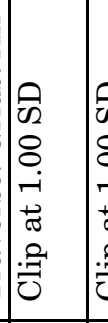 & & 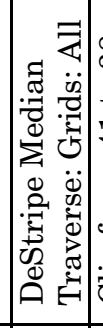 & & 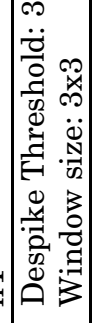 & 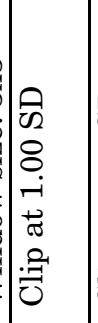 & 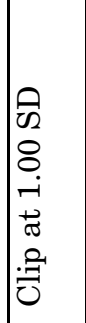 \\
\hline 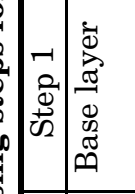 & 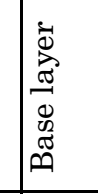 & 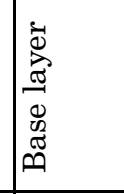 & 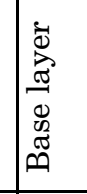 & 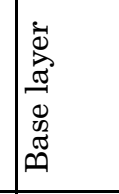 & 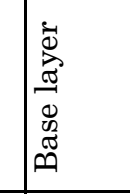 & 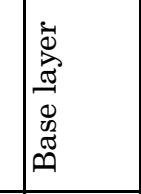 & 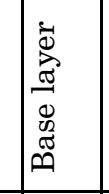 & 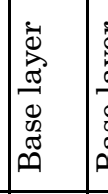 & 离 & 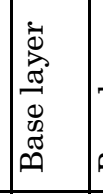 & 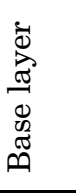 & 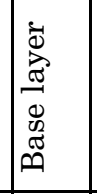 & 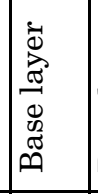 & 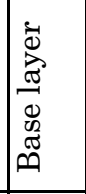 \\
\hline 疍 & 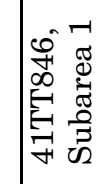 & 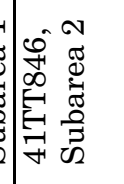 & 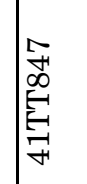 & 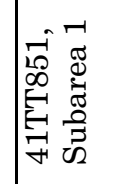 & 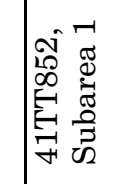 & 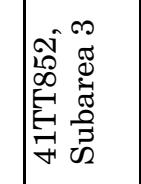 & 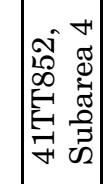 & 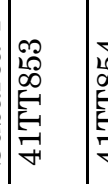 & 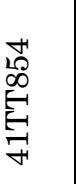 & 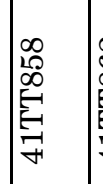 & ర్రి & 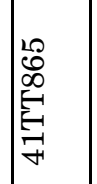 & 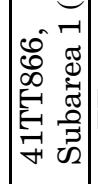 & 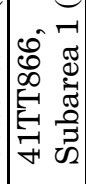 \\
\hline
\end{tabular}




\begin{tabular}{|c|c|c|c|c|c|c|c|c|}
\hline 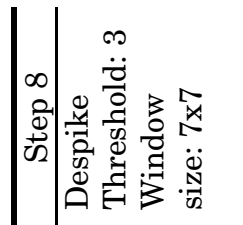 & & & & & & & & \\
\hline 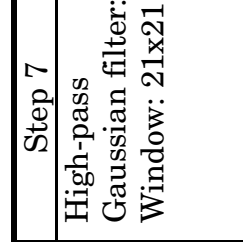 & & & 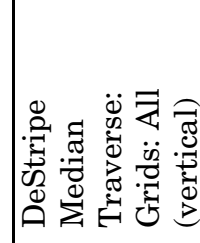 & & & & & \\
\hline 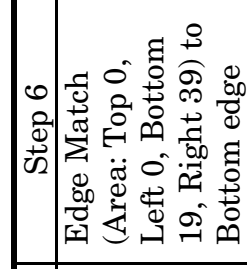 & & & 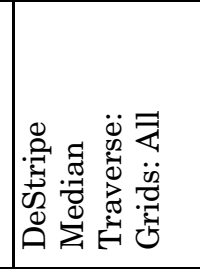 & & & & & \\
\hline 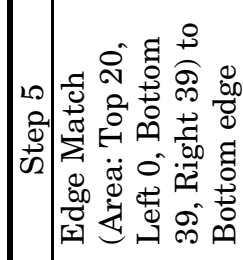 & & 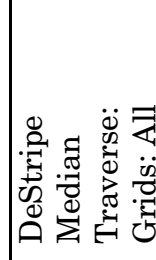 & 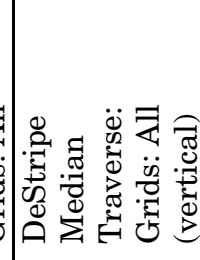 & 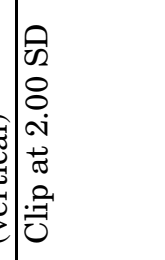 & & & & 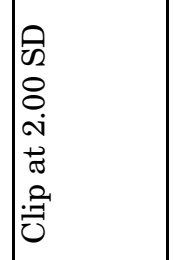 \\
\hline 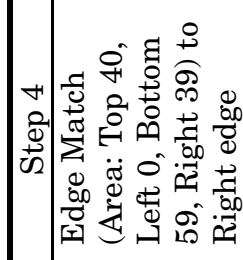 & 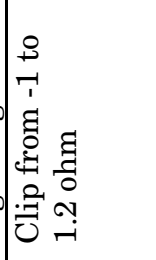 & 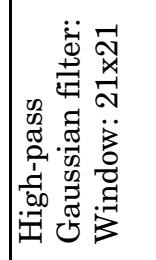 & 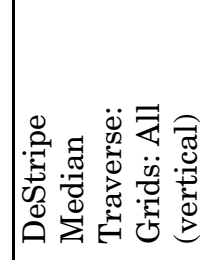 & 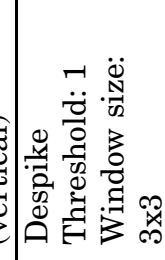 & 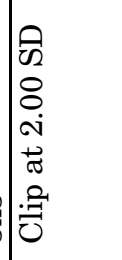 & 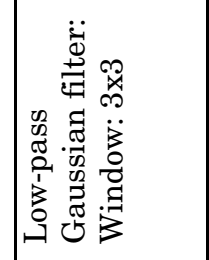 & & 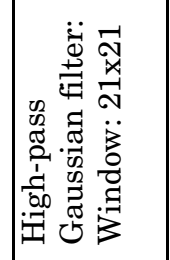 \\
\hline 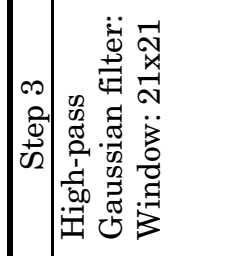 & 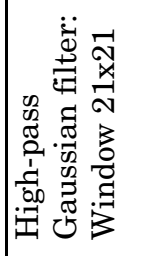 & 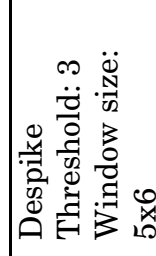 & 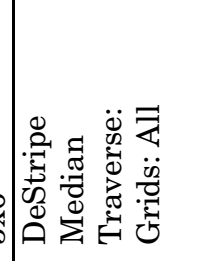 & 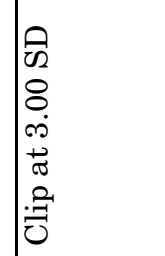 & 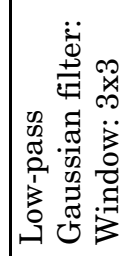 & 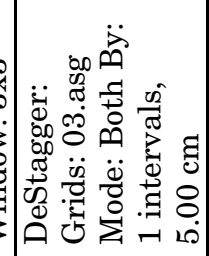 & & 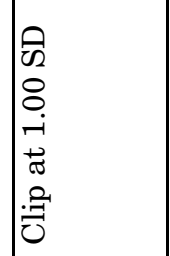 \\
\hline 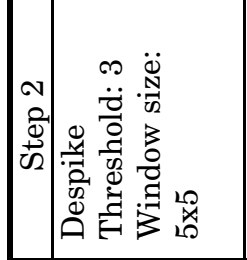 & 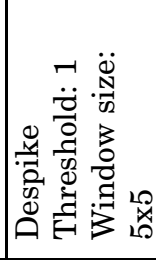 & 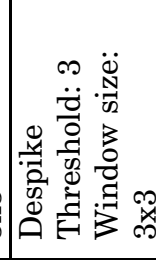 & 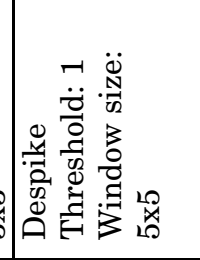 & 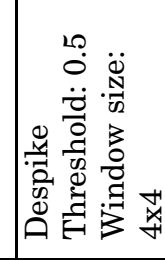 & 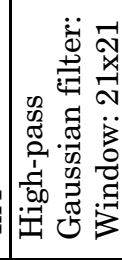 & 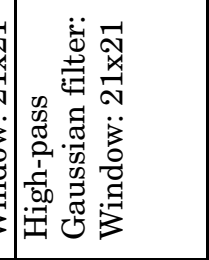 & 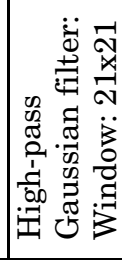 & 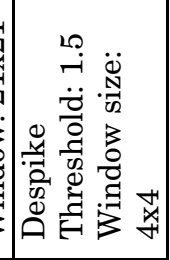 \\
\hline 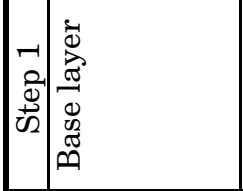 & 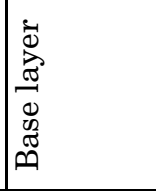 & 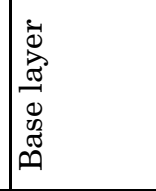 & 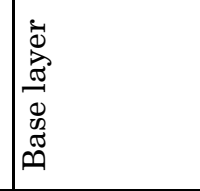 & 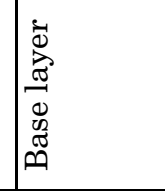 & 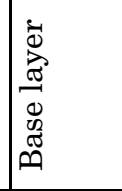 & 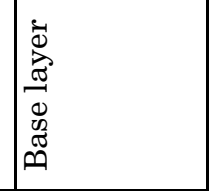 & 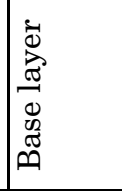 & 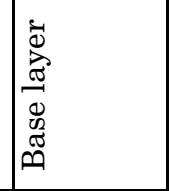 \\
\hline 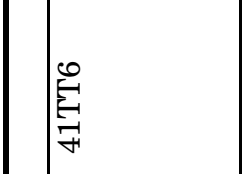 & 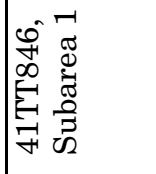 & 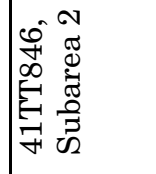 & 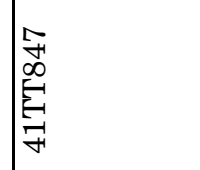 & 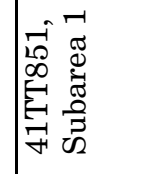 & 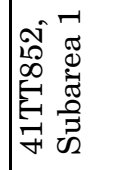 & 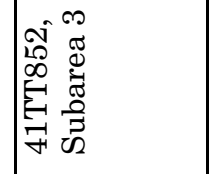 & 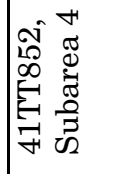 & 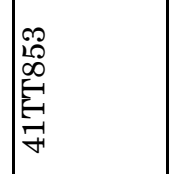 \\
\hline
\end{tabular}




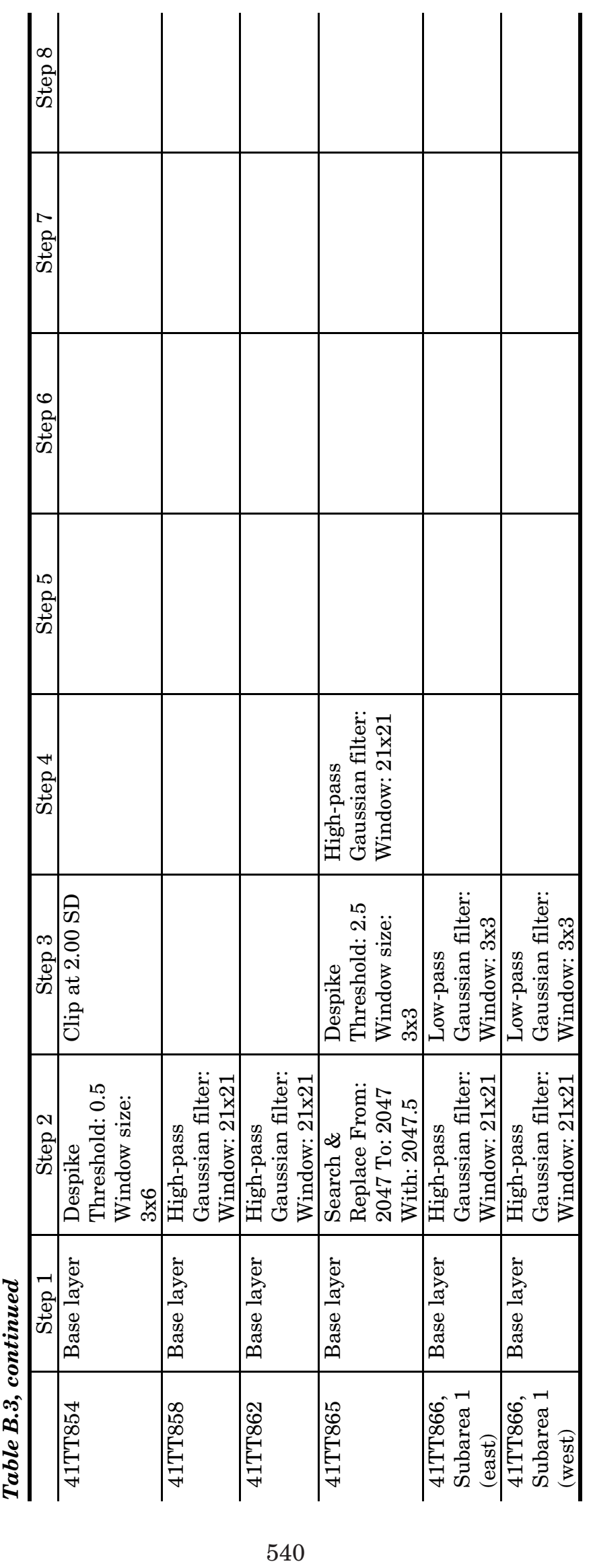




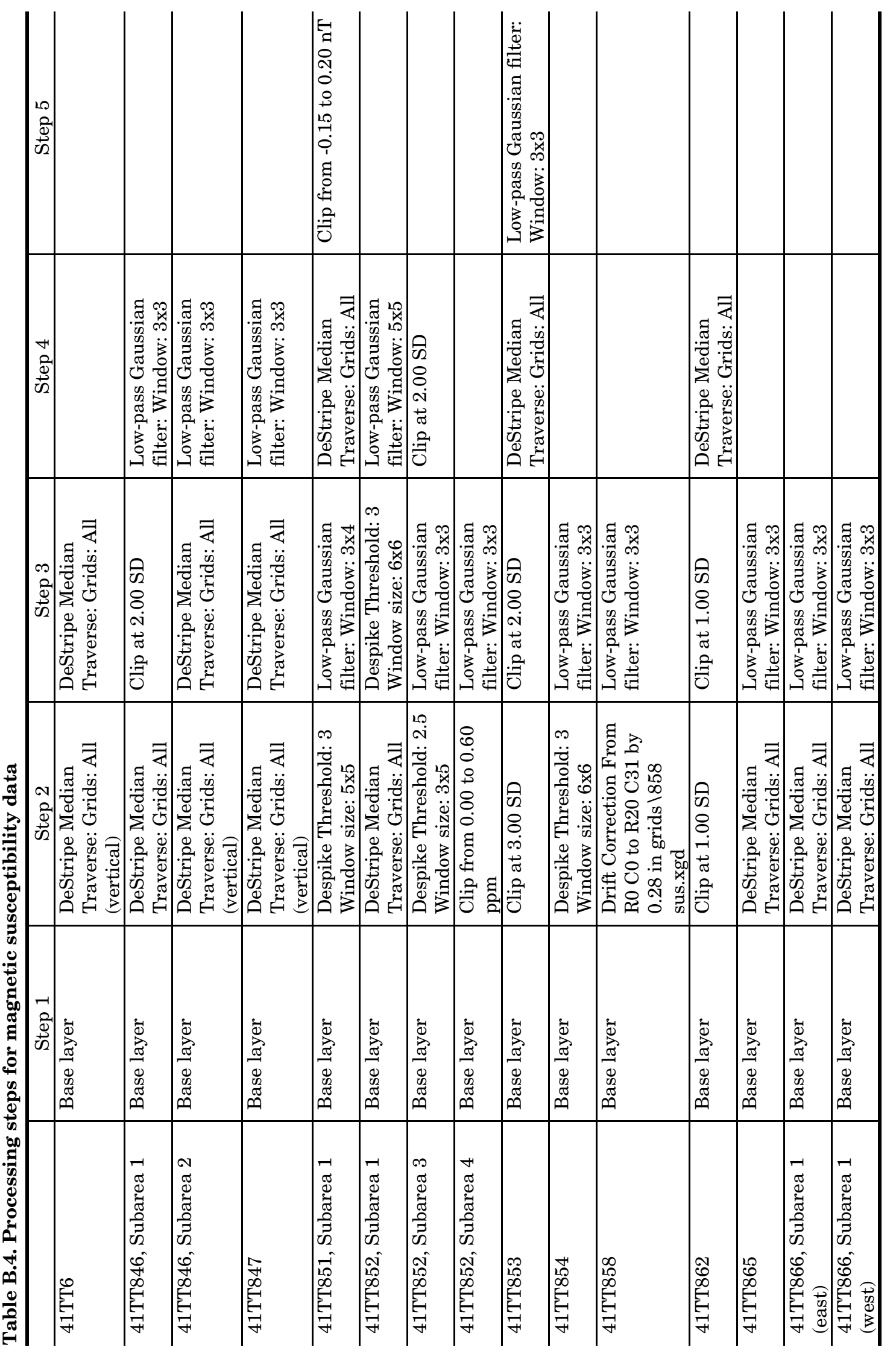


delays between surveying adjacent grids, or heading error from magnetic instruments. The mean, mode, or median value of each grid or traverse is subtracted from the grid or traverse, effectively zeroing the mean, mode, or median. When the mean is used, thresholds are set to exclude extreme data points.

\section{Despike}

Despiking is used to remove outliers from the data set. These can be the result of small pieces of surface iron in magnetometer data or erroneous readings in resistivity data. A uniform weighted window is passed through the data set to remove all values exceeding a specified threshold. Both the window size and threshold are adjustable. Mean or median values can be used for the threshold.

\section{Destagger}

Destaggering is performed to correctly align readings from adjacent traverses. Data can become skewed if the surveyor incorrectly triggers the instrument. Destaggering data simply shifts the traverses a specified interval. A cubic spline algorithm is used to calculate the shifted data points to ensure a smooth curve from the existing data.

\section{High/Low Pass}

High- and low-pass filters are used to remove high- or low-frequency components in a geophysical survey. A high-pass filter calculates the mean of a window of a specified size, then subtracts this mean from the center value. A low-pass filter calculates the mean of a window of a specified size and replaces the center value with the mean. Either filters can use uniform or Gaussian weighting. With uniform weighting means, all values within the window are given equal weight. Gaussian weighting gives a higher weight to values closer to the center of the window. One of the most common applications of the high-pass filter is to remove the geological background from resistivity data (Somers 2006:118-119). Low-pass filters are more commonly applied to lessen the effects of background noise. Both filters should be used with caution, and close attention should be made to their resulting effects, thus assuring that no processing artifacts are created and that no significant anomalies are removed as a result of their application (Kvamme 2006c).

\section{Amplitude Slice or Time Slice}

Amplitude slice maps are a three-dimensional tool for viewing differences in reflected amplitudes across a given surface at various depths. Amplitude slice maps are generated through the comparison of reflected amplitudes between raw vertical profiles. Amplitude variations are analyzed at each location in a grid where there is a recorded reflection. The individual profiles are combined into a data cube, and the amplitudes of all traces are compared to the amplitudes of all nearby traces. This database or data cube can then be "sliced" horizontally and displayed to show the variation in reflection amplitudes at a sequence of depths in the ground.

\section{SITE CONDITIONS AND GENERAL CONSIDERATIONS}

Ground cover at all 11 sites was optimal for geophysical survey. The sites were covered in low-lying grass. No trees or shrubby plants were in the survey areas. The sites were, in general, all far enough away from any obstructions such as fencing or electric lines that magnetic interference was not an issue. At 41TT865, however, there was a fence bordering the western side of the survey block that produced significant interference. A high-voltage line crossed the area approximately $20 \mathrm{~m}$ north of the survey area. Transmission interference was noted in the northern portion of the survey block. This interference was most obvious in the conductivity data set.

Prior to data collection, all geophysical survey areas were scanned with metal detectors. All positive "hits" were marked with nonmagnetic flags and later excavated. The sediments from these metal detector scans were passed through 1/4-inch wire cloth, and the remaining debris was inspected. The modern metal debris was discarded, but all metal material of potential archeological significance was collected.

\section{GEOPHYSICAL SURVEY RESULTS}

Attachment B.1 (in digital form only) contains images representing the results of the 
geophysical surveys at all 11 sites. The results are discussed site by site below.

\section{TT6}

Geophysical survey at 41TT6 did not locate any clear signs of Caddo architecture or archeological features. During the site preparation work, a significant amount of metal debris was removed from the survey area, especially in the northeast quadrant of the survey grid.

One interesting geophysical area is apparent in all four data sets. This area is on the south edge of the survey grid $30 \mathrm{~m}$ from the western edge. In the conductivity data, this area is indicated by a low or negative conductivity anomaly, while in the magnetometer data the area is not represented by a single anomaly but is instead a noisy area with several small low-intensity dipole readings. A dipole is a particular type of signal that is produced in magnetic data sets when an object maintains its own magnetic field or remnant magnetism (Kvamme 2006b:207). Geophysically, for our purposes, a dipole is represented by a paired high and low return, although technically it is a field that consists of equal-strength positive and negative point sources with strengths that decrease as the inverse cube of distance, and both strength and direction change with latitude (Milsom 2005:4). Resistivity data show a high or positive resistance anomaly in the central part of the grid. The area in question is the most diffuse in the magnetic susceptibility data. Given the size of this set of anomalies, this particular area is considered most likely to be a geological feature.

Another likely geological trend in the geophysical data begins in the same area and runs diagonally to the northeast. This trend is most legible in the magnetometer and magnetic susceptibility data. It may represent the area of the landform that has thicker $\mathrm{A}$ and $\mathrm{E}$ horizon sands.

The northwestern and northeastern corners of the magnetometer grid survey area have strong dipole returns. The anomaly in the northeastern corner also appears as a positive magnetic susceptibility anomaly. These dipole returns are pieces of metal debris that the presurvey metal detecting failed to locate.

\section{$41 T T 846$}

The archaeogeophysical results from the Subarea 1 grid at 41TT846 did not locate any prehistoric architectural features. The conductivity data show two linear high-conductive anomalies with areas of low conductivity in between. The magnetometer data are relatively quiet with limited areas of increased magnetic activity, though there are a fair number of dipolar returns caused by metal debris. A brush push pile that contained metal fencing debris flanked the far western edge of the survey area. A positive halo resulting from this metal debris can be seen in the bottom of the grid. The resistivity data are very similar to the mirror image of the conductivity data; where the conductivity data consist of linear high-conductive anomalies, the resistivity data consist of linear anomalies of low resistance. Magnetic susceptibility is the noisiest data set. Areas of noted magnetic enhancement in the magnetometer data are also areas of higher magnetic susceptibility.

Geophysical survey in the two Subarea 2 grids also did not locate any clear signs of Caddo architecture or archeological features. The northern grid has a high linear conductive anomaly flanked by areas of low conductivity. The magnetometer data are generally quiet with limited areas of increased magnetic activity and a few dipolar anomalies in the south part of the grid and what appears to be an area of magnetic enhancement in the north. As in the Subarea 1 grid, the resistivity data present a mirror image of the conductivity data. The northern part of the grid, which is magnetically enhanced, is also an area of high resistance. Areas of magnetic enhancement in the magnetometer data are also areas of higher magnetic susceptibility.

In the southern Subarea 2 grid, conductivity data randomly fluctuates from low to high readings and consequently is not useful for either archeological or geological interpretations. There are several anomalies in the magnetometer data, but none have any recognizable archeological significance. In the southwest corner is a diagonal linear feature; this negative magnetic feature is in three of the four data sets. An S-shaped positive magnetic feature extends across much of the eastern half of the survey area. With this shape, this anomaly is likely geological in nature, though it also suspiciously resembles a cow trail; however, there was nothing visible at the surface at the time the data were collected. A large dipole return in the middle of the southern end of the survey area is obviously a piece of metal that the metal detecting failed to locate. Resistivity 
data show the diagonal linear anomaly in the southwest corner; this is a negative resistance anomaly roughly the same dimensions as in the magnetometer data. A large positive resistance anomaly is slightly north of the large dipole anomaly in the magnetometer data.

There is one overall trend in the resistivity data in the southern Subarea 2 grid. The southwestern portion tends to be much noisier than the northeastern corner. This conforms to some degree to the overall topography of the survey area, but as no detailed topographic data were collected during the archaeogeophysical investigations, a topographic, soils, or geological explanation of this trend cannot be evaluated. Sediments in this area were of uniform thickness (ca. 18-44 cm) overlying a sandy clay Bt horizon.

The magnetic susceptibility data in the south grid also are quite noisy. However, two general characteristics are noted: these include the previously mentioned diagonal linear feature in the southeastern corner and three generally circular areas of enhanced magnetic susceptibility. Given their size and shape, it was recommended they be evaluated by hand excavations or backhoe trenching to determine their archeological significance, if any. To err on the side of caution, the diagonal linear feature noted in the magnetometer, resistivity, and magnetic susceptibility data also was considered worthy of ground-truthing to be certain of its origin, although it was considered unlikely to be related to prehistoric occupation of the site. This area was more likely to be a buried trench of some sort. The fact that it is a negative magnetic anomaly suggests it is probably not any sort of buried metal (cable or metal pipe); however, it could well be a buried nonferrous object (probably a pipe).

\section{TT847}

Geophysical survey at $41 \mathrm{TT} 847 \mathrm{did}$ not locate any clear signs of Caddo architecture or evidence of archeological features. Of the various sites discussed here, this one has the noisiest data sets. The conductivity, magnetometer, and resistivity data are good examples of noisy data sets, with no apparent patterns. The magnetic susceptibility data set is markedly different from the other three data sets, however, in that it does not exhibit the same degree of noise.
Three small anomalies (low- or negativesusceptibility areas surrounding central high or positive anomalies) include in the middle of the eastern portion of the survey area; these are in approximately the same area as three small (ca. $80 \mathrm{~cm}$ in diameter) burned rock features detected in test excavation units between $23-46 \mathrm{~cm}$ below the surface (Hatfield et al. 2008:18-19, Figure 8). There is a fourth small anomaly (marked by a positive magnetic susceptibility area) in the west-central part of the grid, in an area that was not investigated by hand excavation units or backhoe trenches (Hatfield et al. 2008:Figure 8); this may mark another burned rock feature. A much larger positive magnetic susceptibility anomaly is apparent along the eastern edge of the survey area; this may be from cattle feeders that had been in this area.

\section{George Richey Site (41TT851)}

The southern and southeastern portion of the survey grid in Subarea 1 at this site is an area of enhanced magnetic susceptibility. This area also has significantly more compact sediments. This area of magnetic enhancement may be the product of modern disturbance, apparently introduced modern road deposits (Hatfield et al. 2008:25). In the center of the survey area is a large anomaly in both the magnetometer and magnetic susceptibility data that is interpreted as metal debris.

There are several areas of positive conductivity and areas of positive resistivity; these are shown as darker areas on the data maps. The positive conductivity areas are primarily in the southern part of the survey grid, as well as in one area in the east-central part. There are two areas of positive resistivity. One is in the southern and southwestern part of the grid, apparently extending to the west and south outside of the grid; it is an estimated $26 \mathrm{~m}$ east-west and $13 \mathrm{~m}$ north-south. This same area is marked by low negative conductivity, with several small notable peaks of low conductivity. The second area of positive resistivity is in the northern and north-central part of the survey grid; this roughly circular area extends at least $28 \mathrm{~m}$ east-west and $35 \mathrm{~m}$ north-south, probably going north outside the survey grid. As discussed below, both of these areas of positive resistivity are associated with areas of midden deposits or feature clusters (Hatfield et al. 2008:Figure 12). 


\section{William Ford Site (41TT852)}

Subarea 1 at the William Ford site produced complex geophysical results that may be correlated with archeological features and areas of archeological interest. Magnetometer data display a complex pattern of anomalies (both positive and negative) that extend across much of the eastern and northern parts of the survey grid. Notable are two circular areas in the eastern and western parts; these are an estimated $8.0 \mathrm{~m}$ and $9.3 \mathrm{~m}$ in size and were considered to potentially represent Caddo structures, though subsequent excavation did not bear this out. The eastern one is defined by a medium-intensity circular trend, while the western one is defined by a mediumintensity trend intermixed with strong dipolar anomalies.

Resistance data from Subarea 1 consists of several high-resistance anomalies in the eastern portion of the survey area, encompassing one of the circular anomalies detected in the magnetometer data. The structure-sized western circular anomaly in the magnetometer data is not apparent in the resistivity data. There is a general north-south trend of clustered highand low-resistance data values cutting across the grid that follows the slope of the landform (Hatfield et al.2008:Figure 13) and the thickness of the archeological deposits in Subarea 1 (Hatfield et al. 2008:34).

Predictably, a large area of high conductivity is in the western part of the Subarea 1 survey area, in virtual opposition to the findings from the resistance data. High-resistance anomalies and low-conductivity anomalies appear to correlate to thicker sandy deposits and flatter topography, while the high-conductive anomalies appear to correlate with areas where the clay subsoil is closer to the surface.

Magnetic susceptibility data show a diffuse high-susceptibility anomaly in the southeastern quadrant of the Subarea 1 survey area, extending to the south and west outside the grid; this area measures at least $25 \mathrm{~m}$ north-south and $19 \mathrm{~m}$ east-west. It likely corresponds partly to anthropogenic or midden deposits documented during earlier archeological investigations at the site (Perttula and Nelson 2002; Wilder and Fields 2005). There is a second slightly larger diffuse area of magnetic susceptibility in the northwestern portion of the survey area.
The most dominant anomaly in the magnetometer data from Subarea 3 is the strong dipole created by the pole of a utility line that traverses the site. Resistance data depict high-resistance anomalies that correspond to the crest of the landform and probably delineate deeper sand deposits. Conductivity data display two high-conductive anomalies along the northeastern and southeastern quadrants of the survey grid, both along the slope of the landform below the crest of the upland ridge to the south (with low conductivity). These high-conductive anomalies may represent areas where the clay subsoil is closer to the surface. Directly west of the utility line in Subarea 3 is an area of enhanced magnetism that is apparent in both the magnetic susceptibility and magnetometer data. This area was recommended for test excavations to discern if the anomaly is a result of anthropogenic deposits.

The magnetometer data from Subarea 4 are dominated by disturbance from a pipeline that crosses to the north of the site. High-resistance anomalies are on the crest of the landformrunning east-west-and likely correspond to deeper sand deposits. Conductivity data are dominated by a high-conductive anomaly on the northwestern edge of the grid, which corresponds to the location of the buried pipeline. Magnetic susceptibility data also show ground disturbance from the buried pipeline as well as two diffuse high-susceptibility anomalies on the crest of the landform in the eastern half of the grid. The larger of the two is about $15 \mathrm{~m}$ in diameter and was recommended for ground-truthing to determine if it represents an anomaly of archeological significance.

\section{James Richey Site (41TT853)}

Magnetometer data from the James Richey site (41TT853) display a broad diffuse trend of magnetic enhancement in the central and southern parts of the grid survey area, below the crest of the landform on the toeslope. Highresistance anomalies are on the same portion of the landform, and also in the southern portion of the survey area surrounding a large oak tree whose root ball probably affected the resistance readings. High-conductive anomalies are in the southwestern corner of the grid and the northwest quadrant, perhaps corresponding to areas where the clay subsoil is closer to the modern ground 
surface. Conversely, low-conductivity areas were found running north-south across much of the survey grid, corresponding to areas of magnetic enhancement and high-resistance anomalies. Magnetic susceptibility data show a series of generally high-susceptibility anomalies across much of the central and southern parts of the grid survey area, as well as several linear (east-west or north-south) low-susceptibility anomalies in the southern, central, and northern quadrants. One larger area of lowmagnetic susceptibility (ca. $13 \times 10 \mathrm{~m}$ ) in the central part of the southern grid area closely corresponds to a cluster of cultural features found in subsequent testing, and this same area has notable high-resistance anomalies.

\section{TT854}

The geophysical data from 41TT854 do not show anomalies with much potential for archeological significance. In the magnetometer data, the northern half of the grid survey area is magnetically enhanced, and there are highmagnetic susceptibility values in this same area. This broad area of increased magnetism corresponds to the crest of the upland landform and areas of deeper archeological deposits (Hatfield et al. 2008:56). An area of positive conductivity anomalies is in the southwestern quadrant of the survey area, while lowconductivity areas dominate the remainder of the grid. This latter has deeper sandy deposits, and the high-conductivity areas probably represent the parts of the grid that have shallower sandy $\mathrm{A}$ and $\mathrm{E}$ horizons overlying the clay B horizon. There is a band of positive-resistivity anomalies on the crest of the landform, trending east-west, as well as a smaller positive-resistance anomaly in the east-central part of the grid.

\section{$41 T T 858$}

The geophysical data from 41TT858 do not show any compelling patterning. Magnetometer data define two areas with slight magnetic enhancement in the eastern (near the crest of the upland landform) and western parts of the survey grid. Resistance data show no clear patterning in either high-or low-resistivity values, and no anomalies are evident. There is a broad linear high-conductive anomaly on the southern and southwestern edges, probably in areas with shallow soils overlying clay subsoil. A high magnetic susceptibility anomaly is on the western side of the grid, partially overlapping with the high-conductivity anomaly and one of the magnetically enhanced areas.

\section{TT862}

The conductivity data from 41TT862 consist of a linear anomaly running northeast to southwest across the southeast corner of the grid survey area. There is a general trend of lowconductive readings in the center, with higherconductive readings in the north and northeast portions of the grid. The magnetometer data show two strong dipolar anomalies in the center of the survey area as well as one in the northwest portion. A linear anomaly consisting of a northeast-southwest magnetic high with a large diffuse magnetic low halo is in the southeast corner. The magnetic susceptibility data includes three high-susceptibility anomalies in the center of the grid. A subtle high-susceptibility linear anomaly is in the northeast corner, and there is a diffuse high-susceptibility trend along the western side of the survey area. The same northeast-southwest linear anomaly that is legible in the conductivity and magnetometer data is present in the magnetic susceptibility data; this is a buried gas line. The resistivity data are noisy and consist mainly of alternating high and low readings. The diagonal linear anomaly in the southeast corner is legible as a low-resistance anomaly; however, it is much subtler than in the other three data sets.

\section{TT865}

The most significant anomaly in the conductivity data from 41TT865 is caused by transmission interference from a power line approximately $15 \mathrm{~m}$ north of the survey area. This shows as a combination large positive and negative conductivity anomaly on the northern edge of the grid. The magnetometer data show several repeating dipole anomalies along the central and western parts of the grid, terminating $20 \mathrm{~m}$ from the south end of the grid with an intense dipole anomaly almost $15 \mathrm{~m}$ in width. This large dipole is the metal corner of a fence that flanks the western edge of the survey block. The eastern edge and middle of the survey area displays enhanced magnetism, which may 
be associated with archeological depositsspecifically Caddo midden deposits-that are present directly to the west.

Resistivity data contain a striking positive resistance anomaly in the approximate center of the survey area that trends to the northeast, essentially surrounding the area of magnetic enhancement detected in the magnetometer data. This positive resistance feature corresponds to the midden deposit on a topographic high identified in previous fieldwork (Perttula et al. 2002:85-95; Wilder and Fields 2005). The northern edge of the anomaly is defined by an area of neutral resistance that correlates with a low washed-out area at the edge of the rise. East of the positive resistance anomaly is an area of neutral resistance. This area was flagged for further investigation for two reasons: (1) its proximity to the prehistoric Caddo midden, and (2) the fact that it contains a series of complex magnetic returns, including magnetically enhanced data values.

The magnetic susceptibility data show a positive magnetic anomaly that corresponds approximately to the center of the positive resistance anomaly discussed above, as well as to the Caddo midden on the rise in the floodplain. This high magnetic susceptibility anomaly measures approximately $16 \mathrm{~m}$ northsouth and $7.8 \mathrm{~m}$ east-west. There also are two diagonal linear anomalies in the south end of the survey block, both a maximum of ca. $1.25 \mathrm{~m}$ in width. The northern end of each begins in the east-central part of the grid, and they extend at least $40 \mathrm{~m}$ south or south-southwest to the southern end of the grid. There were no visible markings on the surface corresponding to these linear anomalies. Interpretation based on the geophysical data is uncertain, but one possibility is that they represent screens or fences erected around one side of the rise and midden deposits; such features have been detected in archeological (Early 1993; Perttula 2005) and geophysical (McKinnon 2008; Perttula et al. 2008:Figure 11) investigations at several Caddo sites of approximately the same age as 41TT865 in the Red River and Ouachita River valleys in northeastern Texas and southwestern Arkansas. Considering the proximity and relationship of these diagonal anomalies to the area of enhanced magnetism as well as the high magnetic susceptibility anomaly that corresponds to the midden, both linear anomalies were considered worthy of further investigation.

The larger resistivity anomaly and smaller magnetic susceptibility anomaly both apparently correspond to the Late Caddo midden deposits located by Perttula et al. (2002) and Wilder and Fields (2005). From the geophysical data alone, it was not possible to discern which of the two anomalies has the best spatial co-association with the midden, although the magnetic susceptibility anomaly best overlaps with the extent of the natural rise; Perttula et al. (2002) note that midden deposits are also present in Trench 17 just south of the rise itself. Further investigation was recommended to resolve which data set is more affected by the geophysical character of the midden deposits. Investigation also was recommended in the area of enhanced magnetism in the magnetometer data set. While there are no identifiable geophysical patterns there clearly representing signatures of Caddo architecture or features, the area's proximity to the Caddo midden and the general spatial trend identified in the distribution of magnetic disturbances or magnetic enhancement indicated that ground-truthing was warranted here.

A small swath of radar data was collected over the heart of the midden deposit. Using field plots of the resistivity data as a guide, a small area measuring $4.5 \mathrm{~m}$ east-west and $40 \mathrm{~m}$ north-south was collected with the GPR. This area started $20 \mathrm{~m}$ north of the southern edge of the larger survey area and $10 \mathrm{~m}$ east from its western edge. Eight amplitude or time-slice maps were created. Each slice is 4 ns thick and overlaps the above slice by $2 \mathrm{~ns}$ (i.e., slice \#1 is from $0-4$ ns, and slice \#2 is from 2-6 ns, etc.). No hyperbolic anomalies exist in any of the profiles collected, making accurate depth measurements using velocity analysis impossible. Hyperbolic anomalies are simply the result of radar returns from a discrete object such as a rock or tree root. Even if not related to a geophysical target, hyperbolic anomalies can be used to determine the dielectric properties of the soil, thus providing a more accurate depth assessment.

The first $4 \mathrm{~ns}$ of depth is dominated by high-intensity reflections; this is a usual occurrence often referred to as the "near field effect" (Conyers 2004:76). In the time slices at 4-10 ns deep (slice \#3 from 4-8 ns and slice \#4 from $6-10 \mathrm{~ns}$ ) the area with midden deposits 
(N4-22 on the radar swath) is apparent as a high-amplitude reflection, while the remaining area has consistently low-amplitude reflections. This pattern disappears by $12 \mathrm{~ns}$. In the absence of velocity analysis or a field-conducted velocity test, only an extremely rough approximation of depth could be made using relative dielectric permittivity (RDP) depth charts (e.g., Conyers 2004:86, Table 4.1). The crudeness of this approximation is based on determining the RDP for any given soil conditions. An average organicrich surface soil has an RDP of 12 (Conyers 2004:47, Table 3.1). This would place the 10 $\mathrm{ns}$ anomalies at approximately $45 \mathrm{~cm}$ below the surface, suggesting a bottom depth of the midden. Based on the depth of artifacts recovered in the midden deposits in hand excavations, the midden extended to about $40 \mathrm{~cm}$ below surface (Hatfield et al. 2008:66), closely approximating the RDP estimates. Earlier investigations by Perttula et al. (2002:88) suggested that in some circumstances the midden deposits extended to a maximum of ca. $54 \mathrm{~cm}$.

\section{TT866}

The conductivity data from the east grid at 41TT866 show a large diffuse high-conductive anomaly in the southwest corner of the survey area. The remaining portions are areas of low conductivity. The magnetometer data exhibit a few dipolar signals from metal objects and a northeast-southwest diagonal trend of magnetic noise. This is the result of a buried PVC water line; this same magnetic trend is mirrored in the magnetic susceptibility and resistivity data. The magnetic susceptibility data contain two high-susceptibility anomalies in the northern portion and a large diffuse high anomaly at the eastern edge. The predominant anomaly is the northwest-southeast linear one. The resistivity data contain a diffuse high-resistance trend in the center of the survey area, along with the linear low-resistance anomaly mirroring the same northwest-southeast line that is apparent in the magnetometer and magnetic susceptibility data.

The conductivity data from the western grid contains no significant anomalies and consists of a slight trend of increasing conductivity on the eastern side. The magnetometer data are quite noisy and consist of an area of enhanced magnetism in the western portion. Magnetic susceptibility data show a high-susceptibility anomaly in the northwest corner and alternating low and high noise throughout the remaining portions. Resistivity data indicate a general diffuse trend of higher readings in the center with low-resistance trends on both the eastern and western sides.

\section{ARCHEOLOGICAL FEATURES AND AREAS OF ARCHEOLOGICAL INTEREST COMPARED TO THE GEOPHYSICAL DATA FINDINGS}

In this section, we consider in more detail the relationships between the archaeogeophysical findings (as defined by anomalies of different magnetic character and spatial extent) at the 11 sites and the findings from the subsequent archeological test excavations (but generally not the more-extensive data recovery excavations, which were done after this analysis was completed). Specifically, we explore the geophysical-archeological associations regarding sites with no identified cultural features, sites with few identified features, and sites with clusters of features. It is clear from this review that the spatial extent and intensity of prehistoric Caddo habitation features and archeological deposits in the project area is lowin part a product of the need to define a project corridor for development where only limited areas of significant archeological deposits on sites are to be affected by that developmentand this is also evident in the low number of identified geophysical anomalies that were thought to have any archeological significance.

\section{Sites with No Cultural Features}

Several sites or subareas within sites investigated had no archeological features that were identified during extensive hand and machine-aided test excavations (Hatfield et al. 2008). These include 41TT6, 41TT846, Subarea 4 at the William Ford site (41TT852), 41TT854, 41TT858, and the east grid at 41TT866.

The archaeogeophysical data from each of these produced no compelling evidence of archeological features or significant areas of archeological deposits. Rather, most of the anomalies that were discerned could be interpreted most reasonably as relating to either geology/topography or differences in soil 
thickness across the geophysical survey grids. In other cases, the archaeogeophysical results are the product of modern disturbances, such as buried pipelines (see Subarea 4 at the William Ford site and 41TT866. In a few instances, areas of magnetic enhancement or areas with highsusceptibility anomalies were recommended for further archeological investigation, but the results of that work did not identify significant archeological deposits or preserved archeological features.

\section{Sites with Few Cultural Features}

Five sites have only a few archeological features that were documented in the geophysical survey grids by manual test excavations and backhoe trenching. These are 41TT847, Subarea 3 at the William Ford site (41TT852), 41TT862, $41 \mathrm{TT} 865$, and the west grid at 41TT866.

At 41TT847, Features 1 and 2 are apparent as high readings in both the magnetometer and magnetic susceptibility data. Both features are burned rock concentrations, probably the remnants of hot rock cooking activities (cf. Thoms 2008). Feature 1 contained 17 burned rocks (weighing $2.3 \mathrm{~kg}$ ) found approximately $30-40 \mathrm{~cm}$ below the surface. There was no soil staining or charcoal present and no associated oxidized/ burned areas. Feature 2 consisted of 68 burned rocks (weighing $9.6 \mathrm{~kg}$ ) located at $26-46 \mathrm{~cm}$ below the surface. As with Feature 1, no soil staining or oxidized/burned areas were noted in association; however, charcoal was present.

In Subarea 3 of the William Ford site, Feature 48 is a burned-rock scatter that is $183 \times 160 \mathrm{~cm}$ in size and located between 7 and $15 \mathrm{~cm}$ below the surface. This feature is apparent as a positive magnetic anomaly, a high-resistance anomaly, and a high-magnetic susceptibility anomaly.

Excavations at 41TT862 only identified one feature, a burned-rock hearth that measured $170 \times 160 \mathrm{~cm}$ and was composed of a single layer of scattered rocks between 28 and $34 \mathrm{~cm}$ below the surface. This feature is legible in the magnetometer, conductivity, and magnetic susceptibility data.

Archaeogeophysical investigations at 41 TT865 were successful in identifying the presence and extent of a Caddo midden deposit on a natural rise in the Tankersley Creek floodplain. Anomalies in the resistance, magnetic susceptibility, and radar data confirmed the location of the midden deposits, as well as their estimated depth. The archaeogeophysical investigations also identified an area of magnetic enhancement in proximity to the midden deposits that may mark intact archeological features and deposits associated with the midden.

\section{Sites with Clusters of Cultural Features}

Three sites or subareas have clusters of cultural features (i.e., pits, postholes, burials, and burned rock concentrations): Subarea 1 at the George Richey site (41TT851), Subarea 1 at the William Ford site (41TT852), and the James Richey site (41TT853). All three also have midden deposits.

There are two main clusters of features at the George Richey site that correspond to geophysical anomalies. Features 9, 10, 16, 17, and 19 are all clustered in an area of moderate magnetism within an area of higher magnetic readings. Features 8 and 18 are both located on dipolar magnetic anomalies. In the southern portion of Subarea 1, Features 1, 12,13, and 15 are legible in the magnetometer data. Feature 1 is a negative anomaly, and the other three are positive magnetic anomalies. This southern cluster of features is apparently associated with one or more circular Caddo structures (Hatfield et al 2008:27). These features are 14-24 cm in diameter and are between 42 and $58 \mathrm{~cm}$ below the surface. This cluster of features is on the outer edge of the large high magnetic susceptibility anomaly that is in the southeastern corner of the survey grid. There are two areas of positive resistivity within the survey grid: one in the southern and southwestern part is an estimated to be $26 \mathrm{~m}$ east-west and $13 \mathrm{~m}$ north-south; the second area, in the northern and north-central part, is roughly circular and covers at least $28 \mathrm{~m}$ east-west and $35 \mathrm{~m}$ north-south. Both of these areas are associated with areas of midden deposits or feature clusters.

In Subarea 1 at the William Ford site (41TT852), Features 21, 33, 41, and 42 are all recognizable as positive magnetic anomalies. These features are described as postholes and range from 13 to $23 \mathrm{~cm}$ in diameter and are defined between 15 and $62 \mathrm{~cm}$ below the surface. Magnetic susceptibility data also define a diffuse high-susceptibility anomaly in 
the southeastern part of the survey area that measures at least $25 \mathrm{~m}$ north-south and $19 \mathrm{~m}$ east-west. This anomaly appears to partly correspond to midden deposits. Two circular anomalies in the magnetometer data (these are also found within either high-resistivity or high-conductivity areas) that were considered possible structure locations are adjacent to the aforementioned areas of high magnetic susceptibility; subsequent excavation did not find structures at these locations, however.

At the James Richey site (41TT853), the clearest archaeogeophysical and archeological correlation of geophysical anomalies and archeological features is Feature 6. Feature 6 is a pit measuring $37 \times 37 \mathrm{~cm}$ that was identified between 10 and $36 \mathrm{~cm}$ below the surface. The feature is located over a positive magnetic anomaly and in the middle of a much larger highconductive anomaly. The association of the other features with specific geophysical anomalies is more nebulous. The core cluster of features (Feature 10,14-16,18-21, and 23), among them a human burial (Feature 18), is in an area of middle-range values in the magnetometer data with Features 10 and 21-23 on the edges of areas of slightly enhanced magnetic anomalies and with low magnetic susceptibility data. There is a larger area of low magnetic susceptibility (ca. $13 \times 10 \mathrm{~m}$ ) in the central part of the southern grid survey area that closely corresponds to this feature cluster, and this same area has a notable area of high-resistance anomalies.

\section{Summary}

Geophysical surveys were successful in locating general areas of archeological significance and in some cases individual archeological features. Magnetic susceptibility and magnetometer surveys were the most productive of the five methods used. Thermal features such as burned rock clusters produce the highest-contrast geophysical signatures.

\section{GEOPHYSICAL RESEARCH IN CADDO ARCHEOLOGY: GEOPHYSICALLY SUBTLE SIGNATURES OF HABITATION}

Archaeogeophysical prospecting using electromagnetic conductivity, magnetometry, electrical resistivity, ground-penetrating radar, and magnetic susceptibility has been shown to be useful for locating buried architectural remains and other kinds of features at a variety of prehistoric Caddo habitation sites. Examples of this work in east Texas and northwestern Louisiana are becoming commonplace in cultural resource management work as well as on Caddo archeological research projects in general (Walker and Perttula 2008a:162-168).

The subtle nature of the anomalies at a number of Caddo habitation sites suggests that a dynamic research design allowing for the feedback of results from archeological excavations and geophysical survey work is a prerequisite to the successful integration of the results and interpretations from both kinds of investigations. There is a great range in the types, visibility, and interpretability of geophysical anomalies of archeological significance on Caddo habitation sites, and at most such sites, including the ones reported here, geophysical survey results are much different than the spectacular and easily interpretable results from the George C. Davis (Creel et al. 2005; Osburn et al. 2008) and Grandview sites (Lockhart 2007) in east Texas and southwestern Arkansas, respectively, which have geophysically unique characteristics that enhanced the geophysical anomalies and features identified there.

Another example is from the Hill Farm site (41BW169), a large (ca. $675 \times 135 \mathrm{~m}$ ) late Texarkana phase (ca. A.D. 1500-1600) site with two spatially discrete Caddo habitation areas. A total of 10 circular Caddo structures are readily identifiable in magnetometer data. At least 2 structures may show evidence of burning, a widespread practice throughout the Caddo area when a structure was abandoned, and another structure has a magnetic signature suggesting it has an extended entranceway (Perttula et al. 2008). In 3 cases, the magnetic patterning consists of a series of positive magnetic returns comprising the outer ring or wall arc of the structures. Another feature also has a considerable amount of remote sensing information from within the structure, namely several small monopolar positive magnetic returns just inside the walls of the structure that may represent small storage pits. Even at this site, with very clear geophysical signatures of Caddo houses (Walker and Perttula 2008a:Figure $7 \mathrm{~d}-\mathrm{f}$ ), other houses less than $10 \mathrm{~m}$ in diameter are more subtle geophysically. They consist of a central monopolar positive return with a circular 
to semicircular series of returns encircling a central hearth feature.

The magnetometer evidence from the Middle Caddo Leaning Rock site (41SM325) is a good example of the magnetic signature of a small Caddo site in the sandy soil that is found throughout east Texas (Walker 2008). As with a few of the sites investigated as part of the Mount Pleasant project, while no clear architectural patterns are obvious in the geophysical data, a close look reveals a fair amount of archeological information. Whether caused by the actual magnetic properties of sherds, general magnetic enhancement of anthropogenic deposits, or simply geological phenomena, there appears to be an area of magnetic enhancement that corresponds to the overall distribution of artifacts and known features (a 12-m-diameter midden deposit, as well as postholes and pits) at this Caddo residential settlement (Walters 2008:Figures 1 and 8). This pattern has been observed in magnetometer data sets at other Caddo habitation sites (Walker and Perttula 2008a), where it appears that densities of pottery sherds and burned organic materials raised the magnetic background. It is unclear what exactly is causing this magnetic enhancement: the intensity of burning and the discarding of burned materials, the clay bodies of the sherds themselves, the high densities of such sherds in subsurface contexts, or the simple fact that they have been fired. Lipo et al. (2004:80) have suggested "positive magnetization also occurs in organic-rich materials such as midden deposits, as these conditions may cause authigenic mineral growth."

Geophysical surveys at the Middle Caddo Tallow Grove (41NA231) and Beech Ridge (41NA242) sites, for instance, identified subtle geophysical anomalies visible on shaded relief maps (Walker and Perttula 2008b). These small habitation sites are on an alluvial knoll and a nearby elevated upland ridge overlooking a creek floodplain. Four areas were identified at the two sites that represent possible prehistoric Caddo house areas, midden areas, or deposits with organic- or mineral-rich inclusions (i.e., areas with high densities of discarded ceramic vessel sherds, burned clay, and burned sediments) that are the product of intensive but localized occupations or trash accumulation. Excavations in these areas documented discrete occupational areas and concentrated organic deposits (including two large midden deposits at the Tallow Grove site) in each of these four areas, along with evidence for Caddo house construction, hearths, and the use of large pits (first for storage, and then for trash disposal) (Perttula 2008). In the case of the Beech Ridge site, the two areas of Caddo structures and domestic debris are apparently separated by a courtyard or open area characterized by limited amounts of trash and correspondingly low or quiet magnetic returns. Midden and occupational areas are marked by high magnetic anomalies and areas of magnetic enhancement.

The Burnitt site (165A204) is a wellpreserved sixteenth-century Caddo habitation site in the northwestern Louisiana uplands, about $15 \mathrm{~km}$ east of the Sabine River. Prior to excavation in the proposed highway right of way, a 0.4-acre area was examined with magnetic susceptibility, gradiometer, electromagnetic conductivity, resistivity, and ground-penetrating radar (Kelley 2006:Figures 5-4 to 5-8). The magnetic susceptibility survey results showed a $12 \times 8-m$ circular area that proved to be a prehistoric midden deposit; three smaller anomalies detected by magnetic susceptibility were cultural pit features (Kelley 2006:30). The other geophysical techniques were less successful in detecting anomalies of a prehistoric Caddo origin. There was an area of moderate magnetic enhancement in the gradiometer data that was shown to correspond to a cluster of pits and postholes associated with a 5.4-m circular Caddo structure underlying the previously mentioned midden deposits. One area of high resistance corresponded to the southern part of the midden, but no anomalies indicative of pit features were detected with this technique.

A final example of geophysical findings on east Texas Caddo habitation sites comes from the magnetometer survey at the Tyson site (41SY92). That work produced no definitive evidence of Caddo architecture (Walker and Perttula 2008a:Figure 6), although the available archeological data suggest that there may be the remains of several structures at the site (Middlebrook 1994). However, given the apparent low-contrast archeological anomalies and the high-contrast matrix present theretypical attributes of Caddo sites in much of east Texas-defining individual features was difficult at Tyson. The magnetometer data are quite noisy, a situation where the signal-to- 
noise ratio is not satisfactory for immediate archeological interpretation. The signal-to-noise ratio on any specific Caddo habitation site is not easily predictable and can be the result of many variables.

\section{PERSPECTIVES ON CADDO GEOPHYSICAL RESEARCH: STRATEGIES FOR ARCHAEOGEOPHYSICAL INVESTIGATIONS}

It is important in advancing the field of Caddo geophysical research that archeological data, particularly information on the structure and character of the archeological record from excavations, be acquired in a manner that it can be closely integrated with the geophysical survey data from the same sites. As such, the geophysical survey data can be viewed "as an extension of the archeological record that includes measures of electromagnetic spectra beyond the human visual range" (Lipo et al. 2004:79). Each form of data, whether archeological or geophysical, constitutes independent but different kinds of information about the archeological record under investigation; synthesis of both is a necessity. "Sole reliance on geophysics, however, is dangerous, as it tends to foster a rigid equation of features with significance" (Rafferty 2008:108); the same is true with respect to a sole reliance on archeological findings.

It is important that future joint geophysical and archeological investigations at Caddo habitation sites give relatively close attention to areas of potential archeological significance marked by subtly defined geophysical anomalies and areas of magnetic enhancement, not just those areas that may have clear and legible geophysical signatures of Caddo features and structures. Caution should always be exercised when excavating in such areas defined by geophysical survey, being mindful of the possibility that any magnetic anomalies may be represented by subtle soil color or texture variations that may be easily overlooked. Similarly, the anomalies detected may be sufficiently subtle that the temptation may arise (in the absence of other data) to conclude that no anomalies of archeological significance actually exist in a defined area of archeological study. Such hasty conclusions should be resisted without first taking a comprehensive view of the structure and character of a site's archeological record from subsurface explorations in the same study areas.

To build on the geophysical findings that are being obtained from Caddo habitation sites in east Texas, some form of ground-truthing is absolutely essential to better ascertain the archeological context and cultural association of the various anomalies identified in the work. Ground-truthing should consist of a program of systematic shovel testing across the larger geophysical anomalies or areas of magnetic enhancement as well as controlled hand-excavated units in key locales within geophysical survey grids that have more interpretable geophysical-archeological signatures (i.e., signatures of Caddo structures). Such archeological investigations, if carefully done and specifically targeted to these locations to minimize damage to a site's archeological deposits, are certainly necessary to further advance and develop interpretations of the cultural significance of the geophysical features and anomalies detected at any Caddo site.

However, ground-truthing of geophysical anomalies should not be designed solely to target what are thought to be archeological features, since there is more to a Caddo habitation site than features, including outdoor activity areas, courtyards, and concentrated deposits of artifacts and organic remains. It is the interrelationship of features, concentrations of artifacts, open areas, and other spatial characteristics of Caddo domestic settlements that is the key to interpreting and understanding Caddo residential settlement organization.

It is far too early to predict the frequency or relative proportion of Caddo sites that will produce clear and interpretable architectural features or other archeological areas of interest in geophysical survey investigations. We do have an understanding of why some sites have a positive feature signal-to-noise ratio coupled with well-preserved archeological features detectable in geophysical surveys, as in the case of the George C. Davis site or the Hill Farm site. However, the opposite question is more challenging: Does the absence of geophysical anomalies or features in a geophysical investigation truly indicate the absence of preserved archeological features? Determining the feature signal-to-noise ratio of any one site-or more simply put, determining if there is too much noise, be it from modern cultural clutter, 
background geological and soil conditions, or both-is, and should continue to be, an empirical observation, backed by continued archeological investigations. Convincing ourselves that we have enough data to start to understand all the factors that affect the legibility of geophysical data from sites that have not been thoroughly investigated archeologically would be an unfortunate mistake.

For future archaeogeophysical studies at Caddo habitation sites, an important strategy is to use multiple instruments (Kvamme 2007). Different geophysical instruments "sense" different physical properties of the soil and are differentially effected by extraneous modern cultural debris and metal. The current state of the art that should be emulated when employing multiple geophysical instruments consists of using a series of statistical models and algorithms to combine these multiple data sets into what has been termed a "GIS fusion" (see Kvamme 2007). Lockhart's (2007) work at the Tom Jones site has demonstrated that using a suite of geophysical techniques, including fluxgate gradiometery, electromagnetic induction (magnetic susceptibility and conductivity), resistance, and ground-penetrating radar, can help tease out archeological nuances in the deposits and features preserved there that were not legible in any one data set.

Archaeogeophysics at Caddo sites also offers the potential for research investigations that can focus their attention and study on prehistoric landscapes used by Caddo peoples and communities at a greater degree of resolution than has previously been possible. When the opportunity presents itself, large-scale geophysical surveys at multiple spatial scales of culturally and temporally associated Caddo sites should be devised in conjunction with expansive archeological investigations within natural bounded landscape areas (i.e., a specific part of a stream basin in a dissected upland setting or a patch of Holocene alluvium along a major river). The results from such work should provide archeologists with the best and most-complete depiction of how the
Caddo constructed and used landscapes, at least at specific times in their history.

Finally, another consideration in future work at Caddo habitation sizes is the size of the geophysical survey units that should be employed. At the George C. Davis site (Creel et al. 2005), emphasis was placed on collecting and processing large amounts of geophysical data for broad community-level analyses covering many hectares. This approach has proven useful in many regions, not just east Texas, for identifying, discussing, and interpreting the patterning of many house clusters as well as spatial patterning in prehistoric community layout (Kvamme 2003). However, as previously mentioned, the George C. Davis site geophysical data set is uncommonly clean due to a relatively shallow plow zone directly overlying a dense and ironrich clay subsoil (Bruseth et al. 2007; Creel et al. 2005). For prehistoric Caddo habitation sites in deeper sands with more-complex sediment packages-which means most Caddo sites in much of east Texas-collecting geophysical data in smaller units, or breaking down survey units to smaller sizes during data processing, may prove to be very useful in reducing the noise created by various nonarcheological impediments and thus increase the likelihood that archeological features and deposits of interest can be identified through archaeogeophysical surveys.

\section{ACKNOWLEDGMENTS}

There are several individuals we would like to thank for their help with this project. Bo Nelson, Mark Walters, and Tony Chapa helped with the data collection. Bo and Mark both ran the resistivity meter on parts of the sites (Bo stuck an electrode through his boot and foot, and Mark just simply broke the electrode frame!). Charles Frederick (co-principal investigator) and Michael Wilder (project archeologist) helped with rope management and metal detecting and laid out the survey areas. Macky McIntosh helped clear many of the sites and helped set up survey grids. 


\section{REFERENCES CITED}

Bartington, Geoff, and C. E. Chapman

2004 A High-Stability Fluxgate Magnetic Gradiometer for Shallow Geophysical Survey Applications. Archaeological Prospection 11:19-34.

Bevan, Bruce M.

1983 Electromagnetics for Mapping Buried Earth Features. Journal of Field Archaeology $10: 47-54$

1998 Geophysical Exploration for Archaeology: An Introduction to Geophysical Exploration. Special Report No. 1. Midwest Archeological Center, National Park Service, Lincoln, Nebraska.

Bruseth, James E., William T. Pierson, and Rob M. Johnson

2007 Large-Area Remote Sensing Coverage of Archaeological Sites with a Dual-Track, Cart-Mounted Cesium Magnetometer. Journal of Field Archaeology 32(1):1-15.

Clay, Berle R.

2006 Conductivity Survey: A Survival Manual. In Remote Sensing in Archaeology: An Explicitly North American Perspective, edited by Jay K. Johnson, pp. 79-107. University of Alabama Press, Tuscaloosa.

Conyers, Lawrence B.

2004 Ground-Penetrating Radar. AltaMira Press, Walnut Creek, California.

Conyers, Lawrence B., and Jeffrey Lucius

1996 Velocity Analysis in Archaeological GroundPenetrating Radar Studies.Archaeological Prospection 3:25-38.

Conyers, Lawrence B., Eileen G. Ernenwein, Michael Grealy, and Kelsey M. Lowe

2008 Electromagnetic Conductivity Mapping for Site Prediction in Meandering River Floodplains. Archaeological Prospection 15:81-91.

Creel, Darrell G., Dale Hudler, Samuel M. Wilson, T. Clay Schultz, and Chester P. Walker

2005 A Magnetometer Survey of Caddoan Mounds State Historic Site. Technical Report 51. Texas Archeological Research Laboratory, The University of Texas at Austin.
Dalan, Rinita A

2006 Magnetic Susceptibility. In Remote Sensing in Archaeology:An Explicitly North American Perspective, edited by Jay K. Johnson, pp. 161-203. University of Alabama Press, Tuscaloosa.

2008 A Review of the Role of Magnetic Susceptibility in Archaeogeophysical Studies in the USA: Recent Developments and Prospects. Archaeological Prospection 15:1-31.

Dalan, Rinita A., and S. K. Banerjee

1998 Solving Archaeological Problems Using Techniques of Soil Magnetism. Geoarchaeology 13:3-36.

David, A.

1995 Geophysical Survey in Archaeological Field Evaluation. Ancient Monuments Laboratory, English Heritage Society, London.

Early, Ann M. (editor)

1993 Caddoan Saltmakers in the Ouachita Valley: The Hardman Site. Research Series No. 43. Arkansas Archeological Survey, Fayetteville.

Ernenwein, Eileen G.

2008 A Geophysical View of Pueblo Escondido: Implications for the Pithouse to Pueblo Transition in the Jornada Mogollon. Bulletin of the Texas Archeological Society 79:125-145.

Gaffney, Chris, John A. Gater, P. Linford, V. Gaffney, and R. White

2000 Large-Scale Systematic Fluxgate Gradiometry at the Roman City of Wroxeter. Archaeological Prospection 7:81-99.

Gaffney, Chris, and John Gater

2003 Revealing the Buried Past: Geophysics for Archaeologists. Tempus, Gloucestershire, Great Britain. 
Grealy, Michael, and Lawrence B. Conyers

2008 EM31 Geophysical Survey Methods, Results, and Recommendations. In Integrated Cultural Resources Investigations for the Bowie County Levee Realignment Project, Bowie County, Texas and Little River County, Arkansas, by ScottA. Sundermeyer, John T. Penman, and Timothy K. Perttula, pp. 91-107. Miscellaneous Reports, Report of Investigations No. 29. LopezGarcia Group, Dallas, Texas.

Hatfield, Virginia, Karl W. Kibler, and Ross C. Fields 2008 Interim Report on Eligibility Testing at 41TT6, 41TT846, 41TT847, 41TT851, 41TT852, 41TT853, 41TT854, 41TT858, 41TT862, 41TT865, and 41TT866, U.S. Highway 271 Mount Pleasant Relief Route, Titus County, Texas (Atlanta District: CSJ 0919-30-027). Prewitt and Associates, Inc., Austin.

Kelley, David B.

2006 The Burnitt Site:A Late Caddo Occupation in the Uplands of the Sabine River Basin in Louisiana. Coastal Environments, Inc., Baton Rouge, Louisiana.

Kvamme, Kenneth

2003 Geophysical Surveys as Landscape Archaeology. American Antiquity 68:435-457.

2006a Integrating Multidimensional Geophysical Data.Archaeological Prospection 13:57-72.

2006b Magnetometry:Nature's Gift to Archaeology. In Remote Sensing in Archaeology: An Explicitly North American Perspective, edited by Jay K. Johnson, pp. 205-233. University of Alabama Press, Tuscaloosa.

2006c Data Processing and Presentation. In Remote Sensing in Archaeology: An Explicitly North American Perspective, edited by Jay K. Johnson, pp. 235-250. University of Alabama Press, Tuscaloosa.

2007 Integrating Multiple Geophysical Data Sets. In Remote Sensing in Archaeology, edited by James Wiseman and Farouk ElBaz, pp. 345-374. Springer, New York.

Kvamme, Kenneth, Jay K. Johnson, and Bryan S. Haley

2006 Multiple Methods Surveys: Case Studies. In Remote Sensing in Archaeology: An Explicitly North American Perspective, edited by Jay K. Johnson, pp. 251-267. University of Alabama Press, Tuscaloosa.
Lipo, Carl P., Robert C. Dunnell, and Donald O. Larsen 2004 Studying the Evolution of Complex Societies: Recent Geophysical Studies in the Central Mississippi River Valley. Missouri Archaeologist 65:68-106.

Lockhart, Jami J.

2007 Prehistoric Caddo of Arkansas: A Multiscalar Examination of Past Cultural Landscapes. Ph.D. dissertation, Department of Anthropology, University of Arkansas, Fayetteville.

Maki, David

2008 Geophysical Survey at the Kansas Monument Site (14RP1). Available at http://www.archaeophysics.com/pawnee/ index.html.

McKinnon, Duncan P.

2008 An Archaeogeophysical Analysis of Central Caddo Settlement Patterning at Battle Mound (3LA1). Master's thesis, Department of Anthropology, University of Arkansas, Fayetteville.

Middlebrook, Tom

1994 An Update of Archaeological Investigations at the Tyson Site (41SY92). Journal of Northeast Texas Archaeology 3:1-36.

Milsom, John

2005 Field Geophysics: The Geological Field Guide Series. Third edition. Wiley, West Sussex.

Osburn, Tiffany, James Bruseth, and William Pierson 2008 Magnetometer Investigations at the George C. Davis Site, a Prehistoric Caddo Village. Bulletin of the Texas Archeological Society 79:191-200.

Perttula, Timothy K.

2005 1938-1939 WPA Excavations at the Hatchel Site (41BW3) on the Red River in Bowie County, Texas. Southeastern Archaeology 24:180-198.

Perttula, Timothy K. (editor)

2008 Lake Naconiche Archeology, Nacogdoches County, Texas: Results of the Data Recovery Excavations at Five Prehistoric Archeological Sites. 2 vols. Report of Investigations No. 60. Archeological and Environmental Consultants, LLC, Austin. 
Perttula, Timothy K., and Bo Nelson

2002 Additional Archeological Survey Investigations at 41TT851 for the Proposed U.S. 271 Mt. Pleasant Loop, Titus County, Texas. Archeological and Environmental Consultants, LLC, Austin.

Perttula, Timothy K., Bo Nelson, and T. Clay Schultz 2002 Archaeological Survey of the U.S. 271, Mount Pleasant Loop, Titus County, Texas for the Texas Department of Transportation. Archeological and Environmental Consultants, LLC, Austin.

Perttula, Timothy K., Chester P. Walker, and T. Clay Schultz

2008 A Revolution in Caddo Archaeology: The Remote Sensing and Archaeological View from the Hill Farm Site (41BW169) in Bowie County, Texas. Southeastern Archaeology 27(1):93-107.

Rafferty, Janet

2008 Settlement Patterns, Occupations, and Field Methods. In Time's River: Archaeological Syntheses from the Lower Mississippi River Valley, edited by Janet Rafferty and Evan Peacock, pp. 99-124. University of Alabama Press, Tuscaloosa.

Somers, Lewis

2006 Resistivity Survey. In Remote Sensing in Archaeology:An Explicitly North American Perspective, edited by Jay K. Johnson, pp. 109-129. University of Alabama Press, Tuscaloosa.

Thoms, Alston V.

2008 The Fire Stones Carry: Ethnographic Records and Archaeological Expectations for Hot-Rock Cookery in Western North America. Journal of Anthropological Archaeology 27(4):443-460.

Walker, Chester P.

2007a Report of Technical Findings at Sites 41TT851 and 41TT854. AGA Report 200714. Archaeo-Geophysical Associates, LLC, Austin. 2007b Report of Technical Findings at Sites 41TT852, 41TT853 and 41TT858. AGA Report 2007-18. Archaeo-Geophysical Associates, LLC, Austin.

2007c Geophysical Survey of Archaeological Sites 41TT6, 41TT846, 41TT847, and 41TT865. AGA Report 2007-1. Archaeo-Geophysical Associates, LLC, Austin.

2008 Cesium Magnetometer Survey at the Leaning Rock Site (41SM325). Caddo Archeology Journal 17:7-12.

Walker, Chester P., and Timothy K. Perttula

2008a Geophysical Investigations on Caddo Sites in East Texas and Surrounding States. Bulletin of the Texas Archeological Society 79:159-176.

2008b Geophysical Surveying at the Tallow Grove (41NA231), Foggy Fork (41NA235), and Beech Ridge (41NA242) Sites. In Lake Naconiche Archeology, Nacogdoches County, Texas: Results of the Data Recovery Excavations at Five Prehistoric Archeological Sites, edited by Timothy K. Perttula, pp. 289-306. 2 vols. Report of Investigations No. 60. Archeological and Environmental Consultants, LLC, Austin.

Walters, Mark

2008 Life on Jackson Creek, Smith County, Texas: Archeological Investigations of a 14th Century Caddo Domicile at the Leaning Rock Site (41SM325). Caddo Archeology Journal 17:1-114.

Wilder, Michael, and Ross C. Fields

2005 Interim Report on Auger Sampling of 10 Sites, U.S. Highway 271 Mount Pleasant Relief Route, Titus County, Texas (CSJ 0919-30-027). Prewitt and Associates, Inc., Austin. 


\title{
APPENDIX C: Stratigraphic Integrity Analysis for 41TT852 and 41 TT853
}

\author{
Charles D. Frederick
}





\section{INTRODUCTION}

This appendix reports the results of a series of investigations designed to assess the stratigraphic integrity of the unconsolidated sands that contain the Titus phase Caddo artifacts at $41 \mathrm{TT} 852$ and $41 \mathrm{TT} 853$, two of the archeological sites along the proposed route of the U.S. Highway 271 relief route in Mount Pleasant, Texas. This analysis addresses one of the major research themes identified in the research design for the testing phase of the project (Frederick 2005).

Understanding the stratigraphic integrity of archeological sites in the "sandy mantle," as the sandy soils of east Texas are often called, and the geodynamic processes that act upon them, has been a recurrent theme in east Texas archeology, starting with the Texas Historical Commission's Archeology of the Eastern Planning Region (Kenmotsu and Perttula 1993:10). It has also been the source of considerable debate among members of the archeological community, perhaps best exemplified by the discussions in Thoms (1995), Thoms et al. (1993, 1994), Bruseth and Martin (2001), and Frederick and Bateman (2001). The relevance of this issue also transcends Texas (e.g., Leigh 1998, 2001).

The concept of integrity in archeological investigations is a broad one with many complexions. One of the most thoughtful examinations of this issue is in the protocol recently compiled by the Archeological Studies Branch of the Environmental Affairs Division, Texas Department of Transportation. The protocol identifies four key components of archeological integrity: (1) spatial integrity, (2) stratigraphic integrity, (3) perishable material preservation integrity, and (4) durable material preservation integrity. Archeological sites of the sandy mantle are often thought to lack stratigraphic integrity due to postdepositional mixing, although they sometimes retain a semblance of spatial integrity due to the preservation of structural features cut into the top of the argillic horizon. In most cases, however, this lack of stratigraphic integrity is assumed rather than demonstrated. Finding methods capable of assessing integrity independently has been challenging.

For this study, three analytical methods were chosen that provide complimentary perspectives on the stratigraphic integrity of the archeological deposits. The samples used were collected from test unit excavations to facilitate direct comparisons with the archeological assemblages. The three methods are singlegrain optically stimulated luminescence (OSL) dating, the depth distribution of cesium-137, and stratigraphic variation in various basic soil properties such as texture, magnetic susceptibility, and phosphorus content.

Optically stimulated luminescence dating is one of the most promising methods for assessing deposit integrity. This novel approach permits researchers to measure the amount of time that has passed since a single grain of quartz sand, or a population of sand grains, was last exposed to sunlight (an event known as "resetting" or "bleaching"). This dating method has evolved over the last two decades to become a significant addition to the archeologist's tool kit and has provided insight into the internal dynamics of soils and sedimentary deposits that were hitherto unknown or difficult to observe (cf. Bateman et al. 2003; Frederick et al. 2005; Heimsath et al. 2002). The basic principles of this method are briefly described in Frederick (2005) and discussed in considerably more detail in Duller (2008) and Attachment C.1 (in digital format only).

Two forms of OSL dating are currently in use: standard aliquot dating and single-grain dating. In standard aliquot dating, the sample age is derived from measurements of populations of sand grains on one or more 1-cm-diameter discs (where each measured disc is an "aliquot"). Typically, a single disc will hold around 2,000 grains, and a single standard aliquot OSL date may involve computing the average age from 15 to 25 discs. Recent developments in luminescence dating now permit measuring the OSL ages of individual sand grains (cf. Duller 2008), a method that allows more accurate depositional ages to be determined. One single-grain OSL date can determine the age of a population of individual sand grains ranging from as few as 20 grains to more than 200 . This approach permits researchers to see the age structure of the sand. Sediments that have been deposited by normal sedimentary transport processes generally exhibit grain age populations with normal and relatively narrow distributions. Deposits that have experienced either poor resetting or postdepositional mixing exhibit broad, often polymodal, grain age distributions, 
overdispersion, and significant skewing. When the age of the sedimentary matrix can be directly compared with an archeological assemblage of known age, a powerful tool emerges for assessing the integrity of a deposit.

Also of interest here are grains that have been reset so recently that they exhibit no OSL signal. These grains, called zero-dose grains, are below the detection limit of the OSL method and generally are between 10 and 100 years old. The precise time they represent is difficult to determine, but the depth distribution of zerodose grains provides a very useful measure of recent particle mobility in the profile.

The second method used in assessing the integrity of the deposits was the depth distribution of radiocesium, or cesium-137. Cesium is an alkali metal that has a single stable isotope and 35 unstable isotopes, none of which are naturally occurring. One of these unstable isotopes, ${ }^{137} \mathrm{Cs}$, is widely employed in the earth sciences because it has a relatively long halflife (37.17 years). The decay of ${ }^{137} \mathrm{Cs}$ to ${ }^{137} \mathrm{Ba}$ results in the emission of a beta particle and a gamma ray, the latter of which can be measured by gamma-ray spectrometry (Beer et al. 1985; Faure and Mensing 2005:678).

Most of the cesium-137 in the environment today was produced by atmospheric testing of nuclear weapons between 1945 and 1980 and by the accidental explosion of the Chernobyl nuclear reactor (Faure and Mensing 2005:678$679)$. Most of the fallout of ${ }^{137} \mathrm{Cs}$ occurred between 1962 and 1966, and historical records, such as the Dye 3 Greenland ice core, indicate that it peaked in 1963. As a result, the depth distribution of ${ }^{137} \mathrm{Cs}$ in a soil profile reflects biological activity in the soil that has occurred in the last 47 to 65 years; before the Chernobyl event, most researchers considered it indicative of activities that have occurred in the soil since the peak fallout in the early 1960s (Poreba 2006).

The depth distributions of short-lived radioisotopes like ${ }^{137} \mathrm{Cs}$ and ${ }^{210} \mathrm{~Pb}$, sometimes referred to as tracers, have been extensively used in examining the issue of bioturbation in marine (e.g., Maire et al. 2008; Lecroart et al. 2010; Smith et al. 1993) and terrestrial sediments (e.g., Fujiyoshi and Sawamura 2004; Müller-Lemans and van Dorp 1996; Tyler et al. 2001) as well as in studies of soil erosion in terrestrial settings (e.g., Poreba 2006). Where the sedimentation rate is slow to nonexistent and disturbance processes negligible (e.g., no erosion and minimal bioturbation), the concentration of such short-lived radioisotopes should be at or very close to the air-soil or watersediment interface. As such, the shape of the depth distribution curve is widely viewed as a means of evaluating short-term deposit integrity as well as an indication of how a deposit may have been disturbed.

The third method documented the depth variation in basic soil physical properties such as the particle size distribution, magnetic susceptibility, and phosphorous. It also included examination of the profiles for evidence of sedimentary structures that would directly indicate depositional integrity.

In this study, the data generated by the OSL dating and the cesium and bulk soil analyses are evaluated in light of the questions identified in the testing phase research design (Frederick 2005):

1. Is there evidence (analytical or stratigraphic) that the deposits above the subsoil retain stratigraphic integrity?

2. What processes (natural or cultural) have or are affecting deposit integrity?

3. Are shallow sandy profiles more disturbed than thick ones?

\section{METHODS}

Three column profiles were sampled for this study. All sample columns were collected from or immediately adjacent to a testing phase excavation unit to permit comparison of the resulting data to the artifact distributions. Profile 1 was collected at 41TT852 adjacent to Test Units 6 and 9 within House 1. Profile 2, also from 41TT852, was collected outside House 1 adjacent to Test Unit 13 (Trench 10). Profile 3 was collected at 41 TT853 adjacent to Test Unit 16, which was next to Trench 30 . This trench bisected a pimple mound. The sediments in each profile were first described using methods similar to those of Schoeneberger et al. (2002) and then sampled.

\section{Field Sampling}

The OSL samples were collected in black 5-cm-diameter PVC pipe that was hammered 
into the test unit wall. The OSL samples were collected at $10-\mathrm{cm}$ increments starting at $10 \mathrm{~cm}$ below the ground surface. The plastic tube was hammered into the exposure until the outwardfacing end cap was distended, indicating that the tube was tightly packed with sand. The tube was then removed from the exposure, capped, taped, and labeled. A 50-g Ziploc bag of sediment was then collected for moisture content from the back of the hole left by the PVC tube. The air from this sample was removed, and the bag was closed with duct tape and placed inside another bag.

The samples were sent to the OSL lab at the Sheffield Centre for International Drylands Research at the University of Sheffield (UK) for dating. The reported dates were arrived at by applying a finite mixture model, which is commonly employed in OSL dating when mixing is thought to have occurred and serves as a convenient means of extracting a central age or De value for each component within a sample data set (Jacobs et al. 2008:1813). The results of this work are presented in Attachment C.1.

For the cesium-137 and soil properties analyses, columns of bulk soil samples were collected in $5-\mathrm{cm}$ increments immediately adjacent to the OSL sample columns. These samples were generally less than $200 \mathrm{~g}$ and were collected in a continuous column. Higherresolution samples of the bulk matrix for assays of magnetic susceptibility and phosphorus content were collected with small (1-inch or $2.5-\mathrm{cm}$ ) plastic paleomagnetic sample boxes. The boxes were hammered into the exposure to form a 2.5 -cm increment sample column.

\section{Laboratory Analysis Methods}

\section{Particle Size Analysis}

Texture analysis was performed using the hydrometer-sieve method (cf. ASTM 1985; Bouyoucos 1962; Gee and Bauder 1986). Samples were first weighed moist and then gently passed through a $2-\mathrm{mm}$ sieve. Coarse material caught on the sieve was sieved again at a 1-phi interval, and the mass on each sieve was recorded. A split of the $<2$-mm-size material (roughly $70 \mathrm{~g}$ ) was then soaked in $50 \mathrm{ml}$ of a 5 percent sodium pyrophosphate solution overnight and mixed in a mechanical mixer for 5 minutes before being diluted to 1 liter with distilled water. This mixture was placed in a 1-liter settling jar, mechanically agitated for 1 minute, and set on a table. Hydrometer readings were made at different time intervals (specifically 1, 3.5, $15,45,300$, and 1,440 minutes). To calibrate the hydrometer, a control hydrometer and temperature reading was made at intervals on a jar filled with nothing but distilled water and sodium pyrophosphate solution. A small split of the $<2-\mathrm{mm}$ soil was also oven-dried to determine the moisture content and correct the moist sample mass used in the hydrometer analysis (hygroscopic moisture correction). After 24 hours, the contents of the hydrometer jar were wet-sieved through a 53-micron sieve, and the sand retained on the sieve was transferred to a beaker and oven-dried at $105^{\circ} \mathrm{C}$. This sand was subsequently sieved at 0.5 -phi intervals once dry, and the mass retained on each sieve was recorded. From these data, the percentages of gravel, sand, silt, and clay were calculated as well as the mean, standard deviation (or sorting), skewness, and kurtosis (Table C.1).

\section{Magnetic Susceptibility}

The magnetic susceptibility samples were dried and weighed, and low-frequency $(470 \mathrm{~Hz})$ and high-frequency $(4700 \mathrm{~Hz})$ magnetic susceptibility (kappa) was measured on the 0.1 setting on a Bartington MS2 meter and an MS2b sensor (Dearing 1999a). The masscorrected magnetic susceptibility $\left(\mathrm{chi}\right.$, or $\left.\mathrm{X}_{\mathrm{lf}}\right)$ and coefficient of frequency dependency $\left(\mathrm{X}_{\mathrm{fd}}\right)$ were then calculated. The coefficient of frequency dependency $\left(\mathrm{X}_{\mathrm{fd}}\right)$ is the percent difference in magnetic susceptibility measured at low and high frequencies (calculated as: $\mathrm{X}_{\mathrm{fd}}=\left(\mathrm{X}_{\mathrm{lf}}-\mathrm{X}_{\mathrm{hf}}\right) /$ $\mathrm{X}_{\mathrm{lf}} * 100$ ). Elevated values of $\mathrm{X}_{\mathrm{fd}}$ (ca. $>10$ percent; Gale and Hoare 1991:213) are indicative of increased concentrations of fine-grained ferrimagnetic minerals, most often maghemite, in topsoils (Dearing 1999b; Dearing et al. 1996). The magnetic susceptibility values are presented in Table C.2 in SI units $\left(10^{-8} \mathrm{~m}^{3} \mathrm{~kg}^{-1}\right)$.

\section{Phosphorus Analysis}

Since phosphorus is commonly concentrated by human activity, its depth distribution was investigated. It was not clear which phosphorus measure would be most useful, so two fractions were measured: total phosphorus and available phosphorus. Soil samples used 
Excavations along the U.S. Highway 271 Mount Pleasant Relief Route

Table C.1. Results of texture and cesium-137 analyses of three soil profiles from 41 TT852 and 41 TT853

\begin{tabular}{|c|c|c|c|c|c|c|c|c|c|c|c|c|c|c|}
\hline No. & $\begin{array}{c}\text { Depth } \\
(\mathrm{cm})\end{array}$ & $\begin{array}{c}=63 \mu \\
(\%)\end{array}$ & $\begin{array}{l}=2 \mu \\
(\%)\end{array}$ & \begin{tabular}{|c|} 
Gravel \\
$(\%)$
\end{tabular} & $\begin{array}{c}\text { Sand } \\
(\%)\end{array}$ & $\begin{array}{l}\text { Silt } \\
(\%)\end{array}$ & $\begin{array}{c}\text { Clay } \\
(\%)\end{array}$ & $\begin{array}{c}\text { Textural } \\
\text { Class } \\
\end{array}$ & $\begin{array}{c}\text { Mean } \\
(\mathrm{phi})\end{array}$ & $\begin{array}{c}\text { Sorting } \\
\text { (phi) }\end{array}$ & $\begin{array}{c}\text { Skewness } \\
\text { (phi) }\end{array}$ & $\begin{array}{c}\text { Kurtosis } \\
\text { (phi) }\end{array}$ & $\begin{array}{c}\mathrm{mBq} / \mathrm{g} \\
\mathrm{dry}\end{array}$ & $\begin{array}{c}\mathrm{pCi} / \mathrm{g} \\
\text { dry }\end{array}$ \\
\hline \multicolumn{15}{|c|}{ Profile 1: 41TT852 } \\
\hline 1 & 2.5 & 55.8 & 94.4 & 0 & 55.8 & 38.7 & 5.6 & sandy loam & 4.31 & 1.67 & 0.30 & 1.11 & 8.36 & 0.23 \\
\hline 2 & 7.5 & 55.3 & 94.4 & 0 & 55.3 & 39.1 & 5.6 & sandy loam & 4.44 & 1.78 & 0.34 & 1.00 & 7.25 & 0.20 \\
\hline 3 & 12.5 & 55.3 & 94.4 & 0 & 55.3 & 39.1 & 5.6 & sandy loam & 4.44 & 1.78 & 0.34 & 1.00 & 1.15 & 0.03 \\
\hline 4 & 17.5 & 52.5 & 92.2 & 0 & 52.5 & 39.7 & 7.8 & sandy loam & 4.62 & 1.93 & 0.37 & 1.22 & 1.37 & 0.04 \\
\hline 5 & 22.5 & 51.4 & 92.2 & 0 & 51.4 & 40.8 & 7.8 & sandy loam & 4.85 & 1.84 & 0.49 & 1.00 & 0.93 & 0.03 \\
\hline 6 & 27.5 & 51.4 & 91.9 & 0 & 51.4 & 40.4 & 8.1 & sandy loam & 4.70 & 2.00 & 0.38 & 1.16 & 1.07 & 0.03 \\
\hline 7 & 32.5 & 49.7 & 88.8 & 0 & 49.7 & 39.0 & 11.2 & loam & 5.03 & 2.31 & 0.44 & 1.10 & 1.30 & 0.04 \\
\hline 8 & 37.5 & 45.1 & 82.4 & 0 & 45.1 & 37.3 & 17.6 & loam & 6.23 & 3.45 & 0.53 & 0.51 & 1.33 & 0.04 \\
\hline 9 & 42.5 & 40.6 & 74.0 & 0 & 40.6 & 33.5 & 26.0 & loam & 7.00 & 4.15 & 0.52 & 0.30 & na & na \\
\hline 10 & 47.5 & 38.1 & 75.7 & 0 & 38.1 & 37.6 & 24.3 & loam & 6.94 & 4.05 & 0.38 & 0.33 & na & na \\
\hline \multicolumn{15}{|c|}{ Profile 2: 41TT852 } \\
\hline 1 & 2.5 & 54.7 & 98.0 & 0 & 54.7 & 43.3 & 2.0 & sandy loam & 4.44 & 1.88 & 0.33 & 0.56 & 16.06 & 0.43 \\
\hline 2 & 7.5 & 51.3 & 96.6 & 0 & 51.3 & 45.3 & 3.4 & sandy loam & 4.57 & 1.86 & 0.33 & 0.60 & 3.48 & 0.09 \\
\hline 3 & 12.5 & 49.8 & 95.9 & 0 & 49.8 & 46.1 & 4.1 & sandy loam & 4.58 & 1.86 & 0.31 & 0.66 & 1.07 & 0.03 \\
\hline 4 & 17.5 & 47.9 & 95.7 & 0 & 47.9 & 47.9 & 4.3 & sandy loam & 4.66 & 1.92 & 0.28 & 0.68 & 1.37 & 0.04 \\
\hline 5 & 22.5 & 47.3 & 95.9 & 0 & 47.3 & 48.7 & 4.1 & sandy loam & 4.87 & 1.79 & 0.42 & 0.41 & 1.04 & 0.03 \\
\hline 6 & 27.5 & 44.9 & 94.8 & 0 & 44.9 & 50.0 & 5.2 & sandy loam & 4.83 & 2.04 & 0.29 & 0.67 & 1.52 & 0.04 \\
\hline 7 & 32.5 & 44.7 & 94.7 & 0 & 44.7 & 50.0 & 5.3 & sandy loam & 4.90 & 2.12 & 0.31 & 0.62 & 1.37 & 0.04 \\
\hline 8 & 37.5 & 44.1 & 93.3 & 0 & 44.1 & 49.2 & 6.7 & \begin{tabular}{|l|} 
sandy loam \\
\end{tabular} & 4.86 & 2.06 & 0.33 & 0.87 & 1.00 & 0.03 \\
\hline 9 & 42.5 & 42.6 & 90.8 & 0 & 42.6 & 48.2 & 9.2 & loam & 5.12 & 2.31 & 0.32 & 0.92 & na & na \\
\hline 10 & 47.5 & 40.3 & 85.1 & 0 & 40.3 & 44.8 & 14.9 & loam & 5.74 & 2.89 & 0.41 & 0.73 & na & na \\
\hline 11 & 52.5 & 37.3 & 79.5 & 0 & 37.3 & 42.2 & 20.5 & loam & 6.56 & 3.65 & 0.50 & 0.44 & na & na \\
\hline 12 & 57.5 & 36.8 & 77.3 & 0 & 36.8 & 40.5 & 22.7 & loam & 6.79 & 3.87 & 0.51 & 0.37 & na & na \\
\hline \multicolumn{15}{|c|}{ Profile 3: 41TT853 } \\
\hline 1 & 2.5 & 62.8 & 95.9 & 0 & 62.8 & 33.1 & 4.1 & sandy loam & 4.19 & 1.65 & 0.39 & 0.89 & 4.48 & 0.12 \\
\hline 2 & 7.5 & 62.3 & 96.1 & 0 & 62.3 & 33.8 & 3.9 & sandy loam & 4.27 & 1.70 & 0.40 & 0.92 & 6.36 & 0.17 \\
\hline 3 & 12.5 & 63.6 & 96.6 & 0 & 63.6 & 33.0 & 3.4 & sandy loam & 4.16 & 1.60 & 0.38 & 0.95 & 4.40 & 0.12 \\
\hline 4 & 17.5 & 63.1 & 96.4 & 0 & 63.1 & 33.3 & 3.6 & sandy loam & 4.17 & 1.60 & 0.37 & 1.00 & 3.18 & 0.09 \\
\hline 5 & 22.5 & 61.7 & 96.5 & 0 & 61.7 & 34.8 & 3.5 & sandy loam & 4.33 & 1.52 & 0.48 & 0.77 & 1.33 & 0.04 \\
\hline 6 & 27.5 & 62.2 & 95.6 & 0 & 62.2 & 33.4 & 4.4 & sandy loam & 4.22 & 1.64 & 0.37 & 1.02 & 0.96 & 0.03 \\
\hline 7 & 32.5 & 62.6 & 95.2 & 0 & 62.6 & 32.6 & 4.8 & sandy loam & 4.23 & 1.65 & 0.37 & 1.04 & 1.55 & 0.04 \\
\hline 8 & 37.5 & 61.8 & 94.9 & 0 & 61.8 & 33.1 & 5.1 & sandy loam & 4.27 & 1.68 & 0.38 & 1.04 & 0.89 & 0.02 \\
\hline 9 & 42.5 & 62.0 & 94.5 & 0 & 62.0 & 32.4 & 5.6 & sandy loam & 4.36 & 1.77 & 0.41 & 1.01 & na & na \\
\hline 10 & 47.5 & 60.6 & 94.0 & 0 & 60.6 & 33.4 & 6.0 & sandy loam & 4.39 & 1.80 & 0.40 & 1.06 & na & na \\
\hline 11 & 52.5 & 61.5 & 92.5 & 0 & 61.5 & 31.1 & 7.5 & sandy loam & 4.50 & 1.91 & 0.44 & 1.16 & na & na \\
\hline 12 & 57.5 & 57.8 & 90.2 & 0 & 57.8 & 32.3 & 9.9 & sandy loam & 4.82 & 2.22 & 0.49 & 1.07 & na & na \\
\hline 13 & 62.5 & 57.1 & 86.3 & 0 & 57.1 & 29.2 & 13.7 & sandy loam & 5.34 & 2.74 & 0.58 & 0.84 & na & na \\
\hline 14 & 67.5 & 53.3 & 81.5 & 0 & 53.3 & 28.2 & 18.5 & sandy loam & 6.28 & 3.66 & 0.66 & 0.44 & na & na \\
\hline 15 & 72.5 & 51.8 & 78.4 & 0 & 51.8 & 26.6 & 21.6 & $\begin{array}{l}\text { sandy clay } \\
\text { loam }\end{array}$ & 6.57 & 3.94 & 0.67 & 0.30 & na & na \\
\hline
\end{tabular}

for the phosphorus analysis were obtained from the magnetic susceptibility sample boxes once that analysis was complete. The dry, pulverized soil samples were sent to the Central Analytical Lab (Department of Soil and Crop Science) at Oregon State University. The total phosphorus analysis employed a Kjehldahl digestion with concentrated sulphuric acid (Horneck et al. 1989; Taylor 2000). The available phosphorus was analyzed using the Bray-1 method described by Olsen and Sommers (1982; see also Bray and Kurtz 1945), which uses dilute hydrochloric acid 
and ammonium fluoride to obtain extractable phosphorus (Horneck et al. 1989). The results are presented in Table C.2.

\section{Cesium-137}

Twenty-four bulk soil samples were sent to Mass Spec Services of Orangeburg, New York, for analysis of ${ }^{137} \mathrm{Cs}$ activity. Approximately $60 \mathrm{~g}$ of soil were selected from each 5-cm-increment bulk sample in the top $40 \mathrm{~cm}$ of the soil profile, with 8 samples assayed from each profile. Cesium-137 was measured by direct gamma spectral analysis using high-purity germanium detectors calibrated with multiple nuclide standards (Department of Energy 1990). The soil samples were first dried, then homogenized and weighed into a standard analysis container and placed in a standard position relative to the detector within a heavy metal shield to reduce ambient radiation. Gamma spectral data were acquired over a period near 1,000 minutes, after which the spectrum was analyzed by computer. Cesium-137 activity and detection limit were calculated by integrating the spectral region at $662 \mathrm{KeV}$ produced by its short-lived daughter product, $\mathrm{Ba}-137 \mathrm{~m}$. The ${ }^{137} \mathrm{Cs}$ activity for each soil sample is reported by $5-\mathrm{cm}$ increment in Table C. 1 in picoCuries per gram of dry soil (pCi/g dry) as well as the equivalent SI unit, the millibecquerel ( $\mathrm{mBq} / \mathrm{g}$ dry).

\section{Single-Grain OSL}

The methods used in preparing, dating, and analyzing the optically stimulated luminescence samples are described in detail in Attachment C.1. In general terms, once the samples arrived at the lab, they were opened under controlled redlight conditions, and assuming that this material had been exposed to light during sampling, the outer 2 inches of each sample were removed and discarded. The thin sliver of sediment remaining in the center of the tube was then extracted and processed to yield only quartz sand. Then a single sand grain was placed into each of the one hundred 300-micron-diameter pits on a 9.6-mm-diameter stainless steel disc. The disc was mounted into a Riso TL DA-15 single-grain reader so that each grain could be OSL dated. Grains with unsuitable attributes were rejected, but for most samples the measurement of 300 grains yielded more than 50 usable grains. Dose rate for the samples was determined by elemental analysis of the uranium (U), thorium (Th), rubidium (Rb), and potassium (K) content by means of inductively coupled plasma spectrometry. Age data obtained from the analysis were subjected to a finite mixture model analysis to determine groupings within the data, and the results reported highlight the dominant component determined by this method. Because nearly all of the samples were collected from depths of less than $50 \mathrm{~cm}$, and the cosmogenic dose could not be excluded from the dose rate measurement, the measured ages are probably slightly older than they would be if the cosmogenic dose was excluded. The raw data provided in the attachment to this appendix lists grain ages as equivalent doses, but for the sake of clarity, these were converted to ages in years. A range of descriptive statistics for each sample are provided in Table C.3.

\section{RESULTS}

In the discussions that follow, a general temporal bracket of ca. 400-600 years B.P. has been applied to the Titus phase occupations for comparison with the OSL data. Radiocarbon dating of the site deposits indicates that the principal Caddo occupation at each occurred between 500 and 600 years B.P. (A.D. 1400 and 1500).

\section{Profile 1}

Profile 1 was collected from the southeast wall of adjacent Test Units 6 and 9 at Subarea 1 of $41 \mathrm{TT} 852$, within the arc of postholes that defines House 1. This column sample is within Feature 13, a broad, matrix-defined, shallow pit that included charcoal and some daub. Feature 13 yielded two radiocarbon dates: one from a hickory nutshell collected at $30-37 \mathrm{~cm}$ below the ground surface yielded a calibrated age of $428 \pm 72$ years B.P. (conventional radiocarbon age of $400 \pm 40$ years B.P., Beta-242378). The second date, obtained from a piece of oak charcoal collected between 30 and $39 \mathrm{~cm}$ below the surface, has a calibrated radiocarbon age of $757 \pm 39$ years B.P. (conventional radiocarbon age of $840 \pm 40$ years B.P., Beta-242379). The results of the lab analyses are presented in Figure C.1.

\section{Soil Stratigraphy}

This profile exhibited a Ap-A-E/Bt-Bt soil profile where melanization (darkening) of the soil occurred to a depth of $32 \mathrm{~cm}$ (Table C.4). 
Table C.2. Results of magnetic susceptibility and phosphorus analyses of three soil profiles from 41TT852 and 41 TT853

\begin{tabular}{|c|c|c|c|c|c|}
\hline No. & $\begin{array}{c}\text { Cube } \\
\text { Depth } \\
(\mathrm{cm}) \\
\end{array}$ & $\mathrm{X}_{\mathfrak{l f}}$ & $\begin{array}{l}X_{\mathrm{fd}} \\
(\%) \\
\end{array}$ & $\begin{array}{c}\text { Kjeldahl P } \\
(\mathrm{ppm})\end{array}$ & $\begin{array}{r}\text { Bray P } \\
(\mathrm{ppm}) \\
\end{array}$ \\
\hline \multicolumn{6}{|c|}{ Profile 1: 41TT852 } \\
\hline & $\mathrm{cm}$ & & $\%$ & $\mathrm{ppm}$ & $\mathrm{ppm}$ \\
\hline 1 & 3.0 & 150.3 & 4.9 & 200 & 14 \\
\hline 2 & 6.0 & 75.8 & 7.4 & 163 & 9 \\
\hline 3 & 8.0 & 71.3 & 6.7 & 143 & 8 \\
\hline 4 & 10.5 & 101.9 & 7.8 & 158 & 10 \\
\hline 5 & 12.5 & 80.0 & 7.8 & 147 & 11 \\
\hline 6 & 16.0 & 74.5 & 7.9 & 164 & 10 \\
\hline 7 & 18.5 & 83.6 & 7.6 & 149 & 9 \\
\hline 8 & 21.0 & 78.0 & 8.2 & 174 & 16 \\
\hline 9 & 23.5 & 69.4 & 8.1 & 170 & 17 \\
\hline 10 & 27.0 & 73.4 & 7.9 & 187 & 24 \\
\hline 11 & 29.0 & 80.2 & 8.1 & 186 & 27 \\
\hline 12 & 33.0 & 86.5 & 8.1 & 183 & 33 \\
\hline 13 & 34.5 & 57.0 & 8.7 & 189 & 34 \\
\hline 14 & 37.0 & 56.9 & 8.6 & 221 & 34 \\
\hline 15 & 39.0 & 62.8 & 10.2 & 241 & 33 \\
\hline \multicolumn{6}{|c|}{ Profile 2: 41TT852 } \\
\hline & $\mathrm{cm}$ & & $\%$ & $\mathrm{ppm}$ & $\mathrm{ppm}$ \\
\hline 1 & 2.0 & 63.5 & 7.7 & 160 & 8 \\
\hline 2 & 4.0 & 68.6 & 6.9 & 141 & 9 \\
\hline 3 & 6.2 & 72.3 & 6.4 & 153 & 8 \\
\hline 4 & 8.5 & 84.4 & 7.7 & 151 & 6 \\
\hline 5 & 12.0 & 65.7 & 8.8 & 133 & 5 \\
\hline 6 & 15.0 & 69.8 & 8.4 & 107 & 6 \\
\hline 7 & 17.0 & 63.2 & 9.9 & 126 & 5 \\
\hline 8 & 20.0 & 56.8 & 8.5 & 114 & 5 \\
\hline 9 & 22.5 & 78.5 & 8.8 & 112 & 5 \\
\hline 10 & 25.5 & 66.3 & 10.3 & 113 & 5 \\
\hline 11 & 27.5 & 58.9 & 8.2 & 113 & 6 \\
\hline 12 & 30.5 & 60.6 & 8.7 & 136 & 7 \\
\hline 13 & 32.5 & 63.7 & 10.0 & 140 & 7 \\
\hline 14 & 36.0 & 60.1 & 7.8 & 132 & 6 \\
\hline 15 & 38.0 & 56.2 & 8.7 & 132 & 6 \\
\hline 16 & 40.5 & 52.8 & 10.0 & 142 & 9 \\
\hline 17 & 43.0 & 54.9 & 9.5 & 130 & 8 \\
\hline 18 & 45.5 & 49.8 & 10.3 & 130 & 8 \\
\hline 19 & 49.0 & 52.6 & 9.8 & 133 & 9 \\
\hline 20 & 52.0 & 53.5 & 12.0 & 149 & 9 \\
\hline 21 & 56.0 & 51.0 & 11.9 & 137 & 7 \\
\hline 22 & 58.5 & 44.5 & 11.5 & 159 & 9 \\
\hline
\end{tabular}

\begin{tabular}{|c|c|c|c|c|c|}
\hline No. & $\begin{array}{c}\text { Cube } \\
\text { Depth } \\
(\mathrm{cm})\end{array}$ & $X_{1 f}$ & $\begin{array}{l}X_{\mathrm{fd}} \\
(\%) \\
\end{array}$ & $\begin{array}{c}\text { Kjeldahl P } \\
(\mathrm{ppm})\end{array}$ & $\begin{array}{c}\text { Bray P } \\
(\mathrm{ppm})\end{array}$ \\
\hline \multicolumn{6}{|c|}{ Profile 3: 41TT853 } \\
\hline & $\mathrm{cm}$ & & $\%$ & $\mathrm{ppm}$ & ppm \\
\hline 1 & 2.5 & 50.4 & 8.0 & 158 & 13 \\
\hline 2 & 5.0 & 51.1 & 8.2 & 148 & 8 \\
\hline 3 & 7.2 & 53.1 & 7.5 & 165 & 13 \\
\hline 4 & 9.2 & 54.2 & 8.8 & 151 & 7 \\
\hline 5 & 11.6 & 64.2 & 3.7 & 149 & 6 \\
\hline 6 & 13.4 & 47.7 & 8.4 & 140 & 10 \\
\hline 7 & 16.0 & 50.6 & 8.5 & 150 & 6 \\
\hline 8 & 18.5 & 53.5 & 8.7 & 126 & 5 \\
\hline 9 & 21.2 & 52.7 & 9.6 & 127 & 5 \\
\hline 10 & 23.6 & 54.2 & 8.3 & 120 & 5 \\
\hline 11 & 26.0 & 62.3 & 7.2 & 98 & 4 \\
\hline 12 & 28.5 & 49.7 & 8.4 & 113 & 4 \\
\hline 13 & 31.2 & 59.0 & 7.8 & 102 & 4 \\
\hline 14 & 35.5 & 53.1 & 7.7 & 103 & 3 \\
\hline 15 & 36.5 & 53.4 & 8.4 & 102 & 5 \\
\hline 16 & 39.5 & 54.1 & 8.5 & 104 & 7 \\
\hline 17 & 41.5 & 50.4 & 8.2 & 99 & 4 \\
\hline 18 & 44.2 & 51.1 & 8.0 & 112 & 7 \\
\hline 19 & 47.5 & 53.7 & 8.6 & 108 & 4 \\
\hline 20 & 50.5 & 50.2 & 8.8 & 96 & 4 \\
\hline 21 & 52.5 & 56.8 & 8.1 & 87 & 3 \\
\hline 22 & 55.0 & 52.4 & 9.3 & 88 & 3 \\
\hline 23 & 57.2 & 59.7 & 9.0 & 101 & 5 \\
\hline 24 & 60.0 & 60.9 & 10.1 & 116 & 6 \\
\hline 25 & 63.2 & 63.2 & 10.1 & 114 & 6 \\
\hline 26 & 65.4 & 75.0 & 11.8 & 114 & 6 \\
\hline 27 & 68.2 & 73.3 & 12.9 & 110 & 6 \\
\hline 28 & 70.5 & 77.1 & 15.0 & 105 & 6 \\
\hline
\end{tabular}




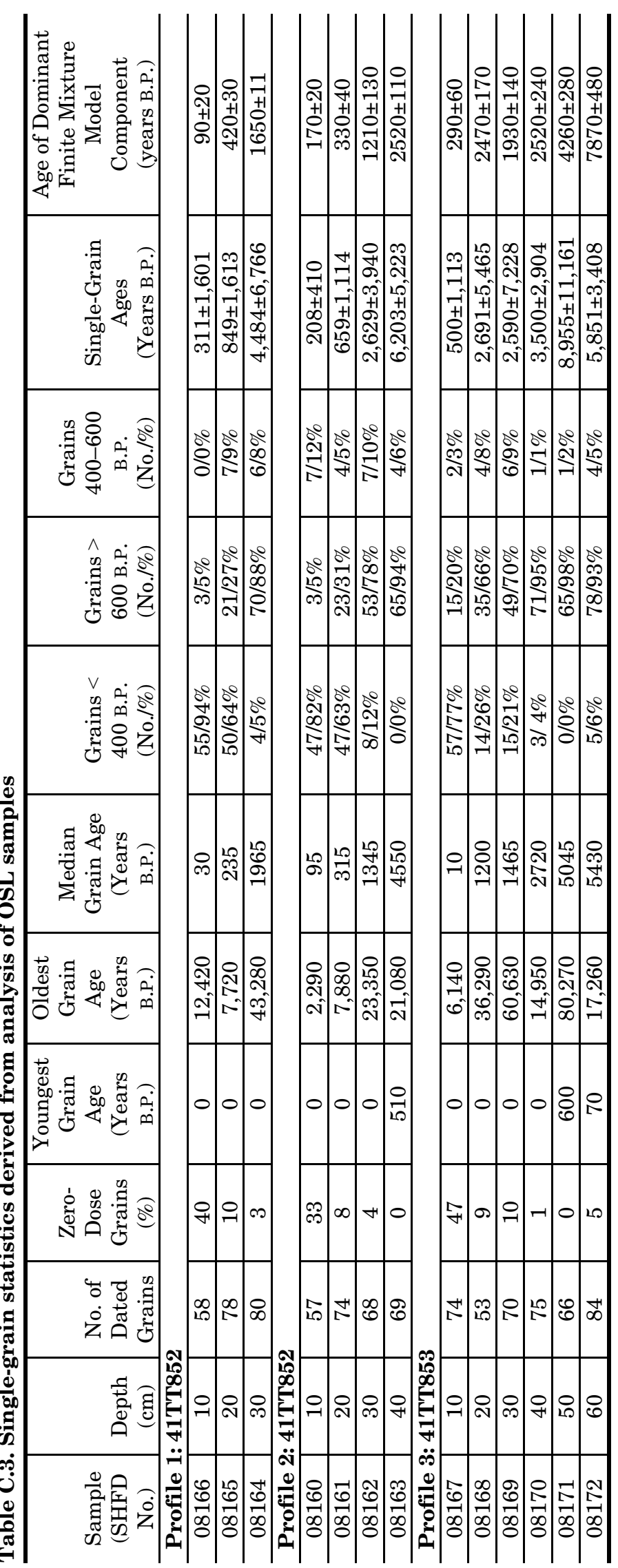




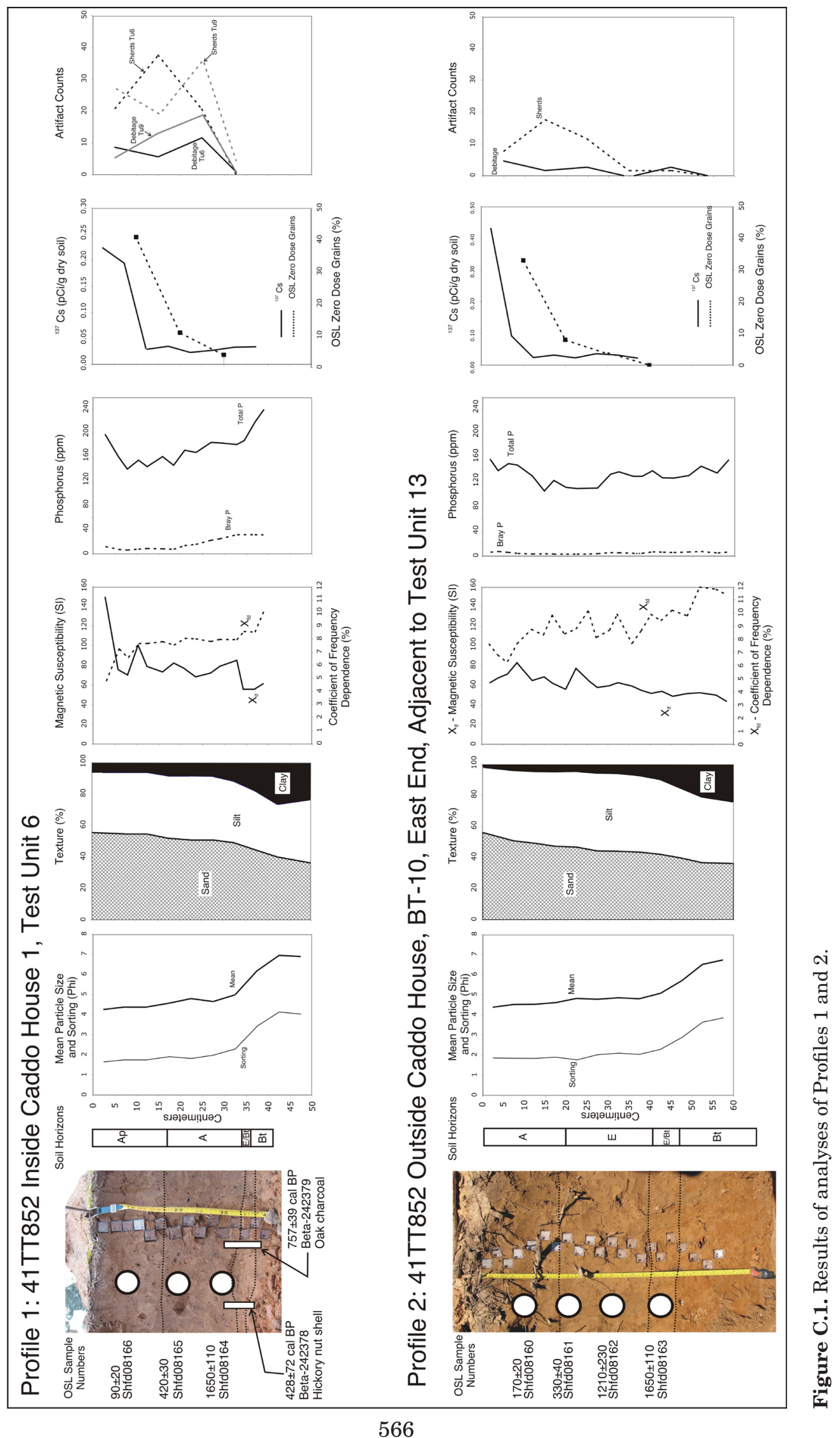


Cultural material appeared to be scattered throughout the melanized portion of the profile. A small number of iron-manganese nodules less than $3 \mathrm{~mm}$ in diameter were present throughout most of the solum. A transitional horizon was present between the sandy portion of the solum and the argillic horizon, and the lab data clearly show that the clay content increased gradually through this zone rather than abruptly at the argillic horizon interface. The Bt horizon contained greater than 18 percent more clay than the overlying sands.

The magnetic susceptibility values generally decreased with depth, and the proportion of the magnetic susceptibility attributable to pedogenesis (as suggested by the coefficient of frequency dependence of $\mathrm{X}_{\mathrm{fd}}$ ) increased with depth and was greatest in the argillic horizon. Phosphorus values were elevated in the top $10 \mathrm{~cm}$ and then decreased dramatically, but they gradually increased with depth, notably rising in the argillic horizon. This suggests that phosphorus is sorbed onto clays and not fixed well by the sands.

\section{Artifact Distribution}

The artifact distribution in Test Units 6 and 9 can be compared to this column profile sample. In both units, the debitage peaked in Level 3, whereas the number of sherds was highest in Level 2 of Test Unit 6 and Level 3 of Test Unit 9. In both test units a partial level was excavated just above the argillic horizon $(30-36 \mathrm{~cm})$. Four sherds were recovered from Test Unit 9, and a single piece of debitage was found in this level of Test Unit 6 . All of the sherds appeared to be consistent with a Titus phase occupation, and the depth distribution of the artifacts suggests that there has been substantial vertical disturbance of the artifact assemblage within the upper $30 \mathrm{~cm}$.

\section{Matrix Age Structure}

Three single-grain OSL samples were collected from this profile at $10-\mathrm{cm}$ increments. The shallowest sample was collected from $10 \mathrm{~cm}$ below the ground surface (Shfd08166); 58 grains were dated from this sample. The age of the dominant mode of the single-grain age distribution as determined by the finite mixture model age was $90 \pm 20$ years B.P. The simple average of the measured grain ages was 311 years B.P., and the median age was 30 years B.P. Forty percent of the measured grains were zerodose grains that had been exposed to the sun recently (presumably in the last decade or so), and the oldest grain was reset approximately 12,420 years ago. Approximately 94 percent of the grains were younger than the Titus phase occupation (which for discussion purposes is here bracketed between 400 and 600 years B.P.), and 5 percent of the grains were older than this.

A total of 78 sand grains were dated from the sample collected from $20 \mathrm{~cm}$ below the surface (Shfd 08165). The age of the dominant mode of the single-grain age distribution as determined by the finite mixture model was $420 \pm 30$ years B.P. The simple average of the measured grain ages was 849 years B.P., and the median age was 235 years B.P. Approximately two-thirds of the grains (64 percent) were younger than the Titus phase occupation and 27 percent were older. Ten percent of the grains were zero-dose

Table C.4. Profile1 description

\begin{tabular}{l|l|c|l}
\hline Zone & Horizon & Depth $(\mathrm{cm})$ & \multicolumn{1}{c}{ Description } \\
\hline 1 & Ap & $0-8$ & $\begin{array}{l}\text { Brown (7.5YR 4/4, m) sandy loam, very friable, massive, clear smooth } \\
\text { boundary }\end{array}$ \\
\hline 2 & A & $8-32$ & $\begin{array}{l}\text { Brown }(7.5 Y R ~ 4 / 3 . ~ M) \text { sandy loam, very friable, weak medium subangular } \\
\text { blocky structure to massive, clear irregular boundary, common (5-7 percent) } \\
\text { fine (2-3 mm) black iron-manganese nodules }\end{array}$ \\
\hline 3 & E/Bt & $32-38$ & $\begin{array}{l}\text { Strong brown (7.5YR 4/6, m) loam, very friable, massive, abrupt irregular } \\
\text { boundary, few to common (3-5 percent) fine (1-3 mm) black iron-manganese } \\
\text { nodules }\end{array}$ \\
\hline 4 & Bt & $38-40+$ & $\begin{array}{l}\text { Yellowish red (5YR 4/6, m) loam, friable, strong coarse subangular blocky } \\
\text { structure, few (1-3 percent) fine (1-3 mm) black iron-manganese nodules }\end{array}$ \\
\hline
\end{tabular}


grains and had been reset recently, and the oldest dated grain was last exposed to the sun 7,720 years ago.

The lowest sample from this profile was collected from $30 \mathrm{~cm}$ below the surface just above the E/Bt horizon (Shfd08164); 80 grains were dated. About 3 percent of the measured grains were zero-dose grains that had been recently reset, whereas the oldest dated grain was last exposed to the sun around 43,280 years ago. Finite mixture modeling of the grain age distribution identified four components, and the age of the dominant mode was $1650 \pm 110$ years B.P. About 5 percent of the grains were younger than the period of the Titus phase occupation, and 88 percent were older. The simple average of the dated grains is 4,484 years B.P., and the median grain age is 1,965 years B.P.

The left side of Figure C.2 shows histograms of the grain-age distributions for these samples and the progressive change in the shape of the distribution with increasing depth below surface. The age population is quite peaked near the ground surface and becomes much more widely spread with depth. The age distribution also becomes progressively skewed with increasing depth.

\section{Zero-Dose Grains and Cesium-137}

The depth distribution of cesium-137, which has a very short half-life, compares very favorably with the depth distribution of zero-dose grains identified by the OSL dating. The shape of the cesium-137 curve suggests that this profile has been relatively undisturbed in the last 60 years (the period since atmospheric testing of nuclear weapons started and atmospheric cesium-137 production began), and most of the cesium measured was in the top $10 \mathrm{~cm}$. The OSL singlegrain age distribution of the sample from $10 \mathrm{~cm}$ suggests that 66 percent of the sand grains in this sample were exposed to sunlight in this same period of time. Approximately 18 percent of the grains in the sample collected from $20 \mathrm{~cm}$ and 4 percent of the grains in the sample from $30 \mathrm{~cm}$ were exposed to sunlight in the last 60 years.

\section{Discussion}

The artifact distributions and OSL age data clearly indicate that this deposit has experienced significant disturbance. The presence of significant numbers of Titus phase artifacts in all four excavation levels presents contrasting mismatches between the age of the matrix and the artifact assemblage, with the top $10 \mathrm{~cm}$ mostly postdating the Titus phase occupation and the third level significantly predating the occupation. The second excavation level exhibits some age properties consistent with Titus phase, but only at the aggregate level (such as the finite mixture model main mode) as only 9 percent of the dated grains fall within the Titus phase. Both of the radiocarbon ages obtained from Feature 13 came from Level 3 , and both are significantly younger than the sedimentary matrix, suggesting that the dated materials were intruded into this older sediment, like the artifacts, presumably by postdepositional pedoturbation. The histograms of grain age (see Figure C.2) show that, at the aggregate level, the grain population increases with depth. But the standard deviation of the population increases much faster, since the dispersion increases dramatically, with much older grains becoming common with increasing depth. Considered together, these data suggest that this profile has experienced significant vertical mobility at a granular level.

\section{Profile 2}

Profile 2 was collected from Trench 10 adjacent to Test Unit 13 at 41TT852, well north of the two arcs of postholes marking houses.

\section{Soil Stratigraphy}

The soil profile exposed at the north end of Trench 10 was slightly deeper than that of Profile 1, with the top of the Bt horizon at $48 \mathrm{~cm}$ (Table C.5). A thin (2 cm) O horizon was present at the surface, and the A horizon beneath it was $16 \mathrm{~cm}$ thick. A distinct $\mathrm{E}$ horizon was between 18 and $40 \mathrm{~cm}$. A transitional horizon separated the unconsolidated sands from the argillic horizon. This E/Bt horizon contained distinct fragments of the Bt horizon surrounded by unconsolidated sand similar to the overlying $\mathrm{E}$ horizon. This portion of the profile appeared to be an argillic horizon that is degrading, most likely through ferrolysis (cf. Brinkman 1970, 1979; Van Ranst and De Coninck 2002). As in Profile 1, there was a gradual increase in clay within the $\mathrm{E} / \mathrm{Bt}$ horizon 


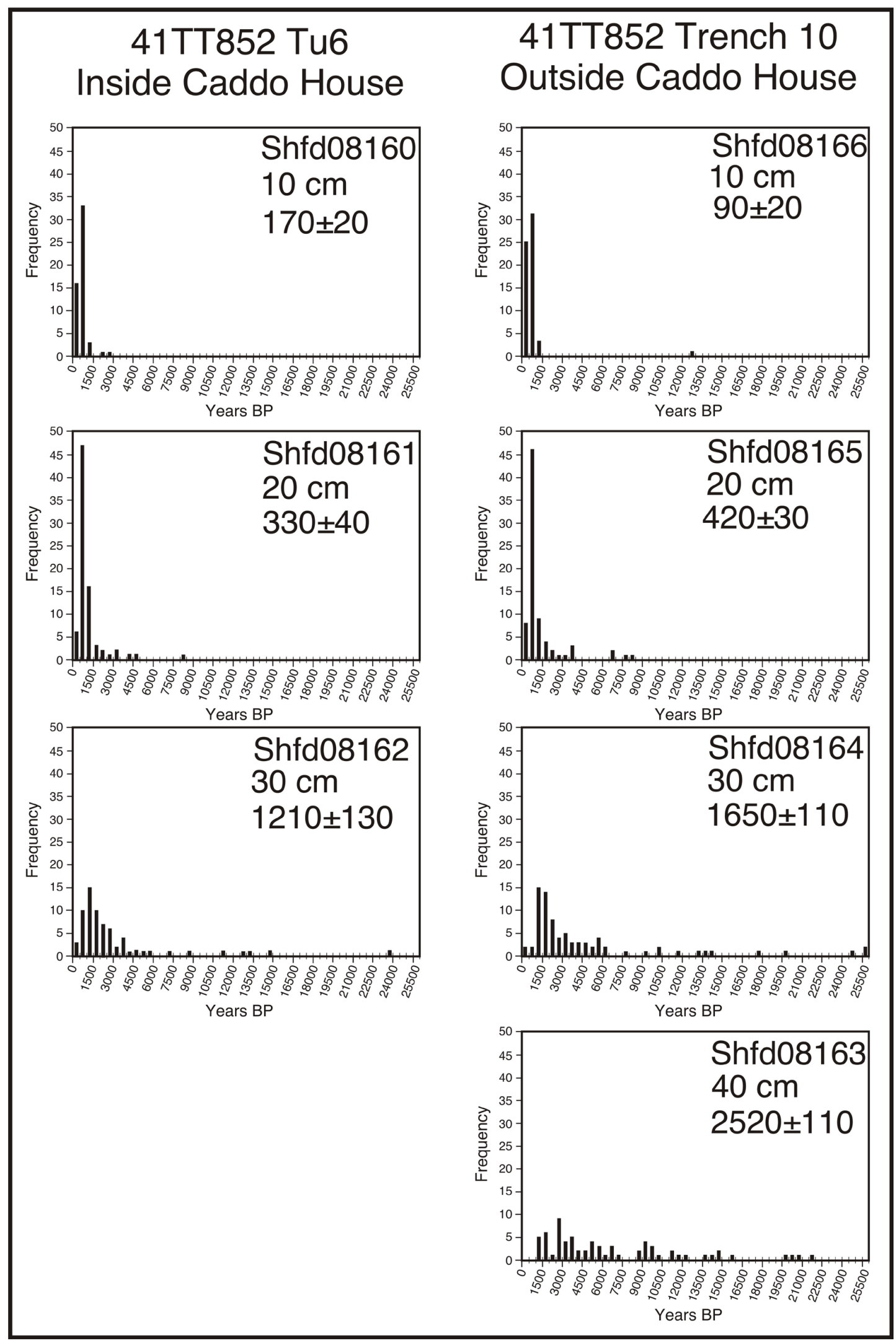

Figure C.2. Histograms of grain-age distributions for OSL samples from 41TT852. 
rather than an abrupt change at the top of the argillic horizon. The Bt horizon contained around 15 percent more clay than the overlying sands.

The results of the magnetic susceptibility analysis show a gradual decrease with depth, and as in Profile 1, an increase in $\mathrm{X}_{\mathrm{fd}}$ within the argillic horizon (see Figure C.1). Phosphorus was slightly elevated near the surface and in the argillic horizon, but the range of variation was significantly less than was observed in Profile 1.

\section{Artifact Distribution}

The artifact distribution within Test Unit 13 was compared with the analytical data obtained from Profile 2. Like the test units adjacent to Profile 1, the artifacts recovered from Test Unit 13 were consistent with a Titus phase occupation and exhibited a nearly normal depth distribution, with the mode (36 percent) occurring in Level 2 and only 13 percent in Levels 4 and 5 (30-50 cm below surface).

\section{Matrix Age Structure}

Four single-grain OSL samples were obtained at $10-\mathrm{cm}$ intervals from Profile 2, starting at $10 \mathrm{~cm}$ below the surface. Fifty-seven grains were dated from the uppermost sample (Shfd08160), and the dominant mode identified by the finite mixture model returned an age of $170 \pm 20$ years B.P. The average grain age was 208 years, and the median grain age was 95 years. One-third of the dated grains were zero-dose grains that had been reset recently.
The oldest dated grain was exposed to sunlight around 2,290 years ago, and the vast majority of the dated grains (82 percent) were younger than the Titus phase occupation. Only 3 grains (5 percent) were older than 600 years.

The OSL sample collected from $20 \mathrm{~cm}$ below the surface was slightly lower than the mode of the artifact distribution. Sixty percent (33 of 55) of the prehistoric artifacts recovered from Test Unit 13 were found in the top two levels. The dominant mode identified by finite mixture modeling returned an age of $330 \pm 40$ years B.P., and the average grain age and median grain age were 659 years and 315, respectively. All three of these are approximately the same age as the Titus phase occupation. But these statistics are at the aggregate level, and only 5 percent of the grains actually dated to the $400-600$ year B.P. period. Eight percent of the dated grains had been reset recently (i.e., were zero-dose grains), and 63 percent of the dated grains were younger than the Titus phase. The oldest dated grain in this sample was last exposed to the sun 7,880 years ago.

At $30 \mathrm{~cm}$ below the surface, the majority of grains (78 percent) were older than the Titus phase, and the dominant mode of the finite mixture model was $1210 \pm 130$ years B.P. Only 4 percent of the grains had been reset recently, and 12 percent were younger than 400 years B.P. In contrast, almost one-third (27 percent) of the Titus phase artifact assemblage was from Level $3(20-30 \mathrm{~cm})$ in Test Unit 13. The average grain age was 2629 years B.P., and half of the grains dated younger than 1345 years B.P. (the

Table C.5. Profile 2 description

\begin{tabular}{l|l|c|l}
\hline Zone & Horizon & $\begin{array}{c}\text { Depth } \\
(\mathrm{cm})\end{array}$ & \multicolumn{1}{c}{ Description } \\
\hline 1 & O & $0-2$ & $\begin{array}{l}\text { Dark brown }(7.5 Y R ~ 3 / 2, \mathrm{~m}) \text { organic matter, loose, single grain, abrupt smooth } \\
\text { boundary }\end{array}$ \\
\hline 2 & A & $2-18$ & $\begin{array}{l}\text { Brown }(7.5 Y R ~ 4 / 4, \mathrm{~m}) \text { sandy loam, very friable, weak coarse subangular blocky } \\
\text { structure, gradual smooth boundary }\end{array}$ \\
\hline 4 & E & $18-40$ & $\begin{array}{l}\text { Brown (7.5YR 5/4, m) sandy loam, very friable, weak medium subangular } \\
\text { blocky structure, clear irregular boundary }\end{array}$ \\
\hline 5 & Bt & $40-48$ & $\begin{array}{l}\text { Strong brown (7.5YR 4/6, m) sandy loam with distinct fragments of yellowish } \\
\text { red (5YR 4/6) loam, very friable, moderate medium subangular blocky } \\
\text { structure, clear smooth boundary; few (1-3 percent) fine (1-3 mm) black iron- } \\
\text { manganese nodules }\end{array}$ \\
\hline
\end{tabular}


median). The oldest grain in this sample was 23,350 years B.P. Hence, the matrix here is significantly older than the artifact assemblage.

The lowest sample dated in Profile 2 was from the E/Bt horizon at a depth of $40 \mathrm{~cm}$. The dominant mode identified by finite mixture modeling yielded an age of $2520 \pm 110$ years B.P., but most of the other measures of grain age are significantly older than this suggests. The average grain age (6203 years B.P.) and the median age (4550 B.P.) both indicate that this population is more dispersed than the finite mixture model age suggests, and the standard deviation of the entire dated grain population is 5523 years B.P. Although seven artifacts were recovered from Test Unit 13 between 30 and $40 \mathrm{~cm}$, there were no grains younger than the Titus phase in the sedimentary matrix, and 94 percent of the grains were older than 600 years B.P.

\section{Zero-Dose Grains and Cesium-137}

Profile 1, the majority of the cesium-137 was recovered in the top $10 \mathrm{~cm}$, which suggests that this profile has been little disturbed since 1944. In fact, this profile appears to have experienced the least disturbance of the three examined profiles since cesium fallout began. The distribution of the zero-dose grains declines exponentially with increasing depth, with onethird of the grains in the top $10 \mathrm{~cm}$ having been exposed to sunlight recently, whereas only 8 percent and 4 percent of those in the samples at 20 and $30 \mathrm{~cm}$ had.

\section{Discussion}

Profile 2 revealed significant mismatches between the age of the artifacts and the age of the sandy matrix that surrounded them. At $10 \mathrm{~cm}$ below the surface, where nearly 24 percent of the Titus phase artifact assemblage was found, the majority of the sand grains (82 percent) have been exposed to sunlight since 400 B.P., and 33 percent have been exposed recently. In Levels 3 and 4 , where 40 percent of the artifact assemblage was recovered, the majority of the sedimentary matrix was older than 600 years B.P. (78 percent in Level 3 and 94 percent in Level 4), and the oldest grains were very old (23,350 B.P. in Level 3 and 31,080 B.P. in Level 4). This suggests that this profile has been profoundly affected by pedoturbation in the period since the Caddo abandoned the site.

\section{Summary of Results from 41TT852, Profiles 1 and 2}

The two profiles sampled at 41TT852 were designed to compare the chronological structure of the sediment inside and outside a Caddo house, with the expectations that these two contexts might be significantly different. The results show that the chronological structure of the deposits are almost identical and exhibit similar patterns. In both profiles the age of the sand matrix increases with depth, and the ages obtained for the dominant mode of the finite mixture model increase exponentially with depth. Mismatches between the age of the artifacts and the age of the sedimentary matrix are frequent, with shallow samples being younger than their artifacts and deeper sands being older, often much older. Indeed, the single-grain age distribution progresses with increasing depth from a unimodal one near the surface, to a broadly dispersed and skewed unimodal distribution, to a polymodal widely dispersed population just above the argillic horizon. This pattern suggests pedoturbation rather than normally deposited geological sediments becoming increasingly older with depth.

Although the OSL dating results for the two profiles are similar, the magnetic susceptibility and total phosphorus analyses revealed significant differences between the two. Figure C.3 shows that magnetic susceptibility and total phosphorus were enhanced in the profile within House 1. Magnetic susceptibility in both profiles was elevated near the surface (more significantly within the house than outside) and generally decreased with depth. Phosphorus exhibited a different trend. In both profiles, it was elevated near the modern surface but decreased with depth until appreciable clay appeared, where it began to rise again in the argillic horizon. This suggests that phosphorus within these sandy soils is best sorbed by clays and is rather mobile within the sands. Interestingly, phosphorus shows no clear stratigraphic correlation with the depth distribution of the artifacts, but the values of $\mathrm{P}$ from the Bt horizon under the Caddo house are significantly larger than those outside it, 


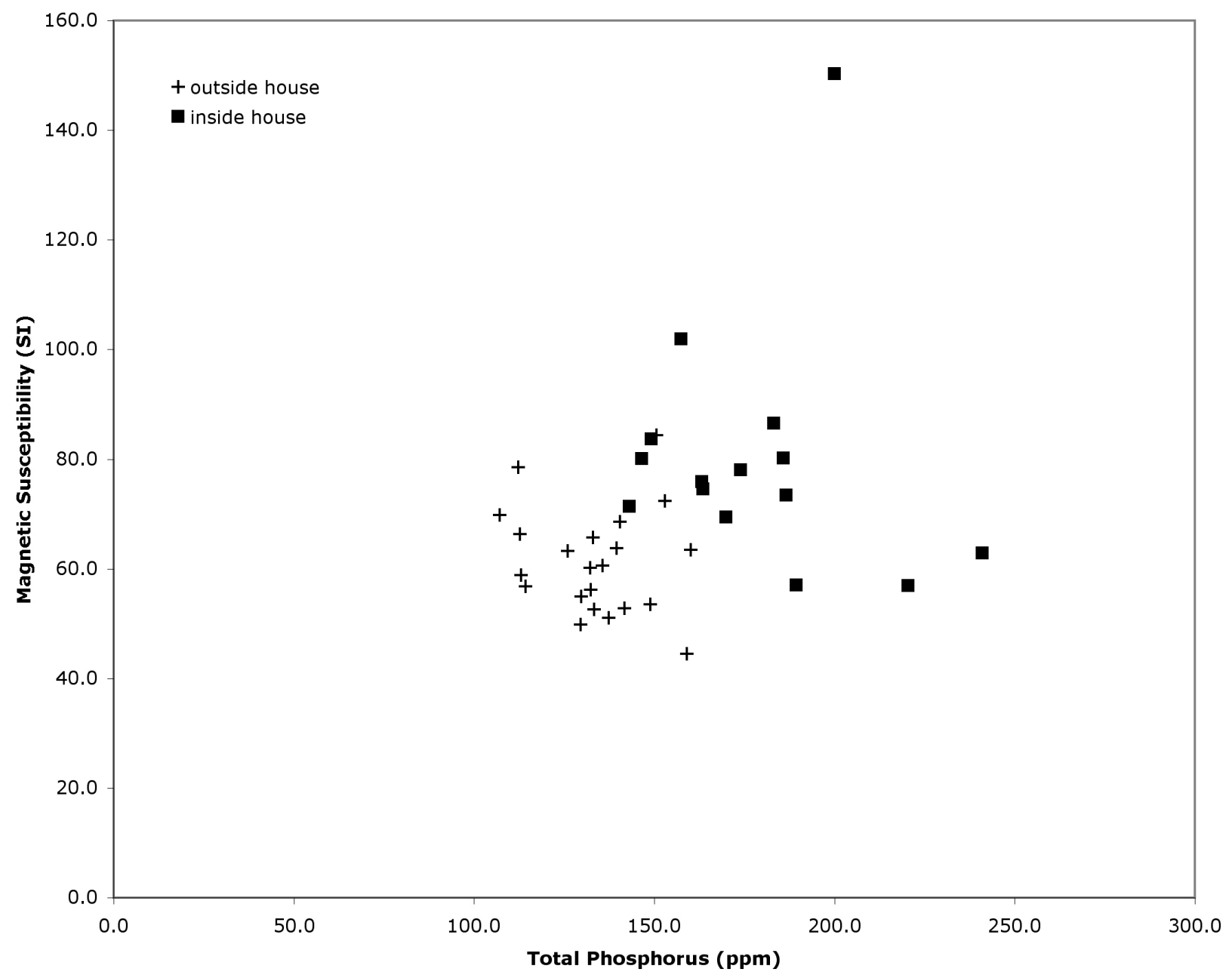

Figure C.3. Magnetic susceptibility and total phosphorus values of Profiles 1 and 2.

suggesting that the differences between the two profiles relate to human activity. This is vaguely reminiscent of work in the Maya lowlands that found that traces of past human activity were best preserved in the subsoil (Johnson et al. 2007; Sweetwood et al. 2009).

\section{Profile 3}

Profile 3 was collected from 41TT853, a site on a narrow interfluvial ridge that slopes westward toward Tankersley Creek. A single profile was sampled adjacent to Test Unit 16 in Trench 30 . This trench was cut across a pimple mound that was on the shoulder of the slope, and the sands were about $50 \mathrm{~cm}$ thick. The sample column was collected from the west wall of Test Unit 16, which produced the greatest number of artifacts at this site during testing as well as the greatest number of lithic artifacts. Sixteen presumably Titus phase sherds were recovered from this unit, with 93 percent of them within the top three levels.

Five OSL samples were collected at 10-cm intervals, and 15 bulk soil samples were collected at 5 -cm intervals for particle-size and cesium-137 analyses. Twenty-eight $2.5-\mathrm{cm}$ plastic box samples were collected for magnetic susceptibility and elemental analyses from the top $70 \mathrm{~cm}$ of the profile. The results of the lab analyses performed on this profile are shown in Figure C.4. 


\section{Soil Stratigraphy}

Test Unit 16 revealed an A1-A2-E-E/ Bt-Bt profile, where unconsolidated sands comprised the upper $50 \mathrm{~cm}$ of the solum (Table C.6). The sandy clay loam Bt horizon contained almost 16 percent more clay than the $\mathrm{A}$ and $\mathrm{E}$ horizon sandy loams, and the latter contained a large amount of silt (32-33 percent). The unconsolidated sands were separated from the argillic horizon by a transitional zone that appeared to contain fragments of Bt horizon sandy clay loam separated by unconsolidated sands. It is interpreted as an argillic horizon being degraded by ferrolysis.

The magnetic susceptibility profile displays several very small-magnitude peaks, but the general trend with depth is relatively low values within the sandy portion of the solum and elevated values within the argillic horizon. Both of the phosphorus measures show similar depth profiles, with values that are about one order of magnitude different. Both show phosphorus elevated in the top $25 \mathrm{~cm}$ and then declining with increased depth until the argillic horizon is reached, at which point the values climb again slightly.

\section{Artifact Distribution}

The majority of the lithic material and 10 percent of the artifacts recovered in testing at 41TT853 were from Trench 30 and Test Unit 16 (Hatfield et al. 2008). The depth distribution of debitage in this unit was bimodal, with a peak in Level $2(10-20 \mathrm{~cm})$ and a second peak in Level 5 $(40-50 \mathrm{~cm})$. All ceramic sherds but one were in a unimodal distribution that peaked in Level 2. The abundant lithic material, its bimodal depth distribution, and the recovery of Late Archaic diagnostics elsewhere at the site led to the impression that this part of the site may have been occupied in the Late Archaic period as well as during the Titus phase.

\section{Matrix Age Structure}

The six single-grain OSL samples collected from this profile constitute the deepest and most-continuous column in this study (Figure C.5). The uppermost sample was collected at $10 \mathrm{~cm}$ (Shfd08167), and 74 grains were dated. Of these, nearly half (47 percent) were zero- dose grains that had been recently exposed to sunlight. Of the three components identified by finite mixture modeling, the dominant mode yielded an age of $290 \pm 60$ years B.P., whereas the average grain age was 500 years and the median grain age was 10 years. The majority of the grains in this sample (77 percent) were younger than Titus phase, whereas 20 percent of the grains were older than 600 years B.P. This level contained 18 percent of the artifacts recovered from this test unit, and the majority of these are most likely associated with the Titus phase.

The OSL sample collected from $20 \mathrm{~cm}$ (Shfd08169) coincided with Level 2, which yielded 23 percent of the artifacts in Test Unit 16 and was the upper peak of the lithic distribution and the sole peak of the ceramic distribution. The OSL ages from this sample appear anomalously old (as discussed below), and the dominant mode of the finite mixture model yielded an age of $2470 \pm 170$ years B.P. The average age of the dated grains in this sample was 2691 years B.P., and the median grain age was 1200 years B.P. Nine percent of the dated grains had been recently reset (i.e., were zero-dose grains), and 26 percent of the grains yielded reset ages younger than 400 years B.P. Two thirds (66 percent) of the grains were older than the Titus phase, and the oldest grain in this sample was last exposed to sunlight 36,290 years ago.

Level 3 yielded 18 percent of the artifacts in this test unit, and 70 sand grains were dated from the OSL sample collected at $30 \mathrm{~cm}$ (Shfd08169). Ten percent of the dated grains were zero-dose grains, and 21 percent yielded ages younger than the Titus phase. The dominant of the four components identified by the finite mixture model yielded an age of $1930 \pm 140$ years B.P., whereas the average grain age was 2,590 years B.P. and the median grain age was 1465 years B.P. The majority of the grains in this sample were older than the Titus phase, and 46 percent were more than 1,600 years old. The oldest dated grain in this sample was last exposed to sunlight 60,630 years ago.

Only one zero-dose grain was identified among the 75 grains dated from $40 \mathrm{~cm}$ below the ground surface (Shfd08170). Only 4 percent of the dated grains yielded ages younger than the Titus phase, whereas 95 percent were older than 600 years B.P. The largest of the four components identified by finite mixture modeling yielded an 


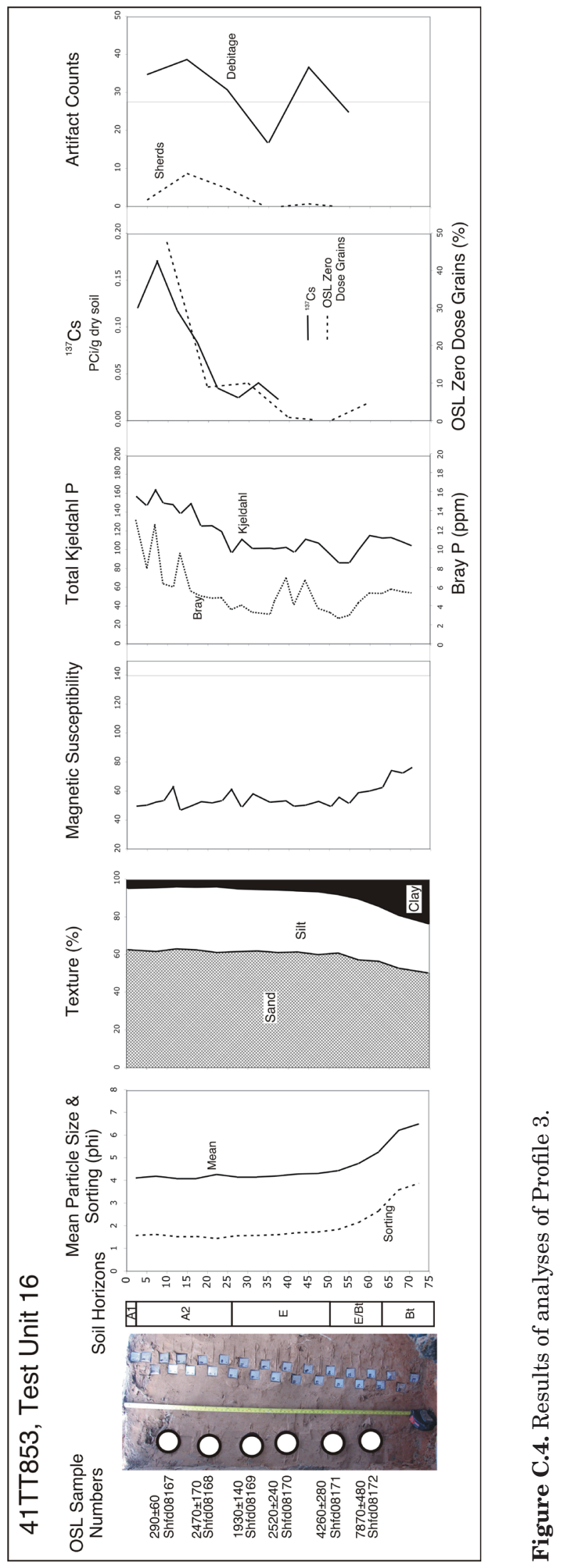


Appendix C: Stratigraphic Integrity Analysis for 41 TT852 and $41 T T 853$

Table C.6. Profile 3 description

\begin{tabular}{l|l|c|l}
\hline Zone & Horizon & $\begin{array}{c}\text { Depth } \\
(\mathrm{cm})\end{array}$ & \multicolumn{1}{|c}{ Description } \\
\hline 1 & A1 & $0-2$ & $\begin{array}{l}\text { Brown }(7.5 Y R ~ 4 / 3, \mathrm{~m}) \text { sandy loam, loose to very friable, single grain, clear } \\
\text { smooth boundary }\end{array}$ \\
\hline 2 & A2 & $2-26$ & $\begin{array}{l}\text { Brown (10YR 4/3, m) sandy loam, very friable, weak medium subangular } \\
\text { blocky structure to massive, diffuse smooth boundary }\end{array}$ \\
\hline 3 & E & $26-50$ & $\begin{array}{l}\text { Strong brown (7.5YR 4/6, m) sandy loam, very friable, weak medium } \\
\text { subangular blocky structure to massive, diffuse smooth boundary }\end{array}$ \\
\hline 5 & E/Bt & $50-63$ & $\begin{array}{l}\text { Brown (7.5YR 5/4, m) sandy loam with distinct fragments of reddish brown } \\
\text { (5YR 4/4, m) sandy clay loam, very friable, moderate medium subangular } \\
\text { blocky structure, clear smooth boundary, degraded argillic horizon }\end{array}$ \\
\hline
\end{tabular}

age of $2520 \pm 240$ years B.P., whereas the average grain age was 3,500 years and the median was 2,720 years B.P. All of these measures are probably older than the untyped dart point that was recovered from this level.

The sample collected at $50 \mathrm{~cm}$ depth came from the E/Bt horizon, and the youngest and oldest among the 66 dated sand grains were 600 and 80,270 years B.P. respectively. No grains younger than the Titus phase were identified, but one grain of Titus-phase age was present. At $4260 \pm 280$ years B.P., the largest of the five components identified by the finite mixture model is younger than the median ( 5045 years B.P.) and average grain ages (8955 years B.P.).

The deepest and oldest sample was collected from $60 \mathrm{~cm}$, just above the argillic horizon. Eighty-four grains were dated, and 5 percent of these were recently reset zero-dose grains. The grain-age distribution, like that for the sample at $50 \mathrm{~cm}$, was very dispersed. The finite mixture model identified five components, the dominant of which dated $7870 \pm 480$ years B.P. The average grain age was 5,851 years B.P. and the median was 5,430 years B.P. Eight grains yielded Pleistocene resetting ages of more than 10,000 years.

This profile is not only deeper but also dates older than either of the shallower profiles examined at 41TT852. As with the other two profiles, the grain-age distribution is peaked near the surface, and the central tendency of the population gets older with increasing depth. The grain-age histogram also exhibits a progressively broader and more dispersed age distribution with increasing depth.

\section{Zero-Dose Grains and Cesium-137}

The depth distribution of the cesium-137 in this profile is slightly different than that observed in Profiles 1 and 2 at 41TT852, where the majority of the cesium- 137 was in the top $10 \mathrm{~cm}$. Here, the cesium is most common in the $5-10-\mathrm{cm}$ sample and is deflected deeper into the soil, with significant values as deep as $20 \mathrm{~cm}$. This suggests that there has been significant disturbance of the upper $20 \mathrm{~cm}$ in the last 70 years.

The zero-dose grains exhibit a depthfrequency profile that is similar in shape to the cesium-137 distribution, suggesting that whatever is moving the cesium is also moving the zero-dose grains. At $10 \mathrm{~cm}$, nearly half of the measured grains (47 percent) had been recently reset, and the next two samples exhibited around one-fifth of that amount.

\section{DISCUSSION OF THE RESULTS}

The work performed here provides several ways to view the age of the sedimentary matrix that hosts the archeological remains at $41 \mathrm{TT} 852$ and $41 \mathrm{TT} 853$. Each of these perspectives provides some insight into the dynamic processes at work in these sandy soils. The most enlightening results were obtained by comparing the age structure of the sand with the age of the archeological inclusions, but some of the observations on short-term processes, specifically the depth distributions of zero-dose grains and cesium-137, are interesting as well. 


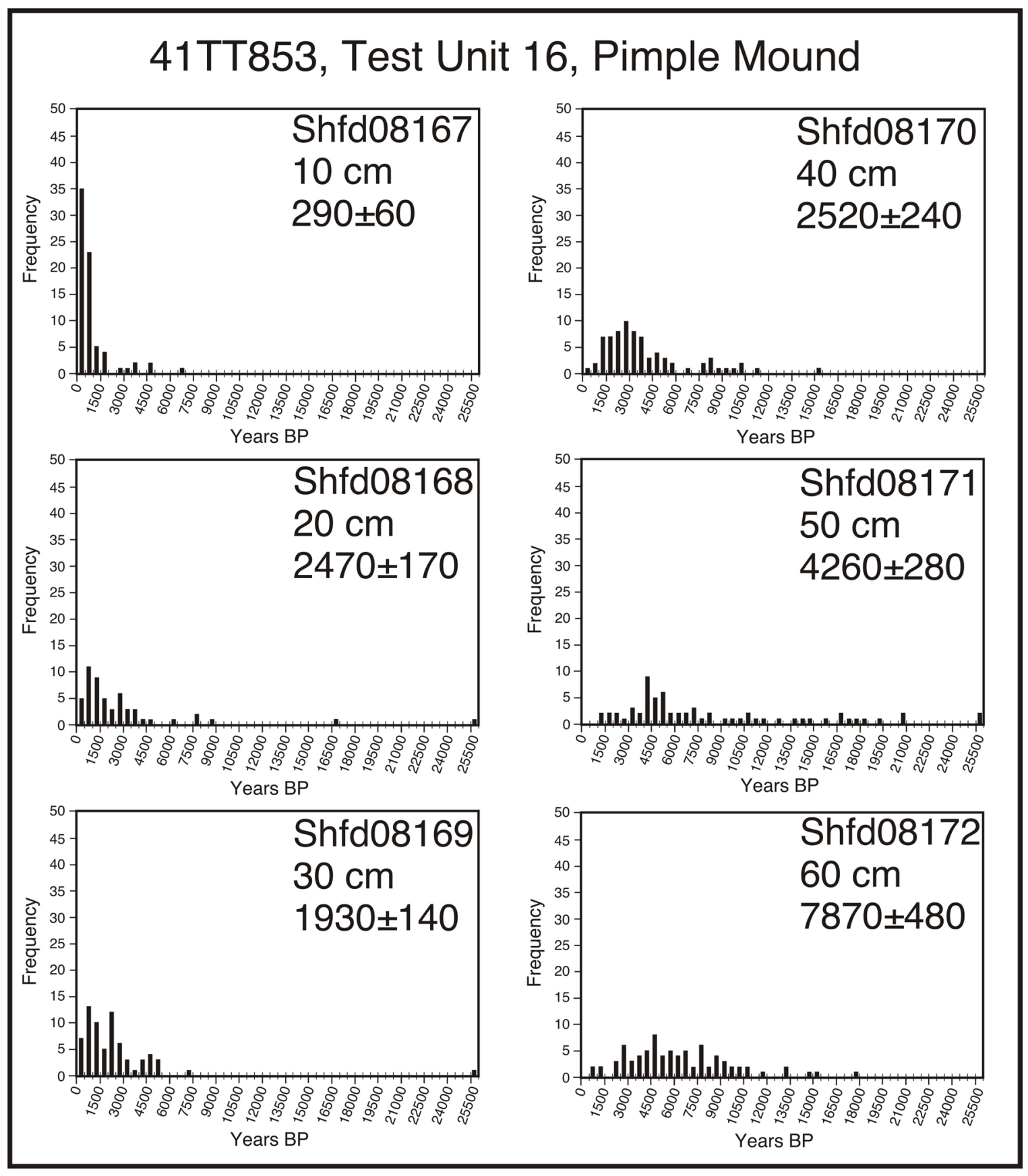

Figure C.5. Histograms of grain-age distributions for OSL samples from 41TT853.

\section{Soil Stratigraphy and Lithology}

Stratigraphically speaking, the three profiles examined here were nearly identical and varied primarily in terms of the thickness of the unconsolidated sands and the complexity and thickness of the topsoil. The A horizon was thickest in Profile 1 and thinnest in Profile 2 . The transition to the argillic horizon and the properties of the Bt horizon were nearly identical in each profile, although the thickness of the E/Bt horizon varied slightly.

Texturally, the sandy portion of the three soil profiles was quite homogeneous. All of the 
sandy mantle deposits that were examined were sandy loams that contained a significant amount of silt (30-50 percent). The inclusion of such a large amount of silt places the mean particle size in the coarse silt range, between 4 and 5 phi, and yields sorting values between poorly and very poorly sorted. The amount of silt in the sandy epipedons is generally inconsistent with eolian sand, which may have small amounts of silt but rarely in quantities as large as this.

The argillic horizons were not sampled extensively, but at least two samples were collected from the top of the Bt horizon in each profile. As can be seen on Figure C.6, these deposits were significantly finer-textured (mean values of fine silt, between 6 and 7 phi) and either very poorly or extremely poorly sorted. Trenching at several sites (41TT851, 41TT852, and 41TT853) revealed evidence of degrading argillic horizons where the interface between the argillic horizon and the overlying sand was not a sharp line but rather a transitional zone where fragments of the argillic horizon were surrounded by loose sand. These fragments increased in size and frequency down the profile to the top of the argillic horizon. In some places, the tongues of sand between the fragments of suspended argillic horizon were white (albic tongues, especially right on top of the solid argillic horizon) and were clearly zones of intense chemical degradation where the clays within the argillic horizon are being broken down, presumably by ferrolysis (Brinkman 1970, 1979). It is unclear how long this process takes to achieve the appearance noted in the field, but this degraded interface is inconsistent with an erosional surface that is often evoked when mima-like or pimple mounds are argued to be eolian dunes or nebkhas (e.g., Otvos 2004; Seifert et al. 2009). The gradational interface was best developed on flat surfaces like at 41TT851 and was less pronounced on slightly sloping surfaces, like those noted here at 41TT852 and 41TT853.

\section{Age Structure of the Solum}

The single-grain age data for the OSL dates can be viewed in several ways (see Table C.3). Attachment C.1 presents the age of the dominant component in each sample population as determined by finite mixture modeling, which is perhaps the best measure of the depth progression in the central tendency of the grain- age population. Figure C.7 plots these ages by depth both separately and together, and this shows several noteworthy points. First, the ages increase with depth in an exponential fashion. Second, there is a remarkable degree of consistency between the profiles. Third, Profile 3 shows a prominent age reversal at $20 \mathrm{~cm}$.

A somewhat different image is presented by the grain-age histograms (see Figures C.2 and C.5), which show the distribution of grain ages in 500-year increments for each OSL sample. As a group, there is a consistent trend with depth, which is summarized in Figure C.8. Near the ground surface, the age distributions are mostly normally distributed and peaked, exhibiting little skewing or dispersion. But with increasing depth, the age distribution progressively shifts, becoming less peaked and more skewed and exhibiting significant dispersion. This progression is present in all three profiles, but the shallowest profile (Profile 1) does not exhibit the extreme skewness and older ages observed in the deepest one (Profile 3).

\section{Zero-Dose Grains}

From a formation process perspective, one of the most compelling data sets is the depth distribution of sand grains that have been reset so recently that they have no measurable OSL signal, the so-called zero-dose grains. These sand grains were recently exposed to the sun and have since returned to depth, and as such, they provide an index of how individual particles move in these sandy deposits. For this analysis, the OSL samples were intentionally collected at regular intervals to see what kind of patterns are present with increasing depth, both in terms of grain age and zero-dose grains.

In each profile, the number of zero-dose grains declines exponentially with depth (Figure C.9), although Profile 3 exhibits more variation than the other two. The $10-\mathrm{cm}$ sample in each profile contained the largest proportion of zerodose grains, ranging from a low of 33 percent in Profile 2 to a high of 47 percent in Profile 3. These astounding figures indicate that a third to a half of the sediment in the top $10 \mathrm{~cm}$ was on the surface in the last 10 years and since diffused back down to $10 \mathrm{~cm}$. At $20 \mathrm{~cm}$, only 8-10 percent of the sand population was recently at the surface, and at $30 \mathrm{~cm}$ two of the profiles had 3-4 percent zero-dose grains. 


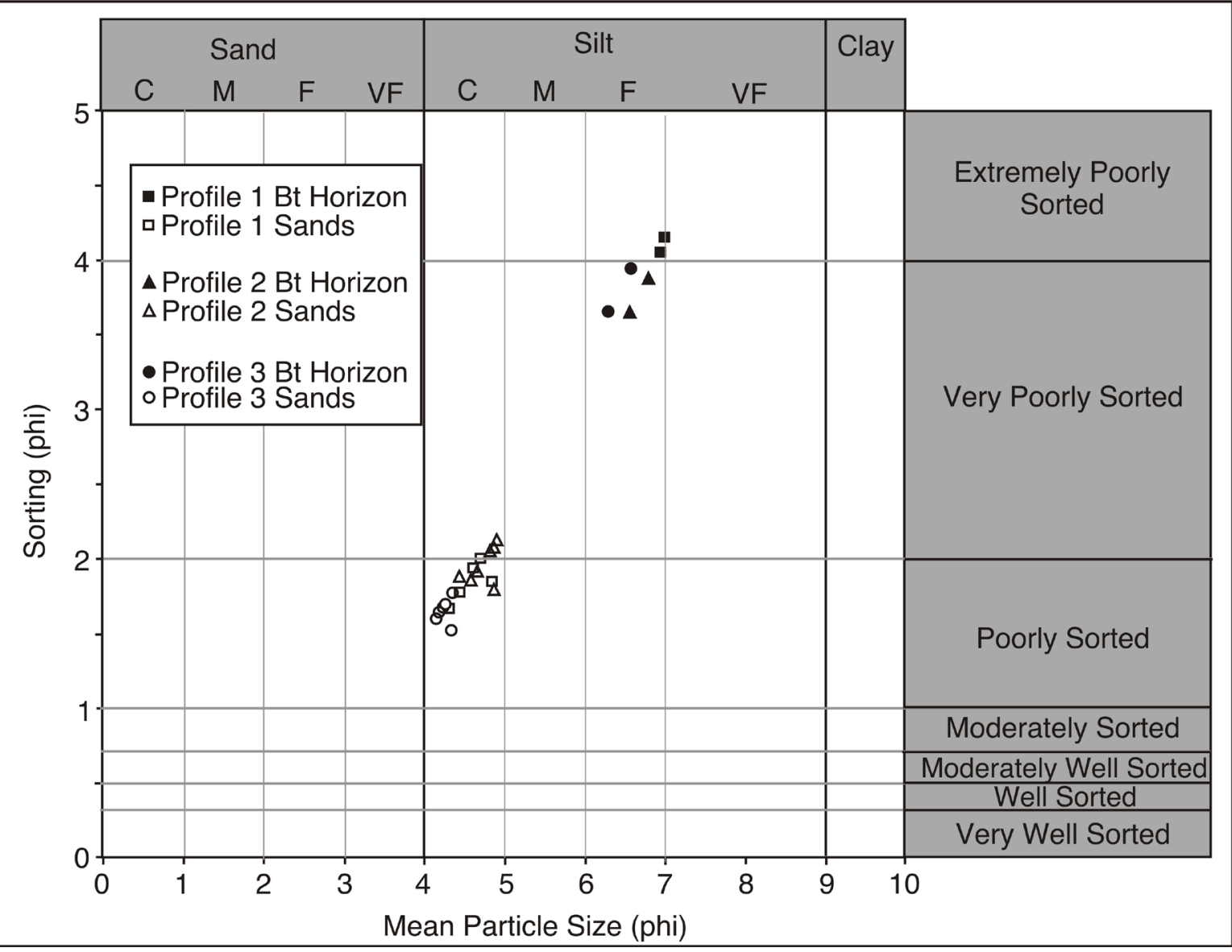

Figure C.6. Mean particle size versus sorting (standard deviation) for sandy epipedons and the subsoil argillic horizons. Note: $\mathrm{C}=$ coarse, $\mathrm{M}=$ medium, $\mathrm{F}=$ fine, and $\mathrm{VF}=$ very fine.

The implication is that there is rapid turnover of the sediment in the upper $20 \mathrm{~cm}$, and that, depending upon how much time is represented by the zero-dose grain population, these figures can be used to estimate how long it takes for the entire solum to be reset. So, for instance, if the zero-dose grains are considered to be equal to a period of approximately 10 years, then the top $10 \mathrm{~cm}$ of the soil in these columns was completely overturned (exhumed, exposed to sunlight, and returned to depth) in a period between 20 and 60 years. But because the dating also determined when each grain in the sample was last reset, we can see that this is an oversimplification because every $10 \mathrm{~cm}$ sample had grains that were greatly in excess of this age (ranging from 2,290 years in Profile 2 to 12,420 years in Profile 1). Likewise, the number of grains with ages in excess of 60 years in the 10-cm samples ranged from 37 percent in Profile 1 to 54 percent in Profile 2. This reflects the fact that the movement of sediment in these profiles is not unidirectional but bidirectional. The zero-dose grains point to the dynamic nature of downward mobility. Assessing the upward mobility component is much more challenging. The prevalence of zero-dose grains in the $10-\mathrm{cm}$ samples points to a highly active bioexhumation process as well as a diffusion process that subsequently disperses these grains into the subsurface. Both of these processes actively affect the manner in which artifacts are buried in this setting.

\section{Cesium-137}

Eight samples collected in 5-cm increments were submitted from each of the analyzed 


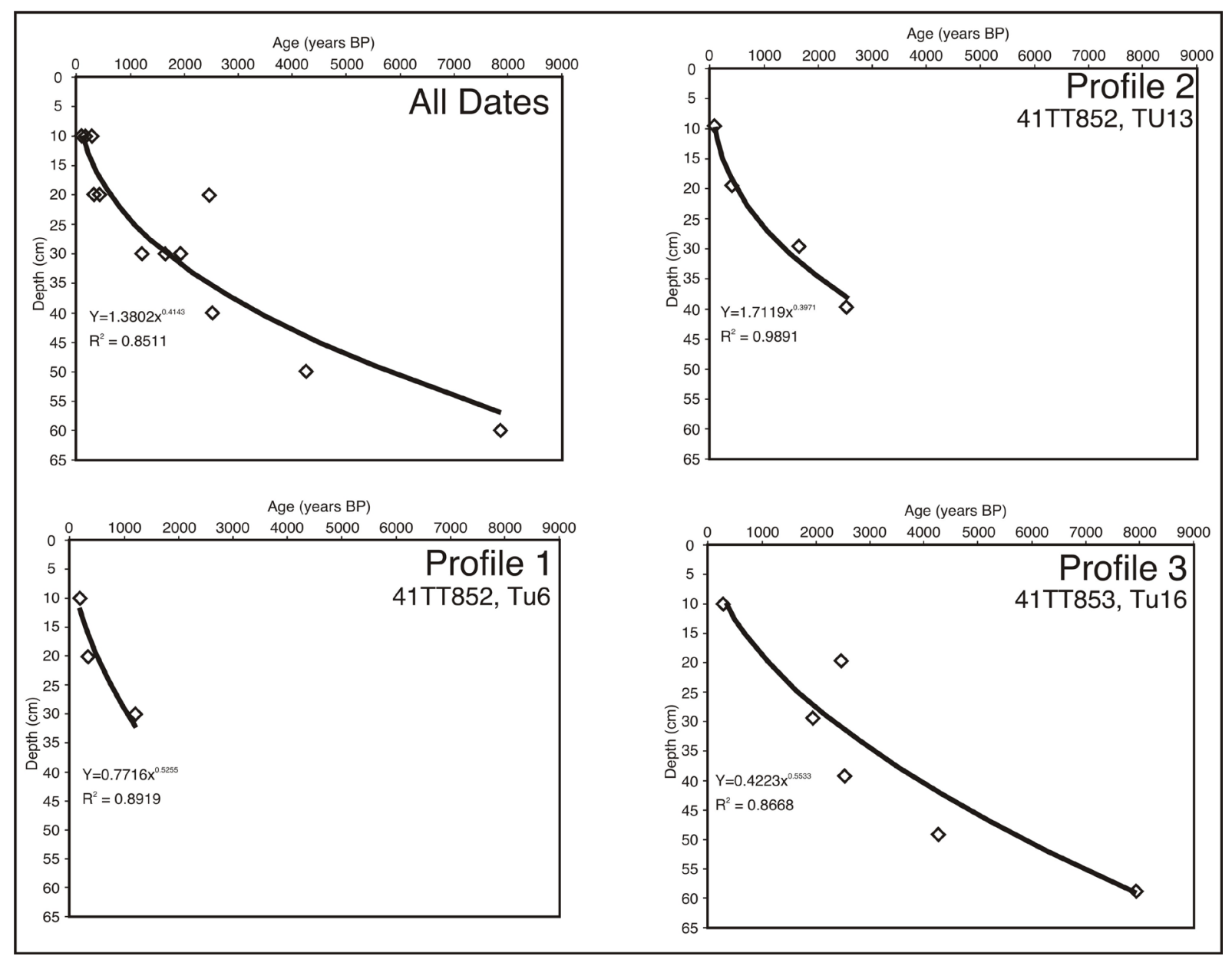

Figure C.7. Main OSL age component determined by finite mixture modeling as a function of depth for each profile, as well as all of the samples together.

profiles for analysis of cesium-137. The total amount of ${ }^{137} \mathrm{Cs}$ activity observed was nearly identical in Profiles $1\left(0.625 \mathrm{pCi} / \mathrm{g}_{\mathrm{dry}}\right)$ and 3 $\left(0.615 \mathrm{pCi} / \mathrm{g}_{\mathrm{dry}}\right)$ and slightly greater in Profile $2\left(0.727 \mathrm{pCi} / \mathrm{g}_{\mathrm{dry}}\right)$. Figure C.10, with the depth distribution of ${ }^{137} \mathrm{Cs}$ for each profile, shows that Profile 2 exhibits the least-disturbed ${ }^{137} \mathrm{Cs}$ distribution (with 59 percent of the total cesium activity in the $0-5$-cm sample) and Profile 3 the most disturbed, with the ${ }^{137} \mathrm{Cs}$ activity almost evenly spread across the top $20 \mathrm{~cm}$.

As might be expected on theoretical grounds, this compares favorably with the OSL data for zero-dose grains, most clearly expressed by the uppermost sample in each profile. The 10-cm sample in Profile 2 has the fewest zerodose grains (33 percent), whereas Profile 3 has the most (47 percent). Hence, both indexes concur on the degree and nature of the recent disturbance of the profiles.

\section{General Observations}

The overall impression of the upland soils within the project area is that they are ancient soils formed on Tertiary bedrock that are subjected to extensive internal reorganization by pedoturbation. The sandy part of the solum, which was investigated here, appears to be subjected to extensive pedoturbation, and the subsoils (the argillic horizons) appear to be actively degrading.

The following sections address the three principal research questions posed: 


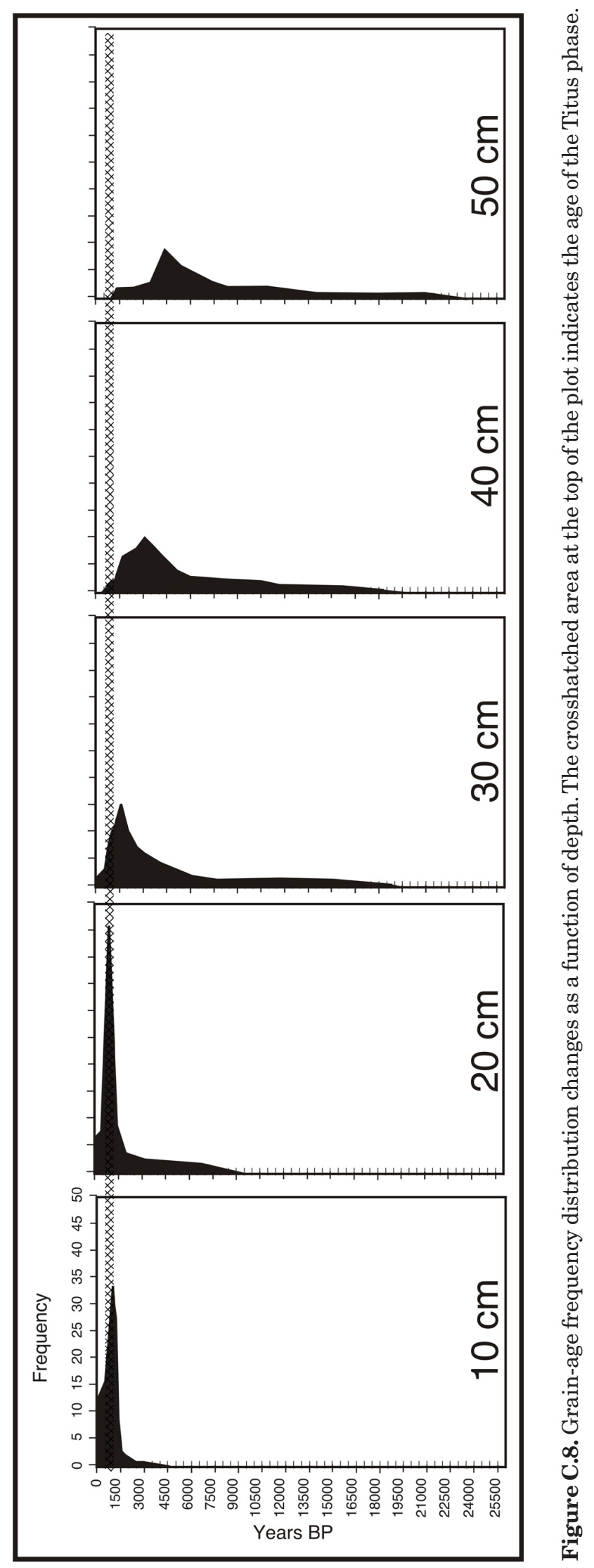




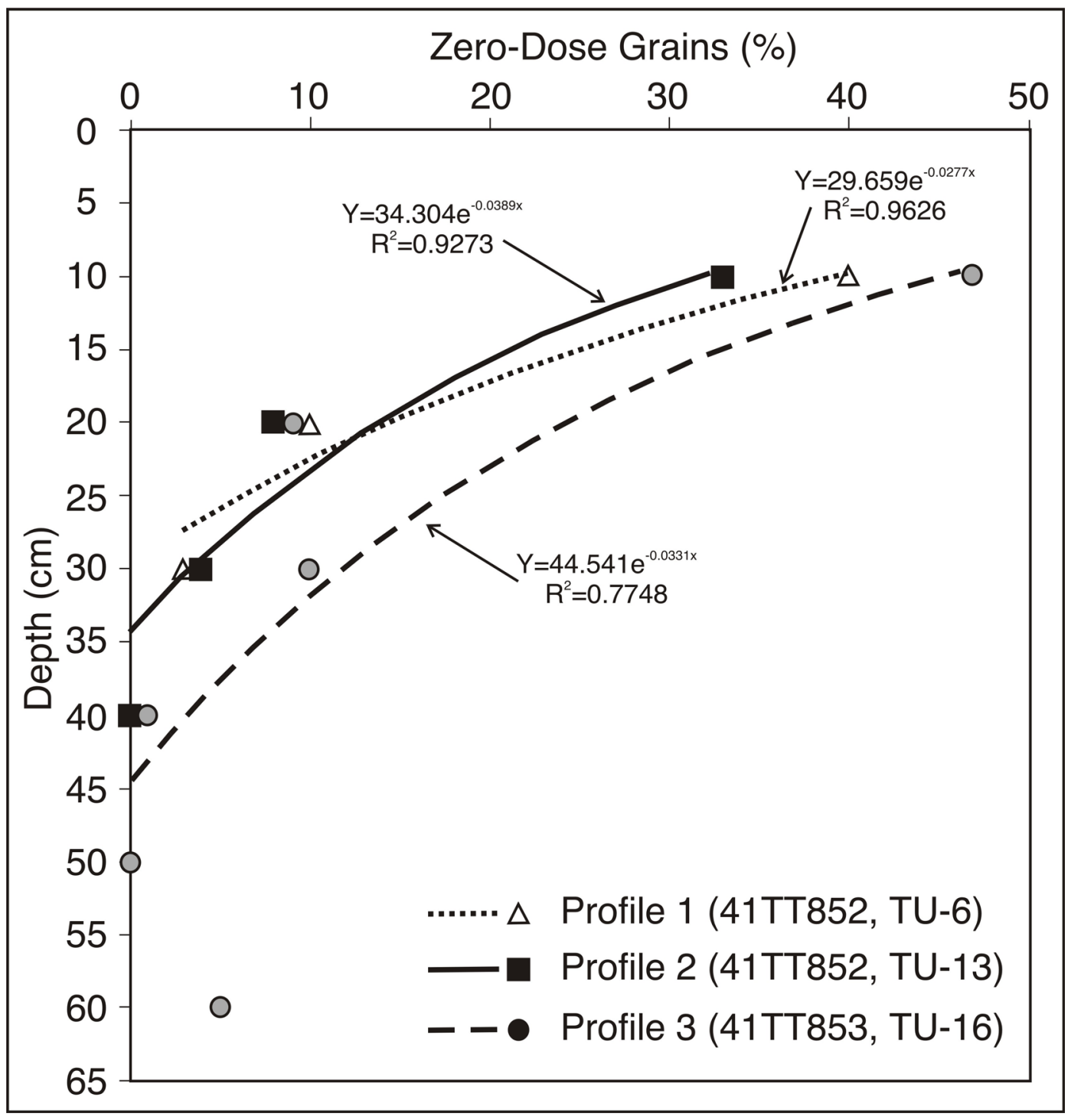

Figure C.9. Plot of the percent of zero-dose grains in each profile by depth.

3. Is there evidence (analytical or stratigraphic) that the deposits above the subsoil retain stratigraphic integrity?

4. What processes (natural or cultural) have or are affecting deposit integrity?

5. Are shallow sandy profiles more disturbed than thick ones?

\section{Stratigraphic Integrity?}

The excavations revealed no sedimentological features and few cultural features that suggested that the sandy sediments are in situ. Rather, they provided ample evidence that Late Caddo artifacts are widely dispersed in the soil profile, which suggests that the deposits do not retain stratigraphic integrity. Although a few matrix-defined features were observed in the field (either broad pits like Feature 13 at 41 TT852 or occasional postholes), most of the features noted were discovered at the top of the argillic horizon and not in the unconsolidated sands. As such, there was overall little anecdotal evidence to suggest that there is stratigraphic integrity within the sands. 


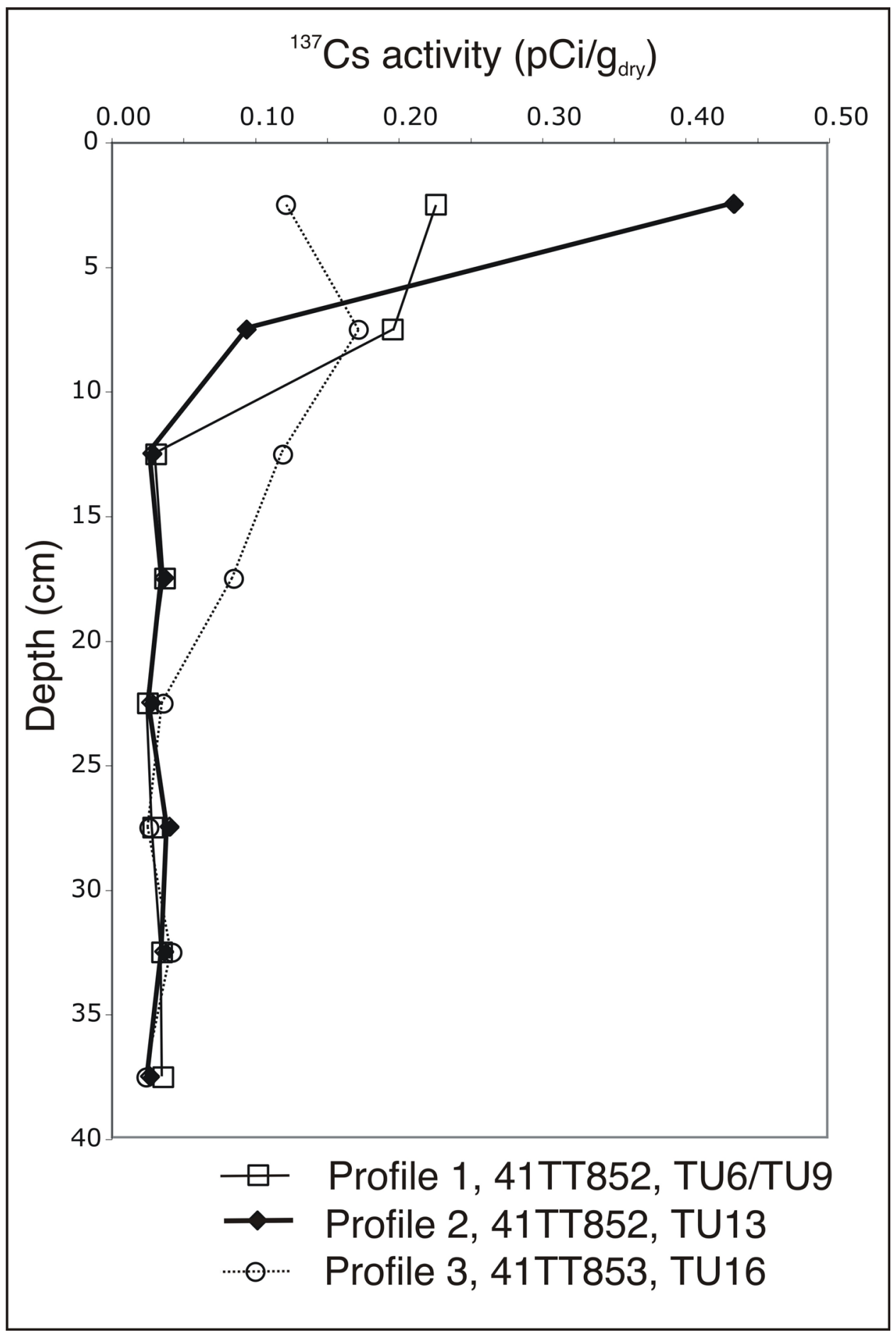

Figure C.10. Depth distributions of cesium-137. 
The analytical evidence provides a more detailed answer to this question. When the stratigraphic distributions of the Titus phase artifacts are considered together with the ages of the sedimentary matrix and the distributions of cesium-137, it becomes clear that the artifacts were in sediments that predate and postdate the Titus phase. If the burial of these artifacts was the result of normal sedimentation, then the artifacts on the occupation surface/zone would be in sediments approximately contemporaneous with the occupation (cf. Bush and Feathers 2003) and would be buried by sediments with matrix ages younger than the Titus phase. This is not the case.

The wide range of artifact age-matrix age relationships observed here most closely resembles the expectations of a deposit that has been altered by postdepositional bioturbation, specifically bioexhumation and subsequent biodiffusion. The exponential decrease in zero-dose grains and cesium-137 both show that there is extensive downward particle movement in the near-surface environment in some profiles, and both methods indicate consistent yet subtle variations in the degree of this activity between the examined profiles. Extrapolation of short-term rates of particle diffusion from the zero-dose grains and cesium137 data yield anomalously high rates of particle exhumation and subsequent diffusion, which can be seen by the age structure of the sands in each sample.

\section{Processes Responsible?}

The fact that the matrix ages exhibit a consistent age-depth profile in all three columns suggests that disturbance processes are similar between the column locations and on a relatively small scale (close to or at the granular level), which implies that insects may play a significant role. The cesium and OSL zero-dose grain distributions are inconsistent with large animal disturbance but within expectations for activity by insects and worms.

That said, the clear downward dispersion of the artifacts, which are too big for most insects to move, indicates that fossorial animals were also at work, although their role in the last 60 years has been minimal in two of the three profiles. There is evidence from Profile 3 that largevolume movement of sediment is occurring, given the clear out-of-sequence age at $20 \mathrm{~cm}$ and the nearly uniform distribution of cesium-137 in the upper $20 \mathrm{~cm}$.

\section{Are Shallow Profiles More Disturbed?}

Where the depth to the B horizon is shallow, the age of the matrix at the subsoil interface is younger than it is where the sands are thicker. This most likely reflects the fact that thinner sola are more readily and completely overturned than thicker sola. That said, the age-depth relationships observed in the three profiles are almost identical and point toward a fairly consistent process.

\section{SUMMARY}

The results of detailed analysis of three soil columns from two archeological sites examined along the U.S. Highway 271 relief route around Mount Pleasant indicate that the main factor in archeological site burial is postdepositional pedoturbation. The high silt content of the sandy sediment is inconsistent with eolian deposition, and consistent mismatches between matrix and artifact ages could only have been created by disturbance. The numbers of recently reset sand grains in the top $30 \mathrm{~cm}$ of the solum indicate that downward biogenic sediment transfers are highly active and, at least in the recent past, primarily associated with small fauna. But the significant dispersion of the coarser artifact assemblage indicates that large disturbance processes (e.g., fossorial mammals, tree throws) have been at work as well. The results demonstrate the utility of methods such as single-grain OSL dating used in tandem with the depth distribution of temporally diagnostic artifact assemblages in revealing the complex formation processes associated with pedoturbation of soils, as has long been argued by Donald Johnson and his colleagues (Johnson et al. 1987, 2005). 


\section{REFERENCES CITED}

American Society for Testing Materials (ASTM)

1985 Standard Test Method for Particle Size Analysis of Soils. D-422-63 (1972). 1985 Annual Book of ASTM Standards 04.08:117-127. American Society for Testing Materials, Philadelphia.

Bateman, M. D., C. D. Frederick, M. K. Jaiswal, and A. K. Singhvi

2003 Getting to Grips with Bioturbation Using Luminescence. Quaternary Science Reviews 22:1169-1176.

Beer, J., M. Andreé, H. Oeschger, B. Stauffer, R. Balzer, G. Bonani, C. Stoller, M. Suter, and W. Wölfli

$1985{ }^{10} \mathrm{Be}$ Variations in Polar Ice Cores. In Greenland Ice Core: Geophysics, Geochemistry, and the Environment, edited by C. C. Langway Jr., H. Oeschger, and W. Dansgaard, pp. 66-70. Geophysical Monograph 33, American Geophysical Union, Washington, D.C.

Bouyoucos, G. J.

1962 Hydrometer Method Improved for Making Particle Size Analyses of Soils. Agronomy Journal 54:464-465.

Bray, R. H., and L. T. Kurtz

1945 Determination of Total, Organic, and Available Forms of Phosphorus in Soils, Soil Science 59:39-45.

Brinkman, R.

1970 Ferrolysis, A Hydromorphic Soil Forming Process. Geoderma 3:199-206.

1979 Ferrolysis, A Soil Forming Process in Hydromorphic Conditions. Agricultural Research Reports 887. Centre for Agricultural Publishing and Documentation, Wageningen, The Netherlands.

Bruseth, James E., and William A. Martin

2001 OSL Dating and Sandy Mantle Sites in East Texas. Current Archaeology in Texas $3: 12-17$.

Bush, D. A., and James K. Feathers

2003 Application of OSL Single-Aliquot and Single-Grain Dating to Quartz from Anthropogenic Soil Profiles in the SE United States. Quarternary Science Reviews 22:1153-1159.
Dearing, J. A., L. K. Hay, S. M. J. Baban, A. S Huddleston, E. M. H. Wellington, and J. P. Loveland

1996 Magnetic Susceptibility of Soil: An Evaluation of Conflicting Theories Using a National Data Set. Geophysical Journal International 127:728-734.

Dearing, John

1999a Environmental Magnetic Susceptibility Using the Bartington MS2 System. Electronic document, http://www.gmw.com/ magnetic_properties/pdf/omo409\%20J Dearing_handbook_1557.pdf.

1999b Magnetic Susceptibility. In Environmental Magnetism: A Practical Guide, edited by J. Walden, F. Oldfield, and J. Smith, pp. 35-62. Technical Guide No. 6. Quaternary Research Association, London.

Department of Energy

1990 EML Procedures Manual, HASL-300. 28th ed. HASL-300-ED.27-Vol. 1, Department of Energy, Environmental Measurements Laboratory, New York.

Duller, G. A. T

2008 Luminescence Dating: Guidelines on Using Luminescence Dating in Archaeology. English Heritage, Swindon, United Kingdom.

Faure, Gunter, and Theresa M. Mensing

2005 Isotopes: Principles and Applications. 3rd edition. John Wiley \& Sons, Hoboken, New Jersey.

Frederick, Charles D.

2005 Research Design for Testing of 11 Sites, U.S. Highway 271 Mount Pleasant Relief Route, Titus County, Texas (CSJ 0919-30027). Prewitt and Associates, Inc., Austin, Texas.

Frederick, C. D., and M. D. Bateman 2001 OSL Dating and Sandy Mantle Sites in East Texas: A Reply. Current Archaeology in Texas 3(2):14-18. 
Frederick, Charles D., Mark D. Bateman, and Andy Carr

2005 Evaluating the Formation Processes of Sandy Sites in Flat Landscapes at Avon Park Air Force Range. In Archaeological and Geomorphological Investigations on the Avon Park Air Force Range, Highlands and Polk Counties, Florida, by Michael Wilder and Charles D. Frederick. GeoMarine, Inc., Plano, Texas.

Fujiyoshi, R., and S. Sawamura

2004 Mesoscale Variability of Vertical Profiles of Environmental Radionuclides $\left({ }^{40} \mathrm{~K},{ }^{226} \mathrm{Ra}\right.$, ${ }^{210} \mathrm{~Pb},{ }^{137} \mathrm{Cs}$ ) in Temperate Forest Soils in Germany. Science of the Total Environment 320:177-188.

Gale, Stephen J., and Peter G. Hoare

1991 Quaternary Sediments: Petrographic Methods for the Study of Unlithified Rocks. Belhaven Press, London.

Gee, G. W., and J. W. Bauder

1986 Particle Size Analysis. In Methods of Soil Analysis, Part 1. Physical and Mineralogical Method. Agronomy Monograph No. 9 (2nd Edition), edited by Arnold Klute, pp. 383412. American Society of Agronomy and Soil Science Society of America, Madison, Wisconsin.

Hatfield, Virginia, Karl W. Kibler, and Ross C. Fields 2008 Interim Report on Eligibility Testing at 41TT6, 41TT846, 41TT847, 41TT851, 41TT852, 41TT853, 41TT854, 41TT858, 41TT862, 41TT865, and 41TT866, U.S. Highway 271 Mount Pleasant Relief Route, Titus County, Texas (Atlanta District: CSJ 0919-30-027). Prewitt and Associates, Inc., Austin, Texas.

Heimsath, Arjun M., John Chappell, Nigel A. Spooner, Danièle G. Questiaux

2002 Creeping Soil. Geology 30(2):111-114.

Horneck, D. A., J. M. Hart, K. Topper, and B. Loepsell 1989 Methods of Soil Analysis Used in the Soil Testing Laboratory at Oregon State University. Soil Monograph 89:4. Agricultural Experiment Station, Oregon State University, Corvalis.

Jacobs, Z., A. G. Wintle, R. G. Roberts, and G.A.T. Duller 2008 Equivalent Dose Distributions from Single Grain of Quartz at Sibudu, South Africa: Context, Causes and Consequences for Optical Dating of Archaeological Deposits. Journal of Archaeological Science 35:1808-1820.
Johnson, D. L., J. E. J. Dormier, and D. N. Johnson 2005 Reflections on the Nature of Soil and Its Biomantle. Annals of the Association of American Geographers 95(11):11-31.

Johnson, D. L., D. Watson-Stegner, D. N. Johnson, and R. J. Schaetzl

1987 Proisotropic and Proanisotropic Processes of Pedoturbation. Soil Science 143(4):278-292.

Johnson, Kristofer D., David R. Wright, and Richard E. Terry

2007 Application of Carbon Isotope Analysis to Ancient Maize Agriculture in The Petén Region of Guatemala. Geoarchaeology 22:313-336.

Kenmotsu, Nancy Adele, and Timothy K. Perttula (editors)

1993 Archeology in the Eastern Planning Region, Texas: A Planning Document. Department of Antiquities Protection, Cultural Resource Management Report 3. Texas Historical Commission, Austin.

Lecroart, Pascal, Olivier Maire, Sabine Schmidt, Antoine Grémare, Pierre Anschutz, and Filip J. R. Meysman

2010 Bioturbation, Short-Lived Radioisotopes, and the Tracer-Dependence of Biodiffusion Coefficients. Geochimica et Cosmochimica Acta 74(21):6049-6063.

Leigh, D. S.

1998 Evaluating Artifact Burial by Eolian Versus Bioturbation Processes, South Carolina Sandhills, USA. Geoarchaeology 13:309-330.

2001 Buried Artifacts in Sandy Soil:Techniques for Evaluating Pedoturbation Versus Sedimentation. In Earth Sciences and Archaeology, edited by Paul Goldberg, Vance T. Holliday, and C. Reid Ferring, pp. 269-296. Kluwer Academic, New York.

Maire, Olivier, Pascal Lecroart, Filip Meysman, Rutger Rosenberg, Jean-Claude Duchêne, Antoine Grémare

2008 Quantification of Sediment Reworking Rates in Bioturbation Research: A Review. Aquatic Biology 2:219-238.

Müller-Lemans, Hans, and Fritz Van Dorp

1996 Bioturbation as a Mechanism for Radionuclide Transport in Soil: Relevance of Earthworms. Journal of Environmental Radioactivity 31(1):7-20. 
Olsen, S. R., and L. E. Sommers

1982 Phosphorus. In Methods of Soil Analysis, Part 2, edited by A. L. Page, R. H. Miller, and D. R. Keeney, pp. 403-430. Agronomic Monographs 9. American Society of Agronomy, Madison, Wisconsin.

Otvos, Ervin G.

2004 Prospects for Interregional Correlations Using Wisconsin and Holocene Aridity Episodes, Northern Gulf of Mexico Coastal Plain. Quaternary Research 61:105-118.

Poreba, Grzegorz J.

2006 Caesium-137 as a Soil Erosion Traces: A Review. Geochronometria 25:37-46.

Schoeneberger, P. J., D. A. Wysocki, E. C. Benham, and W. D. Broderson (editors)

2002 Field Book for Describing and Sampling Soils. Version 2.0. Natural Resources Conservation Service, National Soil Survey Center, Lincoln, Nebraska.

Seifert, Christopher, L. Randel Tom Cox, Steven L. Forman, Tom L. Foti, Thad A. Wasklewicz, and Andrew T. McColgan

2009 Relict Nebkhas (Pimple Mounds) Record Prolonged Late Holocene Drought in the Forested Region of South-Central United States. Quaternary Research 71:329-339.

Smith, C. R., R. H. Pope, D. J. DeMaster, and L. Magaard

1993 Age-Dependent Mixing in Deep-Sea Sediments. Geochimica et Cosmochimica Acta 57:1473-1488.

Sweetwood, Ryan V., Richard E. Terry, Timothy Beach, Bruce H. Dahlin, and David Hixson

2009 The Maya Footprint: Soil Resources of Chunchucmil, Yucatan, Mexico. Soil Science Society of America Journal 73:1209-1220.

Taylor, M. D.

2000 Determination of Total Phosphorus in Soil Using Simple Kjeldahl Digestion. Communications in Soil Science and Plant Analysis 31:2665-2670.
Thoms, Alston V.

1995 Sediments and Natural Site Formation Processes at 41WT5. In The Anson Jones Plantation: Archaeological and Historical Investigations at 41WT5 and 41WT6, Washington County, Texas, edited by Shawn Bonath Carlson, pp. 107-132. Reports of Investigations No. 2. Center for Environmental Archaeology, Texas A\&M University, College Station.

Thoms, Alston V., and Ben A. Olive

1993 The ASTRC Landscape and Natural Site Formation Processes: Sandy Mantle Sediments and Reconstituted Cultural Stratigraphy. In The Brazos Valley Slopes Archaeological Project, edited by Alston V. Thoms, pp. 61-80. Reports of Investigations No. 14. Archaeological Research Laboratory, Texas A\&M University, College Station.

Thoms, Alston V., Ben W. Olive, and Patricia Clabaugh 1994 Disarticulation of the Valley Branch Site: Landscape Evolution and Natural Site Formation Processes. In The Valley Branch Archaeological Project: Excavations at an Archaic Site (41MU55) in the Cross Timbers Uplands, North Central Texas, edited by Alston V. Thoms, pp. 167-192. Reports of Investigations No. 15. Archaeological Research Laboratory, Texas A\&M University, College Station.

Tyler, A. N., S. Carter, D. A. Davidson, D. J. Long, and R. Tipping

2001 The Extent and Significance of Bioturbation on ${ }^{137} \mathrm{Cs}$ distributions in Upland Soils. Catena 43:81-99.

Van Ranst, E., and F. De Coninck

2002 Evaluation off Errolysis in Soil Formation. European Journal of Soil Science 53:513-519. 


\section{APPENDIX D: Historic Landscape Study}

Amy E. Dase and

Stephanie L. Katauskas 



\section{INTRODUCTION}

This report documents the methods and results of a historic landscape study incorporated into the National Register of Historic Places and State Antiquities Landmark eligibility testing of 11 prehistoric archeological sites in Titus County, Texas. Prewitt and Associates, Inc., performed this work under Contract No. 575XXSA006, Work Authorization No. 57553SA006, with the Texas Department of Transportation (TxDOT), Environmental Affairs Division, and Texas Antiquities Permit No. 4303 issued by the Texas Historical Commission. Planned construction of a relief route for U.S. Highway 271 around the southwest side of Mount Pleasant, Texas, necessitated the project.

Geographically, the study area is roughly bounded by U.S. Highway 67 on the north, U.S. Highway 271 on the southeast, Tankersley Creek on the west, and the City of Mount Pleasant on the east (Figure D.1). The landscape of the project corridor is dominated by the floodplain of Tankersley Creek, a major south-flowing tributary of Big Cypress Creek, and adjacent uplands east of Tankersley Creek. Landforms throughout the project area include floodplains, floodplain rises, toe slopes, upland slopes, and uplands. Stands of woods and open pastures dominate the landscape. Current land use in the project area consists of pastures, timber stands, and highway, utility, and railroad rights of way.

The primary intent of the historic landscape study is to determine historic occupation (ca. 1820-present) and land use that affected the study area over time and possible consequences to archeological features. The three goals were to document information about the landscape in the study area during the earliest period of Euro-American settlement, to determine whether available archival sources could identify locations of historic landscape features for periods subsequent to initial settlement, and to clarify the location of a Caddo cemetery known as the Thomas B. Caldwell cemetery. As described below, efforts to meet these goals, which were only partially successful, included a combination of archival and oral history research, with the former applying more to the first two goals and the latter relating solely to the third goal. The research began with a literature review of secondary sources on Titus County history and pertinent historic landscape studies in Texas and other regions of the country. Archival research included examination of land grant files, abstracts of title for land surveys, the county's official public records, and ad valorem tax records; manuscript slave, population, and agricultural decennial census records; and a series of historic aerial photographs and maps. Oral history research was limited to interviewing individuals knowledgeable about the histories of the land parcels situated near the possible location of the Caldwell cemetery.

This report consists of three main parts. The first addresses the methods and results of the research on reconstructing the landscape during the early period of Euro-American settlement and determining whether archival sources can identify landscape features for periods subsequent to initial settlement. The second addresses efforts to pinpoint the location of the Caldwell cemetery. The third provides a brief historic context that pertains to the study area and the county as a whole.

\section{THE LANDSCAPE DURING AND AFTER INITIAL SETTLEMENT}

In most parts of Texas, the changes that accompanied Euro-American settlement represented a dramatic shift in land use activities as well as the magnitude of landscape modification. Even where historic land use followed similar prehistoric practices (e.g., deforestation, cultivation, etc.), the scale of activity eventually, if not immediately, eclipsed prehistoric aboriginal activities. The relative contrast may have been less dramatic in the Caddo heartland than elsewhere in the state, as this region had been the seat of sedentary agricultural populations for a significant period prior to Euro-American incursion, unlike much of the rest of Texas. But because so many questions remain about the nature and magnitude of Caddo land use, it is difficult to form a solid image of the extent of this contrast.

The earliest Euro-American layout of space and subsequent restructuring can reveal much about values that change and those that retain a semblance of continuity. Even a small plot of ground can identify its occupant, give status, and establish relationships with the next plot over. Along with natural limits that waterways and topographic features define, fences, fields, roads, windbreaks, schools, dwellings, and indus- 


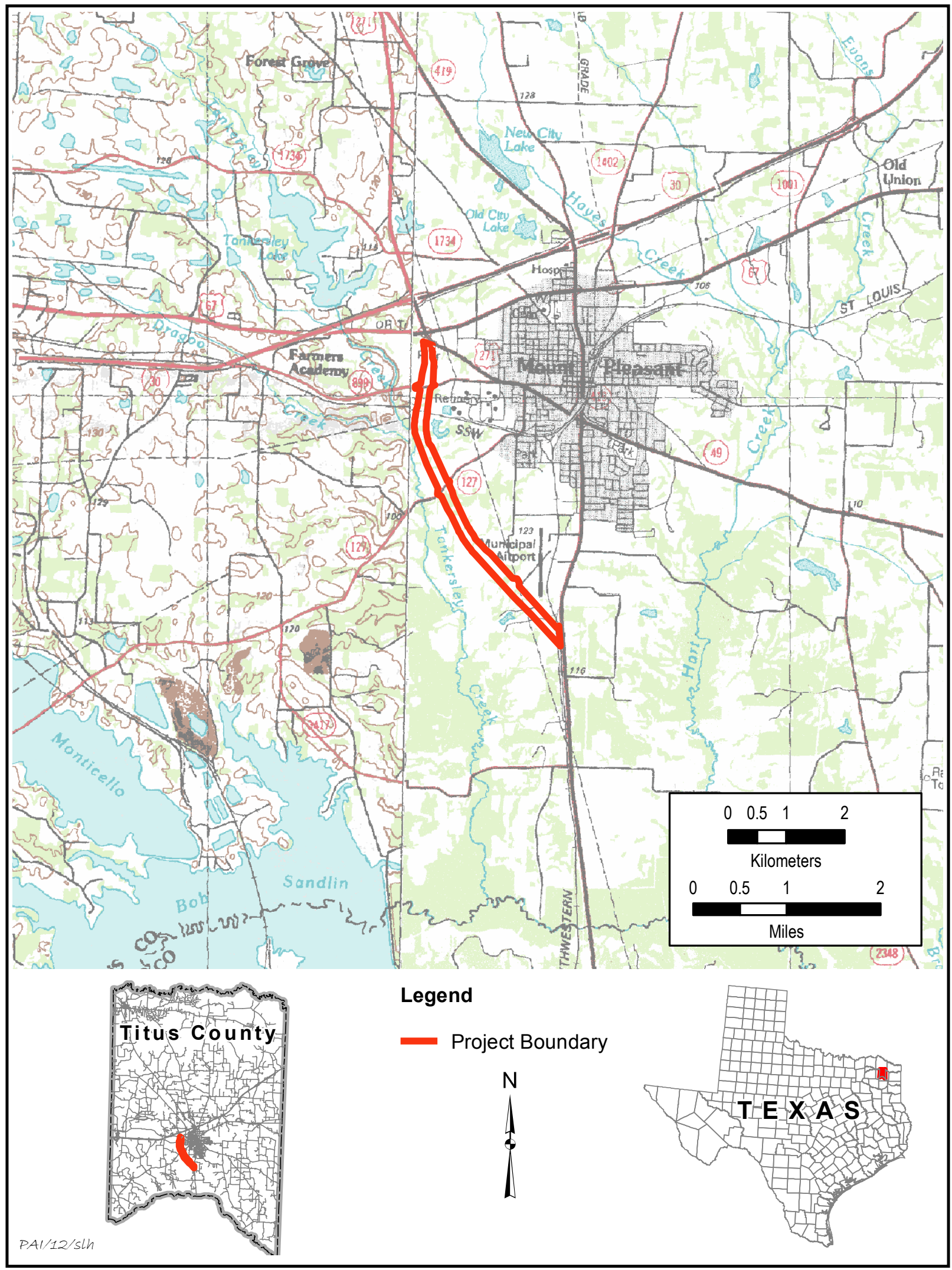

Figure D.1. Map showing the location of the historic landscape study area. 
trial complexes all have boundaries. Boundaries both divide one occupant from another and bind each together. A network of boundaries and the way a people living within them organize space reflect the shifting nature of priorities and culture. More importantly for this project, peeling back layers of information could convey how the environment of this place changed over almost two centuries.

Local records, when available, may reveal the size and location of land parcels, early speculative activity, and settlement patterns through time. Tracing ownership history and tax records, in conjunction with county-level agricultural decennial census data, may illustrate change or continuity in land use over time for each parcel. Early maps and county commissioner's and district court records may exhibit how plantations, farmsteads, roads, fencing, and drainage shaped the landscape. State and federal population censuses, both aggregate and manuscript, can monitor local demographic change that might have influenced land use as the result of ethnic affiliations, family size, and, before the Civil War, the slave population. Source materials available for the twentieth century, including historic aerial photographs and soil survey maps, can document agricultural activities.

The following research questions guided the literature review and archival research. How has vegetation in the project area changed in the historic period? How did land ownership, and therefore partitioning, and land use change through time? Do historic-period maps that include the study area identify specific land use information? As described below, results of the literature review and archival research unfortunately provided only very incomplete answers to these questions.

\section{Literature Review and Archival Research}

The literature review of Titus County history included investigating secondary sources and aggregate population and agricultural decennial census schedules. Only one known local history source was published before World War II (Russell 1937), and its contents are limited to narrative history. The initial literature review included several secondary sources on local history published between the 1960s and 1980s that were the basis for contemporaneous and more-recent cultural resources management reports, which merely encapsulate the dated secondary sources (Bell 1981; Blackard 1964; Brown and Gust 1976; Connor 1975; Cruse and Brownlow 1996; Ellis 1983; Embrey 1970; Glander and Bond 1986; Jurney 1961; Perttula and Nelson 2002; Prikryl et al. 1984; Quasqui Centennial Committee 1971; Russell 1965a, 1965b, 1974; Skokan 1994). In an attempt to address this data gap, additional materials were located through interlibrary loan.

The literature review identified secondary materials of pertinent historic landscape studies in Texas and other regions of the country. Known studies of interest could enlighten understanding layers of the study area's landscape with analysis of its agricultural, geographical, ecological, anthropological, and environmental history (Cowdrey 1996; Cronon 1983; Doolittle 2000; Goetzman 1966; Isaac 1982; Mangelsdorf 1974; Meinig 1986, 1993; Rippon 2004). It was anticipated that additional landscape studies, likely those more relevant to this study area, would be located and reviewed, but limitations of archival research precluded the need to pursue other sources.

Archival research included examination of land grant files, abstracts of title for land surveys, the county's official public records, and ad valorem tax records; manuscript slave, population, and agricultural census decennial records; and a series of historic aerial photographs and maps. Research at the Texas General Land Office provided insight about who initiated land surveys in the study area, and when they did so (Miller 1967, 1972). Specific natural and manmade witness points defining the periphery of each survey were extracted from the field notes of each land grant. Witness points included the types, numbers, and, sometimes the diameter of trees and waterways that intersect and mark survey boundaries.

Research related to official public records was completed in Mount Pleasant and Austin. Abstracts of title for the eight land grants in the study area were examined at Greene Title and Abstract, a company with longstanding tenure in Mount Pleasant. The abstracts of title typically noted grantors, grantees, date of transaction, and volume and page number of the official public record, at a minimum. In some cases, boundary descriptions, though cryptic, were included in the abstracts of title (Greene 
Title and Abstract). Research on Titus County official public records was completed at the county clerk's office to the degree possible. Deeds, probate, commissioner's court, and district court records that predate 1911 were almost exclusively those relaying State of Texas patents, and not conveyances of land between property owners. Twentieth-century official public records were intact at the clerk's office and provided complete chain of title documentation for that era. Ad valorem tax records were available from 1846 to 1910 at the Texas State Library and Archives (Titus County Official Public Records).

Manuscript census records were briefly consulted for the decennials 1850-1930. The population census enumerates detailed demographic and personal information, such as an individual's name, gender, race, age, kinship, native state or country, occupation, education and literacy levels, and property ownership. The slave census, for the 1850 and 1860 decennials, provides limited demographic and personal information about the slave population. The agricultural decennial census is only available for 1850-1880 and enumerates information specific to all but the smallest farms; for example, in 1850 farms that produced less than $\$ 100$ of products were excluded. By 1870 , farms of less than three acres or that produced less than $\$ 500$ of products were excluded. Beside each listed farm owner or manager is number of improved and unimproved acres and cash value of the farm, farming machinery, livestock, animals slaughtered during the past year, and homemade manufactures. The manuscript data also indicate numbers of specific livestock owned and crops raised. The 1880 schedules provide additional details, such as the amount of acreage for each crop, number of poultry, and number of eggs.

Graphic sources were consulted for additional primary documentation. After a careful search, it became apparent that few maps of the study area were available (Anonymous [1858]; Morris and Armstrong 1948; Rice and Watson 1909; Texas State Highway Department 1940, 1961) An aerial image dating to 1935 was consulted (Tobin International 1935).

Endeavors to locate several additional archival sources were unsuccessful. Early Department of Agriculture records that might contain manuscript soil survey field sheets developed in Titus County ca. 1909 either do not exist or are not cataloged for access, according to staff of the National Archives and Records Administration. The Fairchild Aerial Survey, Inc., collection at Whittier College, California Institute of Technology, and other facilities had no known aerial images of the study area. Relevant twentieth-century materials of the Texas Commission on Environmental Quality and the Environmental Protection Agency would require access through the Freedom of Information Act, but personnel at the agencies suggested the limited amount of useful information would likely not reveal the kinds of information sought for understanding changes to the study area's landscape.

\section{Results}

The literature review of local history sources revealed that, almost without exception, these publications are colloquial, narrow in concept, and suggest neither interpretation nor analysis. Still, several sources parallel each other, repeating narrated events-local, state, and national-as they affected Anglo American residents, particularly local men who were of means. They deliver adequate and accurate basic facts. This leaves a void, however, not only in interpretation and analysis, but also depiction of both the local African American presence, which exceeded 20 percent of the county's total population between 1860 and 1900, and the female population, which generally comprised half of the county's total population. Aggregate population and agricultural census schedules furthered understanding of these unexplored subjects. More-recent publications supplemented knowledge of local African Americans and women and enhanced, if nominally, previously unaccounted for analysis and interpretation (Campbell 1989; City of Mount Pleasant 2007; Jones 2005; Harper 2001, 2006; Kirby 2001; Kurimski 2007; Laing 2003; Reynolds 2007a, 2007b; Russell 2001a, 2001b, 2007). These materials provided enough information to prepare a brief historic context that pertains as much as possible to the study area, but applies broadly to the county as a whole; the final section of this report presents this context.

More recently published and more regionally similar historic landscape studies would have augmented and refined the appropriate theoretical approach to this study area, if enough 
reliable archival documentation had been found to justify expanding insights into these types of sources. However, the limited results of the archival research efforts diminished the need to do this; therefore, additional studies were not consulted.

Archival research led to disappointing results. Eight land grants encompassing almost 4,800 acres traverse the study area: the John Greenwood, Shem Harris, L. M. Jones, P. M. Otwell, Ambrose Ripley, William Stokes, John Thompson, and John Watson Surveys (Texas General Land Office 1845, 1853, 1855a, 1855b, 1857, 1859a, 1859b, 1860a, 1860b, 1861) (Figure D.2). Only a handful of land grant surveys were patented before 1850 in present-day Titus County, none of which are in the study area. Many patents for local land grants, including all of those in the study area, were made in the 1850 s and 1860s. Several who held land in the study area also owned other local parcels, and some had holdings elsewhere in the state.

These eight land grants were initially surveyed during a span of more than 50 years; three of them were surveyed before 1840, and five of them were surveyed between 1853 and 1855 . Clustering the land grants in the study area into these two periods, and accounting for and comparing witness points between and among them, revealed no meaningful patterns (Tables D.1 and D.2). Post oak, blackjack oak, hickory, and red oak were the predominant trees used as witness points, generally mirroring results from another study that was conducted in Titus and Camp Counties (Perttula 2005:13-15).

With witness points limited to peripheral boundaries, this information does not convey attributes of the broader historical landscape among or between time intervals, which makes the total number of witness points so small that the data cannot be construed as statistically significant for representing almost 4,800 acres. The types of witness points evident on these particular land grants did not extend to roads, fences, or other identified features that might reasonably expand understanding of the historic landscape. Overall, the information collected in this part of the study provides neither the quantity nor quality of data necessary for understanding vegetation patterns in the study area in the $1850 \mathrm{~s}$. Additional study to include other surrounding land surveys and thus try to put the current study area in its broader geo- graphic context would not necessarily provide useful information based on the presumption that these would also convey a relatively low number of witness points.

Most of Titus County's early official public records burned in an 1895 courthouse fire. In only a few cases did landowners refile deeds recording their holdings. Deeds that predate 1911 are almost exclusively those relaying State of Texas patents in the study area, and not conveyances of land between property owners. As a result, documenting historical ownership of the land in any part of the county, from its 1846 founding until about 1900 , is almost impossible. To contend with this limitation, abstracts of title were considered potentially useful, although nineteenth-century chain of title documentation still could not be demonstrated. Efforts to document chain of title were made for about half of the 48 land parcels in the study area. Of the approximately 24 parcels researched, most have no related official public records on file with the county clerk that predate 1925 . The chain of title on 2 parcels could be traced back to 1917, and 1 chain of title could be traced to 1911. Ultimately, with so many conveyances having similar names on proximate parcels of land, it was not possible to link the owners to the parcels through official public record research.

Ad valorem tax records were the last resource reviewed in hopes of linking owners and their land use activities to land parcels. Between 1846 and about 1880, the tax records do not clearly indicate which activities (e.g., numbers of livestock, value of improvements) occurred on which of the several parcels a landowner held, again reducing opportunities to connect historical ownership with land use.

Without a physical link between landowner and land, manuscript census records can only produce limited results. For example, Martin $\mathrm{H}$. Barnett owned several slaves in 1850, and he was farming on the 200-acre L. M. Jones Survey patented to him, but the value of that tract was lumped with his many other local land holdings, which, in sum, were valued at $\$ 40,000$ that year. The location of his family's residence, those of his slaves, and the locations of crops and livestock cannot be accurately plotted in the study area or elsewhere. Thus, the demographics can be enumerated, but monitoring where and how they changed the study area are not possible. Nevertheless, manuscript population data was 


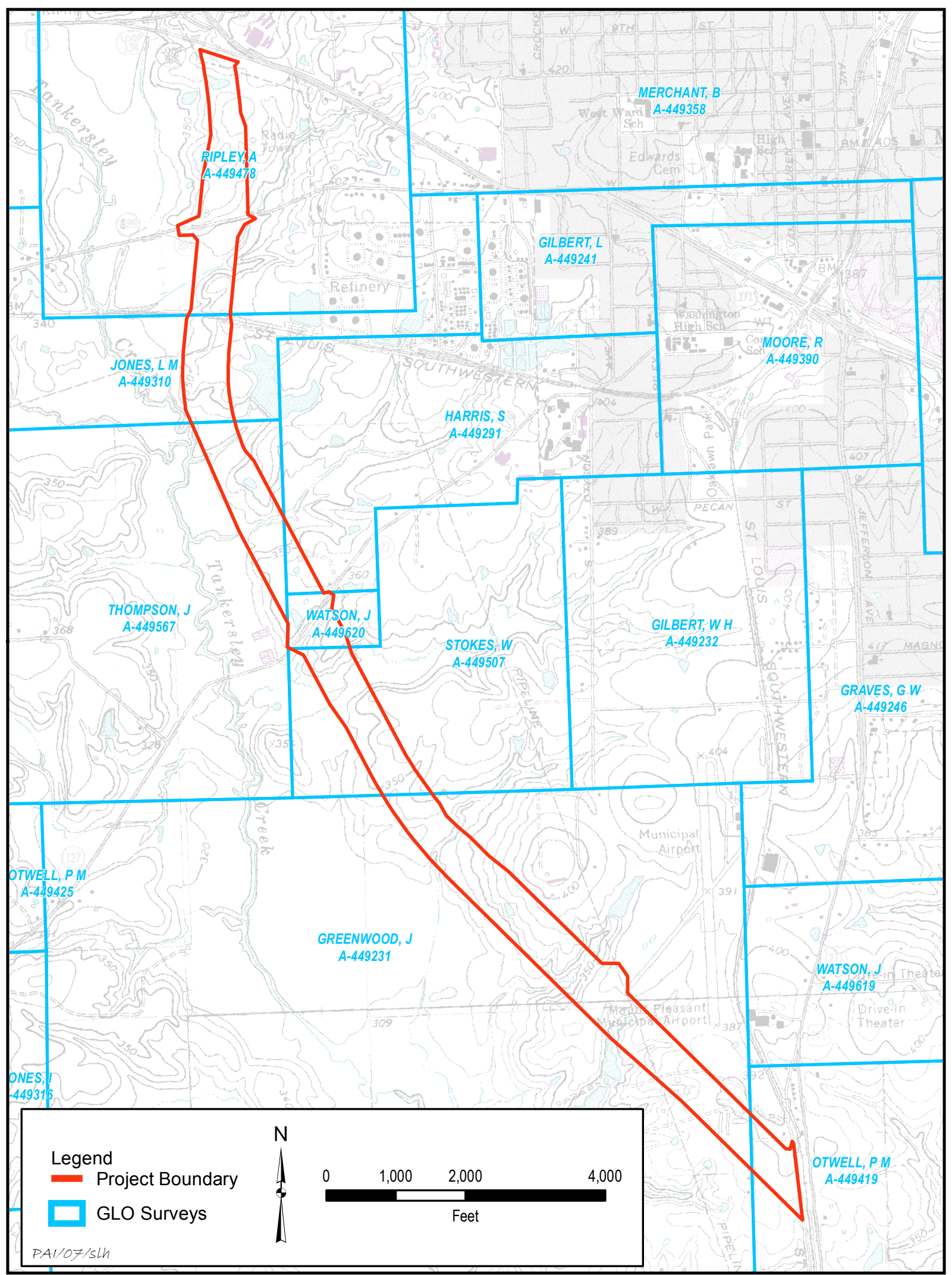

Figure D.2. The historic landscape study area superimposed on an excerpt from a 1949 map showing Texas General Land Office surveys (Morris and Armstrong 1949). 
Table D.1. Trees as witness points on land grant surveys in the historic landscape study area

\begin{tabular}{l|c|c}
\hline \multicolumn{1}{c|}{ Land Grant } & $\begin{array}{c}\text { Acreage of } \\
\text { Land Grant }\end{array}$ & $\begin{array}{c}\text { Number of } \\
\text { Trees }\end{array}$ \\
\hline $\begin{array}{l}\text { John Greenwood } \\
\text { Survey }\end{array}$ & 2,302 & 9 \\
\hline $\begin{array}{l}\text { Shem Harris } \\
\text { Survey }\end{array}$ & 320 & 20 \\
\hline $\begin{array}{l}\text { L. M. Jones } \\
\text { Survey }\end{array}$ & 200 & 19 \\
\hline $\begin{array}{l}\text { P. M. Otwell } \\
\text { Survey }\end{array}$ & 320 & 7 \\
\hline $\begin{array}{l}\text { Ambrose Ripley } \\
\text { Survey }\end{array}$ & 640 & 8 \\
\hline $\begin{array}{l}\text { William Stokes } \\
\text { Survey }\end{array}$ & 320 & 13 \\
\hline $\begin{array}{l}\text { John Thompson } \\
\text { Survey }\end{array}$ & 640 & data \\
\hline $\begin{array}{l}\text { John Watson } \\
\text { Survey }\end{array}$ & 27 & 8 \\
\hline Total & 4,769 & 84 \\
\hline
\end{tabular}

Table D.2. Type and number of trees as witness points on land grant surveys in the historic landscape study area

\begin{tabular}{l|c|c}
\hline \multicolumn{1}{c|}{ Type of Tree } & Number & Percent \\
\hline Ash & 2 & 2.4 \\
\hline Blackjack oak & 17 & 20.2 \\
\hline Elm & 1 & 1.2 \\
\hline Hickory & 17 & 20.2 \\
\hline Linn & 1 & 1.2 \\
\hline Post oak & 26 & 31.0 \\
\hline Red oak & 14 & 16.7 \\
\hline Walnut & 2 & 2.4 \\
\hline White oak & 2 & 2.4 \\
\hline Willow oak & 2 & 2.4 \\
\hline Total & 84 & 100.0 \\
\hline
\end{tabular}

collected for those individuals known to have been property owners to provide some level of understanding about those who held land in the study area (U.S. Department of the Interior, Census Office). This provided some, though limited, depth to the brief historic context that concludes this report.

Graphic sources revealed limited useful information for understanding the landscape of the study area. No nineteenth-century map provides information at a useful scale. The earliest map with details about the study area dates to 1909 and shows local roadways and soil types but only a few buildings that intersect the study area (Figure D.3). It was the mid-1930s before another map with detail of the study area was produced, and it was largely limited to roadways, waterways, and a few buildings (Figure D.4). An aerial image dating to 1935 was consulted (Tobin International 1935). It shows the most detail about land use in the study area (i.e., mostly cleared and under cultivation or in pastures). However, its application to understanding land use is limited to an isolated period that is very late in the historic period.

It was hoped that compiling information on how Euro-American use of the landscape in the study area-from earliest settlement, to later plantations and yeoman farms, to the gradual shift to industrial/agribusiness land use-could provide a coherent image of how the landscape continued to evolve after the Caddo were removed from their ancestral lands. However, both the limited quantity and unsatisfactory quality of the available archival records preclude ably documenting historic occupation and land use over time, much less possible consequences to archeological features.

\section{THE LOCATION OF THE THOMAS B. CALDWELL CEMETERY}

Archeologists from The University of Texas at Austin excavated a prehistoric Caddo cemetery, known as the Thomas B. Caldwell cemetery, in 1934 (Goldschmidt 1934, 1935). The site was assigned the trinomial 41TT6. Long after the excavations, 41TT6 was plotted on modern U.S. Geological Survey topographic maps at the Texas Archeological Research Laboratory as being on an upland interfluve that is within the proposed right of way for the U.S. Highway 271 relief route (Figure D.5). However, based on investigations in 2002, Perttula et al. (2002) noted that this plotted location conflicts with the original description provided in the excavation report. This discrepancy and information from current landowners suggest that the true location of the cemetery was about $300 \mathrm{~m}$ west of the plotted location, on a site now recorded as $41 T T 846$ (see Figure D.5). This potential location is outside the proposed U.S. Highway 271 relief 


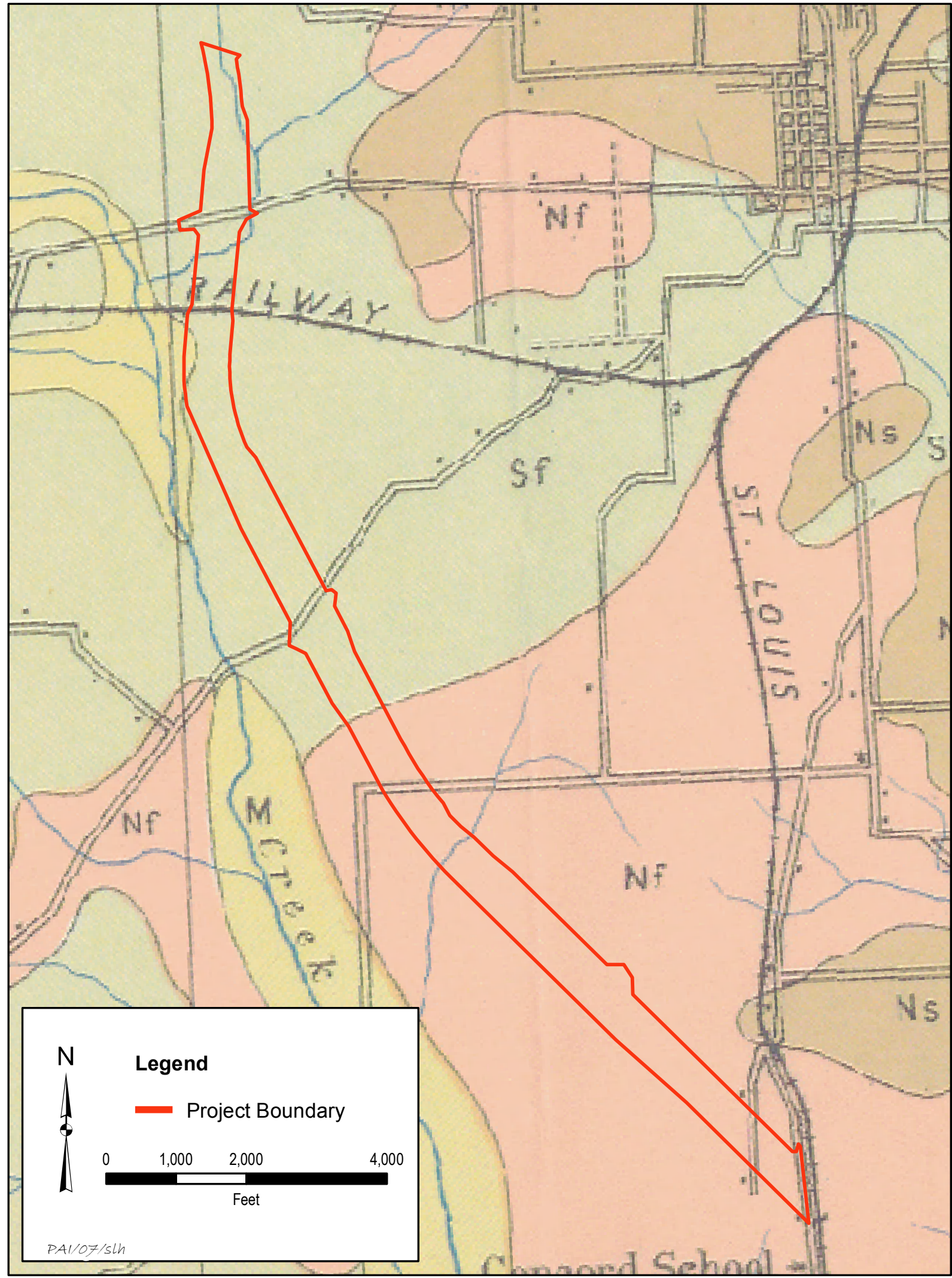

Figure D.3. The historic landscape study area superimposed on an excerpt from the 1909 soil survey map (Rice and Watson 1909). 


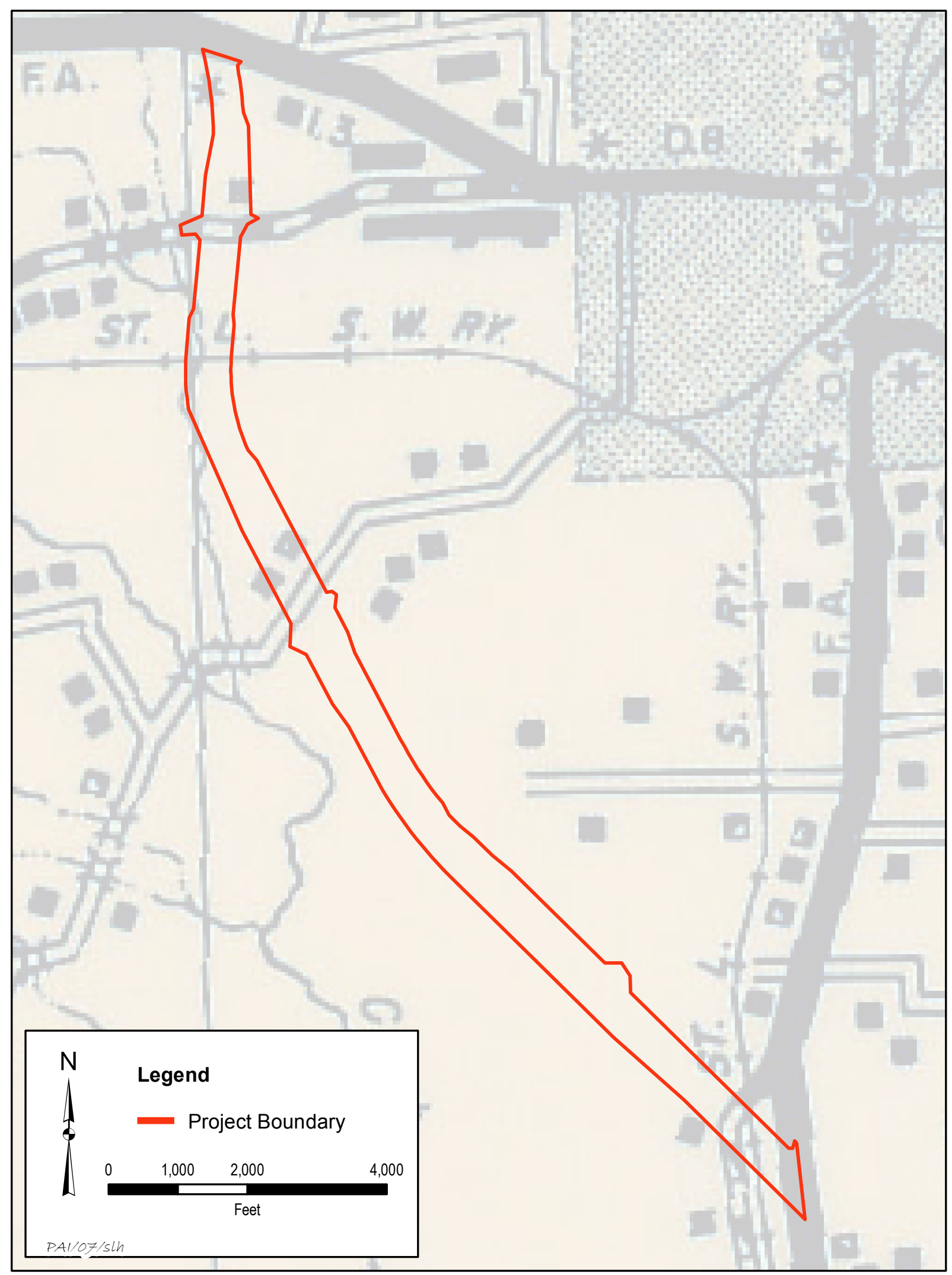

Figure D.4. The historic landscape study area superimposed on an excerpt from the 1936 State Highway Department map (Texas State Highway Department 1940). 
Figure D.5. Plotted, but likely inaccurate, location of the Thomas B. Caldwell cemetery (as 41TT6) on the Timothy McAlester et ux land parcel, and suggested true location of the cemetery as part of 41TT846 on the Charles S. Caldwell et al. and Priefert Development Corporation land parcels. 
route right of way by about $90 \mathrm{~m}$. Research, therefore, included efforts to resolve this discrepancy with archival and oral history sources to determine if any unexcavated portion of this cemetery might remain in the project area.

\section{Archival Research}

Archival research intended to document the true location of the Caldwell cemetery was conducted at the Titus County Clerk's office in Mount Pleasant and at Texas A\&M UniversityCommerce. Because the county's official public records had burned in an 1895 courthouse fire, only twentieth-century ownership of the three adjacent land parcels could be recounted to determine if any document about these parcels referenced the Caldwell cemetery and its location. Three parcels that intersect close to the likely true location of the Caldwell cemetery are referred to herein. One tract is identified as the Timothy McAlester et ux parcel, on which part of 41TT6 was initially plotted, likely inaccurately, and that contains part of 41TT846. A second tract is identified as the Charles S. Caldwell et al. parcel, on which part of 41TT846 is situated; the 1934 excavation report indicates that the cemetery was near the east edge of this parcel (Goldschmidt 1934). The third tract is identified as the Priefert Development Corporation parcel, on which the north part of 41TT846 is situated (see Figure D.5). No twentieth-century warranty deed, deed of trust, lis pendens, or probate file relevant to these three parcels references a cemetery. Local newspapers were reviewed for mention of the 1934 excavations but revealed no information about the cemetery or its location.

Archival research did reveal information about previous owners of these three land parcels. The Timothy McAlester et ux parcel was once part of Theophilus A. Jackson's holdings out of the John Greenwood Survey, and commonly referred to as the Jackson home place (Texas General Land Office 1855c; Titus County Abstract of Title; Titus County Deed Records). Born in Alabama, Jackson was a 40-year-old widower by 1860, when he farmed in Upshur County and was raising two small daughters. By 1880, Jackson resided in Titus County with his brother. Twenty years later, Jackson was farming on land he owned with help from his widowed daughter and her three children (U.S. Department of the Interior, Census Office
1860, 1880, 1900a). The Charles S. Caldwell et al. and Priefert Development Corporation parcels were once part of Thomas Buncombe Caldwell's holdings out of the John Greenwood and William Stokes Surveys (Texas General Land Office 1855c, 1861; Titus County Abstract of Title; Titus County Deed Records). Caldwell had been in the county since the 1870s, and it is likely he occupied this or one of his other rural land holdings in Titus County until sometime between 1900 and 1910, by which time he and his wife, Bessie Slaughter Caldwell, had moved to Mount Pleasant (U.S. Department of the Interior, Census Office 1880, 1900a, 1910a).

\section{Informant Research}

Interviews were conducted with several individuals to determine if they had knowledge of either the Caldwell cemetery or the original excavation of that cemetery. Informant candidates were local people familiar with various parcels of land on which the Caldwell cemetery might be situated. Knowledgeable informants were Bill Priefert's administrative assistant at the Priefert Development Corporation; Joyce Caldwell, wife of Charles S. Caldwell; Sam Russell, attorney for the Margaret Caldwell Hart estate; and Timothy McAlester. Most were unaware of the Caldwell cemetery or its location, with the exception of Joyce Caldwell. She indicated that her husband, Charles S. Caldwell, was a child when the excavation took place and knew its location. Mrs. Caldwell had been informed several years ago about the location of the excavations, and indicated she might be able to point out its general location. In a subsequent interview, Mr. Caldwell recalled being at the excavations when he was a boy, and both he and his wife indicated that they took place near the northeast corner of Thomas Caldwell's holdings, which is the location of the western part of 41TT846. The Caldwells were unable to visit and confirm the location on the ground, but they readily identified it on a modern aerial photograph.

\section{Results}

No conclusive proof in either the archival or oral record documents the location of the Caldwell cemetery. However, available information points to a location straddling the boundary between the Charles S. Caldwell et al. and 
Priefert Development Corporation land parcels. This is based mostly on Charles Caldwell's memory of the excavation location, which is supported by the fact that the Caldwell family owned both of these parcels in 1934, but not the McAlester parcel to the east where 41TT6 is plotted. A 1935 aerial photograph further supports the revised location of the Caldwell cemetery since it shows an area of disturbance about the same size as the 1934 excavations straddling the east-west fence line between the Caldwell and Priefert Development Corporation parcels. Figure D.6 depicts the excavations, as shown in the 1934 report, superimposed over this disturbed area. Although the excavation plan cannot be georeferenced, it matches the size and position astride the property line of the disturbed area.

\section{HISTORIC CONTEXT FOR THE STUDY AREA}

The heavily forested landscape of what would become Titus County remained substantially unexplored until the early nineteenth century. Anglo American settlement was slow to take permanent hold but proceeded as an outgrowth movement from the quickly crowding Louisiana, Arkansas, and south-central Texas regions. Local availability of land and establishment of travel routes overland, such as the Cherokee Trace, and along rivers on steamboats to inland ports like Jefferson, drew settlers to the area. Once in Titus County, newcomers encountered the remaining native groups. Tensions and conflict arose from the frequent talk of relocating Native Americans (Jurney 1961:15; Russell 1965a:42). To protect against Indian raids, the settlers built an unnamed fort 3 miles north of Winfield. Two-thirds of the brick fort was below ground. Each side of the above-ground section had loopholes from which to shoot (Jurney 1961:15). It was obvious, however, that more protection was necessary. In 1838, Captain W. B. Stout and 38 men established Fort Sherman on the Cherokee Trace 1 mile north of the Cypress Creek crossing and 13 miles southwest of the future site of Mount Pleasant. The stockade fort, built of 10-inch logs, enclosed a large area that had several houses (Russell 1965a:44-45; Russell 2001b).

The earliest known Anglo American local settler to the area was Kendall Lewis. A native of Virginia, he was raised in Choctaw Indian country in western Georgia. There, he married Kizah Cornells, a half-breed Creek Indian. The Lewis family came to Texas in the early 1830 s and settled on the Choctaw Trail. Soon after, Lewis moved his family 7 miles east of what would become Mount Pleasant, on Swauano Creek. Their house became a stop for Choctaws, Caddos, traders, and others travelling the Choctaw Trail, and their adequate supply of pioneer travelers' needs transformed their home into an informal trading post. Lewis was said to have owned the first tract of land surveyed in the county on March 30, 1838. He became a successful trader of land certificates, buying and locating them. Surveys bearing his name are in Bowie, Red River, Franklin, Lamar, Fannin, and Titus Counties (Russell 2001a).

Although Lewis apparently had a good relationship with local Native Americans, most American settlers who came to the region were suspicious of both full- and half-blood Indians, as well as Anglo Americans who had close associations with them. A neighbor of the family believed "[Lewis] was a white man turned Indian, wore a blanket like an Indian, dressed like one, acted like one and always had a bunch of Indians hanging around his house." Continued local conflict between settlers and Indians furthered distrust of the family, especially after Indians murdered another settler's family in 1841. The Lewis family's alliances with Indians proved suspect in the aftermath of this attack, and they were forced to move to the Choctaw Nation in Oklahoma the following year (Perttula and Nelson 2002; Russell 1965a:3-4; Russell 2001a).

Ambrose Ripley came to Texas from Madison County, Alabama, in the 1830s with his wife, Rachel Wood Ripley, and extended family. In 1837, Ripley established a home at the junction of the Nacogdoches Road (formerly referred to as the Cherokee Trace) and Choctaw Trail, on a stream now known as Ripley Creek. On April 10, 1841, while Ripley was away surveying land, Indians attacked his farmstead, killing his wife, a son and daughter, some small children, and a servant. Two daughters escaped to a neighboring farm for help. About 80 men organized to search for those responsible. They found a band of Indians in Wise County and recovered several possessions believed to be from the Ripley home, including horses and cooking utensils (Jurney 1961:16; Russell 1965a:4). Ripley remarried and 

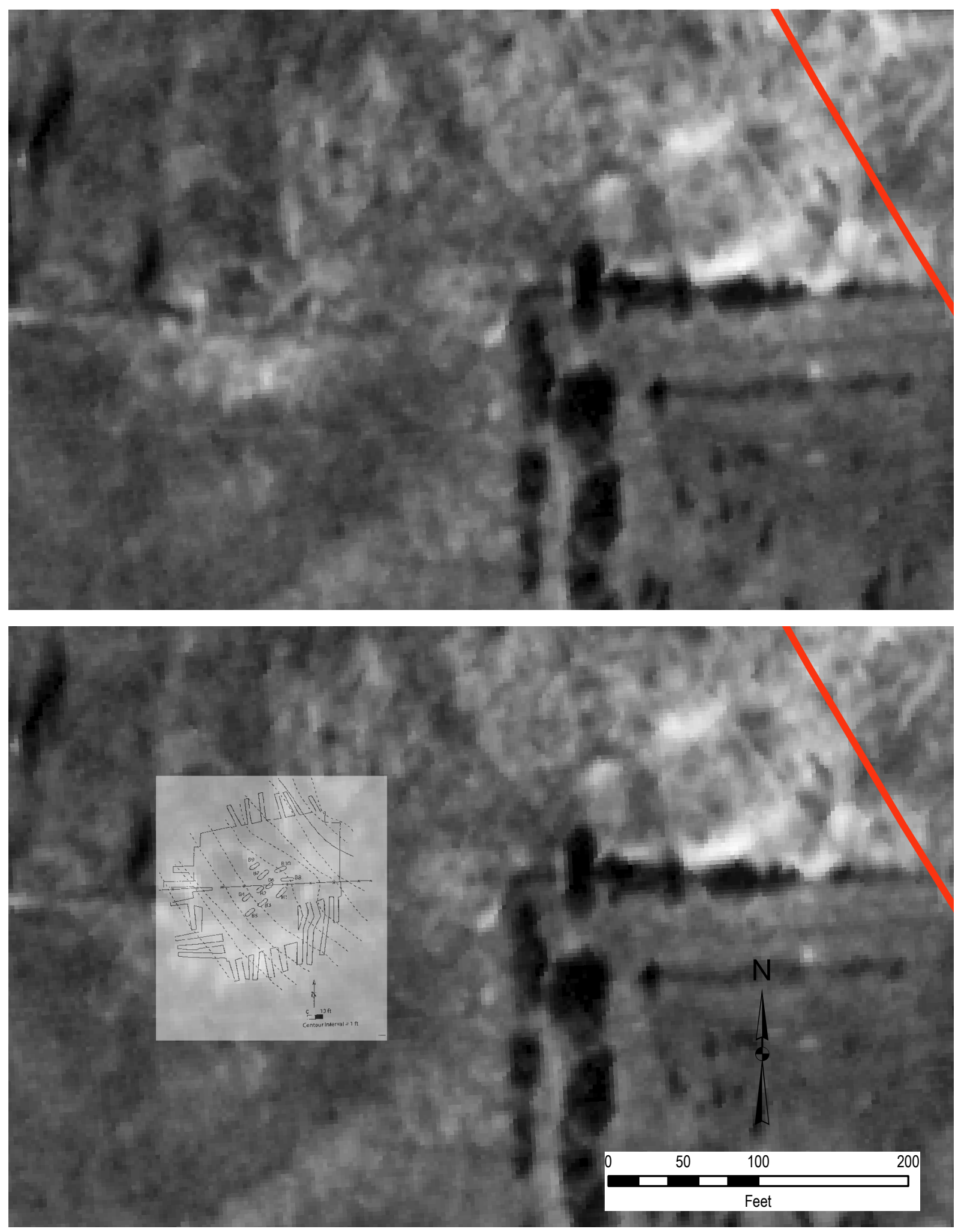

Figure D.6. A 1935 aerial photograph of the likely location of the Thomas B. Caldwell cemetery with the 1934 excavation superimposed (lower image). 
became quite successful in Mount Pleasant. He resided in Titus County until at least the $1850 \mathrm{~s}$, when he may have moved westward with his children to Hunt County (U.S. Department of the Interior, Census Office 1850, 1900b, 1910b).

By the 1840 s, Indians were mostly eradicated in the area between the Sulphur and Sabine Rivers, and more families began to move into the vicinity. Settlers, who mostly traveled by oxen-pulled wagons, found a mild climate, good potable water, plentiful timber sources, and abundant wild game (Jurney 1961:15, 18; Prikryl et al. 1984). Many families who settled in the area descended from the Lowland South, primarily Alabama, Mississippi, and Georgia, and were not members of the upper, slaveholding class. Instead, they were yeoman farmers who came to Texas seeking opportunity for owning land. Upon arrival, settlers utilized building methods with which they were familiar. The first homes they built were usually modest one- or two-pen log buildings. As soon as they could, settlers improved these original dwellings or built new ones. Common improvements were adding pens, some with an open "dog trot" between, enclosing the dog trot, or cladding the log exterior with wood siding. Chimneys were composed of sticks and mud. Later versions of dwellings might have a side-gable orientation and full-length front porch. This house type was prevalent on small farms in the region, and after a prominent Texas architectural historian called it the East Texas House, others studying the discipline adopted the term to describe this ubiquitous form (Alexander 1966; Russell 1937:135-137).

Titus County was isolated in the early years after its establishment. On the frontier, settlers had no stores, churches, schools, or sources of news. Farmers were generally self-sufficient and assembled, prepared, or constructed every item they needed. They made their own tools for farming and livestock management. Tallow candles or pine knots were burned to provide lighting. Brush or split log rails created fencing to bound their farms. Settlers grew their own subsistence and feed crops, including corn, oats, and potatoes. Clearing the forested land proved difficult, but every year local farmers cleared more land for cultivation (Jurney 1961:17, 20; Skokan 1994).

Henry W. Jones Sr. came to Lamar County, Texas, from Kentucky in the late 1830s. Jones settled in Titus County around 1840 . He pat- ented 640 acres southeast of Mount Pleasant and two tracts of 320 acres each in northeast Titus County on the Sulphur River. One of his tracts was "on the road from Hugh's to Kendall Lewis', who lived on Swauano Creek. Jones operated the first ferry in Titus County on his Sulphur River tract and later built a toll bridge known as Jones's Crossing. He built a log cabin on the south side of present-day Lide Avenue, north of Dellwood Park. A successful farmer, Jones amassed much acreage in Titus County, including land in the study area. After the Ripley murders, he joined the group in pursuit of the Indians and also fought the last Indian battle in Titus County along Harts Creek. The first district felony case in the county was held at his house in 1846. His daughter, Mattie Jones, married William Nugent, who was later associated with the study area (Russell 1965b:28, 56-57; Russell 1974:155-156).

Although settlement was sparse, enough people lived in the area to justify the formation of a county. The first state legislature established Titus County, which also included all of present-day Morris and Franklin Counties, in 1846. The county was named for Andrew J. Titus, an influential Republic of Texas statesman and a leader in the effort to secure statehood. Titus came to Texas with his father in 1832 on a government mission to resettle Choctaw and Chickasaw Indians to Indian Territory (Laing 2003; Russell 1937:4). The younger Titus settled near Clarksville and opened the Clarksville-toJefferson Road. This corridor linked Red River County to Jefferson by way of Mount Pleasant (Jurney 1961:24). The road made possible transport of goods to and from Jefferson, which, previously, could only be reached by riverboat. By 1847, the county's population had reached 2,440 (Harper 2001).

A commission appointed to select a central location for the county seat chose Mount Pleasant. Daniel McCall platted the new town along the cardinal directions in a grid pattern, five blocks wide and nine blocks long, with a courthouse square in the middle. The 1859 courthouse was built of logs. A two-story brick building later replaced the log building. Caddo Indian legend credits the name of the city to mounds in and near the original town site. Many Indians knew of the "great mound," and they started calling it the happy, or pleasant, mound in their language. Early settlers repeated the 
name, first calling the general area Pleasant Mound, then finally naming the town Mount Pleasant (Jurney 1961:26, 94).

Most settlers who arrived in Titus County came from the southern states and brought their traditions and cultural practices, including slavery, to Texas. In fact, the slave population in the county grew faster than the Anglo American population in the antebellum period. The slave population grew from 243 in 1846 to 448 in 1850 (Campbell 1989:266; Harper 2001). Martin H. Barnett owned a large plantation in the county. He came to Texas from Tennessee, established a farm on Green Hill, and had a residence in Mount Pleasant as well (Russell 1937:160). At its height, Barnett's plantation had between 25 and 40 slaves working the land. His son, J. R. Barnett, acknowledged that the slaves had difficult work and poor living conditions (Jurney 1961:29-30; Russell 1937:23).

Titus County's economy was almost entirely based on agriculture in 1850 . Corn was the most important feed crop, and cotton was the most important cash crop. Less than half of local landowners (43 percent) operated with 20 acres or fewer in cultivation; the rest ( 67 percent) had more than 20 acres. The county's 269 farms produced 66,000 bushels of corn and 292 bales of cotton in 1850. Cattle, sheep, and hogs were a prevalent part of the local agricultural landscape, and that same year farmers reported 6,838 cattle, 1,014 sheep, and 12,315 hogs. Allowed to graze on the open range most of the time, animals, mainly hogs, were butchered when autumn weather turned cool, usually providing enough meat for the rest of the year (Harper 2001; Jurney 1961:20, 27-28).

Population growth expedited changes to the local agricultural economy. Between 1850 and 1860 , the county's population increased from 3,636 to 9,648 . Farmers continued to raise their own foodstuffs to support their families, slaves, and livestock, but many participated in the rapidly developing market economy. Participation depended, in large part, on the labor of slaves. Between 1850 and 1860, the slave population grew markedly from 448 to 2,040 ; in four years time, just before the end of the Civil War, the county's slave population peaked at 3,580 (Campbell 1989:266; Harper 2001).

As the Civil War loomed, county residents voted in favor of secession, but it was not an overwhelming majority: 411 to 285 . Eight companies and one reserve company formed in Titus County in 1861; another company formed two years later. Some local historians maintain that more than 1,500 Titus County men served the Confederacy-but not all joined the fight in Texas. Many went to the southeastern states of their origin, since threats to their native land were more serious those than in Texas (Harper 2001; Russell 1937:9). Other Confederate soldiers settled in Titus County after war's end, and they contributed to the number of local soldiers who had participated in battle.

Those who remained in Titus County during the war contributed to the effort. Mount Pleasant was home to a Confederate transportation depot, which employed blacksmiths, carpenters, harness makers, and wheelwrights. The depot built wagons, fitting the horse or mule teams with harnesses, for men and supplies to move to the front lines (City of Mount Pleasant 2007). Titus County furnished the Confederate commissary with beef, butter, corn, rice, cotton, oats, sweet potatoes, flour, cornmeal, leather, lumber, pottery, tobacco, whiskey, and wool. Local industry also supported the war with nine sawmills, eight gristmills, seven tanneries, and a steam-powered distillery (Kurimski 2007). Typical farm life was disrupted with so many men away at war, and in their absence women often ran family agricultural operations and financial affairs. Martin Barnett's wife handled the plantation affairs exclusively, including dealing with slave traders and disciplining slaves with corporal punishment. Running the Barnett plantation proved difficult, and no improvements were made to their holdings during the war (Russell 1937:22).

The economy in Titus County was slow to recover after the war. Many local businesses were at a standstill, which contributed to the general downturn in economic affairs. Plantation owners had lost their labor source, and much land went untilled (Jurney 1961:54-56). Local planters continued operations by dividing their land into shares, and about two years after the war many freedman returned to again work the land as sharecroppers, tenant farmers, or day laborers (Kirby 2001; Russell 1937:30). Still, the local economy was ailing, especially after both the corn and cotton crops failed in 1867 (Harper 2001).

During Reconstruction, citizens were discouraged and bitter under the control of oc- 
cupying Federal troops, and a range of lawless activities resulted. Union forces conscripted local men to perform public service in the form of menial tasks. In opposition, many former Confederate soldiers became outlaws, joined gangs, and committed crimes in the area. Henry W. Jones Sr. was shot dead on a Mount Pleasant street by a rival's employee in the late 1870 s (Russell 1965b:57). The Ku Klux Klan was very active in the county during Reconstruction, so much so that, in an 1867 report, Maj. Samuel Henry Starr recommended moving freedmen out of the county to prevent a slaughter. This turmoil did not dissuade an influx of newcomers from other southern states settling in Titus County in the last quarter of the nineteenth century. Transplants arrived by wagon train and often settled in the general locality of friends or near others from their home state (Harper 2001; Jurney 1961:64-71).

Thomas Buncombe Caldwell came to Mount Pleasant in the 1870s. Caldwell grew up in Quincy, Florida, where his father owned a successful plantation. He served five years in the Confederate Army, but, when he returned to Florida after the war, his father's plantation was ruined. Apparently, he and his brother, Bogan, fled to Texas after killing a man. Thomas Caldwell spent time in Pecos County until 1870. He also spent time in Jefferson County, Mount Pleasant, and Franklin County. He settled in Gray Rock, south of Mount Pleasant, where he clerked in a store. Caldwell opened his own store there in 1880. Caldwell returned to Florida to bring his mother to Texas, and they settled in Franklin County before coming to Titus County. Caldwell amassed 1,100 acres in the area that he farmed. In 1880, he built the first brick store in Mount Pleasant and sold general merchandise. Later, he organized the First National Bank of Mount Pleasant and the Morris County National Bank. Caldwell sold the store to his brother in 1892. He married Bessie Slaughter in 1902. They built a large brick home, considered a showplace in Mount Pleasant. The house, which took up a square block, was destroyed by fire in 1962, 37 years after Caldwell died (Russell 1974:37-39).

Some residents were new to Titus County, but not to Texas. Felix W. Fitzpatrick was born in Texas in 1849 and came to Mount Pleasant in the 1870s. He went into business with William Christian, a prominent Mount Pleasant citizen, selling farm equipment. The men soon opened a grocery store in Mount Pleasant. Fitzpatrick married Christian's daughter, Mary. The Fitzpatricks were considered a cultured family. Despite owning a large amount of acreage, the Fitzpatricks opted to live in town. Their large, two-story home, built in the 1880 s, was a local social center. Fitzpatrick moved to Fort Worth around 1913 (Russell 1965b:102-103; Russell 1974:99-100).

Titus County retained its agricultural economy well after the war and into the twentieth century. Cotton became an even more important local crop. The agricultural system that produced this crop, however, reverted from an owner-operated to a tenant-operated one. By 1900, 49 percent of Titus County farmers were tenants, most of whom were sharecroppers; 30 years later, 61 percent of local farmers were tenants (Perttula and Nelson 2002).

In 1875, the state legislature carved two new counties, Morris and Franklin, from Titus County. Residents living in extreme eastern and western Titus County favored the split, since the long commute to the central seat of Mount Pleasant most inconvenienced them. Poor road conditions and yearly flooding of area creeks and the Sulphur River hampered wagons and the animals that pulled them. This was particularly difficult for those who lived at the county's western reaches, 23 miles away, and at its eastern reaches, 30 miles away. The new boundaries wedged Titus County between Morris County to its east and Franklin County to its west (Jurney 1961:161-162).

Until the early 1880 s, Jefferson was the closest trading center to Titus County. At 100 miles round trip, which took about a week, it was an inconvenient journey. However, the arrival of the railroad in Mount Pleasant boosted both the local economy and the population, and the town became a more lucrative trade center. The east line of the Red River Branch of the Missouri, Kansas, and Texas Railway was the first to lay track in Titus County, but its location in the extreme southeast corner of the county provided little benefit to the county as a whole. In 1879, the Tyler Tap, Tyler to Mount Pleasant, provided a regional link in Mount Pleasant. In 1880, the Texas and Arkansas Railway, also known as the Cotton Belt, came through Mount Pleasant from the north. Later, the railway placed headquarters for the division supervisor office of the Cotton Belt in Mount Pleasant. Another regional 
line laid in 1912 linked Mount Pleasant to Paris (Jurney 1961:94-95; Russell 1937:95). Largely because of this rail system, Mount Pleasant had become a recognized regional transportation hub by the close of the nineteenth century.

The town square of Mount Pleasant developed into the social and commercial center of Titus County. It was usually heavy with the wagon traffic of farmers coming to town, tying their teams to the hitching rail on the square, and spending the day taking care of their business. In the middle of the square, the Titus County courthouse was the center of much activity. The brick courthouse, which replaced the original log building, had collapsed during the Civil War. It was rebuilt only to be destroyed by fire in 1895 . No accident, several versions of the origin of the fire exist. Some propose a man awaiting trial on a felony charge set the fire in an effort to destroy evidence against him; others suggest a county official, who found himself short of county funds, set the fire to destroy all records that might incriminate him (Jurney 1961:94; Russell 1965a:239-240). The fire destroyed numerous county records, including warranty deeds and deeds of trust. A new courthouse was built on the old foundation in 1896 .

In the early twentieth century, Mount Pleasant developed into a resort destination. Around 1900, Jessie Reed acquired 120 acres from the Henry W. Jones Sr. tract on Town Branch, near present-day Dellwood Park. Reed developed his holdings as a resort, marketing a close association with the chalybeate springs that fed into Town Branch. Reed advertised widely that the "Iridescent Springs" could cure many common ailments. He had several buildings including a café and camp houses. Only marginally successful, Reed was forced to sell the property in lieu of back taxes to H. W. Peterman in 1906. In 1907, Peterman sold the property to M. C. Wolf and Associates, who organized the Red Mineral Springs Development Company and commenced construction of a large-scale resort-style hotel. A wood-rail tramcar line carried guests between town and the resort. In spite of glowing testimonials of the springs' healing properties, the general public's belief in the curative waters was already waning. The resort venture closed permanently and wilderness reclaimed the landscape. More recently, the area has been developed for recreational use (City of Mount Pleasant 2007; Kurimski 2007).
At the turn of the century, lignite mining developed into a productive local industry and, by 1908 , employed as many as 35 to 65 men. School superintendent L. C. Libby initially saw potential for lignite mining in 1902 and formed the Libby Brick and Coal Company in 1908. Production varied by demand but sometimes reached 300 tons per day. The Cotton Belt Railroad established a side road named Nodena to load lignite and bricks onto rail cars for delivery to customers across the nation. Lignite was mined in an area about four miles west of Mount Pleasant from about 1920 through the 1930s, when demand dropped as the availability of natural gas grew (City of Mount Pleasant 2007).

Mirroring national trends of the early twentieth century, Titus County developed and improved local roadways. Rural roads were rough and frequently impassable with large rocks, felled trees, and mud blocking pathways that were barely improved in many cases. The growing popularity and affordability of automobiles made apparent the need to improve roadways. Mount Pleasant hardware store merchant Henry Wilson realized the number of automobiles in the county was destined to increase and pushed for better roads. He argued new roads would be vital to local development and prosperity. Largely due to Wilson's efforts, a $\$ 1$ million bond issue passed in 1916 for road construction. He was also able to convince Titus County commissioners to take responsibility for building and maintaining county roads. Previously, men in the county were required to donate their labor annually for road maintenance. As a result, Titus County boasted some of the best-paved roads in east Texas (City of Mount Pleasant 2007; Jurney 1961:87).

Agriculture remained the mainstay of the local economy well into the twentieth century. Before the advent of the Great Depression, many rural families were already living in impoverished conditions. The price of cotton reached record lows and Titus County farmers suffered. The county's population declined from 18,128 in 1920 to 16,003 in 1930 . The value of Titus County farms dropped in the 1930s, as did farm tenancy (Harper 2001).

Government entities were helpful in providing employment to those without work during the Great Depression. Civilian Conservation Camp \#2886 established an office in Mount Pleasant on Edwards Avenue. The Works Progress Administration and the Public Works 
Administration also provided relief to unemployed in the area (Kurimski 2007).

The discovery of oil and the emergence of modern manufacturing in Titus County helped foster the economy after the Great Depression. The 1936 discovery of oil in northern Titus County caused a resurgence for the local economy. The discovery drew manufacturing enterprises to the area and stimulated the economy through World War II. By 1947, the number of local manufacturing workers had risen to 368 , and that number continued to climb until the 1980s. The county's agricultural economy gradually changed during the post-World War II era. The number of farms in the county declined between 1940 and 1982 from 2,146 to 778, but the average acreage increased substantially from fewer than 88 acres per farm to 245 acres (Harper 2001; Perttula and Nelson 2002).

Despite a gradual loss of population, Mount Pleasant remains the industrial center of Titus County. A meat-packing plant, milk-processing plant, chicken-processing plant, barrel and stave factory, door and sash factory, and ranch equipment manufacturing plant support the local economy (Cruse and Brownlow 1996). Mount Pleasant remains the commercial center for local farmers who continue to raise crops and livestock. The town not only serves as a retail center for Titus County, but for surrounding Franklin, Camp, and Morris Counties as well (Harper 2001; Russell 2007).

\section{REFERENCES CONSULTED}

Alexander, Drury Blakeley

1966 Texas Homes of the Nineteenth Century. University of Texas Press, Austin.

Anonymous

[1858] Titus and Cass Counties [hand-drawn map], Image No. 16897. Texas General Land Office, Austin.

Bell, Milton

1981 The Alex Justiss Site: A Caddoan Cemetery in Titus County. Publications in Archaeology, Highway Design Division, Report 21. State Department of Highways and Public Transportation, Austin.

Blackard, Morris

1964 The History of Titus County, Texas, 19291964. M.A. thesis, The University of Texas at Austin.

Brown, Deborah, and Katharine Gust

1976 Between the Creeks: Recollections of Northeast Texas. Encino Press, Austin.

Campbell, Randolph B.

1989 An Empire for Slavery: The Peculiar Institution in Texas 1821-1865. Louisiana State University Press, Baton Rouge, Louisiana.
City of Mount Pleasant

2007 Our History. City of Mount Pleasant. Electronic document, http://www.mpcity. net/history.htm, accessed October 16, 2007.

Connor, Jean

1975 A Short History of Morris County. Daingerfield Bicentennial Commission, Daingerfield, Texas.

Cowdrey, Albert E.

1996 This Land, This South: An Environmental History. New Perspectives on the South, revised edition, Charles P. Rowland, general editor. The University Press of Kentucky, Lexington.

Cronon, William

1983 Changes in the Land: Indians, Colonists, and the Ecology of New England. Hill and Wang, New York.

Cruse, Maria E., and Russell K. Brownlow

1996 Cultural Resource Survey for the MSW Landfill Expansion City of Mount Pleasant, Titus County, Texas. Espey, Huston and Associates, Inc., Austin. 
Doolittle, William E.

2000 Cultivated Landscapes of Native North America. Oxford Geographical and Environmental Studies, edited by Gordon Clark, Andrew Goudie, and Ceris Peach. Oxford University Press, New York.

Ellis, John Marion, II

1983 The Way It Was: A Personal Memoir of Family Life in East Texas. Texian Press, Waco, Texas.

Embrey, C. L.

1970 Our Good Old Days. By the author, Laird Hill, Texas.

Glander, Wayne, and Clell Bond

1986 Cultural Resources Survey of the MonticelloWinfield Coal Surface Mine, Titus County, Texas. Espey, Huston \& Associates, Inc., Austin.

Goetzman, William H.

1966 Exploration and Empire: The Explorer and the Scientist in the Winning of the American West. Alfred A. Knopf, Inc., New York.

Goldschmidt, W. R.

1934 Excavation of a Burial site on Thomas B. Caldwell Plantation in Titus County, Texas. Manuscript on file, Texas Archeological Research Laboratory, The University of Texas at Austin.

1935 Some Archeological Sites in Titus County and Their Relation to EastTexas Prehistory. M.A. thesis, Department of Anthropology, The University of Texas at Austin.

Greene Title and Abstract

Abstracts of Title. Greene Title and Abstract, Mount Pleasant, Texas.

Harper, Cecil, Jr.

2001 The Handbook of Texas Online, s.v. "Titus County." Electronic document, http://www. tsha.utexas.edu/handbook/online/articles/ TT/hct6.html, accessed various dates 2007.

2006 The Handbook of Texas Online, s.v. "Stoneware Pottery." Electronic document, http:// www.tsha.utexas.edu/handbook/online/ articles/SS/bcs1.html, accessed various dates 2007.

Isaac, Rhys

1982 The Transformation of Virginia, 1740-1790. W. W. Norton \& Company, New York.
Jones, C. Allan

2005 Texas Roots: Agriculture and Rural Life Before the Civil War. Texas A\&M University Press, College Station.

Jurney, Richard Loyall

1961 The History of Titus County 1846-1960. Royal Publishing Company, Dallas.

Kirby, Mary Laschinger

2001 The Handbook of Texas Online, s.v. "Upshur County." Electronic document, http://www. tsha.utexas.edu/handbook/online/articles/ UU/hcu1.html, accessed October 17, 2007.

Kurimski, Christina

2007 History [of] Mount Pleasant, Titus County, Texas. TXGenWeb Project, Titus County, Texas Electronic document, http://www. rootsweb.com/ txtitus/pleasant.htm, accessed October 16, 2007.

Laing, Wesley N.

2003 The Handbook of Texas Online, s.v. "Andrew Jackson Titus." Electronic document, http://www.tsha.utexas.edu/handbook/ online/articles/TT/fti6.html, accessed November 27, 2007.

Mangelsdorf, Paul C.

1974 Corn: Its Evolution and Improvement. The Belknap Press of Harvard University Press, Cambridge, Massachusetts.

Meinig, D. W.

1986 The Shaping of America: A Geographical Perspective on 500 Years of History; Volume 1: Atlantic America, 1492-1800. Yale University Press, New Haven, Connecticut.

1993 The Shaping of America: A Geographical Perspective on 500 Years of History; Volume 1: Continental America, 1800-1867. Yale University Press, New Haven, Connecticut.

Miller, Thomas Lloyd

1967 Bounty and Donation Land Grants of Texas, 1835-1888. University of Texas Press, Austin.

1972 The Public Lands of Texas, 1519-1970. University of Oklahoma Press, Norman.

Morris, G. C., comp., and Altea Armstrong, drawer 1948 Titus County [hand-drawn map], Image No. 63067. Texas General Land Office, Austin. 
Perttula, Timothy K. (editor)

2005 Archeological Investigations at the Pilgrim's Pride Site (41CP304), a Titus Phase Community in the Big Cypress Creek Basin, Camp County, Texas. Report of Investigations No. 30. Archeological and Environmental Consultants, LLC, Austin.

Perttula, Timothy K., and Bo Nelson

2002 Archeological Survey of Lake Bob Sandlin State Park, Titus County, Texas. Report of Investigations No. 48. Archeological and Environmental Consultants. LLC, Austin.

Prikryl, Daniel J., Kathleen Gilmore, Ross C. Fields, and Nancy Reese

1984 Archeological and Historical Investigations at 41TT310, Lake Bob Sandlin State Park, Titus County, Texas. Reports of Investigations No. 27. Prewitt and Associates, Inc., Austin.

Quasqui Centennial Committee

1971 Titus County Celebrates 125 Years. N.p., Mount Pleasant, Texas.

Reynolds, Joe

2007a "J. H. King: Genealogy and Family History of John Henry King." TXGenWeb Project: Titus County, Texas. Electronic document, http://www.rootsweb.com/ txtitus/hjking3. htm [accessed January 2007].

2007b “J. H. King: John Henry King Memories of North East Texas, 1846-1859." TXGenWeb Project: Titus County, Texas. Electronic document, http://www.rootsweb. com/ txtitus/hjking 1.htm, accessed January 2007.

Rice, Thomas D., and E. B. Watson, surveyors

1909 Soil Map, Texas, Titus County Sheet. U.S. Department of Agriculture, Bureau of Soils, Filed Operations, Washington, D.C.

Rippon, Stephen

2004 Historic Landscape Analysis: Deciphering the Countryside. Practical Handbooks in Archaeology No. 16. Council for British Archaeology, Walmgate, York, United Kingdom.

Russell, Norman Calvin

1937 The History of Titus County Since 1860. M.A. thesis, Department of History, East Texas State Teachers College, Commerce.
Russell, Traylor

1965a History of Titus County, Volume 1. W. M. Morrison, Waco, Texas.

1965b History of Titus County, Volumes 1 and 2. W. M. Morrison, Waco, Texas.

1974 Pioneers and Heroes of Titus County. Rotary Club of Mount Pleasant, Mount Pleasant, Texas.

2001a The Handbook of Texas Online, s.v. "Kendall Lewis." Electronic document, http://www. tsha.utexas.edu/handbook/online/articles/ LL/fle44.html, accessed various dates 2007.

2001b The Handbook of Texas Online, s.v. "Fort Sherman." Electronic document, http:// www.tsha.utexas.edu/handbook/online/ articles/FF/qcf12.html, accessed various dates 2007.

2007 The Handbook of Texas Online, s.v. "Mount Pleasant, Texas." Electronic document, http://www.tsha.utexas.edu/handbook/ online/articles/MM/hem7.html, accessed various dates 2007 .

Skokan, Elizabeth

1994 Cultural Resources Survey of Portions of the Monticello B-2 Surface Lignite Mine, Titus County, Texas. Espey, Huston and Associates, Inc., Austin.

Texas General Land Office

1845 John Thompson Survey, Panola District, Second Class Headright Grant, File No. 21, Abstract 567. Patented to John Thompson on April 12, 1845.

1853 Ambrose Ripley Survey, Red River District, Third Class Headright Grant, File No. 109, Abstract 478. Patented to Ambrose Ripley on January 24, 1853.

1855a John Watson Survey, Red River District, Donation Grant, File No. 66, Abstract 619. Patented to John Hendricks, assignee, on February 28, 1855.

1855b John Watson Survey, Red River District, Donation Grant, File No. 66, Abstract 620. Patented to John Hendricks, assignee, on February 28, 1855.

1855c John Greenwood Survey, Red River District, First Class Headright Grant, File No. 479, Abstract 231. Patented to John Greenwood on March 8, 1855. 
1857 Shem Harris Survey, Red River District, Bounty Grant, File No. 70, Abstract 291. Patented to Shem Harris on August 6, 1857.

1859a L. M. Jones Survey, Red River District, Fourth Class Headright Grant, File No. 458, Abstract 310. Patented to M. H. Barnett, assignee, on January 10, 1859.

1859b L. M. Jones Survey, Red River District, Fourth Class Headright Grant, File No. 458, Abstract 311. Patented to M. H. Barnett, assignee, on January 10, 1859.

1860a P. M. Otwell Survey, Red River District, Third Class Headright Grant, File No. 280, Abstract 419. Patented to Henry W. Jones, assignee, on January 6, 1860.

1860b P. M. Otwell Survey, Red River District, Third Class Headright Grant, File No. 280, Abstract 420. Patented to VincentA. Davis, assignee, on November 22, 1870.

1861 William Stokes Survey, Red River District, Third Class Headright Grant, File No. 299 Abstract 507. Patented to John Hendricks, assignee, on February 20, 1861.

Texas State Highway Department

1940 General Highway Map, Franklin County, Morris County, Titus County, Camp County. Texas State Highway Department, in cooperation with the U.S. Department of Agriculture, Bureau of Public Roads, 1936. Partially revised to February 1, 1940.

1961 General Highway Map, Franklin County, Morris County, Titus County, Camp County. Texas State Highway Department, in cooperation with the U.S. Department of Agriculture, Bureau of Public Roads, 1956. State highways revised to January 1, 1961.

Titus County Official Public Records

Ad Valorem Tax Records. Texas State Library and Archives, Austin.

County Commissioner's Court Minutes. Titus County Clerk, Mount Pleasant Deed Records. Titus County Clerk, Mount Pleasant.
District Court Records. Titus County Clerk, Mount Pleasant.

Probate Records. Titus County Clerk, Mount Pleasant.

Tobin International

1935 Titus County [aerial image]. Electronic document, P2 Energy Solutions, San Antonio.

U.S. Department of the Interior, Census Office

1850 Titus County, Texas, manuscript population schedule. Heritage Quest ${ }^{\mathrm{TM}}$ Online, subscription database, accessed various dates 2007.

1860 Titus County, Texas, manuscript population schedule. Heritage Quest ${ }^{\mathrm{TM}}$ Online, subscription database, accessed various dates 2007.

1870 Titus County, Texas, manuscript population schedule. Heritage Quest ${ }^{\mathrm{TM}}$ Online, subscription database, accessed various dates 2007.

1880 Titus County, Texas, manuscript population schedule. Heritage Quest ${ }^{\mathrm{TM}}$ Online, subscription database, accessed various dates 2007.

1900a Titus County, Texas, manuscript population schedule. Heritage Quest ${ }^{\mathrm{TM}}$ Online, subscription database, accessed various dates 2007.

1900b Hunt County, Texas, manuscript population schedule. Heritage Quest ${ }^{\mathrm{TM}}$ Online, subscription database, accessed various dates 2007.

1910a Titus County, Texas, manuscript population schedule. Heritage Quest ${ }^{\mathrm{TM}}$ Online, subscription database, accessed various dates 2007.

1910b Hunt County, Texas, manuscript population schedule. Heritage Quest ${ }^{\mathrm{TM}}$ Online, subscription database, accessed various dates 2007.

1920 Titus County, Texas, manuscript population schedule. Heritage Quest ${ }^{\mathrm{TM}}$ Online, subscription database, accessed various dates 2007.

1930 Titus County, Texas, manuscript population schedule. Heritage Quest ${ }^{\mathrm{TM}}$ Online, subscription database, accessed various dates 2007. 

APPENDIX E: Metric Data for Stone Tools (compact disk only) 



\section{APPENDIX F: Macrobotanical Plant Remains}

Leslie L. Bush, Ph.D., R.P.A.

Macrobotanical Analysis

Manchaca, Texas 



\section{INTRODUCTION}

The three main sites examined for this project are west of the modern town of Mount Pleasant near the confluence of Tankersley Creek and Dragoo Creek. The sites are situated at the edge of the uplands to the east of Tankersley Creek. Site 41TT853, the smallest one, lies between the other two. Each site is next to an intermittent stream that drains west to Tankersley Creek. Tankersley Creek itself flows south to join Big Cypress Creek, which today forms the border between Titus and Camp Counties. Big Cypress Creek eventually drains into Caddo Lake and thence into the Red River in Louisiana.

Upland soils in the area of the sites are fine sandy loams in the Freestone or Woodtell series. Soils along Tankersley Creek at and downstream from the sites are Estes clay loam, frequently flooded (Soil Survey Staff 2008). Farther upstream (north), the soils along Tankersley and Dragoo Creeks become Nahatche silty clay loam, also frequently flooded.

Mean annual precipitation in Titus County during the period 1951-1980 was 45.5 inches $(1,156 \mathrm{~mm})$. Precipitation is distributed fairly evenly over the year, with peaks in April and September. Thunderstorms are common in April and May. The frost-free season in Titus County today averages 233 days and runs from March 23 through November 12 (Natural Fibers Information Center 1987:475-476).

All three sites have multiple components, but radiocarbon dates indicate that the predominant occupations are Middle to Late Caddo. The main component at 41TT851 is slightly earlier (A.D. 1300) than those at the other two sites (A.D. 1400-1500).

\section{ECOLOGICAL SETTING}

The Mount Pleasant sites lie in the Post Oak Savannah ecological region, which many ecologists conceptualize as a transition zone between the Eastern Woodlands and the grasslands of the midcontinent (Diggs et al. 2006). Other authors point out that the Post Oak Savannah is floristically similar to the Piney Woods, a perspective that may help make sense of the extension of Caddo culture outside the Piney Woods region in Texas (MacRoberts and MacRoberts 2004; MacRoberts et al. 2002).
The Post Oak Savannah is broadly characterized by sandy soils, grasslands, and widely spaced trees. The most common trees are post oak (Quercus stellata) and blackjack oak (Q. marilandica). Common grasses include the tallgrass prairie trio of little bluestem (Schizachyrium scoparium), Indiangrass (Sorghastrum nutans), and switchgrass (Panicum virgatum) (Diggs et al. 2006:116). There is much local variation within the Post Oak Savannah, however. Hickories (primarily Carya texana) as well as oaks would have been common in the uplands surrounding Tankersley Creek. In the wetter areas along the creek, water oak (Quercus nigra) and post oak would dominate floodplain forests along with elms (Ulmus spp.) and green ash (Fraxinus pennsylvanica). Grape vines (Vitis spp.), poison ivy (Toxicodendron radicans), cane (Arundinaria gigantea), sedges (Cyperaceae), and wetland grasses such as wild rye (Elymus spp.) and wood oats (Chasmanthium spp.) would also have been common (Diggs et al. 2006:122-3).

Modern equivalents exist for most prehistoric plant communities in East Texas despite changes in the abundance and structure of the communities (Diggs et al. 2006:87). The most notable changes on the Post Oak Savannah since presettlement times include an increase in woody vegetation and the loss of "bottom prairie" communities along major rivers such as the Brazos and Trinity (Diggs et al. 2006 115-116). Pollen studies indicate that use of the modern vegetation zones described above is appropriate for understanding the plants and attendant animal resources available to people during the first and second millennia. Weakly Bog, situated in the Post Oak Savannah vegetation region south of Titus County, provides some of the best data for vegetation reconstruction in the eastern half of Texas during the last 3,000 years (Bousman 1998). Pollen profiles from this bog indicate oak and later oak/hickory woodlands, suggesting that modern plant communities generally provide good analogs for historical Texas plant communities during the last 3,000 years. A recent study by Bruce Albert in southwest Upshur County provides supporting data for the period of occupation at the Mount Pleasant sites (Albert 2007). Some fluctuations in rainfall and temperature have taken place (Bousman 1998:204), but even decades-long fluctuations in rainfall patterns seem to be part of the natural 
background of late Holocene climate patterns (Stahle and Cleaveland 1992). In addition, more frequent fires would have made the woody vegetation less prominent than during the last century or so (Diggs et al. 2006; MacRoberts et al. 2002).

\section{METHODS}

Flotation samples were processed at Prewitt and Associates, Inc., in a Flote-Tech flotation machine with bottom mesh openings of $1.0 \mathrm{~mm}$. Although bottom mesh openings of $0.6 \mathrm{~mm}$ are optimal for the recovery of small seeds, the sandy soils are unlikely to have passed through this mesh size (Bush 2001:91-92 and Table 3.10; Hunter and Gassner 1998). The presence of uncarbonized carpetweed seeds (Mollugo verticillata) in 161 of the 227 flotation samples demonstrates that the system was sufficient for the recovery of many small seeds. Carpetweed seeds have an average diameter of about $0.7 \mathrm{~mm}$. Not all carbonized plant material rose to the top of the flotation tank to be included in the original light fractions, however. Flotation heavy fractions were inspected for charcoal, which was removed by hand and added to the light fractions prior to sorting.

Flotation samples were sorted according to standard procedures at the Macrobotanical Analysis laboratory in Manchaca, Texas (Pearsall 2000). Each sample was weighed on an Ohaus Scout II 200x0.01-g electronic balance before being size-sorted through a stack of graduated geologic mesh. Materials that did not pass through the No. 10 mesh ( $2 \mathrm{~mm}$ ) were completely sorted, and all carbonized botanical remains were counted, weighed, recorded, and labeled. Uncarbonized botanical material greater than $2 \mathrm{~mm}$ (usually rootlets) was weighed, recorded, and labeled as "contamination." Materials that fell through the 2-mm mesh ("residue") were examined under a stereoscopic microscope at 7-45x magnification for carbonized botanical remains. Identifiable material other than wood, corn, and nutshell was removed from residue, counted, weighed, recorded and labeled. Samples were examined for ceramics and faunal material greater than $2 \mathrm{~mm}$ and any smaller material that appeared identifiable. The little such nonbotanical material found was counted, weighed, labeled, and returned to Prewitt and Associates for analysis. Partially carbonized remains from the site were treated in the same manner as fully carbonized material. Other uncarbonized macrobotanical remains were recorded on a presence/ absence basis on laboratory forms.

Plant samples that were not flotation-processed were not usually sieved in the laboratory. Rather, any chunks of soil were removed by hand. When loose soil was encountered, samples were placed on a No. 10 mesh $(2 \mathrm{~mm})$, and the soil that fell through the mesh was scanned for plant material. Soil that included small flecks of charcoal was retained and labeled as "residue." Soil without charcoal (e.g., sand scraped from the interior of hickory nutshells) was discarded after a microscopic check for any possible charcoal.

Radiocarbon samples were handled using latex gloves, forceps, and freshly washed glassware. Contact with paper and other plant products was avoided. Carbon samples were not screened in the laboratory. Otherwise, identification of carbon samples proceeded as for flotation samples.

Wood charcoal identification, whether from hand-collected or flotation samples, was attempted for 20 randomly selected specimens from each sample. Wood charcoal fragments were snapped to reveal a transverse section and examined under a stereoscopic microscope at 28-180x magnification. When necessary, tangential or radial sections were examined for ray seriation, presence of spiral thickenings, types and sizes of intervessel pitting, and other minute characteristics that can only be seen at the higher magnifications of this range.

Botanical materials were identified to the lowest possible taxonomic level by comparison to materials in the Macrobotanical Analysis comparative collection and through the use of standard reference works (e.g., Core et al. 1979; Davis 1993; Hoadley 1990; InsideWood 2004; Martin and Barkley 1961; Panshin and de Zeeuw 1980). Plant nomenclature follows that of the PLANTS Database (USDA, NCRS 2011).

\section{RESULTS}

\section{Hand-Collected Samples}

Fifty hand-collected samples, many considered candidates for radiocarbon dating, from 37 contexts were analyzed in two different phases of the project (Table F.1). Identifications include samples from tested sites 41TT847 and 41TT865 in addition to the three other sites reported here. 
Table F.1. Hand-collected macrobotanical samples

\begin{tabular}{|c|c|c|c|c|c|c|c|}
\hline Site & Provenience & $\begin{array}{c}\text { Feature } \\
\text { Type }\end{array}$ & $\begin{array}{l}\text { Plant } \\
\text { Part }\end{array}$ & Identification & $\begin{array}{c}\text { Common } \\
\text { Name }\end{array}$ & No. & $\begin{array}{c}\text { Weight } \\
\text { (g) }\end{array}$ \\
\hline $41 \mathrm{TT} 847$ & F-2 & $\begin{array}{l}\text { burned rock } \\
\text { cluster }\end{array}$ & Wood & $\begin{array}{l}\text { Quercus subg. } \\
\text { Lobatae }\end{array}$ & Red group oak & 3 & 0.16 \\
\hline 41TT851, Subarea 1 & $\begin{array}{l}\text { F-9 } \\
\text { (2 samples) }\end{array}$ & pit, large & Wood & $\begin{array}{l}\text { Quercus subg. } \\
\text { Quercus }\end{array}$ & $\begin{array}{l}\text { White group } \\
\text { oak }\end{array}$ & 12 & 1.91 \\
\hline 41TT851, Subarea 1 & $\begin{array}{l}\text { F-9 } \\
\text { (2 samples) }\end{array}$ & pit, large & Wood & Carya spp. & Hickory & 3 & 0.06 \\
\hline 41TT851, Subarea 1 & $\begin{array}{l}\text { F-9 } \\
\text { (2 samples) }\end{array}$ & pit, large & Wood & Not examined & & 59 & 0.78 \\
\hline 41TT851, Subarea 1 & F-17 & pit, large & Nutshell & Carya spp. & Hickory & 12 & 0.24 \\
\hline 41TT851, Subarea 1 & F-20 & pit, smudge & Ind. & & & 13 & 1.72 \\
\hline 41TT851, Subarea 1 & $\begin{array}{l}\text { F-28 } \\
(2 \text { samples })\end{array}$ & pit, large & Wood & $\begin{array}{l}\text { Quercus subg. } \\
\text { Lobatae }\end{array}$ & Red group oak & 6 & 0.85 \\
\hline 41TT851, Subarea 1 & $\begin{array}{l}\text { F-28 } \\
\text { (2 samples) }\end{array}$ & pit, large & Nutshell & Carya sp. & Hickory & 1 & 0.67 \\
\hline 41TT851, Subarea 1 & F-110 & pit, large & Wood & $\begin{array}{l}\text { Quercus subg. } \\
\text { Quercus }\end{array}$ & $\begin{array}{l}\text { White group } \\
\text { oak }\end{array}$ & 24 & 9.15 \\
\hline 41TT851, Subarea 1 & $\begin{array}{l}\text { F-188 } \\
\text { (2 samples) }\end{array}$ & pit, large & Nutshell & Carya sp. & Hickory & 9 & 0.9 \\
\hline 41TT851, Subarea 1 & $\begin{array}{l}\text { F-188 } \\
\text { (2 samples) }\end{array}$ & pit, large & Wood & Carya $\mathrm{sp}$. & Hickory & 3 & 0.11 \\
\hline 41TT851, Subarea 1 & $\begin{array}{l}\text { F-188 } \\
\text { (2 samples) }\end{array}$ & pit, large & Wood & $\begin{array}{l}\text { Liquidambar } \\
\text { styraciflua }\end{array}$ & Sweetgum & 2 & 0.08 \\
\hline 41TT851, Subarea 1 & \begin{tabular}{|l} 
F-188 \\
(2 samples)
\end{tabular} & pit, large & Wood & $\begin{array}{l}\text { Quercus subg. } \\
\text { Lobatae }\end{array}$ & Red group oak & 136 & 5.47 \\
\hline 41TT851, Subarea 1 & $\begin{array}{l}\text { F-188 } \\
\text { (2 samples) }\end{array}$ & pit, large & Wood & $\begin{array}{l}\text { Quercus subg. } \\
\text { Quercus }\end{array}$ & $\begin{array}{l}\text { White group } \\
\text { oak }\end{array}$ & 2 & 0.12 \\
\hline 41TT851, Subarea 1 & \begin{tabular}{|l} 
F-188 \\
(2 samples)
\end{tabular} & pit, large & Wood & Not examined & Not examined & 290 & 4.23 \\
\hline 41TT851, Subarea 1 & $\begin{array}{l}\text { F-188 } \\
\text { (2 samples) }\end{array}$ & pit, large & Bark & & & 1 & 0.02 \\
\hline 41TT851, Subarea 1 & F-189 & pit, large & Nutshell & Carya sp. & Hickory & 10 & 2.79 \\
\hline 41TT851, Subarea 1 & F-189 & pit, large & Wood & $\begin{array}{l}\text { Quercus subg. } \\
\text { Lobatae }\end{array}$ & Red group oak & 6 & 0.91 \\
\hline 41TT851, Subarea 1 & F-189 & pit, large & Wood & $\begin{array}{l}\text { Quercus subg. } \\
\text { Quercus }\end{array}$ & $\begin{array}{l}\text { White group } \\
\text { oak }\end{array}$ & 7 & 0.31 \\
\hline 41TT851, Subarea 1 & F-189 & pit, large & Wood & Carya sp. & Hickory & 2 & 0.06 \\
\hline 41TT851, Subarea 1 & F-189 & pit, large & Root & & & 2 & 1.64 \\
\hline 41TT851, Subarea 1 & F-205/16 & pit, large & Wood & $\begin{array}{l}\text { Quercus subg. } \\
\text { Lobatae }\end{array}$ & Red group oak & 2 & 0.07 \\
\hline 41TT851, Subarea 1 & F-205/16 & pit, large & Bark & & & 2 & 0.13 \\
\hline 41TT851, Subarea 1 & F-347 & pit, small & Wood & Hardwood & Hardwood & 33 & 0.64 \\
\hline 41TT852, Subarea 1 & $\begin{array}{l}\mathrm{F}-13 \\
(2 \text { samples })\end{array}$ & pit, large & Nutshell & Carya spp. & Hickory & 7 & 1.02 \\
\hline 41TT852, Subarea 1 & $\begin{array}{l}\text { F-13 } \\
\text { (2 samples) }\end{array}$ & pit, large & Wood & $\begin{array}{l}\text { Quercus subg. } \\
\text { Quercus }\end{array}$ & $\begin{array}{l}\text { White group } \\
\text { oak }\end{array}$ & 8 & 0.23 \\
\hline 41TT852, Subarea 1 & $\begin{array}{l}\mathrm{F}-13 \\
(2 \text { samples })\end{array}$ & pit, large & Wood & Quercus spp. & Oak & 10 & 0.28 \\
\hline 41TT852, Subarea 1 & $\begin{array}{l}\text { F-13 } \\
\text { (2 samples) }\end{array}$ & pit, large & Wood & Not examined & & 22 & 0.10 \\
\hline 41TT852, Subarea 1 & F-14 & pit, smudge & Wood & $\begin{array}{l}\text { Quercus subg. } \\
\text { Quercus }\end{array}$ & $\begin{array}{l}\text { White group } \\
\text { oak }\end{array}$ & 10 & 2.32 \\
\hline 41TT852, Subarea 1 & F-14 & pit, smudge & Wood & Not examined & & 333 & 7.52 \\
\hline 41TT852, Subarea 1 & F-15 & pit, smudge & Nutshell & Carya spp. & Hickory & 1 & 0.87 \\
\hline
\end{tabular}


Table F.1, continued

\begin{tabular}{|c|c|c|c|c|c|c|c|}
\hline Site & Provenience & $\begin{array}{c}\text { Feature } \\
\text { Type }\end{array}$ & $\begin{array}{l}\text { Plant } \\
\text { Part }\end{array}$ & Identification & $\begin{array}{c}\text { Common } \\
\text { Name }\end{array}$ & No. & $\begin{array}{c}\text { Weight } \\
\text { (g) }\end{array}$ \\
\hline 41TT852, Subarea 1 & F-15 & pit, smudge & Wood & $\begin{array}{l}\text { Quercus subg. } \\
\text { Quercus }\end{array}$ & $\begin{array}{l}\text { White group } \\
\text { oak }\end{array}$ & 6 & 1.71 \\
\hline 41TT852, Subarea 1 & F-15 & pit, smudge & Wood & Ulmus spp. & Elm & 2 & 0.06 \\
\hline 41TT852, Subarea 1 & F-15 & pit, smudge & Wood & Carya spp. & Hickory & 2 & 0.32 \\
\hline 41TT852, Subarea 1 & F-15 & pit, smudge & Wood & Not examined & & 10 & 0.33 \\
\hline 41TT852, Subarea 1 & $\begin{array}{l}\text { F-90 } \\
\text { (4 samples) }\end{array}$ & midden & Nutshell & Carya sp. & Hickory & 8 & 3.96 \\
\hline 41TT852, Subarea 1 & $\begin{array}{l}\text { F-90 } \\
\text { (4 samples) }\end{array}$ & midden & Wood & $\begin{array}{l}\text { Quercus subg. } \\
\text { Quercus }\end{array}$ & $\begin{array}{l}\text { White group } \\
\text { oak }\end{array}$ & 2 & 0.24 \\
\hline 41TT852, Subarea 1 & F-189 & pit, large & Wood & Carya sp. & Hickory & 11 & 1.01 \\
\hline 41TT852, Subarea 1 & F-189 & pit, large & Wood & Quercus sp. & Oak & 29 & 2.09 \\
\hline 41TT852, Subarea 1 & F-189 & pit, large & Wood & $\begin{array}{l}\text { Quercus subg. } \\
\text { Lobatae }\end{array}$ & Red group oak & 1 & 0.05 \\
\hline 41TT852, Subarea 1 & F-189 & pit, large & Wood & $\begin{array}{l}\text { Quercus subg. } \\
\text { Quercus }\end{array}$ & $\begin{array}{l}\text { White group } \\
\text { oak }\end{array}$ & 3 & 0.09 \\
\hline 41TT852, Subarea 1 & F-189 & pit, large & Wood & Ind. & Ind. & 1 & 0.18 \\
\hline 41TT852, Subarea 1 & F-193 & pit, large & Nutshell & Carya sp. & Hickory & 76 & 17.74 \\
\hline 41TT852, Subarea 1 & F-193 & pit, large & Nutshell & Juglandaceae & $\begin{array}{l}\text { Hickory/ } \\
\text { walnut family }\end{array}$ & 23 & 0.24 \\
\hline 41TT852, Subarea 1 & F-193 & pit, large & Wood & Acer sp. & Maple & 2 & 0.14 \\
\hline 41TT852, Subarea 1 & F-193 & pit, large & Wood & Carya sp. & Hickory & 15 & 1.68 \\
\hline 41TT852, Subarea 1 & F-193 & pit, large & Wood & \begin{tabular}{|l|} 
Diospyros \\
virginiana
\end{tabular} & Persimmon & 3 & 0.42 \\
\hline 41TT852, Subarea 1 & F-193 & pit, large & Wood & $\begin{array}{l}\text { Quercus subg. } \\
\text { Lobatae }\end{array}$ & Red group oak & 3 & 0.72 \\
\hline 41TT852, Subarea 1 & F-193 & pit, large & Wood & Salicaceae & $\begin{array}{l}\text { Willow/cotton- } \\
\text { wood family }\end{array}$ & 5 & 0.30 \\
\hline 41TT852, Subarea 1 & F-193 & pit, large & Wood & $\begin{array}{l}\text { Ulmus } \\
\text { americana }\end{array}$ & American elm & 5 & 0.24 \\
\hline 41TT852, Subarea 1 & F-193 & pit, large & Ind. & & & 1 & 0.01 \\
\hline 41TT852, Subarea 1 & F-321 & pit, small & Wood & $\begin{array}{l}\text { Quercus subg. } \\
\text { Lobatae }\end{array}$ & Red group oak & 4 & 0.29 \\
\hline 41TT852, Subarea 1 & F-423 & pit, smudge & Wood & $\begin{array}{l}\text { Quercus subg. } \\
\text { Quercus }\end{array}$ & $\begin{array}{l}\text { White group } \\
\text { oak }\end{array}$ & 17 & 0.38 \\
\hline 41TT852, Subarea 1 & F-442 & pit, small & Nutshell & Juglandaceae & $\begin{array}{l}\text { Hickory/ } \\
\text { walnut family }\end{array}$ & 1 & 0.07 \\
\hline 41TT852, Subarea 1 & F-484 & pit, large & Nutshell & Carya sp. & Hickory & 1 & 0.30 \\
\hline 41TT852, Subarea 1 & $\mathrm{~F}-490$ & pit, large & Wood & Carya sp. & Hickory & 4 & 0.15 \\
\hline 41TT852, Subarea 1 & $\mathrm{~F}-490$ & pit, large & Nutshell & Carya sp. & Hickory & 1 & 0.12 \\
\hline 41TT852, Subarea 1 & F-490 & pit, large & Wood & $\begin{array}{l}\text { Quercus subg. } \\
\text { Quercus }\end{array}$ & $\begin{array}{l}\text { White group } \\
\text { oak }\end{array}$ & 2 & 0.68 \\
\hline 41TT852, Subarea 1 & F-518 & pit, large & Nutshell & Carya sp. & Hickory & 2 & 1.77 \\
\hline 41TT852, Subarea 1 & F-544 & pit, small & Wood & Carya sp. & Hickory & 4 & 0.15 \\
\hline 41TT852, Subarea 1 & F-544 & pit, small & Nutshell & Carya sp. & Hickory & 1 & 0.12 \\
\hline 41TT852, Subarea 1 & F-544 & pit, small & Wood & $\begin{array}{l}\text { Quercus subg. } \\
\text { Quercus }\end{array}$ & $\begin{array}{l}\text { White group } \\
\text { oak }\end{array}$ & 2 & 0.68 \\
\hline $41 \mathrm{TT} 853$ & $\mathrm{~F}-2$ & burial & Nutshell & Carya spp. & Hickory & 1 & 0.07 \\
\hline $41 \mathrm{TT} 853$ & $\mathrm{~F}-2$ & burial & Wood & Quercus spp. & Oak & 1 & 2.27 \\
\hline $41 \mathrm{TT} 853$ & $\begin{array}{l}\text { F-6 } \\
(2 \text { samples }) \\
\end{array}$ & pit, small & Nutshell & Carya spp. & Hickory & 25 & 1.82 \\
\hline $41 \mathrm{TT} 853$ & $\begin{array}{l}\text { F-6 } \\
(2 \text { samples })\end{array}$ & pit, small & Wood & Ulmus spp. & Elm & 4 & 0.32 \\
\hline
\end{tabular}


Table F.1, continued

\begin{tabular}{|c|c|c|c|c|c|c|c|}
\hline Site & Provenience & $\begin{array}{l}\text { Feature } \\
\text { Type }\end{array}$ & $\begin{array}{l}\text { Plant } \\
\text { Part }\end{array}$ & Identification & $\begin{array}{l}\text { Common } \\
\text { Name }\end{array}$ & No. & $\begin{array}{l}\text { Weight } \\
\text { (g) }\end{array}$ \\
\hline 41TT853 & $\begin{array}{l}\text { F-6 }(2 \\
\text { samples })\end{array}$ & pit, small & Wood & $\begin{array}{l}\text { Quercus } \\
\text { virginiana }\end{array}$ & Live oak & 6 & 0.69 \\
\hline 41TT853 & $\begin{array}{l}\text { F-6 } \\
\text { (2 samples) }\end{array}$ & pit, small & Wood & Quercus spp. & Oak & 3 & 0.65 \\
\hline $41 \mathrm{TT} 853$ & $\begin{array}{l}\text { F-6 } \\
\text { (2 samples) } \\
\end{array}$ & pit, small & Wood & $\begin{array}{l}\text { Quercus subg. } \\
\text { Quercus }\end{array}$ & $\begin{array}{l}\text { White group } \\
\text { oak }\end{array}$ & 7 & 0.20 \\
\hline 41TT853 & $\begin{array}{l}\text { F-6 } \\
(2 \text { samples }) \\
\end{array}$ & pit, small & Wood & Not examined & & 85 & 2.53 \\
\hline 41TT853 & $\begin{array}{l}\text { F-12 } \\
(2 \text { samples }) \\
\end{array}$ & pit, large & Nutshell & Carya spp. & Hickory & 43 & 5.09 \\
\hline 41TT853 & $\begin{array}{l}\text { F-12 } \\
\text { (2 samples) }\end{array}$ & pit, large & Nutshell & Juglandaceae & $\begin{array}{l}\text { Hickory/ } \\
\text { walnut family }\end{array}$ & 2 & 0.17 \\
\hline 41TT853 & $\begin{array}{l}\text { F-12 } \\
(2 \text { samples }) \\
\end{array}$ & pit, large & Wood & $\begin{array}{l}\text { Quercus subg. } \\
\text { Quercus }\end{array}$ & $\begin{array}{l}\text { White group } \\
\text { oak }\end{array}$ & 8 & 1.90 \\
\hline 41TT853 & $\begin{array}{l}\text { F-12 } \\
\text { (2 samples }) \\
\end{array}$ & pit, large & Wood & Carya spp. & Hickory & 4 & 2.04 \\
\hline 41TT853 & $\begin{array}{l}\text { F-12 } \\
(2 \text { samples }) \\
\end{array}$ & pit, large & Ind. & & & 2 & 0.56 \\
\hline 41TT853 & F-14 & pit, small & Wood & $\begin{array}{l}\text { Quercus } \\
\text { virginiana }\end{array}$ & Live oak & 1 & 0.12 \\
\hline 41TT853 & F-14 & pit, small & Wood & $\begin{array}{l}\text { Quercus subg. } \\
\text { Quercus }\end{array}$ & $\begin{array}{l}\text { White group } \\
\text { oak }\end{array}$ & 3 & 0.11 \\
\hline 41TT853 & $\mathrm{F}-16$ & pit, smudge & Bark & & & 13 & 1.16 \\
\hline 41TT853 & $\mathrm{F}-16$ & pit, smudge & Wood & Quercus spp. & Oak & 5 & 0.18 \\
\hline 41TT853 & $\begin{array}{l}\text { F-17 } \\
\text { (3 samples) }\end{array}$ & pit, large & Wood & $\begin{array}{l}\text { Quercus subg. } \\
\text { Quercus }\end{array}$ & $\begin{array}{l}\text { White group } \\
\text { oak }\end{array}$ & 7 & 0.18 \\
\hline 41TT853 & $\begin{array}{l}\text { F-17 } \\
\text { (3 samples) }\end{array}$ & pit, large & Nutshell & Carya spp. & Hickory & 2 & 1.57 \\
\hline 41TT853 & $\begin{array}{l}\text { F-17 } \\
\text { (3 samples) } \\
\end{array}$ & pit, large & Nutshell & Juglandaceae & $\begin{array}{l}\text { Hickory/ } \\
\text { walnut family }\end{array}$ & 1 & 0.11 \\
\hline 41TT853 & $\mathrm{F}-20$ & pit, small & Nutshell & Carya spp. & Hickory & 4 & 0.24 \\
\hline $41 \mathrm{TT} 853$ & F-28 & pit, large & Wood & Quercus sp. & Oak & 5 & 0.04 \\
\hline $41 \mathrm{TT} 853$ & F-35 & pit, large & Wood & Quercus sp. & Oak & 3 & 0.31 \\
\hline $41 \mathrm{TT} 853$ & F-35 & pit, large & Wood & $\begin{array}{l}\text { Quercus subg. } \\
\text { Lobatae }\end{array}$ & Red group oak & 9 & 0.21 \\
\hline $41 \mathrm{TT} 853$ & F-44 & noncultural & Wood & Quercus sp. & Oak & 1 & 0.71 \\
\hline $41 \mathrm{TT} 853$ & $\begin{array}{l}\text { F-45 } \\
(2 \text { samples }) \\
\end{array}$ & pit, large & Wood & $\begin{array}{l}\text { Quercus subg. } \\
\text { Lobatae }\end{array}$ & Red group oak & 29 & 1.62 \\
\hline $41 \mathrm{TT} 853$ & $\mathrm{~F}-47$ & pit, smudge & Wood & $\begin{array}{l}\text { Quercus subg. } \\
\text { Lobatae }\end{array}$ & Red group oak & 28 & 2.09 \\
\hline 41TT865 & \begin{tabular}{|l} 
TU 10, \\
Level 3 \\
\end{tabular} & na & Wood & Carya spp. & Hickory & 1 & 0.10 \\
\hline 41TT865 & \begin{tabular}{|l} 
TU 10, \\
Level 3 \\
\end{tabular} & na & Nutshell & Carya spp. & Hickory & $\overline{1}$ & 0.25 \\
\hline $41 \mathrm{TT} 865$ & \begin{tabular}{|l} 
TU 10, \\
Level 3 \\
\end{tabular} & na & Nut husk & Carya spp. & Hickory & 42 & 6.00 \\
\hline $41 \mathrm{TT} 865$ & $\begin{array}{l}\text { TU 10, } \\
\text { Level } 4 \\
\end{array}$ & na & Wood & Quercus spp. & Oak & 10 & 1.52 \\
\hline
\end{tabular}

Note Ind. = Indeterminable 
Plants identified for possible radiocarbon dating consist of wood charcoal, hickory nutshell, and hickory nut husk. Woods identified were oaks, hickory, elm, sweetgum, maple, persimmon, and willow or cottonwood. Fragments of uncarbonized bark and roots were also present but are interpreted as modern. The semicarbonized red group oak wood and indeterminable woods are more difficult to interpret. These materials were recovered in carbonized form, which is believed to be ancient. The semicarbonized wood may have been preserved from Caddo occupation of the sites but was not recommended for radiocarbon dating because so many more appropriate samples were available. All kinds of plant remains recovered in the hand-collected samples were also present in the flotation samples.

\section{Flotation Samples}

Two hundred twenty-seven flotation samples representing 2,331 liters of soil were examined from the data recovery excavations at 41TT851, 41TT852, and 41TT853. Feature types are primarily pits and postholes, with midden deposits and the fill of a burial represented at 41TT852 (Table F.2).

\section{Uncarbonized Plant Remains}

Nearly all flotation samples included uncarbonized plants in the form of rootlets. Uncarbonized seeds present in flotation samples at each site are shown in Table F.3. Uncarbonized seeds are a common occurrence at most archeological sites, but they usually represent seeds of modern plants that have made their way into the soil either through their own dispersal mechanisms or by faunalturbation, floralturbation, or argilliturbation (Bryant 1985:51-52; Miksicek 1987:231-232). In all except the driest areas of North America, uncarbonized plant material on open-air sites can be assumed to be of modern origin unless compelling evidence suggests otherwise (Lopinot and Brussell 1982; Miksicek 1987:231). Two lines of evidence indicate that uncarbonized seeds at the Mount Pleasant sites are modern. First are the plant taxa themselves. With few exceptions, the seeds consist of weedy annuals likely to be present at disturbed sites undergoing archeological investigation. The exceptions are blackberry, grape, maple, and elm, all which would be expected in the vicin-
Table F.2. Analyzed flotation samples by feature type

\begin{tabular}{l|c|c|c}
\hline Feature Type & $\begin{array}{c}\text { Total } \\
\text { Liters }\end{array}$ & $\begin{array}{c}\text { Total } \\
\text { Samples }\end{array}$ & $\begin{array}{c}\text { Total } \\
\text { Features }\end{array}$ \\
\hline 41TT851, Subarea 1: \\
\hline Pit, large & 679.0 & 28 & 18 \\
\hline Pit, small & 207.5 & 31 & 30 \\
\hline Pit, smudge & 14.5 & 3 & 3 \\
\hline Posthole & 157.0 & 41 & 41 \\
\hline Noncultural & 2.5 & 1 & 1 \\
\hline Total & $1,092.5$ & 104 & 93 \\
\hline 41TT852, Subarea 1: & 76.0 & 5 & 3 \\
\hline Midden & 3.0 & 1 & 1 \\
\hline Burial & 237.0 & 9 & 9 \\
\hline Pit, large & 366.0 & 36 & 32 \\
\hline Pit, small & 80.5 & 11 & 9 \\
\hline Pit, smudge & 99.0 & 21 & 20 \\
\hline Posthole & 861.5 & 83 & 74 \\
\hline Total & & & \\
\hline 41TT853: & 264.0 & 13 & 9 \\
\hline Pit, large & 90.5 & 11 & 11 \\
\hline Pit, small & 10.0 & 1 & 1 \\
\hline Pit, smudge & 12.5 & 4 & 4 \\
\hline Posthole & 377.0 & 29 & 25 \\
\hline Total & \multicolumn{5}{|l}{} \\
\hline
\end{tabular}

ity of Tankersley Creek today. Second, there is little overlap between uncarbonized seeds and carbonized (archeological) seeds. Only five taxa are present in both forms: Chenopodium, purslane, amaranth, blackberry, and grape, likely reflecting the continued presence of these plants in anthropogenic environments of the site area in ancient and modern times. Methodologically, Chenopodium and purslane are more problematic than the other three taxa since these seeds are black in uncarbonized form. Carbonized Chenopodium could usually be distinguished from uncarbonized by differences in size and shape. Most of the uncarbonized seeds are probably the adventive Chenopodium album. In addition, carbonized Chenopodium was generally in poor condition and uncarbonized Chenopodium in excellent condition, making the two forms easy to distinguish under the microscope. Purslane presented a greater problem. Unless they were clearly uncarbonized or clearly 
Table F.3. Uncarbonized seeds from flotation samples

\begin{tabular}{|c|c|c|c|c|}
\hline Botanical Name & Common Name & $41 \mathrm{TT} 851$ & 41TT852 & $41 \mathrm{TT} 853$ \\
\hline Acalypha sp. & Copperleaf & $\mathrm{X}$ & $\mathrm{X}$ & $\mathrm{X}$ \\
\hline Acer sp. & Maple & $\mathrm{X}$ & & \\
\hline Allium sp. & Wild garlic & $\mathrm{X}$ & & \\
\hline Amaranthus sp. & Amaranth & $\mathrm{X}$ & $\mathrm{X}$ & \\
\hline Ambrosia sp. & Ragweed & $\mathrm{X}$ & & \\
\hline Asteraceae & Daisy family & $\mathrm{X}$ & & \\
\hline Carex sp. & Sedge & $\mathrm{X}$ & & $\mathrm{X}$ \\
\hline Chamaesyce sp. & Sandmat & $\mathrm{X}$ & $\mathrm{X}$ & \\
\hline Chenopodium sp. & Goosefoot & $\mathrm{X}$ & $\mathrm{X}$ & $\mathrm{X}$ \\
\hline Chenopodium/Amaranthus spp. & Cheno/am & $\mathrm{X}$ & & \\
\hline Corydalis sp. & Fumewort & $\mathrm{X}$ & $\mathrm{X}$ & $\mathrm{X}$ \\
\hline Croton spp. & Croton & $\mathrm{X}$ & $\mathrm{X}$ & $\mathrm{X}$ \\
\hline Cucurbita sp. & Squash/gourd & $\mathrm{X}$ & & \\
\hline Cyperaceae & Sedge family & $\mathrm{X}$ & & \\
\hline Cyperus sp. & Flatsedge & $\mathrm{X}$ & $\mathrm{X}$ & $\mathrm{X}$ \\
\hline Euphorbiaceae & Spurge family & $\mathrm{X}$ & $\mathrm{X}$ & $\mathrm{X}$ \\
\hline Iva annua & Sumpweed & $\mathrm{X}$ & & \\
\hline Lamiaceae & Mint family & $\mathrm{X}$ & $\mathrm{X}$ & $\mathrm{X}$ \\
\hline cf. Ligustrum sp. & cf. Privet & $\mathrm{X}$ & & $\bar{X}$ \\
\hline Mollugo verticillata & Carpetweed & $\mathrm{X}$ & $\mathrm{X}$ & $\mathrm{X}$ \\
\hline Oenothera sp. & Evening primrose & $\mathrm{X}$ & $\mathrm{X}$ & \\
\hline Oxalis sp. & Woodsorrel & $\mathrm{X}$ & $\mathrm{X}$ & $\mathrm{X}$ \\
\hline Panicodae & Panicoid grass & $\mathrm{X}$ & $\mathrm{X}$ & \\
\hline Phytolacca americana & Pokeweed & $\mathrm{X}$ & $\mathrm{X}$ & $\mathrm{X}$ \\
\hline Poaceae & Grass family & $\mathrm{X}$ & $\mathrm{X}$ & $\mathrm{X}$ \\
\hline Polygonum sp., lenticular & Smartweed & & $\mathrm{X}$ & \\
\hline Polygonum sp., trigonous & Knotweed & $\mathrm{X}$ & & \\
\hline Portulaca oleracea & Purslane & $\mathrm{X}$ & $\mathrm{X}$ & $\mathrm{X}$ \\
\hline Prunella sp. & Selfheal & $\mathrm{X}$ & $\mathrm{X}$ & $\mathrm{X}$ \\
\hline Ranunculus sp. & Buttercup & $\mathrm{X}$ & & \\
\hline Rubus sp. & Blackberry & $\mathrm{X}$ & $\mathrm{X}$ & $\mathrm{X}$ \\
\hline Rudbeckia/Echinacea spp. & Coneflower & & $\mathrm{X}$ & \\
\hline Rumex crispus & Curly dock & & $\mathrm{X}$ & $\mathrm{X}$ \\
\hline Scirpus sp. & Bulrush & $\mathrm{X}$ & $\mathrm{X}$ & $\mathrm{X}$ \\
\hline Solanum sp. & Nightshade & $\mathrm{X}$ & & \\
\hline Stellaria media & Chickweed & $\mathrm{X}$ & & $\mathrm{X}$ \\
\hline Ulmus sp. & Elm & $\mathrm{X}$ & & \\
\hline Unknown & Unknown & $\mathrm{X}$ & $\mathrm{X}$ & $\mathrm{X}$ \\
\hline Verbascum sp. & Mullein & $\mathrm{X}$ & $\mathrm{X}$ & \\
\hline Viola sp. & Violet & $\mathrm{X}$ & & \\
\hline Vitis sp. & Grape & & $\mathrm{X}$ & $\mathrm{X}$ \\
\hline
\end{tabular}


carbonized, purslane seeds were broken to check for carbonization (Pearsall 2000).

\section{Semicarbonized Plant Remains}

For the flotation samples, only carbonized and a few semicarbonized remains are treated as ancient in this analysis. Bark is present in both uncarbonized and semicarbonized form, so it is included with the modern contamination. A small amount of semicarbonized material is also present in carbonized form but not uncarbonized form. This material is treated as ancient. It consists of five fragments of a hardwood from Feature 319 at 41TT851, a corn cupule with a single brown spot from Feature 27 at 41TT851, one fragment of maple wood from Feature 243 at 41TT852, and three acorn nutshell fragments from Feature 437 at 41TT852. The corn cupule is especially likely to be ancient, since it would not be expected among the modern plants in the site area, where the land has been in pasture for many years.

\section{Carbonized (Ancient) Plant Remains}

A summary of the ancient plant remains for each of the three sites is given in Table F.4. These remains are presented by individual site and feature type in Tables F.5-F.7. Attachment F.1 (in digital form only) contains complete identifications for each lot.

\section{Site 41TT851}

\section{Characteristics of the Sample}

Overall botanical density in the flotation samples from 41TT851 is $0.069 \mathrm{~g} /$ liter (excluding hand-collected remains from the eight features with flotation samples). Samples are fairly uniform in their contents since all represent general site debris. Three pit features have unusually large samples, making up 24 percent of the total liters processed: Feature 28 (82.5 liters), Feature 188 (86.5 liters), and Feature 189 (98.0 liters).

Plant remains from $41 \mathrm{TT} 851$ were recovered from pits and postholes. When all wood charcoal in a posthole is of a single type, it can suggest that the fragments represent structural wood in primary (or possibly secondary) context. Only one context at $41 T$ T851 contains only a single type of wood (large pit Feature 110). Much decaying bark was also noted in this pit, though, raising the possibility that the charcoal represents a burned stump rather than archeological remains. None of the features identified as postholes contained only a single type of wood. Postholes at the site are interpreted as having filled with general site debris when the posts decayed or were moved to another location. The three smudge pits contain modest quantities of what appears to be general site debris, although one (Feature 319) also has a large quantity of decayed wood that could not be identified.

\section{Fuel Wood}

Wood charcoal recovered from archeological contexts at 41TT851 is assumed to represent fuel wood, mostly in secondary context (as noted above, Feature 319 probably represents a primary context). Identification was attempted for 1,646 pieces of wood charcoal from flotation, of which 733 are identifiable to botanical family, genus, or species. Of the identifiable wood charcoal, 77 percent is oak. Hickory is next most common, at 18 percent of the assemblage. Twelve other woods make up the remaining 5 percent.

\section{Agricultural Products}

Corn is the only clearly agricultural plant recovered from 41TT851, but only $0.37 \mathrm{~g}$ were recovered in the $1,092.5$ liters of flotationprocessed fill. Most of the corn remains are cupules or glumes $(\mathrm{n}=45,0.31 \mathrm{~g})$, but six kernel fragments were recovered from five contexts. Overall, corn was identified in 18 of the 104 samples, for a ubiquity of 17.3 percent.

A total of 11 small, starchy seeds that were cultivated elsewhere in the eastern woodlands were recovered from 41TT851. Their status at 41TT851 is unclear. The seeds are few in number, which argues against cultivation; however, all seeds, including corn kernels, are rare at 41TT851. Whether the small starchy seeds at 41 TT851 represent the same species as the cultivated varieties is also not clear. Features 9 and 189 each yielded a single specimen of trigonous knotweed. Although similar to erect knotweed (Polygonum erectum), the specimens 
Table F.4. Carbonized plant material from flotation samples

\begin{tabular}{|c|c|c|c|c|c|c|c|}
\hline & & \multicolumn{2}{|c|}{$41 \mathrm{TT} 851$} & \multicolumn{2}{|c|}{ 41TT852 } & \multicolumn{2}{|c|}{$41 \mathrm{TT} 853$} \\
\hline Botanical Name & Common Name & No. & $\begin{array}{l}\text { Weight } \\
(\mathrm{g})\end{array}$ & No. & $\begin{array}{l}\text { Weight } \\
(\mathrm{g}) \\
\end{array}$ & No. & $\begin{array}{l}\text { Weight } \\
(\mathrm{g})\end{array}$ \\
\hline \multicolumn{8}{|l|}{ Wood charcoal } \\
\hline Acer sp. & Maple & 3 & 0.04 & 5 & 0.11 & & \\
\hline Aesculus sp. & Buckeye & 2 & 0.02 & 2 & 0.01 & & \\
\hline Carya illinoinensis & Pecan & 1 & 0.06 & & & & \\
\hline Carya sp. & Hickory & 129 & 2.02 & 173 & 2.82 & 20 & 0.27 \\
\hline Catalpa sp. & Catalpa & 4 & 0.03 & & & & \\
\hline Celtis sp. & Hackberry & & & 1 & 0.01 & & \\
\hline Diospyros virginiana & Persimmon & & & 6 & 0.07 & 3 & 0.03 \\
\hline Fraxinus sp. & Ash & 6 & 0.07 & 2 & 0.04 & 2 & 0.02 \\
\hline Ilex sp. & Holly & 2 & 0.05 & & & & \\
\hline Juglans nigra & Black walnut & & & 1 & 0.01 & & \\
\hline Liquidambar styraciflua & Sweetgum & 11 & 0.11 & 2 & 0.04 & & \\
\hline Morus sp. & Mulberry & 4 & 0.05 & 4 & 0.07 & & \\
\hline Platanus occidentalis & Sycamore & & & 1 & 0.01 & & \\
\hline Prunus sp. & Plum/cherry & 2 & 0.02 & 9 & 0.13 & 1 & 0.01 \\
\hline Quercus subg. Lobatae & Red group oak & 237 & 3.17 & 201 & 2.73 & 116 & 1.66 \\
\hline Quercus subg. Quercus & White group oak & 172 & 1.99 & 466 & 7.08 & 88 & 1.55 \\
\hline Quercus sp. & Oak & 156 & 3.06 & 128 & 2.80 & 54 & 0.58 \\
\hline Salicaceae & Willow/cottonwood family & & & 1 & 0.02 & & \\
\hline Salix spp. & Willow & 1 & 0.01 & & & & \\
\hline Sambucus nigra & Elderberry & & & 1 & 0.01 & & \\
\hline Ulmus americana & American elm & 2 & 0.02 & 3 & 0.07 & & \\
\hline Ulmus rubra & Slippery elm & 1 & 0.03 & & & & \\
\hline Ulmus sp. & Elm & & & 15 & 0.12 & 2 & 0.03 \\
\hline Diffuse-porous hardwood & Diffuse-porous hardwood & 3 & 0.05 & 4 & 0.03 & & \\
\hline Ring-porous hardwood & Ring-porous hardwood & 7 & 0.06 & 5 & 0.07 & & \\
\hline Hardwood & Hardwood & 69 & 1.07 & 33 & 0.50 & 2 & 0.02 \\
\hline Unknown & Unknown & & & 1 & 0.01 & & \\
\hline Indeterminable & Ind. & 834 & 5.81 & 1 & 0.01 & 220 & 2.16 \\
\hline Not examined & Not examined & 1708 & 26.94 & 3131 & 42.87 & 1308 & 12.70 \\
\hline \multicolumn{8}{|l|}{ Nutshell } \\
\hline Carya sp. & Hickory & 775 & 24.26 & 546 & 19.23 & 281 & 8.15 \\
\hline Juglandaceae & Hickory/walnut family & 131 & 1.11 & 93 & 0.95 & 66 & 0.60 \\
\hline Juglans nigra & Black walnut & 4 & 0.09 & & & & \\
\hline Quercus sp. & Acorn & 166 & 0.75 & 194 & 0.74 & 13 & 0.06 \\
\hline \multicolumn{8}{|l|}{ Nutmeat } \\
\hline Juglandaceae & Hickory/walnut family & & & 22 & 0.07 & & \\
\hline \multicolumn{8}{|l|}{ Cultigens } \\
\hline $\begin{array}{l}\text { Zea mays, cupules and } \\
\text { glumes }\end{array}$ & Corn & 45 & 0.31 & 918 & 5.07 & 244 & 1.26 \\
\hline Zea mays, kernels & Corn & 6 & 0.06 & 17 & 0.22 & 6 & 0.07 \\
\hline Phaseolus vulgaris & Common Bean & & & 26 & 0.28 & & \\
\hline Phaseolus/Diospyros & Bean/persimmon & & & 49 & 0.27 & & \\
\hline \multicolumn{8}{|l|}{ Possible cultigens } \\
\hline Amaranthus sp. & Amaranth & & & 1 & 0.01 & & \\
\hline Chenopodium sp. & Goosefoot & 3 & 0.02 & 8 & 0.06 & & \\
\hline
\end{tabular}


Table F.4, continued

\begin{tabular}{|c|c|c|c|c|c|c|c|}
\hline & & \multicolumn{2}{|c|}{ 41TT851 } & \multicolumn{2}{|c|}{ 41TT852 } & \multicolumn{2}{|c|}{$41 \mathrm{TT} 853$} \\
\hline Botanical Name & Common Name & No. & $\begin{array}{c}\text { Weight } \\
(\mathrm{g})\end{array}$ & No. & $\begin{array}{c}\text { Weight } \\
(\mathrm{g})\end{array}$ & No. & $\begin{array}{c}\text { Weight } \\
\text { (g) }\end{array}$ \\
\hline Hordeum pusillum & Little barley & & & 2 & 0.01 & & \\
\hline Hordeum/Elymus sp. & Little barley/Wildrye & 1 & 0.01 & & & & \\
\hline Panicum sp. & Panicgrass & & & 17 & 0.09 & & \\
\hline Phalaris caroliniana & Maygrass & 5 & 0.03 & 148 & 0.35 & 4 & 0.02 \\
\hline Polygonum erectum & Erect knotweed & & & 4 & 0.03 & & \\
\hline Polygonum sp., trigonous & Knotweed & 2 & 0.02 & & & & \\
\hline \multicolumn{8}{|l|}{ Other seeds } \\
\hline Asteraceae & Daisy family & & & 2 & 0.02 & 2 & 0.02 \\
\hline Cyperaceae & Sedge family & & & 1 & 0.01 & & \\
\hline Diospyros virginiana & Persimmon & & & 13 & 0.14 & & \\
\hline Fabaceae & Legume & & & 7 & 0.03 & & \\
\hline Fragaria sp. & Strawberry & & & & & 2 & 0.02 \\
\hline Galium sp. & Stick-tight & & & 3 & 0.02 & & \\
\hline Poaceae & Grass family & 6 & 0.04 & 5 & 0.04 & 1 & 0.01 \\
\hline Polygonum sp., lenticular & Smartweed & & & 2 & 0.01 & & \\
\hline Portulaca oleracea & Purslane & 4 & 0.03 & 919 & 0.40 & 1 & 0.01 \\
\hline Rhus sp. & Sumac & 1 & 0.01 & 6 & 0.04 & & \\
\hline Sambucus nigra & Elderberry & & & & & 1 & 0.01 \\
\hline Solanum sp. & Nightshade & & & & & 2 & 0.01 \\
\hline Tradescantia sp. & Spiderwort & & & & & 1 & 0.01 \\
\hline Verbena sp. & Verbena & 2 & 0.01 & & & 1 & 0.01 \\
\hline Vitis sp. & Grape & 1 & 0.01 & 1 & 0.01 & & \\
\hline Unknown & Unknown & & & 4 & 0.04 & & \\
\hline Indeterminable & Ind. & 16 & 0.07 & 9 & 0.09 & & \\
\hline \multicolumn{8}{|l|}{ Monocot stems } \\
\hline Arundinaria gigantea & Cane & 5 & 0.07 & 4 & 0.04 & 6 & 0.04 \\
\hline Poaceae & Grass family & & & 3 & 0.03 & 1 & 0.01 \\
\hline \multicolumn{8}{|l|}{ Other material } \\
\hline Bark & & 143 & 1.85 & 19 & 0.33 & 1 & 0.02 \\
\hline Bulb scale & & 2 & 0.03 & & & & \\
\hline Fruit & & 1 & 0.01 & & & 4 & 0.01 \\
\hline Catkin & & & & & & 1 & 0.01 \\
\hline Fungus & & & & & & 1 & 0.01 \\
\hline Unknown & & 4 & 0.02 & 1 & 0.01 & 3 & 0.01 \\
\hline Indeterminable & & 186 & 1.66 & 147 & 1.08 & 80 & 1.67 \\
\hline Totals & & & 75.15 & & 89.36 & & 31.07 \\
\hline
\end{tabular}

Note: Ind. = Indeterminable

are nearly symmetrical and thus may not represent the cultivated species, which tends to have one elongated corner. A grass seed from Feature 335 is in poor condition and may represent either little barley (Hordeum pusillum; considered cultivated on some sites) or wild rye (Elymus sp.; not generally considered cultivated, but known in the form of starch grains at 41PT186 in the Texas Panhandle, and also recovered in carbonized form from archeological sites in the northeast [Crawford and Smith 2003]). 
Table F.5. Carbonized plant material from flotation by feature type for 41 TT851

\begin{tabular}{|c|c|c|c|c|c|c|c|c|}
\hline & \multicolumn{2}{|c|}{ Large Pits } & \multicolumn{2}{|c|}{ Smudge Pits } & \multicolumn{2}{|c|}{ Other Small Pits } & \multicolumn{2}{|c|}{ Postholes } \\
\hline & No. & Weight (g) & No. & Weight $(\mathrm{g})$ & No. & Weight (g) & No. & Weight $(\mathrm{g})$ \\
\hline \multicolumn{9}{|l|}{ Wood charcoal } \\
\hline American elm & & & & & 2 & 0.02 & & \\
\hline Ash & & & & & 5 & 0.06 & 1 & 0.01 \\
\hline Buckeye & 2 & 0.02 & & & & & & \\
\hline Catalpa & 2 & 0.02 & & & & & 2 & 0.01 \\
\hline Hickory & 70 & 1.18 & 4 & 0.09 & 40 & 0.42 & 15 & 0.33 \\
\hline Holly & & & & & 2 & 0.05 & & \\
\hline Maple & 2 & 0.03 & & & & & 1 & 0.01 \\
\hline Mulberry & 1 & 0.02 & & & 2 & 0.02 & 1 & 0.01 \\
\hline Red group oak & 129 & 2.01 & 3 & 0.08 & 72 & 0.78 & 33 & 0.30 \\
\hline White group oak & 87 & 1.10 & 1 & 0.04 & 42 & 0.45 & 42 & 0.40 \\
\hline Oak & 53 & 1.77 & 21 & 0.58 & 46 & 0.29 & 36 & 0.42 \\
\hline Pecan & & & & & 1 & 0.06 & & \\
\hline Plum/cherry & 1 & 0.01 & & & & & 1 & 0.01 \\
\hline Slippery elm & 1 & 0.03 & & & & & & \\
\hline Sweetgum & 7 & 0.09 & 2 & 0.01 & 2 & 0.01 & & \\
\hline Willow & & & & & 1 & 0.01 & & \\
\hline Diffuse-porous hardwood & 1 & 0.01 & & & 2 & 0.04 & & \\
\hline Ring-porous hardwood & 1 & 0.01 & & & 6 & 0.05 & & \\
\hline Hardwood & 19 & 0.38 & 6 & 0.05 & 28 & 0.54 & 16 & 0.10 \\
\hline Indeterminable & & & 821 & 5.75 & & & 13 & 0.06 \\
\hline Not examined & 1361 & 19.98 & 152 & 4.47 & 137 & 1.68 & 58 & 0.81 \\
\hline \multicolumn{9}{|l|}{ Nutshell } \\
\hline Hickory & 620 & 19.69 & 6 & 0.21 & 138 & 4.21 & 11 & 0.15 \\
\hline Hickory/walnut & 93 & 0.82 & 2 & 0.03 & 21 & 0.17 & 14 & 0.08 \\
\hline Black walnut & & & & & 4 & 0.09 & & \\
\hline Acorn & 54 & 0.19 & 4 & 0.02 & 103 & 0.49 & 5 & 0.05 \\
\hline \multicolumn{9}{|l|}{ Cultigens } \\
\hline Corn cupules and glumes & 24 & 0.17 & 16 & 0.09 & 3 & 0.03 & 2 & 0.02 \\
\hline Corn kernels & 5 & 0.05 & & & 1 & 0.01 & & \\
\hline \multicolumn{9}{|l|}{ Possible cultigens } \\
\hline \multicolumn{9}{|l|}{ Erect knotweed } \\
\hline Goosefoot & 3 & 0.02 & & & & & & \\
\hline Knotweed & 2 & 0.02 & & & & & & \\
\hline Little barley/wildrye & & & & & 1 & 0.01 & & \\
\hline Maygrass & 4 & 0.02 & & & 1 & 0.01 & & \\
\hline \multicolumn{9}{|l|}{ Panicgrass } \\
\hline \multicolumn{9}{|l|}{ Other seeds } \\
\hline Grape & 1 & 0.01 & & & & & & \\
\hline Grass & 3 & 0.01 & 2 & 0.02 & & & 1 & 0.01 \\
\hline Purslane & 3 & 0.02 & & & 1 & 0.01 & & \\
\hline Sumac & 1 & 0.01 & & & & & & \\
\hline Verbena & & & & & 1 & 0.01 & & \\
\hline Indeterminable & 14 & 0.05 & & & 2 & 0.02 & & \\
\hline \multicolumn{9}{|l|}{ Monocot stems } \\
\hline Cane & 4 & 0.06 & & & 1 & 0.01 & & \\
\hline \multicolumn{9}{|l|}{ Other material } \\
\hline Bark & 14 & 0.24 & 32 & 0.32 & 93 & 1.19 & 4 & 0.10 \\
\hline Bulb scale & 2 & 0.03 & & & & & & \\
\hline Fruit & & & & & 1 & 0.01 & & \\
\hline Unknown & & & & & 4 & 0.04 & & \\
\hline Indeterminable & 155 & 1.37 & 1 & 0.02 & 21 & 0.20 & 9 & 0.07 \\
\hline Totals & & 49.44 & & 11.78 & & 10.99 & & 2.95 \\
\hline
\end{tabular}

Note: Excludes $0.1 \mathrm{~g}$ of hickory/walnut nutshell from a noncultural feature. 
Excavations along the U.S. Highway 271 Mount Pleasant Relief Route

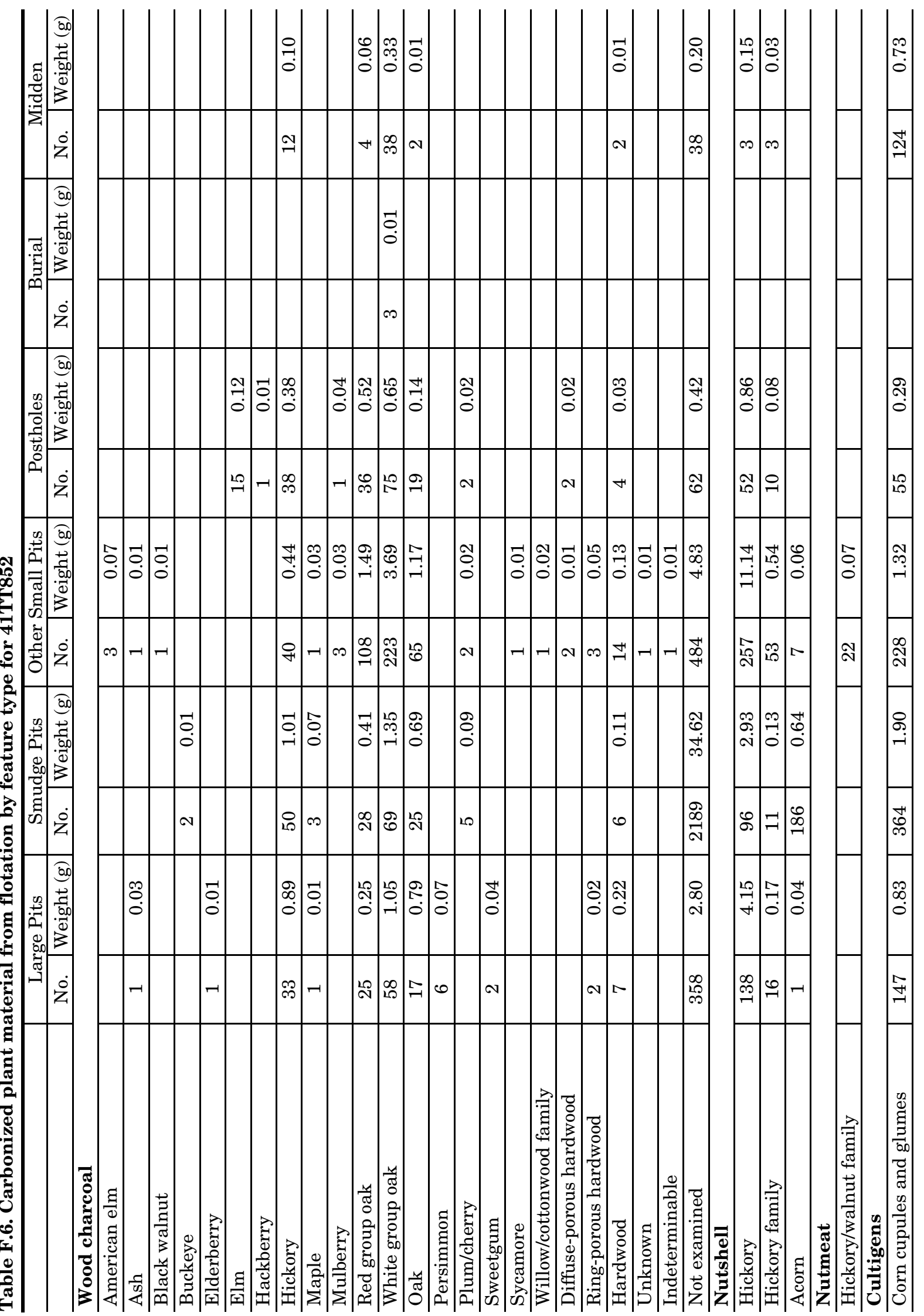


Appendix F: Macrobotanical Plant Remains

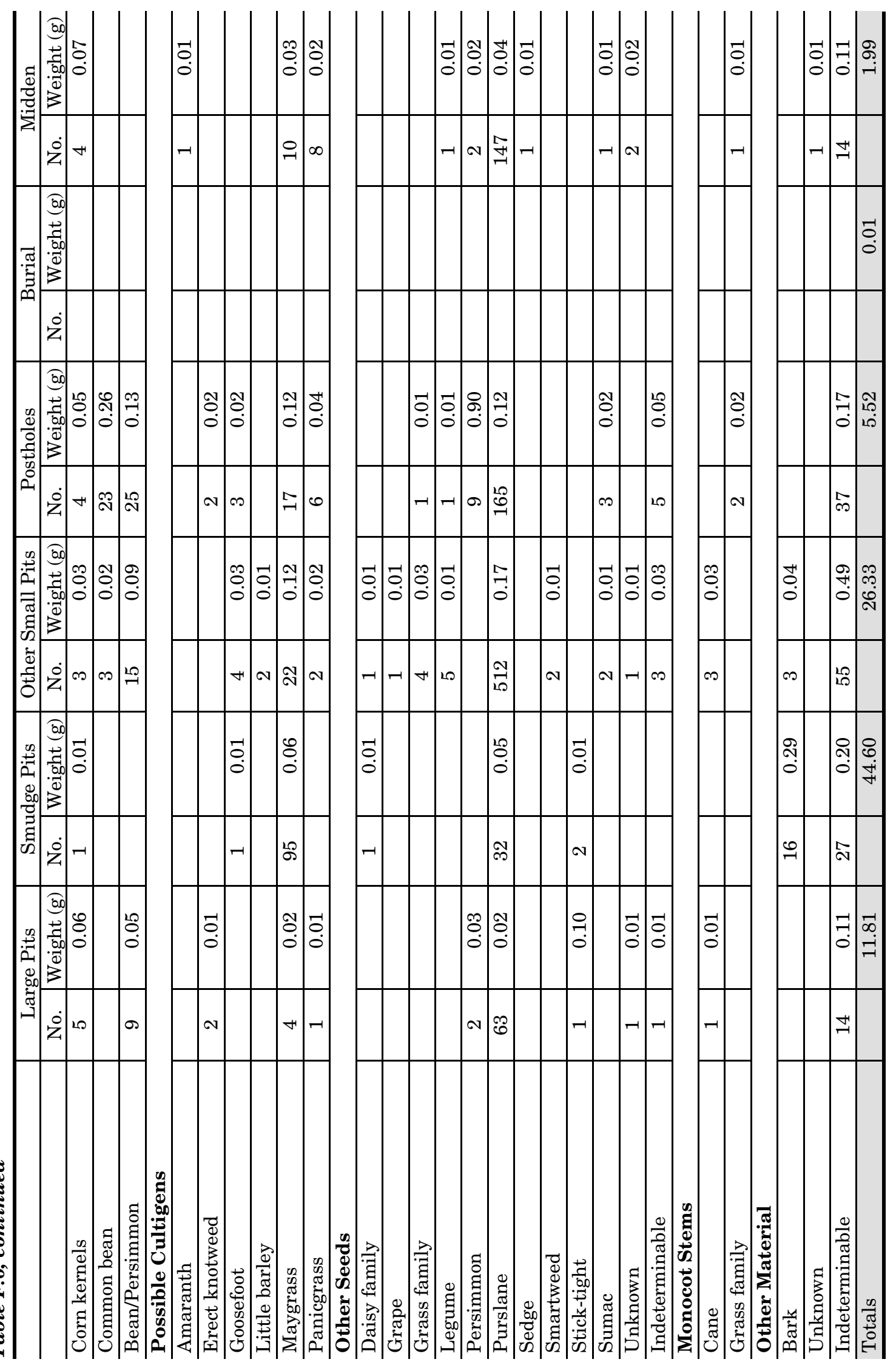


Table F.7. Carbonized plant material from flotation by feature type for 41 TT853

\begin{tabular}{|c|c|c|c|c|c|c|c|c|}
\hline & \multicolumn{2}{|c|}{ Large Pits } & \multicolumn{2}{|c|}{ Smudge Pits } & \multicolumn{2}{|c|}{ Other Small Pits } & \multicolumn{2}{|c|}{ Postholes } \\
\hline & No. & $\begin{array}{l}\text { Weight } \\
\text { (g) }\end{array}$ & No. & $\begin{array}{c}\text { Weight } \\
\text { (g) }\end{array}$ & No. & $\begin{array}{l}\text { Weight } \\
\text { (g) }\end{array}$ & No. & $\begin{array}{c}\text { Weight } \\
\text { (g) }\end{array}$ \\
\hline \multicolumn{9}{|l|}{ Wood charcoal } \\
\hline Ash & 1 & 0.01 & 1 & 0.01 & & & & \\
\hline Elm & 1 & 0.01 & & & 1 & 0.02 & & \\
\hline Hickory & 6 & 0.10 & 3 & 0.04 & 11 & 0.13 & & \\
\hline Red group oak & 66 & 0.87 & 15 & 0.25 & 14 & 0.37 & 21 & 0.17 \\
\hline White group oak & 35 & 0.66 & 1 & 0.01 & 36 & 0.61 & 16 & 0.27 \\
\hline Oak & 27 & 0.34 & & & 22 & 0.20 & 5 & 0.04 \\
\hline Persimmon & 3 & 0.03 & & & & & & \\
\hline Plum/cherry & 1 & 0.01 & & & & & & \\
\hline Hardwood & & & & & 2 & 0.02 & & \\
\hline Indeterminable & & & 220 & 2.16 & & & & \\
\hline Not examined & 769 & 7.92 & 186 & 1.49 & 244 & 2.22 & 109 & 1.07 \\
\hline \multicolumn{9}{|l|}{ Nutshell } \\
\hline Hickory & 176 & 5.60 & 66 & 1.12 & 23 & 0.70 & 16 & 0.73 \\
\hline Hickory/walnut family & 47 & 0.40 & 9 & 0.09 & 8 & 0.07 & 2 & 0.04 \\
\hline Acorn & 13 & 0.06 & & & & & & \\
\hline \multicolumn{9}{|l|}{ Cultigens } \\
\hline Corn cupules and glumes & 89 & 0.45 & 148 & 0.76 & 7 & 0.05 & & \\
\hline Corn kernels & 6 & 0.07 & & & & & & \\
\hline \multicolumn{9}{|l|}{ Possible cultigens } \\
\hline Maygrass & 4 & 0.02 & & & & & & \\
\hline \multicolumn{9}{|l|}{ Other seeds } \\
\hline Daisy family & 1 & 0.01 & & & 1 & 0.01 & & \\
\hline Elderberry & 1 & 0.01 & & & & & & \\
\hline Grass family & 1 & 0.01 & & & & & & \\
\hline Nightshade & 2 & 0.01 & & & & & & \\
\hline Purslane & & & 1 & 0.01 & & & & \\
\hline Spiderwort & & & 1 & 0.01 & & & & \\
\hline Strawberry & 2 & 0.02 & & & & & & \\
\hline Verbena & 1 & 0.01 & & & & & & \\
\hline \multicolumn{9}{|l|}{ Monocot stems } \\
\hline Cane & 5 & 0.03 & & & 1 & 0.01 & & \\
\hline Grass family & 1 & 0.01 & & & & & & \\
\hline \multicolumn{9}{|l|}{ Other material } \\
\hline Bark & 1 & 0.02 & & & & & & \\
\hline Fruit & 4 & 0.01 & & & & & & \\
\hline Catkin & 1 & 0.01 & & & & & & \\
\hline Fungus & 1 & 0.01 & & & & & & \\
\hline Unknown & 3 & 0.01 & & & & & & \\
\hline Indeterminable & 43 & 0.25 & & & 34 & 1.30 & 3 & 0.12 \\
\hline Totals & & 16.97 & & 5.95 & & 5.71 & & 2.44 \\
\hline
\end{tabular}




\section{Wild Food Plants}

Nut resources are by far the most common food plants recovered on the site. Nutshell is a waste product that burns easily. It is also dense and tough enough to survive well at archeological sites. At 41TT851, hickory nutshell dominates the assemblage, with $24.26 \mathrm{~g}$ recovered. Acorn is also well represented ( $\mathrm{n}=166,0.75 \mathrm{~g}$ ), and black walnut is present in two samples $(\mathrm{n}=4$, $0.09 \mathrm{~g}$ ). Other wild plants from the site may have been used for food (grape, purslane, bulbs) or medicine (verbena).

\section{Fiber Plants}

River cane (Arundinaria gigantea) is present but very sparse. Stems of smaller, moredelicate members of the grass family were not recovered, but the six grass family seeds could represent use of other grass stems for fiber.

\section{Site 41TT852}

\section{Characteristics of the Sample}

Although fewer lots were analyzed from 41TT852 than from 41TT851, botanical density at this site was higher $(0.104 \mathrm{~g} /$ liter; excluding hand-collected remains from the nine features with flotation samples), and more plant taxa were identified. Domesticated beans are the most notable addition to the taxa list at this site. As at 41TT851, flotation samples mostly represent general site debris from secondary or tertiary contexts. Samples range in size from 1.0 liter to 57.5 liters. No single feature accounts for a large percentage of the flotation fill, with even the best-represented feature (Feature 189) making up only 7 percent of the flotation volume.

\section{Fuel Wood}

Fuel wood at 41 TT852 is very similar to that at 41TT851, both in composition and in presumed origin. Identification was attempted for 1,065 wood charcoal fragments, of which 1,021 could be identified to family, genus, or species. Seventy-eight percent of the assemblage consists of oak and 17 percent of hickory. Fourteen other woods make up the remaining 5 percent.

\section{Agricultural Products}

Corn and beans are the known agricultural products recovered. As at 41TT851, corn is mostly present in the form of loose cupules. Corn was identified in 41 samples for a ubiquity of 49.4 percent. Beans were found in 5 samples.

Small starchy seeds at 41TT852 include goosefoot and maygrass, like at 41TT851, but also little barley and erect knotweed. One of the two erect knotweed seeds from Feature 55 is a striate morph, which may have implications for domestication (Dunavan 1993). Two additional potential starchy cultigens were identified at 41TT852: amaranth, a later addition to the starchy seed complex (Fritz 1990), and panicgrass. Maygrass is the most common of the starchy seeds, with 148 specimens appearing in 30 samples for a ubiquity of 36 percent.

\section{Wild Food Plants}

Nutshell is common at 41TT852. It is largely hickory, with acorn also present. Nutmeat is present in a single lot from Feature 492. The nutmeat is from the hickory family, which is less common archeologically than acorn nutmeats. Presumably, the oilier hickory family nutmeats burn to ash more easily than starchier acorns.

Purslane is by far the most common small wild seed recovered. Although the seed is black in uncarbonized form, these specimens do appear to be carbonized, and many were broken in the laboratory to be certain of their state. After purslane, persimmon is the next most common seed. Other small seeds include small weedy members of the legume family, sumac, stick-tight, grape, daisy family, sedge family, grass family, and smartweed.

\section{Fiber Plants}

Large monocot stem fragments were identified as cane (Arundinaria gigantea). Smaller, more-delicate grass stems that could not be identified to species were also recovered.

\section{Site 41TT853}

\section{Characteristics of the Sample}

Overall botanical density at $41 \mathrm{TT} 853$ is intermediate between other two sites at $0.082 \mathrm{~g} /$ 
liter (excluding hand-collected remains from the six features with flotation samples). Feature 17, a large pit, accounts for a little more than onethird of the soil matrix processed (132.5 of 377.0 liters). The botanical density of this feature is slightly lower than the site as a whole $(0.068 \mathrm{~g} /$ liter). Feature 47 is notable for a much higher density than average at $0.595 \mathrm{~g} /$ liter. The high botanical density suggests that plants in this pit were carbonized in situ and not moved or scattered afterwards. The high botanical density is thus consistent with field identification of this feature as a thermal pit. The decayed wood present in the feature suggests a smudge pit, but other remains are also present, which is not typical of smudge pits. Plant remains in this feature include many corn cupules, the unidentifiable (decayed) wood mentioned above, an assortment of identifiable hardwoods, hickory family nutshell, a purslane seed, and a spiderwort seed.

As at the other two sites, postholes at 41TT853 appear to contain general site debris rather than remains of actual wooden posts. One feature does contain only a single type of wood charcoal, but this is a pit feature, Feature 58. No semicarbonized plant remains were present in Feature 58, and botanical remains provide no indication that the feature is not archeological. In addition to the wood charcoal, which is all red group oak, two hickory nutshell fragments were recovered from Feature 58.

\section{Fuel Wood}

A total of 508 wood charcoal fragments were examined for identification, of which 286 could be identified to family, genus, or species. Most of the unidentifiable wood is decayed wood from Feature 47, the thermal feature discussed above. Wood at 41TT853 is 89 percent oak, more than at the other two sites. The remaining woods are hickory (7 percent) and four other taxa (4 percent).

\section{Agricultural Products}

Corn was present in 11 samples for 37.9 percent ubiquity. None in the four posthole samples contain corn, although these represent only 12.5 liters of fill in total. Maygrass was only potentially cultivated starchy seed present.

\section{Wild Food, Medicinal, and Fiber Plants}

Nutshell at 41TT853 is similar in composition and density to the other sites, i.e., mostly hickory with a smaller amount of acorns. Small wild seeds include the edible fruits strawberry and elderberry, plus the possible medicinal plants nightshade and spiderwort, none of which are present at the other sites. Fiber plants are represented by both cane and small grass stems.

\section{DISCUSSION}

\section{Ecological Exploitation}

Archeological theories known variously as the "firewood indifference hypothesis" or the "Principal of Least Effort" predict that fuel wood from archeological sites should reflect in a relatively straightforward manner the local environment at the time of occupation (Asch and Asch 1986; Shackelton and Prins 1992). Self-pruning trees may be overrepresented archeologically, and species intended for other uses may be underrepresented (Asch and Asch 1986; Dufraisse 2008). In addition, ethnohistorical sources indicate that Native Americans were well aware of the burning properties of different woods and exploited them accordingly (e.g., Gilmore 1933:139; Zigmond 1981:57). Nonetheless, the broad assumption of firewood indifference is followed here.

Trees exploited for fuel at these sites suggest the upland oak savannah that would have been present in the immediate vicinity. Woods other than oak and hickory likely came from the slopes and riparian forest associated with Tankersley Creek. Other than this riparian fuel wood, plants from moist or wet areas are nearly absent. Smartweed (lenticular Polygonum spp.) was recovered from one site and grape from two sites, but no aquatic tubers or lotus seeds and little cane were found.

Even the fields in this area were likely in the uplands. For ancient maize agriculture in the southeast, the greatest risk to crops was usually spring flooding rather than frosts or insufficient rain (Scarry 1986). East Texas rivers flood frequently and quickly, and their floodplains can be wet. Agricultural fields probably were not on river floodplains but rather on tributary streams, second terraces, or in upland 
areas. Even the soils along Tankersley Creek, clay loams and silty clay loams, may have been too heavy to till with digging sticks. The sandy soils of the upland areas immediately adjacent to the sites may have been more appropriate for ancient agriculture, especially if the streams that are intermittent today flowed more steadily in the past.

\section{Plant Cultivation}

\section{Corn}

No corn cob fragments (i.e., conjoined ranks of cupules) were recovered. Even whole cupules were rare. Because loose cupules have more scope to become distorted in burning, measurements were taken only on cupules that still attached lengthwise to one or more other whole cupules (i.e., cupules in a rank). Of the 277 flotation and hand-collected samples examined for this project, only 2 contained conjoined cupules. Four sets of conjoined cupules are illustrated in Figure F.1. Measurements taken according to Robert Bird's (1994) instructions are given in Table F.8. As shown in Table F.9, measurements on cupules from the Mount Pleasant sites are consistent with measurements taken of Caddo corn from Texas sites such as Stallings Ranch, Sha'chahdínnih (Timber Hill), Pine Tree Mound, and Oak Hill Village.

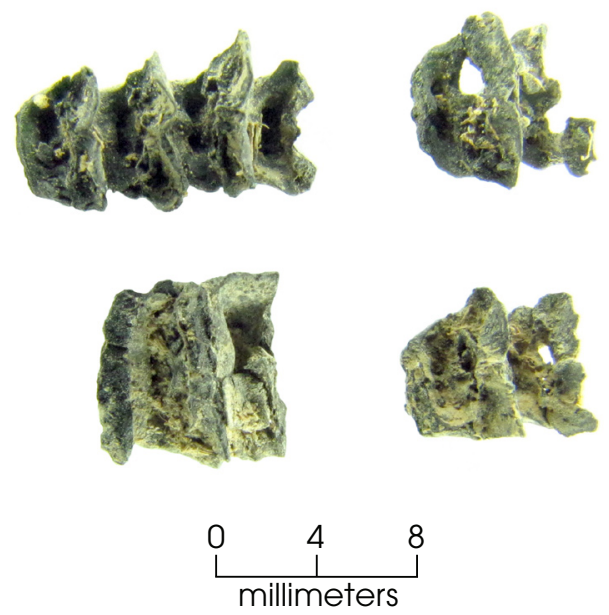

Figure F.1. Conjoined corn cupules from smudge pit Feature 546 at $41 \mathrm{TT} 852$.
Attempts to correlate morphological variation in carbonized corn cobs and kernels with particular varieties of corn have been largely inconclusive (Benz 1994; King 1994). Variation in maize processing techniques and the processes of preservation, deposition, and recovery further complicate matters (Goette et al. 1994). One researcher posts a disclaimer that "Measurements of cob diameter [etc.]...have no particular interpretive significance" (Puseman 2006). Nonetheless, there is an interpretive tradition in Texas that associates archeological corn cobs with known corn types. Eileen Goldborer (2002:85) summarizes it thus: "Corn recovered from a number of well-investigated prehistoric archeological sites in East Texas give a general impression of representing a small variety of Eastern Complex corn."

An additional 12 cupules from two hamlets will not provide appreciable resolution to a vague and impressionistic situation, but they do provide additional data points. Measurements of corn from the Mount Pleasant sites are provided for comparison with other sites rather than to assign the archeological corn to living or historically known corn types. The cupule measurements shown in Table F.8 are consistent with Goldborer's impression of small Eastern Complex corn in east Texas. Cupule widths are in the 4-8-mm range, and lengths are less than widths (Goldborer 2002). One lot from Sha'chahdínnih may represent the larger variety of Eastern Complex corn, since its cupule width exceeds the $8.5-\mathrm{mm}$ threshold used by many authors to separate larger and smaller varieties of Eastern Complex corn (Bird and Dobbs 1986; Goldborer 2002).

Cupules and kernels can indicate ancient social practice because burned cupules are a byproduct of corn processing, while kernels indicate corn consumption. In the Mississippian Moundville settlement system of west-central Alabama, there is an inverse correlation between plant-processing waste and high-status sites or locations (Welch and Scarry 1995:406). Simply put, corn cupules indicate low status and corn kernels indicate high status. A similar pattern may be evident at the Pine Tree Mound site in Harrison County, Texas, where kernel:cupule ratios are between 2 and 32 times higher in the ceremonial precinct than in all other areas (Bush 2012). The kernel:cupule ratios at the Mount Pleasant sites are 0.19 for 41TT851, 
Table F.8. Measurements of conjoined corn cupules (in mm)

\begin{tabular}{c|c|c|c|c|c}
\hline Site & Specimen & $\begin{array}{c}\text { Cupule } \\
\text { Width }\end{array}$ & $\begin{array}{c}\text { Average } \\
\text { Cupule Length }\end{array}$ & $\begin{array}{c}\text { Total Rank } \\
\text { Length }\end{array}$ & $\begin{array}{c}\text { Cupules in } \\
\text { Rank }\end{array}$ \\
\hline 41TT852, Feature 546 & 1 & 7.00 & 2.95 & 5.9 & 2 \\
\hline & & 6.40 & 2.95 & & 2 \\
\hline & 2 & 4.40 & 3.00 & 6.0 & \\
\hline & & 4.50 & 3.00 & & 2 \\
\hline & 3 & 4.60 & 3.10 & 6.2 & \\
\hline & 4 & 4.90 & 3.10 & & \\
\hline & & 4.80 & 2.65 & 10.6 & \\
\hline & & 4.20 & 2.65 & & \\
\hline & & 4.50 & 2.65 & & \\
\hline & Mean & 4.60 & 2.65 & & \\
\hline
\end{tabular}

Table F.9. Corn (Zea mays) cupule measurements from sites in northeast Texas (in mm)

\begin{tabular}{l|c|c|l}
\multicolumn{1}{c|}{ Site } & Cupule Width & $\begin{array}{c}\text { Cupule Thickness } \\
\text { (height) }\end{array}$ & \multicolumn{1}{c}{ Reference } \\
\hline 41RK214 (Oak Hill Village), Feature 85 & 4.70 & 2.18 & Elson et al. 2004 \\
\hline 41RK214 (Oak Hill Village), Feature 86* & 4.84 & 3.08 & Elson et al. 2004 \\
\hline 41TT852 & 4.99 & 2.87 & this report \\
\hline 41HS15 (Pine Tree Mound) & 5.26 & 2.30 & Bush 2012 \\
\hline 41NA60 (Henry M.), Lot 160b & 5.37 & 1.50 & Bush 2010a \\
\hline 41LR297 (Stallings Ranch) & 5.38 & 3.06 & Bush 2008a \\
\hline 41MR211 (Sha'chahdínnih), Lot 175 & 5.90 & 2.40 & Goldborer 2002 \\
\hline 41TT853 & 5.90 & 2.80 & this report \\
\hline 41NA60 (Henry M.), Lot 292 & 6.14 & 2.30 & Bush 2010a \\
\hline 41NA60 (Henry M.), Lot 160a & 6.90 & 1.95 & Bush 2010a \\
\hline 41SM404, Feature 1 & 7.05 & 3.36 & Bush 2010b \\
\hline 41MR211 (Sha'chahdínnih), Lot 52B & 7.30 & 2.90 & Goldborer 2002 \\
\hline 41MR211 (Sha'chahdínnih), Lot 51 & 8.08 & 3.80 & Goldborer 2002 \\
\hline 41MR211 (Sha'chahdínnih), Lot 52A & 9.20 & 3.30 & Goldborer 2002 \\
\hline
\end{tabular}

*Average of measurements given in Table 91.

0.04 for $41 \mathrm{TT} 852$, and 0.06 for $41 \mathrm{TT} 853$. As expected for outlying hamlets, the latter two of these have more cupules than a high-status area such as the ceremonial precinct at Pine Tree Mound, where the kernel:cupule ratio is 0.16 . The relationship between outlying hamlets like the Mount Pleasant sites and areas such as the habitation areas at Pine Tree Mound, where ratios range from less than 0.01 to 0.08 , is not certain, however.

\section{Beans}

Common beans were recovered only from 41TT852. AMS dates on common beans indicate their cultivation in the Tehuacán Valley by 2500 B.P. and in Tamaulipas by 1300 B.P. (Kaplan and Lynch 1999). Beans appear relatively late in the Eastern Woodlands, with the earliest AMS dates on beans at around A.D. 1270 (Hart and Scarry 1999). Beans are relatively rare at Texas 
archeological sites, partly because they appear so late in time but also because they were not routinely exposed to fire. Beans dry naturally on the plant and have no need for parching before storage, they are usually cooked by boiling, and their waste products (pods) quickly burn to ash. Fray Francisco Casañas de Jesus Maria noted "five or six kinds of beans-all of them good" in his 1691 report (Hatcher 1927a:211).

\section{Small Starchy Seeds}

Starchy seeds of the Eastern Agriculture Complex were recovered in flotation samples from all three sites. These grains are of particular interest to archeologists because they are part of a complex of native starchy seeds that were cultivated in parts of the Eastern Woodlands of North America prior to the advent of corn agriculture. Amaranth, another of these small starchy-seeded crops, appears to have been a later introduction rather than an indigenous domesticate (Fritz 1990).

Little barley, maygrass, and species of Chenopodium grow wild in many parts of the Eastern Woodlands, including modern Titus County. Erect knotweed's distribution is less clear, but it is probably present in east Texas under Polygonum aviculare. No changes in seed attributes associated with intensive cultivation have been identified for maygrass, erect knotweed, or little barley (but see Hunter 1992 for some possibilities). Thin seed testa $(<20 \mu)$ is an indicator of domestication in Chenopodium (Smith 1992). Thin seed coats are also associated with truncate margin morphology (Smith 1992:187). The Chenopodium specimens at the Mount Pleasant sites appear to be nonwild types. Embryos are missing from most specimens, meaning margin morphology cannot be assessed, but the missing embryos are themselves suggestive of domestication. Seed coats appear to be thin or intermediate.

Woodland period cultivation of native starchy seeds was centered in the central Mississippi and Ohio River Valleys, roughly in the areas of the later Mississippian and Fort Ancient cultures (Johannessen 1993:Figure 5-1). Morphological correlates of domestication appear for Chenopodium by the Late Archaic (Smith 1992), and the seeds are found in large quantities on Woodland sites in the American Bottom. Starchy seed cultivation was either absent or less important in other areas of the
Eastern Woodlands. Native starchy seeds are found in low quantities in Late Woodland samples in west-central Alabama (Scarry 1986), and they also appear at Moundville, "although these indigenous seed crops were not as important in the Moundville area as they were in some other parts of the southeast" (Welch and Scarry 1995:405).

In the Lower Mississippi Valley, there is little evidence of native starchy seed use until Marksville times, but even then cultivation is "not on the scale of their trading partners to the north" (Fritz 2000:238). Only in the northern part of the Lower Mississippi Valley does precorn cultivation seem to have been important, as at the Taylor Mounds site in southeastern Arkansas (Fritz 2000:238). In contrast to the situation in the Lower Mississippi Valley, the Arkansas River Valley saw intensive cultivation of native seed crops and, by A.D. 700, the use of maize. Evidence comes from the Toltec Mounds site associated with the Plum Bayou culture (Fritz 2000).

These seeds do show up sporadically at east Texas sites (Table F.10). They are typically not abundant nor ubiquitous. Site 41TT852, where maygrass appears in 36 percent of the samples, is a rare example of relative ubiquity. The seeds are easy to dismiss on any single site as accidental inclusions, but taken together, the pattern is suggestive, especially given the low abundance and ubiquity of small wild seeds at east Texas sites in general.

The presence of all four starchy seeds at Late Caddo sites such as $41 \mathrm{TT} 852$ is particularly interesting. In regions where they were intensively cultivated, the importance of native seed crops waned after the introduction of corn. Although native starchy seed exploitation was never terribly important in northeast Texas, it does seem to have persisted longer than in the American Bottom. Native seed cultivation also appears to have continued in the Lower Mississippi Valley, where historic Natchez Indians grew what was probably Chenopodium (Smith 1992).

\section{Fiber Plants}

\section{Cane}

River cane is present at all three sites. Cane is the only North American member of the 
卷

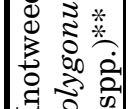

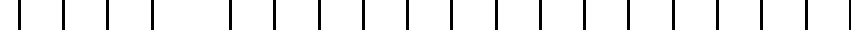

बृ

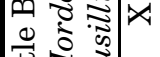

莺过

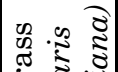

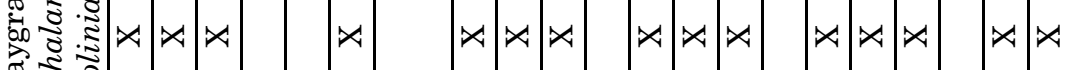
$\sum_{2}^{\infty} \bar{E}$

ह ई

ช

용

ปี

ठิ ठ

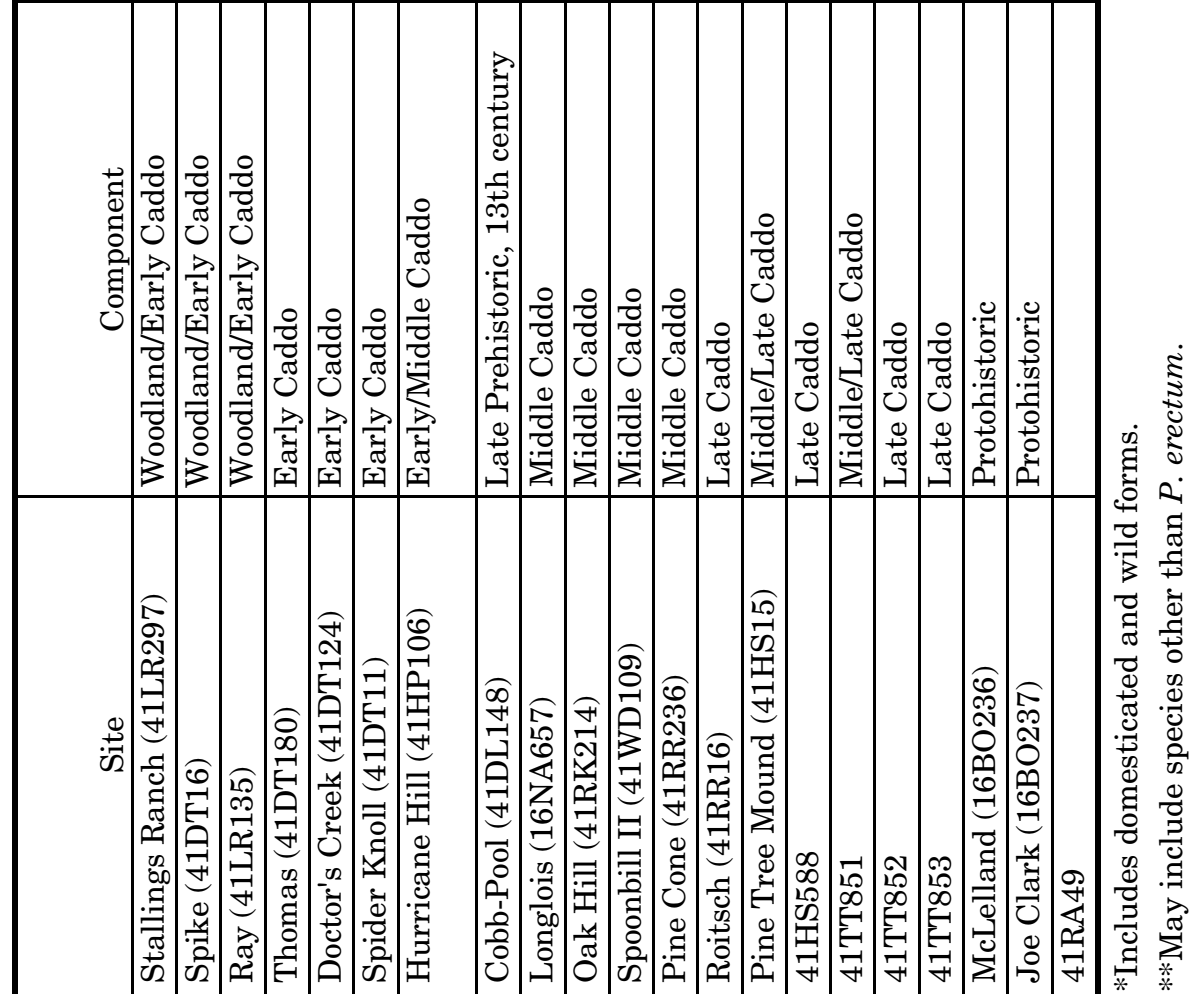


bamboo tribe, a woody group of the grass family (Diggs et al. 2006: 836). A facultative wetlands plant, it grows in moist woods and low areas generally (USDA, NRCS 2011). Although cane is rare today, it was once far more abundant in east Texas, where it could occur in dense monocultural stands referred to as canebrakes (Correll and Johnston 1970:112). One nineteenth-century canebrake in Wharton County is said to have been 75 miles long and 1-3 miles wide (Diggs et al. 2006:836). By 1905, James Gow reported that cane was only locally abundant, in swamp, hammock, and hardwood bottom forests. "Dense cane brakes occur at remote intervals in the bottom lands of the Sabine and Neches rivers and a few of their smaller tributaries" (Gow 1905:47).

Native people used cane in many items, including mats, baskets, screens to divide rooms, spear shafts, arrow shafts, pipe stems, blow guns, flutes, and blow tubes used in healing (Moerman 1998:104). Henri Joutel mentions use of cane for torches: "They had lit some dry canes to see better because they do not have knowledge of candle-making nor of burning oil (although they make oil with nuts)" (Foster 1998:235).

Caddo people were particularly famous for cane mats and baskets. Hidalgo, Casañas, and Espinosa all mention baskets or boxes that they describe as made of reed (Hatcher 1927b:56; Hatcher 1927c:156). Spanish writers seem to have used "reed" (or at least a word translated into English "reed") for various large grass species. Cane is the more likely identification here, especially since adjectives such as "big" or "strong" modify the plant described. The common reed, Phragmites australis, was probably only a minor component of wetlands in ancient times (Diggs et al. 2006) and would have been more common nearer the coast than in the Caddo area. The larger cane baskets in Caddo country were used to contain crops in storage areas, and loosely woven baskets were useful in sifting and winnowing (Swanton 1996:157). Hidalgo particularly admired the colored cane floor mats, noting "very curious rugs of reed of different colors which could be used in ladies' drawing rooms [in Europe]" (Hatcher 1927b:56).

\section{Herbaceous Grasses}

Most famously, Caddos used smaller, more-delicate grasses than cane to thatch their large domed houses (Swanton 1996:148-154).
Grass stems were also used to make items such as coiled baskets. Although grass seeds are generally edible, the small wild grass seeds found at all three Mount Pleasant sites may represent uses of grass for fiber rather than food.

\section{Other Wild Plants}

\section{Nut Resources}

Nut mast is grouped here among the plant resources that would have been gathered rather than cultivated, although more than one authority has suggested the possibility that hickory trees, in particular, were managed by aboriginal populations (Albert 2007; Delcourt and Delcourt 2004; Munson 1986). Creating open stands of hickory requires only the effort of girdling nonhickory trees in a particular plot. The open stands increase hickory canopy by a factor of about six (Munson 1986). At least as important is the fact that it decreases the ability of squirrels to jump from tree to tree, thus increasing the opportunities for predation by humans. Patrick Munson estimates that these two results increase nut yield in an open plot (defined as nuts on ground at optimum collecting time) by 287 times over the yield in a closed forest. He calculates that five days' labor with a stone axe and annual burning thereafter on one hectare will yield 2,000 calories for 171 days in open stands (Munson 1986).

One reason hickory trees have been the focus of speculation regarding cultivation is that they can be processed far more efficiently than other types of nuts. Traditional hickory processing methods used by Iroquois, Choctaw, Cherokee, and many other peoples involve pounding hickory nuts into small pieces and then heating them in water, where the oil can be skimmed off, the nutmeat retrieved from suspension, and the shells allowed to sink to the bottom (Fritz et al. 2001; Moerman 1998:140 141). Experiments by archeologists show that this process yields a much larger number of calories per hour of labor invested than does cracking and picking (Talalay et al. 1984:353). Other common nuts cannot be processed in this manner because either their meats float (acorn, hazelnut) or the nuts become bitter (walnut).

Like most nuts, hickory nutmeat is high in fat and contains more protein than most plant foods. These nutrients, particularly the linolenic 
fatty acids, may have been critical to huntergatherers who relied on lean meat for a portion of the year (Gardner 1997; Hall 2000:109-110). Acorn nuts contain less fat and protein and more carbohydrates than Juglandaceae nuts (Table F.11). In this respect, they are more comparable to grains than nuts. Acorns require water processing to leach tannins before they are palatable to humans, but then they can then be roasted or ground into flour (Gremillion 2002). Joutel was served a dish of acorn meal cooked in meat broth while staying at a village between the Angelina and Sabine Rivers (Foster 1998:234-235).

In the American Bottom, low nutshell:wood ratios act as a proxy indicator of reliance on agricultural products, as agricultural products replaced wild food plants and agricultural activities restricted time available for nut collection. Nutshell:wood ratios declined from 2.5 to less than 0.5 from Late Archaic through Mississippian times as agriculture became the prevailing subsistence practice in the region (Johannessen 1984). In east Texas, nutshell:wood ratios do not decline in absolute terms over the Late Prehistoric for the region as a whole, but when multicomponent sites are available, there does seem to be a downward trend. For example, Phil Dering documents a decline in nutshell:wood ratios over time at the Broadway site (Dering 2004b). The Mount Pleasant sites are situated sufficiently close together that they share a single local ecology. Because they are all Caddo-period hamlets, seasons of occupation are probably also similar. In this context, it is worth noting that the later two sites (41TT852 and 41TT853) have lower nutshell:wood ratios (0.35 and 0.46) than the earlier site (41TT851,

Table F.11. Proximate analysis of three edible tree nuts (per $100 \mathrm{~g}$ dry weight [USDA, ARS 2010])

\begin{tabular}{l|c|c|c}
\hline & Hickory & $\begin{array}{c}\text { Black } \\
\text { Walnut }\end{array}$ & Acorn \\
\hline Fat (g) & 64 & 59 & 31 \\
\hline Protein (g) & 13 & 24 & 8 \\
\hline Carbohydrate (g) & 18 & 10 & 53 \\
\hline Water (g) & 2 & 5 & 5 \\
\hline Energy (kcal) & 657 & 618 & 509 \\
\hline
\end{tabular}

$0.58)$, suggesting a decrease in the use of wild resources available in the fall.

\section{Greens: Purslane and Spiderwort}

Other than grass family seeds, purslane is the only small wild seed to appear at all three sites. The seeds are abundant at 41TT852, with 919 seeds appearing in 40 flotation samples. Purslane thrives in anthropogenic conditions, so its abundance may reflect its presence at the site during occupation. Purslane greens are edible raw or cooked, and opportunistic use of purslane as a food plant is likely (Moerman 1998:434).

The single spiderwort seed recovered from Feature 47 at 41TT853 may reflect use of tender spiderwort shoots as greens (Moerman 1998). This common wildflower also has medicinal uses (Hamel and Chiltoskey 1975).

\section{Edible Fruits}

Sumac seeds were recovered from 41TT851 and 41TT852. Sumac is a small tree or shrub that thrives on the edges of forests and fields. Sumac fruits dry on the plant, where they often remain available throughout the winter. Ethnographically, sumac fruits are most often boiled to make a lemonade-like drink that is rich in vitamins A and C (Moerman 1998:471-475). The bark and leaves of the plant have important dye and smoking uses as well (Jakes and Ericksen 2001; Knight 1975).

Grape (Vitis spp.) seeds were recovered at two of the sites. Grape leaves, stems, and roots were used in medicine, often for urinary and dermatological problems (Moerman 1998:378-379, 598-600). The flexible vines were valuable in house construction, basketry, fashioning ropes and cordage, and to make hoops for uses such as the roll bars on cradle boards. Grape fruits were used in pink and purple pigments, but their more important use was for food. The berries could be eaten fresh off the vines or dried into raisins for future consumption. Sap from grapevines was also welcome to travelers for its ready availability and slightly sweet flavor. Grape leaves served important uses in cooking, with young grape leaves holding ingredients in convenient packages (as in modern Greek dolmas) and preserving moisture in much the same manner as corn husks for today's tamales. 
Among historical Karok Indians in California, grape leaves were placed over bulbs to conserve moisture while the bulbs cooked in earth ovens (Schenck and Gifford 1952:386). Both Espinosa and St. Denis comment on the high quality of east Texas grapes (Swanton 1996:132,133), and Texas grapes were later instrumental, through viticulturalist Thomas Munson, in saving the European wine industry from the phylloxera blight (Turner 2009:296).

Persimmons were found only at 41TT852, but they are fairly common at Caddo sites. In fact, the east Texas place name Nacogdoches refers to persimmons (Carter 1995:101). The eastern persimmon (Diospyros virginiana) trees in the region bear fleshy edible orange fruit about 3 inches in diameter, smaller than the modern cultivated persimmon (D. kaki) but larger than the Texas persimmon (D. texana), which is black in color. Fray Gaspar José de Solís mentions persimmon fruits made into paste and presented as gifts to the Spanish and French (Swanton 1996:132). Solís describes the tree fruits as coming from "orchards." Given the arguments for native tree cultivation regarding hickories noted above and the rapid adoption of peaches by Native Americans of the Southeast (Gremillion 1993), Solís's description may be more literal than metaphorical. Simpson (1999:141) notes a large population of eastern persimmon trees in the Canadian River valley that he believes were planted by Native Americans.

Two specimens of strawberry and one of elderberry were recovered from 41TTT853. Strawberry is a low herbaceous plant while elderberry is a woody shrub. Like persimmon, these fleshy fruits may be eaten fresh or dried and preserved for consumption outside their season of availability.

\section{Possible Medicinal Plants}

Verbena seeds were recovered from two sites, and a single spiderwort seed was found in Feature 47 at 41 TT853. Both are common wildflowers that have medicinal uses. Interestingly, nearly all ethnographically known uses of verbena are for medicine rather than for food (Moerman 1998:591-592). Stick-tight is a third possible medicinal plant (Gilmore 1991:63, Moerman 1998:241-242), but its sticky burs may also have arrived at the site incidental to other activities.

\section{Other Plants}

The remaining seeds recovered are identifiable only to family, or only one or two specimens were recovered. Smartweed (lenticular Polygonum spp.) deserves special mention, however. It is notable for being one of the very few genera recovered that prefer wet habitats.

\section{SUMMARY}

Most botanical samples from the Mount Pleasant sites represent secondary or tertiary deposition and contain site debris that is largely similar throughout the three sites. At least two contexts are likely to represent primary deposition, though, and both have botanical signatures that support this interpretation: Feature 319 at 41TT851 is a smudge pit that contains large quantities of decayed wood. Such features are known ethnographically and archeologically (Bush 2004:83-84; Dockall et al. 2008:180-181; Murphey 1990:55, Swanton 1979:442-454). Feature 47 at $41 \mathrm{TT} 853$ is a thermal feature that is characterized by a high density of carbonized remains.

The wood charcoal reflects fuel collected from the local environment, with most wood coming from the uplands on which the sites are located and only minor components of the assemblage from the slopes and lowlands associated with Tankersley Creek and its tributaries.

Crop plants recovered consist of corn and beans. The few measurable corn cupules are consistent with other corn recovered on east Texas archeological sites. The starchy-seeded annuals maygrass, Chenopodium, little barley, and erect knotweed were present at the Mount Pleasant sites in small quantities. Their cultigen status is unclear, but economic use is certainly indicated in east Texas.

Wild food resources included nut mast (hickory and acorn) and fleshy fruits such as persimmon, grape, strawberry, and elderberry. Seeds such as purslane indicate the exploitation of leafy greens. Other plants are more likely present on the sites for use as medicinal or fiber plants. 


\section{REFERENCES CITED}

Albert, Bruce M.

2007 Climate, Fire, and Land-use History in the Oak-Pine-Hickory Forests of Northeast Texas during the Past 3500 Years. Castanea 72(2):82-91.

Asch, Nancy B., and David L. Asch

1986 Woodland Period Archeobotany of the Napoleon Hollow Site. In Woodland Period Occupations of the Napoleon Hollow Site in the Lower Illinois Valley, edited by M. D. Wiant and C. R. McGimsey, pp. 427512. Kampsville Archaeological Center Research Series Vol. 6. Kampsville, Illinois.

Benz, Bruce F.

1994 Can Prehistoric Racial Diversification Be Deciphered from Burned Corn Cobs? In Corn and Culture in the Prehistoric New World, edited by Sissel Johannessen and Christine A. Hastorf, pp. 23-34. University of Minnesota Publications in Anthropology No. 5. Westview Press, Boulder, Colorado.

Bird, Robert McK.

1994 Manual for the Measurement of Maize Cobs. In Corn and Culture in the Prehistoric New World, edited by Sissel Johannessen and Christine A. Hastorf, pp. 5-22. University of Minnesota Publications in Anthropology No. 5. Westview Press, Boulder, Colorado.

Bird, Robert McK., and Clark A. Dobbs

1986 Archaeological Maize from the Vosburg Site (21FA2), Faribault County, Minnesota. The Missouri Archaeologist 47:85-105.

Bousman, C. Britt

1998 Paleoenvironmental Change in Central Texas: The Palynological Evidence. Plains Anthropologist 43(164):201-219.

Bryant, John A.

1985 Seed Physiology. The Institute of Biology's Studies in Biology No. 165. Edward Arnold, Ltd., London.

Bush, Leslie L.

2001 Boundary Conditions: Botanical Remains of the Oliver Phase, Central Indiana, A.D. 1200-1450. Ph.D. dissertation, Department of Anthropology, Indiana University, Bloomington.
2004

Boundary Conditions: Botanical Remains of the Oliver Phase, Central Indiana, A.D. 1200-1450. The University of Alabama Press, Tuscaloosa.

2008a Macrobotanical Remains from the 2005 and 2006 Texas Archeological Society Field Schools at the Gene and Ruth Ann Stallings Site (41LR297). Manuscript submitted to the Texas Archeological Society, San Antonio.

2008b Analysis of Macrobotanical Remains. In National Register Testing of Four Sites in the Sabine Mine's Area M, Harrison County, Texas, by John E. Dockall, Stephanie L. Katauskas, and Ross C. Fields, pp. 165186. Reports of Investigations No. 157. Prewitt and Associates, Inc., Austin.

2010a Analysis of Paleobotanical Remains from Henry M. (41NA60), An Allen Phase Caddo Site near Bayou Loco, Nacodogches County, Texas. In An Early Historic Caddo Farmstead at the Henry M. Site (41NA60) by Timothy K. Perttula, Leslie L. Bush, LeeAnna Schniebs, Tom Middlebrook, and P. Shawn Marceaux, pp. 51-94. Stephen F. Austin State University Press, Nacogdoches, Texas.

2010b Plant Remains from Indian Creek 2 (41SM404). Manuscript submitted to PBS\&J, Austin.

2011 Plant Remains from the Longlois Site, 16NA657, A Late-13th Century Occupation in Natchitoches Parish, Louisiana. Manuscript submitted to Northwestern State University of Louisiana, Natchitoches, Louisiana.

2012 Macrobotanical Analysis. In Archeology of the Nadaco Caddo: The View from the Pine Tree Mound Site (41HS15), Harrison County, Texas, Vol. II, edited by Ross C. Fields and Eloise Frances Gadus, pp. 727772. Reports of Investigations No. 164 Prewitt and Associates, Inc., Austin.

Carter, Cecile Elkins

1995 Caddo Indians: Where We Come From. University of Oklahoma Press, Norman. 
Core, H. A., W. A. Cote, and A. C. Day

1979 Wood Structure and Identification. 2nd ed. Syracuse University Press, Syracuse, New York.

Correll, Donovan Stewart, and Marshall Conring Johnston

1970 Manual of the Vascular Plants of Texas. Texas Research Foundation, Renner.

Crane, Cathy J.

1982 Plant Utilization at Spoonbill, An Early Caddo Site in Northeast Texas. Midcontinental Journal of Archaeology 7(1):81-97.

1996 Archaeobotanical Remains. In Archae ological Investigations at Cooper Lake, Delivery Orders Numbers 2, 3, \& 4, 1987, edited by Daniel E. McGregor, Melissa M. Green, David H. Jurney, William A. Martin, Randall W. Moir and Joe W. Saunders, pp. 717-728. Cultural Resource Studies for Cooper Lake, Hopkins and Delta Counties, Texas. Archaeology Research Program, Department of Anthropology, Southern Methodist University, Dallas.

Crawford, Gary W., and Bruce D. Smith

2003 Paleoethnobotany in the Northeast. In People and Plants in Ancient Eastern North America, edited by Paul E. Minnis, pp. $\mathrm{x}-\mathrm{xx}$. Smithsonian Books, Washington, D.C.

Davis, Linda W.

1993 Weed Seeds of the Great Plains:A Handbook for Identification. University Press of Kansas, Lawrence.

Delcourt, Paul A., and Hazel R. Delcourt

2004 Prehistoric Native Americans and Ecological Change: Human Ecosystems in Eastern North America Since the Pleistocene. Cambridge University Press, Cambridge, United Kingdom.

Dering, J. Philip

1993 Macrobotanical Analysis of Samples from Four Woodland and Caddoan Period Sites in the Cooper Lake Area of the Upper Sulphur River. In Excavations at the Tick, Spike, Johns Creek, and Peerless Bottoms Sites, Cooper Lake Project, Delta and Hopkins Counties, Texas, edited by Ross C. Fields, Eloise F. Gadus, L. Wayne Klement, C. Britt Bousman and Jerrilyn B. McLerran, pp. 337-355. Reports of Investigations No. 91. Prewitt and Associates, Inc., Austin.
1994 Analysis of the Plant Remains. In Excavations at the Spider Knoll Site, Cooper Lake Project, Delta County, Texas, by Ross C. Fields, Eloise F. Gadus, L. Wayne Klement, and Karen M. Gardner, pp. 162-171. Reports of Investigations No. 96. Prewitt and Associates, Inc., Austin.

2004a Archaeobotanical Evidence for Agriculture and Wild Plant Use at 41RK214. In The Oak Hill Village Site (41RK214), Rusk County, Texas, edited by Robert Rogers and Timothy K. Perttula. Document No. 030083. PBS\&J, Austin.

2004b Analysis of the Plant Remains from the Broadway Site (41SM273). In Woodland and Caddo Archeology at the Broadway or Kanduts'ah Kuhnihdahahdisa' Site (41SM273) on the City of Tyler-Lake Palestine WTP Project, Smith County, Texas, edited by Timothy K. Perttula and B. Nelson, pp. 123-137. Archeological and Environmental Consultants, LLC, Austin.

n.d. Plant Remains from 41RA49, Rains County, Texas. Manuscript on file, Shumla Archeobotanical Services, Comstock, Texas.

Diggs , George M. Jr., Barney L. Lipscomb, Monique D. Reed, and Robert J. O'Kennon

2006 Illustrated Flora of East Texas, Volume One: Introduction, Pteridophytes, Gymnosperms, and Monocotyledons. Sida, Botanical Miscellany, No. 26. Botanical Research Institute of Texas, Fort Worth.

Dockall, John E., Stephanie L. Katauskas, and Ross C. Fields

2008 National Register Testing of Four Sites in the Sabine Mine's Area M, Harrison County, Texas. Reports of Investigations, No. 157. Prewitt and Associates, Inc., Austin.

Dufraisse, Alexa

2008 Firewood Management and Woodland Exploitation During the Late Neolithic at Lac de Chalain (Jura, France). Vegetation History and Archaeobotany 17:199-210.

Dunavan, Sandra

1993 Reanalysis of Seed Crops from Emge: New Implications for Late Woodland Subsistence-Settlement Systems. In Foraging and Farming in the Eastern Woodlands, edited by C. Margaret Scarry, pp. 98-114. University Press of Florida, Gainesville. 
Elson, Katherine M., Christopher Smith, and Timothy K. Perttula

2004 Additional Maize Studies. In The Oak Hill Village Site (41RK214), Rusk County, Texas, edited by Robert Rogers and Timothy K. Perttula, pp. 323-335. Document No. 030083. PBS\&J, Austin.

Foster, William C. (editor)

1998 The La Salle Expedition to Texas: The Journal of Henri Joutel, 1684-1687. Texas State Historical Association, Austin.

Fritz, Gayle J.

1990 Multiple Pathways to Farming in Precontact Eastern North America. Journal of World Prehistory 4(4):387-435.

1993 Archeobotanical Evidence from the CobbPool Site, A Late Prehistoric Farmstead in Dallas County, Texas. Bulletin of the Texas Archeological Society 64:227-246.

2000 Native Farming Systems and Ecosystems in the Mississippi River Valley. In Imperfect Balance: Landscape Transformations in the Pre-Columbian Americas, edited by David L. Lentz, pp. 225-249. Columbia University Press, New York.

2008 Archeobotanical Remains from Five Sites on the Red River, Northeast Texas. In The Archeology of the Roitsch Site (41RR16), an Early to Historic Caddo Period Village on the Red River in Northeast Texas, by Timothy K. Perttula, pp. 432-446. Special Publication No. 5. Texas Archeological Society, Austin.

Fritz, Gayle J., Virginia Drywater Whitekiller, and James W. McIntosh

2001 Ethnobotany of $\mathrm{Ku}-\mathrm{Nu}-\mathrm{Che}$ : Cherokee Hickory Nut Soup. Journal of Ethnobiology 21(2):1-27.

Gardner, Paul S.

1994 Plant Remains. In The McLelland and Joe Clark Sites: Protohistoric-Historic Caddoan Farmsteads in Southern Bossier Parish, Louisiana, edited by David B. Kelley, pp. 189-212. Coastal Environments, Inc., Baton Rouge, Louisiana.

1997 The Ecological Structure and Behavioral Implications of Mast Exploitation Strategies. In People, Plants, and Landscapes: Studies in Paleoethnobotany, edited by Kristen J. Gremillion, pp. 161-178. The University of Alabama Press, Tuscaloosa.
Gilmore, Melvin R.

1933 Some Chippewa Uses of Plants. Papers of the Michigan Academy of Science, Arts and Letters 17:119-143.

1991 Uses of Plants by the Indians of the Missouri River Region. Originally published 1914. University of Nebraska Press, Lincoln and London.

Goette, Susan, Michele Williams, Sissel Johannessen, and Christine A. Hastorf

1994 Toward Reconstructing Ancient Maize: Experiments in Processing and Charring. Journal of Ethnobiology 14(1):1-21.

Goldborer, S. Eileen

2002 Macrobotanical Evidence of Subsistence at Timber Hill. In Finding Sha'chahdinnih (Timber Hill): The Last Village of the Kadohadacho in the Caddo Homeland, edited by Mark L. Parsons, James E. Bruseth, Jacques Bagur, S. Eileen Goldborer, and Claude McCrocklin, pp. 81-86. Archeological Reports Series No. 3. Texas Historical Commission, Austin.

Goldborer, S. Eileen, and Timothy K. Perttula

1999 Macrobotanical Remains from a Northeast Texas Late Archaic to Middle Caddoan Site: Hurricane Hill (41HP106), Hopkins County. In The Hurricane Hill Site (41HP106): The Archaeology of a Late Archaic / Early Ceramic and Early-Middle Caddoan Site in Northeast Texas, edited by Timothy K. Perttula, pp. 365-382. Special Publication No. 4. Friends of Northeast Texas Archaeology, Pittsburg and Austin.

Gow, James E.

1905 An Ecological Study of the Sabine and Neches Valleys, Texas. Proceedings of the Iowa Academy of Sciences 12:39-50.

Gremillion, Kristen J.

1993 Adoption of Old World Crops and Processes of Cultural Change in the Historic Southeast. Southeastern Archaeology 12(1):15-20.

2002 Foraging Theory and Hypothesis Testing in Archaeology: An Exploration of Methodological Problems and Solutions. Journal of Anthropological Archaeology 21:142-164.

Hall, Grant D.

2000 Pecan Food Potential in Prehistoric North America. Economic Botany 54(1):103-112. 
Hamel, Paul B., and Mary U. Chiltoskey

1975 Cherokee Plants and Their Use-A 400 Year History. Herald Publishing Company, Sylva, North Carolina.

Hart, John P., and C. Margaret Scarry

1999 The Age of Common Beans (Phaseolus vulgaris) in the Northeastern United States. American Antiquity 64(4):653-658.

Hatcher, Mattie Austin

1927a Descriptions of the Tejas or Asinai Indians, 1691-1722, Part I (Casanas de Jesus Maria). Southwestern Historical Quarterly 30:206-218.

1927b Descriptions of the Tejas or Asinai Indians, 1691-1722, Part III (Hidalgo). Southwestern Historical Quarterly 31(October):50-62.

1927c Descriptions of the Tejas or Asinai Indians, 1691-1722, Part IV (Espinosa). Southwestern Historical Quarterly 31(October 1927):150-180.

Hoadley, R. Bruce

1990 Identifying Wood: Accurate Results with Simple Tools. The Taunton Press, Newtown, Connecticut.

Hunter, Andrea A.

1992 Utilization of Hordeum Pusilla (Little Barley) in the Midwest United States: Applying Rindos's Co-evolutionary Model of Domestication. Ph.D. dissertation, Department of Anthropology, University of Missouri-Columbia.

Hunter, Andrea A., and B. R. Gassner

1998 Evaluation of the Flote-Tech Machine-

Assisted Flotation System. American Antiquity 63(1):127-132.

InsideWood

2004-onwards Electronic document, http:// insidewood.lib.ncsu.edu/search, accessed March 31, 2011.

Jakes, Kathryn A., and Annette G. Ericksen

2001 Prehistoric Use of Sumac and Bedstraw as Dye Plants in Eastern North America. Southeastern Archaeology 20(1):56-67.

Johannessen, Sissel

1993 Farmers of the Late Woodland. In Foraging and Farming in the Eastern Woodlands, edited by C. Margaret Scarry, pp. 57-77. University Press of Florida, Gainesville.
1984 Paleoethnobotany. In American Bottom Archaeology: A Summary of the FAI-270 Project Contribution to the Culture History of the Mississippi River Valley, edited by Charles J. Bareis and James W. Porter, pp. 197-214. University of Illinois Press, Urbana, Illinois.

Kaplan, Lawrence, and Thomas F. Lynch

1999 Phaseolus (Fabaceae) in Archaeology: AMS Radiocarbon Dates and their Significance for Pre-Columbian Agriculture. Economic Botany 53(3):261-272.

King, Frances B.

1994 Variability in Cob and Kernel Morphology Characteristics of North American Cultivars. In Corn and Culture in the Prehistoric New World, edited by Sissel Johannessen and Christine A. Hastorf, pp. 35-54. University of Minnesota Publications in Anthropology No. 5. Westview Press, Boulder, Colorado.

Knight, Vernon James Jr.

1975 Some Observations Concerning Plant Materials and Aboriginal Smoking in Eastern North America. Journal of Alabama Archaeology 21(2):120-144.

Lopinot, Neal H., and David Eric Brussell

1982 Assessing Uncarbonized Seeds from Open-air Sites in Mesic Environments: An Example from Southern Illinois. Journal of Archaeological Science 9:95-108.

MacRoberts, Michael H., and Barbara R. MacRoberts 2004 The Post Oak Savanna Ecoregion: A Floristic Assessment of its Uniqueness. Sida 21(1):399-407.

MacRoberts, Barbara R., Michael H. MacRoberts, and James C. Cathey

2002 Floristics of Xeric Sandylands in the Post Oak Savanna Region of East Texas. Sida 20(1):373-386.

Martin, Alexander C., and William D. Barkley

1961 Seed Identification Manual. University of California Press, Berkeley.

Miksicek, Charles H.

1987 Formation Processes of the Archaeobotanical Record. In Advances in Archaeological Method and Theory, Vol. 10, edited by Michael B. Schiffer, pp. 211-247. Academic Press, Inc. 
Moerman, Daniel E.

1998 Native American Ethnobotany. Timber Press, Portland, Oregon.

Munson, Patrick J.

1986 Hickory Silviculture: A Subsistence Revolution in the Prehistory of Eastern North America. Paper presented at the Emergent Horticultural Economies of the Eastern Woodlands Conference, Carbondale, Illinois.

Murphey, Edith Van Allen

1990 Indian Uses of Native Plants. Meyerbooks, Glenwood, Illinois.

Natural Fibers Information Center

1987 The Climates of Texas Counties. Natural Fibers Information Center, The University of Texas at Austin, in cooperation with the Office of the State Climatologist, Texas A\&M University.

Panshin, A. J., and Carol de Zeeuw

1980 Textbook of Wood Technology: Structure, Identification, Properties, and Uses of the Commercial Woods of the United States and Canada. 4th ed. McGraw-Hill Book Company, New York.

Pearsall, Deborah M.

2000 Paleoethnobotany: A Handbook of Procedures. 2nd ed. Academic Press, San Diego.

Puseman, Kathryn

2006 Measurements of Four Corn Cobs from the Bluff Great House, 42SA22674, Southeast Utah. Technical Report 05-93. Paleo Research Institute, Golden, Colorado.

Scarry, C. Margaret

1986 Changes in Plant Procurement and Production during the Emergence of the Moundville Chiefdom. Ph.D. dissertation, Department of Anthropology, University of Michigan, Ann Arbor.

Schenck, Sara M., and E. W. Gifford

1952 Karok Ethnobotany. Anthropological Records 13(6):377-392.

Shackelton, C. M., and F. Prins

1992 Charcoal Analysis and the "Principle of Least Effort”: A Conceptual Model. Journal of Archaeological Science 19:631-638.

Simpson, Benny J.

1999 A Field Guide to Texas Trees. Lone Star Books, Lanham, Maryland.
Smith, Bruce D.

1992 Rivers of Change: Essays on Early Agriculture in Eastern North America. Smithsonian Institution Press, Washington, D.C.

Soil Survey Staff, Natural Resources Conservation Service and United States Department of Agriculture

2008 Web Soil Survey. Electronic document, http://websoilsurvey.nrcs.usda.gov, accessed April 1, 2011.

Stahle, David W., and Malcolm K. Cleaveland

1992 Reconstruction and Analysis of Spring Rainfall over the Southeastern U.S. for the Past 1000 Years. Bulletin of the American Meteorological Society 73(12):1947-1961.

Swanton, John R.

1979 The Indians of the Southeastern United States. Classics of Smithsonian Anthropology, originally published 1946 as Smithsonian Institution Bureau of American Ethnology Bulletin 137. Smithsonian Institution Press, Washington D.C.

1996 Source Material on the History and Ethnology of the Caddo Indians. University of Oklahoma Press, Norman. Originally published 1942 as Bureau of American Ethnology Bulletin 132, Smithsonian Institution, Washington, D.C.

Talalay, Laurie, Donald R. Keller, and Patrick J. Munson

1984 Hickory Nuts, Walnuts, Butternuts, and Hazelnuts: Observations and Experiments Relevant to Their Aboriginal Exploitation in Eastern North America. In Experiments and Observations on Aboriginal Wild Plant Food Utilization in Eastern North America, edited by Patrick J. Munson, pp. 338-359. Prehistory Research Series 6(2). Indiana Historical Society, Indianapolis.

Turner, Matt Warnock

2009 Remarkable Plants of Texas: Uncommon Accounts of Our Common Natives. University of Texas Press, Austin.

USDA, ARS (United States Department of Agriculture, Agricultural Research Service)

2010 USDA National Nutrient Database for Standard Reference. Release 23. Electronic document, http://www.ars.usda.gov/ba/ bhnrc/ndl, accessed March 31, 2011. 
USDA, NRCS (United States Department of Agriculture, Natural Resources Conservation Service)

2011 The PLANTS Database. United States Department of Agriculture, Natural Resources Conservation Service, Electronic document, http://plants.usda.gov, accessed April 8, 2011.
Welch, Paul D., and C. Margaret Scarry 1995 Status-Related Variation in Foodways in the Moundville Chiefdom. American Antiquity 60(3):397-419.

Zigmond, Maurice L.

1981 Kawaiisu Ethnobotany. University of Utah Press, Salt Lake City. 

APPENDIX G: Vertebrate Remains

Brian Sawyer Shaffer 



\section{INTRODUCTION}

The vertebrate remains from six Caddo sites at Mount Pleasant were analyzed to identify the taxa present, exploitation patterns, and site formation issues relative to each of the sites, though small sample sizes limit interpretations at five of the sites. A total of 3,030 specimens were analyzed, with 2,413 being from 41TT851, 394 from 41TT852, and just 223 specimens from the remaining four sites (Tables G.1 and G.2).

\section{METHODS}

Specimens were analyzed using the Zooarchaeological Research Collection at the University of North Texas for comparative identifications. Attributes for each specimen were recorded and tabulated using a faunal analysis coding system (Shaffer and Baker 1992), and the data were imported into Microsoft Excel. Aside from provenience data, attributes recorded included taxon, element, portion of element, side, weathering, breakage, burning, gnawing, and chemical etching; unique observations such as cultural modification and medical disorders were also recorded.

Identifications were made to the most specific level possible given the condition of the remains, available comparative material, and analyst skill (Tables G.1 and G.2). When identifications could only be taken to generalized levels, then an approximate size usually was estimated. For example, in the case of mammals, most of the unidentifiable mammalian remains are of medium-sized to large mammals, approximately the size of canids and deer.

None of the taxa recovered are unexpected given the geographic location of the sites. There is one chronological exception, however. Armadillo remains at 41TT852 and 41TT853 indicate possible postoccupational site disturbance, as the armadillo is a historic natural interloper into the region (Davis and Schmidly 1994) and hence is not part of the prehistoric component of the assemblages.

Specimens were tabulated in two ways. The first was by the number of identified specimens (NISP) (see Table G.1), and the second by the minimum number of individuals (MNI) (see Table G.2). The NISP is the simple raw specimen count by identifiable category. The MNI is the minimum number of individual animals that could have contributed to the sample for each taxon identified. Due to site turbation and the low specimen counts from four of the six sites, MNI was calculated by treating each site as a single aggregate. The simplest method of MNI calculation is to find duplicated elements or portions of elements for each given taxon. This was expanded to include relative aging categories (subadult, adult, and old adult). Even with the age categories, duplication was infrequent, and the MNI for most taxa by site was one. Especially at 41TT851 and 41TT852, such low MNIs probably are not representative of the actual number of animals contributing to the assemblage given the sizes of the sites and the spatial distributions of elements. There is only one taxon with duplication to indicate the presence of more than one individual at each of these two sites, however.

\section{TAPHONOMY}

Frequencies and relative percentages of taphonomic attributes are presented in Table G.3. As with most archeological faunal assemblages, the greatest detriment to identification is gross fragmentation, regardless of the cause. This is followed by processes that damage the bone in other ways such as weathering, burning, and human and animal modification (e.g., food processing and gnawing). Each of these factors may destroy the bone and render morphological identification difficult or impossible by obliterating exterior surface features such as key identifying landmarks.

\section{Breakage}

Less than 1 percent of the specimens recovered from the six sites are unbroken, and these primarily consist of smaller elements such as podials and teeth. The indeterminate listing for breakage type in Table G.3 includes two elements on which original fracture patterns were obscured by subsequent cultural modification. The majority of the other broken elements ( 87 percent) exhibit angular breakage patterns. This type of breakage is reflective of elements that either will not spirally fracture because of their composition (flat bones such as portions of the skull, sternum, or some bones of nonmammals such as turtle shell, and nonbones such as teeth) or because they have lost their ability to break in such a manner via loss of collagen either over time or through taphonomic processes such as weathering, burning, or chemical leaching. This 


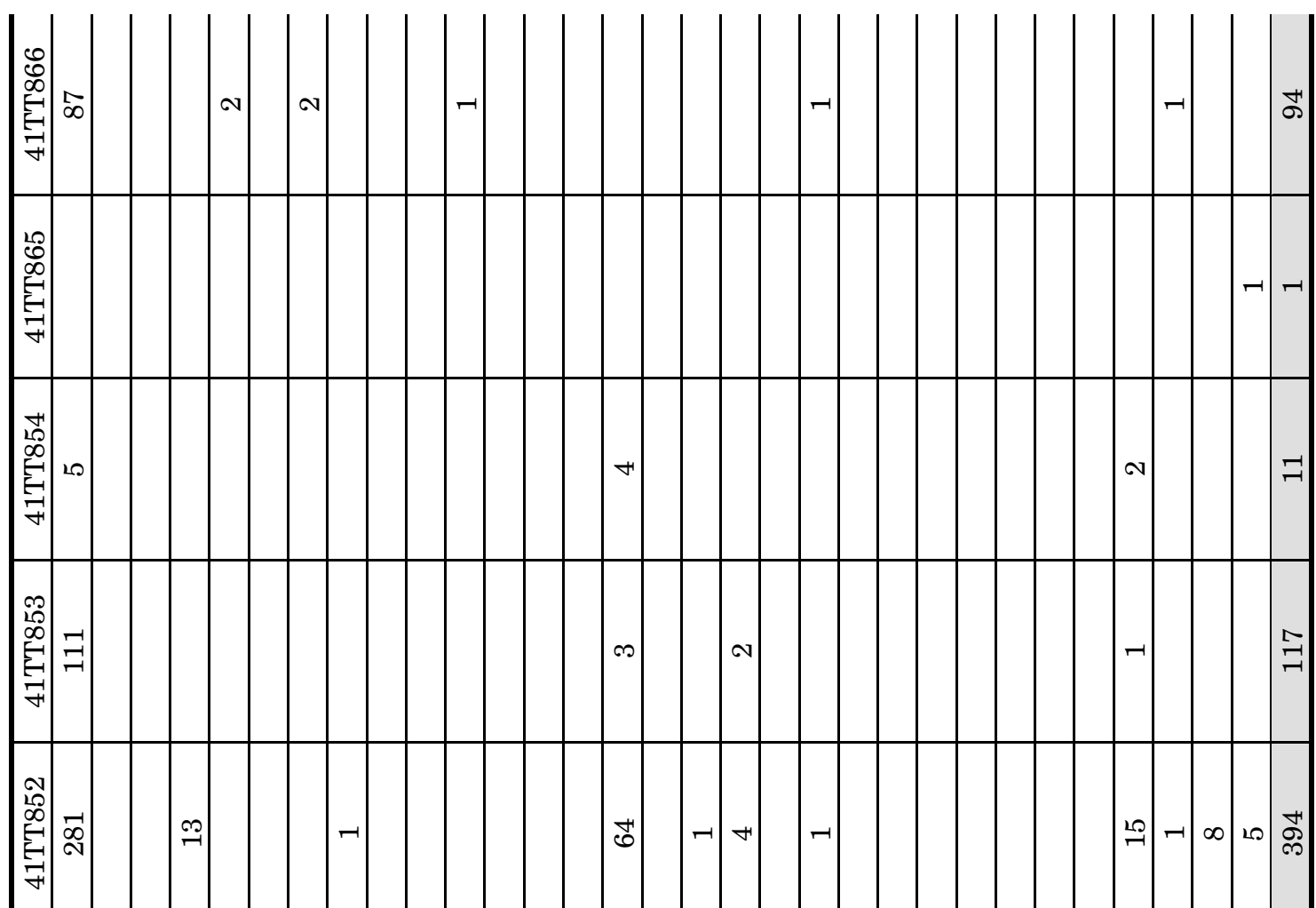

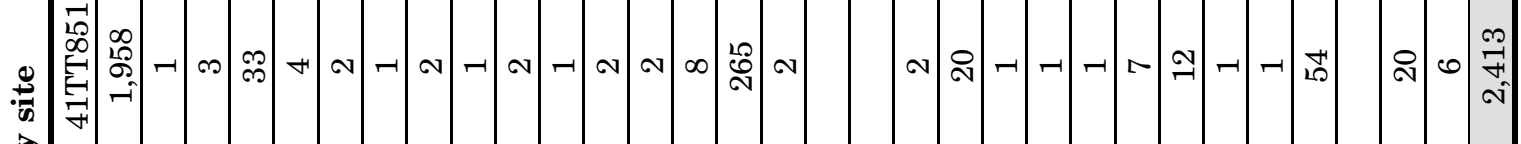


Appendix G: Vertebrate Remains

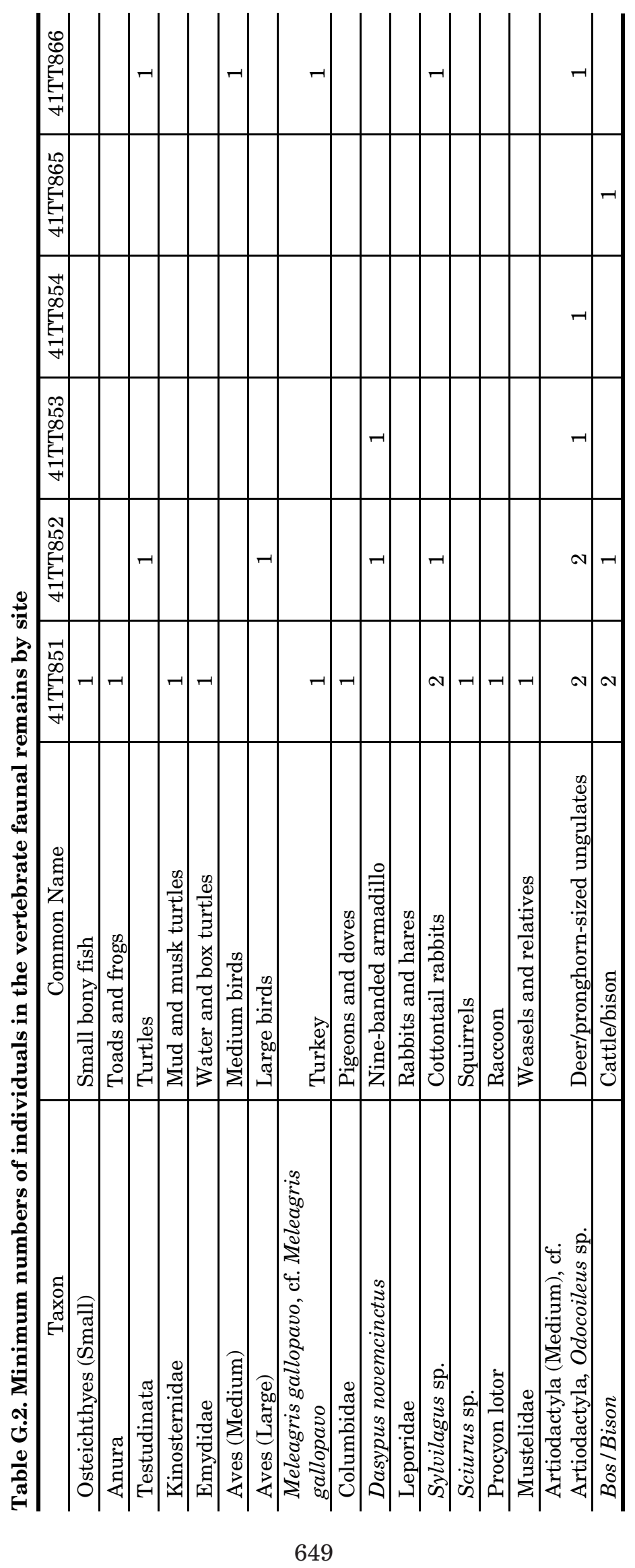


Table G.3. Taphonomy in vertebrate faunal remains by site

\begin{tabular}{|c|c|c|c|c|c|c|c|c|c|c|c|c|}
\hline \multirow[t]{2}{*}{ Taphonomy } & \multicolumn{2}{|c|}{$41 \mathrm{TT} 851$} & \multicolumn{2}{|c|}{$41 \mathrm{TT} 852$} & \multicolumn{2}{|c|}{$41 \mathrm{TT} 853$} & \multicolumn{2}{|c|}{$41 \mathrm{TT} 854$} & \multicolumn{2}{|c|}{$41 \mathrm{TT} 865$} & \multicolumn{2}{|c|}{$41 \mathrm{TT} 866$} \\
\hline & No. & $\%$ & No. & $\%$ & No. & $\%$ & No. & $\%$ & No. & $\%$ & No. & $\%$ \\
\hline \multicolumn{13}{|l|}{ Weathering } \\
\hline Light & 2,411 & 99.9 & 381 & 96.7 & 117 & 100.0 & 11 & 100.0 & 1 & 100.0 & 94 & 100.0 \\
\hline Marked & 2 & 0.1 & 13 & 3.3 & & & & & & & & \\
\hline \multicolumn{13}{|l|}{ Breakage } \\
\hline Unbroken & 15 & 0.6 & 3 & 0.8 & & & & & & & 1 & 1.1 \\
\hline Angular & 2,067 & 85.7 & 351 & 89.1 & 116 & 99.9 & 9 & 81.8 & 1 & 100.0 & 91 & 96.8 \\
\hline Spiral & 326 & 13.5 & 40 & 10.2 & 1 & 0.9 & 2 & 18.2 & & & 2 & 2.1 \\
\hline $\begin{array}{l}\text { Spiral with } \\
\text { Impact Point }\end{array}$ & 3 & 0.1 & & & & & & & & & & \\
\hline Indeterminate* & 2 & 0.1 & & & & & & & & & & \\
\hline \multicolumn{13}{|l|}{ Burning } \\
\hline Unburned & 1,168 & 48.4 & 182 & 46.2 & 18 & 15.4 & 2 & 18.2 & 1 & 100.0 & 31 & 33.0 \\
\hline Charred & 326 & 13.5 & 16 & 4.1 & 1 & 0.9 & & & & & 11 & 11.7 \\
\hline Calcined & 919 & 38.1 & 196 & 49.7 & 98 & 83.8 & 9 & 81.8 & & & 52 & 55.3 \\
\hline \multicolumn{13}{|l|}{ Gnawing } \\
\hline Rodent & 18 & 0.8 & 5 & 1.3 & & & & & & & & \\
\hline \multicolumn{13}{|l|}{ Tool Marks } \\
\hline Cut Marks & 1 & $<0.1$ & 2 & 0.5 & & & & & & & & \\
\hline
\end{tabular}

* The original breakage pattern is indeterminable on two modified elements from 41TT851.

breakage, therefore, usually cannot be tied directly to particular human activities.

Twelve percent of the faunal elements are spirally fractured. Spiral breakage is indicative of specimens that were fractured while the bone was still fresh (containing collagen) (Johnson 1985). Typically in mammals, for example, elements that have the potential to break in this manner are long bones or areas of dense cortical bone such as the neck and part of the blade of the scapula, parts of the pelvis particularly around the acetabulum, the mandible, and sometimes portions of the ribs. Of course, this breakage can occur naturally, by the actions of predators, through food processing, and through unrelated cultural activities such as trampling after discard. No doubt, much of what was observed is due to intentional breakage, some of which is reflected by the presence of dynamic loading impact points that indicate intentional breakage by humans (Johnson 1985). Impact points are present on three elements in the 41TT851 faunal assemblage.

\section{Weathering}

Weathering, the exposure of bone to the environmental elements (sun, rain, heat, cold, etc.) was recorded as being light or marked with marked being specimens that exhibited fine-line fractures or flaking in planes. Only 2 specimens from 41TT851 and 13 from 41TT852 were identified with marked weathering. This indicates that the sample was buried relatively quickly such that exposure on the surface did not produce significant damage and affect identification potential (see Johnson 1985).

\section{Burning}

Burning was a significant factor at the three sites with the largest assemblages. The majority of the burning was in the form of calcination, the near-complete combustion of the bone before losing integrity and resulting in disintegration. Calcined bones most notably are white in color, sometimes with a bluish tint. Charring, or the incomplete combustion of the bone that results in a darkened and usually blackened appearance, was also present. Aside from discoloration and loss of collagen, charring is not nearly as destructive to bone as calcination. Given the high amount of calcined bone relative to charred and unburned bone, it appears that bone was used as a fuel for fire, at 
least part of the time; this would account for a considerable loss of data.

\section{Rodent Gnawing}

Another taphonomic factor identified is animal gnawing. Tooth marks left on bones provide evidence of this activity and can often be used to identify the type of animal involved, such as rodent, carnivore, or other animal type and size. Twenty-three specimens were identified with gnaw marks, all of which were rodent as evidenced by the parallel sets of U-shaped grooves. Of these, 18 were recovered from 41TT851 and 5 were from $41 \mathrm{TT} 852$.

\section{Cultural Modification}

Definite cultural modification was identified in the 41TT851 and 41TT852 faunal assemblages. Aside from the specimens exhibiting dynamic loading impact points noted above, cut marks were observed on three elements in these assemblages. The latter include the proximal end of an Odocoileus sp. radius with numerous cut marks and deer-sized artiodactyl tibia and metatarsal fragments with mid-shaft cut marks. The marks on the Odocoileus sp. element from 41TT851 may be derived from carcass disarticulation/meat removal. The locations of the deep cut marks on the artiodactyl elements from 41TT852 are not clearly indicative of butchering activities. Other culturally modified elements include three tools recovered from 41TT851 and a fragment of modified turtle shell collected from 41TT852. The latter is thin, roughly the size of a dime, and has abraded, uniformly beveled edges. The 41TT851 tool fragments include a distal antler tine fragment (Odocoileus sp.) and a probable bison (Bison bison) horn core/ cranial fragment that bear use-derived modification, and an intentionally modified rib fragment from a medium/large mammal.

\section{DIET AND HABITAT USE}

With the exception of the armadillos, the remains recovered from these sites all potentially represent utilized taxa, though those occurring in extremely low frequencies or without diagnostic indications of human involvement may be intrusive. Fish and aquatic turtles (mud and musk) are the only predominantly aquatic taxa.
Emydid turtles include terrestrial box turtles but also aquatic sliders and cooters, so they may account for additional aquatic exploitation. Similarly, the anuran remains may be from a terrestrial or aquatic species.

Terrestrial and primarily terrestrial taxa include turkey, dove, rabbits, squirrels, raccoons, mustelids (weasels and relatives), and deer and possible bison (cattle/bison). Without diagnostic landmarks, the cattle/bison remains could be from historic cattle and hence are not identified further. However, the context of a modified cattle/ bison element from 41TT851 indicates that it is associated with Caddo occupation of that site and thus is most likely a bison element. By distribution, frequency, and animal size, deer (and deer-sized artiodactyl remains that were likely from deer) represent the primary utilized animal resource at the sites, though cattle/bison could obviously account for several times the volume of resources per animal than deer.

In looking for exploitation factors for the deer and deer-sized artiodactyls, specimens that could be aged were analyzed to determine a preference in hunting. Eight specimens could be aged including teeth and long bone specimens. Using information from Purdue (1983) and Ramsey and Shult (n.d.), all eight specimens were from adults.

\section{SUMMARY}

Analysis of the 3,030 specimens from six Caddo sites in Titus County produced only limited results. Aside from the very small sample sizes at four sizes, it appears that the assemblages may have undergone considerable destruction via burning, the bone scrap being used for fuel. Beyond this, the assemblages appear to have been buried relatively quickly and did not suffer significantly due to exposure to the elements or from damage produced by rodents or carnivores. Of the taxa represented, exploitation appears focused primarily on terrestrial habitats with limited use of aquatic taxa. For the terrestrial taxa, deer and deer-sized artiodactyl remains are the most commonly identified taxa present, with the greatest distributions within and across sites, and are the second-largest animal recovered. Deer appear to be the primary staple resource, though cattle/bison could have provided a significant addition to the diet. 


\section{REFERENCES CITED}

Davis, William B., and David J. Schmidly

1994 The Mammals of Texas. Texas Parks and Wildlife Press, Austin.

Johnson, Eileen

1985 Current Developments in Bone Technology. In Advances in Archaeological Method and Theory, Vol. 8, edited by M. B. Schiffer, pp. 157-235. Academic Press, New York.

Purdue, James R.

1983 Epiphyseal Closure in White-Tailed Deer. Journal of Wildlife Management 47(4):1207-1213.
Ramsey, Charles W., and Milo J. Shult

n.d. The Age of a Deer. Publication No. B-1453. Texas Agricultural Extension Service, Texas A\&M University System, College Station.

Shaffer, Brian S., and Barry W. Baker

1992 A Vertebrate Faunal Analysis Coding System: With North American Taxonomy and dBase Support Programs and Procedures, Version 3.3. Technical Report No. 23. University of Michigan, Museum of Anthropology, Ann Arbor. 


\section{APPENDIX H: Invertebrate Faunal Remains}

Karen M. Gardner 

Table H.1. Inventory of invertebrate faunal remains

\begin{tabular}{|c|c|c|c|c|c|c|c|}
\hline Site & Feature & Provenience & $\begin{array}{c}\text { Depth } \\
(\mathrm{cm})\end{array}$ & No. & Kind & ID & Comments \\
\hline $41 \mathrm{TT} 851$ & 9 & & & 1 & Mussel & Lampsilis hydiana & 1 intact valve \\
\hline $41 \mathrm{TT} 851$ & 9 & & & 1 & Mussel & Lampsilis sp. & \\
\hline $41 \mathrm{TT} 851$ & 9 & & & 26 & & unidentifiable fragments & 3 burned \\
\hline $41 \mathrm{TT} 851$ & 17 & & & 1 & Mussel & Lampsilis teres & \\
\hline $41 \mathrm{TT} 851$ & 17 & & & 13 & & unidentifiable fragments & 2 burned \\
\hline $41 \mathrm{TT} 851$ & 19 & & & 6 & & unidentifiable fragments & \\
\hline $41 \mathrm{TT} 851$ & 28 & & & 1 & Mussel & Lampsilis sp. & burned \\
\hline $41 \mathrm{TT} 851$ & 28 & & & 1 & Mussel & Leptodea fragilis & \\
\hline $41 \mathrm{TT} 851$ & 28 & & & 1 & Snail & Mesodon thyroidus & \\
\hline $41 \mathrm{TT} 851$ & 28 & & & 8 & & unidentifiable fragments & 3 burned \\
\hline $41 \mathrm{TT} 851$ & 58 & & & 1 & & unidentifiable fragment & \\
\hline $41 \mathrm{TT} 851$ & 78 & & & 1 & Snail & Mesodon sp. & \\
\hline $41 \mathrm{TT} 851$ & 155 & & & 1 & & unidentifiable fragment & burned \\
\hline $41 \mathrm{TT} 851$ & 188 & & & 17 & & unidentifiable fragments & 2 burned \\
\hline $41 \mathrm{TT} 851$ & 189 & & & 2 & Mussel & Lampsilis teres & $\begin{array}{l}\text { burned, } 1 \text { nearly } \\
\text { intact valve }\end{array}$ \\
\hline $41 \mathrm{TT} 851$ & 189 & & & 1 & Snail & Rabdotus dealbatus & \\
\hline $41 \mathrm{TT} 851$ & 189 & & & 18 & & unidentifiable fragments & 1 burned \\
\hline $41 \mathrm{TT} 851$ & 198 & & & 1 & & unidentifiable fragment & \\
\hline $41 \mathrm{TT} 851$ & $205 / 16$ & & & 38 & & unidentifiable fragments & \\
\hline $41 \mathrm{TT} 851$ & 233 & & & 12 & & unidentifiable fragments & 2 burned \\
\hline $41 \mathrm{TT} 851$ & 243 & & & 1 & Mussel & Leptodea $\mathrm{sp}$. & \\
\hline $41 \mathrm{TT} 851$ & 243 & & & 20 & & unidentifiable fragments & \\
\hline $41 \mathrm{TT} 851$ & 268 & & & 1 & Mussel & Lampsilis hydiana & \\
\hline $41 \mathrm{TT} 851$ & & 3 & $20-25$ & 1 & Mussel & Leptodea fragilis & \\
\hline $41 \mathrm{TT} 851$ & & 3 & $20-25$ & 2 & & unidentifiable fragments & \\
\hline $41 \mathrm{TT} 851$ & & 3 & $27-30$ & 2 & & unidentifiable fragments & \\
\hline $41 \mathrm{TT} 851$ & & 3 & $30-35$ & 1 & & unidentifiable fragment & \\
\hline $41 \mathrm{TT} 851$ & & 6 & $10-20$ & 1 & & unidentifiable fragment & \\
\hline $41 \mathrm{TT} 851$ & & 6 & $20-25$ & 1 & Mussel & Lampsilis teres & \\
\hline $41 \mathrm{TT} 851$ & & 6 & $20-25$ & 7 & & unidentifiable fragments & \\
\hline $41 \mathrm{TT} 851$ & & 6 & $25-30$ & 1 & & unidentifiable fragment & \\
\hline $41 \mathrm{TT} 851$ & & 6 & $25-34$ & 1 & Mussel & Lampsilis hydiana & \\
\hline $41 \mathrm{TT} 851$ & & 6 & $25-34$ & 2 & & unidentifiable fragments & \\
\hline $41 \mathrm{TT} 851$ & & 6 & $30-35$ & 2 & & unidentifiable fragments & \\
\hline $41 \mathrm{TT} 851$ & & 7 & $30-40$ & 1 & Snail & Rabdotus dealbatus & \\
\hline $41 \mathrm{TT} 851$ & & BHT 40-SE & $0-10$ & 1 & & unidentifiable fragment & \\
\hline $41 \mathrm{TT} 851$ & & BHT 40-SE & $30-35$ & 3 & Mussel & Lampsilis teres & 1 intact valve \\
\hline $41 \mathrm{TT} 851$ & & BHT 40-SE & $30-35$ & 6 & & unidentifiable fragments & \\
\hline $41 \mathrm{TT} 851$ & & stripped area & & 1 & Mussel & Lampsilis $\mathrm{sp}$. & \\
\hline $41 \mathrm{TT} 851$ & & stripped area & & 1 & & Leptodea fragilis & intact valve \\
\hline $41 \mathrm{TT} 851$ & & stripped area & & 7 & & unidentifiable fragments & \\
\hline $41 \mathrm{TT} 852$ & 553 & & & 3 & & unidentifiable fragments & \\
\hline $41 \mathrm{TT} 866$ & 5 & & & 1 & & unidentifiable fragment & burned \\
\hline
\end{tabular}





\section{APPENDIX I: Neutron Activation Analysis of Caddo Ceramics}

Jeffrey R. Ferguson and

Michael D. Glascock

Archaeometry Laboratory

Research Reactor Center, University of

Missouri 



\section{Introduction}

This report describes the preparation, analysis, and interpretation of 45 pottery samples from three sites in Titus County, Texas. The samples include 15 samples from each site: 41TT851, 41TT852, and 41TT853. The sites are all located within a $1.5 \mathrm{~km}$ stretch along the east bank of Tankersley Creek and just west of the town of Mount Pleasant. The goals of the research are to examine both the internal compositional variability with the hope of determining local production signatures as well as compare these samples to the larger east Texas Caddo database. Sample IDs and some basic descriptive information are provided in Appendix 1.

MURR has a large sample of data from Caddo ceramics from east Texas, primarily submitted by Tim Perttula; however, this region exhibits remarkable uniformity in raw clay composition over vast areas. This uniformity in the chemical composition of the raw materials has limited the potential for NAA to distinguish likely ceramic production locations (Ferguson et al. 2008). The current samples fit the usual Caddo pattern of minimal patterned variability, thus we are not surprised to find little difference among the samples from the three near-by sites. The samples from this project also show consistent similarity to the core group established for the region.

\section{Sample Preparation}

Pottery and clay samples were prepared for INAA using procedures standard at MURR. Fragments of about $1 \mathrm{~cm}^{2}$ were removed from each sample and abraded using a silicon carbide burr in order to remove glaze, slip, paint, and adhering soil, thereby reducing the risk of measuring contamination. The samples were washed in deionized water and allowed to dry in the laboratory. Once dry, the individual sherds were ground to powder in an agate mortar to homogenize the samples. Archival samples were retained from each sherd (when possible) for future research.

Two analytical samples were prepared from each source specimen. Portions of approximately $150 \mathrm{mg}$ of powder were weighed into clean high-density polyethylene vials used for short irradiations at MURR. At the same time, $200 \mathrm{mg}$ of each sample was weighed into clean highpurity quartz vials used for long irradiations. Individual sample weights were recorded to the nearest $0.01 \mathrm{mg}$ using an analytical balance. Both vials were sealed prior to irradiation. Along with the unknown samples, Standards made from National Institute of Standards and Technology (NIST) certified standard reference materials of SRM-1633a (coal fly ash) and SRM-688 (basalt rock) were similarly prepared, as were quality control samples (e.g., standards treated as unknowns) of SRM-278 (obsidian rock) and Ohio Red Clay (a standard developed for in-house applications).

\section{Irradiation and Gamma-Ray Spectroscopy}

Neutron activation analysis of ceramics at MURR, which consists of two irradiations and a total of three gamma counts, constitutes a superset of the procedures used at most other NAA laboratories (Glascock 1992; Neff 1992, 2000). As discussed in detail by Glascock (1992), a short irradiation is carried out through the pneumatic tube irradiation system. Samples in the polyvials are sequentially irradiated, two at a time, for five seconds by a neutron flux of $8 \times 10^{13}$ 
$\mathrm{n} \mathrm{cm}^{-2} \mathrm{~s}^{-1}$ The 720 -second count yields gamma spectra containing peaks for nine short-lived elements aluminum $(\mathrm{Al})$, barium $(\mathrm{Ba})$, calcium $(\mathrm{Ca})$, dysprosium $(\mathrm{Dy})$, potassium $(\mathrm{K})$, manganese $(\mathrm{Mn})$, sodium $(\mathrm{Na})$, titanium $(\mathrm{Ti})$, and vanadium $(\mathrm{V})$. The samples are encapsulated in quartz vials and are subjected to a 24-hour irradiation at a neutron flux of $5 \times 10^{13} \mathrm{n} \mathrm{cm}^{-2} \mathrm{~s}^{-1}$. This long irradiation is analogous to the single irradiation utilized at most other laboratories. After the long irradiation, samples decay for seven days, and then are counted for 1,800 seconds (the "middle count") on a high-resolution germanium detector coupled to an automatic sample changer. The middle count yields determinations of seven medium half-life elements, namely arsenic (As), lanthanum (La), lutetium (Lu), neodymium $(\mathrm{Nd})$, samarium $(\mathrm{Sm})$, uranium $(\mathrm{U})$, and ytterbium $(\mathrm{Yb})$. After an additional three- or four-week decay, a final count of 8,500 seconds is carried out on each sample. The latter measurement yields the following 17 long half-life elements: cerium $(\mathrm{Ce})$, cobalt $(\mathrm{Co})$, chromium $(\mathrm{Cr})$, cesium $(\mathrm{Cs})$, europium $(\mathrm{Eu})$, iron $(\mathrm{Fe})$, hafnium (Hf), nickel (Ni), rubidium ( $\mathrm{Rb})$, antimony ( $\mathrm{Sb})$, scandium $(\mathrm{Sc})$, strontium $(\mathrm{Sr})$, tantalum (Ta), terbium (Tb), thorium (Th), zinc $(\mathrm{Zn})$, and zirconium $(\mathrm{Zr})$. The element concentration data from the three measurements are tabulated in parts per million

\section{Interpreting Chemical Data}

The analyses at MURR, described above, produced elemental concentration values for 33 elements in most of the analyzed samples. Data for Ni in many samples was below detection limits (as is the norm for most New World ceramics) and was removed from consideration during the statistical analysis. Calcium levels were found to be high enough (up to 7.4\%) in many specimens to require a calcium correction of the dataset. Because calcium has the potential to affect (dilute) the concentrations of other elements in the analysis, all samples were mathematically corrected to compensate for any possible calcium included effects (the data were examined before and after calcium correction and the results were similar). The following mathematical correction was used as it has been proven to be effective in other calcium-rich datasets (Cogswell et al. 1998:64; Steponaitis et al. 1988):

$$
e^{\prime}=\frac{10^{6} e}{10^{6}-2.5 c}
$$

where $e^{\prime}$ is the corrected concentration of a given element in ppm, $e$ is the measured concentration of that element in ppm, and $c$ is the concentration of elemental calcium in ppm. After the calcium correction, calcium was generally removed from the statistical analyses. Statistical analysis was subsequently carried out on base-10 logarithms of concentrations on the remaining 31 elements.

Use of log concentrations rather than raw data compensates for differences in magnitude between the major elements, such as calcium, on one hand and trace elements, such as the rare earth or lanthanide elements (REEs). Transformation to base-10 logarithms also yields a more normal distribution for many trace elements.

The interpretation of compositional data obtained from the analysis of archaeological materials is discussed in detail elsewhere (e.g., Baxter and Buck 2000; Bieber et al. 1976; Bishop and Neff 1989; Glascock 1992; Harbottle 1976; Neff 2000) and will only be summarized here. The main 
goal of data analysis is to identify distinct homogeneous groups within the analytical database. Based on the provenance postulate of Weigand et al. (1977), different chemical groups may be assumed to represent geographically restricted sources. For lithic materials such as obsidian, basalt, and cryptocrystalline silicates (e.g., chert, flint, or jasper), raw material samples are frequently collected from known outcrops or secondary deposits and the compositional data obtained on the samples is used to define the source localities or boundaries. The locations of sources can also be inferred by comparing unknown specimens (i.e., ceramic artifacts) to knowns (i.e., clay samples) or by indirect methods such as the "criterion of abundance" (Bishop et al. 1992) or by arguments based on geological and sedimentological characteristics (e.g., Steponaitis et al. 1996). The ubiquity of ceramic raw materials usually makes it impossible to sample all potential "sources" intensively enough to create groups of knowns to which unknowns can be compared. Lithic sources tend to be more localized and compositionally homogeneous in the case of obsidian or compositionally heterogeneous as is the case for most cherts.

Compositional groups can be viewed as "centers of mass" in the compositional hyperspace described by the measured elemental data. Groups are characterized by the locations of their centroids and the unique relationships (i.e., correlations) between the elements. Decisions about whether to assign a specimen to a particular compositional group are based on the overall probability that the measured concentrations for the specimen could have been obtained from that group.

Initial hypotheses about source-related subgroups in the compositional data can be derived from non-compositional information (e.g., archaeological context, decorative attributes, etc.) or from application of various pattern-recognition technique to the multivariate chemical data. Some of the pattern recognition techniques that have been used to investigate archaeological data sets are cluster analysis (CA), principal components analysis (PCA), and discriminant analysis (DA). Each of the techniques has its own advantages and disadvantages which may depend upon the types and quantity of data available for interpretation.

The variables (measured elements) in archaeological and geological data sets are often correlated and frequently large in number. This makes handling and interpreting patterns within the data difficult. Therefore, it is often useful to transform the original variables into a smaller set of uncorrelated variables in order to make data interpretation easier. Of the above-mentioned pattern recognition techniques, $\mathrm{PCA}$ is a technique that transforms from the data from the original correlated variables into uncorrelated variables most easily.

PCA creates a new set of reference axes arranged in decreasing order of variance subsumed. The individual PCs are linear combinations of the original variables. The data can be displayed on combinations of the new axes, just as they can be displayed on the original elemental concentration axes. PCA can be used in a pure pattern-recognition mode, i.e., to search for subgroups in an undifferentiated data set, or in a more evaluative mode, i.e., to assess the coherence of hypothetical groups suggested by other criteria. Generally, compositional differences between specimens can be expected to be larger for specimens in different groups than for specimens in the same group, and this implies that groups should be detectable as distinct areas of high point density on plots of the first few components. It is well known that 
PCA of chemical data is scale dependent (Mardia et al. 1979), and analyses tend to be dominated by those elements or isotopes for which the concentrations are relatively large. This is yet another reason for the log transformation of the data.

One frequently exploited strength of PCA, discussed by Baxter (1992), Baxter and Buck (2000z), and Neff (1994, 2002), is that it can be applied as a simultaneous R- and Q-mode technique, with both variables (elements) and objects (individual analyzed samples) displayed on the same set of principal component reference axes. A plot using the first two principal components as axes is usually the best possible two-dimensional representation of the correlation or variancecovariance structure within the data set. Small angles between the vectors from the origin to variable coordinates indicate strong positive correlation; angles at 90 degrees indicate no correlation; and angles close to 180 degrees indicate strong negative correlation. Likewise, a plot of sample coordinates on these same axes will be the best two-dimensional representation of Euclidean relations among the samples in log-concentration space (if the PCA was based on the variance-covariance matrix) or standardized log-concentration space (if the PCA was based on the correlation matrix). Displaying both objects and variables on the same plot makes it possible to observe the contributions of specific elements to group separation and to the distinctive shapes of the various groups. Such a plot is commonly referred to as a "biplot" in reference to the simultaneous plotting of objects and variables. The variable inter-relationships inferred from a biplot can be verified directly by inspecting bivariate elemental concentration plots. [Note that a bivariate plot of elemental concentrations is not a biplot.]

Whether a group can be discriminated easily from other groups can be evaluated visually in two dimensions or statistically in multiple dimensions. A metric known as the Mahalanobis distance (or generalized distance) makes it possible to describe the separation between groups or between individual samples and groups on multiple dimensions. The Mahalanobis distance of a specimen from a group centroid (Bieber et al. 1976, Bishop and Neff 1989) is defined by:

$$
D_{y, X}^{2}=[y-\bar{X}]^{t} I_{x}[y-\bar{X}]
$$

where $y$ is the $1 \mathrm{x} \mathrm{m}$ array of logged elemental concentrations for the specimen of interest, $X$ is the $\mathrm{n} \times \mathrm{m}$ data matrix of logged concentrations for the group to which the point is being compared with $\bar{X}$ being it $1 \mathrm{x} \mathrm{m}$ centroid, and $I_{x}$ is the inverse of the $\mathrm{m} \mathrm{x} \mathrm{m}$ variancecovariance matrix of group $X$. Because Mahalanobis distance takes into account variances and covariances in the multivariate group it is analogous to expressing distance from a univariate mean in standard deviation units. Like standard deviation units, Mahalanobis distances can be converted into probabilities of group membership for individual specimens. For relatively small sample sizes, it is appropriate to base probabilities on Hotelling's $T^{2}$, which is the multivariate extension of the univariate Student's $t$.

When group sizes are small, Mahalanobis distance-based probabilities can fluctuate dramatically depending upon whether or not each specimen is assumed to be a member of the group to which it is being compared. Harbottle (1976) calls this phenomenon "stretchability" in reference to the tendency of an included specimen to stretch the group in the direction of its own location in 
elemental concentration space. This problem can be circumvented by cross-validation, that is, by removing each specimen from its presumed group before calculating its own probability of membership (Baxter 1994; Leese and Main 1994). This is a conservative approach to group evaluation that may sometimes exclude true group members.

Small sample and group sizes place further constraints on the use of Mahalanobis distance: with more elements than samples, the group variance-covariance matrix is singular thus rendering calculation of $I_{x}$ (and $D^{2}$ itself) impossible. Therefore, the dimensionality of the groups must somehow be reduced. One approach would be to eliminate elements considered irrelevant or redundant. The problem with this approach is that the investigator's preconceptions about which elements should be discriminate may not be valid. It also squanders the main advantage of multielement analysis, namely the capability to measure a large number of elements. An alternative approach is to calculate Mahalanobis distances with the scores on principal components extracted from the variance-covariance or correlation matrix for the complete data set. This approach entails only the assumption, entirely reasonable in light of the above discussion of PCA, that most group-separating differences should be visible on the first several PCs. Unless a data set is extremely complex, containing numerous distinct groups, using enough components to subsume at least $90 \%$ of the total variance in the data can be generally assumed to yield Mahalanobis distances that approximate Mahalanobis distances in full elemental concentration space.

Lastly, Mahalanobis distance calculations are also quite useful for handling missing data (Sayre 1975). When many specimens are analyzed for a large number of elements, it is almost certain that a few element concentrations will be missed for some of the specimens. This occurs most frequently when the concentration for an element is near the detection limit. Rather than eliminate the specimen or the element from consideration, it is possible to substitute a missing value by replacing it with a value that minimizes the Mahalanobis distance for the specimen from the group centroid. Thus, those few specimens which are missing a single concentration value can still be used in group calculations.

\section{$\underline{\text { Results }}$}

As is typical for east Texas Caddo ceramics, there is very little obvious compositional patterning. This difficulty recently led to the attempt by Jeff Ferguson and Tim Perttula to reanalyze the entire east Texas Caddo database (Ferguson, et al. 2008). The reanalysis was moderately successful at finding core groups for each of the 11 subregions that divided the area (Figure 1), but there was such significant overlap between the core groups that it is not possible to confidently assign unknown samples to a likely production region. The attempt to project these new data from Titus County against the east Texas Caddo database as well as the larger MURR ceramic database are described below, but first we address internal variability and differences between the samples from the three sites. 


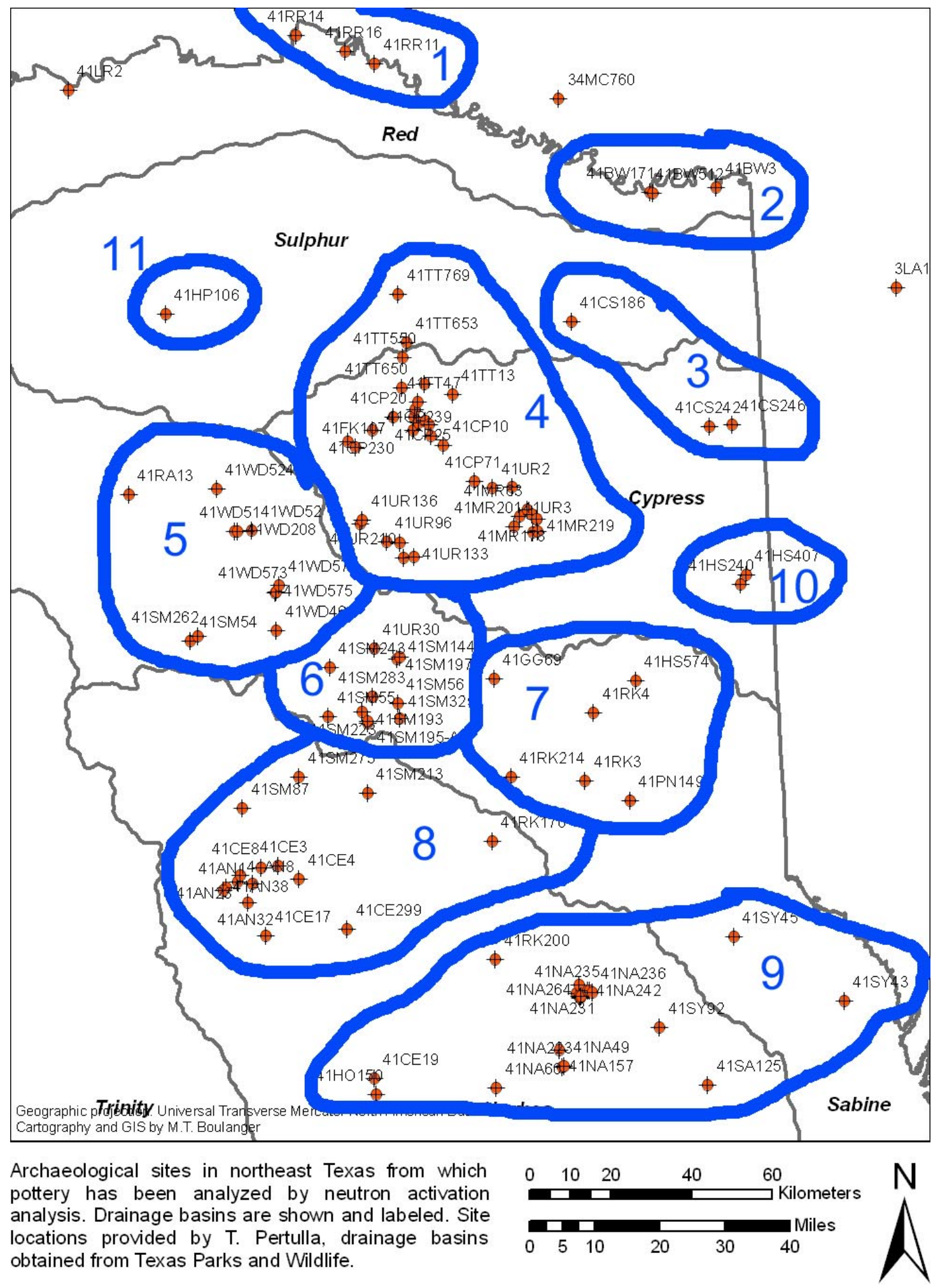

Figure 1. Subregional map of East Texas Caddo database. 


\section{Internal Compositional Variability}

Treating these new data as an isolated dataset is complicated by the small number of samples, but we have still unsuccessfully attempted to find some internal variability and assess this variability relative to the site.

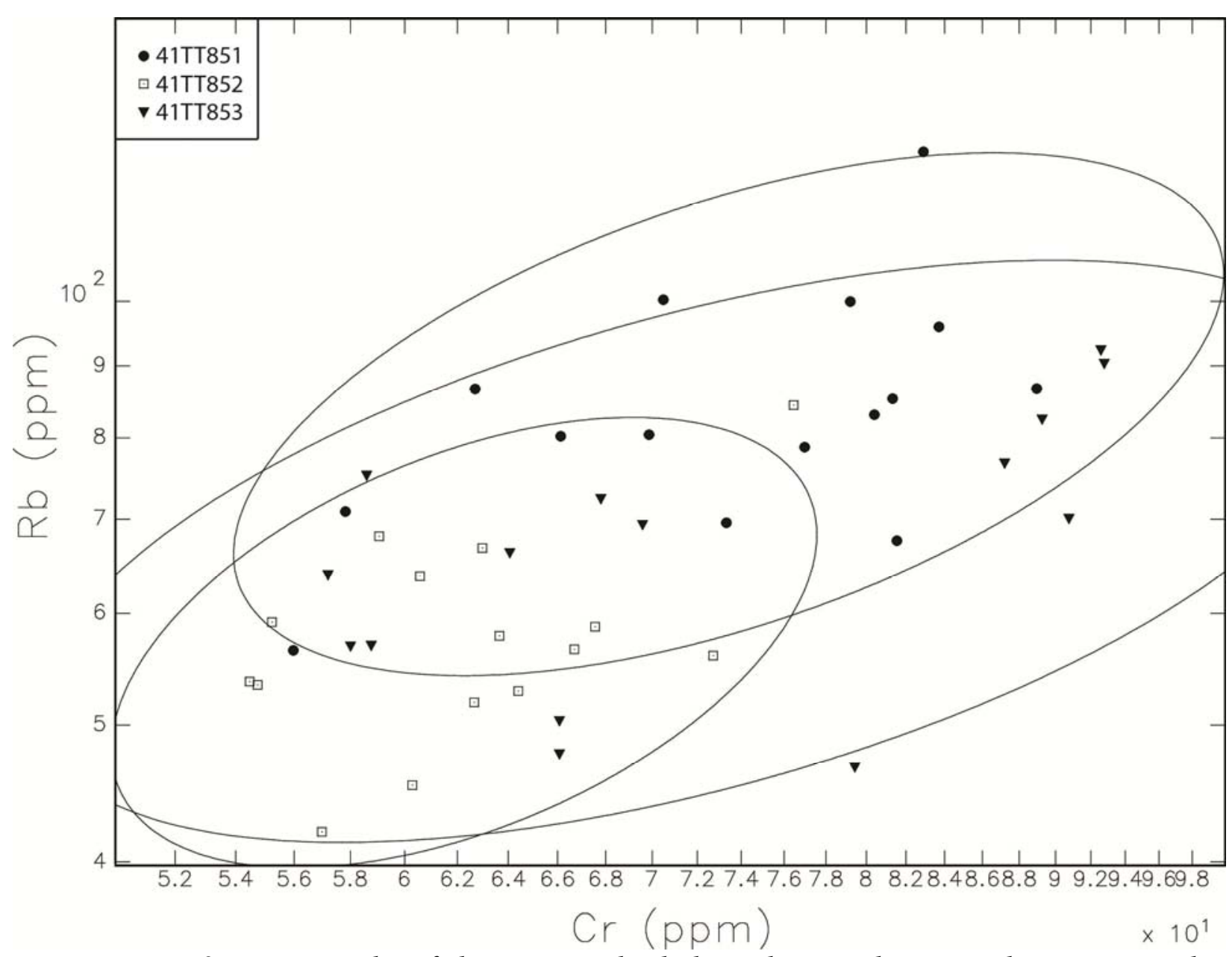

Figure 2. Bivariate plot of chromium and rubidium showing the minimal compositional differences between the samples from the three different sites. Ellipses represent a $90 \%$ confidence level for membership in the group.

There are no obvious compositional differences between the assemblages from the three sites. Figure 2 shows a slightly reduced variability in chromium for the samples from 41TT852, but this difference is minimal and does not hold up for other elements. Figure 3 shows the nearly complete overlap of the samples in a plot of the first two principal components.

It is possible to force some separation using canonical discriminate analysis, but this statistical approach can find separation in small datasets that results from random variation rather than patterned compositional variability. This lack of variability is understandable given the likelihood of ceramic movement within the Caddo region, the occurrence of broad 
compositionally-similar clays, and the extensive use of grog temper.

There are no clear descriptive categories that warrant further investigation. We have not previously noted differences between gray and black paste color (most likely a result of firing conditions and not relating to compositional variability) and all but one of the samples has grog temper. Petrographic analysis might be able to discern patterns in the raw materials not apparent in the bulk chemistry.

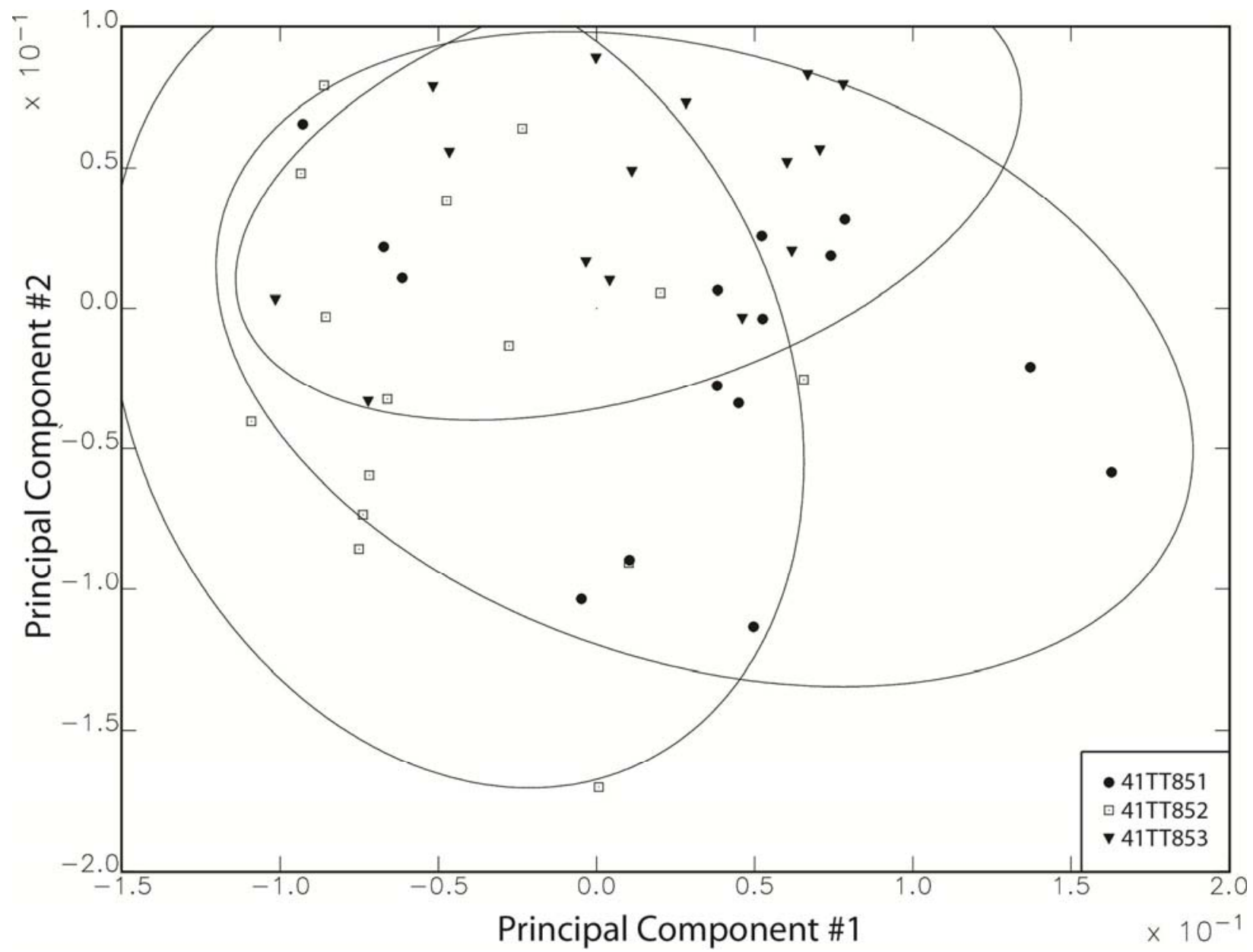

Figure 3. Bivariate plot of principal components 1 and 2 showing the minimal compositional differences between the samples from the three different sites. Ellipses represent a 90\% confidence level for membership in the group.

\section{Comparison with the East Texas Caddo Database}

As described previously, the East Texas Caddo database has been the focus of a recent study (Ferguson et al. 2008). This reinterpretation did not result in the isolation of production regions as initially hoped, with the possible exception of material from the northern portion of the study are along the Red River. Figure 1 is the subregional map used by Ferguson et al. (2008). The 
sample sizes of the subregions vary considerably. Region 4 includes Titus County and has one of the largest samples with over 150 members of the Region 4 Core Group. Unfortunately, almost all of the subregional core groups almost completely overlap with each other, with the notable exception of Subregions 1 and 2. In order to facilitate the comparison with the East Texas Caddo subregional groups, the new data were calcium corrected and concentrations for Ni, $\mathrm{Sr}$, and $\mathrm{Ca}$ were removed.

\section{Subregions $4,5,6,7,8$, and 9}

These six subregions are considered together here because they are all have very similar core groups and they all have sufficient number of samples to allow the projection of groups membership probabilities using almost all of the elements (Na, Al, K, and Ti were not included). Subregion 7 Group 1 also had a large number of members, so it is also included in the comparison. These groups represent the most challenging portion of the East Texas Caddo database reanalysis project because of the overlap. At this point it is difficult to address how much of this overlap is due to large-scale similarities in the clay deposits, the use of grog temper, and/or long-distance exchange of vessels. As shown in Table 1, there are almost no samples with a high probability of membership in only one of these subregional core groups. Perhaps with further refinements of the subregional databases it will be possible to better isolate the core groups.

Table 1. Group membership probabilities based on a Mahalanobis distance projection using the first seven principal components.

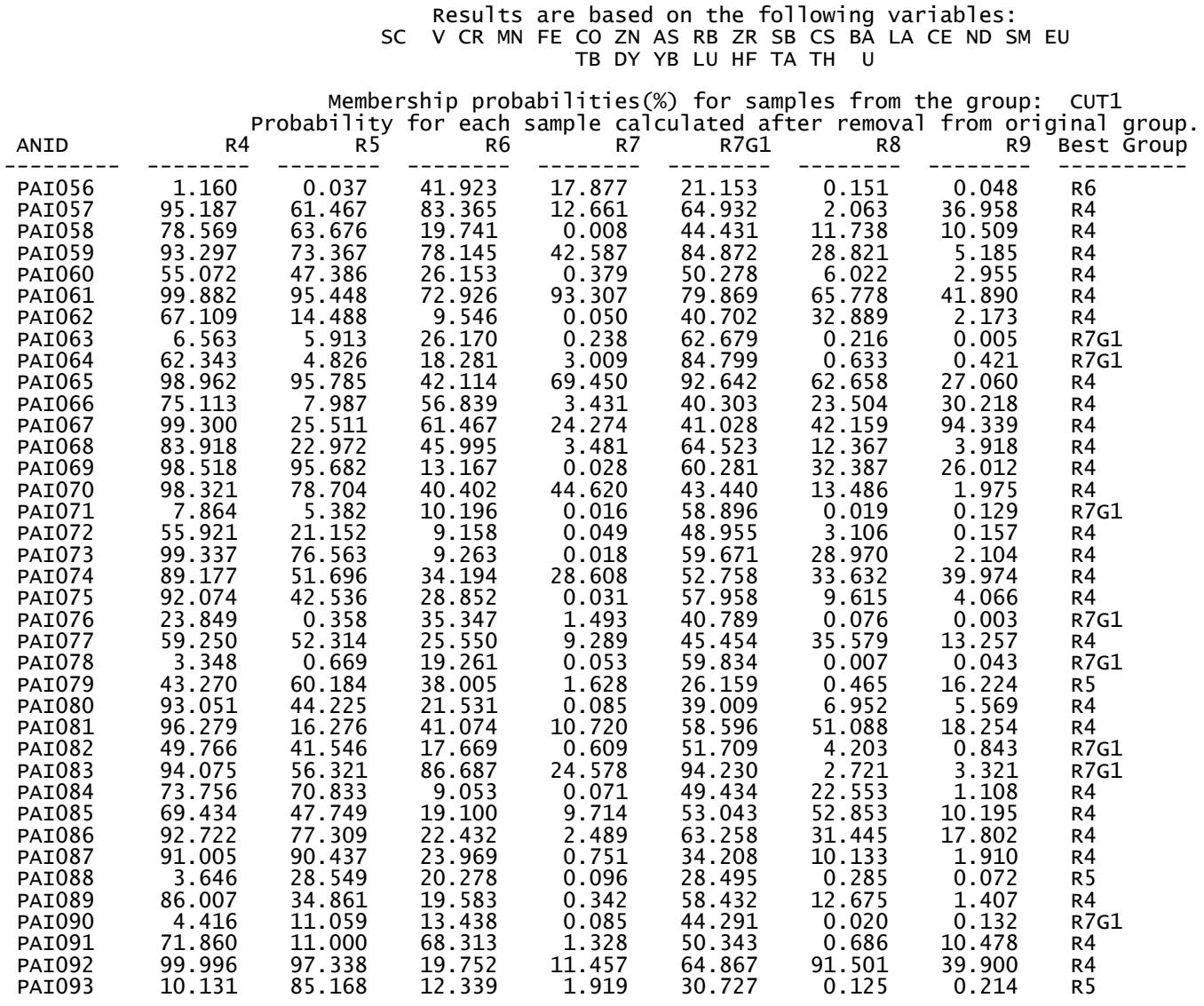




$\begin{array}{rrrrrrrrr}\text { PAI094 } & 99.230 & 71.169 & 97.327 & 8.954 & 38.983 & 24.069 & 25.870 & \text { R4 } \\ \text { PAI095 } & 58.865 & 9.427 & 13.343 & 3.592 & 87.307 & 0.025 & 0.574 & \text { R7G1 } \\ \text { PAI096 } & 12.532 & 0.574 & 23.043 & 0.663 & 63.725 & 1.328 & 0.808 & \text { R7G1 } \\ \text { PAI097 } & 99.270 & 63.841 & 13.379 & 20.852 & 94.457 & 17.079 & 7.183 & \text { R4 } \\ \text { PAI098 } & 0.001 & 0.458 & 17.022 & 0.000 & 31.442 & 0.000 & 0.000 & \text { R7G1 } \\ \text { PAI099 } & 86.686 & 95.455 & 8.329 & 22.591 & 80.825 & 6.890 & 3.497 & \text { R5 } \\ \text { PAI100 } & 93.279 & 99.808 & 85.264 & 64.845 & 64.188 & 60.490 & 38.720 & \text { R5 }\end{array}$

The only particularly noteworthy sample is PAI098. This sample has a very low probability of membership in Group 4 but a reasonable probability of membership in both the Subregion 6 Core Group and Subregion 7 Group 1. All three of these reference groups have a large amount of overlap and most samples in the core groups belong in the other two as well. Thus we think this affiliation of PAI098 is more the result of a statistical anomaly than an indication on nonlocal production and exchange/movement of the vessel.

Group 4 Comparison

We have conducted a more detailed comparison with the core group from the local subregion. Figure 4 is a plot of the Subregion 4 Core Group and the new samples. There are no bivariate plots showing separation between the Region 4 Core and the new samples.

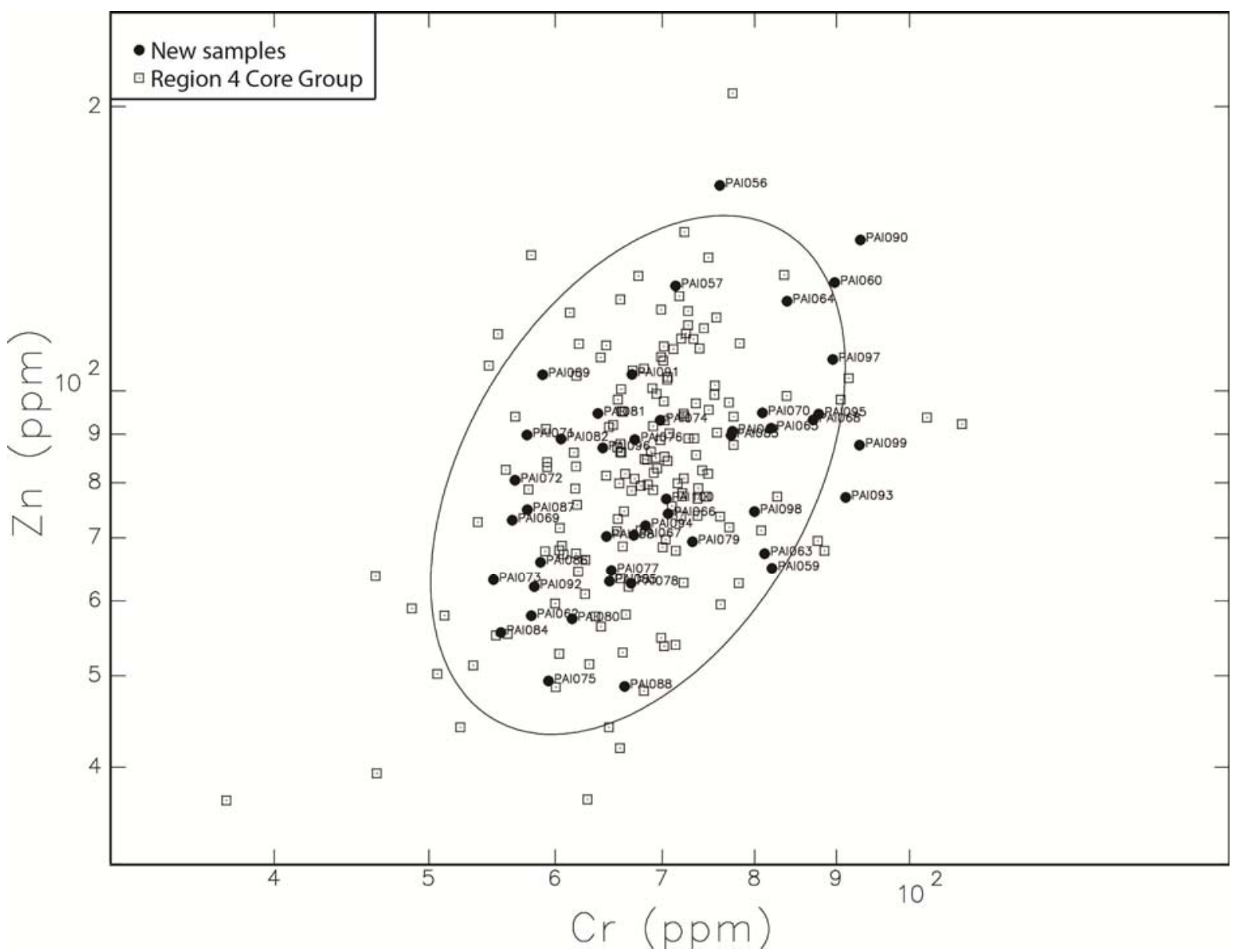

Figure 4. Bivariate plot of chromium and zinc showing the overlap between the new samples and the Subregion 4 Core Group. The new samples are individually labeled and the ellipse is only plotted for the Subregion 4 Core Group. The Ellipse represents a 90\% confidence level for membership in the group. 


\section{Conclusions}

The interpretation of Caddo compositional data is complicated by three major factors: 1) the large-scale similarity of raw clays in the region, 2) the frequent use of grog as temper, and 3) the likely frequent long-distance trade of morphologically similar pottery throughout the region. These factors all contribute to the difficulty in identifying the areas of production at multiple scales. We have demonstrated the similarity between the new samples and the Core Group from the subregion, but unfortunately the Core Groups from most of the Caddo subregions exhibit significant overlap. We were also unable to establish any compositional differences between the assemblages from the three sites.

While it is somewhat disappointing to find unpatterned variability among these data, it likely has some basis in a combination of cultural and geologic factors. More extensive clay sampling studies may help to determine the specific cause.

\section{Acknowledgments}

We acknowledge Tim Ferguson for his role in preparing the samples for irradiation.

\section{$\underline{\text { References Cited }}$}

Baxter, Michael J.

1992 Archaeological uses of the biplot - a neglected technique? In Computer Applications and Quantitative Methods in Archaeology, 1991, edited by G. Lock and J. Moffett. BAR International Series S577, 141-148. Tempvs Reparatvm, Archaeological and Historical Associates, Oxford.

1994 Exploratory Multivariate Analysis in Archaeology. Edinburgh University Press, Edinburgh.

Baxter, M.J. and C.E. Buck

2000 Data Handling and Statistical Analysis. In Modern Analytical Methods in Art and Archaeology, edited by E. Ciliberto and G. Spoto, pp. 681-746. John Wiley and Sons,

Bieber, Alan M. Jr., Dorothea W. Brooks, Garman Harbottle, and Edward V. Sayre

1976 Application of multivariate techniques to analytical data on Aegean ceramics. Archaeometry 18:59-74.

Bishop, Ronald L. and Hector Neff

1989 Compositional data analysis in archaeology. In Archaeological Chemistry IV, edited by R. O. Allen, pp. 576-586. Advances in Chemistry Series 220, American Chemical Society, Washington, D.C.

Bishop, Ronald L., Robert L. Rands, and George R. Holley

1992 Ceramic compositional analysis in archaeological perspective. In Advances in Archaeological Method and Theory, vol. 5, pp. 275-330. Academic Press, New 
York.

Ferguson, Jeffrey R., Timothy K. Perttula, and Michael D. Glascock

2008 Dividing up the Caddo Cultural Landscape: Small-Scale Analysis of a Large

Ceramic INAA Database. Poster presented at the $73^{\text {rd }}$ annual meeting of the Society for American Archaeology. Vancouver, British Columbia.

Glascock, Michael D.

1992 Characterization of archaeological ceramics at MURR by neutron activation analysis and multivariate statistics. In Chemical Characterization of Ceramic Pastes in Archaeology, edited by H. Neff, pp. 11-26. Prehistory Press, Madison, WI.

Harbottle, Garman

1976 Activation analysis in archaeology. Radiochemistry 3:33-72. The Chemical Society, London.

Leese, Morven N. and Peter L. Main

1994 The efficient computation of unbiased Mahalanobis distances and their interpretation in archaeometry. Archaeometry 36:307-316.

Lynott, Mark J., Hector Neff, James E. Price, James W. Cogswell, and Michael D. Glascock 2000 Inferences about prehistoric ceramics and people in Southeast Missouri: Results of ceramic compositional analysis. American Antiquity, 65(1): 103-126.

Neff, Hector

1992 Introduction. In Chemical Characterization of Ceramic Pastes in Archaeology, edited by H. Neff, pp. 1-10. Prehistory Press, Madison, WI.

1994 RQ-mode principal components analysis of ceramic compositional data. Archaeometry 36:115-130.

2000 Neutron activation analysis for provenance determination in archaeology. In Modern Analytical Methods in Art and Archaeology, edited by E. Ciliberto and G. Spoto, pp. 81-134. John Wiley and Sons, Inc., New York.

2002 Quantitative techniques for analyzing ceramic compositional data. In Ceramic Source Determination in the Greater Southwest, edited by D. M. Glowacki and H. Neff. Monograph 44, Cotsen Institute of Archaeology, UCLA, Los Angeles.

Neff, Hector, Ronald L. Bishop, and Edward V. Sayre

1988 A simulation approach to the problem of tempering in compositional studies of archaeological ceramics. Journal of Archaeological Science 15:159-172.

Sayre, Edward V.

1975 Brookhaven Procedures for Statistical Analyses of Multivariate Archaeometric Data. Brookhaven National Laboratory Report BNL-23128. New York. 
Steponaitis, Vincas, M. James Blackman, and Hector Neff

1996 Large-scale compositional patterns in the chemical composition of Mississippian pottery. American Antiquity 61:555-572.

Weigand, Phil C., Garman Harbottle, and Edward V. Sayre

1977 Turquoise sources and source analysis: Mesoamerica and the southwestern U.S.A. In Exchange Systems in Prehistory, edited by T. K. Earle and J. E. Ericson, pp. 15-34. Academic Press, New York. 
Appendix 1: Descriptive information and compositional group assignments

\begin{tabular}{|c|c|c|c|c|c|}
\hline ANID & Site & $\begin{array}{l}\text { Lot } \\
\text { No. }\end{array}$ & Region of USA & Vessel/part & Ceramic Type \\
\hline PAI 056 & 41TT851 & 99 & $\begin{array}{l}\text { Titus County, } \\
\text { Texas }\end{array}$ & Jar near rim & indeterminate \\
\hline PAI 057 & 41TT851 & 106 & $\begin{array}{l}\text { Titus County, } \\
\text { Texas }\end{array}$ & Jar rim & indeterminate \\
\hline PAI 058 & 41TT851 & 107 & $\begin{array}{l}\text { Titus County, } \\
\text { Texas }\end{array}$ & Jar rim & Maydelle \\
\hline PAI 059 & 41TT851 & 189 & $\begin{array}{l}\text { Titus County, } \\
\text { Texas }\end{array}$ & Jar rim & indeterminate \\
\hline PAI 060 & 41TT851 & 273 & $\begin{array}{l}\text { Titus County, } \\
\text { Texas }\end{array}$ & Jar rim & indeterminate \\
\hline PAI 061 & 41TT851 & 358 & $\begin{array}{l}\text { Titus County, } \\
\text { Texas }\end{array}$ & Jar body & Harleton \\
\hline PAI 062 & 41TT851 & 372 & $\begin{array}{l}\text { Titus County, } \\
\text { Texas }\end{array}$ & Jar neck & indeterminate \\
\hline PAI 063 & 41TT851 & 427 & $\begin{array}{l}\text { Titus County, } \\
\text { Texas }\end{array}$ & Jar body & indeterminate \\
\hline PAI 064 & 41TT851 & 430 & $\begin{array}{l}\text { Titus County, } \\
\text { Texas }\end{array}$ & Jar rim & indeterminate \\
\hline PAI 065 & 41TT851 & 430 & $\begin{array}{l}\text { Titus County, } \\
\text { Texas }\end{array}$ & Jar neck & indeterminate \\
\hline PAI 066 & 41TT851 & 558 & $\begin{array}{l}\text { Titus County, } \\
\text { Texas }\end{array}$ & $\begin{array}{l}\text { Deep bowl } \\
\text { body }\end{array}$ & indeterminate \\
\hline PAI 067 & 41TT851 & 558 & $\begin{array}{l}\text { Titus County, } \\
\text { Texas }\end{array}$ & Jar rim & indeterminate \\
\hline PAI 068 & 41TT851 & 632 & $\begin{array}{l}\text { Titus County, } \\
\text { Texas }\end{array}$ & Jar rim & indeterminate \\
\hline PAI 069 & 41TT851 & 651 & $\begin{array}{l}\text { Titus County, } \\
\text { Texas }\end{array}$ & Jar rim & indeterminate \\
\hline PAI 070 & 41TT851 & 670 & $\begin{array}{l}\text { Titus County, } \\
\text { Texas }\end{array}$ & Jar rim & indeterminate \\
\hline PAI 071 & 41TT852 & 118 & $\begin{array}{l}\text { Titus County, } \\
\text { Texas }\end{array}$ & Jar rim & indeterminate \\
\hline PAI 072 & 41TT852 & 129 & $\begin{array}{l}\text { Titus County, } \\
\text { Texas }\end{array}$ & Jar rim & indeterminate \\
\hline PAI 073 & 41TT852 & 136 & $\begin{array}{l}\text { Titus County, } \\
\text { Texas }\end{array}$ & Jar rim & indeterminate \\
\hline PAI 074 & 41TT852 & 175 & $\begin{array}{l}\text { Titus County, } \\
\text { Texas }\end{array}$ & Jar neck & indeterminate \\
\hline PAI 075 & 41TT852 & 176 & $\begin{array}{l}\text { Titus County, } \\
\text { Texas }\end{array}$ & Jar body & $\begin{array}{l}\text { Killough } \\
\text { Pinched }\end{array}$ \\
\hline PAI 076 & 41TT852 & 188 & $\begin{array}{l}\text { Titus County, } \\
\text { Texas }\end{array}$ & Jar body & Harleton \\
\hline PAI 077 & 41TT852 & 191 & $\begin{array}{l}\text { Titus County, } \\
\text { Texas }\end{array}$ & Jar rim & indeterminate \\
\hline PAI 078 & 41TT852 & 305 & $\begin{array}{l}\text { Titus County, } \\
\text { Texas }\end{array}$ & Jar neck & indeterminate \\
\hline PAI 079 & 41TT852 & 305 & $\begin{array}{l}\text { Titus County, } \\
\text { Texas }\end{array}$ & Jar rim & indeterminate \\
\hline
\end{tabular}




\begin{tabular}{|c|c|c|c|c|c|}
\hline PAI 080 & 41TT852 & 326 & $\begin{array}{l}\text { Titus County, } \\
\text { Texas }\end{array}$ & Jar body & Pease \\
\hline PAI 081 & 41TT852 & 334 & $\begin{array}{l}\text { Titus County, } \\
\text { Texas }\end{array}$ & Jar rim & Maydelle \\
\hline PAI 082 & 41TT852 & 344 & $\begin{array}{l}\text { Titus County, } \\
\text { Texas }\end{array}$ & Jar rim & indeterminate \\
\hline PAI 083 & 41TT852 & 475 & $\begin{array}{l}\text { Titus County, } \\
\text { Texas }\end{array}$ & Jar neck & indeterminate \\
\hline PAI 084 & 41TT852 & 615 & $\begin{array}{l}\text { Titus County, } \\
\text { Texas }\end{array}$ & Jar rim & indeterminate \\
\hline PAI 085 & 41TT852 & 617 & $\begin{array}{l}\text { Titus County, } \\
\text { Texas }\end{array}$ & Jar body & indeterminate \\
\hline PAI 086 & 41TT853 & 107 & $\begin{array}{l}\text { Titus } \\
\text { County, Texas }\end{array}$ & Jar body & Pease \\
\hline PAI 087 & 41TT853 & 185 & $\begin{array}{l}\text { Titus } \\
\text { County,Texas }\end{array}$ & Jar rim & indeterminate \\
\hline PAI 088 & 41TT853 & 218 & $\begin{array}{l}\text { Titus } \\
\text { County, Texas }\end{array}$ & Jar neck & Maydelle \\
\hline PAI 089 & 41TT853 & 243 & $\begin{array}{l}\text { Titus } \\
\text { County, Texas }\end{array}$ & Jar neck & indeterminate \\
\hline PAI 090 & 41TT853 & 243 & $\begin{array}{l}\text { Titus } \\
\text { County,Texas }\end{array}$ & Jar near base & $\begin{array}{l}\text { Killough } \\
\text { Pinched }\end{array}$ \\
\hline PAI 091 & 41TT853 & 270 & $\begin{array}{l}\text { Titus } \\
\text { County, Texas }\end{array}$ & Jar rim & indeterminate \\
\hline PAI 092 & 41TT853 & 290 & $\begin{array}{l}\text { Titus } \\
\text { County, Texas }\end{array}$ & Jar rim & indeterminate \\
\hline PAI 093 & 41TT853 & 291 & $\begin{array}{l}\text { Titus } \\
\text { County, Texas }\end{array}$ & Jar rim & indeterminate \\
\hline PAI 094 & 41TT853 & 293 & $\begin{array}{l}\text { Titus } \\
\text { County, Texas }\end{array}$ & Jar rim & indeterminate \\
\hline PAI 095 & 41TT853 & 294 & $\begin{array}{l}\text { Titus } \\
\text { County, Texas }\end{array}$ & Jar neck & indeterminate \\
\hline PAI 096 & 41TT853 & 295 & $\begin{array}{l}\text { Titus } \\
\text { County, Texas }\end{array}$ & Jar neck & Maydelle \\
\hline PAI 097 & 41TT853 & 295 & $\begin{array}{l}\text { Titus } \\
\text { County,Texas }\end{array}$ & Jar rim & indeterminate \\
\hline PAI 098 & 41TT853 & 295 & $\begin{array}{l}\text { Titus } \\
\text { County, Texas }\end{array}$ & Jar neck & indeterminate \\
\hline PAI 099 & 41TT853 & 295 & $\begin{array}{l}\text { Titus } \\
\text { County,Texas }\end{array}$ & Jar rim & indeterminate \\
\hline PAI 100 & 41TT853 & 298 & $\begin{array}{l}\text { Titus } \\
\text { County,Texas }\end{array}$ & Jar body & indeterminate \\
\hline
\end{tabular}



APPENDIX J: Petrographic Analysis of Pottery

Leslie G.Cecil 



\section{INTRODUCTION}

This report describes the petrographic analysis of 45 sherd samples excavated from sites along Tankersley Creek (41TT851, 41TT852, and 41TT853) in Titus County, Texas. Accompanying this report are digital images of each thin section. All images were taken in plane, polarized light with $5 \mathrm{X}$ magnification. Each image is a portion of one of the two fields that were counted for this analysis. Following the identification of the paste groups is a discussion of the results, which highlight the use of petrographic data to better understand Caddo potting behavior.

\section{METHODOLOGY}

Petrographic analysis allows the analyst to identify minerals that are present in the clay pastes of different vessels. Petrography allows analysis of many clay materials and inclusions at one time. One can study "the clay itself, natural inclusions in the clay, purposefully added inclusions, and glazes or slips on the clay surface" (Childs 1989:24).

Petrographic analysis has been adapted from geological techniques of analysis for the study of soils and rocks and is useful for archaeological ceramics because, to a large extent, geological sources differ enough regionally to allow for comparison of different clays (Blatt 1992). These methods are applicable to pottery analysis because pottery can be regarded as metamorphosed sedimentary rock due to the composition of a sherd consisting of clastic grains imbedded in a clay paste which has been transformed to "rock" through the process of firing (Bishop et al. 1982; Rice 1987:376). Understanding these basic principles of geology, plus other principles of optical mineralogy, allow the description of pottery pastes and clays.

There are some limitations to petrographic analysis, however. Thin sectioning may not produce the full mineralogical composition of a pottery sample due to sampling error and because the method of producing thin-section slides involves grinding and polishing of the sample (Orton et al. 1993). In addition to problems with sample preparation, petrographic analysis alone cannot determine the type of clay mineral in the sherd because of the refractive characteristics of clay minerals. Because of these limitations, petrography is often combined with $\mathrm{x}$-ray dif- fraction in order to obtain a full mineralogical complement and INAA to obtain a full elemental complement.

The 45 samples were cut with a wet saw for the preparation of thin-section slides. The sherds were sent to Spectrum Petrographics, where they were embedded in an epoxy block. The most fragile sherds were vacuum impregnated and then embedded in an epoxy block. The block was cut in such a manner that a thin section measuring $0.03 \mathrm{~mm}$ thick resulted. The resulting thin section allowed the analyst to identify minerals in the clay paste with the use of a polarizing microscope.

The polarizing microscope is composed of a light source, a polarizer, a condenser, a rotatable stage, objective, slots for a quartz wedge, an analyzer, and a Bertrand lens. Light originates from a light source at the base of the microscope and passes through the polarizer, which aligns the light waves in a single plane or direction. The polarized light then passes through minerals on the rotatable stage and bends them according to the mineral structure; each mineral and inclusion transmits light differently and is thus identifiable (McLaughlin 1977). The objective magnifies the resulting light waves, and the light passes through an analyzer. Analyzers allow light to vibrate in a plane perpendicular to that of the first polarizer. When the analyzer is in place (crossed nicols), birefringence colors appear and can then be compared to published charts to identify the mineral. If the crossed nicol color, angle of extinction, and other mineralogical characteristics are not sufficient in the identification of the mineral, the Bertrand lens and condenser produce interference figures that determine the mineral's sign (uniaxial or biaxial). Interference colors, in addition to the techniques described above, allow identification of most minerals.

Thin sectioning provides one objective means of classifying pottery pastes through the analysis of mineral size, shape, roundness, and frequency. Mineral size, shape, and roundness are established through a comparison of various graphs and tables (Figures J.1-J.3) (Shackley 1975:44-51). The most common geological method of determining the quantity of minerals in a thin section is point counting. Point counting determines the number of different minerals along a predetermined area (for example, 10 $\mathrm{mm}$ ) of the length and width of the section 
(Chayes 1956). Various studies have employed different methods for counting the frequency of inclusions: Peacock (1973) uses a random grain selection; Middleton et al. (1985) use a variation of systematic sampling along linear transects with tests of accuracy for different thin-section samples; and Dickenson and Shutler (1979) use an area point count (all minerals, inclusions, and voids in the field of view are counted). Middleton et al. (1985) compared area counting to standard geological point counting and determined that the number of minerals counted was equal, and the only difference was that area counting resulted in a smaller mean mineral diameter. Because mean diameter of minerals was not critical and I obtained similar point counts with standard point counts and area point counts (tested on 20 sherds of different matrices), I implemented area counting for a field of view with $4 \mathrm{X}$ magnification (all thin-section images were taken at $5 \mathrm{X}$ magnification).

Before conducting an area count, I scanned the sherd to determine the range of minerals and mineral sizes as well as to note any details of manufacturing techniques and slip thickness. After determining the types of minerals present, I counted two standard image areas to ensure that each area was representative of the sherd as a whole and to detect changes in the clay paste. The first counted area was at the end of the slide farthest from the rim, and the second was determined by rolling a die and moving the slide the corresponding number of centimeters. For example, if I rolled a 5, I moved the slide $5 \mathrm{~cm}$ and centered the microscope in an area that filled the standard image. For each mineral type, I measured the range of mineral sizes (the smallest and the largest), the relative frequency as determined by Figure J.1, the mineral roundness as determined by Figure J.2, the degree of sorting as determined by Figure J.3, the number of minerals in the standard image, the frequency of all of the minerals in the clay paste as determined by Figure J.1, and the clay birefringence. Other abnormalities were also noted.

\section{RESULTS}

As a result of the point counts (Attachment J.1 in digital format), five basic paste groups with some variations within the basic paste groups emerged. Images of all samples are in Attachment J.2 (in digital format). In addition to the miner- alogical differences within the sandy pastes, I observed two general clay paste categories: a bimodal sandy paste and a well-sorted sandy paste. In general, small quartz minerals, biotite, iron, organics, rounded chert, feldspar, and microcline most likely occur because they are part of the clay body that is due to weathering of the clay from a parent material. Culturally added inclusions include the angular, larger quartz, chert, and feldspar, and bone and grog. Finally, when no data are recorded for the organics category, the sherd was too dark, indicating that it was either fired in a reduced atmosphere or incompletely fired resulting in a dark-colored sherd.

\section{Paste Group 1: Sandy Paste (bimodal) with Bone and Grog Inclusions}

This paste group serves as the base paste group from which there are five variants (Paste Groups 1a, 1b, 1c, 1d, and 1e).

\section{Biotite}

No biotite inclusions were counted for this group.

\section{Bone}

Size: Medium (.25-.5 mm), Coarse (.5-1 mm), and Very Coarse (over $1 \mathrm{~mm}$ )

Frequency: Rare (2\%) to Sparse (4\%)

Degree of Sorting: Poor

Roundedness: Angular, High Sphericity; Angular, Low Sphericity; Sub-Angular, High Sphericity; Sub-Angular, Low Sphericity; and Rectangular

Raw Count: High 26, Low 21, Average 24

\section{Chert}

No chert inclusions were counted for this group.

\section{K-feldspar}

No K-feldspar inclusions were counted for this group. 


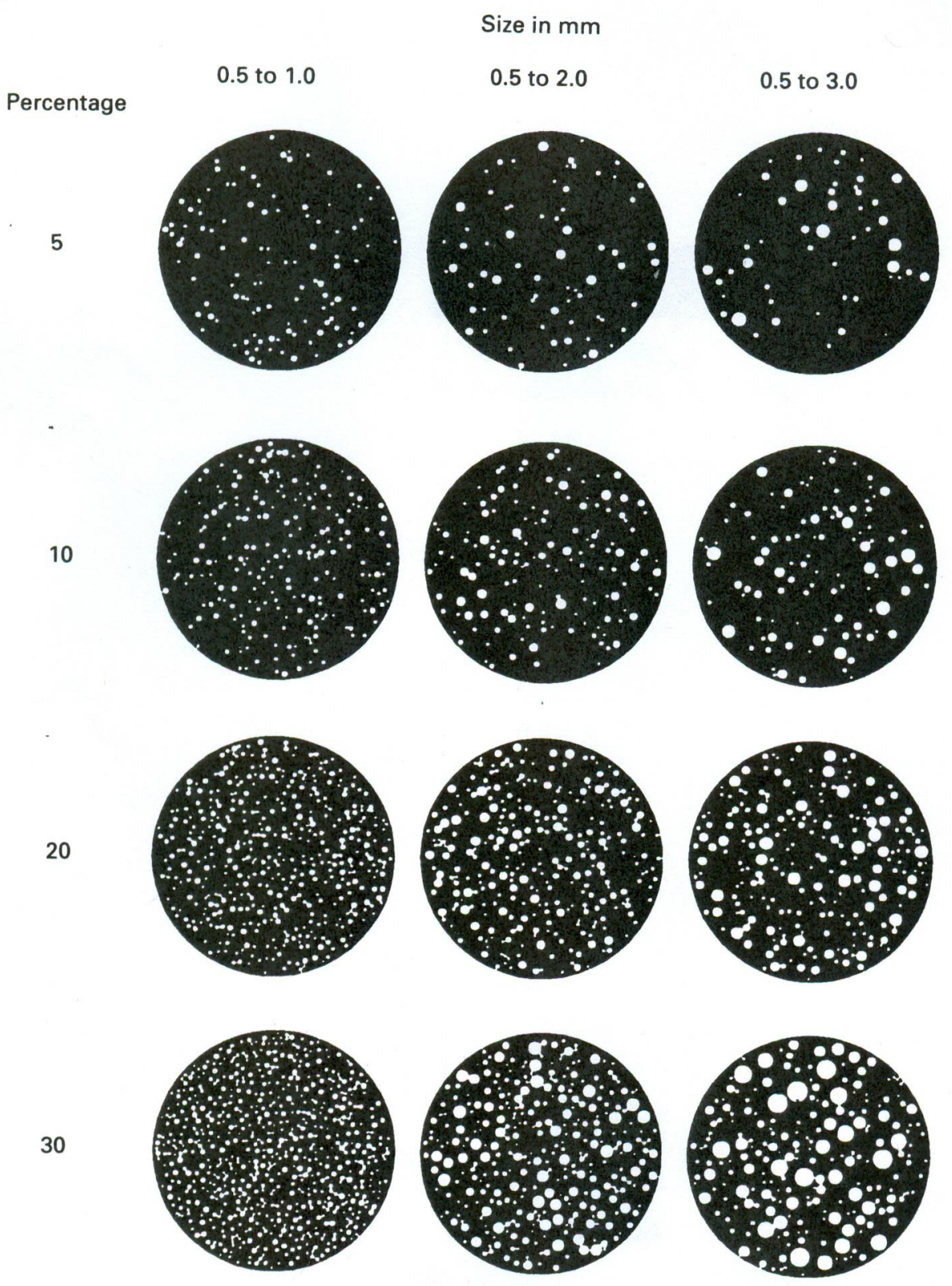

Figure J.1. Percent inclusion estimation chart (Orton et al. 1993:Figure A.4).

\section{Grog}

Size: Medium (.25-.5 mm), Coarse (.5-1 mm), and Very Coarse (over $1 \mathrm{~mm}$ )

Frequency: Rare (1\%) and Sparse (5\%)

Degree of Sorting: Poor
Roundedness: Sub-Angular, High Sphericity;

Sub-Angular, Low Sphericity; SubRounded, High Sphericity; and SubRounded, Low Sphericity

Raw Count: High 42, Low 9, Average 26 
POWERS' SCALE OF ROUNDNESS

\begin{tabular}{|l|c|c|c|c|c|c|}
\hline Class & 1 & 2 & 3 & 4 & 5 & 6 \\
\hline & $\begin{array}{c}\text { Very } \\
\text { Angular }\end{array}$ & Angular & $\begin{array}{c}\text { Sub- } \\
\text { Angular }\end{array}$ & $\begin{array}{c}\text { Sub- } \\
\text { Rounded }\end{array}$ & Rounded & $\begin{array}{c}\text { Well } \\
\text { Rounded }\end{array}$ \\
\hline $\begin{array}{l}\text { High } \\
\text { Sphericity }\end{array}$ & & & & & \\
\hline
\end{tabular}

Figure J.2. Sphericity/roundedness estimation chart (Orton et al. 1993:Figure A.5).

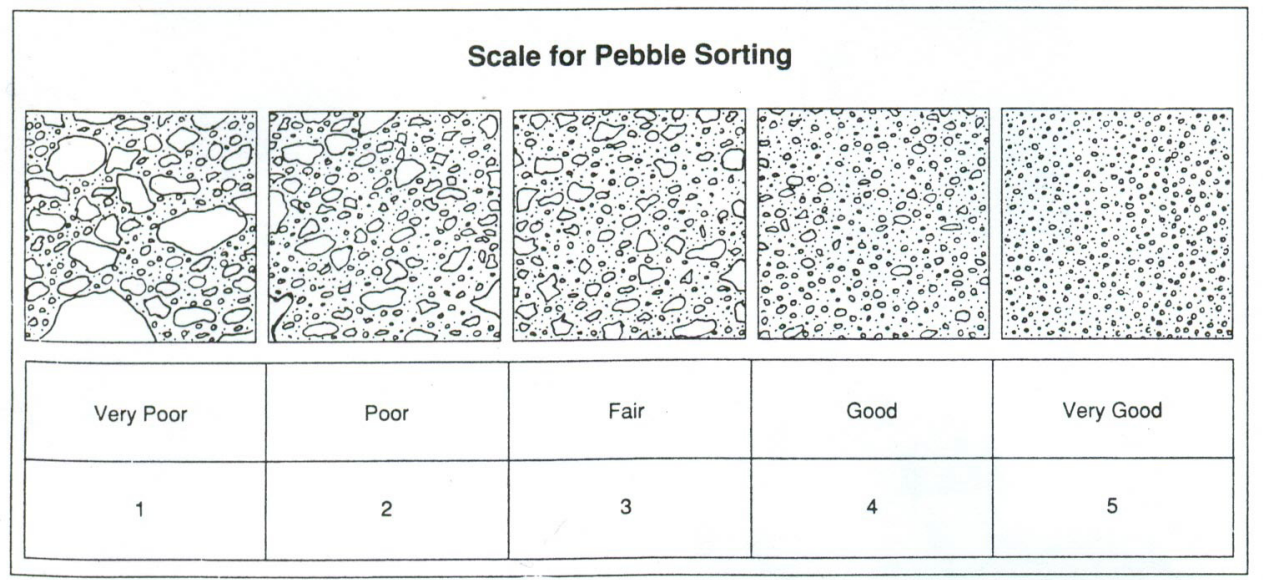

Figure J.3. Inclusion sorting chart (Orton et al.1993:Figure A.6).

\section{Microcline}

No microcline inclusions were counted for this group.
Quartz (small)

Size: Very Fine (up to $.1 \mathrm{~mm}$ ) and Fine (.1-.25 $\mathrm{mm}$ )

Frequency: Common (15\%) to Abundant (25\%) 
Degree of Sorting: Good to Fair

Roundedness: Sub-Angular, High Sphericity; Sub-Angular, Low Sphericity; SubRounded, High Sphericity; Sub-Rounded, Low Sphericity; and Rounded, Low Sphericity

Raw Count: High 1,699, Low 1,557, Average 1,628

\section{Quartz (large)}

Size: Coarse (.5-1 mm) and Very Coarse (over $1 \mathrm{~mm}$ )

Frequency: Rare (3\%) to Sparse (5\%)

Degree of Sorting: Poor

Roundedness: Angular, High Sphericity; Angular, Low Sphericity; Sub-Angular, High Sphericity; and Sub-Angular, Low Sphericity

Raw Count: High 82, Low 47, Average 65

\section{Organics}

Paste was too dark to count inclusions.

\section{Voids}

Size: Medium (.25-.5 mm), Coarse $(.5-1 \mathrm{~mm})$, and Very Coarse (over $1 \mathrm{~mm}$ )

Frequency: Sparse (7\%) to Common (10\%)

Degree of Sorting: Poor

Roundedness: Sub-Angular, High Sphericity; Sub-Angular, Low Sphericity; SubRounded, High Sphericity; Sub-Rounded, Low Sphericity; and Linear

Raw Count: High 114, Low 91, Average 103

Two sherds (PAI058 and PAI063) comprise this base Sand, Bone, and Grog paste group. The small quartz minerals are a natural part of the clay; however, the larger, angular quartz inclusions were culturally added. In addition to the angular quartz, the bone and grog inclusions represent temper added by the Caddo potters. Crushed bone inclusion colors are tan and very dark brown. There are two different kinds of grog: 1) a tan sandy paste and 2) a high birefringent tan sandy paste. The first grog type is very similar to the samples in this paste group.

\section{Paste Group 1a: Sandy Paste (Bimodal) with Bone and Grog Inclusions with Chert}

\section{Biotite}

No biotite inclusions were counted for this group.

\section{Bone}

Size: Medium (.25-.5 mm), Coarse (.5-1 mm), and Very Coarse (over $1 \mathrm{~mm}$ )

Frequency: Rare (1-2\%)

Degree of Sorting: Poor

Roundedness: Angular, High Sphericity; Angular, Low Sphericity; Sub-Angular, High Sphericity; Sub-Angular, Low Sphericity; Sub-Rounded, High Sphericity; Sub-Rounded, Low Sphericity; and Rectangular

Raw Count: High 14, Low 3, Average 9

\section{Chert}

Size Coarse: $(.5-1 \mathrm{~mm})$ and Very Coarse (over $1 \mathrm{~mm}$ )

Frequency: Rare (1\%) and Sparse (3\%)

Degree of Sorting: Poor

Roundedness: Angular, High Sphericity; Angular, Low Sphericity; Sub-Angular, High Sphericity; Sub-Angular, Low Sphericity; Sub-Rounded, High Sphericity; and Sub-Rounded, Low Sphericity

Raw Count: High 36, Low 3, Average 15

\section{K-feldspar}

No K-feldspar inclusions were counted for this group. 


\section{Grog}

Size: Coarse $(.5-1 \mathrm{~mm})$ and Very Coarse (over $1 \mathrm{~mm}$ )

Frequency: Rare (1-2\%) and Sparse (3\%)

Degree of Sorting: Poor

Roundedness: Sub-Angular, High Sphericity;

Sub-Angular, Low Sphericity; Sub-

Rounded, High Sphericity; and Sub-

Rounded, Low Sphericity

Raw Count: High 31, Low 3, Average 15

\section{Microcline}

No microcline inclusions were counted for this group.

\section{Quartz (small)}

Size: Very Fine (up to $.1 \mathrm{~mm}$ ), Fine (.1-.25 $\mathrm{mm})$, and Medium (.25-.5 mm),

Frequency: Common (10-25\%) to Abundant $(30 \%)$

Degree of Sorting: Fair

Roundedness: Sub-Angular, High Sphericity; Sub-Angular, Low Sphericity; SubRounded, High Sphericity; Sub-Rounded, Low Sphericity; and Rounded, Low Sphericity

Raw Count: High 2,144, Low 796, Average 1,267

\section{Quartz (large)}

Size: Coarse $(.5-1 \mathrm{~mm})$ and Very Coarse (over $1 \mathrm{~mm}$ )

Frequency: Common (10-15\%)

Degree of Sorting: Very Poor to Fair

Roundedness: Angular, High Sphericity; Angular, Low Sphericity; Sub-Angular, High Sphericity; and Sub-Angular, Low Sphericity

Raw Count: High 395, Low 141, Average 225

\section{Organics}

Size: Medium (.25-.5 mm) and Coarse (.5-1 $\mathrm{mm}$ )

Frequency: Rare (1-2\%)

Degree of Sorting: Poor

Roundedness: Sub-Rounded, High Sphericity; Sub-Rounded, Low Sphericity; Rounded, High Sphericity; and Rounded, Low Sphericity

Raw Count: High 37, Low 0, Average 6

\section{Voids}

Size: Fine (.1-.25 mm), Medium (.25-.5 mm), Coarse (.5-1 mm), and Very Coarse (over $1 \mathrm{~mm}$ )

Frequency: Rare (1-3\%) and Sparse (4-6\%)

Degree of Sorting: Poor

Roundedness: Sub-Angular, High Sphericity; Sub-Angular, Low Sphericity; SubRounded, High Sphericity; Sub-Rounded, Low Sphericity; and Linear

Raw Count: High 177, Low 63, Average 134

These seven samples (PAI067, PAI071, PAI073, PAI078, PAI082, PAI085, and PAI087) are similar to the base Paste Group 1, but they are distinguished by the presence of chert inclusions. The chert inclusions are most likely culturally added because of their angular nature. The chert was most likely part of the crushed, large, angular quartz sand and a byproduct of the sand addition rather than another potter's choice made during the manufacturing process. Crushed bone inclusion colors are tan and dark red. There are three different kinds of grog: 1) a tan sandy paste; 2 ) a high-birefringent tan sandy paste; and 3) a dark (reduced or incompletely oxidized) sandy paste. The first grog type is very similar to the samples in this paste group. 


\section{Paste Group 1b: Sandy Paste \\ (Bimodal) with Bone and Grog Inclusions with Chert and Microcline}

\section{Biotite}

No biotite inclusions were counted for this group.

\section{Bone}

Size: Coarse $(.5-1 \mathrm{~mm})$ and Very Coarse (over $1 \mathrm{~mm}$ )

Frequency: Sparse (3\%)

Degree of Sorting: Poor

Roundedness: Sub-Angular, High Sphericity and Sub-Angular, Low Sphericity

Raw Count: 42

\section{Chert}

Size: Medium (.25-.5 mm) and Coarse (.5-1 $\mathrm{mm}$ )

Frequency: Rare (1\%) and Sparse (3\%)

Degree of Sorting: Poor

Roundedness: Sub-Rounded, High Sphericity

Raw Count: 2

\section{K-feldspar}

No K-feldspar inclusions were counted for this group.

\section{Grog}

Size: Very Coarse (over $1 \mathrm{~mm}$ )

Frequency: Sparse (3\%)

Degree of Sorting: Poor

Roundedness: Sub-Angular, High Sphericity;

Sub-Angular, Low Sphericity; Sub-

Rounded, High Sphericity; and Sub-

Rounded, Low Sphericity

Raw Count: 16

\section{Microcline}

Size: Coarse (.5-1 mm)

Frequency: Rare $(<1 \%)$

Degree of Sorting: Poor

Roundedness: Sub-Rounded, High Sphericity

Raw Count: 1

\section{Quartz (small)}

Size: Very Fine (up to $.1 \mathrm{~mm}$ ), Fine (.1-.25 $\mathrm{mm})$, and Medium (.25-.5 mm)

Frequency: Common (20\%)

Degree of Sorting: Fair

Roundedness: Sub-Angular, High Sphericity; Sub-Angular, Low Sphericity; SubRounded, High Sphericity; Sub-Rounded, Low Sphericity; and Rounded, Low Sphericity

Raw Count: 1,240

\section{Quartz (large)}

Size: Coarse (.5-1 mm) and Very Coarse (over $1 \mathrm{~mm}$ )

Frequency: Rare (3\%)

Degree of Sorting: Very Poor to Fair

Roundedness: Angular, High Sphericity; Angular, Low Sphericity; Sub-Angular, High Sphericity; and Sub-Angular, Low Sphericity

Raw Count: 63

\section{Organics}

Size: Medium (.25-.5 mm), Coarse (.5-1 mm), and Very Coarse (over $1 \mathrm{~mm}$ )

Frequency: Sparse (5\%)

Degree of Sorting: Poor

Roundedness: Rounded, High Sphericity

Raw Count: 44 
Voids

Size: Medium (.25-.5 mm), Coarse (.5-1 mm), and Very Coarse (over $1 \mathrm{~mm}$ )

Frequency: Sparse (4\%)

Degree of Sorting: Poor

Roundedness: Sub-Rounded, High Sphericity; Sub-Rounded, Low Sphericity; and Linear

Raw Count: 89

Sample PAI056 is different from Paste Group 1 and 1a because of the presence of a microcline inclusion. A distinction can be made between $\mathrm{K}$-feldspar and microcline based on extinction angles and polysynthetic twinning present in the microcline minerals. The microcline inclusion is fairly rounded, suggesting that the mineral was not added in the clay manufacturing process but is natural to the clay or the sand mixture. Although microcline is an igneous material and the sand (quartz) is a sedimentary material, it is possible that the microcline presence results from a weathering process that mixed igneous and sedimentary materials. Alternatively, the microcline could have been culturally added. It could be that the potters were grinding igneous rock or that the stones they were using to process the clay or tempering materials were composed of igneous rock, and the minerals were introduced as a result of grinding and crushing of the clay or temper. The presence of microcline was also noted in samples from Camp County, Texas. The bone inclusions (culturally added) were crushed and were tan and dark brown in color. The grog inclusions (culturally added) represent a tan paste (not birefringent) that is heavily tempered with bimodal (two size categories) quartz sand.

\section{Paste Group 1c: Sandy Paste (Bimodal) with Bone and Grog Inclusions with Chert and K-Feldspar}

\section{Biotite}

No biotite inclusions were counted for this group.
Bone

Size: Medium (.25-.5 mm), Coarse $(.5-1 \mathrm{~mm})$, and Very Coarse (over $1 \mathrm{~mm}$ )

Frequency: Rare (1-2\%)

Degree of Sorting: Poor

Roundedness: Angular, High Sphericity; Angular, Low Sphericity; Sub-Angular, High Sphericity; Sub-Angular, Low Sphericity; Sub-Rounded, High Sphericity; Sub-Rounded, Low Sphericity; and Rectangular

Raw Count: High 15, Low 5, Average 10

\section{Chert}

Size: Coarse (.5-1 mm)

Frequency: Rare (1\%)

Degree of Sorting: Poor

Roundedness: Angular, High Sphericity; Angular, Low Sphericity; Sub-Rounded, High Sphericity; and Sub-Rounded, Low Sphericity

Raw Count: High 13, Low 4, Average 9

\section{K-feldspar}

Size: Medium (.25-.5 mm) to Coarse (.5-1 $\mathrm{mm}$ )

Frequency: Rare (1\%)

Degree of Sorting: Poor

Roundedness: Sub-Rounded, Low Sphericity

Raw Count: High 2, Low 2, Average 2

\section{Grog}

Size: Very Coarse (over $1 \mathrm{~mm}$ )

Frequency: Rare (1\%) and Sparse (3\%)

Degree of Sorting: Poor

Roundedness: Angular, High Sphericity; Angular, Low Sphericity; Sub-Angular, High Sphericity; and Sub-Angular, Low Sphericity 
Raw Count: High 15, Low 11, Average 13

\section{Microcline}

No microcline inclusions were counted for this group.

\section{Quartz (small)}

Size: Very Fine (up to $.1 \mathrm{~mm}$ ), Fine (.1-.25

$\mathrm{mm})$, Medium (.25-.5 mm)

Frequency: Common (20-25\%)

Degree of Sorting: Fair

Roundedness: Sub-Angular, High Sphericity; Sub-Angular, Low Sphericity; SubRounded, High Sphericity; Sub-Rounded, Low Sphericity; Rounded, Low Sphericity; and Rounded, Low Sphericity

Raw Count: High 2,208, Low 1,546, Average 1,877

\section{Quartz (large)}

Size: Coarse (.5-1 mm) and Very Coarse (over $1 \mathrm{~mm}$ )

Frequency: Rare (1\%) and Common (10\%)

Degree of Sorting: Very Poor to Poor

Roundedness: Angular, High Sphericity; Angular, Low Sphericity; Sub-Angular, High Sphericity; and Sub-Angular, Low Sphericity

Raw Count: High 176, Low 78, Average 127

\section{Organics}

Size: Medium (.25-.5 mm) and Coarse (.5-1 $\mathrm{mm}$ )

Frequency: Rare (3\%)

Degree of Sorting: Poor

Roundedness: Sub-Rounded, High Sphericity; Sub-Rounded, Low Sphericity; Rounded, High Sphericity; and Rounded, Low Sphericity

Raw Count: 189

\section{Voids}

Size: Medium (.25-.5 mm), Coarse $(.5-1 \mathrm{~mm})$, and Very Coarse (over $1 \mathrm{~mm}$ )

Frequency: Sparse (5\%)

Degree of Sorting: Poor

Roundedness: Sub-Angular, High Sphericity; Sub-Angular, Low Sphericity; SubRounded, High Sphericity; Sub-Rounded, Low Sphericity; and Linear

Raw Count: High 286, Low 200, Average 243

The two sherds (PAI091 and PAI095) that comprise this paste group are distinguished from those of Paste Group 1 because of the presence of K-feldspar minerals. The low frequency and similar roundness of K-feldspar in the sand (quartz) inclusions suggests that the K-feldspar inclusions are natural to the clay. This may suggest a variation in the clay bed source. The bone inclusions (culturally added) were crushed and were tan and dark red in color. There are three different kinds of grog (culturally added) inclusions: 1) a tan sandy paste; 2) a highbirefringent tan sandy paste; and 3) a dark (reduced or incompletely oxidized) sandy paste. The first grog type is very similar to the samples in this paste group.

\section{Paste Group 1d: Sandy Paste (Bimodal) with Bone and Grog Inclusions with Biotite}

\section{Biotite}

Size: Fine (.1-.25 mm) and Medium (.25-.5 $\mathrm{mm})$

Frequency: Rare (1\%)

Degree of Sorting: Poor

Roundedness: Linear

Raw Count: High 30, Low 9, Average 19

\section{Bone}

Size: Medium (.25-.5 mm), Coarse (.5-1 mm), and Very Coarse (over $1 \mathrm{~mm}$ )

Frequency: Rare (1-2\%) 
Degree of Sorting: Poor

Roundedness: Angular, High Sphericity;

Angular, Low Sphericity; Sub-Angular,

High Sphericity; Sub-Angular, Low

Sphericity; Sub-Rounded, High Sphericity;

Sub-Rounded, Low Sphericity; and

Rectangular

Raw Count: High 23, Low 15, Average 18

\section{Chert}

No chert inclusions were counted for this group.

\section{K-feldspar}

Size: Coarse (.5-1 mm)

Frequency: Rare (1\%)

Degree of Sorting: Poor

Roundedness: Sub-Angular, High Sphericity

Raw Count: High 1, Low 0, Average 1

\section{Grog}

Size: Very Coarse (over $1 \mathrm{~mm}$ )

Frequency: Rare (1\%)

Degree of Sorting: Poor

Roundedness: Sub-Angular, High Sphericity;

Sub-Angular, Low Sphericity; Sub-

Rounded, High Sphericity; and Sub-

Rounded, Low Sphericity

Raw Count: High 9, Low 8, Average 8

\section{Microcline}

No microcline inclusions were counted for this group.

\section{Quartz (small)}

Size: Very Fine (up to $.1 \mathrm{~mm}$ ), Fine (.1-.25 $\mathrm{mm}$ ), and Medium (.25-.5 mm)

Frequency: Common (15\%)

Degree of Sorting: Fair
Roundedness: Sub-Angular, High Sphericity; Sub-Angular, Low Sphericity; SubRounded, High Sphericity; Sub-Rounded, Low Sphericity; Rounded, Low Sphericity; and Rounded, Low Sphericity

Raw Count: High 1,207, Low 975, Average 1,078

\section{Quartz (large)}

Size: Coarse (.5-1 mm) and Very Coarse (over $1 \mathrm{~mm}$ )

Frequency: Sparse (5\%) and Common (15-20\%)

Degree of Sorting: Poor

Roundedness: Angular, High Sphericity; Angular, Low Sphericity; Sub-Angular, High Sphericity; and Sub-Angular, Low Sphericity

Raw Count: High 399, Low 73, Average 242

\section{Organics}

Size: Fine (.1-.25 mm), Medium (.25-.5 mm), and Coarse $(.5-1 \mathrm{~mm})$

Frequency: Sparse (4-5\%)

Degree of Sorting: Poor

Roundedness: Sub-Rounded, High Sphericity; Sub-Rounded, Low Sphericity; Rounded, High Sphericity; and Rounded, Low Sphericity

Raw Count: High 132, Low 57, Average 89

\section{Voids}

Size: Medium (.25-.5 mm), Coarse (.5-1 mm), and Very Coarse (over $1 \mathrm{~mm}$ )

Frequency: Sparse (5-8\%)

Degree of Sorting: Very Poor to Poor

Roundedness: Sub-Angular, High Sphericity; Sub-Angular, Low Sphericity; SubRounded, High Sphericity; Sub-Rounded, Low Sphericity; and Linear

Raw Count: High 116, Low 80, Average 103 
This paste group variant is different from Paste Groups 1a, 1b, and 1c because of the presence of biotite. Sample PAI092 is composed of a high-birefringent clay, but the other two samples do not have this characteristic. The feldspar inclusion in PAI092 is most likely a component of the angular quartz inclusions (culturally added) and not intentionally added as a separate addition, but is present because it was in the sand mixture. The bone inclusions (culturally added) are tan in color. Grog inclusions are either dark brown/black in color or a high-birefringent, sandy, tan clay paste. This group is represented by samples PAI089, PAI092, and PAI093.

\section{Paste Group 1e: Sandy Paste (Bimodal) with Bone and Grog Inclusions with Biotite and Chert}

\section{Biotite}

Size: Fine (.1-.25 mm) and Medium (.25-.5 $\mathrm{mm}$ )

Frequency: Rare (1\%)

Degree of Sorting: Poor

Roundedness: Linear

Raw Count: High 23, Low 2, Average 13

\section{Bone}

Size: Medium (.25-.5 mm), Coarse (.5-1 mm), and Very Coarse (over $1 \mathrm{~mm}$ )

Frequency: Rare (1-2\%)

Degree of Sorting: Poor

Roundedness: Angular, High Sphericity; Angular, Low Sphericity; Sub-Angular, High Sphericity; Sub-Angular, Low Sphericity; Sub-Rounded, High Sphericity; Sub-Rounded, Low Sphericity; and Rectangular

Raw Count: High 13, Low 3, Average 10

\section{Chert}

Size: Medium (.25-.5 mm), Coarse $(.5-1 \mathrm{~mm})$, and Very Coarse (over $1 \mathrm{~mm}$ )
Frequency: Rare (1\%) and Sparse (5\%)

Degree of Sorting: Poor

Roundedness: Angular, High Sphericity; Angular, Low Sphericity; Sub-Angular, High Sphericity; Sub-Angular, Low Sphericity; and Sub-Rounded, Low Sphericity

Raw Count: High 26, Low 1, Average 7

\section{K-feldspar}

Size: Coarse (.5-1 mm)

Frequency: Rare (1\%)

Degree of Sorting: Poor

Roundedness: Sub-Angular, Low Sphericity

Raw Count: High 2, Low 0, Average .4

\section{Grog}

Size: Medium (.25-.5 mm), Coarse (.5-1 mm), and Very Coarse (over $1 \mathrm{~mm}$ )

Frequency: Rare (1-3\%) and Sparse (5\%)

Degree of Sorting: Poor

Roundedness: Sub-Angular, High Sphericity; Sub-Angular, Low Sphericity, SubRounded, High Sphericity; Sub-Rounded, Low Sphericity; Rounded, Low Sphericity; and Rounded, Low Sphericity

Raw Count: High 30, Low 4, Average 16

\section{Microcline}

No microcline inclusions were counted for this group.

\section{Quartz (small)}

Size: Very Fine (up to $.1 \mathrm{~mm}$ ), Fine (.1-.25 $\mathrm{mm})$, and Medium (.25-.5 mm)

Frequency: Common (10-20\%) and Abundant (25-30\%)

Degree of Sorting: Fair 
Roundedness: Sub-Angular, High Sphericity; Sub-Angular, Low Sphericity; SubRounded, High Sphericity; Sub-Rounded, Low Sphericity; Rounded, Low Sphericity; and Rounded, Low Sphericity

Raw Count: High 2,317, Low 639, Average 1,688

\section{Quartz (large)}

Size: Coarse (.5-1 mm) and Very Coarse (over $1 \mathrm{~mm}$ )

Frequency: Rare (1-3) Sparse (8\%), Common (10-15\%), Abundant (25\%)

Degree of Sorting: Very Poor to Poor

Roundedness: Angular, High Sphericity; Angular, Low Sphericity; Sub-Angular, High Sphericity; and Sub-Angular, Low Sphericity

Raw Count: High 407, Low 62, Average 194

\section{Organics}

Size: Fine (.1-.25 mm), Medium (.25-.5 mm), Coarse (.5-1 mm), and Very Coarse (over $1 \mathrm{~mm}$ )

Frequency: Rare (3\%) and Sparse (4-8\%)

Degree of Sorting: Poor

Roundedness: Sub-Rounded, High Sphericity; Sub-Rounded, Low Sphericity; Rounded, High Sphericity; and Rounded, Low Sphericity

Raw Count: High 145, Low 0, Average 105

\section{Voids}

Size: Fine (.1-.25 mm), Medium (.25-.5 mm), Coarse (.5-1 mm), and Very Coarse (over $1 \mathrm{~mm}$ )

Frequency: Sparse (4-8\%) and Common (10\%)

Degree of Sorting: Very Poor to Poor

Roundedness: Sub-Angular, High Sphericity;

Sub-Angular, Low Sphericity; Sub-

Rounded, High Sphericity; Sub-Rounded, Low Sphericity; and Linear
Raw Count: High 148, Low 95, Average 120

This paste group variant is different from Paste Groups 1a, 1b, 1c, and 1d because of the presence of biotite and chert inclusions. The biotite inclusions are part of the clay matrix, and the chert inclusions are most likely mixed with the large, angular quartz sand. While the large sand and chert are angular and were culturally added to the clay paste, there is no reason to believe that the inclusion of chert as temper was deliberate. None of the clay pastes exhibit a high birefringence. The bone inclusion colors range from tan to dark tan to dark red. While there are no definitive data to support this idea, differences in bone colors may reflect differences in temperatures to which the bone was burned for crushing before adding it as temper. The grog inclusions include three different pastes: 1) a high-birefringent tan paste; 2) a dark brown/ black (incompletely oxidized or fired in a reducing environment); and 3) a tan, nonbirefringent sandy paste. Samples PAI060, PAI061, PAI065, PAI066, PAI088, PAI096, PAI097, and PAI098 comprise this paste group.

In an attempt to determine which kind of pottery was used as grog temper, I have made some preliminary observations about this group. The paste of sample PAI066 is visually similar to the tan, non-high-birefringent grog samples in PAI056, PAI057, PAI059, and possibly PAI065. Therefore, it may be possible to suggest that the pottery of the paste type of PAI066 was used by the Caddo potters along the Tankersley Creek to temper other pottery.

\section{Paste Group 2: Sandy Paste (Bimodal) with Grog Inclusions with Biotite}

This paste group serves as the base paste group from which there are two variants (Paste Groups $2 \mathrm{a}$ and $2 \mathrm{~b}$ ).

\section{Biotite}

Size: Medium (.25-.5 mm), Coarse $(.5-1 \mathrm{~mm})$, and Very Coarse (over $1 \mathrm{~mm}$ )

Frequency: Rare (1\%)

Degree of Sorting: Poor

Roundedness: Linear 
Raw Count: 6

\section{Bone}

No bone inclusions were counted for this group.

\section{Chert}

No chert inclusions were counted for this group.

\section{K-feldspar}

No K-feldspar inclusions were counted for this group.

\section{Grog}

Size: Coarse (.5-1 mm) and Very Coarse (over $1 \mathrm{~mm}$ )

Frequency: Rare (1\%)

Degree of Sorting: Poor

Roundedness: Sub-Angular, High Sphericity; Sub-Angular, Low Sphericity, SubRounded, High Sphericity; and SubRounded, Low Sphericity

Raw Count: 6

\section{Microcline}

No microcline inclusions were counted for this group.

\section{Quartz (small)}

Size: Very Fine (up to $.1 \mathrm{~mm}$ ), Fine (.1-.25 $\mathrm{mm})$, and Medium (.25-.5 mm)

Frequency: Common (10\%)

Degree of Sorting: Poor

Roundedness: Rounded, Low Sphericity and Rounded, Low Sphericity

Raw Count: 746

\section{Quartz (large)}

Size: Coarse (.5-1 mm) and Very Coarse (over $1 \mathrm{~mm}$ )

Frequency: Common (10\%)

Degree of Sorting: Poor

Roundedness: Angular, High Sphericity; Angular, Low Sphericity; Sub-Angular, High Sphericity; and Sub-Angular, Low Sphericity

Raw Count: 188

\section{Organics}

Size: Fine (.1-.25 mm) and Medium (.25-.5 $\mathrm{mm}$ )

Frequency: Rare (2\%)

Degree of Sorting: Fair

Roundedness: Sub-Rounded, High Sphericity; Sub-Rounded, Low Sphericity; Rounded, High Sphericity; and Rounded, Low Sphericity

Raw Count: High 145, Low 0, Average 105

\section{Voids}

Size: Medium (.25-.5 mm), Coarse (.5-1 mm), and Very Coarse (over $1 \mathrm{~mm}$ )

Frequency: Sparse (4\%)

Degree of Sorting: Poor

Roundedness: Angular, High Sphericity; Angular, Low Sphericity; Sub-Angular, High Sphericity; Sub-Angular, Low Sphericity; and Linear

Raw Count: 126

Sample PAI079 represents the base paste group sample for Paste Group 2.This paste group is different from Paste Group 1 because of the lack of bone inclusions. The clay has a high birefringence. The grog inclusions represent two different pastes: 1) a lighter tan paste, and 2) a dark (incompletely oxidized or reduced) sandy paste. This sherd is also interesting because of the firing and cooling pattern. The interior core 
has been completely fired (lack of organics), and the outer edge has an oxidized margin. Between the oxidized core and the oxidized margin is an incompletely oxidized layer. According to Rye (1981), this represents a series of firing and cooling episodes.

\section{Paste Group 2a: Sandy Paste (Bimodal) with Grog Inclusions with Biotite and Chert}

\section{Biotite}

Size: Fine (.1-.25 mm) and Medium (.25-.5 $\mathrm{mm}$ )

Frequency: Rare (1\%)

Degree of Sorting: Poor

Roundedness: Linear

Raw Count: High 35, Low 3, Average 19

\section{Bone}

No bone inclusions were counted for this group.

\section{Chert}

Size: Coarse $(.5-1 \mathrm{~mm})$ and Very Coarse (over $1 \mathrm{~mm})$

Frequency: Rare (1\%)

Degree of Sorting: Poor

Roundedness: Sub-Angular, High Sphericity;

Sub-Angular, Low Sphericity; and

Rounded, Low Sphericity

Raw Count: High 8, Low 1, Average 5

\section{K-feldspar}

No K-feldspar inclusions were counted for this group.

\section{Grog}

Size: Coarse $(.5-1 \mathrm{~mm})$ and Very Coarse (over $1 \mathrm{~mm}$ )

Frequency: Rare (1\%)
Degree of Sorting: Poor

Roundedness: Sub-Angular, Low Sphericity and Sub-Rounded, Low Sphericity

Raw Count: High 59, Low 4, Average 32

\section{Microcline}

No microcline inclusions were counted for this group.

\section{Quartz (small)}

Size: Very Fine (up to $.1 \mathrm{~mm}$ ), Fine (.1-.25 $\mathrm{mm})$, and Medium (.25-.5 mm)

Frequency: Common (15-20\%)

Degree of Sorting: Fair

Roundedness: Sub-Angular, High Sphericity; Sub-Angular, Low Sphericity; SubRounded, High Sphericity; Sub-Rounded, Low Sphericity; Rounded, Low Sphericity; and Rounded, Low Sphericity

Raw Count: High 1,826, Low 1,490, Average 1,658

\section{Quartz (large)}

Size: Coarse $(.5-1 \mathrm{~mm})$ and Very Coarse (over $1 \mathrm{~mm}$ )

Frequency: Sparse (4-6\%)

Degree of Sorting: Poor

Roundedness: Angular, High Sphericity; Angular, Low Sphericity; Sub-Angular, High Sphericity; and Sub-Angular, Low Sphericity

Raw Count: High 129, Low 86, Average 108

\section{Organics}

Size: Fine (.1-.25 mm), Medium (.25-.5 mm), and Coarse $(.5-1 \mathrm{~mm})$

Frequency: Sparse (4\%)

Degree of Sorting: Fair

Roundedness: Sub-Rounded, High Sphericity; Sub-Rounded, Low Sphericity; Rounded, 
High Sphericity; and Rounded, Low Sphericity

Raw Count: High 171, Low 0, Average 86

\section{Voids}

Size: Fine (.1-.25 mm), Medium (.25-.5 mm), Coarse $(.5-1 \mathrm{~mm}$ ), and Very Coarse (over $1 \mathrm{~mm}$ )

Frequency: Sparse (5\%)

Degree of Sorting: Poor to Fair

Roundedness: Sub-Angular, High Sphericity; Sub-Angular, Low Sphericity; SubRounded, High Sphericity; Sub-Rounded, Low Sphericity; and Linear

Raw Count: High 224, Low 120, Average 172

This paste group variant is similar to the base of Paste Group 2 with the addition of chert inclusions. Given the size and roundedness of the chert, the chert is most likely a part of the sand (quartz) content and was not an intentional addition to the clay matrix. The clay has a high birefringence. Grog inclusions are a highbirefringent tan sandy paste or a dark sandy paste. Sample PAI070 has a prominent oxidized outer margin.

\section{Paste Group 2b: Sandy Paste (Bimodal) with Grog Inclusions with Chert and K-Feldspar}

\section{Biotite}

Size: Fine (.1-.25 mm) and Medium (.25-.5 $\mathrm{mm}$ )

Frequency: Rare (1\%)

Degree of Sorting: Poor

Roundedness: Linear

Raw Count: High 8, Low 0, Average 3

\section{Bone}

No bone inclusions were counted for this group.

\section{Chert}

Size: Medium (.25-.5 mm), Coarse (.5-1 mm), and Very Coarse (over $1 \mathrm{~mm}$ )

Frequency: Rare (1\%)

Degree of Sorting: Poor

Roundedness: Angular, High Sphericity; Angular, Low Sphericity; Sub-Angular, High Sphericity; Sub-Angular, Low Sphericity; and Sub-Rounded, Low Sphericity

Raw Count: High 10, Low 6, Average 8

\section{K-feldspar}

Size: Coarse (.5-1 mm) and Very Coarse (over $1 \mathrm{~mm}$ )

Frequency: Rare (1\%)

Degree of Sorting: Poor

Roundedness: Angular, Low Sphericity and Sub-Angular, Low Sphericity

Raw Count: High 5, Low 4, Average 3

\section{Grog}

Size: Coarse (.5-1 mm) and Very Coarse (over $1 \mathrm{~mm})$

Frequency: Rare (1-3\%) and Sparse (5\%)

Degree of Sorting: Very Poor to Poor

Roundedness: Angular, High Sphericity; Angular, Low Sphericity; Sub-Angular, High Sphericity; Sub-Angular, Low Sphericity; Sub-Rounded, High Sphericity; and Sub-Rounded, Low Sphericity

Raw Count: High 23, Low 8, Average 15

\section{Microcline}

No microcline inclusions were counted for this group.

\section{Quartz (small)}

Size: Very Fine (up to $.1 \mathrm{~mm}$ ), Fine (.1-.25 $\mathrm{mm})$, and Medium (.25-.5 mm) 
Frequency: Common (10-15\%)

Degree of Sorting: Fair

Roundedness: Sub-Angular, High Sphericity; Sub-Angular, Low Sphericity; SubRounded, High Sphericity; Sub-Rounded, Low Sphericity; Rounded, Low Sphericity; and Rounded, Low Sphericity

Raw Count: High 1,773, Low 888, Average 1,213

\section{Quartz (large)}

Size: Coarse $(.5-1 \mathrm{~mm})$ and Very Coarse (over $1 \mathrm{~mm}$ )

Frequency: Sparse (5\%) and Common (10\%)

Degree of Sorting: Poor

Roundedness: Angular, High Sphericity; Angular, Low Sphericity; Sub-Angular, High Sphericity; and Sub-Angular, Low Sphericity

Raw Count: High 192, Low 92, Average 134

\section{Organics}

Size: Fine (.1-.25 mm) and Medium (.25-.5 $\mathrm{mm}$ )

Frequency: Sparse (8\%)

Degree of Sorting: Fair

Roundedness: Sub-Rounded, High Sphericity; Sub-Rounded, Low Sphericity; Rounded, High Sphericity; and Rounded, Low Sphericity

Raw Count: High 203, Low 0, Average 68

\section{Voids}

Size: Fine (.1-.25 mm), Medium (.25-.5 mm), Coarse (.5-1 mm), and Very Coarse (over $1 \mathrm{~mm}$ )

Frequency: Sparse (5\%) and Common (20\%)

Degree of Sorting: Poor

Roundedness: Sub-Angular, High Sphericity; Sub-Angular, Low Sphericity; Sub-
Rounded, High Sphericity; Sub-Rounded, Low Sphericity; and Linear

Raw Count: High 423, Low 127, Average 244

This paste group is distinguished from Paste Groups 2 and $2 \mathrm{a}$ because of the presence of K-feldspar and chert. The similar angularity of K-feldspar and chert with the large sand (quartz) inclusions suggests that the K-feldspar and chert inclusions are detrital components of the sand mixture that was culturally added to the clay matrix. Grog inclusions were of three different pastes: 1) a dark (incompletely oxidized or reduced) sandy paste; 2 ) a tan sandy paste; and 3) a high-birefringent, tan sandy paste.

A piece of grog in sample PAI094 exhibits an interesting combination of inclusions and voids $(n=423)$. This grog inclusion with a similar high frequency of voids and the dark paste is visually similar to the paste group (Paste Group 4) represented by sample PAI075.

\section{Paste Group 3: Sandy Paste (Bimodal) with Bone Inclusions}

\section{Biotite}

Size: Fine (.1-.25 mm) and Medium (.25-.5 $\mathrm{mm}$ )

Frequency: Rare (1\%)

Degree of Sorting: Poor

Roundedness: Linear

Raw Count: High 5, Low 0, Average 1

\section{Bone}

Size: Medium (.25-.5 mm), Coarse (.5-1 mm), and Very Coarse (over $1 \mathrm{~mm}$ )

Frequency: Sparse (3\%) to Common (10\%)

Degree of Sorting: Very Poor to Poor

Roundedness: Angular, Low Sphericity SubRounded, High Sphericity; and SubRounded, Low Sphericity

Raw Count: High 88, Low 14, Average 44 


\section{Chert}

Size: Coarse (.5-1 mm) and Very Coarse (over $1 \mathrm{~mm})$

Frequency: Rare (1\%)

Degree of Sorting: Poor

Roundedness: Angular, High Sphericity;

Angular, Low Sphericity; Sub-Angular,

High Sphericity; Sub-Angular, Low

Sphericity; and Sub-Rounded, Low

Sphericity

Raw Count: High 22, Low 6, Average 14

\section{K-feldspar}

No K-feldspar inclusions were counted for this group.

\section{Grog}

No grog inclusions were counted for this group.

\section{Microcline}

No microcline inclusions were counted for this group.

\section{Quartz (small)}

Size: Very Fine (up to $.1 \mathrm{~mm}$ ), Fine (.1-.25 $\mathrm{mm})$, and Medium (.25-.5 mm)

Frequency: Common (10-15\%)

Degree of Sorting: Poor to Fair

Roundedness: Sub-Angular, High Sphericity; Sub-Angular, Low Sphericity; SubRounded, High Sphericity; Sub-Rounded, Low Sphericity; Rounded, Low Sphericity; and Rounded, Low Sphericity

Raw Count: High 1,278, Low 691, Average 1,004

\section{Quartz (large)}

Size: Coarse (.5-1 mm), and Very Coarse (over $1 \mathrm{~mm}$ )
Frequency: Common (10-15\%)

Degree of Sorting: Very Poor to Poor

Roundedness: Angular, High Sphericity; Angular, Low Sphericity; Sub-Angular, High Sphericity; and Sub-Angular, Low Sphericity;

Raw Count: High 221, Low 157, Average 184

\section{Organics}

Size: Medium (.25-.5 mm) and Coarse (.5-1 $\mathrm{mm}$ )

Frequency: Rare (1\%)

Degree of Sorting: Poor

Roundedness: Sub-Rounded, High Sphericity; Sub-Rounded, Low Sphericity; Rounded, High Sphericity; and Rounded, Low Sphericity

Raw Count: High 91, Low 0, Average 33

\section{Voids}

Size: Fine (.1-.25 mm), Medium (.25-.5 mm), Coarse (.5-1 mm), and Very Coarse (over $1 \mathrm{~mm})$

Frequency: Rare (2\%) and Sparse (5\%)

Degree of Sorting: Very Poor to Poor

Roundedness: Sub-Angular, High Sphericity; Sub-Angular, Low Sphericity; SubRounded, High Sphericity; Sub-Rounded, Low Sphericity; and Linear

Raw Count: High 224, Low 120, Average 172

This paste group is distinguished from the other paste groups because of the lack of grog temper and the very large bone inclusions. The majority of the bone inclusions are very dark in color (dark brown, black, or dark red) with a minority of the crushed bone being tan in color (the characteristic common in most of the other samples). Again, bimodal quartz is a very prominent inclusion. The small quartz minerals are naturally occurring in the clay matrix, while the larger, more angular quartz (and chert) inclusions are a cultural addition. 
Samples PAI074, PAI076, PAI077, and PAI080 comprise this paste group.

\section{Paste Group 4: Sandy Paste (Bimodal) with Chert Inclusions}

\section{Biotite}

No biotite inclusions were counted for this group.

\section{Bone}

No bone inclusions were counted for this group.

\section{Chert}

Size: Coarse (.5-1 mm) and Very Coarse (over $1 \mathrm{~mm}$ )

Frequency: Rare (1\%)

Degree of Sorting: Poor

Roundedness: Sub-Angular, High Sphericity; Sub-Angular, Low Sphericity; and SubRounded, Low Sphericity

Raw Count: 9

\section{K-feldspar}

No K-feldspar inclusions were counted for this group.

\section{Grog}

No grog inclusions were counted for this group.

\section{Microcline}

No microcline inclusions were counted for this group.

\section{Quartz (small)}

Size: Very Fine (up to $.1 \mathrm{~mm}$ ) and Fine (.1-.25 $\mathrm{mm}$ )
Frequency: Common (10\%)

Degree of Sorting: Fair

Roundedness: Sub-Angular, High Sphericity; Sub-Angular, Low Sphericity; SubRounded, High Sphericity; Sub-Rounded, Low Sphericity; Rounded, Low Sphericity; and Rounded, Low Sphericity

Raw Count: 787

\section{Quartz (large)}

Size: Coarse (.5-1 mm) and Very Coarse (over $1 \mathrm{~mm}$ )

Frequency: Common (10\%)

Degree of Sorting: Very Poor

Roundedness: Angular, High Sphericity; Angular, Low Sphericity; Sub-Angular, High Sphericity; and Sub-Angular, Low Sphericity

Raw Count: 984

\section{Organics}

The paste was too dark to count inclusions for this group.

\section{Voids}

Size: Fine (.1-.25 mm), Medium (.25-.5 mm), Coarse (.5-1 mm), and Very Coarse (over $1 \mathrm{~mm}$ )

Frequency: Common (30\%)

Degree of Sorting: Very Good

Roundedness: Sub-Angular, High Sphericity; Sub-Angular, Low Sphericity; SubRounded, High Sphericity; Sub-Rounded, Low Sphericity; and Linear

Raw Count: 3,936

This paste group, represented by sample PAI075, is different from the other paste groups because of the lack of any culturally added inclusions except for large, angular sand. Chert occurs because it is a detrital component of the sand. This sample is also distinguished by its 
high frequency of voids. As stated above for Paste Group 2b, this sample may be one of the paste groups used for grog temper by the potters.

\section{Paste Group 5: Sandy Paste}

This paste group serves as the base paste group from which there are five variants (Paste Groups 5a, 5b, 5c, 5d, and 5e).

\section{Biotite}

Size: Coarse (.5-1 mm) and Very Coarse (over $1 \mathrm{~mm})$

Frequency: Rare (1\%)

Degree of Sorting: Poor

Roundedness: Linear

Raw Count: 2

\section{Bone}

No bone inclusions were counted for this group.

\section{Chert}

No chert inclusions were counted for this group.

\section{K-feldspar}

No K-feldspar inclusions were counted for this group.

\section{Grog}

No grog inclusions were counted for this group.

\section{Microcline}

No microcline inclusions were counted for this group.

\section{Quartz}

Size: Very Fine (up to $.1 \mathrm{~mm}$ ) and Fine (.1-.25 $\mathrm{mm}$ )
Frequency: Common (10\%)

Degree of Sorting: Fair

Roundedness: Sub-Angular, High Sphericity; Sub-Angular, Low Sphericity; SubRounded, High Sphericity; and SubRounded, Low Sphericity

Raw Count: 1,472

\section{Organics}

Paste was too dark to count inclusions for this group.

\section{Voids}

Size: Very Coarse (over $1 \mathrm{~mm}$ )

Frequency: Sparse (5\%)

Degree of Sorting: Poor

Roundedness: Rectangular and Linear

Raw Count: 81

Sample PAI064 is used as the most basic sample for Paste Group 5.An even mix of quartz minerals ranging in size and roundedness characterizes Paste Group 5.The paste of PAI064 is visually very similar to that of sample PAI063 (Paste Group 1) without the culturally added inclusions of angular quartz, bone, and grog.

\section{Paste Group 5a: Sandy Paste with Grog and Biotite Inclusions \\ Biotite}

Size: Very Fine (up to $.1 \mathrm{~mm}$ )

Frequency: Abundant (30\%)

Degree of Sorting: Very Good

Roundedness: Linear

Raw Count: 1,035

\section{Bone}

No bone inclusions were counted for this group. 


\section{Chert}

No chert inclusions were counted for this group.

\section{K-feldspar}

No K-feldspar inclusions were counted for this group.

\section{Grog}

Size: Coarse (.5-1 mm) and Very Coarse (over $1 \mathrm{~mm}$ )

Frequency: Sparse (5\%)

Degree of Sorting: Poor

Roundedness: Angular, High Sphericity; Angular, Low Sphericity; Sub-Angular, High Sphericity; Sub-Angular, Low Sphericity; Sub-Rounded, High Sphericity; and Sub-Rounded, Low Sphericity

Raw Count: 18

\section{Microcline}

No microcline inclusions were counted for this group.

\section{Quartz}

Size: Very Fine (up to $.1 \mathrm{~mm}$ ) and Fine (.1-.25 $\mathrm{mm}$ )

Frequency: Common (15\%)

Degree of Sorting: Good

Roundedness: Sub-Angular, High Sphericity; Sub-Angular, Low Sphericity; SubRounded, High Sphericity; and SubRounded, Low Sphericity

Raw Count: 1,589

\section{Organics}

Size: Fine (.1-.25 mm) and Medium (.25-.5 $\mathrm{mm})$

Frequency: Sparse (5\%)
Degree of Sorting: Fair

Roundedness: Sub-Rounded, High Sphericity; Sub-Rounded, Low Sphericity; Rounded, High Sphericity; and Rounded, Low Sphericity

Raw Count: 250

\section{Voids}

Size: Fine (.1-.25 mm), Medium (.25-.5 mm), Coarse (.5-1 mm), and Very Coarse (over $1 \mathrm{~mm}$ )

Frequency: Sparse (5\%)

Degree of Sorting: Fair

Roundedness: Sub-Angular, High Sphericity; Sub-Angular, Low Sphericity; SubRounded, High Sphericity; Sub-Rounded, Low Sphericity; and Linear

Raw Count: 111

This sherd paste of this sample (PAI090) is fairly well sorted, with small quartz and a very high frequency of biotite minerals. Both inclusions are natural to the clay paste. This paste group represents the choice of a potter to use a high-micaceous clay with very small sand particles. The grog inclusions (culturally added) are dark brown (incompletely oxidized or reduced) with large quartz minerals.

\section{Paste Group 5b: Sandy Paste with Grog and Chert and K-Feldspar Inclusions}

\section{Biotite}

No biotite inclusions were counted for this group.

\section{Bone}

No bone inclusions were counted for this group.

\section{Chert}

Size: Coarse (.5-1 mm) and Very Coarse (over $1 \mathrm{~mm}$ ) 
Frequency: Rare (1\%)

Degree of Sorting: Poor

Roundedness: Sub-Angular, High Sphericity;

Sub-Angular, Low Sphericity; Sub-

Rounded, High Sphericity; and Sub-

Rounded, Low Sphericity

Raw Count: 11

\section{K-feldspar}

Size: Coarse (.5-1 mm)

Frequency: Rare (1\%)

Degree of Sorting: Poor

Roundedness: Triangular

Raw Count: 1

\section{Grog}

Size: Very Coarse (over $1 \mathrm{~mm}$ )

Frequency: Rare (1\%)

Degree of Sorting: Poor

Roundedness: Rectangular

Raw Count: 5

\section{Microcline}

No microcline inclusions were counted for this group.

\section{Quartz}

Size: Coarse (.5-1 mm)

Frequency: Abundant (50\%)

Degree of Sorting: Good

Roundedness: Angular, High Sphericity; Angular, Low Sphericity; Sub-Angular, High Sphericity; and Sub-Angular, Low Sphericity

Raw Count: 1,157

\section{Organics}

Paste was too dark to count organics for this group.

\section{Voids}

Size: Coarse (.5-1 mm) and Very Coarse (over $1 \mathrm{~mm}$ )

Frequency: Sparse (4\%)

Degree of Sorting: Poor

Roundedness: Sub-Angular, High Sphericity; Sub-Angular, Low Sphericity; Sub-

Rounded, High Sphericity; Sub-Rounded, Low Sphericity; and Linear

Raw Count: 86

While this group represents a nonbimodal paste group, it is different from the Paste Groups 5 and 5 a because it is composed of large, angular quartz minerals. Therefore, the sand (with detrital chert and feldspar) and grog inclusions signify culturally added elements. The grog temper is from a high-birefringent tan clay and a tan, sandy paste. One of the interesting observations about the tan sandy grog temper in this sample is that some of the grog temper is tempered with grog.

\section{Paste Group 5c: Sandy Paste with Grog and Bone and Biotite Inclusions}

\section{Biotite}

Size: Medium (.25-.5 mm)

Frequency: Rare (1\%)

Degree of Sorting: Fair

Roundedness: Linear

Raw Count: 29

\section{Bone}

Size: Fine (.1-.25 mm) to Medium (.25-.5 mm)

Frequency: Sparse (5\%)

Degree of Sorting: Poor 
Roundedness: Sub-Angular, High Sphericity; Sub-Angular, Low Sphericity; SubRounded, High Sphericity; Sub-Rounded, Low Sphericity; and Square

Raw Count: 74

\section{Chert}

No chert inclusions were counted for this group.

\section{K-feldspar}

No k-feldspar inclusions were counted for this group.

\section{Grog}

Size: Medium (.25-.5 mm) to Coarse (.5-1 $\mathrm{mm}$ )

Frequency: Rare (3\%)

Degree of Sorting: Poor

Roundedness: Sub-Angular, High Sphericity and Sub-Angular, Low Sphericity

Raw Count: 17

\section{Microcline}

No microcline inclusions were counted for this group.

\section{Quartz}

Size: Medium (.25-.5 mm), Coarse (.5-1 mm), and Very Coarse (over $1 \mathrm{~mm}$ )

Frequency: Common (20\%)

Degree of Sorting: Fair

Roundedness: Sub-Angular, High Sphericity; Sub-Angular, Low Sphericity; SubRounded, High Sphericity; and SubRounded, Low Sphericity

Raw Count: 1,419

\section{Organics}

Size: Fine (.1-.25 mm) and Medium (.25-.5 $\mathrm{mm})$

Frequency: Rare (3\%)

Degree of Sorting: Fair

Roundedness: Rounded, High Sphericity and Rounded, Low Sphericity

Raw Count: 138

\section{Voids}

Size: Fine (.1-.25 mm), Medium (.25-.5 mm), Coarse $(.5-1 \mathrm{~mm})$ and Very Coarse (over 1 $\mathrm{mm}$ )

Frequency: Common (10\%)

Degree of Sorting: Fair

Roundedness: Sub-Angular, High Sphericity; Sub-Angular, Low Sphericity; SubRounded, High Sphericity; Sub-Rounded, Low Sphericity; and Linear

Raw Count: 404

Sample PAI068 represents this paste group that is tempered with bone and grog inclusions. The biotite inclusions are a natural component of the clay. The crushed bone inclusions range in color from tan to dark red. The grog inclusions are much smaller in size than the other grog inclusions in this study. This may indicate that the potters crushed the pottery used for grog more finely than what was used to manufacture other pottery. The grog inclusions are dark brown/black (incompletely oxidized or reduced) sandy with tan bone inclusions.

\section{Paste Group 5d: Sandy Paste with Grog and Bone and Chert Inclusions}

\section{Biotite}

Size: Fine (.1-.25 mm) and Medium (.25-.5 $\mathrm{mm})$

Frequency: Rare (1\%)

Degree of Sorting: Poor 
Roundedness: Linear

Raw Count: High 9, Low 0, Average 2

\section{Bone}

Size: Medium (.25-.5 mm), Coarse (.5-1 mm), and Very Coarse (over $1 \mathrm{~mm}$ )

Frequency: Rare (1-3\%) to Sparse (5\%)

Degree of Sorting: Poor

Roundedness: Angular, Low Sphericity; SubRounded, High Sphericity; Sub-Rounded, Low Sphericity; and Sub-Rounded, Low Sphericity

Raw Count: High 49, Low 11, Average 31

\section{Chert}

Size: Coarse $(.5-1 \mathrm{~mm})$ and Very Coarse (over $1 \mathrm{~mm}$ )

Frequency: Rare (1\%)

Degree of Sorting: Poor

Roundedness: Angular, High Sphericity; Angular, Low Sphericity; Sub-Angular, High Sphericity; Sub-Angular, Low Sphericity; and Sub-Rounded, Low Sphericity

Raw Count: High 10, Low 4, Average 7

\section{K-feldspar}

No K-feldspar inclusions were counted for this group.

\section{Grog}

Size: Coarse $(.5-1 \mathrm{~mm})$ and Very Coarse (over $1 \mathrm{~mm}$ )

Frequency: Rare (3\%)

Degree of Sorting: Very Poor and Poor

Roundedness: Angular, High Sphericity; Angular, Low Sphericity; Sub-Angular, High Sphericity; Sub-Angular, Low Sphericity; Sub-Rounded, High Sphericity; and Sub-Rounded, Low Sphericity
Raw Count: High 30, Low 4, Average 13

\section{Microcline}

No microcline inclusions were counted for this group.

\section{Quartz}

Size: Fine (.1-.25 mm), Medium (.25-.5 mm), Coarse (.5-1 mm), and Very Coarse (over $1 \mathrm{~mm}$ )

Frequency: Common (15-20\%)

Degree of Sorting: Fair

Roundedness: Sub-Angular, High Sphericity; Sub-Angular, Low Sphericity; SubRounded, High Sphericity; Sub-Rounded, Low Sphericity; Rounded, Low Sphericity; and Rounded, Low Sphericity

Raw Count: High 1,662, Low 711, Average 1,139

\section{Organics}

Size: Fine (.1-.25 mm), Medium (.25-.5 mm), and Coarse $(.5-1 \mathrm{~mm})$

Frequency: Rare (2\%)

Degree of Sorting: Fair

Roundedness: Sub-Rounded, High Sphericity; Sub-Rounded, Low Sphericity; Rounded, High Sphericity; and Rounded, Low Sphericity

Raw Count: High 36, Low 0, Average 9

\section{Voids}

Size: Fine (.1-.25 mm), Medium (.25-.5 mm), Coarse (.5-1 mm), and Very Coarse (over $1 \mathrm{~mm})$

Frequency: Rare (3\%) and Sparse (5-8\%)

Degree of Sorting: Very Poor to Poor

Roundedness: Sub-Angular, High Sphericity; Sub-Angular, Low Sphericity; SubRounded, High Sphericity; Sub-Rounded, Low Sphericity; and Linear 


\section{Chert}

Size: Medium (.25-.5 mm), Coarse (.5-1 mm), and Very Coarse (over $1 \mathrm{~mm}$ )

Frequency: Rare (1\%)

Degree of Sorting: Poor

Roundedness: Sub-Rounded, Low Sphericity; Sub-Rounded, High Sphericity; and Rounded, High Sphericity

Raw Count: High 17, Low 1, Average 7

\section{K-feldspar}

groups: 1) a high-birefringent tan paste; 2) a non-birefringent tan sandy paste; and 3) a dark brown/black (reduced or incompletely oxidized) sandy paste.

Sample PAI072 is visually similar to the grog temper with a high birefringence. This paste might have been used by the Tankersley Creek potters for grog during pottery manufacture of other pottery pastes.

\section{Paste Group 5e: Sandy Paste with Grog and Bone and Chert and K-Feldspar Inclusions}

\section{Biotite}

Size: Medium (.25-.5 mm)

Frequency: Rare (1\%)

Degree of Sorting: Poor

Roundedness: Linear

Raw Count: High 5, Low 0, Average 2

\section{Bone}

Size: Medium (.25-.5 mm), Coarse (.5-1 mm), and Very Coarse (over $1 \mathrm{~mm}$ )

Frequency: Rare (1-3\%)

Degree of Sorting: Poor

Roundedness: Angular, Low Sphericity SubRounded, High Sphericity; Sub-Rounded, Low Sphericity; and Sub-Rounded, Low Sphericity

Raw Count: High 26, Low 2, Average 12
Size: Coarse (.5-1 mm) and Very Coarse (over $1 \mathrm{~mm}$ )

Frequency: Rare (1\%)

Degree of Sorting: Poor

Roundedness: Angular, Low Sphericity; SubRounded, High Sphericity; Sub-Rounded, Low Sphericity; and Sub-Rounded, Low Sphericity

Raw Count: High 4, Low 1, Average 3

\section{Grog}

Size: Medium (.25-.5 mm), Coarse (.5-1 mm), and Very Coarse (over $1 \mathrm{~mm}$ )

Frequency: Rare (2-3\%)

Degree of Sorting: Poor

Roundedness: Angular, High Sphericity; Angular, Low Sphericity; Sub-Angular, High Sphericity; Sub-Angular, Low Sphericity; Sub-Rounded, High Sphericity; and Sub-Rounded, Low Sphericity

Raw Count: High 33, Low 10, Average 18

\section{Microcline}

No microcline inclusions were counted for this group. 


\section{Quartz}

Size: Fine (.1-.25 mm), Medium (.25-.5 mm), Coarse (.5-1 mm), and Very Coarse (over $1 \mathrm{~mm}$ )

Frequency: Common (15-20\%) and Abundant $(25 \%)$

Degree of Sorting: Poor to Fair

Roundedness: Sub-Angular, High Sphericity; Sub-Angular, Low Sphericity; SubRounded, High Sphericity; Sub-Rounded, Low Sphericity; Rounded, Low Sphericity; and Rounded, Low Sphericity

Raw Count: High 1,990, Low 884, Average 1,284

\section{Organics}

Size: Fine (.1-.25 mm), Medium (.25-.5 mm), and Coarse $(.5-1 \mathrm{~mm})$

Frequency: Rare (3\%)

Degree of Sorting: Fair

Roundedness: Sub-Rounded, High Sphericity; Sub-Rounded, Low Sphericity; Rounded, High Sphericity; and Rounded, Low Sphericity

Raw Count: High 127, Low 0, Average 60

\section{Voids}

Size: Medium (.25-.5 mm), Coarse (.5-1 mm), and Very Coarse (over $1 \mathrm{~mm}$ )

Frequency: Sparse (5-8\%)

Degree of Sorting: Poor to Fair

Roundedness: Sub-Angular, High Sphericity; Sub-Angular, Low Sphericity; Sub-

Rounded, High Sphericity; Sub-Rounded, Low Sphericity; and Linear

Raw Count: High 161, Low 108, Average 140

Samples (PAI057, PAI084, PAI086) in this group are different from those of the other paste groups in Paste Group 5 because of the presence of chert and K-feldspar inclusions. While these inclusions are generally angular in nature, they are most likely part of the quartz (sand) component that was culturally added to the clay base. Therefore, while the chert and K-feldspar were added to the clay, they most likely were not intentionally added to the clay separate from the intentional addition of the quartz. The crushed bone is tan and dark brown in color. The grog inclusions are one of three paste groups: 1 ) a high-birefringent tan paste; 2) a nonbirefringent tan sandy paste; and 3) a dark brown/black (reduced or incompletely oxidized) sandy paste.

\section{DISCUSSION}

As is typical of most sherds from east Texas, the pastes are characterized as sandy pastes. While these samples all have a high frequency of quartz, there are two kinds of pastes: a bimodal sandy paste and a well-mixed sandy paste. These two basic kinds of pastes were then divided into five different paste groups with variations within three of those paste groups. The majority of the samples exhibit a bimodal distribution of quartz inclusions suggesting that there is a fine-sized fraction of quartz sand that is natural to the clay and a larger, more angular quartz sand that the Caddo potters were intentionally processing and adding as temper to the clay matrix. It also appears that there are three different sands used by the Caddo at Tankersley Creek: 1) pure quartz; 2) quartz with detrital chert; and 3) quartz with detrital chert and K-feldspar. This could be the result of three sources of quartz sand. When sorting the samples based on those that have no chert or K-feldspar, those that have chert, and those that have chert and K-feldspar, there are no overwhelming patterns, but some ideas can be suggested. Each site tends to have approximately half of its samples tempered with sands with chert and K-feldspar. Site 41TT851 has the fewest samples with quartz with detrital chert, and site 41TT853 has the most samples with quartz with detrital chert and K-feldspar. This may suggest that upriver clays and sands were weathered from parent material richer in those two minerals than downriver clays and sands.

Also similar to the majority of sherds from east Texas, grog and bone inclusions are prominent. The bone inclusions range in color, with the majority exhibiting a light to dark tan color. Although no studies have been conducted as to the meaning of the different color of bone, it is possible that the differences are a result of 
the temperature to which the bone was heated before crushing to make temper. In addition to the variety of bone colors, these samples also contained a variety of grog paste types. The majority of the grog paste types were composed of highly birefringent tan pastes and dark brown/ black sandy pastes. While this study did not seek to determine if these grog pastes are the same pastes as the sherds to which they were added as temper, two of the above paste groups demonstrate some visual similarities. Sample PAI072, a tan paste with high birefringence, is visually similar to the grog temper with a high birefringence. This paste might have been used by the Tankersley Creek potters for grog. In addition to PAI072 (and other pottery like it) being the possible source of grog, there is a very unusual black paste with a number of small voids. Sample PAI075 (and other pottery like it) may have been used as grog tempering as seen in sample PAI094.

There are no obvious correlations between paste groups, site, ceramic type, or exterior decoration. While there is nothing obvious, when examining the five paste groups as wholes without the variations within each paste group, two minor patterns can be suggested. First, Paste Group 3 is only composed of pottery from site 41TT852.Second, most of the samples from 41TT853 are members of Paste Group 1. When compared to pottery paste groups from the Pine Tree Mound site, the pastes of Paste Group 2 and $2 \mathrm{~b}$ at Tankersley are visually the same as those of Paste Group 3 at the Pine Tree Mound site (Cecil 2012).

Finally, although INAA data was not incorporated with this report, the grog in these samples will greatly affect the chemical data. Not only is the majority of this sample tempered with grog of a different origin than the original clay matrix from which the vessels were made, but some of the grog used in manufacture also was tempered with grog. Grog alone will dilute the chemical signature of the sample; add into the analysis grog tempered with grog, and the dilution is even greater.

\section{REFERENCES CITED}

Bishop, Ronald L., Robert L Rands, and G. R. Holley 1982 Ceramic Compositional Analysis in Archaeological Perspective. In Advances in Archaeological Method and Theory, edited by Michael B. Schiffer, Vol. 5, pp. 275-330. Academic Press, New York.

Blatt, Harvey

1992 Sedimentary Petrology. Freeman and Co., New York.

Cecil, Leslie G.

2012 Petrographic Analysis of Pottery and Clay Samples. In Archeology of the Nadaco Caddo: The View from the Pine Tree Mound Site (41HS15), Harrison County, Texas, Vol. II, edited by Ross C.Fields and Eloise Frances Gadus, pp. 797-826. Prewitt and Associates, Inc., Austin.
Chayes, Felix

1956 Petrographic Modal Analysis. John Wiley, New York.

Childs, S. T.

1989 Petrographic Analysis of Archaeological Ceramics. Material Research Science 25:24-29.

Dickenson, William R., and Richard Shutler Jr. 1979 Petrography of Sand Tempers in Pacific Island Potsherds. Geological Society of America Bulletin, Part II, 90:1644-1701.

McLaughlin, R. J. W.

1977 Atomic Absorption Spectroscopy. In Physical Methods in Determinative Mineralogy, edited by J. Zussman, pp. 371-389. Academic Press, London. 
Middleton, A. P., I. C. Freestone, and M. N. Lesse 1985 Textural Analysis of Ceramic Thin Sections: Evaluations of Grain Sampling Procedures. Archaeometry 27(1):64-74.

Orton, Clive, Paul Tyers, and Alan Vince 1993 Pottery in Archaeology. Cambridge University Press, Cambridge, United Kingdom.

Peacock, D. P. S.

1973 The Black-Burnished Pottery Industry in Dorset. Research Reports Council for British Archaeology 10:63-65.
Rice, Prudence M.

1987 Macanché Island, El Petén, Guatemala: Excavation, Pottery, and Artifacts. University of Florida Press, Gainesville.

Rye, Owen S.

1981 Pottery Technology. Tarazacum, Washington, D.C.

Shackley, Myra L.

1975 Archaeological Sediments: A Survey of Analytical Methods. John Wiley, New York. 



\section{APPENDIX K: Analysis of the Anderson Collection}

Ross C. Fields, Eloise Frances Gadus, and Virginia Hatfield 



\section{INTRODUCTION}

This appendix describes artifacts collected by members of the Anderson family from property they own approximately $0.6 \mathrm{~km}$ west of the U.S. Highway 271 Mount Pleasant relief route corridor, near its north end on the west side of Tankersley Creek. This effort was prompted by a report that some of these artifacts were from a small Caddo cemetery, and it was felt that documenting these materials would complement the descriptions of the grave goods from the Thomas B. Caldwell and A. P. Williams cemeteries, two other Caddo cemeteries near but outside the immediate project area (see Chapter 7).

On April 29, 2010, the senior author spent time on the property with Rick Anderson and his son Luke, viewing the collection and interviewing them about the circumstances that led to the recovery of the artifacts. Mr. Anderson had laid out on a table 11 Caddo pots, 2 celts, and some charcoal that he said were from graves; a grooved axe that reportedly came from Tankersley Creek at the east edge of his property; and about 150 projectile points (mostly darts, but some arrows) and maybe 50 other items (bifaces, concretions, interesting rocks, etc.) that had been picked up as surface finds on the property over the years.

Rick Anderson's grandfather, Duncan (Bunkem) Anderson, once owned and farmed substantial acreage on the west side of Tankersley Creek in the vicinity of FM 899. Over the years, he occasionally picked up artifacts in plowed fields and other exposed areas, resulting in the collection of ca. 200 projectile points and other items. That property ultimately was divided into eastern and western parts, with the former going to Rick Anderson's father (Jack) and the latter to the family of one of Jack Anderson's siblings. Rick Anderson remembers that, probably sometime in the 1960s, his father and an uncle dug up 8-10 graves on a knoll next to Tankersley Creek. Much later, Rick himself dug up a single grave. This was the only one to have bones in it; the others had no bones. He said they could not see grave pits, but he was clear that the graves were oriented east-west. His father and uncle apparently split up the grave goods, and they may not have kept pots that were badly broken. Still, the materials in his possession (11 pots and 2 celts) are well less than half of what would be expected from a cemetery of that size, based on what was recovered from the Thomas B. Caldwell and A. P. Williams cemeteries, and recent documentation of another private collection from the area lists 66 vessels that came from this same cemetery (Perttula et al. 2012). Apparently, most of the pots the Andersons found left their possession at some point. Rick Anderson did not recall any arrow points or artifacts such as ear spools being found, and he seemed certain that none of the graves was large enough to have held more than a single individual. The materials were not kept separate by grave. Mr. Anderson agreed to let us borrow the artifacts for documentation and inclusion in this report.

After looking at the artifacts, the senior author accompanied the Andersons to look at where the burials came from. A number of recorded sites are on their property, and it is clear that the cemetery was on 41TT18 (Duncan Anderson Farm site), which was documented first in the 1930s around the time of the work at the Caldwell and Williams cemeteries, judging from the key site file card at the Texas Archeological Research Laboratory (Perttula et al. 2012:9). This site was revisited, and several others (41TT672-41TT676) were recorded in 1994 during a survey by the Texas Water Development Board for a water supply pipeline for Mount Pleasant. As of 2010, 41TT18 was in pasture atop a prominent knoll overlooking Tankersley Creek to the northeast. There was no evidence of looted graves or archeology on the surface, which showed moderate disturbance from hog rooting.

\section{CERAMIC VESSELS FROM 41TT18}

The 11 vessels consist of 2 bottles, 4 bowls, and 5 jars. The bottles and a compound bowl can be typed as Ripley Engraved, and there are single examples of Pease Brushed-Incised and Belcher Ridged jars, as well as an effigy bowl. The other five vessels are untyped: 2 undecorated simple bowls, 1 brushed jar, 1 incised and appliquéd jar, and 1 punctated jar (the latter could be called Mockingbird Punctated [Perttula et al. 2012:10]). This assemblage is generally consistent with the part of the Margaret Hinton collection that reportedly came from the same site, although Pease Brushed-Incised and 
Belcher Ridged jars are missing from the latter (Perttula et al. 2012:262-327). Typed vessels in that collection consist of 18 Ripley Engraved carinated bowls, 2 Ripley Engraved compound bowls, 2 Ripley Engraved bottles, 4 Maydelle Incised jars, 1 Bullard Brushed jar, 1 Killough Pinched jar, 2 Mockingbird Punctated jars, and 1 La Rue Neck Banded jar. These typed vessels and the characteristics of the untyped ones indicate that the cemetery dates to the Late Caddo Titus phase (Perttula et al. 2012:41).

\section{Vessel 1}

Vessel 1 is a complete Ripley Engraved compound bowl with everted rim, rolled lip, and flat base (Figure K.1). It is $12.0 \mathrm{~cm}$ tall with a rim height of $3.6 \mathrm{~cm}$. The orifice diameter is $28.0 \mathrm{~cm}$, while the neck and body diameters are 23.8 and $23.4 \mathrm{~cm}$; the base diameter is $9.0 \mathrm{~cm}$. Wall thickness at the rim is $0.51 \mathrm{~cm}$. Its volume is $3,300 \mathrm{ml}$. The vessel is tempered with grog and bone and has burnished exterior and interior surfaces, both of which are gray; the core color is unknown. The engraved decoration, which retains red pigment, is a band of alternating elements between the carnations, repeated nine times around the vessel. The band is demarcated by upper and lower engraved lines. Primary decorative elements are open circles and bars, while secondary elements are curvilinear hatching and horizontal lines around the rim. Some of the iterations of the open circle are almost oval, which is reminiscent of the teardrop element seen on Vessel 2 below. There is no rim/lip elaboration. No burned encrustations are evident on the surfaces.

\section{Vessel 2}

Vessel 2 is a nearly complete Ripley Engraved bottle with bell-shaped body, slightly everted rim, rounded lip, and flat base (Figure $\mathrm{K} .2$ ). It is $13.5 \mathrm{~cm}$ tall with a neck height of $6.6 \mathrm{~cm}$. The orifice, neck, body, and base diameters are $3.4,4.2,8.0$, and $6.9 \mathrm{~cm}$. Wall thickness at the rim is $0.40 \mathrm{~cm}$. Its volume is 150 $\mathrm{ml}$. The vessel has bone temper and a burnished, light brown exterior. Both the interior and the core are gray. The engraved decoration, which retains red pigment, consists of a medallion motif repeated four times around the body. Each medallion encloses an open teardrop as the primary element. This is called an open teardrop because it has a hatched or negative teardrop at its center. The medallions and teardrop elements alternate the direction of their pointed ends, extending from two horizontal lines at the neck or a single horizontal line at the base of the bottle. Secondary elements filling the spaces between the medallions include hatching and a sinuous element resembling the SZ element. The use of a teardrop as a primary element on a Ripley Engraved bottle is not common. There is no rim/lip elaboration. No burned encrustations are evident on the exterior.

\section{Vessel 3}

Vessel 3 is a complete Pease Brushed-Incised jar with an everted rim with four peaks, rounded lip, and flat base (Figure K.3). It is $15.0 \mathrm{~cm}$ tall with a rim height of $3.6 \mathrm{~cm}$. Orifice, neck, body, and base diameters are 11.5, 10.6, 11.8, and $6.4 \mathrm{~cm}$. Wall thickness at the rim is $0.55 \mathrm{~cm}$. Its volume is $900 \mathrm{ml}$. The vessel has grog and bone temper. The exterior is burnished, and the interior is smoothed; both surfaces are light brown, and the core color is unknown. Both the body and rim are decorated. The body has panels demarcated by four sets of three vertical lines, which are offset between the rim peaks. The four body panels contain diagonal incising; this is interpreted as incising rather than brushing because it is widely spaced and appears to have been done with a single-tipped tool. The rim has panels also marked by four sets of three vertical lines, but positioned below the rim peaks. These panels contain three evenly spaced horizontal rows of stick punctations below the lip, in the middle of the rim, and at the neck. Slight burned encrustations are evident on the exterior of the rim.

\section{Vessel 4}

Vessel 4 is a complete Belcher Ridged jar with a short everted rim, rounded lip, and flat base (Figure K.4). It is $14.0 \mathrm{~cm}$ tall with a rim height of just $1.3 \mathrm{~cm}$. Orifice, neck, body, and base diameters are 10.6, 10.0, 12.5, and $7.8 \mathrm{~cm}$. Wall thickness at the rim is $0.44 \mathrm{~cm}$. Its volume is 900 $\mathrm{ml}$. The jar has bone temper. The interior surface is smoothed. Both the interior and exterior are gray, and the core is black. The rim has fine vertical brushing that stops at a horizontal line around the neck. The body is covered with closely 

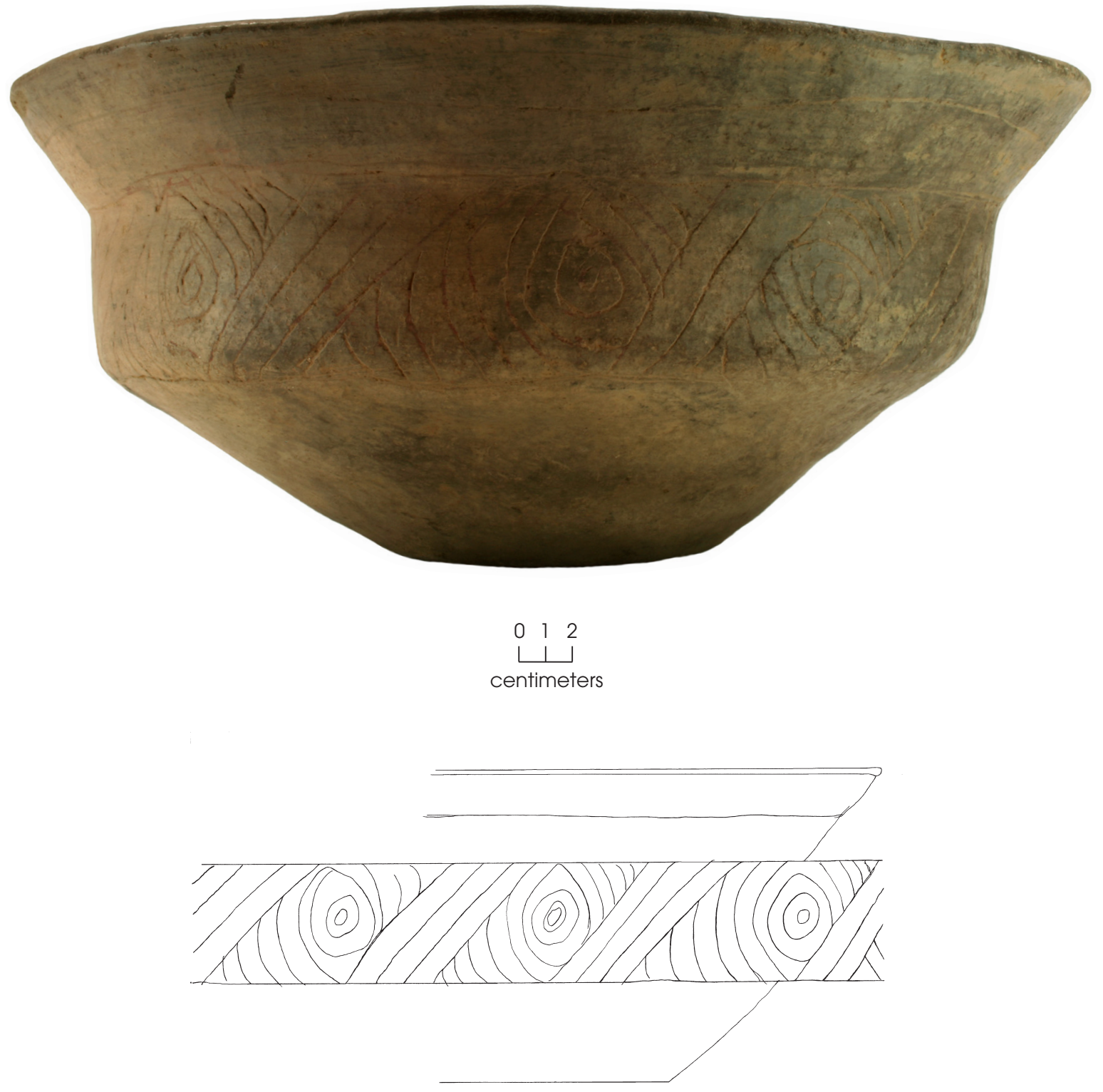

Figure K.1. Ripley Engraved compound bowl (Vessel 1) from 41TT18.

spaced vertical ridges that appear to have fine vertical brushing between them. The ridges extend from the neck to the base. There is no rim/ lip elaboration. Minimal burned encrustations are evident on the exterior.

\section{Vessel 5}

Vessel 5 is an untyped, deep simple bowl, about 95 percent complete, with an everted rim, flat lip, and flat base (Figure K.5). One side has been damaged, perhaps because a pick or some other square tool went through the bowl during excavation. It is $14.5 \mathrm{~cm}$ tall, with an orifice diameter of $17.7 \mathrm{~cm}$ and a base diameter of $9.6 \mathrm{~cm}$. Wall thickness at the rim is $0.44 \mathrm{~cm}$. Its volume is $1,850 \mathrm{ml}$. The vessel has grog temper. The exterior and interior surfaces are smoothed; the exterior is light brown, while the interior and core are black. It is undecorated and has no 

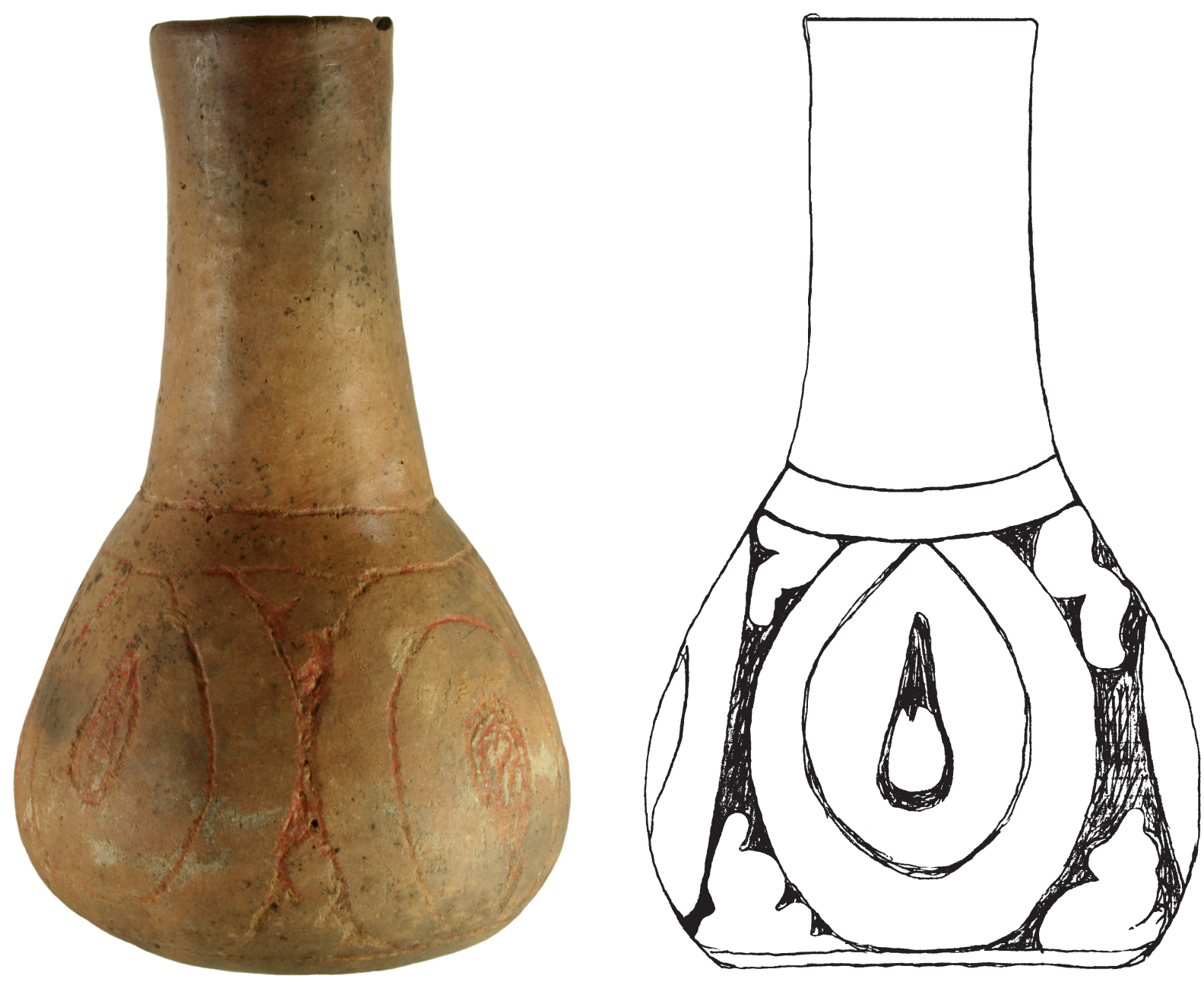

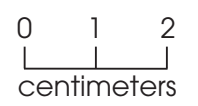

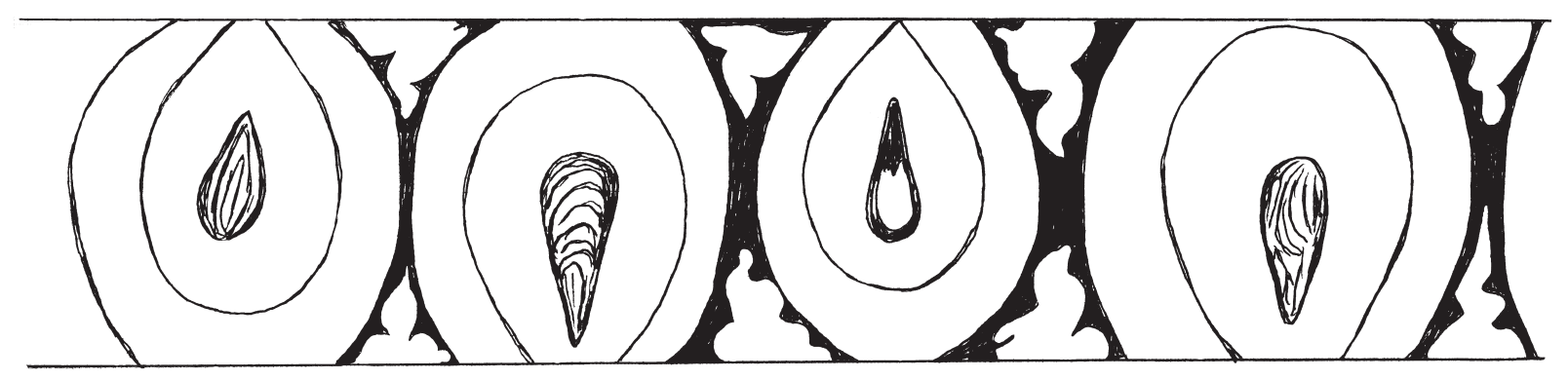

Figure K.2. Ripley Engraved bottle (Vessel 2) from 41TT18. 


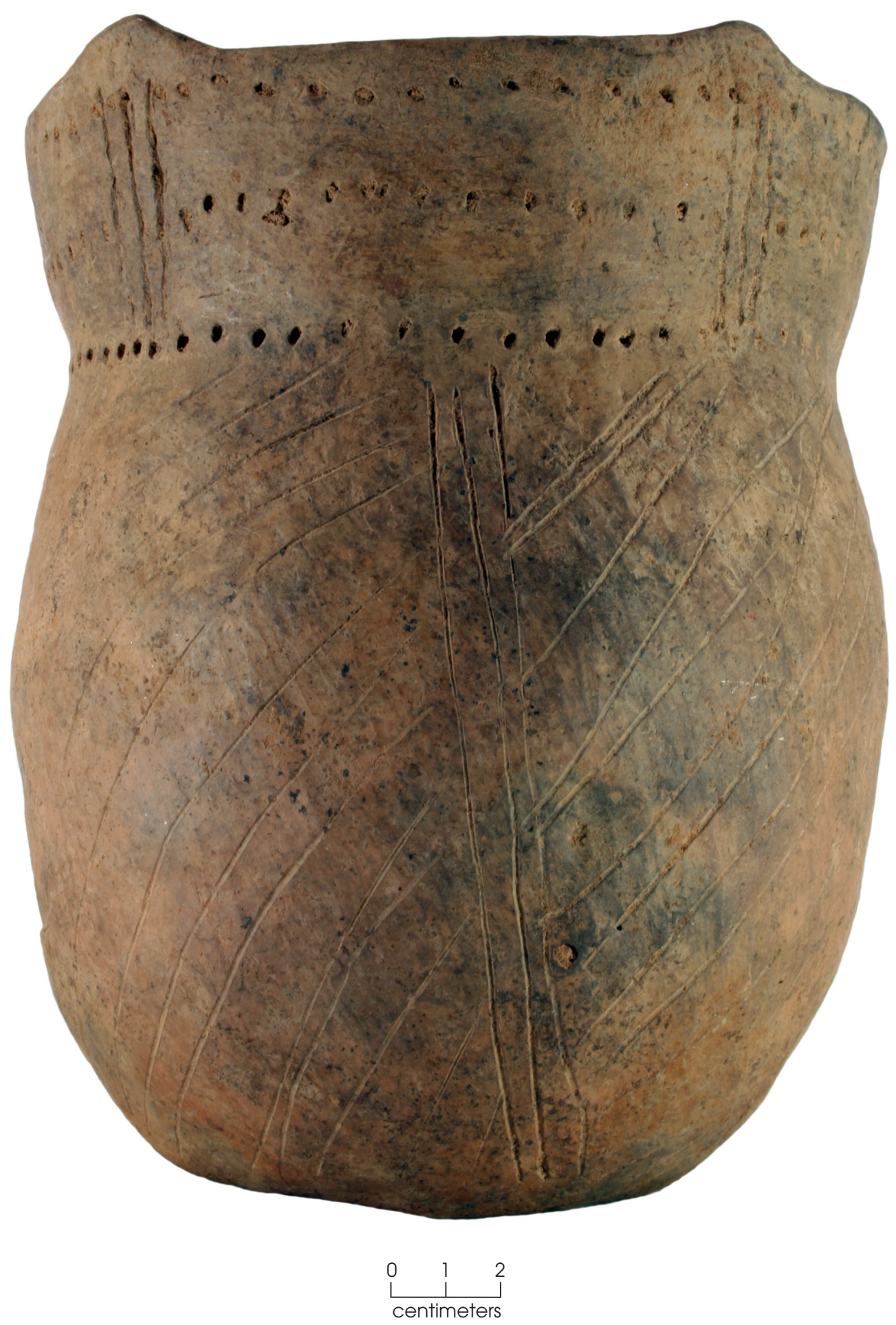

Figure K.3. Pease Brushed-Incised jar (Vessel 3) from 41TT18. 


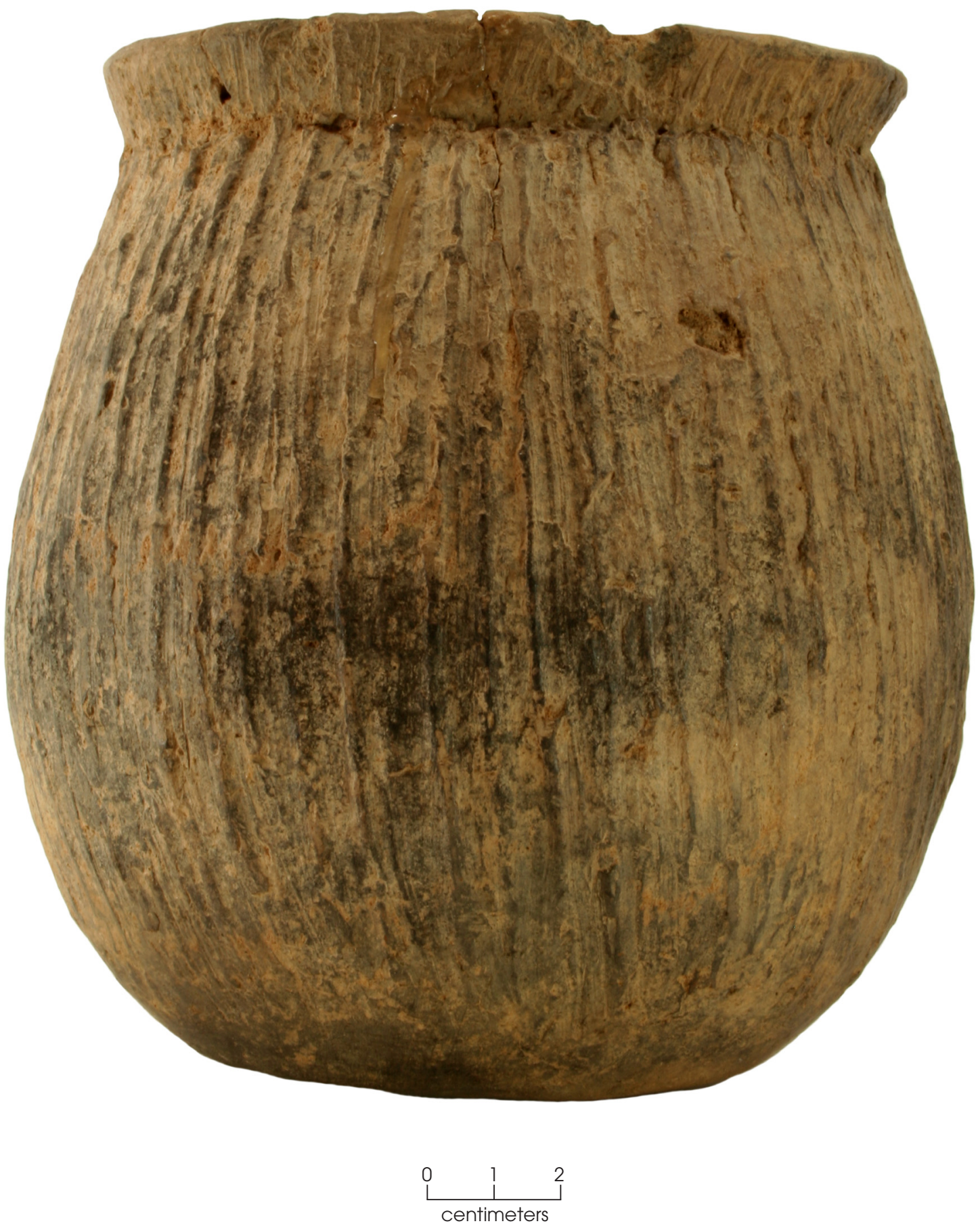

Figure K.4. Belcher Ridged jar (Vessel 4) from 41TT18. 


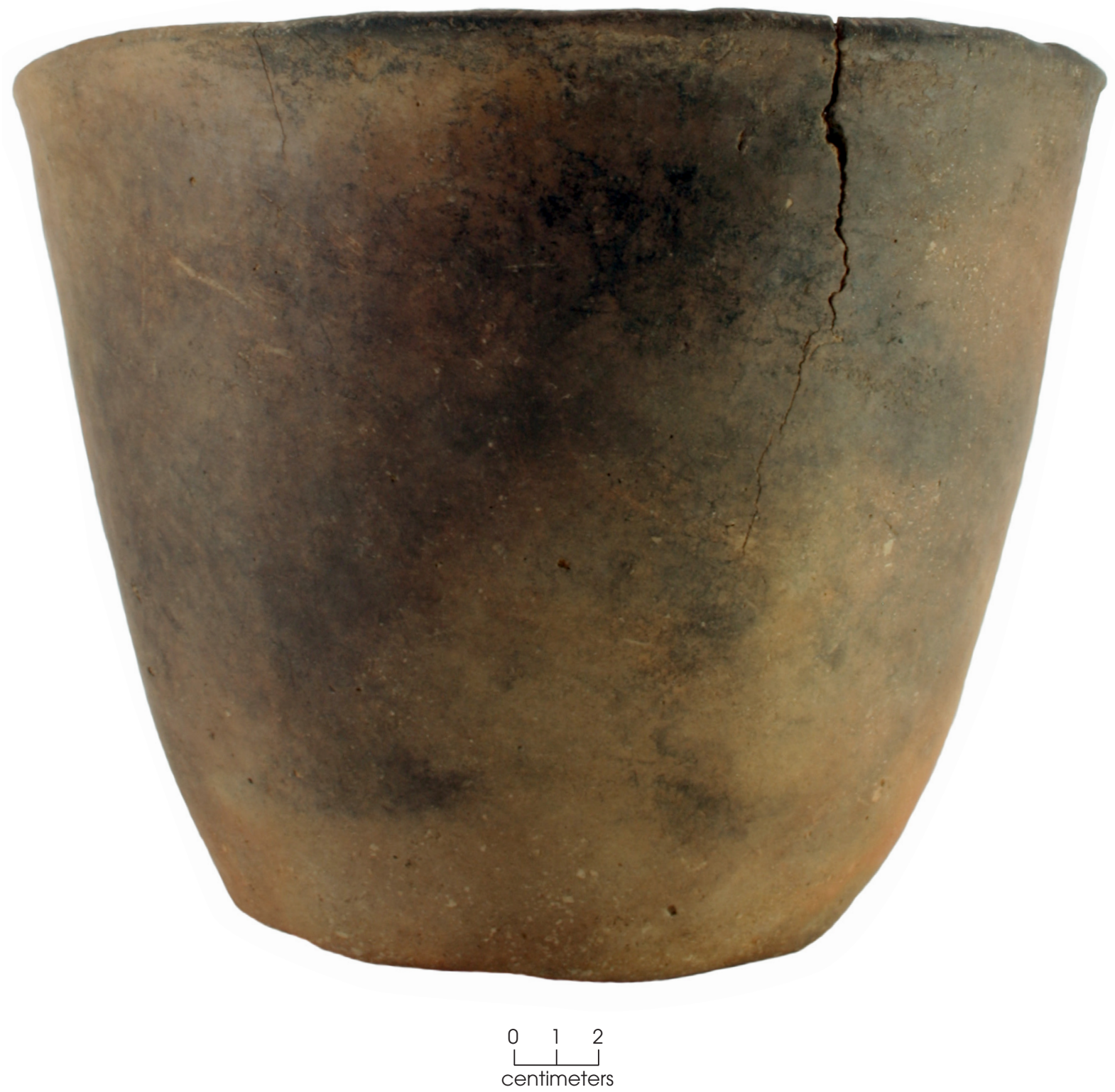

Figure K.5. Untyped simple bowl (Vessel 5) from 41TT18.

rim/lip elaboration. No burned encrustations are evident on the surfaces.

\section{Vessel 6}

Vessel 6 is an untyped simple bowl, about 99 percent complete, with a straight rim, tapered lip, and flat base (Figure K.6). The rim is thickened, such that there is a slight ridge where the rim transitions to the body wall. The lip of the vessel has a fine scalloped edge. The bowl is $9.8 \mathrm{~cm}$ tall with a rim height of $1.3 \mathrm{~cm}$. Orifice diameter is $15.0 \mathrm{~cm}$, and base diameter is $7.6 \mathrm{~cm}$. Wall thickness at the rim is $0.57 \mathrm{~cm}$. Its volume is $850 \mathrm{ml}$. It has bone temper and voids that probably represent leached bone. The exterior and interior surfaces have a red slip. The core is black. Other than the slip, the vessel is not decorated. No burned encrustations are evident. 


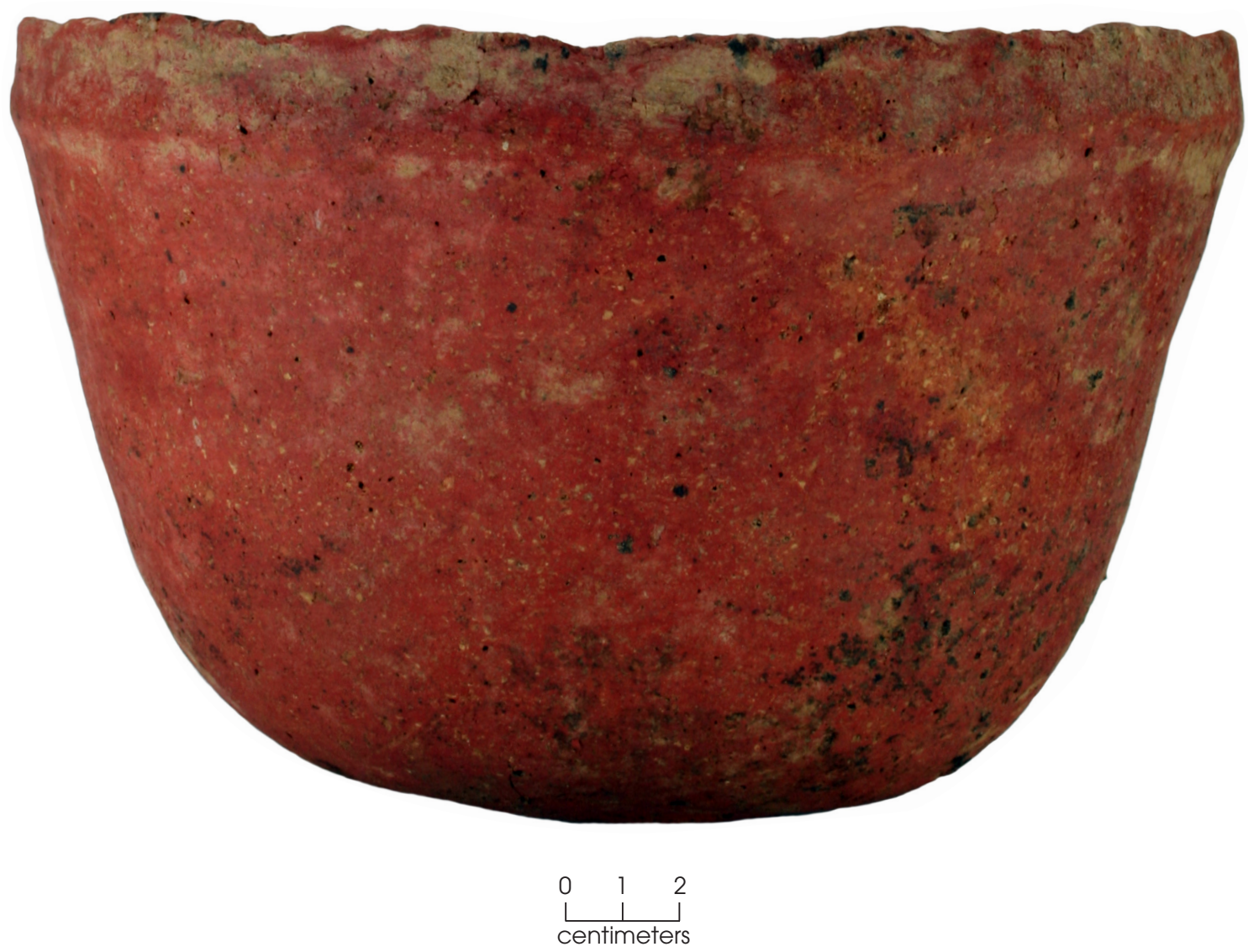

Figure K.6. Untyped red-slipped simple bowl (Vessel 6) from 41TT18.

\section{Vessel 7}

Vessel 7 is an untyped jar, about 99 percent complete, with everted rim, rolled lip, and flat base (Figure K.7). It is called a jar because of a constriction that could be considered a neck; however, the vessel form approaches a deep bowl or even a beaker. It is $13.5 \mathrm{~cm}$ tall with a rim height of $3.7 \mathrm{~cm}$. Orifice, neck, body, and base diameters are $16.2,14.0,12.9$, and $7.5 \mathrm{~cm}$. Wall thickness at the rim is $0.66 \mathrm{~cm}$. Its volume is $1,250 \mathrm{ml}$. The jar has bone temper and voids that probably are leached bone. The dark brown exterior surface is burnished, and the black interior surface is smoothed. The core is black. The rim has horizontal brushing, while the body is undecorated. There is no rim/lip elaboration. Limited burned encrustations are evident on the exterior.

\section{Vessel 8}

Vessel 8 is a complete jar with slightly everted rim with four peaks, rounded lip, and flat base (Figure K.8). The vessel form is similar to some examples of Pease Brushed-Incised (Suhm and Jelks 1962:Plate 60). However, since this jar lacks the characteristic body panels of Pease, no type assignment is given here. It is $17.7 \mathrm{~cm}$ tall with a rim height of $8.5 \mathrm{~cm}$. Orifice, neck, body, and base diameters are 14.0, 13.5, 14.2 , and $9.2 \mathrm{~cm}$. Wall thickness at the rim is $0.55 \mathrm{~cm}$. Its volume is $1,800 \mathrm{ml}$. The vessel has grog and bone temper. The light to dark brown exterior surface is burnished, while the black interior is smoothed; core color is unknown. There are three evenly spaced horizontal rows of stick punctations just below the lip, partway 


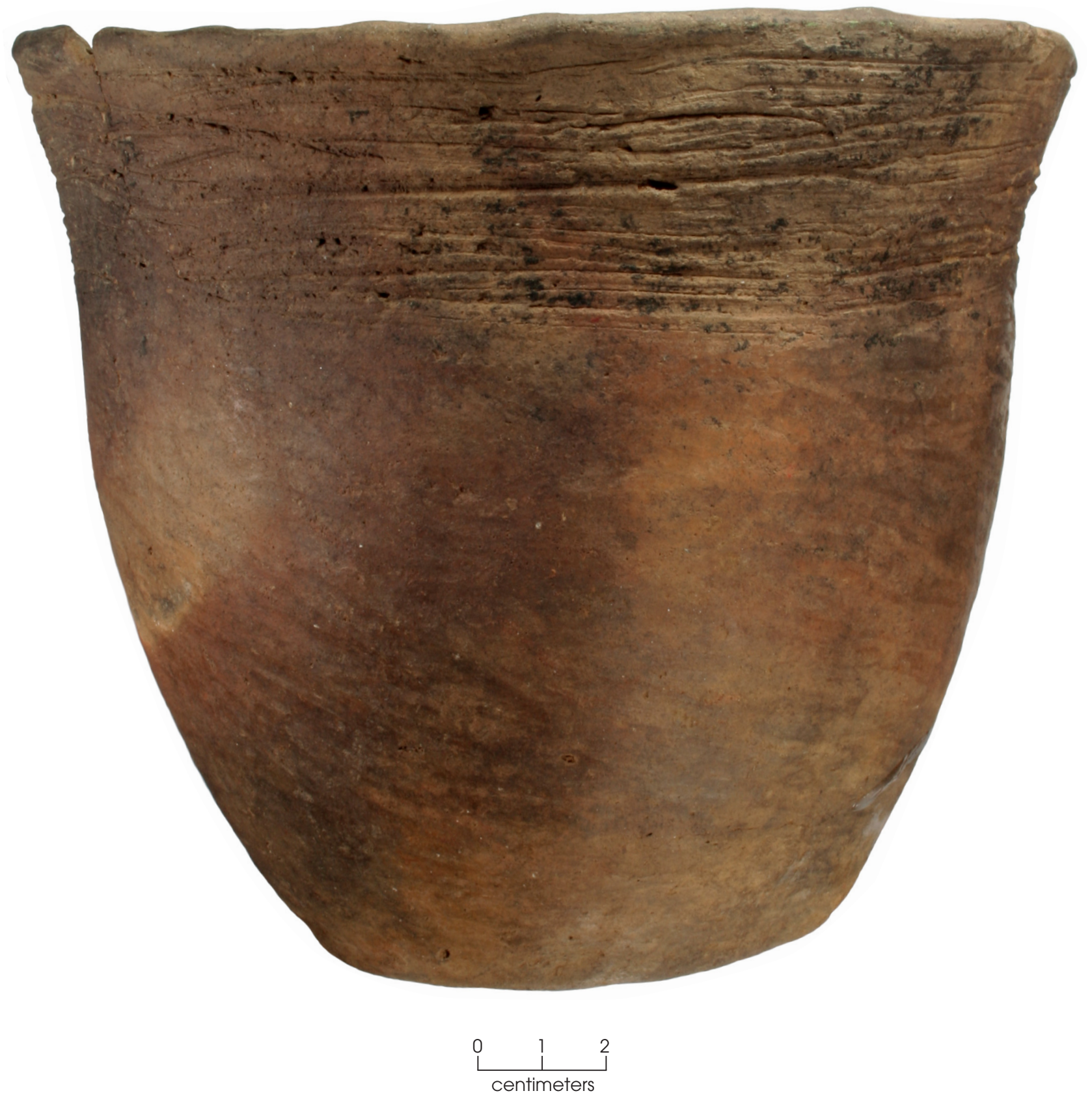

Figure K.7. Untyped brushed jar (Vessel 7) from 41TT18. 


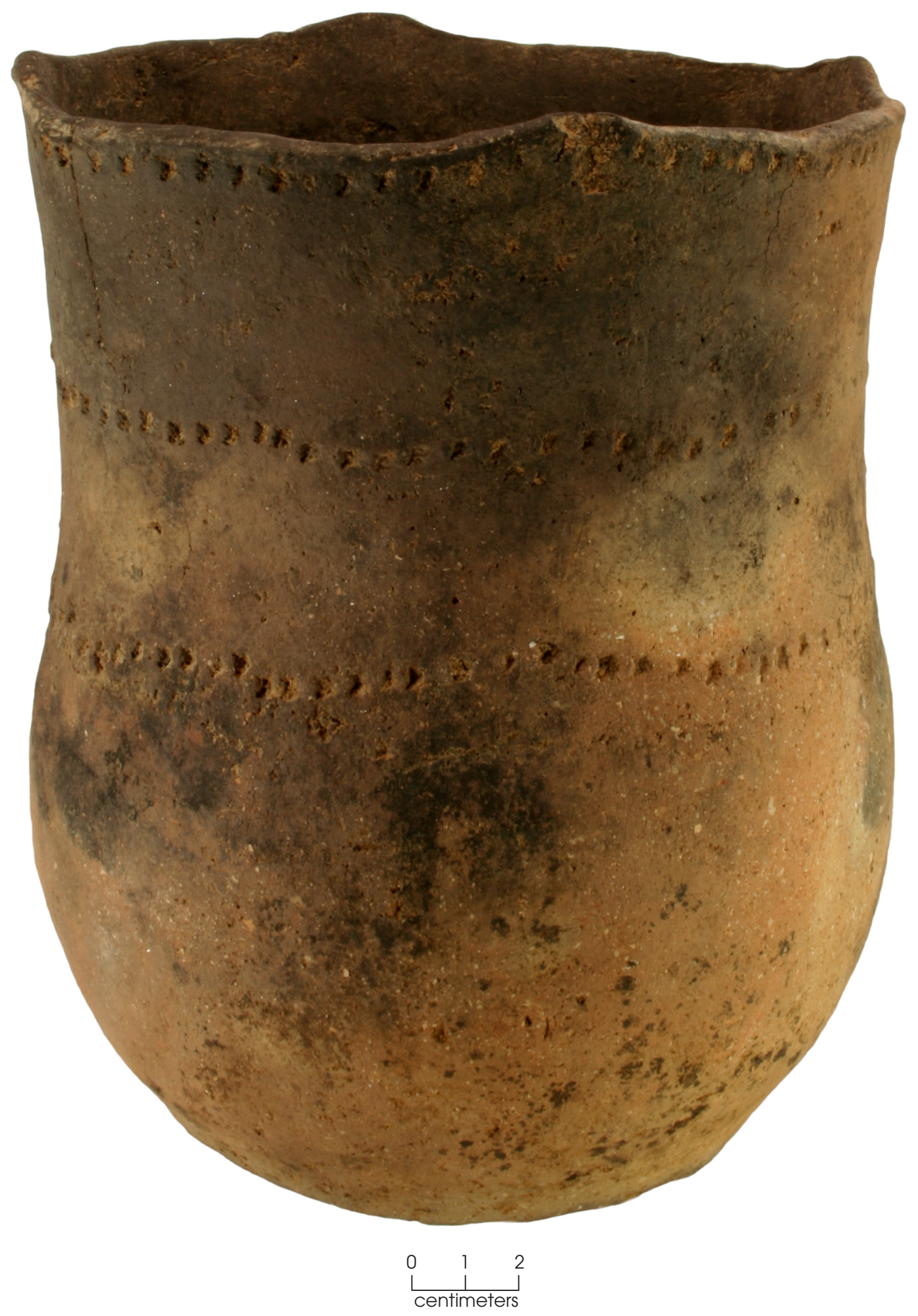

Figure K.8. Untyped punctated jar (Vessel 8) from 41TT18. 


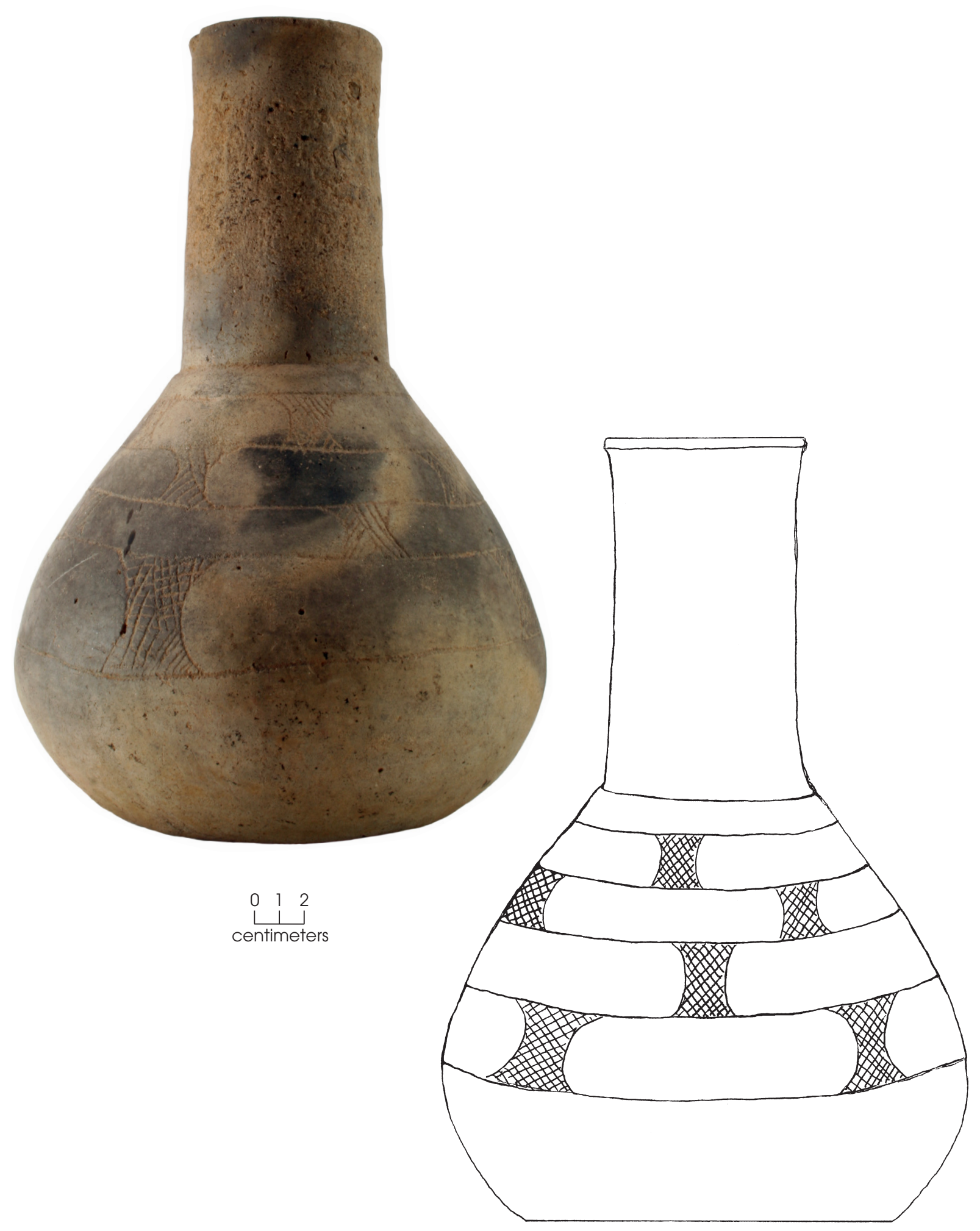

Figure K.9. Ripley Engraved bottle (Vessel 9) from 41TT18. 
down the rim, and just below the neck. The body is undecorated. Limited burned encrustations are evident on the exterior.

\section{Vessel 9}

Vessel 9 is a complete Ripley Engraved bottle with bell-shaped body, long neck, everted rim, rounded lip, and flat base (Figure K.9). It is $21.2 \mathrm{~cm}$ tall with a neck height of $9.8 \mathrm{~cm}$. The orifice, neck, body, and base diameters are 5.2, $5.6,14.2$, and $9.7 \mathrm{~cm}$. Wall thickness at the rim is $0.49 \mathrm{~cm}$. Its volume is $1,010 \mathrm{ml}$. The bottle has grog and bone temper. The light brown exterior is burnished. Interior surface treatment and color are unknown, as is core color. Engraved decoration extends from the base of the neck, which is demarcated by a single horizontal line, to the body carination. Four adjoining horizontal bands encircle the bottle within this field. Each is composed of a series of empty oblong panels with areas of crosshatching between panels, repeating four times around the vessel. The panels in adjacent bands are offset from one another. It is typed as Ripley Engraved because the overall structure of this motif is similar to that on Ripley bottles with concentric bands and pendant triangles from the Pine Tree Mound site and 41HS718 nearby (Gadus et al. 2006:82-90). There is no rim/lip elaboration. No burned encrustations are evident on the exterior.

\section{Vessel 10}

Vessel 10 is a complete simple effigy bowl with slightly inverted rim, rounded lip, and rounded base (Figure K.10). It is $7.9 \mathrm{~cm}$ tall from the base to the lip and $13.9 \mathrm{~cm}$ tall overall. The orifice, body, and base diameters are 14.2, 14.5, and $9.2 \mathrm{~cm}$. Wall thickness at the rim is $0.47 \mathrm{~cm}$. Its volume is $800 \mathrm{ml}$. It contains bone temper and has voids that probably represent leached bone. The exterior is burnished, while the interior is smoothed; both surfaces are light brown, and the core is gray. Animal effigies appliquéd to the rim and lip distinguish this bowl. One is an apparent bird head and neck with curved beak and three-lobed crest. The head faces outward from the center of the bowl. On the opposite side of the rim is a flat and rounded tail. Thus, between these two appendages, the bowl itself becomes the bird body. Three horizontal incised lines containing red pigment encircle the rim to join the bird's head and tail. The second animal effigy stands upon the tail. This animal is a quadruped with long tail, bulging eyes, and long snout. There is also a faint line of ticking along its backbone. It is impossible to tell what actual animal this quadruped represents, if any. It may be mythological, as its long tail extends down below the bird's flat tail and ends where it intersects the third incised line around the rim. This creature faces the same direction as the bird head and appears to be riding the bird's tail. No burned encrustations are evident on the bowl surfaces.

\section{Vessel 11}

Vessel 11 is a nearly complete untyped jar with everted rim containing two strap handles, rolled lip with ticking, and flat base (Figure K.11). It is $19.6 \mathrm{~cm}$ tall with a rim height of $4.3 \mathrm{~cm}$. The orifice, neck, body, and base diameters are 17.5, $15.2,17.0$, and $10.1 \mathrm{~cm}$. Wall thickness at the rim is $0.48 \mathrm{~cm}$. Its volume is $3,050 \mathrm{ml}$. The jar contains grog temper. The exterior is burnished, and the interior is smoothed; both surfaces are dark brown, as is the core. This jar has four large triangular medallions formed by sets of opposed deep incisions around the body. They extend from the neck three-quarters of the way to the base and are reminiscent of medallions on Harleton Appliqué vessels, though executed by incising rather than appliqué. The only applique on this vessel is on the two handles, each of which has three vertical lines of appliqué. The rim contains broad crosshatching formed by deep incising. No burned encrustations are evident on the surfaces.

\section{GROOVED AXE}

A grooved axe was collected from Tankersley Creek not far upstream from FM 899. It is mostly complete with large portions of the polished surface intact on the sides and around the edges of the ends, but with large fractured areas on both ends (Figure K.12a). The axe is of hematite and is well polished. The distal end may have had additional polish after the fractures removed parts of the surface, but this polish is less extensive. The existing original polished surface shows striations and some crazing. The axe measures $11.6 \mathrm{~cm}$ long, $7.7 \mathrm{~cm}$ wide, and $5.9 \mathrm{~cm}$ thick, and it weighs $630.0 \mathrm{~g}$. 


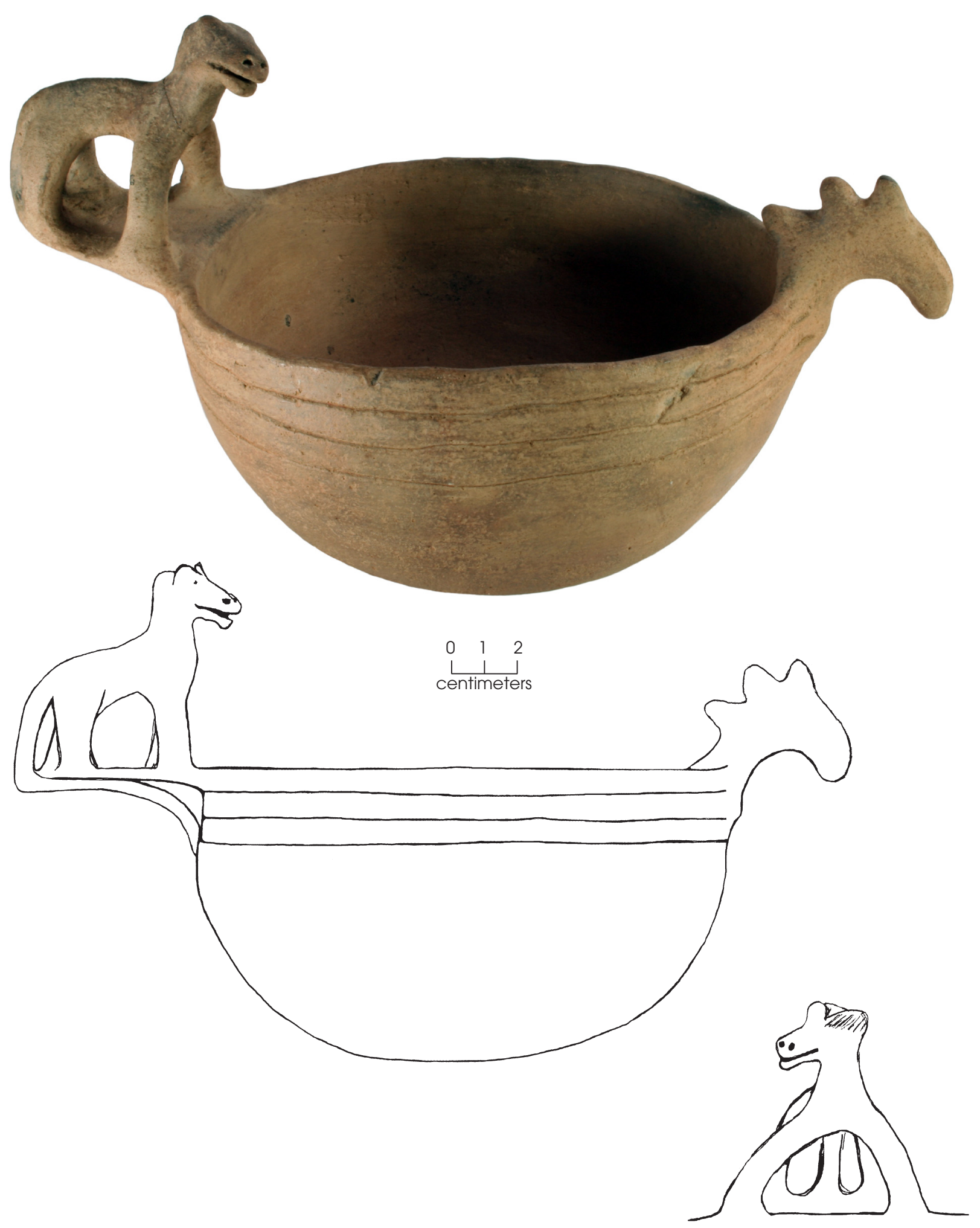

Figure K.10. Effigy bowl (Vessel 10) from 41TT18. 


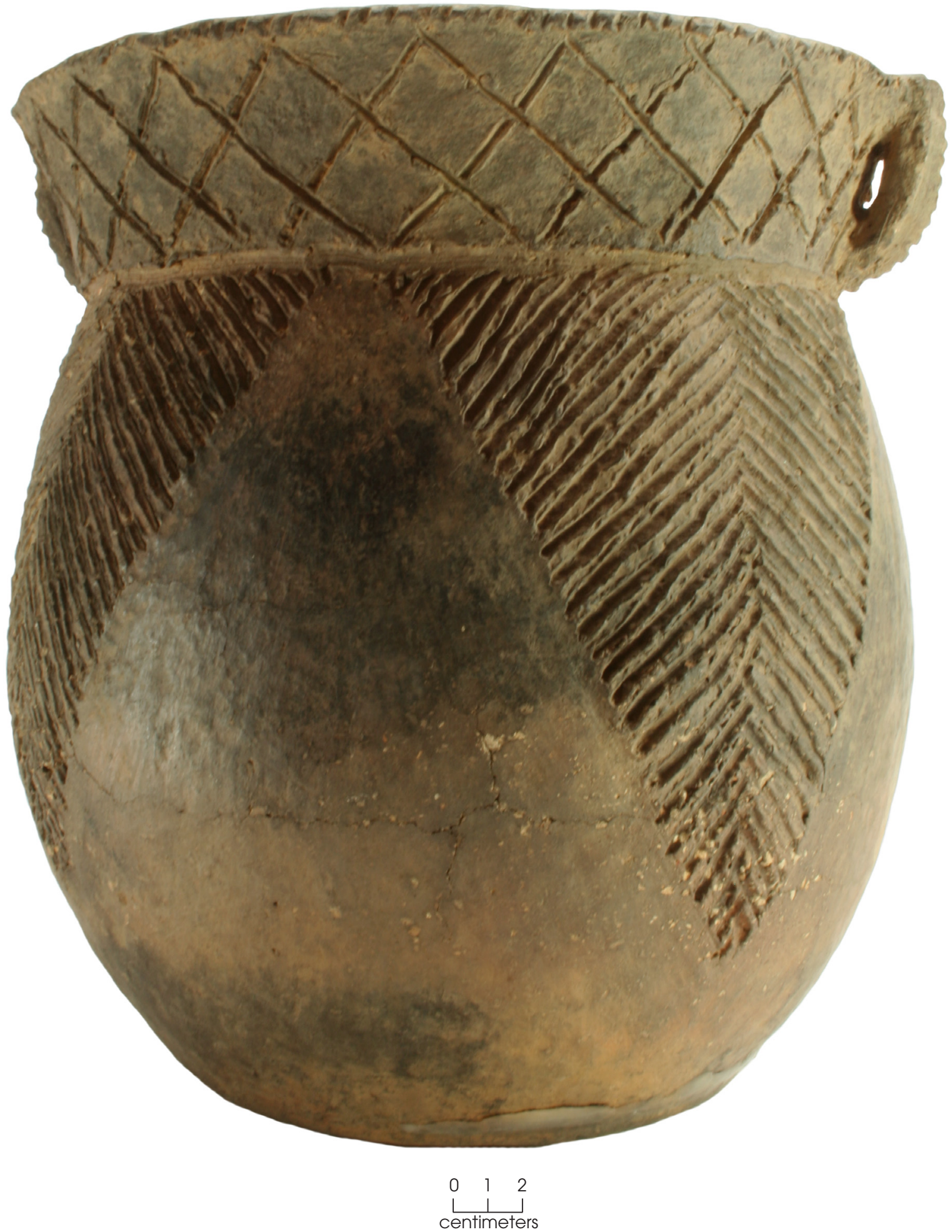

Figure K.11. Untyped incised jar (Vessel 11) from 41TT18. 


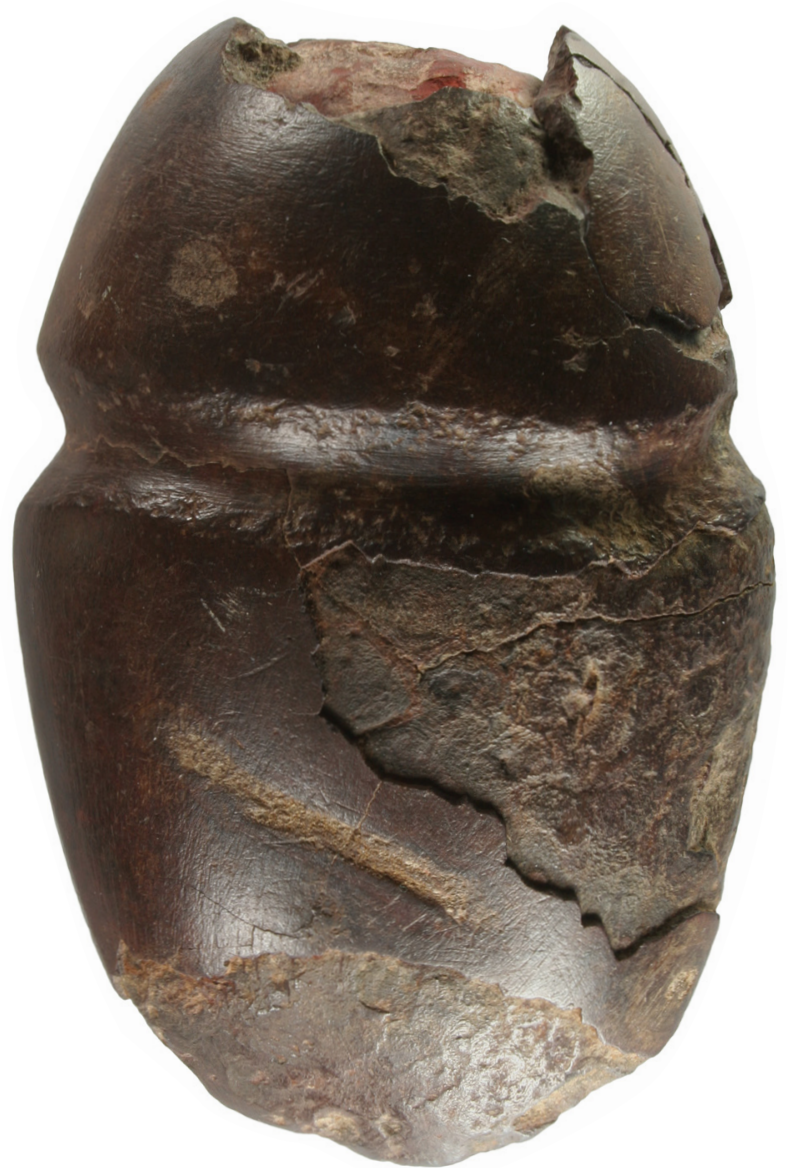

a

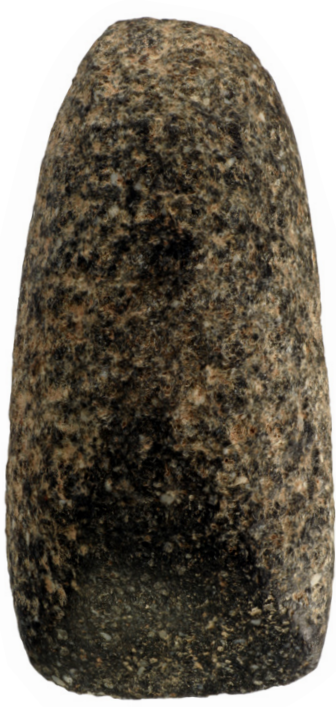

C

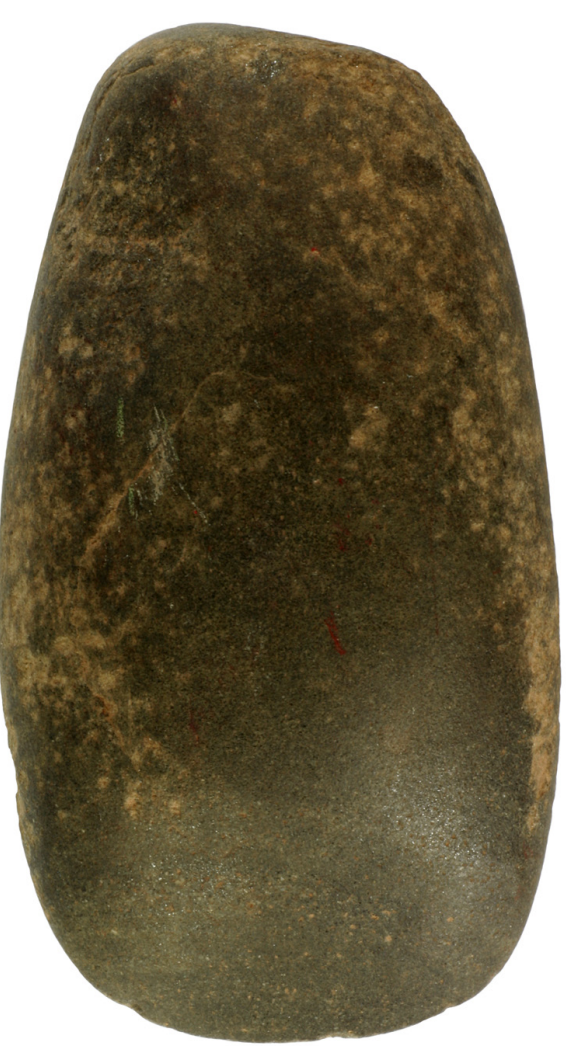

$\mathrm{b}$

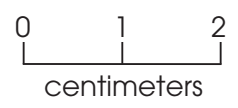

Figure K.12. A grooved axe (a) and two celts from 41TT18 (b and c) in the Anderson collection. 


\section{CELTS FROM 41TT18}

Two celts reportedly are from graves at 41TT18 (Figure K.12b-c). Both are complete and are of greenish gray andesite. They have elliptical cross sections with one beveled end that is well polished and one rounded end that has some polish and served as the hafted end. One is $10.3 \mathrm{~cm}$ long, $5.7 \mathrm{~cm}$ wide, and $3.2 \mathrm{~cm}$ thick and weighs 280.6; the other is $7.0 \mathrm{~cm}$ long, $3.4 \mathrm{~cm}$ wide, and $2.8 \mathrm{~cm}$ thick and weighs $136.3 \mathrm{~g}$.

\section{CHIPPED STONE ARTIFACTS}

The collection contains 216 chipped stone artifacts collected over the years from the Anderson property. Specific proveniences are not known. They could be from some of the known Native American sites on the property (41TT672-41TT676) or from locations not recorded as sites. According to Rick Anderson, none are from the burials at 41TT18, though.

\section{Arrow Points}

The 18 arrow points consist of 2 Alba, a possible Alba, an Alba or Friley, 2 Bassett, 2 Bonham, 3 Catahoula, 2 Friley, 2 Scallorn, a possible Scallorn, and 2 untyped. These are mostly of local materials (14 chert and 1 quartz) with only 2 of Edwards chert and 1 of nonlocal gray chert. Table K.1 lists their metric attributes.

The two Alba points are both complete, with straight bases, straight stems, and serrated blades (Figure K.13a-b). One is dark olive brown semitranslucent Edwards chert, and the other is a yellowish brown local chert. The possible Alba point is quartz, with heavy blade serration, and missing part of the base (Figure K.13c). What remains of the stem is straight. The Alba or Friley is of local red chert, has a straight stem, and is missing part of the base which otherwise appears straight (Figure K.13d). It has moderate blade serration, and the blade has been reworked to the point that it slightly recurves. The fractures at the proximal end include fractures to the shoulders, removing the barbs, as well as a corner of the base. What remains of the stem suggests this specimen is an Alba, but the slight recurved blade edges suggest is might be a Friley.
The two Bassett points are both well made and have pointed bases, contracting stems, long barbs, and serrated blades (Figure K.13e-f). One is dark yellowish brown local chert and is complete with moderate blade serration. The other is a nonlocal mottled yellowish brown with gray chert and has only slight blade serration. Neither shows retouch on their blade edges; they may have been burial inclusions, though Rick Anderson reported that no points came from 41TT18.

One of the two Bonhams is of reddish brown local chert and is missing a small portion of the base (Figure K.13g). It is well made, and the blade edges have moderate serration but no retouch. The other is complete and has a slightly irregular convex base and straight stem (Figure K.13h). It is of olive green Edwards chert and has moderate blade serration. The blade shows slight retouch.

The three Catahoula points, one complete and two proximal fragments, all have flared shoulders with squared barbs, straight stems, and straight bases. The complete one is of reddish brown local chert and has heavy blade serration and an asymmetrical blade shape from extensive retouch (Figure K.13i). One of the proximal fragments is dark brown chert, and one is of reddish brown chert, both local materials (Figure K.13j-k).

The two Friley points have expanding stems and well-defined shoulders that recurve toward the distal ends of the points (Figure K.13l-m). Both are mostly complete, with one missing a barb and the other missing the tip of the blade and part of the base. The one missing a barb has a straight to convex base, slightly expanding stem, and heavy blade serration; it is of reddish brown local chert. The other Friley, a lighter reddish brown local chert, has a straight stem and slight serration on the edges of the recurved blade.

The two Scallorns and possible Scallorn have distinct barbs, expanding stems, and straight to convex bases. One, of dark reddish brown local chert, is complete with a moderately serrated recurved blade (Figure K.13n). The other is a light reddish and yellowish brown local chert that is missing its barbs and has heavy blade serration (Figure K.13o). The possible Scallorn is missing the tip of the blade and has a straight base, an expanding stem, and a reworked irregularly recurved blade (Figure 


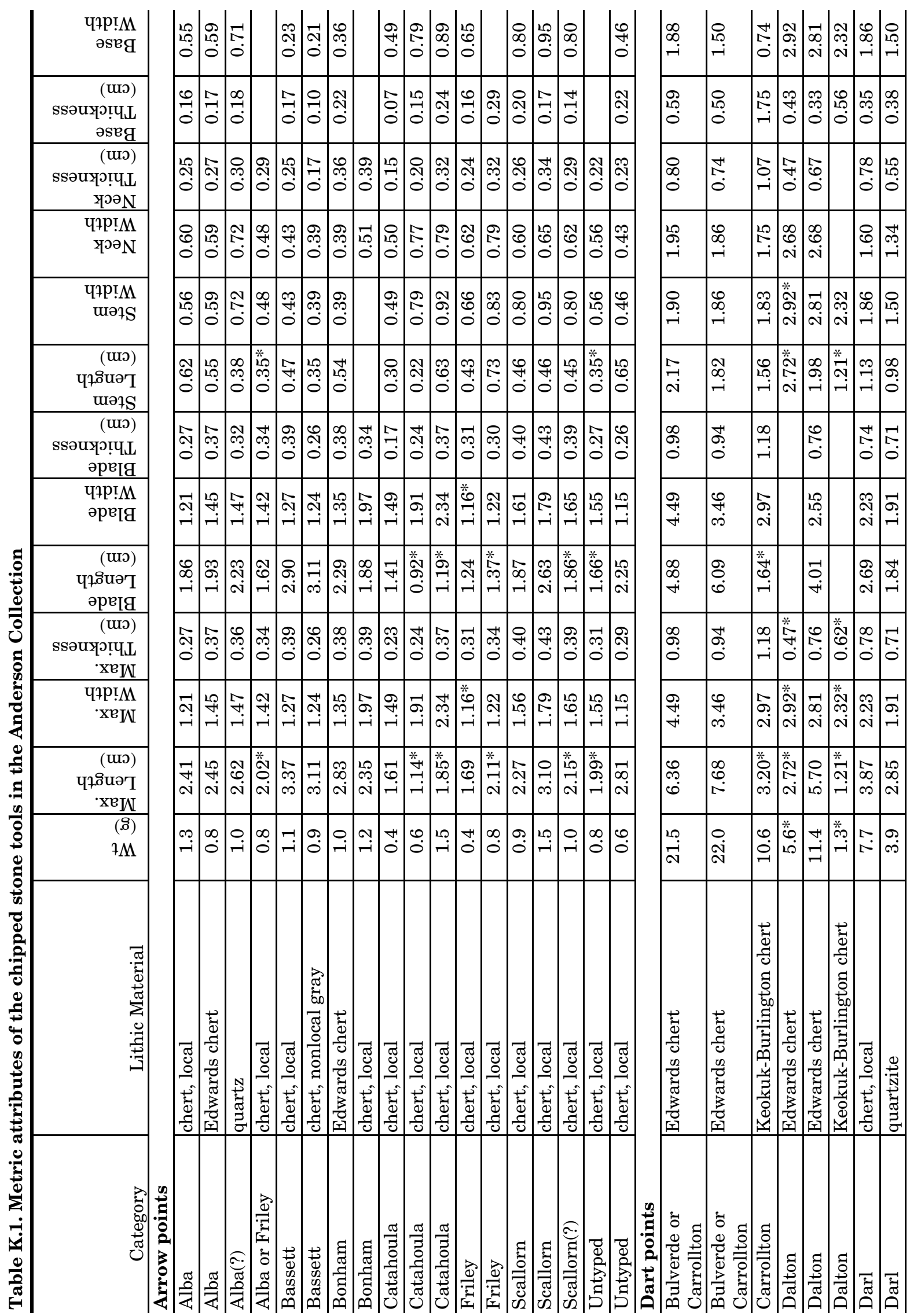




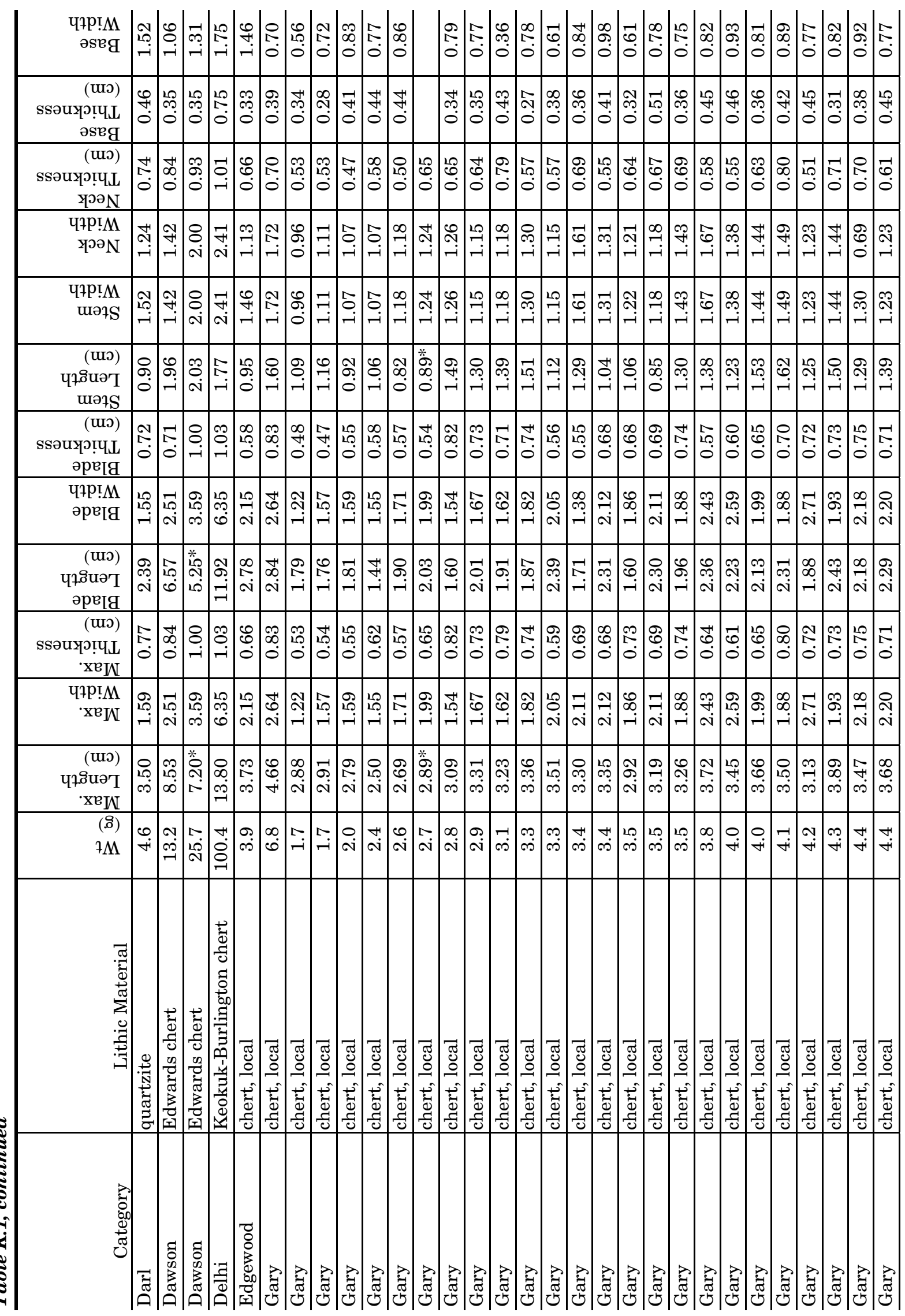


чาр!M $\mid$ ว

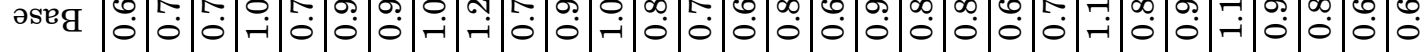

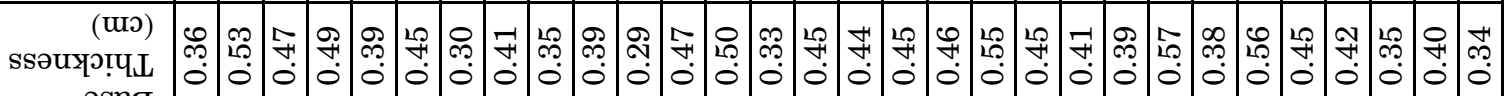

(ய2)

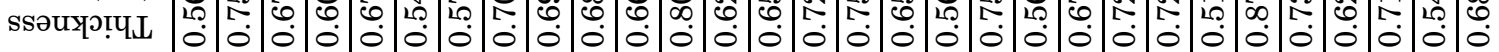
уәә

Чтр!M

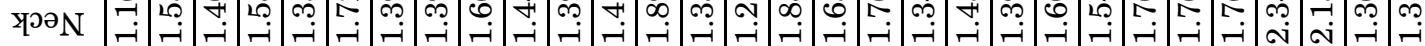

Ч位M

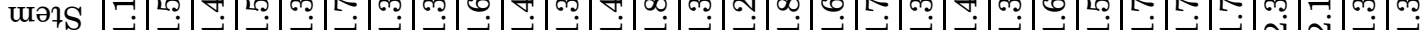

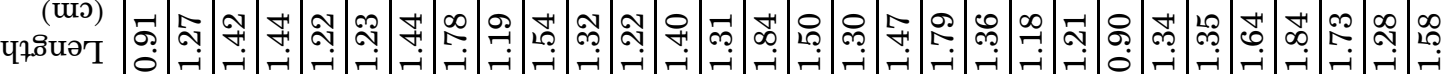
шәнТ

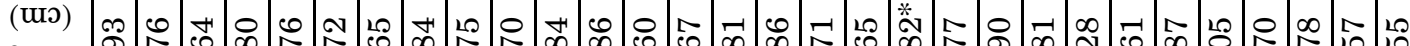

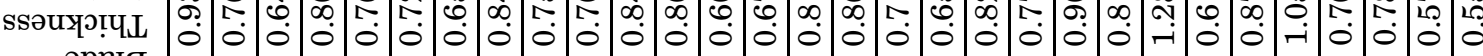
әретя

чтр!M әрв Iq

(ய0) ஜ ЧұВินәТ

(ய0)

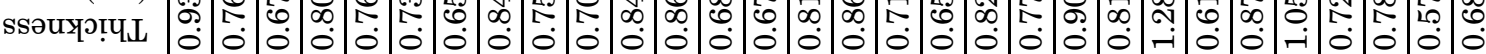
xejN

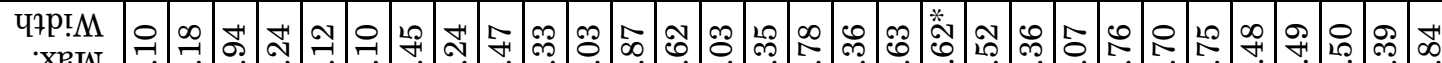

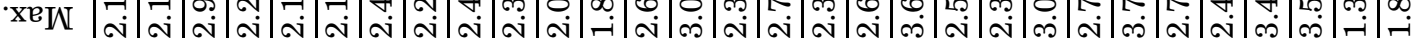

(ய0)

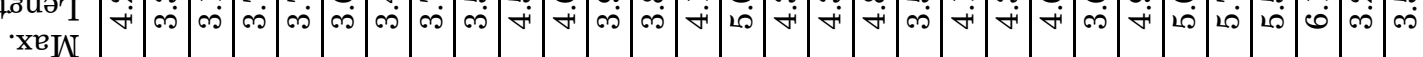

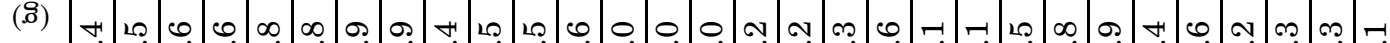

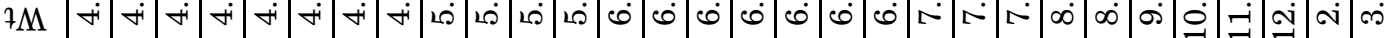

尝

淙 t

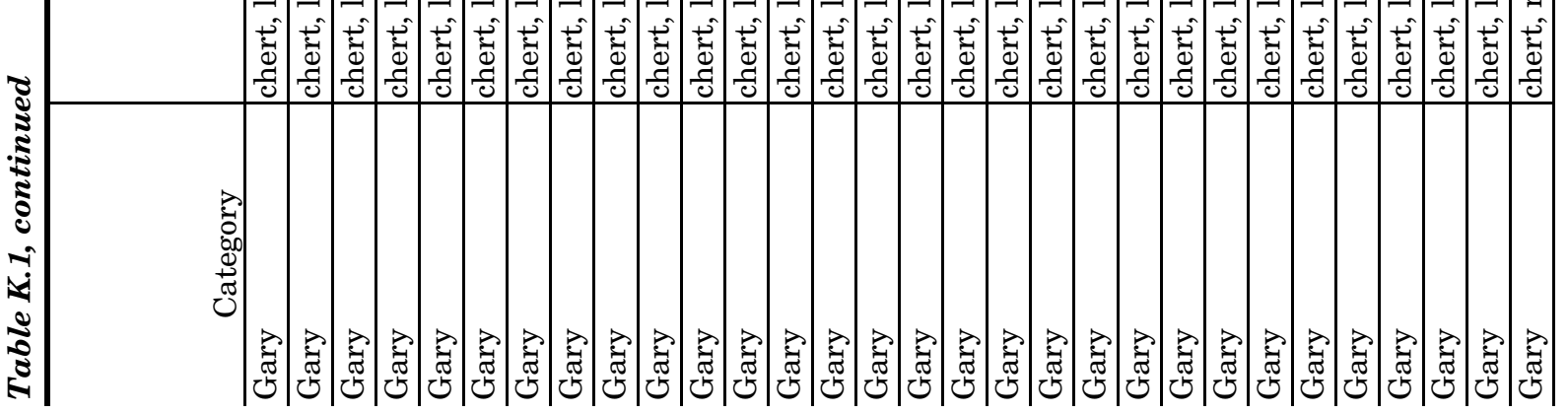




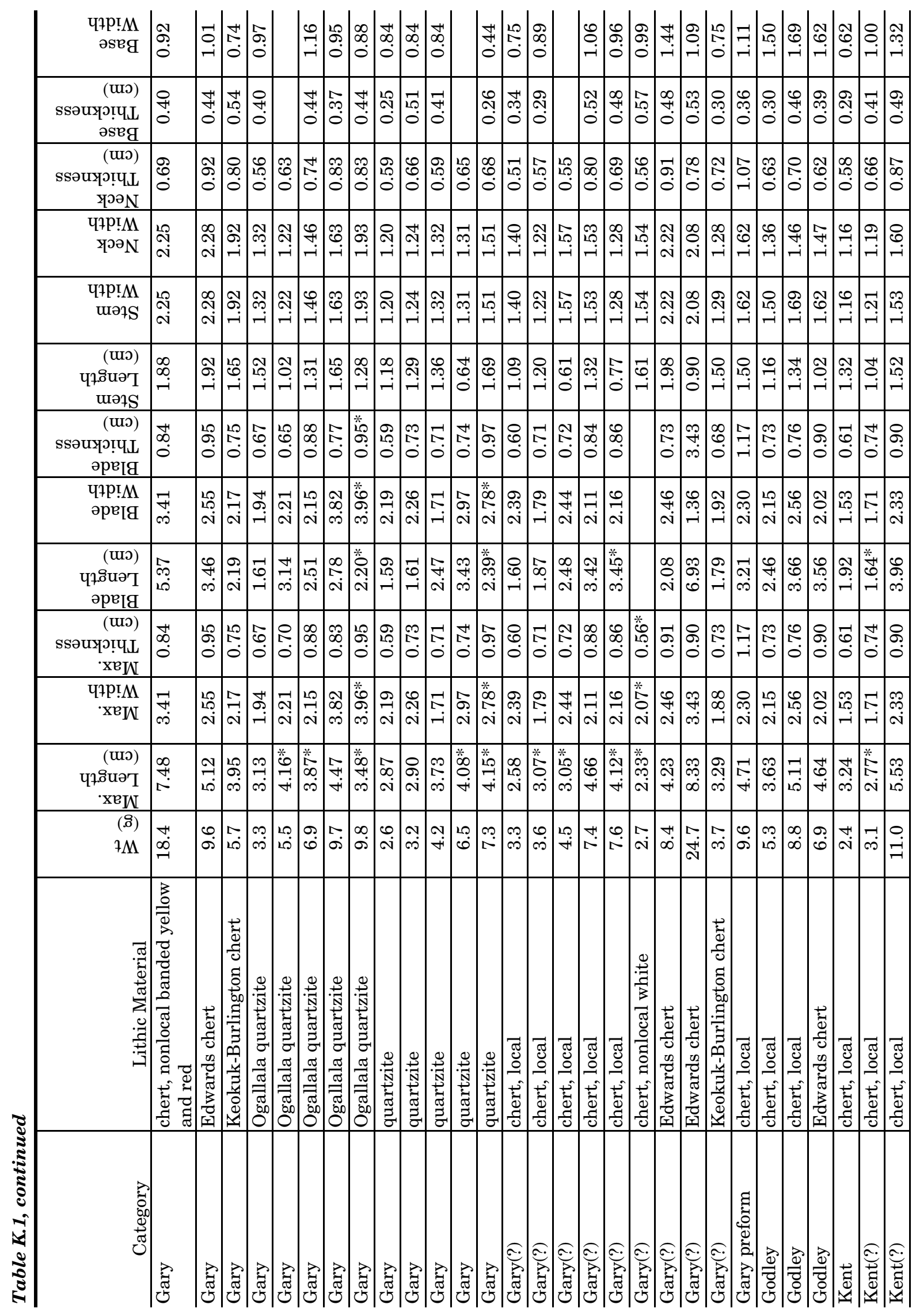




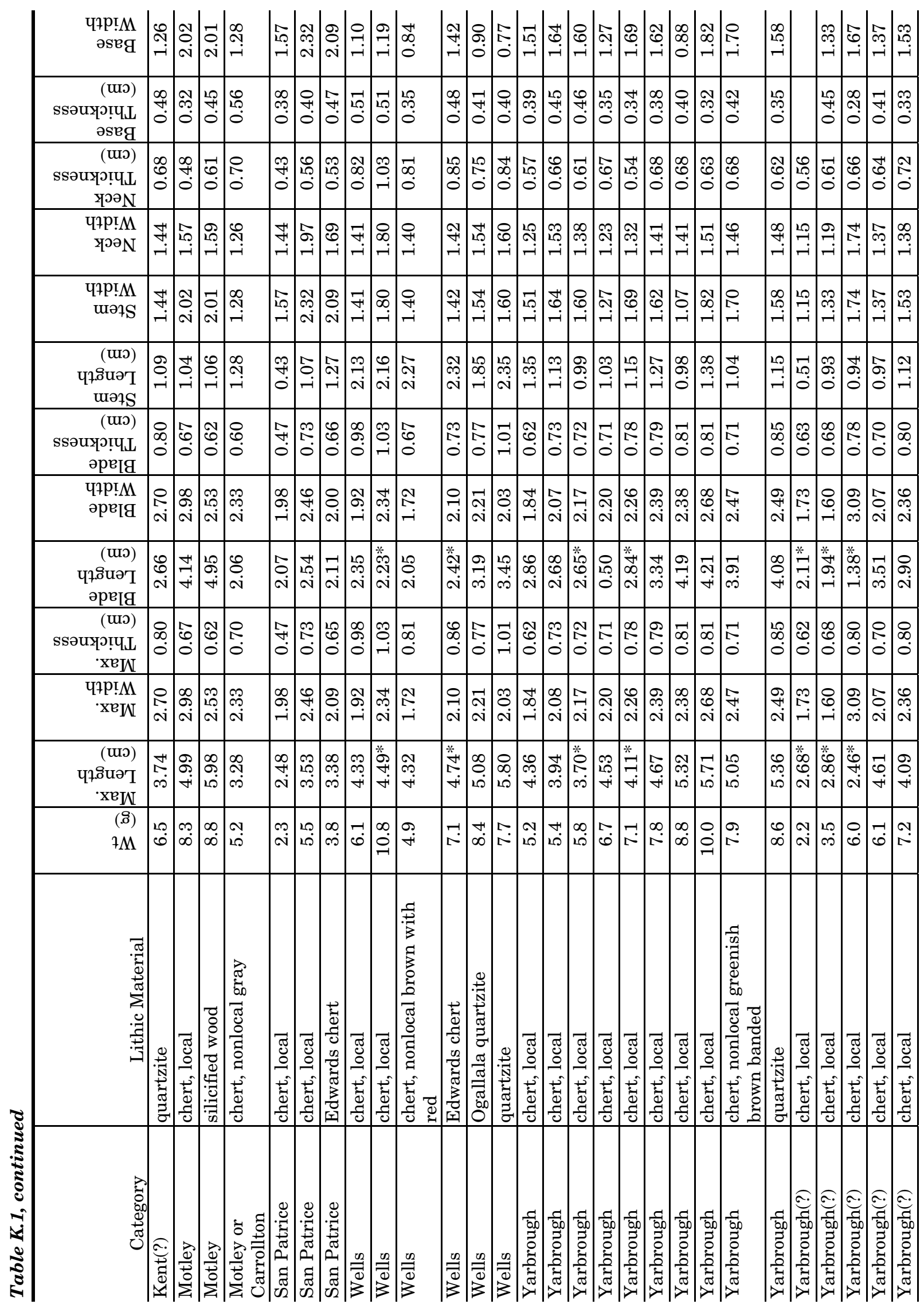




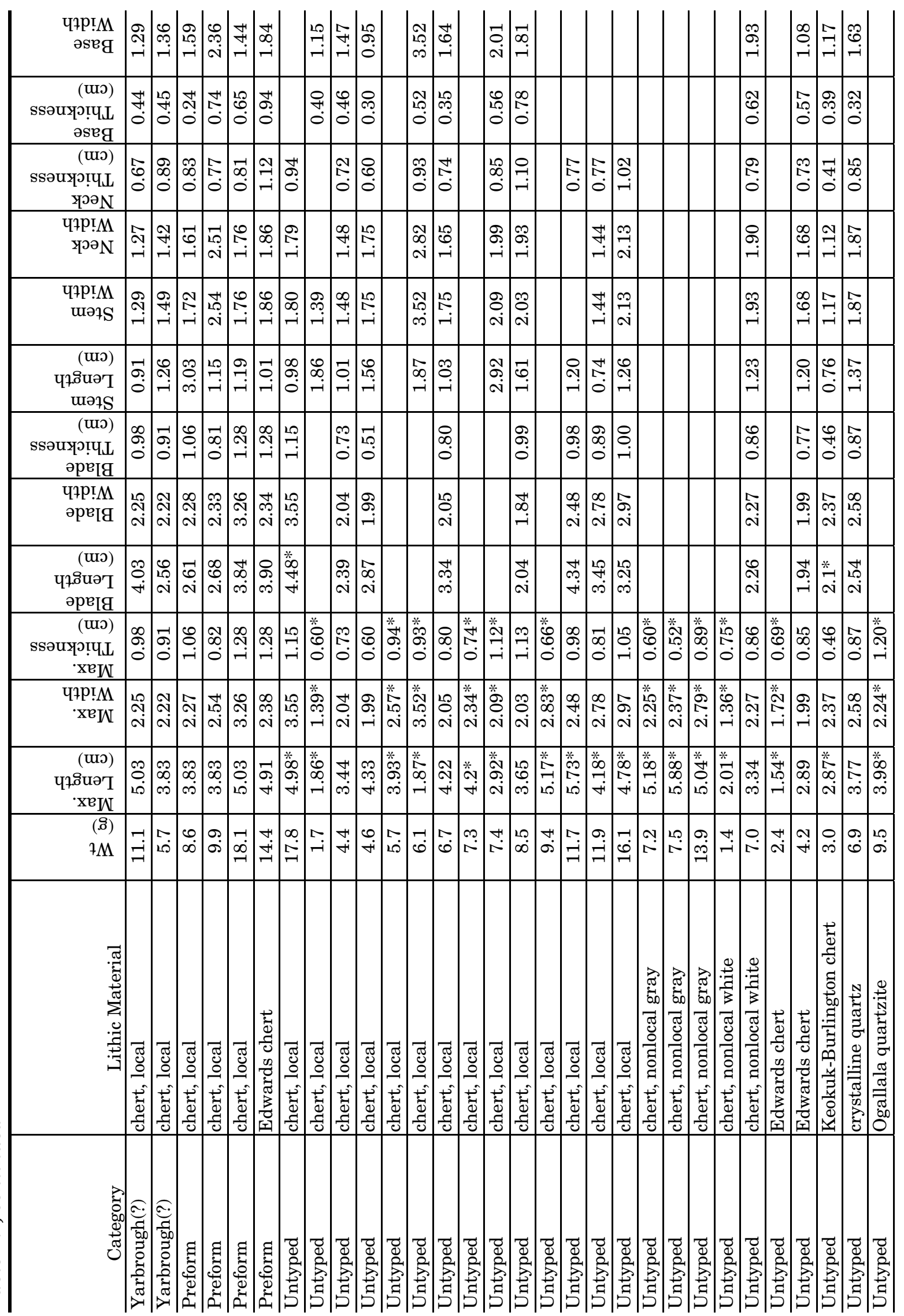




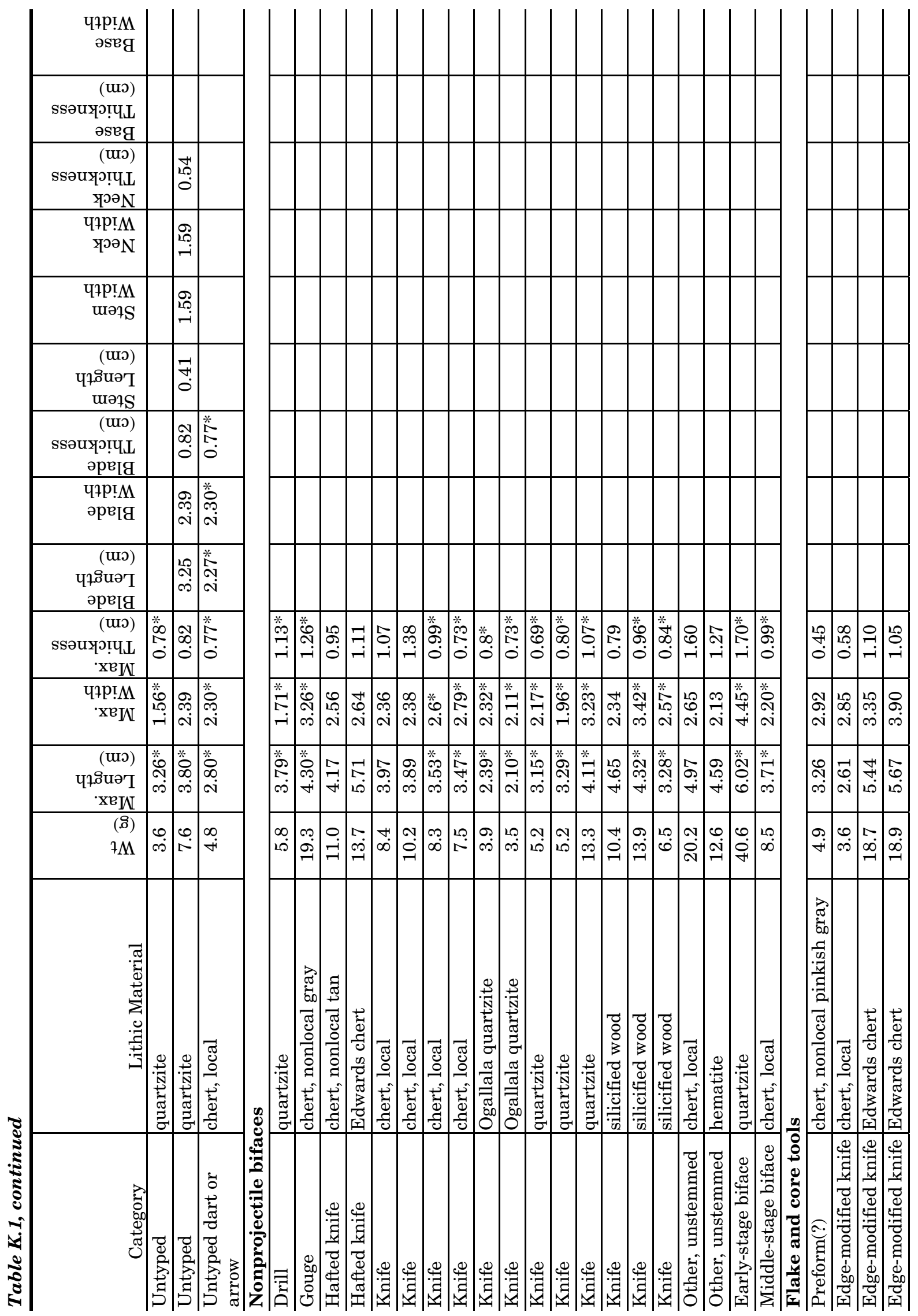




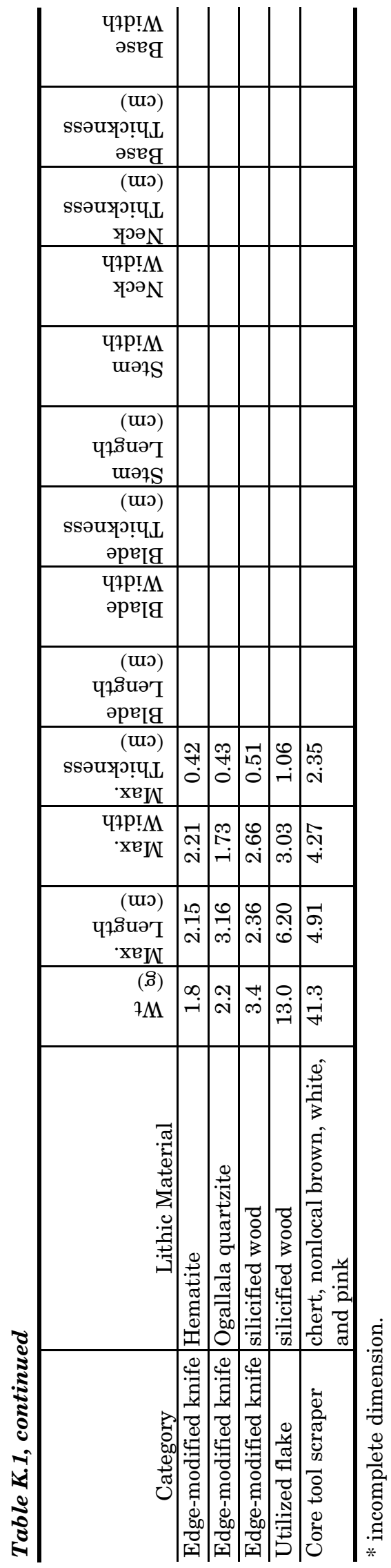




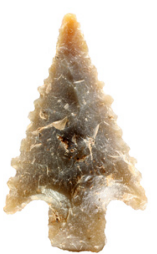

a

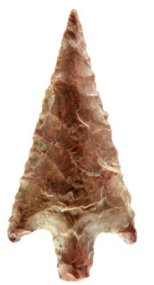

g

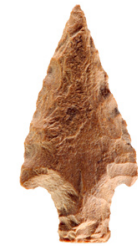

$\mathrm{b}$

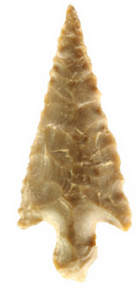

$\mathrm{h}$

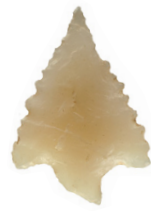

C
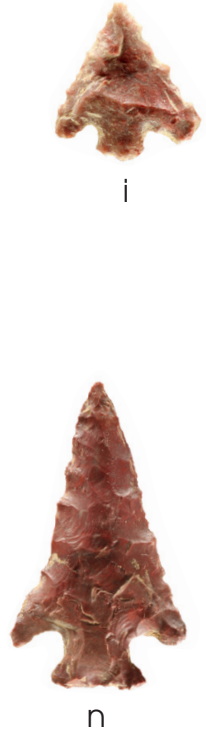
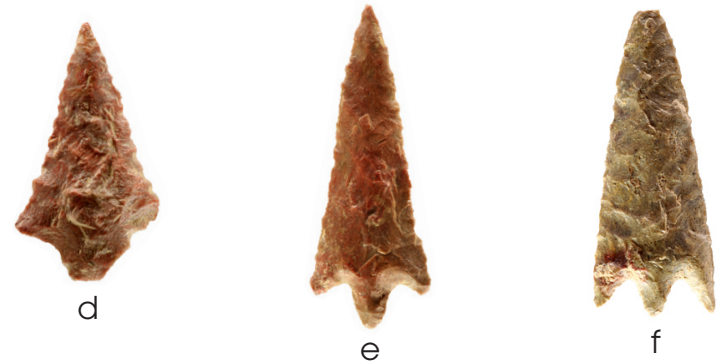

f
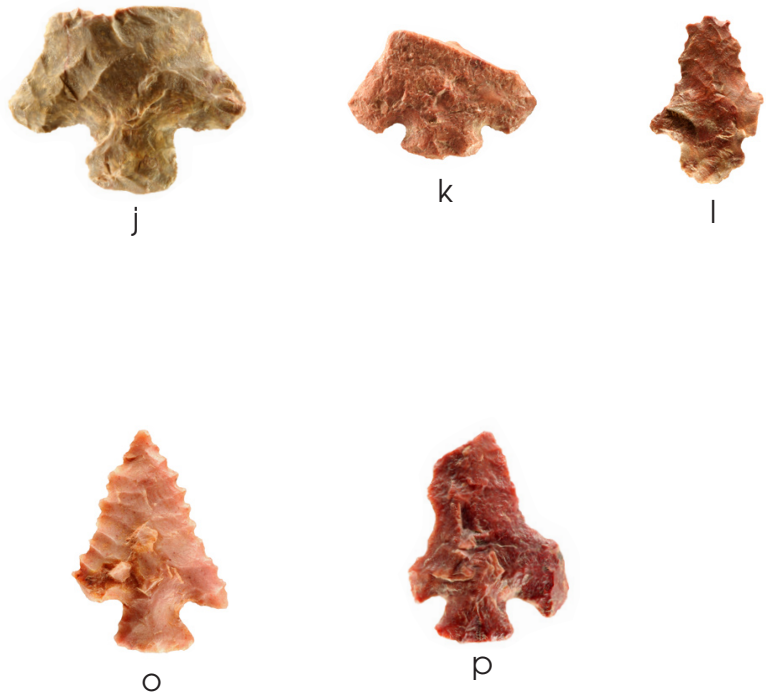

$\mathrm{P}$

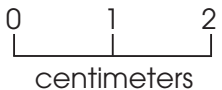

Figure K.13. Arrow points in the Anderson collection. (a-b) Alba; (c) possible Alba; (d) Alba or Friley; (e-f) Bassett; (g-h) Bonham; (i-k) Catahoula; (l-m) Friley; (n-o) Scallorn; (p) possible Scallorn.

K.13p). The barbs are suggestive of Catahoula points, but the stem and base are more consistent with Scallorn. It is of dark reddish brown chert.

One of the two untyped arrow points is of reddish brown local chert and is missing a portion of the blade and the entire stem. It has serration on the blade edges. The other untyped point is of reddish brown chert and is a retouched flake that retains cortex on one face and has a weakly formed stem. Part of the base is missing. This may be a preform.

\section{Dart Points}

The 158 dart points consist of 2 Bulverde or Carrollton, 1 Carrollton, 3 Dalton, 3 Darl, 2 Dawson, 1 Delhi, 1 Edgewood, 68 Gary, 9 possible Gary, 1 Gary preform, 3 Godley, 1 Kent, 3 possible Kent, 2 Motley, 1 Motley or Carrollton, 3 San Patrice, 6 Wells, 10 Yarbrough, 7 possible Yarbrough, 4 dart point preforms, 26 untyped, and 1 untypeable fragment that may be a dart or an arrow point. These are mostly of local ma- 

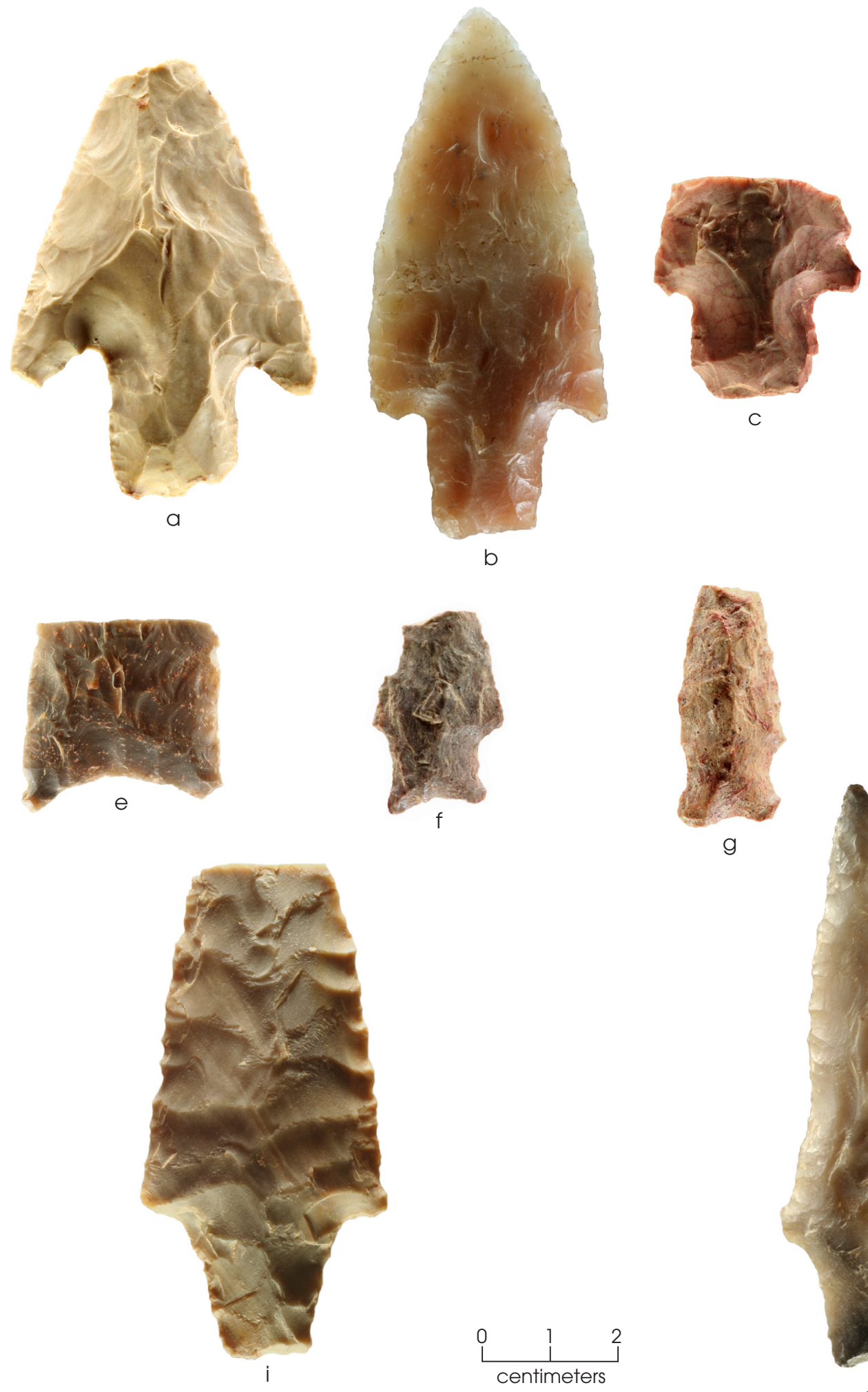
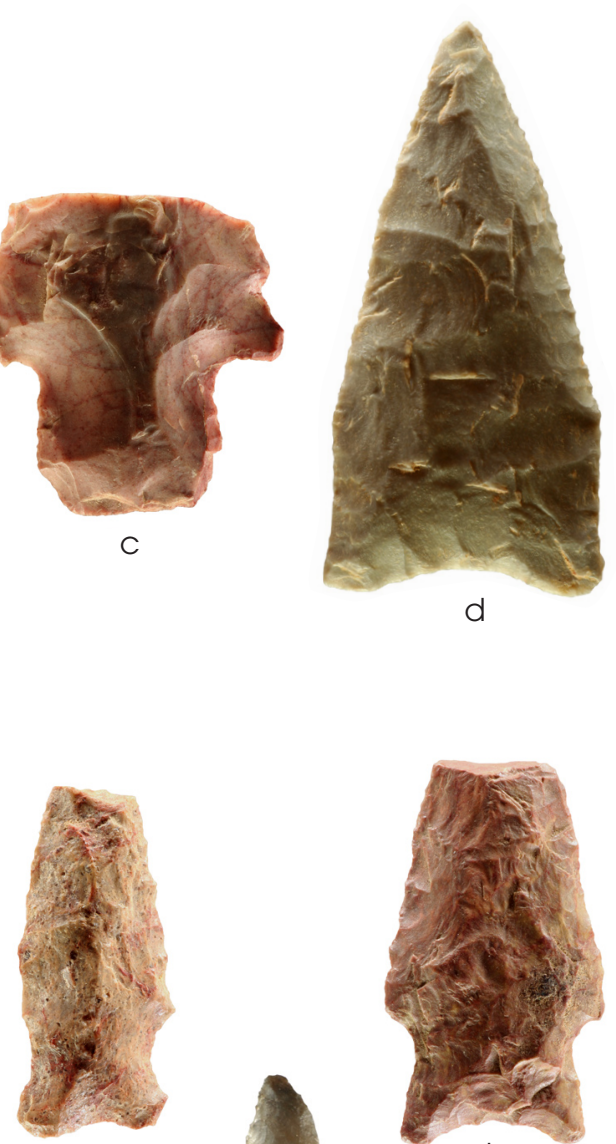

9

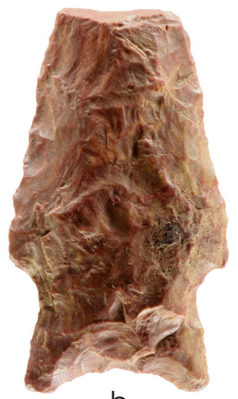

$\mathrm{h}$

Figure K.14. Dart points in the Anderson collection. (a-b) Bulverde or Carrollton; (c) Carrollton; (d-e) Dalton; (f-h) Darl; (i-j) Dawson. 
terials (105 chert, 19 quartzite, 1 silicified wood, and 1 quartz) with only 15 of Edwards chert, 6 of Keokuk-Burlington chert, and 11 of other nonlocal chert. Table K.1 lists their metric attributes.

Two fairly large, broad-bladed projectile points are either Bulverde or Carrollton. The first is somewhat thick with a long rectangular stem (Figure K.14a). The rounded base corners are more similar to Carrollton than Bulverde, but the large blade and general shape of the stem are like Bulverde, although the base is not thinned, and the barbs are a little longer than is typical for Bulverde. It has a straight base and stem and is missing the very end of the distal tip. The blade has alternate edge beveling, moderate serration, and retouch. It is of very light brown to white chert that may be Edwards. The second one is of a banded yellowish brown Edwards chert (Figure K.14b). It has a straight base, straight stem, and moderate blade serration on the symmetrically retouched blade. The barbs are short but broad. This stem is rectangular and has basal thinning typical of Bulverde.

The Carrollton point is a proximal fragment retaining some of the blade and has a straight base and straight stem (Figure K.14c). It is of pinkish white chert with reddish brown inclusions that is heat-treated Keokuk-Burlington. No retouch is evident on what remains of the blade, and there is no base or stem edge grinding.

The first of the three Daltons is a complete specimen of dark gray opaque Edwards chert (Figure K.14d). The base is concave and has basal thinning and ground edges. The stem is straight and has ground edges. The blade has moderate serration and beveled edges and has been reworked extensively but symmetrically. The second Dalton point is a proximal fragment made of a dark gray semitranslucent Edwards chert (Figure K.14e). It has a concave base, straight stem, basal thinning, and base and stem edge grinding. The third Dalton (not illustrated) is also a proximal fragment, although very small, and has a straight stem and concave base. It has base and stem edge grinding and is of KeokukBurlington white chert.

The three Darl points have concave bases and expanding stems. All three are proximomedial fragments. One is of reddish brown local chert (Figure K.14f), and the other two are quartzite (Figure K.14g-h). All of the remaining blade portions have moderate serration. None has stem or basal edge grinding or alternate blade edge beveling.

The two Dawson points have straight bases, contracting stems, blade serration, and some blade retouch. One of banded brown and gray Edwards chert is well made but missing the upper portions of the distal end (Figure K.14i). The blade has distinctive parallel flaking and heavy serration. The other, of banded gray Edwards chert, is complete and has moderate to heavy serration (Figure K.14j). The blade has been extensively reworked, creating an irregular blade edge and small hinge fractures along the centerline of the blade face.

The Delhi point is very large with a broad blade, contracting stem, and straight although slanted base (Figure K.15a). It is made of Keokuk-Burlington chert. The large size and relatively light edge retouch indicate this specimen was unused or used very little, and thus it may have been a ceremonial artifact.

The single Edgewood is of yellowish brown local chert and has an expanding stem and concave base (Figure K.15b). It has moderate blade serration, extensive and symmetrical blade reworking, and alternate blade edge beveling.

There are 68 Gary points, 9 possible Garys, and 1 Gary preform. Figures K.15c-m and K.16 illustrate a subset of these. They vary in length, width, and thickness; range from finely to coarsely flaked; and range from having welldefined barbs to rounded indistinct shoulders. Most of the Garys and possible Garys are complete $(n=63)$, but 4 are missing parts of the bases, and 10 are proximo-medial fragments. Most have contracting stems $(n=75)$, but 1 has an irregularly shaped stem and 1 has an indeterminate stem shape. Most $(n=52)$ have rounded (convex) bases, although 7 have fairly straight bases, 2 have irregular bases, and 16 have indeterminate bases. Local materials make up 90 percent of the Garys and possible Garys, predominantly chert $(\mathrm{n}=59)$ with some quartzite $(\mathrm{n}=10)$. The nonlocal materials include banded yellow and red chert $(n=1)$, Edwards chert $(\mathrm{n}=3)$, Keokuk-Burlington chert $(n=2)$, and white chert $(n=2)$. Blade serration is present on 62 percent $(n=49)$ of these specimens, 94 percent $(n=73)$ have some degree of retouch, and blade beveling is present on 27 percent $(\mathrm{n}=21)$. These conform with several of Schambach's (1998) Gary varieties, with most belonging to the classic Gary variety 


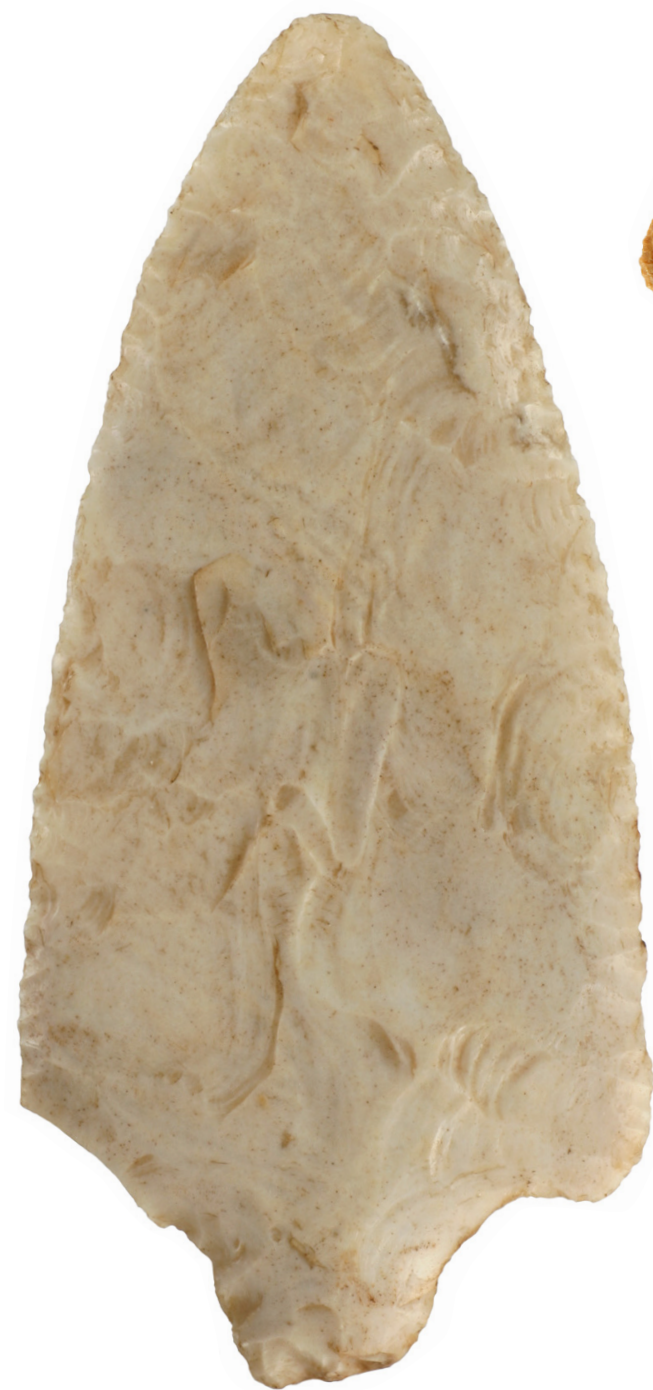

a

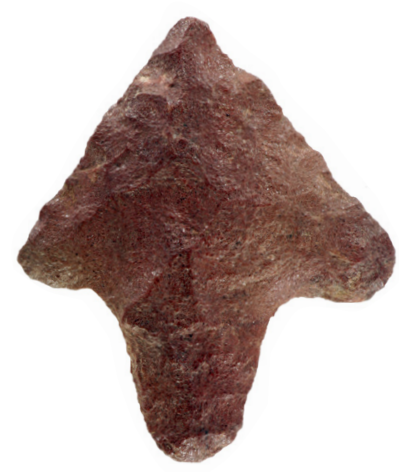

j

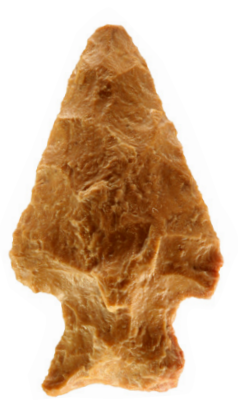

b

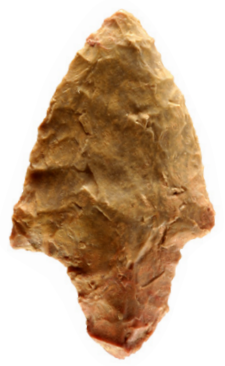

e

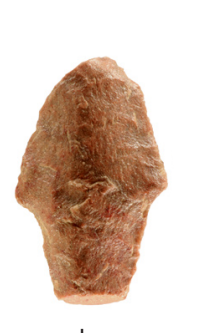

$\mathrm{h}$

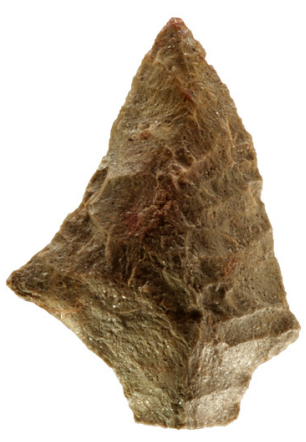

C
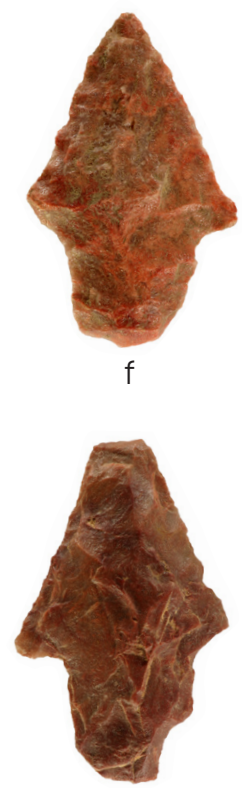

i

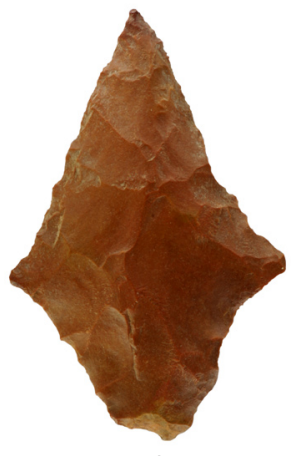

d

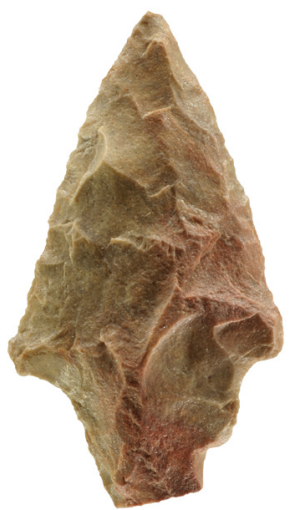

g

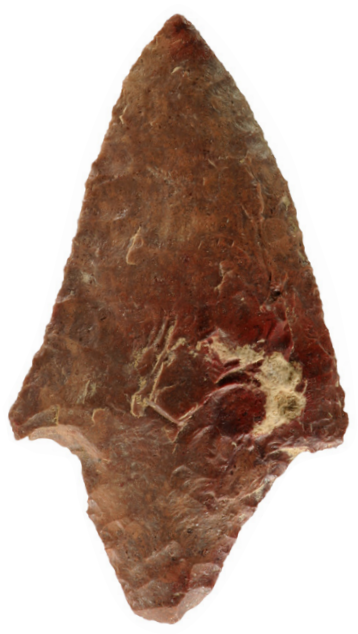

m

Figure K.15. Dart points in the Anderson collection. (a) Delhi; (b) Edgewood; (c-i) Gary, variety Gary; (j-m) Gary, variety Le Flore. 


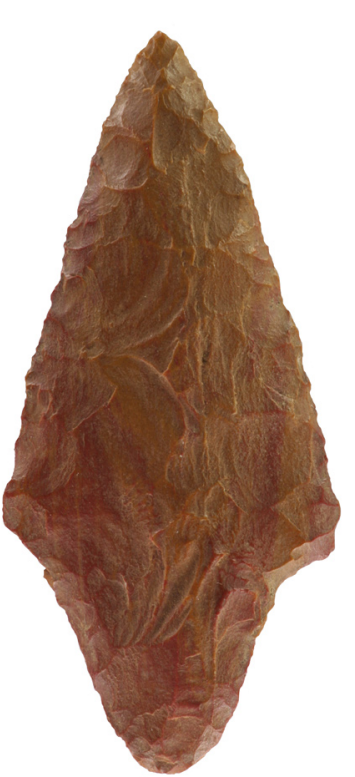

a
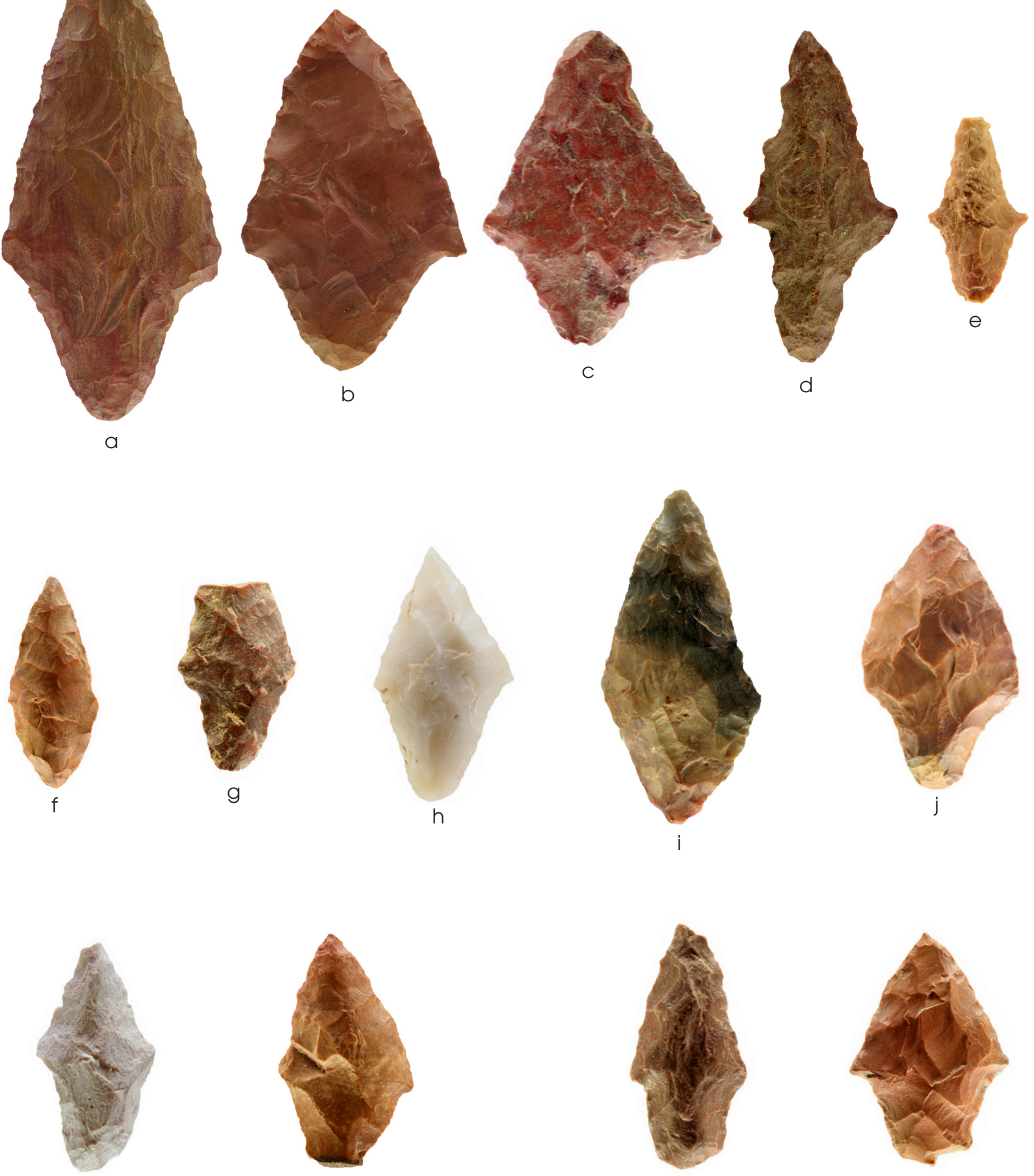

$2 \quad m$
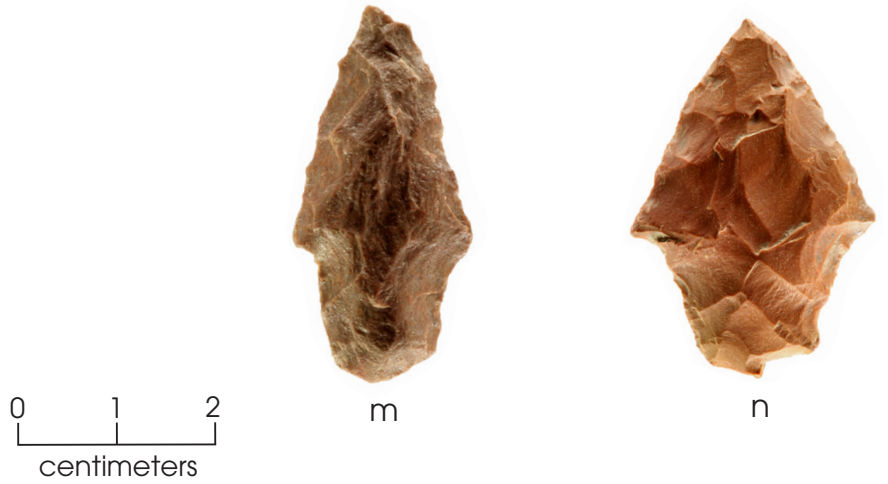

$\mathrm{n}$

Figure K.16. Dart points in the Anderson collection. (a-c) Gary, variety Le Flore; (d-f) Gary, variety Camden; (g-i) Gary, variety Camden subgroup A; (j) Gary, variety Manice; (k-m) Gary, variety Malvern; (n) Gary, variety Bodcaw. 
( $\mathrm{n}=26$; Figure K.15c-i). Other varieties noted include Le Flore $(\mathrm{n}=12$; Figure $\mathrm{K} .15 \mathrm{j}-\mathrm{m}$ and Figure K.16a-c), Camden ( $\mathrm{n}=9$; Figure K.16d-f), Camden subgroup A ( $\mathrm{n}=9$; Figure K.16g-i), Manice ( $\mathrm{n}=9$; Figure K.16j), Malvern $(\mathrm{n}=8$; Figure K.16k-m), and Bodcaw $(\mathrm{n}=4$; Figure K.16n). The Gary preform is complete and made of local brown chert. It has a convex base, contracting stem, and irregular blade.

The three Godleys have convex bases and expanding stems. One is of local yellowish brown chert (Figure K.17a), one is of nonlocal translucent pink and red Edwards chert (Figure K.17b), and one is of local reddish brown chert (Figure K.17c). All three have been retouched, and two have moderate blade serration. The one of Edwards chert has blade beveling.

The single Kent point has a straight base and slightly contracting stem; it of local reddish brown chert (Figure K.17d). It has extensive retouch, creating some irregularity on the blade edges. The three possible Kents include one that is missing part of the distal end (Figure K.17e). It is made of local olive brown chert and has an irregularly shaped stem and straight base. The blade has extensive retouch and slight serration, the stem and blade have alternate edge beveling, and there is cortex on the base. A complete possible Kent is of quartzite and has heavy blade serration and moderate and symmetrical blade retouch; it is missing a small part of the distal tip (Figure K.17f). Slight discoloration and pot lid fractures indicate it was heat treated. The third possible Kent point is of dark yellowish brown local chert and has a straight base and stem. The blade has slight serration, moderate and symmetrical retouch, and alternate edge beveling.

One of the two Motley points, of light brown chert, has a convex base and expanding stem (Figure K.17g); it has heavy blade serration and retouch. The other Motley is made of silicified wood and has an irregular base, an expanding stem, and retouch on the blade edges (Figure K.17h). A possible Motley or Carrollton, of medium to dark gray nonlocal (possibly Edwards) chert, is complete with a concave base and straight stem (Figure K.17i). It has heavy serration and retouch on the blade edges.

The three San Patrice points have concave bases, expanding stems, and stem and basal edge grinding. All are complete with some degree of retouch. One of local yellowish brown chert with cortex on one face was made on a flake blank (Figure K.17j). Another is of tan Edwards chert and has thermal (pot lid) fractures on the blade (Figure K.17k). The blade was reworked such that it tapers, and it probably was used as a drill or perforator. The third San Patrice is made of yellowish brown chert and has heavy serration, basal thinning, and alternate blade edge beveling, with an extensively reworked blade (Figure K.17l).

Four of the Wells points are complete, and two are proximo-medial fragments. One complete one is of nonlocal brown chert with red mottles (Figure K.18a). It has a convex base, contracting stem, and ground stem and basal edges. Another complete specimen, of light brown local chert, has an irregular base and straight stem (Figure K.18b). It has heavy serration and extensive and asymmetrical crude retouch that left hinge fractures on the blade faces. There is some cortex on the base. One of the proximo-medial fragments shows some retouch following the break (Figure K.18c). It has a straight base and contracting stem and is of local reddish brown chert. There is moderate serration and retouch on what remains of the blade. The other proximo-medial fragment is of tan with yellowish and reddish brown Edwards chert (Figure K.18d). It has a straight stem and convex base with stem edge grinding. The other two Wells are both complete and of quartzite (Figure K.18e-f). Both have contracting stems and straight bases, moderate to heavy serration, and moderate and symmetrical retouch on the blade edges; one has blade beveling.

There are 10 Yarbrough points and 7 possible Yarbroughs. One Yarbrough that is missing the distal tip is of local reddish brown chert (Figure K.18g). It has a straight base and expanding stem as well as moderate blade serration, moderate and symmetrical retouch, and stem edge grinding. The second Yarbrough, also with a straight base and expanding stem, is complete and of local mottled brown chert (Figure K.18h). It has heavy serration, extensive symmetrical retouch, and stem and base edge grinding. The third Yarbrough is missing the tip of the distal end and is of local dark reddish brown chert with a convex base and expanding stem (Figure K.18i). It has moderate blade serration, moderate and symmetrical blade retouch, and alternating blade beveling, but no stem or base edge grinding. The fourth Yarbrough, of local brown chert, has a concave base and ex- 

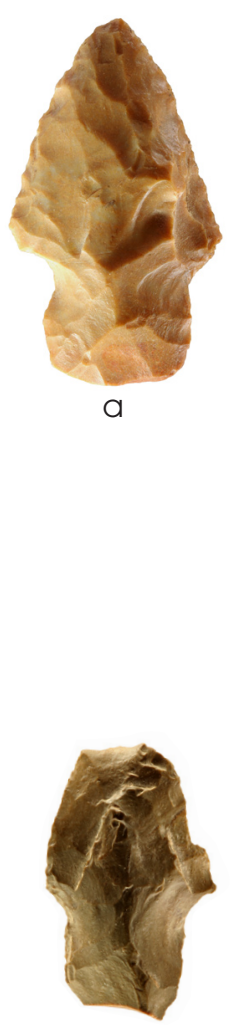

e

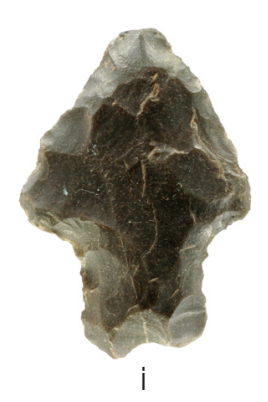

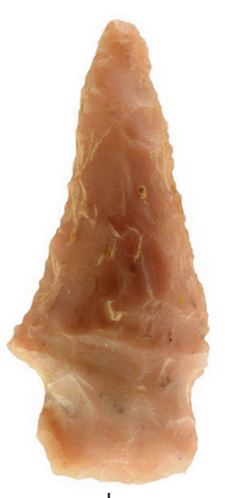

b
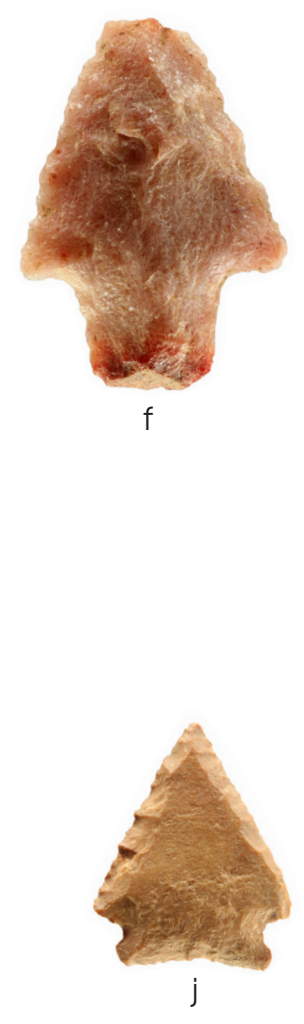
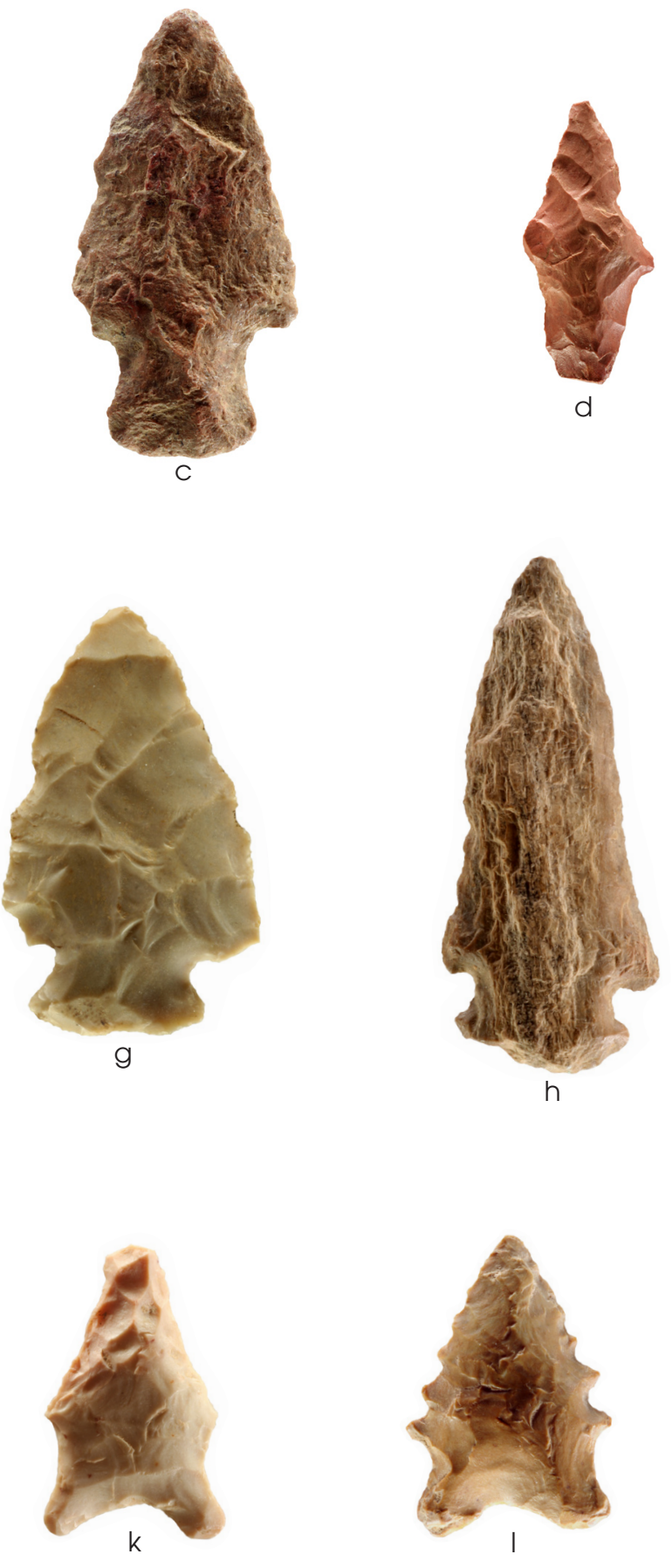

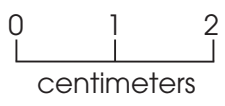

Figure K.17. Dart points in the Anderson collection. (a-c) Godley; (d) Kent; (e-f) possible Kent; (g-h) Motley; (i) Motley or Carrollton; (j-l) San Patrice. 

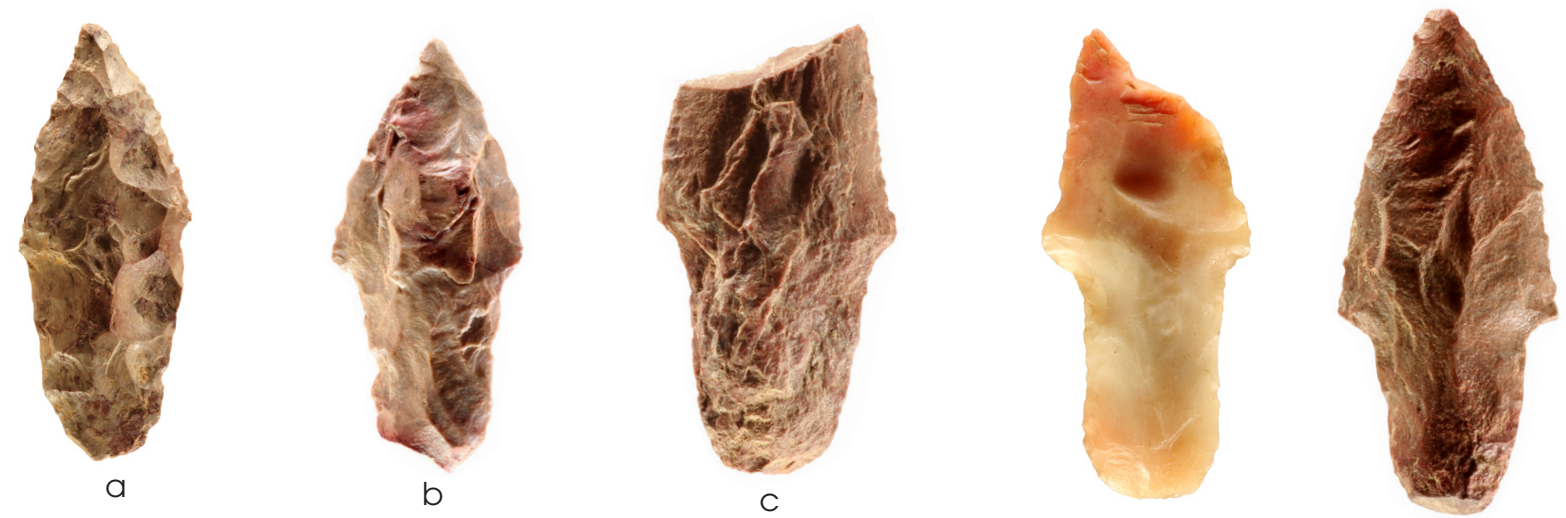

d

e
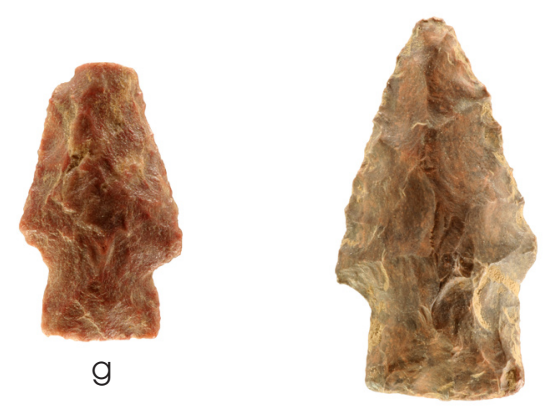

h
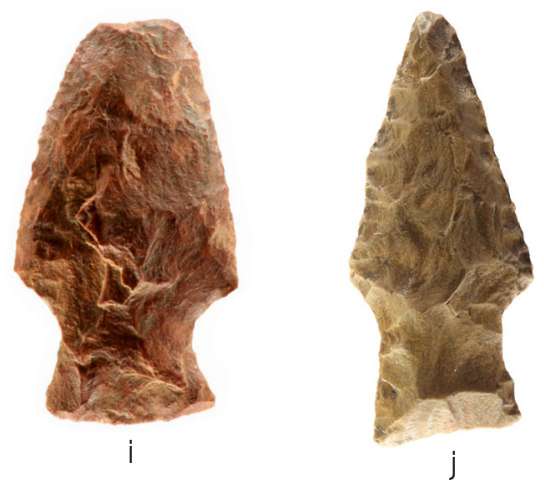

f
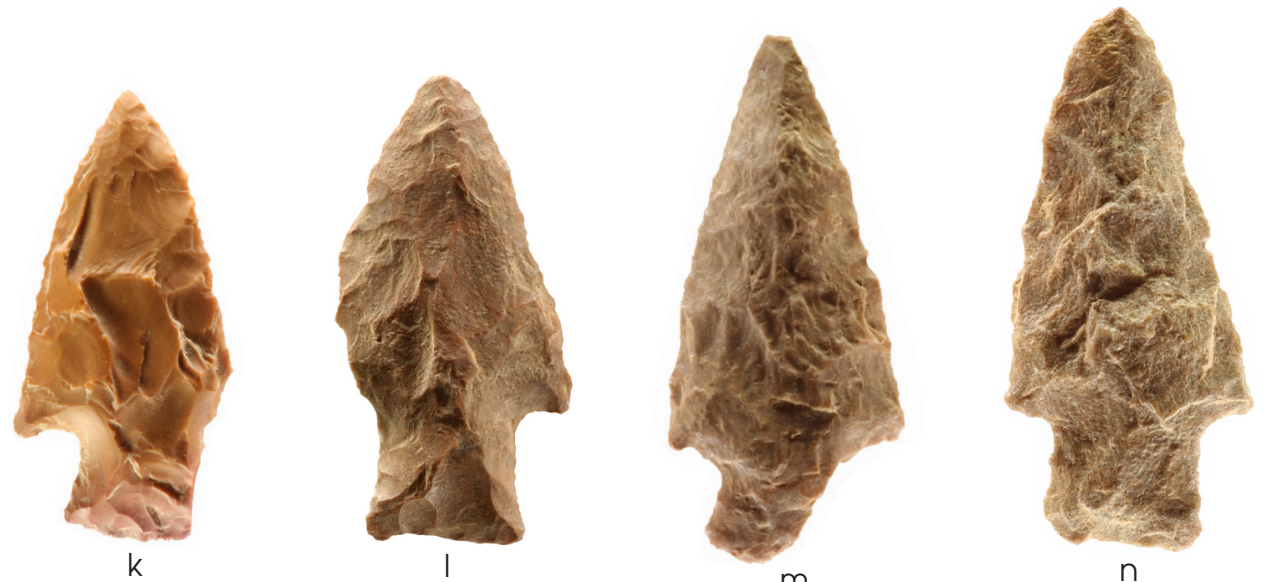

$n$

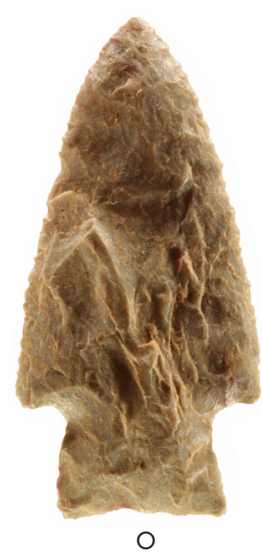

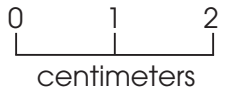

Figure K.18. Dart points in the Anderson collection. (a-f) Wells; (g-o) Yarbrough. 
panding stem (Figure K.18j). It has moderate blade serration and moderate, symmetrical retouch. The fifth Yarbrough, of yellowish brown local chert, has a convex base, expanding stem, and short barbs (Figure K.18k). The blade has heavy serration with extensive and symmetrical retouch, and the base is fractured. The sixth Yarbrough, of local light brown chert, has a concave base and expanding stem (Figure K.18l). It is missing a barb, and the blade has moderate serration and moderate irregular retouch. The seventh Yarbrough is nearly complete and of mottled brown local chert. It has an expanding stem and what looks like a convex base, although a corner of the base is missing. The blade has moderate and symmetrical retouch, moderate serration, and alternate blade edge beveling. It has short barbs and the stem edges are ground. The eighth Yarbrough has a straight base and expanding stem and is of a yellowish brown quartzite (Figure K.18m). It has heavy serration and moderate symmetrical retouch on the blade. The ninth Yarbrough, of banded greenish brown nonlocal chert, has a straight base and expanding stem (Figure K.18n). It has moderate and symmetrical retouch and moderate blade serration. The last Yarbrough has a convex base and expanding stem and is of yellowish brown local chert (Figure K.180). It has moderate and symmetrical retouch and moderate serration on the blade edges and cortex on one blade face.

One possible Yarbrough, of reddish brown local chert, is missing part of the distal end (Figure K.19a). The blade has extensive symmetrical retouch. Another specimen is complete, of mottled brown local chert, and has a straight base and expanding stem (Figure K.19b). The stem is irregular, and the blade has heavy serration and moderate asymmetrical retouch. A third possible Yarbrough is of light brown local chert and has a straight to slightly expanding stem and straight base (Figure K.19c). The blade has moderate serration and extensive symmetrical blade serration. Another possible Yarbrough is a proximo-medial fragment of light reddish brown local chert (Figure K.19d). It is missing part of the tip and has moderate symmetrical blade edge retouch, light blade serration, and stem edge grinding. The fifth possible Yarbrough, of local light brown chert, has a straight base and expanding stem (Figure K.19e). It has heavy serration and moderate asymmetrical retouch. One proximal fragment that may be a Yarbrough has a straight base and straight stem (Figure K.19f). The base is somewhat irregular and may be unfinished. It is of a brown local chert. The last possible Yarbrough, which is missing the base and is of reddish brown local chert, has a contracting stem (Figure K.19g).

The four dart point preforms are complete. One has an irregular base and stem and a triangular blade. It is of a local red chert. Another has a straight base, contracting stem, and irregularly shaped blade. It is of brown local chert. Some reworking is evident on the blade edges. A third preform of light brown translucent chert (possibly Edwards) has moderate blade serration and steep beveled blade edges and probably was used as a knife. The fourth preform, of a local red chert, has a straight base but irregular stem and blade.

There are 26 untyped dart points, of which 9 are complete, 12 are distal or mediodistal fragments, 4 are proximal fragments, and 1 is a medial fragment. Figure K. $19 \mathrm{~h}-\mathrm{k}$ illustrates 4 of these. The lithic materials are mostly (70 percent) locally available, including 14 of chert, 3 of quartzite, and 1 of quartz. The remaining specimens are nonlocal Edwards chert $(\mathrm{n}=2)$, gray chert $(\mathrm{n}=3)$, Keokuk-Burlington chert $(n=1)$, and other white chert $(n=2)$. The stem shapes vary; 4 are contracting, 3 are expanding, 5 are straight, 1 is irregular, and 13 are indeterminate. The base shapes include 2 concave, 1 convex, 5 straight, 2 irregular, and 16 indeterminate. Sixteen of these pieces are retouched. The blade edges of 12 have some serration, and 4 have alternate edge beveling. Three have stem edge grinding, and 1 has basal edge grinding.

One incomplete untyped point has an indeterminate base, expanding stem, and beveled and serrated blade that is retouched. It is made of light brown local chert. It is a very thin, very finely flaked specimen and could be either a small dart point or an arrow point.

\section{Bifaces}

The bifacial artifacts that are not projectile points consist of a drill, a gouge, 2 hafted knives, 12 unhafted knives, 2 indeterminate unstemmed tools, an early-stage biface, and a middle-stage biface. Table K.1 lists the metric attributes of these artifacts. The drill is of quartzite and is a distal fragment that is irregular with sinuous 


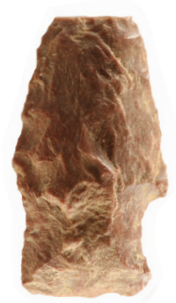

a

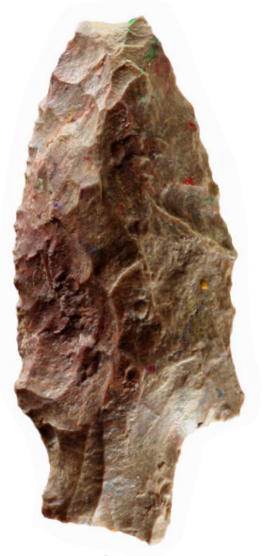

b

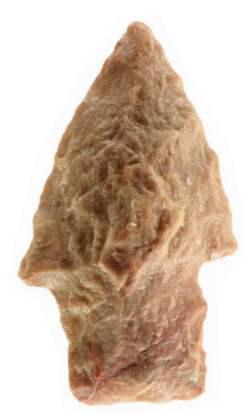

C

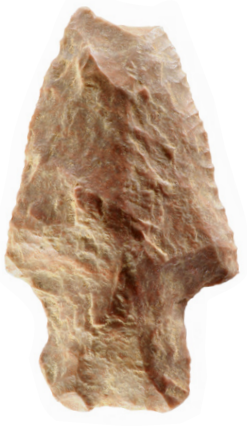

d

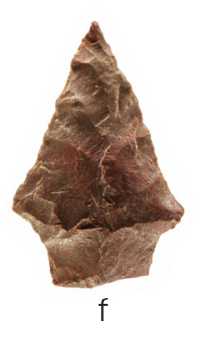

e

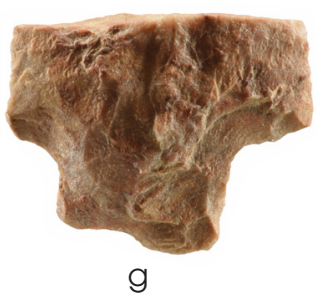

9

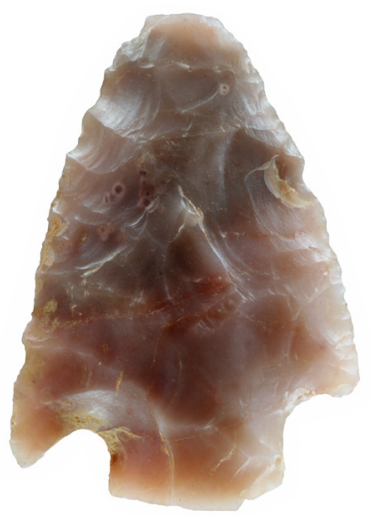

h
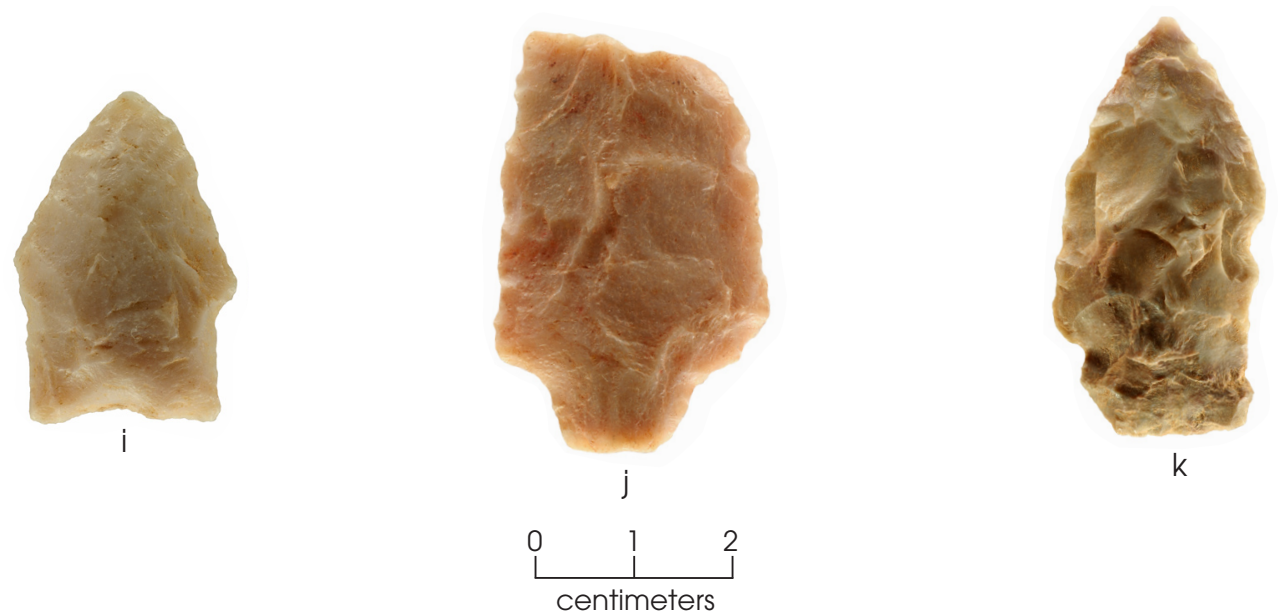

Figure K.19. Dart points in the Anderson collection. (a-g) Possible Yarbrough; (h-k) untyped. 
lateral edges. The gouge, of brownish gray chert, has steep retouch on the proximal end (creating the gouge edge) and retouch on the blade edges. Both hafted knives are complete. One, of dark yellowish brown Edwards chert, has extensive retouch on the distal end. The other is of tan chert that is probably nonlocal. The hafted end is not well shaped but is suggestive of a haft. The blade edges have extensive retouch and multiple hinge fractures. Of the 12 unhafted knives, 4 are of local chert, 5 are of quartzite, and 3 are of silicified wood. Three are complete, and nine are distal fragments. Four of the distal fragments have alternate edge beveling. All of the knives have retouch or use wear along the blade edges indicative of use as knives.

The unstemmed bifacial artifacts of indeterminate function are both complete. One is made on a small cobble of local yellowish brown chert. There is cortex on the proximal and distal ends. It appears to be a finished artifact. The other is hematite and was worked from the proximal and distal ends, almost thinned, with hinge fractures on one end. It was possibly used as a scraper or gouge. The early-stage biface is a distal fragment of quartzite. It has sinuous lateral edges. The middle-stage biface is a distal fragment that was broken during manufacture and is of light brown and yellowish brown chert. There was some reshaping retouch.

\section{Flake and Core Tools}

The nine flake and core tools include one unifacial tool that is possibly a preform for an arrow point. It is of a pinkish gray chert and has a notch on one side with edge modification on the same edge. There are also six edge-modified tools and a utilized flake with wear indicative of use as knives. One core tool has steep edge retouch consistent with use as a scraper and utilization on two other edges. It is a nonlocal mottled and patinated brown, white, and pink chert. Table K.1 lists the metric attributes of these tools.

\section{Debitage}

There are 11 pieces of debitage in the collection: 3 of silicified wood that are larger than $50 \mathrm{~mm} ; 2$ of reddish brown local chert that are $25-38 \mathrm{~mm} ; 3$ of Edwards chert that are between 19 and $25 \mathrm{~mm}$; 2 that are of local brown with red chert that are between 12.5 and $19 \mathrm{~mm}$; and 1 that is of white chert (possible KeokukBurlington) that is in the $12.5-19 \mathrm{~mm}$ range.

\section{REFERENCES CITED}

Perttula, Timothy K., P. Shawn Marceaux, and Bo Nelson

2012 Study of the Margaret Hinton Collection of Caddo Pottery Vessels from Northeast Texas Caddo Cemeteries. Archeological and Environmental Consultants, LLC, Austin.
Schambach, Frank F.

1998 Pre-Caddoan Cultures in the Trans-Mississippi South: A Beginning Sequence. Research Series 53. Arkansas Archeological Survey, Fayetteville. 
